\title{
PRE-SERVICE MATHEMATICS TEACHERS' KNOWLEDGE OF FUNCTIONS: A MIXED METHODS SEQUENTIAL EXPLANATORY STUDY
}

Presentada por Edgar John Sintema para optar al grado de

Doctor por la Universidad de Valladolid

Dirigida por:

Prof. Dr. José María Marbán Prieto 


\title{
PRE-SERVICE MATHEMATICS TEACHERS' KNOWLEDGE OF FUNCTIONS: A MIXED METHODS SEQUENTIAL EXPLANATORY STUDY
}

\author{
Edgar John Sintema \\ B.A.ED, University of Zambia, Zambia, 2014 \\ MSc, Copperbelt University, Zambia, 2017 \\ Under the supervision of Prof. Dr. José María Marbán Prieto
}

Submitted in partial fulfilment of the requirements for the degree of

Doctor of Philosophy in Transdisciplinary Research in Mathematics Education

School of Doctoral Studies

Faculty of Education and Social Work

University of Valladolid, Spain

October 2020 


\section{Keywords}

Mathematics pre-service teachers, MPCK perceptions, Mathematical Pedagogical Content Knowledge, Common Content Knowledge, Specialised Content Knowledge,

Knowledge of Content and Students, concept of a function, Sequential explanatory mixed methods, 


\section{Abstract}

It is common knowledge that teachers cannot teach students and help them learn and comprehend concepts they themselves do not understand. Thus, the purpose of this mixed methods sequential explanatory study was to examine knowledge held by pre-service secondary mathematics teachers in the topic of functions. The study attempted to characterize the depth of their subject-matter and pedagogical content knowledge of the concept of a function. In the first phase (quantitative) of the study, the investigation focused on categorizing pre-service teachers based on their level of knowledge of the concept of a function. In particular, the grouping was based on their Mathematical Pedagogical Content Knowledge perceptions, Common Content Knowledge, Specialized Content Knowledge, and Knowledge of Content and Students related to their knowledge of the concept of a function.

To accomplish the first phase of the study, data were collected using two surveys: a functions survey and the pedagogical content knowedge survey $(\mathrm{N}=150)$. A two-step cluster analysis procedure was performed to categorize participants into groups based on the common content knowledge, specialized content knowledge, and knowledge of content and students. This technique was chosen because of its potential effectiveness in the context of this study to group participants based on their knowledge features provided by data from the surveys. Pre-service teachers' responses to survey items were also analysed using descriptive statistics for each cluster. A one-way multivariate analysis of variance was also performed to compare participants' knowledge between the two clusters. A follow-up discriminant function analysis identified one variable which best predicted the group membership: common content knowledge.

In the second phase (qualitative), three cases were selected, two from Cluster 1 and one from Cluster 2 using a typical response and maximum variation principle for in-depth examination. Data for this phase were collected from multiple sources: Vignettes, functions survey, semi-structured interviews, lesson plans and the classroom teaching activity. Data were analysed for each case and across cases for an in-depth understanding of participants' knowledge of the concept of a function. 
The integration of results from the quantitative and qualitative phases was done during the discussion and interpretation stage of the entire outcome of the investigation based on the findings of the two phases, it was concluded that preservice teachers who participated in this study had insufficient knowledge of the concept of a function. Policy implications were suggested for the Ministriy of General Education and that of Higher Education. 


\section{Table of Contents}

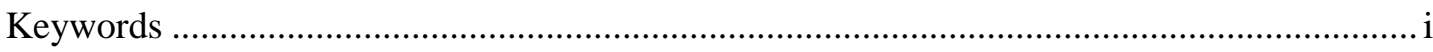

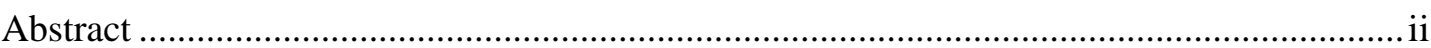

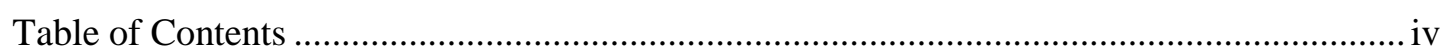

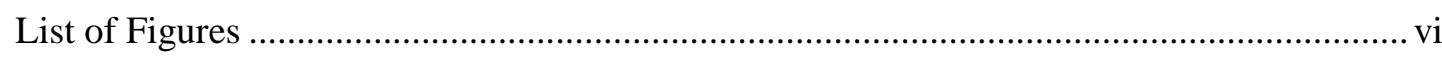

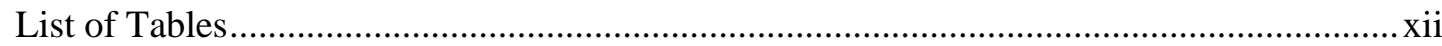

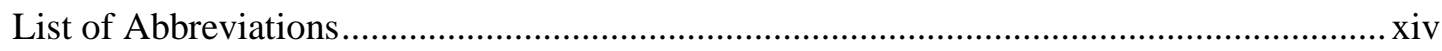

Statement of Original Authorship ................................................................................ Xvi

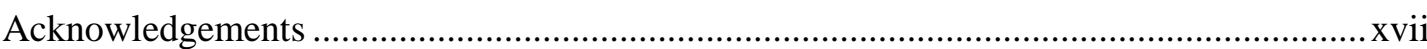

Chapter 1: Introduction ..................................................................................... 1

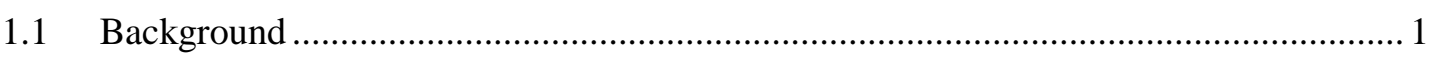

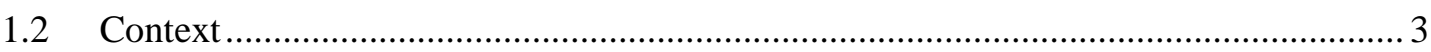

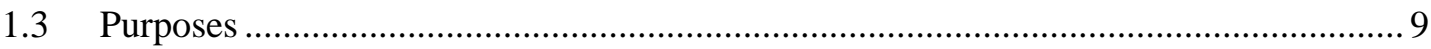

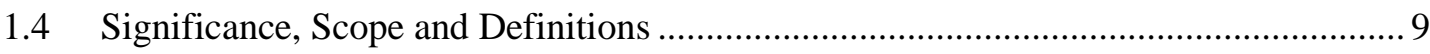

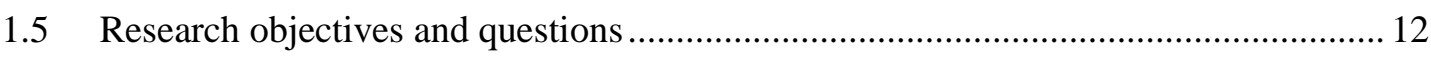

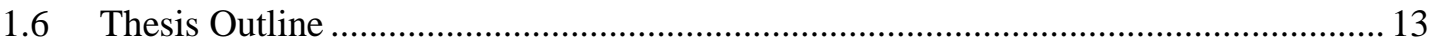

Chapter 2: $\quad$ Literature Review ........................................................................ 15

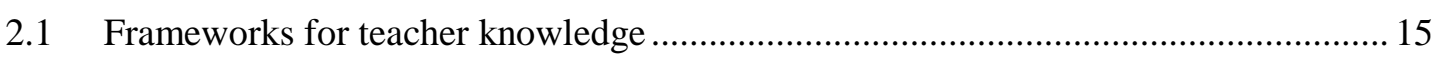

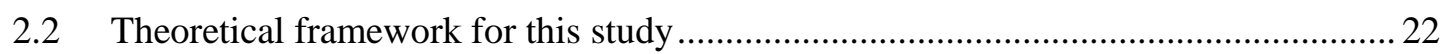

2.3 Overview of literature about MPCK and the function concept ...................................2 26

2.4 Pre-service teachers' CCK, SCK, KCT and KCS of the concept of a function ............ 44

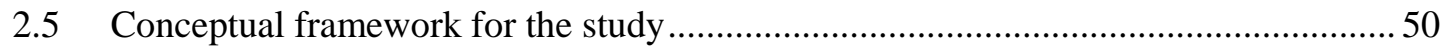

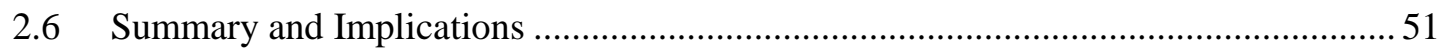

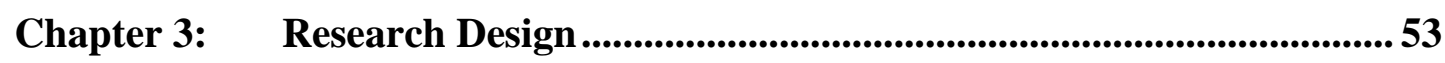

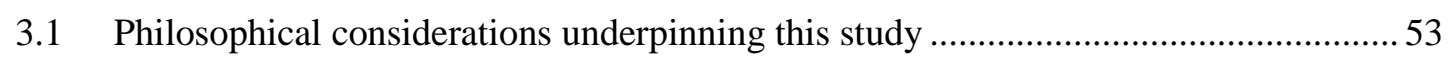

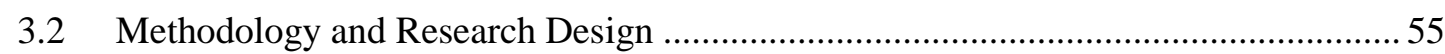

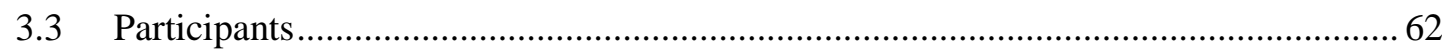

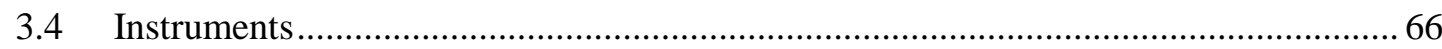

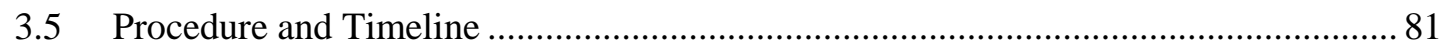

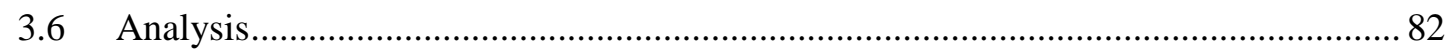

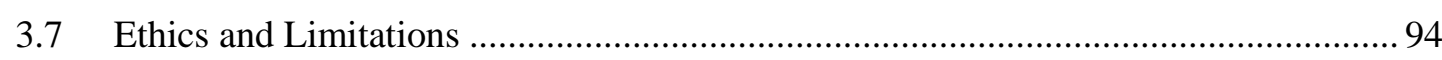

Chapter 4: Results.......................................................................................97

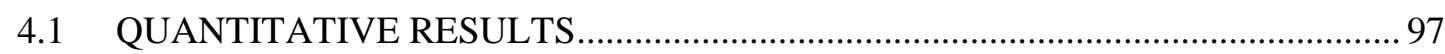

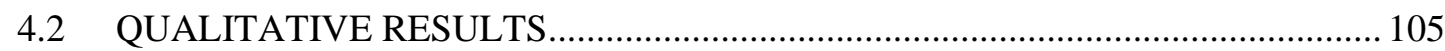

Chapter 5: Analysis............................................................................................. 241

iv Pre-service mathematics teachers' knowledge of functions: A mixed methods sequential explanatory study 
5.2 DISCUSSION OF QUALITATIVE RESULTS.......................................................25

Chapter 6: Conclusions ................................................................................. 275

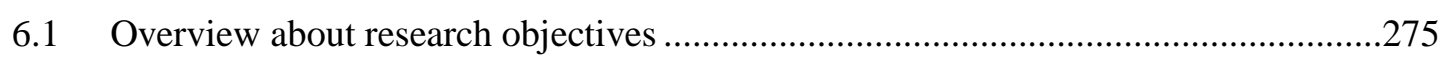

6.2 Overview about methodological choices and decisions for the study .......................277

6.3 Overview of pre-service secondary mathematics teachers' MPCK perceptions ........279

6.4 Overview of pre-service secondary mathematics teachers' common content knowledge

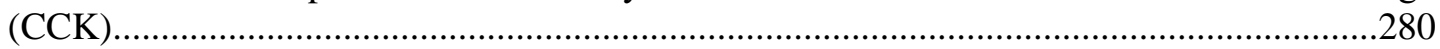

6.5 Overview of pre-service secondary mathematics teachers' specialized content

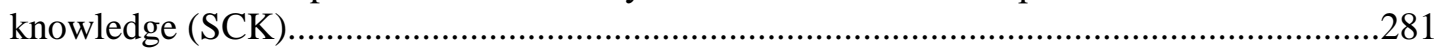

6.6 Overview of pre-service secondary mathematics teachers' knowledge of content and

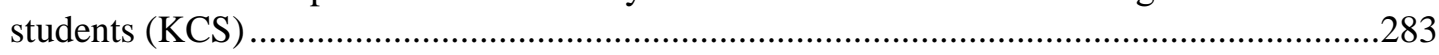

6.7 New and Unique contribution of this study to existing knowledge about mathematics

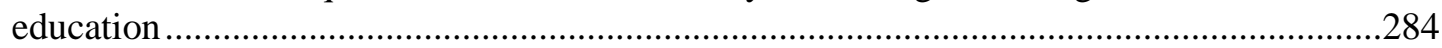

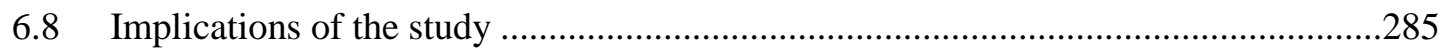

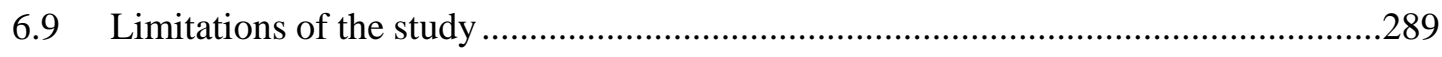

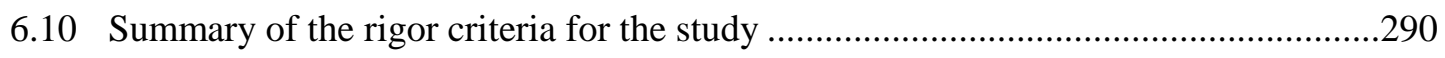

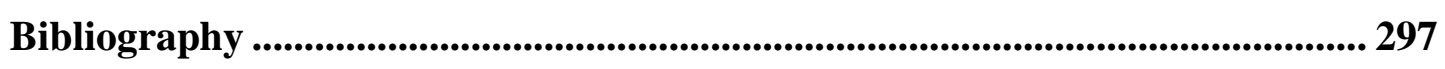

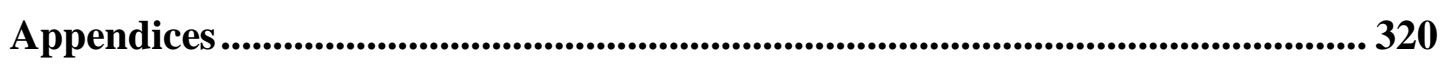

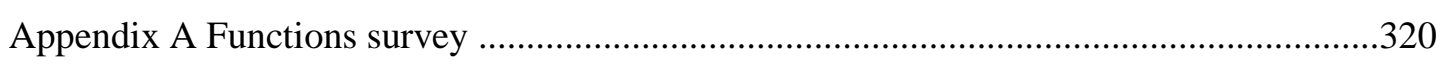

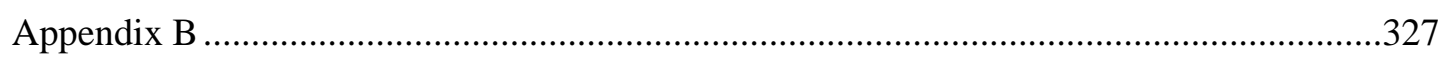

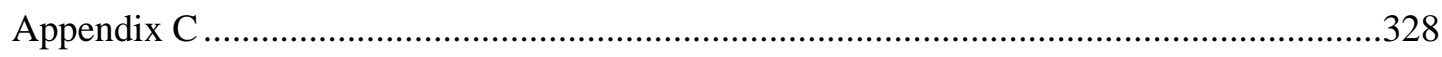

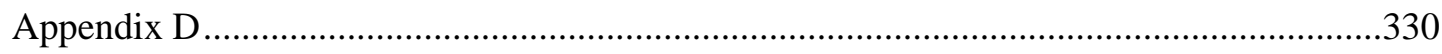

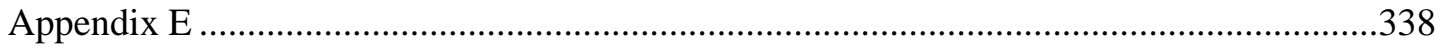

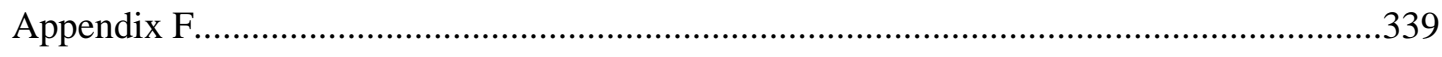

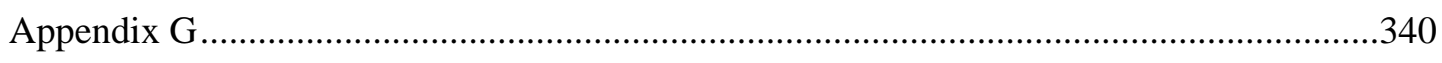

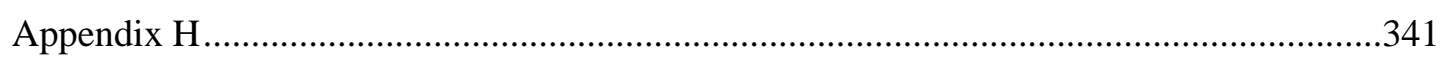

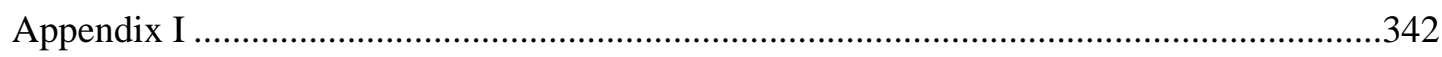

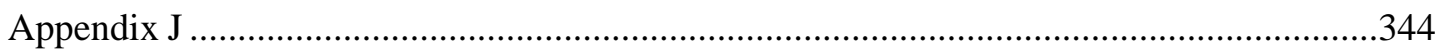

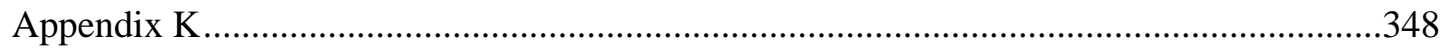

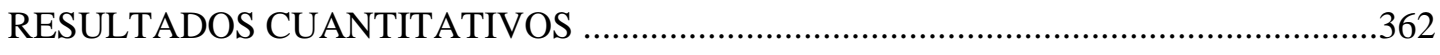

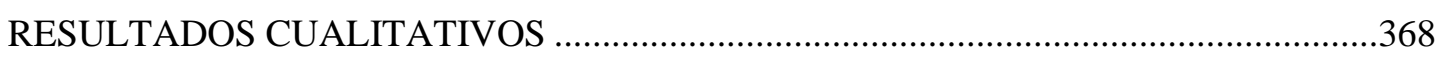




\section{List of Figures}

Figure 1.Teachers' professional qualifications by gender (MOGE, 2017) .................. 2

Figure 2. Trends of performance of Grade 12 students in national examinations

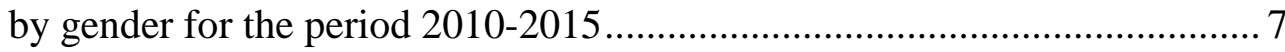

Figure 3. Zambia senior secondary curriculum structure (Adapted from ZCEF,

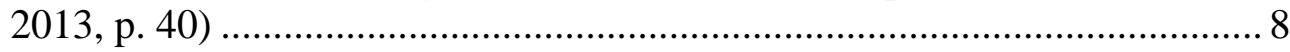

Figure 4. Visual representation of theThesis outline............................................... 14

Figure 5. Framework for teacher knowledge ofr teaching by Lee Shulman (Adapted from Somayajuru, 2012) ............................................................ 18

Figure 6. Grossman's model of teacher knowledge (Grossman, 1990, p. 5) ............. 20

Figure 7. TPACK framework (Koehler \& Mishra, 2009, p. 63) ................................ 22

Figure 8. Visual model of the MSTK framework (Carrillo et al., 2013, p. 2989) ..... 24

Figure 9. MKT framework (Hill et al., 2008, p. 377) ............................................. 25

Figure 10. PCK model for teaching functions (Adapted from Grossman, 1990; Magnusson et al., 1999, Abell, 2008) ....................................................... 42

Figure 11. MKT framework (Hill et al., 2008, p. 377) ............................................... 44

Figure 12. Conceptual framework for mathematics secondary teachers' knowledge of the function concept ........................................................ 51

Figure 13. A visual representation of the sequential explanatory design procedure (adapted from Creswell, 2017, p. 2009)...................................... 60

Figure 14. Visual representation of the validation process .................................... 71

Figure 15. Confirmatory factor analysis model ................................................... 75

Figure 16. Cluster comparison of prospective mathematics secondary teachers'

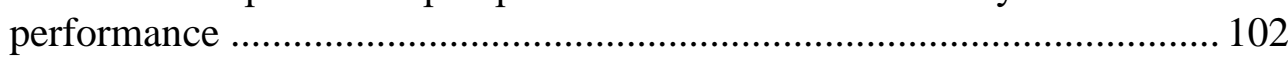

Figure 17. Excerpt of Teacher X's answer to item 1(a)(i) .................................... 106

Figure 18. Excerpt of Teacher X's answer to item 1(a)(ii) .................................... 107

Figure 19. Excerpt of Teacher X's answer to item 1(b)(i) ..................................... 107

Figure 20. Excerpt of Teacher X's answer to item 1(b)(ii) ................................... 109

Figure 21. Graphs of functions and non-functions................................................. 109

Figure 22. Excerpt of Teacher X's answer to item 1(e) ....................................... 110

Figure 23. Cards showing graphs of functions................................................... 111

Figure 24. Excerpt of Teacher X's answer to item 2(d)...................................... 114

Figure 25. Excerpt of Teacher X's answer to item 3(a) ...................................... 115

Figure 26. Graphs of functions and non-functions.............................................. 116

Figure 27. Excerpt of Teacher X's answer to item 3(b) ...................................... 116

vi Pre-service mathematics teachers' knowledge of functions: A mixed methods sequential explanatory study 
Figure 28. Excerpt of Teacher X's answer to item 4(a)

Figure 29. Excerpt of Teacher X's answer to item 4(b) 118

Figure 30. Excerpt of Teacher X's answer to item 4(c) 119

Figure 31. Excerpt of Teacher X's answer to item 5(a) 120

Figure 32. Excerpt of Teacher X's answer to item 5(c) 121

Figure 33. Excerpt of Teacher X's answer to item 5(d). 122

Figure 34. Excerpt of Teacher Y's answer to item 1(a)(i) 123

Figure 35. Excerpt of Teacher Y's answer to item 1(a)(ii) 124

Figure 36. Excerpt of Teacher Y's answer to item 1(b)(i). 124

Figure 37. Excerpt of Teacher Y's answer to item 1(b)(ii) 125

Figure 38. Examples of graphs of functions and non-functions 126

Figure 39. Excerpt of Teacher Y's answer to item 1(e). 126

Figure 40. Cards showing examples of functions and non-functions 127

Figure 41. Excerpt of Teacher Y's answer to item 2(d). 130

Figure 42. Excerpt of Teacher Y's answer to item 3(a). 131

Figure 43. Textbook examples of functions and non-functions..... 132

Figure 44. Excerpt of Teacher Y's answer to item 3(b). 133

Figure 45. Excerpt of Teacher Y's answer to item 4(b). 133

Figure 46. Excerpt of Teacher Y's answer to item 4(c) 134

Figure 47. Excerpt of Teacher Y's answer to item 4(d). 135

Figure 48. Excerpt of Teacher Y's answer to item 5(a) 136

Figure 49. Excerpt of Teacher Y's answer to item 5(c) 136

Figure 50. Excerpt of Teacher Y's answer to item 5(d). 137

Figure 51. Excerpt of Teacher Z's answer to item 1(a)(i). 139

Figure 52. Excerpt of Teacher Z's answer to item 1(a)(ii) 139

Figure 53. Excerpt of Teacher Z's answer to item 1(b)(i) 140

Figure 54. Excerpt of Teacher Z's answer to item 1(b)(ii).. 141

Figure 55. Functions and non-functions 141

Figure 56. Excerpt of Teacher Z's answer to item 1(e) 142

Figure 57. Cards showing graphs of functions 143

Figure 58. Excerpt of Teacher Z's answer to item 2(c) 144

Figure 59. Excerpt of Teacher Z's answer to item 2(d) 145

Figure 60. Excerpt of Teacher Z's answer to item 3(a) 146

Figure 61. Functions and non-functions 146

Figure 62. Excerpt of Teacher Z's answer to item 3(b) 147 
Figure 63. Excerpt of Teacher Z's answer to item 4(b) 147

Figure 64. Excerpt of Teacher Z's answer to item 4(c) 148

Figure 65. Excerpt of Teacher Z's answer to item 4(d) 149

Figure 66. Excerpt of Teacher Z's answer to item 5(a) 150

Figure 67. Excerpt of Teacher Z's answer to item 5(c) 151

Figure 68. Excerpt of Teacher Z's answer to item 5(d) 151

Figure 69. Excerpt of Teacher X's answer to item 1(c) 152

Figure 70. Excerpt of Teacher X's answer to item 1(d). 153

Figure 71. Cartesian plane showing positions of the points $\mathrm{X}$ and $\mathrm{Y}$ 153

Figure 72. Excerpt of Teacher X's answer to item 1(f) 154

Figure 73. Excerpt of Teacher X's answer to item 2(a) 155

Figure 74. Excerpt of Teacher X's answer to item 2(b). 157

Figure 75. Excerpt of Teacher X's answer to item 2(e)..... 158

Figure 76. Graph of the function $\mathrm{f}(\mathrm{x})=\mathrm{ax} \mathrm{x}^{2}+\mathrm{bx}+\mathrm{c}$ 158

Figure 77. Excerpt of Teacher X's answer to item 3(c) 159

Figure 78. Excerpt of Teacher X's answer to item 4(a) 160

Figure 79. Excerpt of Teacher X's answer to item 4(e).... 161

Figure 80. Excerpt of Teacher X's answer to item 5(b). 162

Figure 81. Excerpt of Teacher X's answer to item 9(a)..... 163

Figure 82. Excerpt of Teacher X's answer to item 9(b)..... 163

Figure 83. Excerpt of Teacher X's answer to item 9(c). 164

Figure 84. Excerpt of Teacher Y's answer to item 1(c). 165

Figure 85. Excerpt of Teacher Y's answer to item 1(d). 165

Figure 86. XY-Plane showing the points $X$ and $Y$. 166

Figure 87. Excerpt of Teacher Y's answer to item 1(f) 166

Figure 88. Excerpt of Teacher Y's answer to item 2(a) 167

Figure 89. Excerpt of Teacher Y's answer to item 2(b). 169

Figure 90. Excerpt of Teacher Y's answer to item 2(e) 170

Figure 91. Graph of $\mathrm{f}(\mathrm{x})=a \mathrm{x}^{2}+\mathrm{bx}+\mathrm{c}$ 170

Figure 92. Excerpt of Teacher Y's answer to item 3(c) 171

Figure 93. Excerpt of Teacher Y's answer to item 4(a) 172

Figure 94. Excerpt of Teacher Y's answer to item 4(e) 173

Figure 95. Excerpt of Teacher Y's answer to item 5(b). 174

Figure 96. Excerpt of Teacher Y's answer to item 9(a) 174

Figure 97. Excerpt of Teacher Y's answer to item 9(b). 175

viii Pre-service mathematics teachers' knowledge of functions: A mixed methods sequential explanatory study 


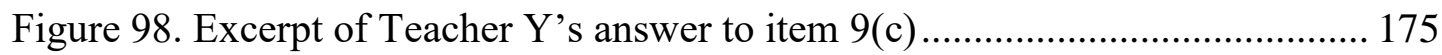

Figure 99. Excerpt of Teacher Z's answer to item 1(c) ....................................... 176

Figure 100. Excerpt of Teacher Z's answer to item 1(d) ....................................... 177

Figure 101. XY-Plane showing points X and Y .................................................. 177

Figure 102. Excerpt of Teacher Z's answer to item 1(f) ....................................... 178

Figure 103. Excerpt of Teacher Z's answer to item 2(a) ...................................... 178

Figure 104. Excerpt of Teacher Z's answer to item 2(b) ...................................... 180

Figure 105. Excerpt of Teacher Z's answer to item 2(e) ...................................... 181

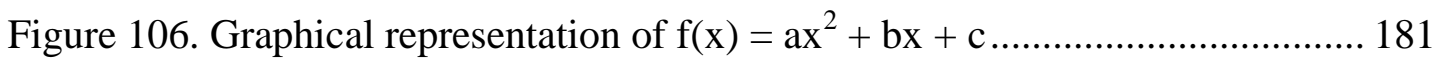

Figure 107. Excerpt of Teacher Z's answer to item 3(c) ...................................... 182

Figure 108. Excerpt of Teacher Z's answer to item 4(a) ...................................... 183

Figure 109. Excerpt of Teacher Z's answer to item 5(b) ....................................... 184

Figure 110. Excerpt of Teacher Z's answer to item 9(a) ...................................... 185

Figure 111. Excerpt of Teacher Z's answer to item 9(b) ...................................... 185

Figure 112. Excerpt of Teacher Z's answer to item 9(c) ..................................... 185

Figure 113. Excerpt LP1 of Teacher X's lesson plan on inverse functions ............. 187

Figure 114. Excerpt LP2 of Teacher X's lesson plan on inverse functions ............. 187

Figure 115. Excerpt LP3 of Teacher X's lesson plan on inverse functions............. 188

Figure 116. Excerpt LP4 of Teacher X's lesson plan on inverse functions ............. 188

Figure 117. Teacher X's class exercise on iverse functions .................................. 190

Figure 118. Excerpt LP5 of Teacher X's lesson plan on composite functions ........ 191

Figure 119. Excerpt LP6 of Teacher X's lesson plan on composite functions ........ 192

Figure 120. Excerpt LP7 of Teacher X's lesson plan on composite functions ........ 192

Figure 121. Teacher X's response to vignette 1................................................... 194

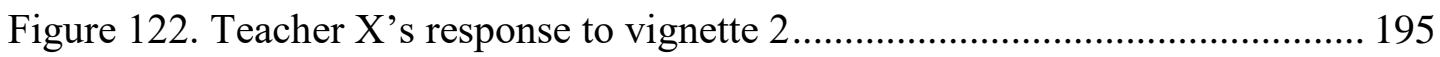

Figure 123. Teacher X's response to vignette 3.................................................. 196

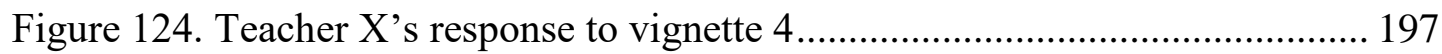

Figure 125. Teacher X's response to vignette 5 .................................................. 198

Figure 126. Teacher X's response to vignette 6................................................... 199

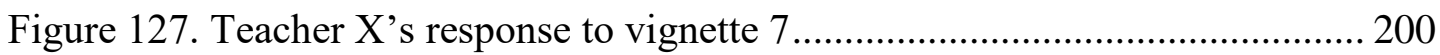

Figure 128. Teacher X's response to vignette 8 f.................................................. 202

Figure 129. Excerpt of Teacher X's answer to item 6(a) ....................................... 203

Figure 130. Excerpt of Teacher X's answer to item 6(b)..................................... 203

Figure 131. Excerpt of Teacher X's answer to item 6(c) ....................................... 204

Figure 132. Excerpt of Teacher X's answer to item 6(d) ....................................... 204 
Figure 133. Excerpt of Teacher X's answer to item 6(e) ....................................... 205

Figure 134. Excerpt of Teacher X's answer to item 7(b) ...................................... 206

Figure 135. Excerpt of Teacher X's answer to item 7(c) ...................................... 207

Figure 136. Excerpt of Teacher X's answer to item 8(b) ....................................... 208

Figure 137. Excerpt LP8 of Teacher Y's lesson plan on inverse functions ............. 208

Figure 138. Excerpt LP9 of Teacher Y's lesson plan on inverse functions ............. 209

Figure 139. Excerpt LP10 of Teacher Y's lesson plan on inverse functions ........... 209

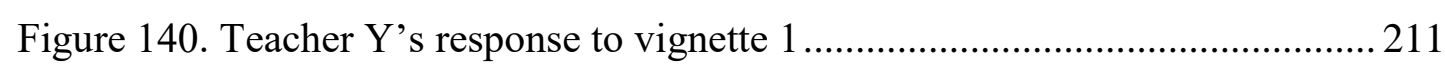

Figure 141. Teacher $Y$ 's response to vignette 2 ................................................ 212

Figure 142. Teacher Y's response to vignette 3 ............................................... 213

Figure 143. Teacher $Y$ 's response to vignette 4 ..................................................... 214

Figure 144. Teacher Y's response to vignette 5 ................................................. 215

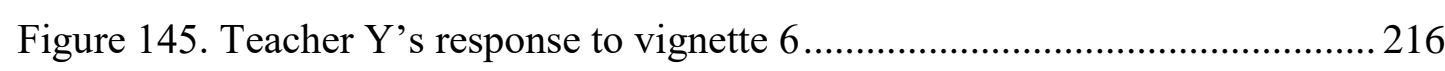

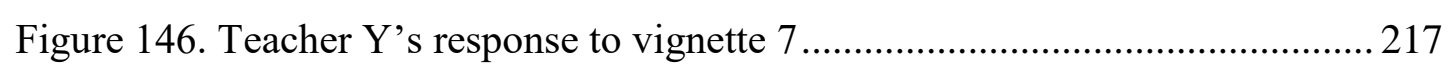

Figure 147. Teacher Y's response to vignette 8 ................................................... 218

Figure 148. Teacher $Y$ 's response to vignette 8 continued .................................... 219

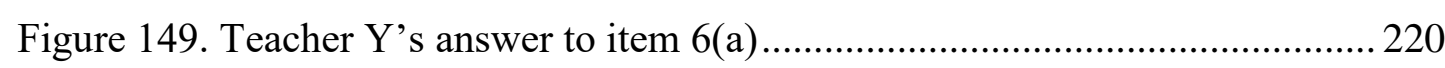

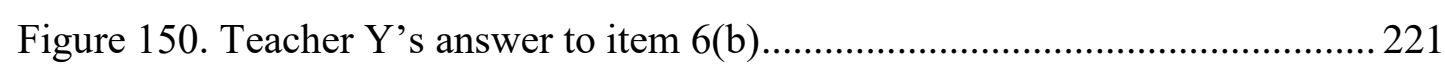

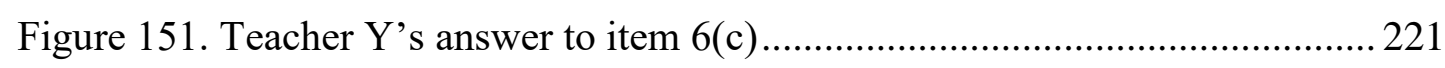

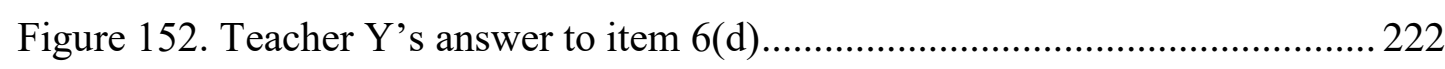

Figure 153. Teacher Y's answer to item 6(e) ......................................................... 222

Figure 154. Teacher Y's answer to items 7(a), 7(b) and 7(c) .............................. 223

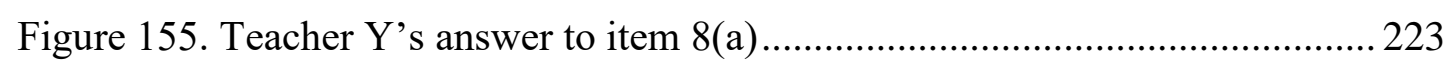

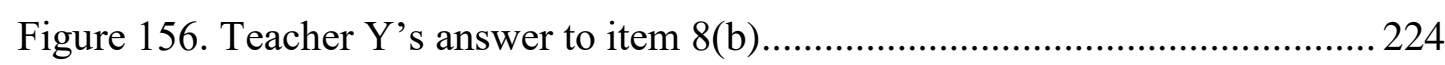

Figure 157. Excerpt LP11 of Teacher Z's lesson plan on inverse functions ........... 225

Figure 158. Excerpt LP12 of Teacher Z's lesson plan on inverse functions ........... 226

Figure 159. Excerpt LP13 of Teacher Z's lesson plan on composite functions....... 228

Figure 160. Excerpt LP14 of Teacher Z's lesson plan on composite functions....... 228

Figure 161. Teacher Z's response to vignette 1 .................................................. 230

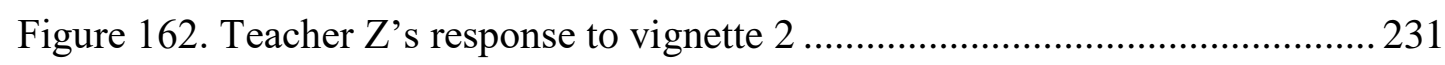

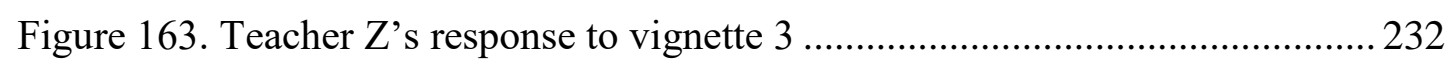

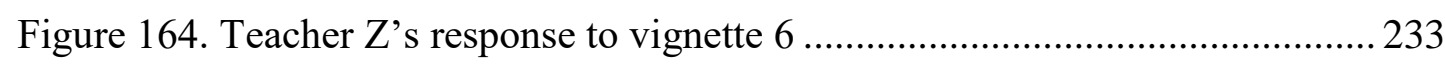

Figure 165. Teacher Z's response to vignette 7 ............................................... 234

Figure 166. Excerpt of Teacher Z's answer to item 6(a) ...................................... 235

Figure 167. Excerpt of Teacher Z's answer to item 6(b) .................................... 236

x Pre-service mathematics teachers' knowledge of functions: A mixed methods sequential explanatory study 
Figure 168. Excerpt of Teacher Z's answer to item 6(c) ..................................... 236

Figure 169. Excerpt of Teacher Z's answer to item 6(d) ....................................... 237

Figure 170. Excerpt of Teacher Z's answer to item 6(e) …................................. 237

Figure 171. Excerpt of Teacher Z's answer to items 7(a), 7(b) and 7(c) ................ 238

Figure 172. Excerpt of Teacher Z's answer to item 8(b) ...................................... 239

Figure 173. Framework for the rigor criteria of the current study .......................... 292 


\section{List of Tables}

Table 1. Specific outcomes from the topic functions in the Zambian syllabus ........ 31

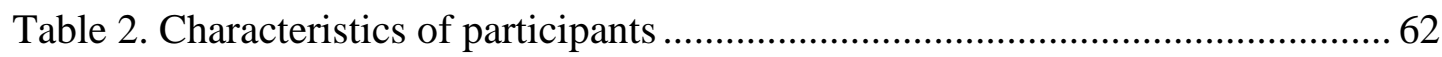

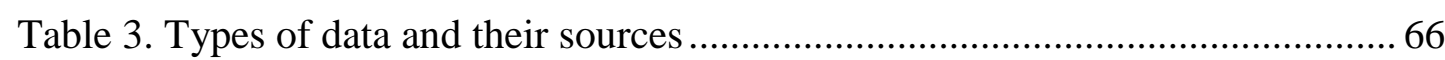

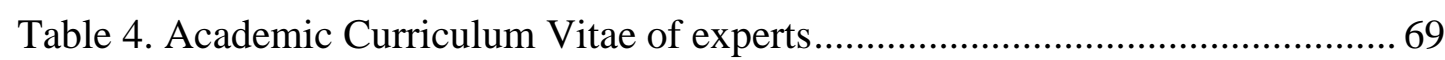

Table 5. Item content validity index for the clarity, coherence and relevance of

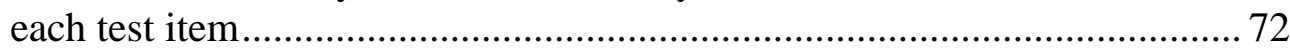

Table 6. Item content validity index for the clarity, coherence and relevance of each test item continued ........................................................................ 72

Table 7. Item content validity index for the clarity, coherence and relevance of each test item continued ........................................................................... 73

Table 8. Item content validity index for the sufficiency of test items....................... 73

Table 9. Cronbach alpha reliability coefficients of factors of the original scale ....... 74

Table 10. Factor loadings of the MPCK components ............................................. 76

Table 11. Fornell-Larcker criterion for checking discriminant validity.................... 77

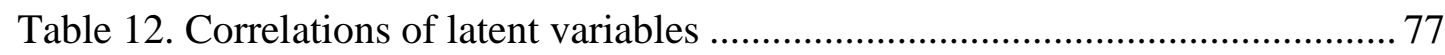

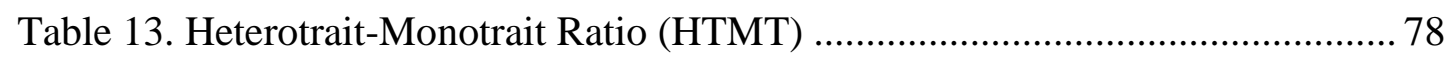

Table 14. Adjusted model: summary of adjusted model indices ............................... 78

Table 15. Framework for analysing pre-service teachers' CCK and SCK ................ 86

Table 16. Framework for analysing pre-service teachers' KCS .............................. 88

Table 17. Results of the auto-clustering for the two-step cluster analysis ................. 98

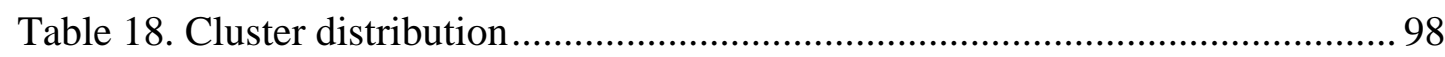

Table 19. Cluster profiles of pre-service teachers .................................................... 99

Table 20. Results of the independent samples t-test of pre-service teachers'

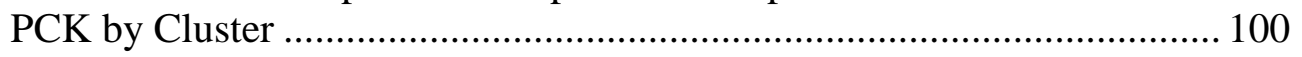

Table 21. Correlations between MPCK sub-factors................................................ 100

Table 22. Performance profiles of pre-service mathematics teachers by cluster for each knowledge dimension .......................................................... 101

Table 23. Knowledge profiles of prospective Zambian mathematics teachers based on their CCK, SCK and KCS................................................. 102

Table 24. Performance profiles of prospective mathematics teachers by cluster for the constructs of knowledge domains .................................................. 103

Table 25. Between levels of cluster effects of prospective secondary mathematics teachers' knowledge of the function concept ...................... 104

Table 26. Multivariate analysis of prospective secondary mathematics teachers' knowledge of the function concept between clusters.................................. 104

xii Pre-service mathematics teachers' knowledge of functions: A mixed methods sequential explanatory study 
Table 27. Test of equality of cluster mean scores for prospective secondary mathematics teachers' knowledge of the function concept

Table 28. Standardized and unstandardized canonical discriminant function coefficients. 105

Table 29. $\mathrm{X}$ and $\mathrm{Y}$ values of the function function $f(x)=-2 x^{2}-x+8 \ldots \ldots \ldots \ldots \ldots \ldots . . . . . . .156$

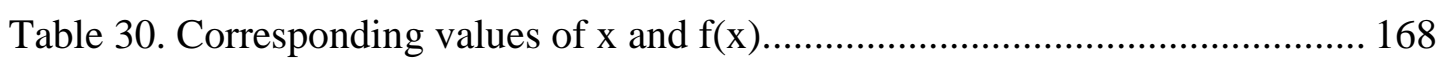

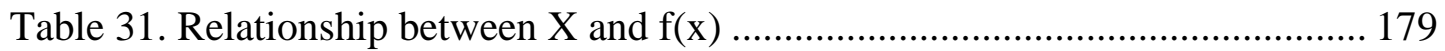

Table 32. Final results of pre-service teachers' performance in the MPCK functions survey.... 250

Table 33. Zambian national examinations results for Grade 12 mathematics and Additional mathematics 288 


\section{List of Abbreviations}

AVE $\quad-$ Average Variance Extracted

B.A. ED - Bachelor of Arts with Education

BIC - Bayesian Criterion

BSc.ED - Bachelor of Science with Education

CCK - Common Content Knowledge

CDC - Curriculum Development Centre

CFA - Confirmatory Factor Analysis

CPD - Continous Professional Development

CVI - Content Validity Index

DFA - Discriminant Fanction Analysis

ECE - Early Childhood Education

HTMT $\quad-$ Heterotait-Monotrait

I-CVI - Item Content Validity Index

KC $\quad-$ Knowledge of Curriculum

KCS $\quad-$ Knowledge of Content and Students

KCT - Knowledge of Content and Teaching

KL $\quad-$ Knowledge of Learners

KM $\quad-$ Knowledge of Misconceptions

KMLS $\quad-$ Knowledge of Mathematical Language and Symbols

KTS $\quad-$ Knowledge of Teaching Strategies

LP $\quad$ - Lesson Plan

MANOVA - Multivariate Analysis of Variance

MESVTEE - Ministry of Education, Science, Vocational Training and early Education 


\begin{tabular}{|c|c|}
\hline MKT & - Mathematical Knowledge for Teaching \\
\hline MOGE & - Ministry of General Education \\
\hline MPCK & - Mathematical Pedagogical Content Knowledge \\
\hline MPhil & - Master of Philosophy \\
\hline $\mathrm{MSc}$ & - Master of Science \\
\hline MSE & - Mathematics and Science Education \\
\hline NCTM & - National Council of Teachers of Mathematics \\
\hline NFI & - Normed Fit Index \\
\hline PCK & - Pedagogical Content Knowledge \\
\hline Ph.D. & - Doctor of Philosophy \\
\hline PLS & - Partial Least Squares \\
\hline PSSM & - Principles and Standards for School Mathematics \\
\hline PTE & - Primary Teacher Education \\
\hline S-CVI & - Scale Content Validity Index \\
\hline SCK & - Specialized Content Knowledge \\
\hline SMK & - Subject Matter Knowledge \\
\hline SPSS & - Satistical Package for Social Sciences \\
\hline SRMR & - Standardized Root Mean Residual \\
\hline STE & - Secondary Teacher Education \\
\hline TPACK & - Technological Pedagogical Content Knowledge \\
\hline
\end{tabular}




\section{Statement of Original Authorship}

The work contained in this thesis has not been previously submitted to meet requirements for a Doctoral degree award at the University of Valladolid or any other higher education institution. To the best of my knowledge and belief, the thesis contains no material previously published or written by another person except where due reference is made.

Date: 


\section{Acknowledgements}

Firstly, I would like to sincerely thank the distinduished academics who willingly accepted to serve on my thesis committee. Secondly, I would like to express my gratitude to my thesis supervisor, Professor Jose Maria Marban Prieto without whom I would never have completed and earned this degree. Professor Marban, I am profoundly honoured and exceedingly humbled for the opportunity to work under your guidance. The content of this thesis mirrors your effort and intellectual guidance. You read, revised and edited my work in a scholarly manner. You provided valuable feedback that helped me complete my studies on time. You are a distinguished scholar whose work ethic I will always endeavor to emulate. I would also like to thank Professor Patrick Azere Phiri for his involvement in the project in its early stages.

I would like to thank officers at the international relations office of the University of Valladolid for facilitating my travel and stay during my mobility stay in spain. Marian and Miguel, thank you for everything. Your contribution was key to the success of this degree. I also wish to thank members of the Department of Mathematics Education at the University of Valldolid for your support. Special thanks go to Astrid and Maria Luisa for always making me feel part of the staff and family.

I also would like to thank my parents Michael and Dyness Sintema for always believing in my abilities and encouraging me to pursue my academic dreams. Thank you to my brothers Kenndy and Armstrong for your support and my sisters Concilia, Bridget, Loveness, Majorie and Sharon for always being there for me. To my cousin, Brenda, thank you for everything. To my late sister Yvonne, I know you are proud of me in your resting place. Continue resting in eternal peace.

I would like to extend my gratitude to all the pre-service teachers who participated in this study. Thank you for finding time off your busy academic schedule to participate in the data collection phase of the study. To the Universities that allowed me to conduct research in their institutions, thank you for your help. 
Most of all, I would like to thank my wife Phanny Mumba Sintema and my lovely daughter Blessings Sintema. Where do I even begin? You have been with me from the first day of this difficult journey through to the beautiful end. You made numerous sacrifices to ensure that I achieve this academic milestone. Phanny, your voice of reason, patience and inspiration has been the rock on which my strength rested. You lifted me up during my weakest moments of this journey. Blessings, it was difficult to equally divide time between research and you. I know I deprived you of many hours of fatherly interaction because of the magnitude of the demands of this work. In spite of all this, you always presented yourself to me with that assuring smile. You are without doubt, Daddy's greatest blessing and genuine source of happiness. This work would not have been accomplished without the love and support of both of you. 


\section{Chapter 1: Introduction}

This chapter outlines the background (Section 1.1) and context (Section 1.2) of the research, and its purposes (Section 1.3). Section 1.4 describes the significance and scope of this research and provides definitions of terms used, while Section 1.5 outlines the research objectives. Finally, section 1.6 includes an outline of the remaining chapters of the thesis.

\subsection{BACKGROUND}

Although subject matter knowledge and skills for teaching are widely acknowledged as a central component of what teachers need to master, the design of teacher education curriculum in many colleges of education and universities seem sometimes to ignore the fact that prospective teachers need to master the subject matter knowledge and the skills that are specific to their subject area in order for effective teaching to take place (Mulenga \& Luangala, 2015). Ball and McDiarmid (2010) reported that recent research which focused on the ways in which teachers and teacher candidates understood the subjects that they taught, revealed that teachers often had gaps in knowledge and skills similar to those of their students.

Teacher training in Zambia is geared towards producing teachers who will demonstrate knowledge and understanding of their teaching subjects as well as appropriate pedagogical expertise and a good understanding of their role as teachers (MOGE, 2017). Notwithstanding efforts in improving the quality of teachers at senior secondary school, it has been observed that learning achievement is low among senior secondary school students because there is a shortage of qualified teachers to handle senior secondary school students (MOGE, 2017). It has been reported that about 64 per cent of teachers that are teaching at senior secondary level in Zambia are not adequately qualified, with only 36 per cent holding desired qualifications. It is clear from these statistics that teachers require deeper subject matter and pedagogical content knowledge to improve learning achievement of senior secondary school students. Figure 1 shows professional qualifictation of teachers by gender. It can be seen that the number of teachers holding degrees is 
small for both male and female teachers. This small number includes mathematics teachers who hold degrees.

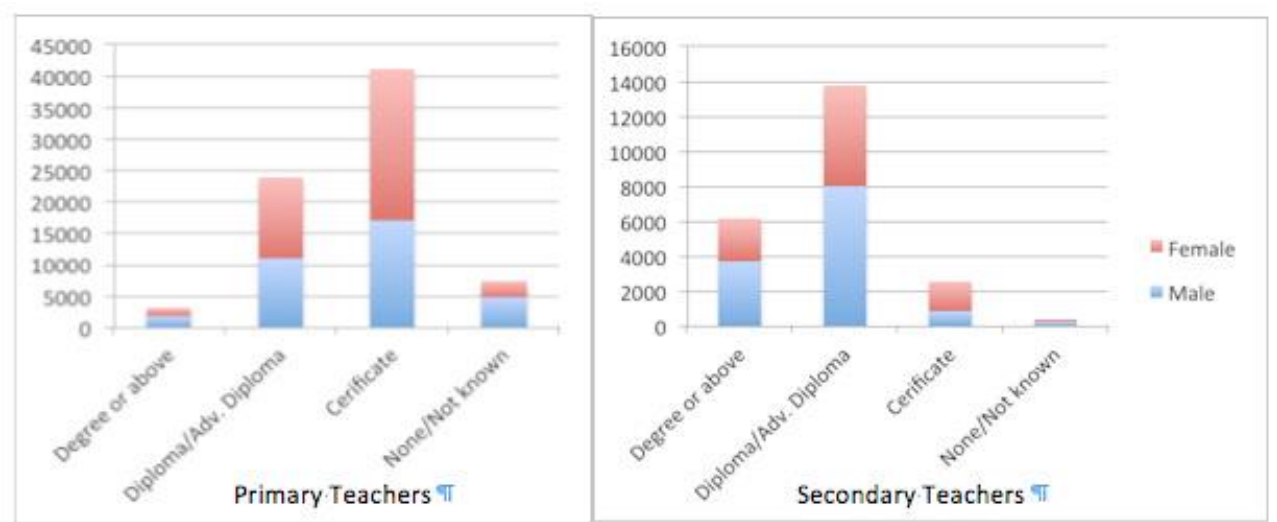

Figure 1.Teachers' professional qualifications by gender (MOGE, 2017)

It is therefore true that all teachers of mathematics in Zambia ought to demonstrate knowledge of mathematics topics in the syllabus and pedagogical expertise in order to teach effectively. The concept of a function is one of the important mathematical concepts which require teachers to exhibit deep understanding.

The concept of a function is central to understanding mathematics, yet students' understanding of functions appears either to be too narrowly focused or to include erroneous assumptions (Clement, 2001). The concept is central to students' ability to describe relationships of change between variables, explain parameter changes, and interpret and analyze graphs. Although the function concept is an important one in mathematics, research studies of high school and college students have shown that it is also one of the most difficult for students to understand (Kontorovich, 2017; Martinez-Planell et al., 2015; Paoletti, 2020; Ubah \& Bansilal, 2018). Thus, for teachers to effectively teach a concept (of functions) they need to possess an adequate level of mathematical knowledge of the concept (of a function) to provide instruction (Simon, 1993).

Although there are many studies on student understanding of the function concept, few studies to assess pre-service teachers' subject-matter and pedagogical content knowledge related to the concept of a function have been carried out. In particular, in Zambia there are barely any studies focused on pre-service teachers' subject-matter and pedagogical content knowledge of the function concept. This leaves teacher education programs in Zambian universities and colleges lacking in an 
understanding of this domain. The lack of studies focused on pre-service teacher' knowledge of the function concept in Zambia has created a gap in knowledge that this study seeks to fill. The original contribution of this study to the body of knowledge is not only outspreading the understanding of the interactions between subject matter knowledge (SMK) and pedagogical content knowledge (PCK) of Zambian pre-service teachers but also giving a foretaste into the Zambian pre-service teachers' competencies regarding the concept of a function and teacher education in Zambia.

\subsection{CONTEXT}

\subsubsection{Motivation}

My dream for mathematics education for Zambia is to see an educational system that maximizes opportunities for all children to learn mathematics at school, supporting them by making available all the resources that will materialize this dream. My dream is also to see teacher education programs able to empower them to assume high responsibility to structure modules that are responsive to ever changing mathematical needs in schools. Thus, I share the vision for mathematics education proposed by the National Council of Teachers of Mathematics (NCTM, 2000) dubbed Principles and Standards for School Mathematics (PSSM):

Imagine a classroom, a school or a school district where all students have access to high quality, engaging mathematics instruction. ... the curriculum is mathematically rich, offering students opportunities to learn important mathematical concepts and procedures with understanding. ... Students confidently engage in complex mathematical tasks chosen carefully by teachers. ... Teachers help students make, refine and explore conjectures on the basis of evidence and use a variety of reasoning and proof techniques to confirm or disprove these conjectures (NCTM, 2000, p. 3).

\subsubsection{Mathematics and teacher education in Zambia}

In Zambia, teacher education is provided by colleges of education and universities which are registered under the Ministry of Higher Education. Teacher education is provided by both public and private institutions for higher education and it is offered at diploma and degree levels under the following categories:

(a) Early Childhood Education (ECE) 
(b) Primary Teacher Education (PTE)

(c) Secondary Teacher Education (STE)

Mathematics is a major component of categories offered by colleges and universities. All the three programs (Early Childhood Education, Primary Education and Secondary Education) prepare teachers to qualify for a diploma or degree in education. Early Childhood Education prepares teachers to teach children between ages of 3 to 6 years in early childhood centers. All students on this program register for a compulsory mathematics education course or subject called pre-mathematics. In this course they learn many aspects of mathematics that they would teach the children. The Primary Teacher Education program prepares teachers who will teach grades 1 to 7 in primary schools and mathematics is taken by all students as a compulsory subject. Secondary Teacher Education program prepares teachers to teach Grades 8 to 12 at secondary school and A-Level mathematics at centers offering the program. Degree graduate teachers will qualify to teach senior secondary school (Grades 10-12) pupils while diploma holders will qualify to teach junior secondary school (Grades 8-9) pupils. Mathematics is an optional subject for students pursuing diploma and degree programs and those aspiring to teach mathematics are required to register the subject as one of the two teaching subjects.

\subsubsection{Teacher Training at the Copperbelt University}

This section highlights teacher training at The Copperbelt University where this study was conducted. According to the official Copperbelt University (www.cbu.edu.zm), The School of Mathematics and Natural Sciences was founded in 2009 with six departments, namely: Department of Physics, Department of Chemistry, Department of Biological Sciences, Department of Computer Science, Department of Mathematics and the Department of Mathematics and Science Education. Teacher training at the Copperbelt University is conducted in the Department of Mathematics and Science Education.

The department offers four-year Bachelor of Science degree programs to students that are planning a career in education. In liaison with the School of Graduate Studies the Department of Mathematics and Science Education also offers two postgraduate degree programs, namely: Master of Science (MSc.), with specialization in Biology Education, Chemistry Education, Mathematics Education or Physics Education, and Doctor of Philosophy (Ph.D.) in Mathematics and Science 
Education. All Masters Programs have duration of two years while Doctoral programs are offered over a period of three years. Suffice to mention here that the Department of Mathematics and Science Education's central role is to prepare and develop skills into graduate teachers for work in high schools and tertiary institutions of higher education. As outlined on the university website (www.cbu.edu.zm);

The overall objective of the [Mathematics and Science education] department is to enable students to acquire sufficient insight in the field of mathematics and science education. It also helps them to acquire practical knowledge which is necessary to function in education and transmission of knowledge. The personal development of students is furthered through independent work and pedagogical practices during their teaching practice.

All pre-service teachers pursuing the Bachelor of Science in Mathematics Education study compulsory Mathematics and Science Education (MSE) courses offered by the Department of Mathematics and Science Education and they take core mathematics content courses from the Department of Mathematics. All students study foundation and advanced mathematics courses. The Department of Mathematics and Science Education offers courses in Communication skills, Introduction to Education, Principles of Education, Education Media Technology, Education Research Methods, Education Administration and Management and Methods of Teaching Mathematics and Science.

Further to these educational courses, all pre-service teachers under this department undertake pedagogical practices through peer teaching within the university and school teaching practice in the final year of their degree program. Peer teaching is a formal preparation of pre-service teachers for school teaching practice. During peer teaching pre-service teachers are asked to prepare detailed lesson plans which they use to teach fellow students under the supervision of a lecturer.

Pre-service teachers' errors and shortcomings are identified at this point and lecturers together with the rest of the pre-service teachers reflect on the delivered lesson and offer advice for improvement on areas of need while pointing out strengths from the lesson. Peer teaching accords pre-service teachers an opportunity to acquire initial experience and practice in teaching and develop and possess important skills in subject matter, communication, motivation and behavioral management skills (Chen, 2017; Males, 2017). School teaching practice is a very 
important phase of teacher training as it gives student teachers an opportunity to experience actual teaching in a school environment and to proficiently apply theories and methods they studied while in university (Ministry of Education, 2013b). Studies have shown that pre-service teachers have exhibited problems in comprehensive math theory and practice (Brown et al., 2019; Basturk, 2009; Hennissen et al., 2017; Tok, 2010) which has led to teacher education providers to place high importance to teaching practice.

Pre-service teachers choose to undertake the school teaching practice in their school of choice. During this practice period pre-service teachers carry out their teaching duties just like the in-service teachers they find in schools. They participate in all school activities both core and extra curricula. They attend all school meetings and all professional development programs such as continuous professional development (CPD) meetings. Teaching practice is done over a period of three months which is a full term in the secondary school academic calendar in Zambia.

\subsubsection{Mathematics and the Secondary School curriculum in Zambia}

Zambia got independence from colonial rule in 1964. The post independent era gave birth to a lot of policy changes in the education sector of a newly independent Central African country with the sole purpose of uplifting the quality of education not only at secondary school level but all other levels. The education act of 1966 provided a legal framework for a thorough examination and major changes to the education system meant to standardize and diversify the curriculum with new topics introduced in the secondary school curriculum. Since then the Ministry of Education, Science, Vocational Training and early Education (MESVTEE) embarked on several reforms and policy changes that have seen a positive transformation of the curriculum. Notable changes included the educational reforms of 1977 and educational policies like Focus on learning (1992),

Other changes included documents like Educating Our Future (1996) and national implementation frameworks like the fifth national development plan. In spite of the educational reforms embarked upon by MESVTEE since 1964, student performance in mathematics at secondary school level has not been good enough (Figure 2). Junior secondary school level has seen less than two-thirds of candidates who sit for mathematics examinations passing mathematics. It is worse with secondary school candidates. On aggregate, one-third of boys and two-thirds of girls 
have completely failed mathematics since 2005, while only half of the boys and onefifth of girls have managed to obtain a pass or better with trigonometric functions being one of the most failed topics at senior secondary school level.

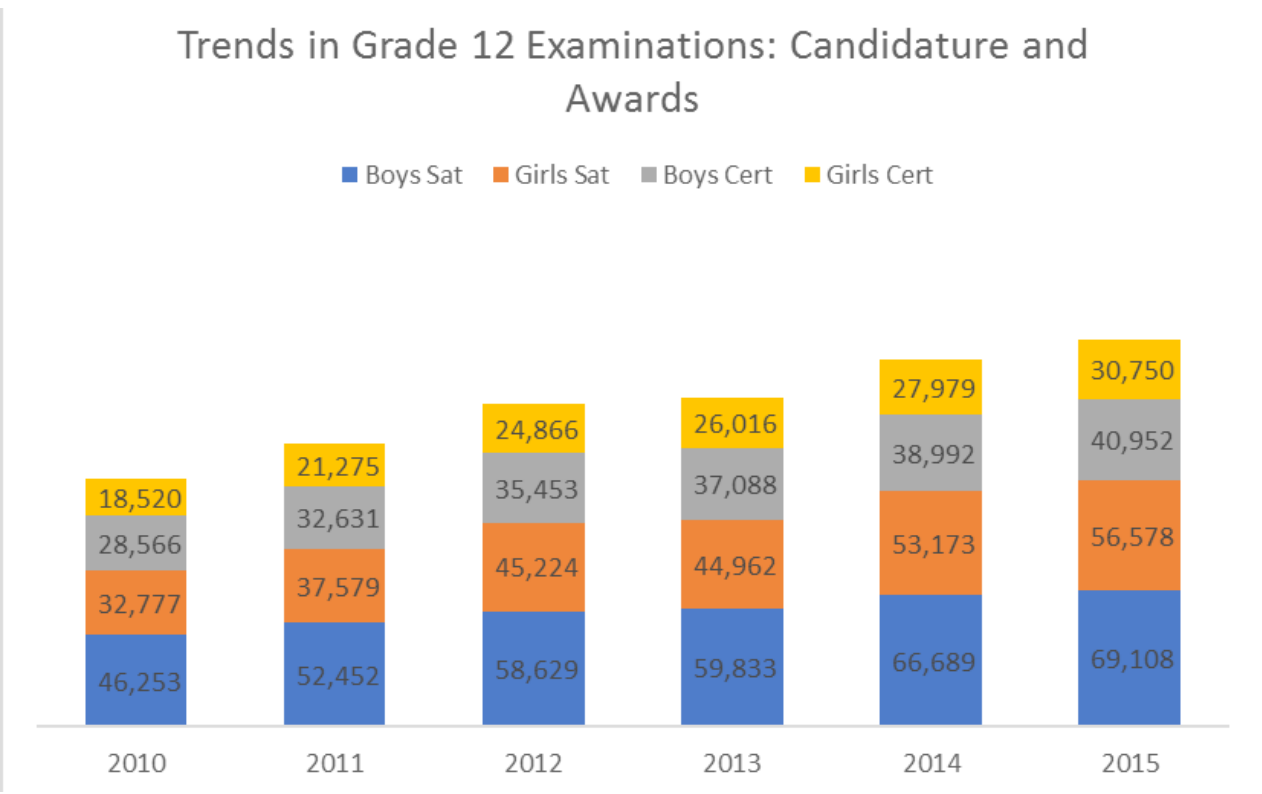

Figure 2. Trends of performance of Grade 12 students in national examinations by gender for the period 2010-2015

The curriculum has undergone several reviews aimed at re-defining desired learner outcomes by changing the content, structure and pedagogical strategies in order to develop a "learner who is responsive, accountable, well-educated and capable of applying knowledge, skills, attitudes and value systems of vocational and life skills to real life" (MESVTEE, 2013, p. 39). The MESVTEE has set as a priority the localization of the school curriculum to adapt it to local needs and circumstances. In its quest to improve and diversify the curriculum and to accord learners an opportunity to enrol in subjects which they have the greatest potential, the MESVTEE reviewed the curriculum by creating a career pathway system.

Two career pathways were formed; academic and vocational with senior secondary schools offering "academic" and "vocational" career pathways. In both pathways mathematics features as a compulsory subject which underpins the importance of the subject to the school curriculum. Figure 3 shows the structure of the senior secondary school curriculum highlighting compulsory subjects in each career pathway. 


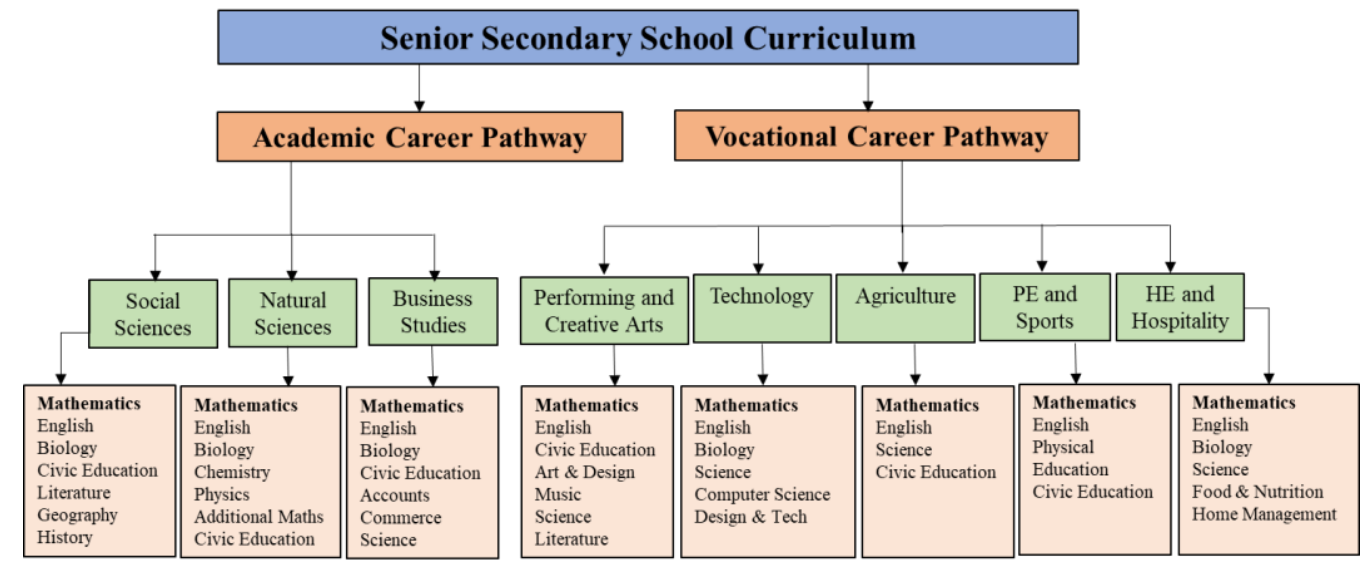

Figure 3. Zambia senior secondary curriculum structure (Adapted from ZCEF, 2013, p. 40)

\subsubsection{Rationale for conducting a study on functions}

The reasons for exclusively focusing on the topic of functions is because "Examining a specific topic also makes more vivid the contrast between some key characteristics of what pre-service teachers have learnt as students and what they need to know as teachers" (Ball, 1990, p. 451).

Studies have revealed that the concept of function is one of the most essential topics in the mathematics curricula of both secondary school and university education and as such it is perceived to be a unifying concept (Dubinsky \& Wilson, 2013; Even \& Tirosh, 1995; Nyikahadzoyi, 2015). It is especially problematic in secondary school for students to understand and teachers to teach satisfactorily. This is supported by evidence from some studies that have revealed that students struggle to understand the concept of functions (Bloch, 2003; Even, 1993; Spyrou \& Zagorianakos, 2010). It was revealed in Spyrou \& Zagorianakos's (2010) study that students had problems observing many-to-one relations as functions.

Several scholars in a variety of studies seem to have a common ground in agreeing that the concept of a function is of fundamental importance in mathematics and that a solid understanding of the topic plays a vital role in the academic pursuit of higher mathematics and in all applied fields (Even, 1998; Watson \& Harel, 2013). According to Akkoc (2008), the concept of a function plays a central role in the study and understanding of topics like pre-calculus, calculus, trigonometry, and in the study of physics and related areas, and they form a solid foundation in secondary school mathematics. 
Having taught functions in secondary school for over 10 years I have observed that indeed students find it difficult to comprehend functions and even relate function concepts to real life situations and to concepts in other related subjects. I have also worked closely with teachers who have come to my school for their teaching practice and how they particularly struggle to effectively unpack the topic into concepts easy enough for their students to understand. Thus, the selection of the topic 'functions' was largely influenced by the aforestated and explained reasons.

\subsection{PURPOSES}

It is common knowledge that teachers cannot teach students and help them learn and comprehend concepts they themselves do not understand (Ball, 1991). According to Isiksal and Cakiroglu (2011) "To improve mathematics instruction, teachers need to challenge and support students and have a sound understanding of the gap between what students know and what they need to learn" (p. 214). Therefore, the purpose of this study was to examine knowledge held by pre-service secondary school mathematics teachers in the topic functions. This study attempted to characterize the depth of Zambian pre-service secondary mathematics teachers' subject-matter and pedagogical content knowledge of the concept of a function. By comparing the level of knowledge of functions of Zambian pre-service secondary mathematics teachers with findings from similar studies carried out in other contexts, this study attempted to bridge a gap in comparative studies in literature.

\subsection{SIGNIFICANCE, SCOPE AND DEFINITIONS}

\section{Significance and scope of the study}

Functions is regarded a very important topic in the Zambian secondary mathematics curriculum and a deeper understanding of the concept of a function creates a solid foundation for learning several other mathematics topics and advanced mathematics concepts. However, there is research evidence suggesting that both preservice and in-service teachers are struggling and exhibit limited knowledge of many aspects of the topic (Cho \& Moore-Rosso, 2014; Kontorovich, 2017; Malambo, 2016; Ubah \& Bansilal, 2018; Wasserman, 2017). 
Thus, this study has important implications for curriculum development in teacher training programs in universities and colleges offering mathematics teacher education in Zambia. The results of this study would help mathematics educators at Copperbelt university and other universities in Zambia in understanding the Common Content Knowledge, Specialized Content Knowledge and teachers' knowledge of student errors, misconceptions and difficulties of the function concept that Zambian

The methods and results employed in the study will serve as a basis for further research in the topic of functions and other areas of mathematics knowledge required of secondary school teachers. The results will also help those responsible for developing appropriate mathematics curricula for pre-service teachers' mathematics content courses at Copperbelt university to structure a curriculum that maximize acquisition of relevant skills.

There is a research gap in teachers' mathematics knowledge for teaching the function concept in Zambia, with one study (Malambo, 2016) being the only extensive study in this regard. Thus, this study aspires to contribute to the knowledge base of what we know about Zambian pre-service secondary teachers' mathematics knowledge for teaching functions. Specifically, the study will contribute to the literature on pre-service Zambian teachers' mathematics knowledge for teaching functions.

\section{Definition of terms}

The following terms and their operational definitions were used throughtout the study. Their applicability to the study is explained in Chapter 2 of the study.

Mathematical knowledge for teaching: Hill et al., (2005) defined it as the

Mathematical knowledge used to carry out the work of teaching mathematics. Examples of this work include explaining terms and concepts to students, interpreting students' statements and solutions, judging and correcting textbook treatment of particular topics, using representations accurately in the classroom, and providing students with examples of mathematical concepts, algorithms, or proofs (p. 373).

Common content knowledge: Refers to knowledge that teachers use to teach mathematics in classrooms. Teachers use this knowledge domain to solve 
mathematical problems as prescribed in the curriculum (Ball et al., 2008). Teachers rely more on common content knowledge in their work of teaching. Common content knowledge is essentially concerned with defining and identification of examples and non-examples of the concept.

Specialized content knowledge: Refers to the special form of knowledge needed by teachers to decompress and unpack concepts in such a way that the content being taught is visible to and learnable by their students (Ball et al., 2008). Thus, this kind of knowledge provides teachers unique mathematical understanding and reasoning which is key to making students understand and develop desired knowledge. For example, teachers must know different definitions of concepts and be able to decide the appropriate definition to use depending on context. Teachers must know alternative ways of solving mathematical problems to elicit understanding by their students.

Pedagogical content knowledge: In the context of this study pedagogical content knowledge basically refers to teachers' knowledge of the difficulties, conceptions, misconception and errors that their students are faced with. The teacher must be able to have knowledge of the thinking process of their students by merely inspecting student solutions to mathematical problems. Teachers must detect errors in student work and must identify misconceptions and conception students have about mathematical concepts. This enables teachers to develop appropriate interventions that promote understanding among their students.

Pre-service mathematics secondary teachers: University students enrolled in a Bachelor of education leading to the award of a degree in mathematics education Mixed methods: According to Creswell and Plano-Clark (2007),

Mixed methods research is a research design which involves philosophical assumpsions that guides the direction of the collection and analysis of data and the mixture of qualitative and quantitative approaches in many phases in the research process. It focuses on the collection, analysis and mixing of both quantitative and qualitative data in a single study or series of studies. Its central premise is that the use of quantitative and qualitative approaches in combination provides a better understanding of research problems than either approach alone (p.5). 


\subsection{RESEARCH OBJECTIVES AND QUESTIONS}

This section outlines the research objectives and questions of this study. The section begins by stating the general objective before the specific objectives. Finally, the research questions that the study sought answers are then listed.

\subsubsection{Research objectives}

\section{General objective}

The general objective of this study was to characterize and describe the subject matter and pedagogical content knowledge levels of Zambian pre-service secondary mathematics teachers concerning the topic of functions by giving a deep reflection of the types of knowledge possessed. The participants were university students originating from The Copperbelt University and Mukuba University located in Copperbelt province of Zambia. All of whom had their majors in Mathematics.

\section{Specific objectives}

1. To characterize the depth of Zambian pre-service secondary mathematics teachers' Common Content Knowledge, Specialized Content Knowledge and Mathematical Pedagogical Content Knowledge of functions.

2. To provide descriptions about differences between Zambian pre-service secondary mathematics teachers' Common Content Knowledge, Specialized Content Knowledge and Knowledge of Content and Students of the function concept.

3. To compare the level of knowledge of functions of Zambian pre-service secondary mathematics teachers with findings from similar studies carried out in Zambia and abroad.

\subsubsection{Research questions}

With the purpose of examining the level of knowledge of Zambian pre-service secondary mathematics teachers in the topic functions, answers to the following questions were sought.

1. What is the level of knowledge of functions among Zambian pre-service secondary school mathematics teachers? Precisely,

(a) What level of Common Content Knowledge of functions is held by preservice secondary mathematics teachers? 
(b) What level of Specialized Content Knowledge of functions is held by preservice secondary mathematics teachers?

(c) What is the level of Knowledge of Content and Students (KCS) related to functions of pre-service secondary mathematics teachers?

(d) What perceptions of Pedagogical Content Knowledge (PCK) of the concept of a function are held by pre- service secondary mathematics teachers?

(e) How do pre-service teachers explain and justify their reasoning when solving questions involving the concept of a function?

2. How does the level of knowledge of functions of Zambian pre-service secondary mathematics teachers reported in Question 1 compare with findings from similar studies carried out in Zambia and abroad?

\subsection{THESIS OUTLINE}

This section presents the outline of the whole thesis. The thesis contains six Chapters (Figure 4) sub-divied into several sections. Figure four only shows the major sections of the Chapters. 


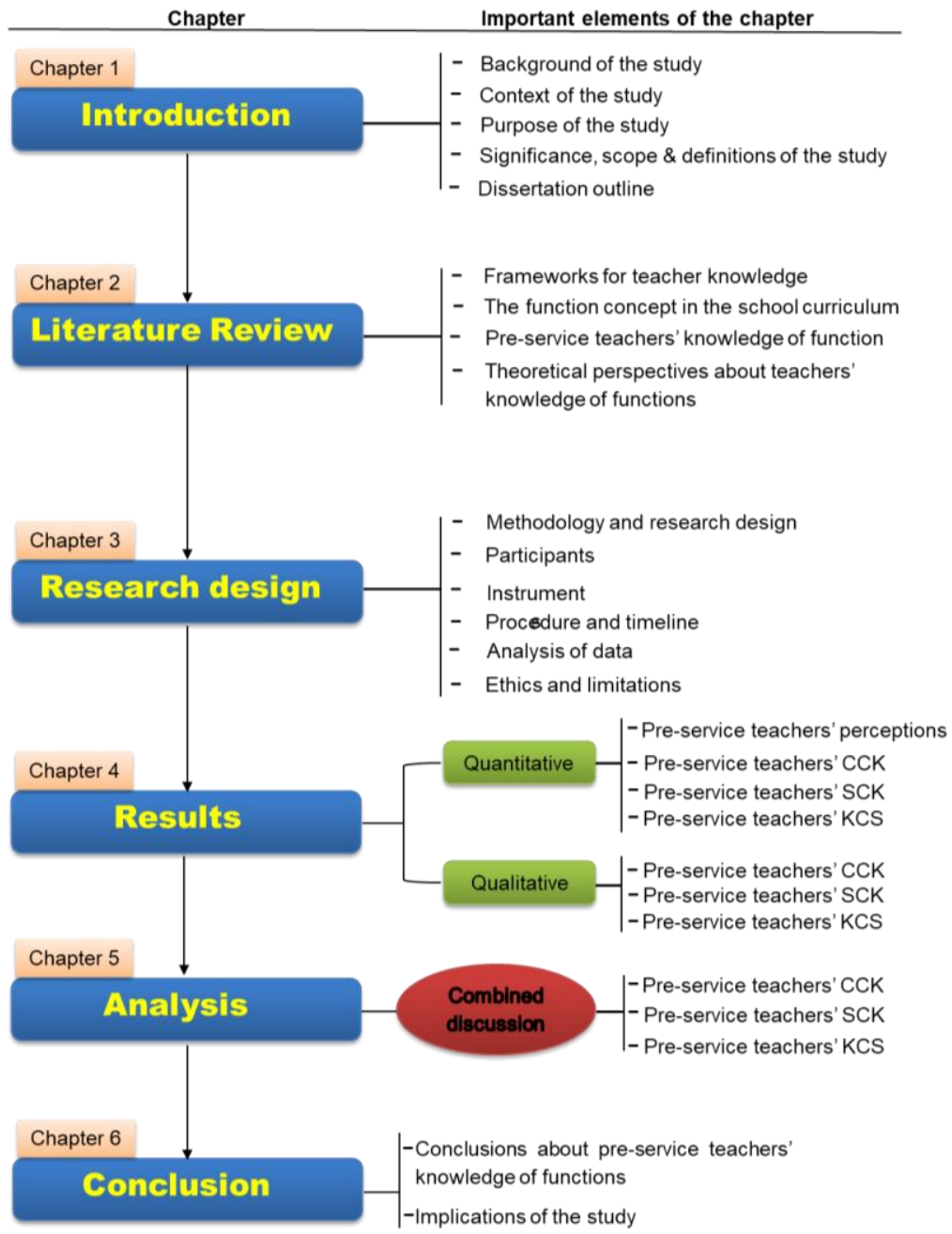

Figure 4. Visual representation of theThesis outline 


\section{Chapter 2: Literature Review}

This chapter begins with a historical background of frameworks for teacher knowledge (section 2.1) and dicusses the theoretical framework for the current study (section 2.2). This is followed by the overview of literature about MPCK and the function concept (section 2.3). A focused review is then presented on pre-service teachers' CCK, SCK, KCT and KCS (section 2.4) before highlighting the conceptual framework (section 2.5). Section 2.6 highlights the summary and implications from the literature for the study.

\subsection{FRAMEWORKS FOR TEACHER KNOWLEDGE}

Several scholars have invested time and energy in research about teacher knowledge. Various theoretical frameworks for teacher knowledge have been formulated with little agreement of the definition of components of these models (Ball et al., 2008; Davis \& Simmt, 2006; Fennema \& Franke, 1992; Grossman, 1990; Leinhard \& Smith, 1985; Mark, 1990; Shulman, 1986; Shulman, 1987). Because the purpose of this study is to gain insight into the subject-matter knowledge and pedagogical content knowledge of pre-service teachers, this section presents a detailed analysis of some of the frameworks provided by these scholars. This detailed review of the frameworks helped the researcher in locating the present study in theory and establish its relevance to the field of mathematics education.

\subsubsection{Pedagogical Content Knowledge (PCK) - Lee Shulman $(1986,1987)$}

Shulman's ideas about knowledge of pedagogy and knowledge of the subject matter gave birth to new perspectives that to this day have redesigned research in the field of mathematics education. What was meant to be Shulman's presidential address to the American Research Association (1986) would later be the focal point and lens through which researchers and teachers perceive the role of (mathematics) content in teaching. Shulman sparked renewed interest among mathematics educators about the subject matter knowledge that is unique to teaching.

Since his presidential address (1986) on teacher knowledge and follow-up Harvard Education review article (1987), Ball et al. (2008) noted that Shulman's 
ideas "have been cited in more than 1200 referred journal articles" (p. 392) on education related research. Shulman (1986) argued that there was a "missing paradigm" in research studies on teaching. He observed that research on education which was largely influenced by behaviourist movement lacked focus on the knowledge of content. Behaviourist oriented research concentrated on processproduct studies which Hill et al. (2005) claimed to be "the large set of studies describing the relationship between teacher behaviours and student achievement" ( $p$. 373) and in studies that investigated teachers' knowledge characteristics.

Shulman contended that there was a knowledge base unique to teaching that deserved to be explored through research. The mid 1980s marked the genesis of research that focused on subject matter knowledge (Shulman, 1987; Wilson et al., 1987; Grossman et al., 1989; Grossman, 1990). Shulman categorized seven knowledge bases for teaching: knowledge of content, knowledge of curriculum, knowledge of pedagogy, pedagogical content knowledge, knowledge of learners and learning, knowledge of context of schooling and knowledge of educational philosophies, goals and objectives (Figure 5). Of interest to this present study is knowledge of content and pedagogical content knowledge bases.

Shulman (1986) posited that content knowledge was "beyond knowledge of the facts or concepts of a domain" ... it is about "the variety of ways in which the basic concepts and principles of the discipline are organized to incorporate its facts" (p. 9). It is implied here that teachers' knowledge of content encompasses knowledge of how to structure and organise concepts of the discipline. Teachers should not simply memorise mathematical concepts or facts but should be able to competently explain conditions under which particular prepositions would or would not hold true. Teachers ought to be able to understand "the set of ways in which truth or falsehood, validity or invalidity, are established" (1986, p. 9) for effective teaching to take place. Any gaps in content knowledge of the teacher entail serious deficiencies in the organisation and structure of learning activities for the learners.

Shulman's conceptualisation of PCK which is his most notable contribution to education was a general framework which was not subject specific. Among the seven categories of knowledge that he postulated, pedagogical content Knowledge has received the most attention from researchers with studies on this topic springing from a wide range of subject areas. According to Shulman (1987), pedagogical content 
knowledge is "the category most likely to distinguish the understanding of the content specialist from that of the pedagogue" (P. 8). This was motivated by the realisation that content and pedagogy were inseparable if effective teaching was to be achieved and the indissoluble bond between the two knowledge bases led to scholars trying to explore mechanisms of finding a balance between them in teacher education. This was justified when Shulman (1987) explained that

Among the categories of knowledge, pedagogical content knowledge is of special interest because it identifies the distinctive bodies of knowledge for teaching. It represents the blending of content and pedagogy into an understanding of how particular topics, problems, or issues are organized, represented and adapted to the diverse interests and abilities of learners, and presented for instruction. (P. 8)

To unpack this knowledge, pre-service teachers should possess specific skills in both content and pedagogy which are acquired during teacher training and developed throughout their teaching career. These skills are necessary for bridging the gap between subject matter knowledge and knowledge for selecting appropriate strategies for effective teaching in classrooms. Shulman (1987) emphasized that pedagogical content knowledge was the very foundation for good teaching when he explained that it constituted

the most useful forms of those ideas, the most powerful analogies, illustrations, examples, explanations and demonstrations-in a word, the most useful ways of representing and formulating the subject that make it comprehensible to others ... pedagogical content knowledge also includes an understanding of what makes the learning of specific topics easy or difficult: the conceptions and preconceptions that students of different ages and backgrounds bring with them to the learning of those most frequently taught topics and lessons. (p. 9)

Zambian pre-service teachers need to employ practical demonstrations in class to compliment verbal expalnations when teaching mathematics and particularly the concept of a function. Analogies and illustrations would enable students relate the concept of a functions to their everyday life at home and at school. If students are able to relate concepts learnt at school to phenomena in their immediate environment it means that they increase chances of fully understanding and applying concepts. 


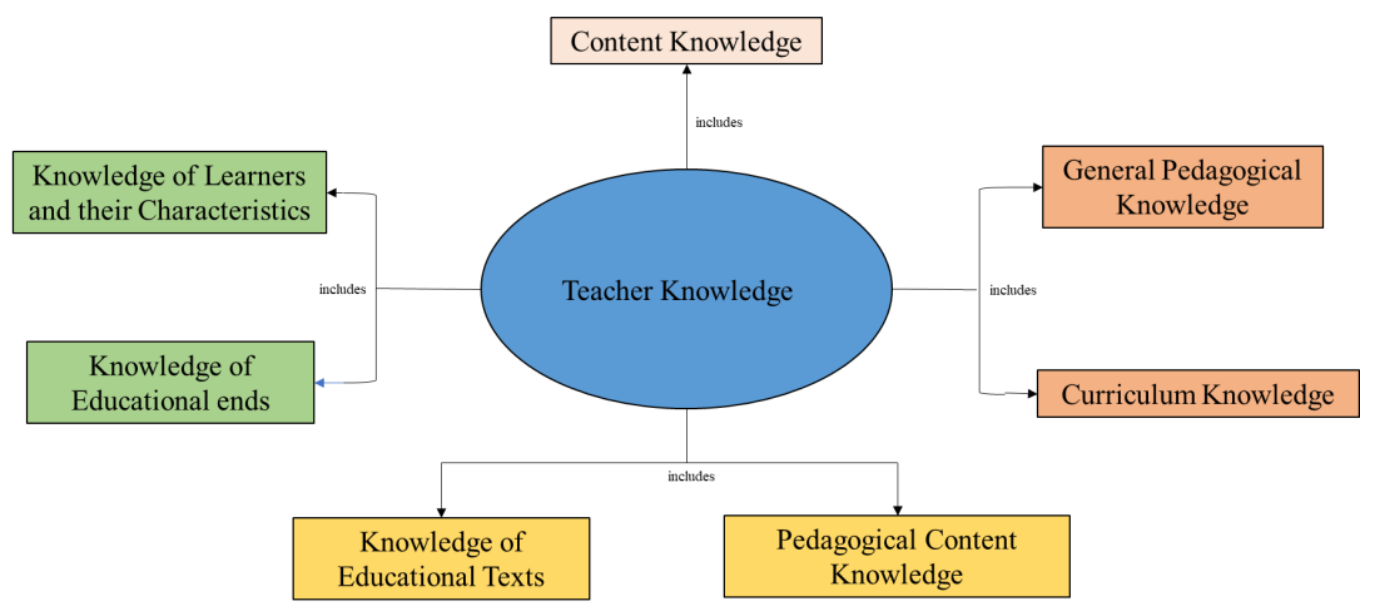

Figure 5. Framework for teacher knowledge ofr teaching by Lee Shulman (Adapted from Somayajuru, 2012)

\subsubsection{Grossman's Model of Teacher Knowledge (1990)}

Grossman's (1990) theoretical framework for teacher knowledge was motivated by Shulman's (1987) conceptualisation of the seven categories of knowledge for teaching. Grossman restructured categories of the knowledge base for teaching initially proposed by Shulman into four interacting knowledge domains. Her proposed framework of teacher knowledge for teaching was composed of: general pedagogical knowledge, pedagogical content knowledge, subject-matter knowledge and knowledge of context.

To come up with these four categories of knowledge, Grossman based her work on case studies of six English teachers in their first year in secondary school. Three teachers were novices without prior teaching experience and the other three had completed a fifth-year teacher education programme. The model was formulated from results obtained by contrasting the two groups of teachers. In her model, Grossman noted that pedagogical content knowledge had a direct interaction with the other three knowledge domains, and beliefs formed part of this category.

According to Grossman (1990), pedagogical content knowledge comprised "knowledge and beliefs about the purposes for teaching a subject at different grade levels." (p. 8) and included students' understanding of concepts of a subject, their conceptions and misconceptions, and teachers' knowledge of instructional strategies suitable to deal with these aspects. One of the factors that influence how teachers teach is their beliefs about the subject, beliefs about teaching and beliefs about learning. This qualifies teacher beliefs to hold an important place in everything a 
teacher does. Grossman et al. (1989) emphasized this point when they stated that "no discussion of teacher knowledge would be complete without an accompanying discussion of teacher beliefs, for it is difficult sometimes to differentiate between the two" (p. 31).

Like Shulman (1987), Grossman et al. maintained that the subject-matter knowledge base should be composed of syntactic and substantive structure of the discipline. Grossman et al. (1989) posited that "substantive structures of a discipline deal with the frameworks or paradigms that are used both to guide inquirí and to make sense of data" (p. 29). This implies that substantive knowledge prescribes how teachers facilitate their students' learning and their own learning of mathematics. Syntactic knowledge deals with understanding how new ideas and knowledge are incorporated in the field. Thus, both substantive and syntactic knowledge types are fundamental in the knowledge development of teachers and in the way they teach their students.

The general pedagogical knowledge category was concerned with teachers' skills in the management of their classrooms during and after lessons, teacher-pupil relationships that ensured that there were no barriers that prevented students from learning during lessons, and teacher knowledge of curriculum implementation. Knowledge of context had to do with understanding the communities where students come from and how best to ensure that a conducive school learning environment was provided for them.

Figure 6 shows Grossman's model of teacher knowledge. It can be seen that knowledge structres and domains are closely related which imploes that Zambian pre-service teachers need to take a holistic approach in their use and implementation of Grossman's model. It is important for hteachers to understand and appreciate communities where their learners come from. Otherwise it would be impossible to manage them during lessons in class. Classroom managent, curriculum implementation by way of structuring instruction is dependent on understanding student characteristics which includes a good understanding of communitires where they live. This would set the tone for effective teaching for the teacher and good inclusive learning for the students. Thus, components of subject matter knowledge are highly related just like those of pedagogical content knowledge and a teacher 
needs to have knowledge of how they interact and complement each other during the teaching process.

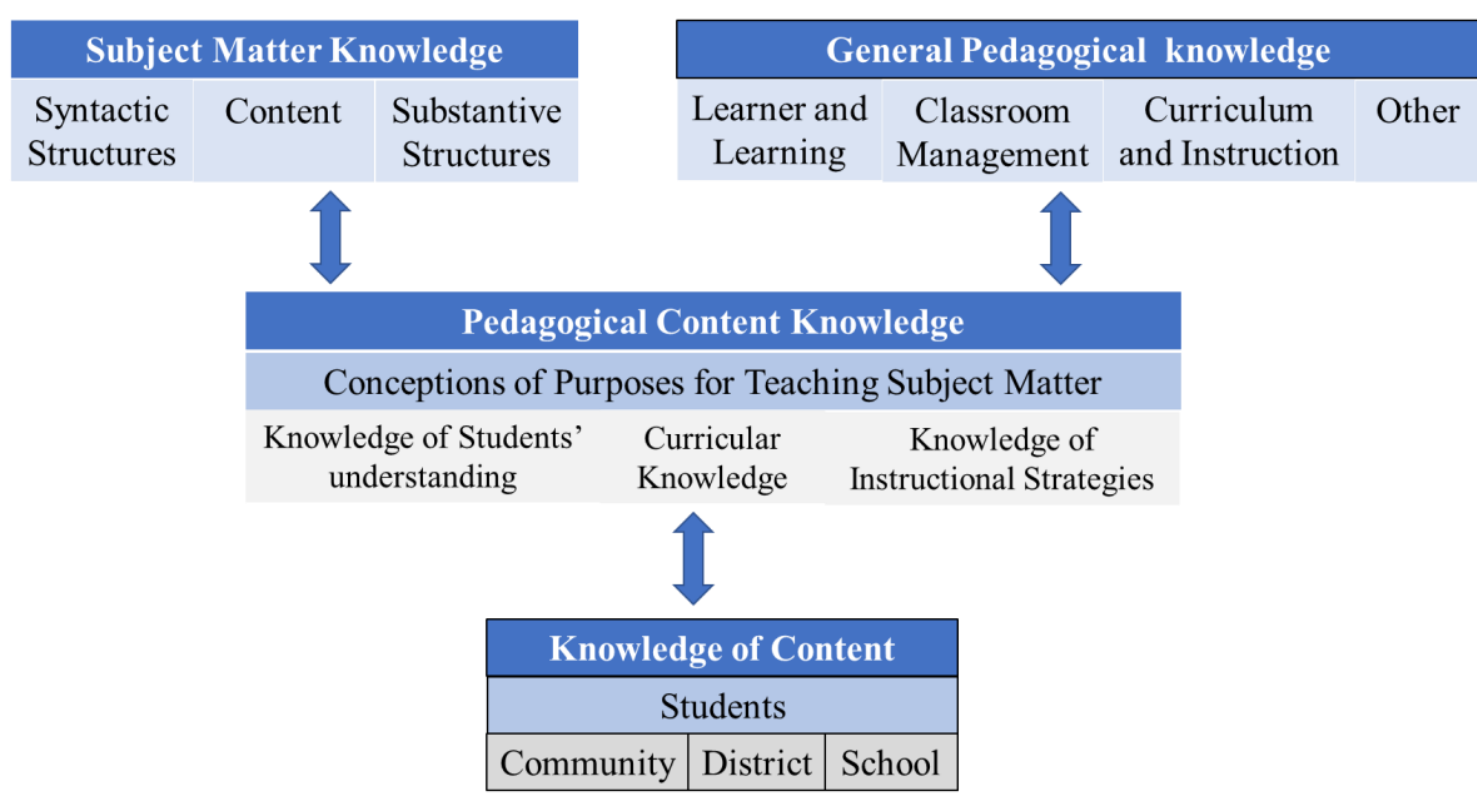

Figure 6. Grossman's model of teacher knowledge (Grossman, 1990, p. 5)

\subsubsection{Technological Pedagogical Content Knowledge (TPACK) Framework - Mishra and Koehler (2006)}

The concept of TPACK was introduced by Mishra and Koehler (2006) as a framework to help teachers integrate technology in their teaching strategies. By the time Mishra and Koehler were launching the TPACK framework, there was already a conceptual framework in play called the Pedagogical Content Knowledge (PCK) introduced by Shulman (1986). For about two decades PCK had well been used and integrated into instruction by teachers and teacher educators.

Mishra and Koehler then added the technology domain to come up with today's TPACK which has proved very successful for teaching with technology. Though conceptualised as a holistic framework for effective teaching with technology, the framework can be broken into three levels of knowledge bases with one level giving rise to the next. The first knowledge base is composed of Technological knowledge (TK), Pedagogical Knowledge (PK) and Content Knowledge (CK) which combine to yield the second knowledge base constituting Technological Content Knowledge (TCK), Technological Pedagogical Knowledge (TPK) and Pedagogical Content Knowledge (PCK). The first and the second level knowledge bases combine to give rise to the third and highest knowledge base known as Technological Pedagogical Content Knowledge (TPACK) which is the heart of the entire concept. Many 
scholars have reiterated that knowledge of TPACK is important for teachers to integrate technology in teaching (Aminah et al., 2020; Chai et al., 2020; Ekmekci et al., 2019; Niess, 2005; Mishra \& Koehler, 2006).

In recent studies researchers have continued to explore how to develop, apply and assess modalities helping pre-service teachers' aquisition of TPACK and to have sound technology decision making (Dalal et al., 2017; Harris et al., 2017) and teachers' capacities for designing learning cultures that embrace use of technology to simplify concepts (Chai et al., 2017).

"Technological Knowledge" refers to student teachers' knowlege of identifying 'technology tools' that should be used in class for effective teaching. "Pedagogical Knowledge" is teachers' knowledge of instructional strategies including knowledge selection of appropriate teaching approaches, skills for assessing and evaluating learner performance and proper delivery of the subject matter. "Content Kowledge" is basically student teachers' knowledge of the subject matter which is aquired through specialised training in colledge or university. "Pedagogical Content Knowledge" being teachers' knowledge of integrating teaching strategies in the effective delivery of content.

“Technological Pedagogical Knowledge" refers to teachers' knowledge of effective use technology with suitable teaching strategies. It is a blend of technology use and teaching strategies and approaches. "Technological Content Knowledge": Teachers' knowledge of understanding which technologies are suitable for teaching specific subject matter and vice-versa and "Technological Pedagogical Content Knowledge" as teachers special knowledge of effectively selecting and integrating the most suitable technologies in teaching content using appropriate pedagogical strategies in a manner that enhances maximum benefit of the learners in the learning process. The TPACK framework as conceptualised by Mishra and Koehler, with all its constracts explained, is presented in Figure 7 hereunder.

With technology taking center stage in education pre-service teachers ought to ensure high rates of technology use during the teaching and learning process. With a lot of modern students having a good technology orienting from home it is important for the teacher to expose them to using technology when learning the concept of a function. Technological tools can be interesting to students when learning grapghing of functions thereby enhancing concept understanding. 


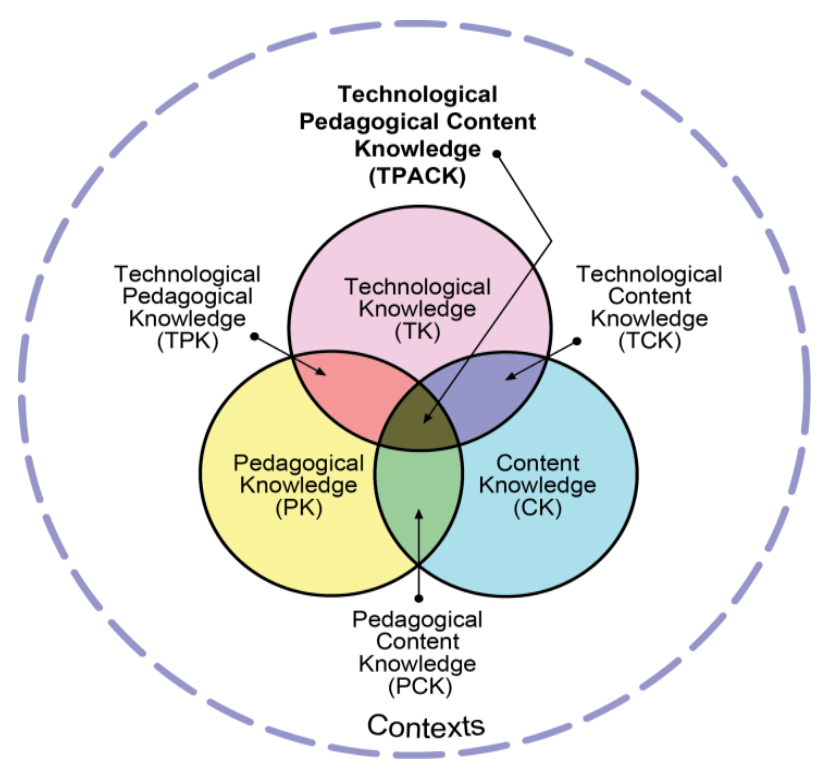

Figure 7. TPACK framework (Koehler \& Mishra, 2009, p. 63)

\subsection{THEORETICAL FRAMEWORK FOR THIS STUDY}

After careful consideration of a number of frameworks needed for teacher knowledge, the Mathematical Knowledge for Teaching (MKT) by Ball and colleagues was adopted to underpin the theoretical base upon which pre-service teachers' knowledge of the function concept would be explored. This framework was selected ahead of many other frameworks for teachers' mathematical knowledge because it comprehensively encampuses both subject matter knowledge and pedagogical content knowledge for teaching. The researcher acknowledges the critics of this model but still found it suitable for addressing the purpose of this study and to provide answers that were sought by the research questions. The MKT provided a sound theoretical foundation for the current study.

\subsubsection{Mathematical Knowledge for Teaching (MKT) Framework - Ball et al. (2008)}

Research has showed that a lot of studies have been conducted in relation to teachers' mathematical knowledge for teaching owing to the fact that teacher's knowledge has great influence on what and how one would teach students in class (Borkoet al., 1992; Even, 1993; Fennema \& Franke, 1992; Ma, 1999; Sowder, Philips, Armstrong \& Schappelle, 1998; Swafford et al., 1997). It is important for a teacher to possess adequate knowledge of mathematics subject matter content and necessary pedagogical knowledge to be able to teach effectively and impact positively on the learners (Doreen et al., 2002; Lappan \& Ferrini-Mundy, 1993; 
NCTM, 1991; The Educational alliance, 2006). Upon extensive review of existing literature about teacher knowledge for teaching, Ball and colleagues (2008) developed a subject specific theoretical framework called Mathematical Knowledge for Teaching (MKT) which has continued to be the main framework for research in teachers' knowledge of mathematics subject matter and pedagogical content knowledge (Cantley et al., 2020; Clark, 2019; Morgart, 2019; Ronau et al., 2020; Sahidin et al., 2019; Scheiner et al., 2019).

It has not gone without criticism of the components that form this framework. A major concern highlighted by Carrillo et al. (2013) being its tendency for the subdomains that make up the model to overlap which led them to re-interpret and rename components of MKT in what they came to refer to as a reformulation of MKT. For instance, Carrillo and collaborators claim that the the conceptualization of the difference between CCK and SCK in the MKT framework seems to suggest that all teachers' knowledge is specialized. This leads to difficulties in applying the MKT framework to specific cases of mathematics lessons especially that it also does not incorporate other important aspects of knowledge like teachers' beliefs about mathematics subject matter and mathematics pedagogy. Carrillo et al. (2013) argued, reasonably so, that there is no clear departure from where CCK ends and where SCK begins. They also contended that CCK would better be defined strictly in terms of "mathematics knowledge itself, without reference to other professionals or qualifications". This argument is valid because much as CCK can include knowledge of other professionals, it is strictly needed for the purpose of teaching and its definition ought to be restricted to mathematics knowledge explicitly referring to teachers. They also argued that the way in which SCK is defined in the MKT framework seems to overlap to other constructs like HCK and KCS and they attempted to redefine MKT constructs in a way that presents explicit demarcations between them.

Their reformulated model was called the Mathematics Teacher's Specialized Knowledge (MTSK). The MTSK on one hand comprised elements related to Mathematics Knowledge (MK) namely Knowledge of Topics (KoT), Knowledge of the Structure of Mathematics (KSM) and Knowledge of the Practice of Mathematics (KPM). On the other hand the MTSK comprised elements that related to teacher's pedagogical content knowledge (PCK) namely Knowledge of Features of Learning 
Mathematics (KFLM), Knowledge of Mathematics Teaching (KMT) and Knowledge of Mathematics Learning Standards (KMLS). The detailed explanations of the MTSK framework are beyond the scope of this study. Thus, for the actual meaning of the knowledge domains that form the framework, details can be obtained from Carrillo et al. (2013). Figure 8 shows a visual representation of the MTSK framework.

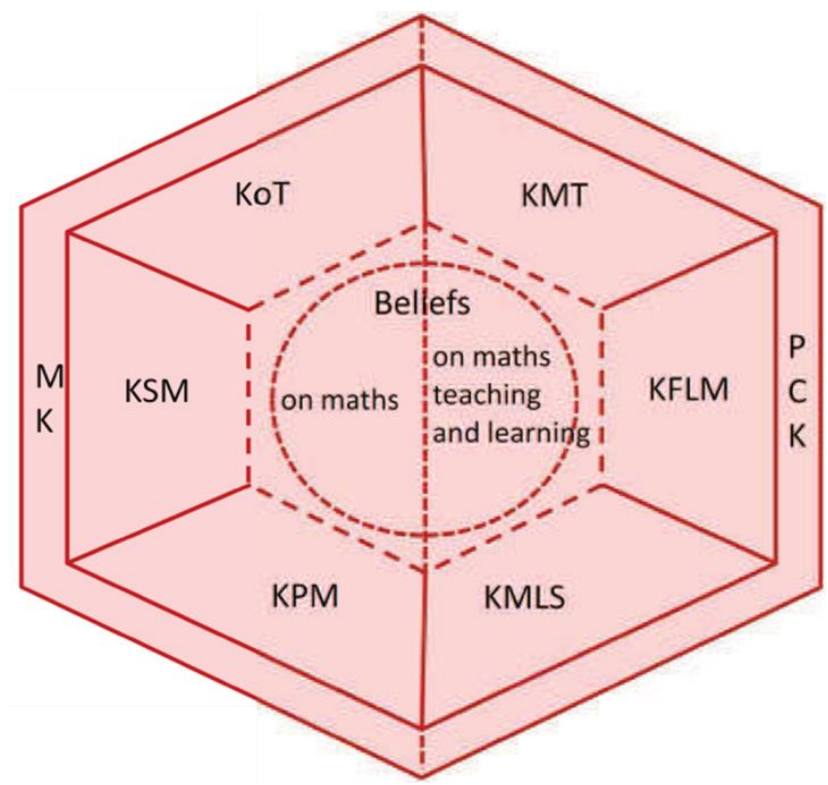

Figure 8. Visual model of the MSTK framework (Carrillo et al., 2013, p. 2989)

However, considering many other characterizations of knowledge that have been developed, as Carrillo and collaborators acknowledge, the MKT remains the most popular theoretical framework and powerful tool for describing knowledge required by teachers in their professional practice. Its tendency to identify elements that constitute Subject matter knowledge and pedagogical content knowledge while emphasizing the need to integrate the two has not only popularized it among researchers but has also made it user friendly for scholars investigating teacher knowledge for teaching mathematics.

What makes the MKT framework to stand out among many models that have been developed to study teacher knowledge of mathematics is basically the differentiation of its main and sub-domains. The two major domains being Subject matter knowledge which comprises specialized content knowledge (SCK), common content knowledge (CCK) and horizon content knowledge (HCK) and the other being pedagogical content knowledge comprising knowledge of content and students 
(KCS), knowledge of content and teaching (KCT) and knowledge of curriculum (KoC). Figure 9 shows a visual representation of the MKT framework.

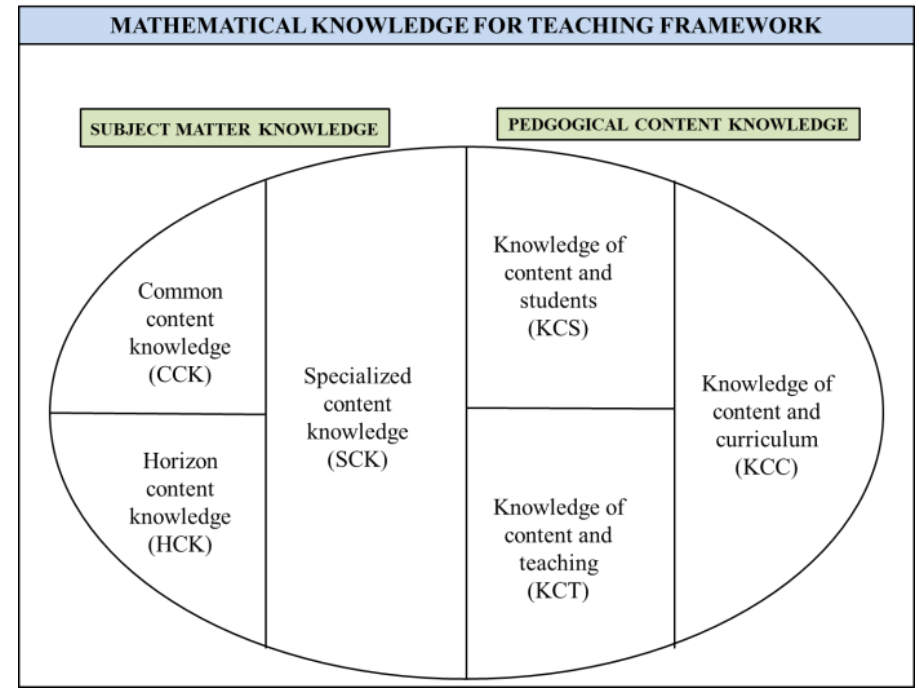

Figure 9. MKT framework (Hill et al., 2008, p. 377)

\section{Common content knowledge (CCK)}

Common content knowledge is mathematical knowledge that is not unique to teachers of mathematics, but is also known and used by other professionals, like engineers and economists to find answers to problems (Bair \& Rich, 2011; Ball et al., 2008). Holmes (2012) adapted this definition and described CCK as "the mathematical knowledge that any educated professional would know" (p. 65). Thus, common content knowledge can be used in similar ways by teachers and other individuals who are in non-teaching professions that nevertheless use mathematics (Malambo, 2016).

CCK is the "knowledge of mathematics that was common across professions and available in the public domain" (Hill et al., 2007, p. 131). Possession of common content knowledge allows teachers to "compute, make correct mathematical statements ... , solve problems" (Hill et al., 2004, p. 16). Common content knowledge also enables teachers to "know the material they teach and recognize when their students give wrong answers or when the text book gives an inaccurate definition and use terms and notations correctly" (Ball \& Phelps, 2008, p. 399). The construct of common content knowledge, as explained by Ball and Phelps, when it was first introduced to the fieled of mathematics education is the kind of mathematical knowledge used by other professionals who are not mathematics educators (Yecihi, 2014). 


\section{Specialized content knowledge (SCK)}

Specialized content knowledge has been conceptualized as knowledge that has a relationship with the practice of teaching, but which is, however, distinctively mathematical (Schilling et al., 2008). Furthermore, Schilling et al., 2008 posit that SCK is:

The mathematical knowledge and skill unique to teaching ... SCK is mathematical knowledge not typically needed for other purposes other than teaching. In looking for patterns in student errors or in sizing up whether a nonstandard approach would work in general ... teachers have to do a kind of mathematical work that others do not. This work involves an uncanny kind of unpacking of mathematics that is not needed or even desirable in settings other than teaching ... everyday tasks of teaching are distinctive to this special work ... something teachers routinely do (p. 400).

The quotation above implies that SCK is unique to people engaged in teaching mathematics. It includes mathematics teachers' ability to make explanations and representations of mathematics concepts, as well as their ability to comprehend solutions that are non-routine (Ball et al., 2005). Arguably, mathematics teachers require specialised knowledge, for instance, for them to be able to assess students' understanding of concepts in mathematics effectively (Malambo, 2016).

One characteristic of a teacher with SCK would be his ability to present mathematical knowledge in a manner that provides meaning to students other than teaching them mathematical procedures alone. These views about SCK are consistent with Bair and rich (2011), who posit that it is "the unique mathematical content knowledge needed for teaching mathematics with understanding" (p. 295). These authors believe that there are certain mathematical demands, such as 'decompressing' of the subject matter (Ball et al., 2008) which are unique to teachers of mathematics. According to Vecihi (2014), pre-service teachers' SCK development was influenced by their common content knowledge development, presence of instructional opportunities to study other pre-service teachers' mathematical errors.

\subsection{OVERVIEW OF LITERATURE ABOUT MPCK AND THE FUNCTION CONCEPT}

This section presents the review of literature about related studies to the current study. The section opens with a detailed discussion about pre-service teachers' 
MPCK perceptions. A comprehensive review of literature about the concept of a function follows which focuses on the function concept in the school mathematics curriculum and pre-service teachers' knowledge of functions. The aspect of preservice teachers' knowledge of the function concept is focused on difficulties preand in-service teachers have about the function concept with some studies highlighting improvements that teachers record when interventions are introduced in professional development programs. The section concludes with a theoretical perspective of teachers' knowledge of the concept.

\subsubsection{Pre-service teachers' Mathematical pedagogical content knowledge (MPCK) perceptions}

Teachers' perceptions about their knowledge of subject-matter play a key role in how well or bad they will implement the mathematics curriculum. For mathematics which has often been a major cause of fear and anxiety among secondary school students (Jeffery et al., 2018) and pre-service teachers (Bates et al., 2011), it is important to continue examining pre-service mathematics teachers' pedagogical content knowledge perceptions in relation to their subject-matter knowledge if we are to achieve a quality and effective pool of teachers in Zambia. The Zambian educational system places great importance on the instructional practices that are used by teachers in classrooms because they are directly related to student outcomes (Ministry of Education, 2013). Good instructional practices that accommodate students' instructional and subject-matter needs are preferred because they usually have a positive impact on student achievement.

Newton et al. (2012) in their study to investigate relationships between mathematics subject matter and teacher efficacy among pre-service teachers found that their teaching of mathematics was largely influenced by low confidence. Gresham (2009) in his study about pre-service teachers' mathematics anxiety and teacher efficacy found a correlation between pre-service teachers' anxiety and their liking of mathematics. The pre-service teachers with a high degree of mathematics anxiety were found to have a low teacher efficacy and were negative about the subject. Thus, teachers' perceptions are important in determining the preparedness of mathematics pre-service teachers to embark on a teaching career (Elmahdi \& Fawzi, 2019). 
In their study of mathematics teachers content knowledge and pedagogical content knowledge in problem posing, Lee et al. (2018) focused on teachers' knowledge of mathematics content, knowledge of content and students and knowledge of content and teaching. The study revealed good content knowledge of problem posing for the participating teachers. With regards to knowledge of content and students, and knowledge of content and teaching, it was revealed that teachers' level of awareness was good despite some observed obstacles that inhibit the effective use of problem posing in class. To increase PCK awareness among preservice teachers, it is important to introduce pedagogical courses from first year when pedagogy is to be taught side-by-side with discipline specific content or to have a pedagogical certified programme in which students would enroll after graduating with a degree in mathematics (Matos, 2020). This would equip preservice teachers with necessary pedagogical skills needed for effective teaching of mathematics.

Sanchez-Jimenez (2020) discussed PCK from the perspective of development of professional knowledge for mathematics teachers. They claimed that professional mathematics knowledge for teachers should be characterized as "mathematics knowledge to teach" and "mathematics knowledge for teaching". The two are crucial in the professional training of a mathematics teacher. The former is concerned with the learning institution where the actual learning occurs whereas the latter refers to the tools the teacher uses in the action of teaching. This perspective is important for teacher training and development of PCK for mathematics teachers because it enhances PCK awareness among mathematics teachers. In fact, in acknowledging the importance of knowledge to teach and knowledge for teaching, da Costa (2020) in his study that investigated knowledge to teach arithmetic concluded that not only was knowledge for teaching structured but also incorporated pedagogical opportunities expressed in the knowledge to teach.

In their study to explore pre- and in-service mathematics and science teachers' technological pedagogical content knowledge (TPACK), Airwaished et al (2017) developed a framework that would be used to capture important qualities of the kind of knowledge necessary for teachers' effective pedagogical practice in an environment that supports use of technology in teaching. This framework was useful in improving in-service teachers' knowledge in some aspects of TPACK. Kim's 
(2017) study about the relationship between pre-service teachers' TPACK and their beliefs found that pre-service teachers who believed in student centered approaches to learning mathematics and technology use in teaching exhibited high levels of mathematics knowledge and TPACK than their counterparts whose belief about teaching was teacher centered. In a similar study Usak et al (2013) found that preservice teachers who enrolled in courses where instructors were learner centered had high achievement and developed positive attitudes toward learning than those whose instructors were teachers centered.

In a study to examine pre-service teachers' knowledge for teaching mathematics, Beswick and Goos (2012) found that teachers with low confidence levels performed poorly, exhibited low knowledge and were less aware of their mathematical knowledge. In another study aimed at assessing pre-service science teachers' PCK and subject matter knowledge, Usak et al (2011) found that preservice teachers had gaps in subject matter knowledge and were teacher centered in their approach to teaching. They also exhibited teaching attitudes that were biased toward memorization of facts at the expense of developing process- oriented skills which are important for learning. In another study aimed at assessing the relationship between teaching experience and PCK, Duran and Usak (2015) revealed that teaching experience had a positive impact on the pedagogical content knowledge of a science teacher although teachers with several years of teaching experience had difficulties with their content knowledge. In a study to examine the interplay between teacher beliefs and teacher knowledge Blomeke et al (2014) revealed that MPCK influenced teachers' beliefs in the sense that it made teachers to have more constructivist beliefs about teaching. The study concluded that teacher education which strengthened pre-service teachers' MPCK developed constructivist teacher beliefs.

\subsubsection{Literature about the concept of a function}

Functions are defined as "a set of ordered pairs, a correspondence, a graph, a dependent variable, a formula, an action, a process or an object" (Selden \& Selden, 1992, p.4). They are regarded by Romberg et al. (1993) as a way to express a relationship between two or more variables. There is a general concensus that a "functional relationship involves some sort of rule that assigns to each element of a given set a unique elemet of some other, not necessarily distinct, set" (Romberg et 
al.1993, p.5). Functions do not necessarily need to show regularity. They do not need to be described by specific algebraic expressions, a graph of a particular shape, or be defined by specific sets of objects. If a function is a relationship between two sets, the two sets don not necessarily need to be sets of numbers. The cardinal thing is that for a relationship to be called a function, it must be defined on every element in the domain, and there should be only one element (image) in the range for each element in the domain. Being one of the most fundamental and highly used concepts in mathematics across many topics, various researchers recommended that functions be included in elementary curriculum and beyond (Kaput, 1989; NCTM, 2000, Rosenburg et al., 1993; Yerushalmy \& Schwartz, 1993; You, 2006).

\section{The function concept in the school mathematics curriculum}

Functions have fundamental importance to mathematics (Even, 1990, 1993; Hatisaru \& Erbas, 2017; Jojo, 2019; NCTM, 2000; MESVTEE “O” Level Mathematics Syllabus, 2013; Selden \& Selden, 1992) and hence, the inclusion of the topic in the secondary school mathematics curriculum. However, the topic has been unpopular among pupils with those that choose to answer trigonometric functions questions during examinations performing poorly. In different countries the approach to teaching the function concept has manifested slight variations as evidenced in recommended syllabus text books used by teachers (Watson \&Harel, 2013).

In the Zambian textbooks the topic starts by describing a relation, progresses to discussing domain and range and further associate relations with functions by determining whether a relation is a function or not (MESVTEE "O" Level Mathematics Syllabus, 2013). This is like the case in other parts of the world. According to Watson and Harel (2013), the approach in the United States of America starts by "defining the concepts of relation, function domain and range in one breath" ... with emphasis that "we learn to identify functions in order to determine whether a relation is a function" (p. 158).

Syllabus textbooks in the United Kingdom present the function concept "in the context of modelling realistic situations" (p.158). This approach shows that "the association with relations is less prevalent” (p. 158). Yavuz and Busturk (2011), reported that the curriculum in France uses everyday real-life situations to demonstrate and define a function which is widely explained in terms of a variable. This approach connects what students already know about functional thunking 
outside formal classroom learning to the theoretical concepts taught in school. This approach is premised on the understanding that real life experiences present situations that promote functional thinking. The Curriculum Development Centre (CDC) in Zambia set general and specific outcomes desirable of secondary school students as regards the concept of a function. Specific outcomes for the Zambian syllabus are presented in Table 1 below

Table 1. Specific outcomes from the topic functions in the Zambian syllabus

\begin{tabular}{lll}
\hline TOPIC & SUB TOPIC & SPECIFIC OUTCOME \\
& Relations & Describe a relation \\
& Determine domain and range \\
& Representation of relations & Represent relations \\
& Types of relations & Identify types of relations \\
& Functions & Determine whether a relation is a function or not \\
Functions & Representation of & Represent functions \\
& functions & \\
& Types of functions & Distinguish types of functions \\
& Linear functions & Identify linear functions \\
& Inverse functions & Find inverse and one-to-one functions \\
& Graphs of linear functions & Draw graphs of linear functions \\
& Application & Solve problems involving linear functions
\end{tabular}

Regarding students' knowledge of definitions, it has been claimed that students face causal and dependence situations in their day-to-day lives which demand application of functional thinking (Mestre, 2014). Such situations imply that students encounter the concept of the function long before they are introduced to its formal learning at school. To this effect, Zaslavsky and Shir (2005) investigated senior secondary school students' conceptions of mathematical definitions. All the participating students were in their $12^{\text {th }}$ grade. Results showed that participants concentrated on logical concerns, and clarity when determining acceptability of definitions. In the case of geometrical definitions, they used they utilized phototypical mental structures when defining objects. This study showed how essential it is for secondary school students to learn definition construction of mathematical concepts. In another study about relations between secondary school students' conceptions about functions and problem solving in different representations, Elia et al. (2007) found that students had challenges in constructing definitions of the 
concept of a function. Findings further showed inconsistencies in participants' knowledge of different representations of functions.

Ability to correctly and meaningfully define the concept of a function has a bearing of how secondary school students would comprehend related concepts. Panaoura et al (2015) investigated secondary school students' definition and problem solving abilities with special focus on the concept of a function. In particular, they asked participants to construct the definition of the concept of a function and provide examples of functions. They further asked participants to solve problems involving functions and translate between different representations of functions. Results showed that participants had difficulties with construction of definition of the function concept and had insufficient knowledge of examples of functions. Participants also exhibited misconceptions as they solved problems involving the concept of a function. Jojo (2019) investigated three secondary school students' understanding of cubic functions. Findings revealed gaps in participants' understanding of the cubic function and concluded that students need good understanding of the cubic function for them them to represent it correctly.

\section{Pre-service teachers' knowledge of functions}

The concept of a function plays an important role throughout the mathematics curriculum. This concept is central to understanding mathematics, yet students' understanding of functions appears either to be too narrowly focused or to include erroneous assumptions (Clement, 2001; Kulm, 2008). According to Romberg et al (1993) "Functions are one of the most powerful and useful notions in mathematics" (p. 1) because "without functional thinking there can be no real understanding or appreciation of mathematics" (Breslich, 1928, p. 28).

Zambia Ministry of General Education views functional thinking as crucial for the development of mathematics literacy. The concept of a function is fundamental to students' ability to describe associations of change between variables, explain parameter changes, and interpret and analyze graphs. This topic is included in the secondary school curriculum in Zambia as a key pre-requisite for learning calculus, equations and trigonometry, among other contents. Because functions can be expressed using different representations, secondary school students are accorded opportunities to use graphs in visualizing mathematical relationships that otherwise could be expressed using symbols. Functions also accord secondary school students' 
opportunities to model real life situations and to understand relationships between phenomena in their environment. Thus, functions in the Zambian mathematics secondary school curriculum are taught early in the $10^{\text {th }}$ grade to enable students acquire important functional thinking skills that are fundamental for developing sound mathematical reasoning. However, the transition from intended curriculum to attained curriculum relies, to a great extent, on the quality of the implemented curriculum and this, in turn, on teacher training.

Although the function concept is viewed as being very important to mathematics, many research studies of high school and college students have shown that it is also one of the most difficult for students to understand and particularly challenging for teachers to teach (Dreyfus \& Eisenberg, 1982; Even, 1993; Leinhardt et al., 1990; Markovits et al., 1988; Sierpinska, 1992; Stein et al., 1990; Tall, 1996). For instance, many students and pre-service teachers have difficulties with transfer among representations to solve algebraic problems and in the construction of graphs (Demana et al., 1993; Dunham \& Osborne, 1991; Eisenberg \& Dreyfus, 1991).

A study by Hart (1981) involving 3,000 middle school students revealed that students could not construct a functional relationship between data pairs and algebraic symbols. To this effect, You (2006) stated that a deep understanding of functions is required for all students and should be demonstrated by their ability to use multiple representations and to make translations among them. For this to be realized students must be accorded opportunities to solve problems that require them to transfer between algebraic, tabular and graphical representations (Cunningham, 2005). It is not surprising that the National Council of Teachers of Mathematics advocated instructional programs from pre-kindergarten through grade 12 that "enable all students to understand patterns, relations, and functions." (NCTM 2000, p. 296). It is thus essential for teachers of mathematics to have a strong understanding of the subject matter knowledge of the material they will teach and the pedagogical knowledge necessary to make the subject content of the function concept comprehensible to students (Kulm, 2008; Mohr, 2008).

It is common knowledge that teachers can not teach students and help them learn and comprehend concepts they themselves do not understand (Ball, 1991) because there is a very strong link between quality teaching and student outcome. There exists a positive correlation between teacher's subject matter knowledge of 
mathematics and of teacher's mathematical pedagogical knowledge (MPCK) with student performance at secondary school level (Goe, 2007). As such it is important to appreciate the interplay between knowing mathematics and teaching it as holistic (Handa, 2011; Mason \& Davis, 2013) because, according to Handa (2011), teaching is the true manifestation of the existing relationship between the teacher and the subject-matter (mathematics). It is during the teaching process that teachers exhibit evidence of knowledge of mathematics in the way they show connections between concepts that govern the function concept, the kind of tasks they prepare for their students and their ability to demonstrate the role of functional thinking in the understanding of other mathematical topics and in real life situations.

Thus, teachers should be able to demonstrate their ability to differenciate between a function and its various representations, and differentiate between the concept of a function as a mapping satisfying a single value and its instantiations (Watson \& Harel, 2013). It is crucial to understand that "different notations afford different conceptualisations on the spectrum ranging from the process-conception of function to the object-conception of function. For example, the notation $f(g(x))$ for the composition of functions $f$ and $g$ is amenable to the process-conception of function, where an input $x$ yields an output $g(x)$ and this, in turn, as an output, yields $f(g(X))$. On the other hand, the notation $f o g$ for the same concept is amenable to the object-coneption of function, in that $o$ is a binary function acting on a pair of functions, $f$ and $g$, to produce a new function, " $f \circ g$ " (Watson \& Harel, 2013, p. 157).

Even (1993) conducted a study on pre-service secondary teachers' knowledge of a function concept. A total of 152 pre-service teachers participated in the study by completing an open-ended questionnaire about their perceived knowledge of functions with a sub-group of 10 participants participating in a follow up interview. Even found that pre-service teachers exhibited deficiencies in their knowledge of the function concept. Results from the questionnaire and interview revealed that participants lacked such characteristics as univalence and arbitrariness of the function concept. These results suggest that there will be a potential discomfort in the way these teachers will teach the topic of functions in secondary school. Their gap in knowledge will most likely be transferred to their learners. 
Stein et al. (1990) studied subject matter knowledge and elementary instruction of in-service teachers in which they investigated the case of functions and graphing. The study involved lesson observation of fifth grade teacher and a follow-up interview to obtain detailed teacher's knowledge levels of the function concept. The findings revealed inadequate knowledge of functions with the teacher showing lack of organized and representational understanding of the function concept. Similarly, You (2006) investigated pre-service teachers' knowledge of linear functions in which the results showed that pre-service teachers performed poorly in subject matter knowledge particularly in terms of representational flexibility.

In recent years, research exclusively or mainly focusing on the mathematical knowledge that is necessary for teaching the concept of a function has been on the increase (Aziz et al., 2018; Aziz \& Kurniassih, 2019; Even, 1992; Kontorovich, 2017; Malambo et al., 2019; McCulloch et al., 2019; Karahasan, 2010; Paoletti et al., 2018; Paoletti, 2020; Taşdan, 2019; Ubah \& Bansilal, 2018; Wasserman, 2017). In spite of the volume of research related to knowledge of the concept of functions, research on pre-service teachers' knowledge of the concept of function, on the one hand, and how their corresponding subject-matter knowledge and their knowledge of content and students interrelate to achieve effective learning goals, on the other hand, is still in its infancy in Zambia, as it is also the case in many other similar international educational contexts. Thus, this study will contribute to shedding light on both issues. Besides, being a study developed within the national context of Zambia, it has drawn its inspiration from the exploratory study by Malambo (2016) about student teachers' content knowledge of functions and trigonometry.

However, this study is significantly different from Malambo's (2016) study in many ways. The two studies are different in their design, focus, approach and depth. In focusing solely on content knowledge of pre-service teachers, part of Malambo's (2016) important resultant argument was that knowledge of advanced mathematics is not a guarantee that one would easily comprehend and teach secondary mathematics effectively. It was difficult in his study to make strong claims about teaching and learning because his study was purely about content knowledge of pre-service teachers. For example, content knowledge is as important as pedagogical knowledge for teachers (Shulman, 1986). Thus, one cannot sufficiently make pedagogical conclusions and claims from a study which was purely focused on describing pre- 
service teachers' content knowledge. This is where a significant departure lies between Malambo's (2016) and the current study.The current study is concerned with both subject-matter and pedagogical content knowledge as complementary and key aspects to effectively teach functions in mathematics classrooms. Herein lies the major contribution of this study in bridging the gap in literatura vis-a-vis Zambian secondary pre-service teachers' knowledge regarding the concept of a function. The stud goes beyond subject matter to examine and describe pre-service teachers' knowledge of sources of students' misconceptions and how these can affect effective teaching and learning if not resolved. By examining pre-service teachers' pedagogical content knowledge perceptions of mathematics this study established an important link between teachers' self-concept of mathematics and their knowledge of the function concept.

Studies that have been conducted in Zambia have investigated pre-service teachers' knowledge of the function concept on a broader basis which included but not limited to definition of a function, quadratic, composite, inverse, one-to-one and different representations of functions. Studies in contexts outside Zambia focused on specific aspects of the function concept where pre-service teachers had difficulties, with other studies extending to secondary school students' difficulties.

In the studies mentioned above, the one conducted by Ubah and Bansilal (2018), the authors investigated prospective mathematics teachers' knowledge of quadratic functions. Their focus was on exploring approaches teachers employed when deriving symbolic equations for graphs of quadratic equations and how they did this in a variety of ways. Findings indicated that participants showed unpreparedness to effectively teach school level concepts and recommended more pedagogical skills.

In a related study, Aziz et al. (2018) examined prospective secondary teachers' views regarding their knowledge of differences between functions and quadratic equations. Participants of that study exhibited deficiencies in ways in which they described and interpreted such differences. This fact was also observed in a case study developed by Sajka (2003) who observed that the participant exhibited limited understanding of the function concept by misinterpreting symbols used when learning functional equations which were intrinsically caused by context that 
restricted the use of symbols during teaching and the kind of examples and tasks teachers selected for their students.

Similarly, Malambo et al. (2019) investigated pre-service mathematics teachers' understanding of secondary school level function concepts. By examining pre-service teachers' depth of knowledge related to the function concept, they argued that studying university level advanced mathematics was not a guarantee for comprehending school level function concepts. Their study revealed that most of the pre-service teachers who participated had problems justifying and explaining their reasoning of aspects of the function concept.

Pre-service teachers have been reported in previous studies of having difficulties with the concept of domain and range of a function (Arnold, 2004; Aziz \& Kurniasih, 2019; Dorko \& Weber, 2014). They exhibited misconceptions and could hardly define domain and range. They often mixed up and confused the two concepts. This is in spite of research evidence showing that strong knowledge of domain and range would improve their comprehension of inverse functions as well as linear transformations. Pre-service teachers were found to have weak knowledge of inverse functions and could not make meaningful connections between inverse functions and other functions. They were also unable to sufficiently explain notation used to denote inverse functions (Even, 1992; Kontorovich, 2017; Paoletti, 2020; Wasserman, 2017). Paoletti et al. (2018) inquired about prospective teachers' knowledge about inverse function concepts with reference to techniques used and their meaning making when learning the topic. Majority of participants in this study showed positive results in the tasks given.

Pre-service teachers have in prior research showed weaknesses in their knowledge of composite functions (Kontorovich, 2017; Karahasan, 2010). It was observed that they had misconceptions about composition of functions and could confuse composition of functions with ordinary multiplication of two algebraic terms. This was an indication that some of them were not ready to teach composite function concepts in secondary school. Their knowledge of quadratic functions was also reported to be weak (Aziz \& Kurniasih, 2019; Huang \& Kulm, 2012). As a result they were unable to select good representations involving quadratic functions for the learners. Their inadequate knowledge of this concept would affect their teaching in future if they did not improve. For example, Aziz and Kurniassih (2019) 
analyzed pre-service secondary mathematics teachers' knowledge of representations of domain and range of functions. Results revealed lack of understanding of both concepts and difficulties in defining or using basic facts related to them.

One of the most researched aspects of the function concept in relation to preservice teachers is their knowledge of different representations of the concept of a function (Aziz \& Kurniasih, 2019; Dorko \& Weber, 2014; Gagatsis \& Shiakalli, 2004; Martinez-Planell et al., 2015). Different representations of the function concept usually take the form of tables, algebraic symbols, ordered pairs and graphical representations. Pre-service teachers have had difficulties in translating from one representation to another and this inability to flexibly move between representations has been a major gap in their knowledge of functions. Their weak knowledge of flexibility to translate between different representations was noted as one of the reasons they had weak mathematical reasoning. The inability to understand different representations of functions was also noted in secondary school students. Secondary school students reported difficulties completing tasks involving different representations (Elia et al., 2007; Hitt, 1998).

Other recent studies focusing on teacher's mathematical knowledge of functions are the one conducted by Hatisaru and Erbas (2017), where the interrelationship between such knowledge and students' outcomes is analyzed, and the work of Steele et al. (2013), who conducted a study to examine in-service and pre-service teachers' knowledge development for teaching the function concept. Results in this latter case indicated a positive growth of teacher's knowledge concerning the definition of the function concept together with the selection of appropriate examples.

Beyond the focus on mathematical content shared by the papers previously mentioned we find Even's (1993) study which, according to our opinion, stands out as one of the most extensive studies about pre-service teachers' subject-matter and pedagogical content knowledge of the concept of a function. Even (1993) studied the interrelations between both types of knowledge in 152 pre-service secondary teachers finding that participants had limited knowledge of the function concept which affected their pedagogical content knowledge.

Nyikahadzoyi (2015) studied teachers' knowledge of the function concept by using a teaching framework inspired by the works of Shulman (1986) and Ball et al. 
(2008). As part of his framework, Nyikahadzoyi holds the view that teachers' knowledge of students and the function concept is premised on teachers' knowledge of student misconceptions, errors and difficulties, together with teacher's ability to anticipate content that will motivate their students and that might likely be challenging for them.

Aksu and Kul (2016) investigated in-service teachers' knowledge of content and students in the sense of the Mathematical Knowledge for Teaching framework established by Ball et al (2008). Their study particularly focused on teachers' knowledge of student errors, misconceptions and difficulties while learning functions in secondary school. Results of the study revealed deficiencies in teachers' knowledge of their learners' difficulties, errors and misconceptions. Hatisaru and Erbas (2017) found some relationship between teachers' MKT and the learning outcomes of their students. The study also indicated that the quality of teachers' pedagogical practices was influenced by their knowledge of the concept.

Functions are a common feature in applied mathematics fields like statistics, engineering and computer programming (Ronau et al., 2014). As such, it is important for mathematics teachers to justify their explanations about aspects of the concept of a function when teaching secondary school students and to use mathematical descriptions and examples that enhance understanding of the concept (Tasdan, 2019). In a study focusing on one mathematics teacher's knowledge of these knowledge indicators, Tasdan (2019) observed and recorded lessons delivered by the teacher and administered a functions survey. She found that the taught lessons were characterized by use of mathematical descriptions and to some extent mathematical explanations with justifications of the concept. However, the study concluded that the teacher exhibited limited mathematical knowledge for teaching the concept of a function. She claimed that descriptions, explanations and justifications of concepts are good indicators of effective teaching.

In another study, Trevisan et al. (2019) used practice based learning to identify learning opportunities concerning the concept of a function. They investigated teacher professional knowledge by concentrating on mathematical knowledge for teaching the concept of a function and knowledge for teaching practice concerning functions. Findings revealed development of learning opportunities for the participants, vis-à-vis consideration of a classroom as a professional learning 
environment. The study also revealed that participants developed skills to design lessons that place students to be at the center of mathematical discussions by encouraging them to fully participate in classroom activities.

In a study to examine pre-service mathematics teachers' knowledge of teaching the function concept, Tasdan and Koyunkaya (2017) observed and recorded lessons of three pre-service teachers teaching the function concept. Results revealed that preservice teachers had limited knowledge regarding teaching of the function concept. Particularly, they had difficulties to replicate their understanding of function concept during their teaching. Results also showed that teaching experience was directly related to teaching of function concept, time and classroom management as well as how teachers communicated with students.

Pazuch and Ribeiro (2017) conducted a literature review focusing on mathematics teachers' professional knowledge of the concept of a function. They emphasized that both pre- and in-service teacher education needed to work on the variation of meanings attributed to the concept of a function. This was aimed at broadening teachers' understanding of the concept and to help them relate it to real life situations for the learners to easily comprehend it. They claimed that teachers conceived functions as materials basing their reasoning on graphical representations to an extent where the abstract conception of relationships between quantities ended up losing meaning. Some studies exclusively investigated pre-service teachers' knowledge of mathematical definitions (Chesler, 2012; Harel et al., 2006; Linchevsky et al., 1992; McCulloch et al., 2019; Moore-Russo, 2008; OuvrierBuffet, 2006; Vinner, 1991; Zaslavsky \& Shir, 2005).

Mathematics is a discipline that uses definitions to describe concepts because they influence the cognitive development of students' mathematical reasoning (Vinner, 1991). The concept of a function is one such topic where definitions are pivotal for teachers to teach effectively and students to comprehend the concept. Thus, students and teachers are expected to master, understand and apply mathematical definitions in various situations when learning mathematics concepts that include the concept of a function. Recognizing their value and significance in the learning of mathematical concepts, definitions have extensively been acknowledged in mathematics education research as being central in understanding concepts Harel et al., 2006; Vinner, 1991). It has been widely acknowledged by mathematics 
education researchers that meaningful construction and application of definitions involving the concept of a function has the potential to improve teachers' selfconcept about mathematics to the extent that their capacity and awareness about students' understanding of concepts can deepen (Ouvrier-Buffet, 2006; Hare et al., 2006).

However, it has been observed that majority of pre- and in-service teachers have difficulties with meaning construction of mathematical definitions as well as alternative evaluating of these definitions in using them to justify their reasoning (Chesler, 2012). This has largely been attributed to the nature of curricular materials that these teachers are exposed to. Definitions in prescribed mathematics textbooks and other curriculum documents that teachers use for the purpose of teaching has been seen to neither support conceptual understanding nor cultivate a solid foundation for nurturing future mathematical engagements (Harel and Wilson, 2011). This is in spite of the underlying importance of their students need to understand definitions of mathematical concepts (Chesler, 2012). An interesting study was conducted by McCulloch et al. (2019). The authors used a vending machine applet to examine pre-service teachers' understanding of functions. Their findings indicated renewed understanding of definitions of the function concept for participants.

To exemplify difficulties that pre- and in-service teachers have when constructing definitions, findings of few mathematics education studies were considered (Chesler, 2012; Linchevsky et al., 1992; Moore-Russo, 2008; Zaslavsky $\&$ Shir, 2005). In a qualitative study of prospective secondary mathematics teachers sense-making about definitions of functions, Chesler (2012) investigated pre-service teachers' choices, usage, evaluation and interpretation of definitions. Findings revealed that majority of pre-service teachers had gaps in knowledge when reasoning with and about mathematical definitions. These deficiencies can act as a barrier in understanding other related concepts of functions. This is because the concept of a function is anchored on how well one understands and applies definitions in their thought processes.

In their study about pre-service teachers, Linchevsky et al. (1992) studied 82 pre-service teachers whose interest was to teach junior secondary school mathematics upon completion of their studies. Of these, only 21 pre-service teachers had knowledge of arbitrariness of definitions. This situation was gloomy because 
majority pre-service teachers who had ambitions to teach mathematics in secondary school were not aware of the arbitrariness of definitions. In a related study, MooreRusso (2008) investigated pre- and in-service mathematics teachers' knowledge of constructing definitions. The study revealed that all the 14 teacher participants had no previous knowledge of constructing definitions. Activities about the slope of a function were designed for the participants. These activities helped them develop deep understanding of definition construction.

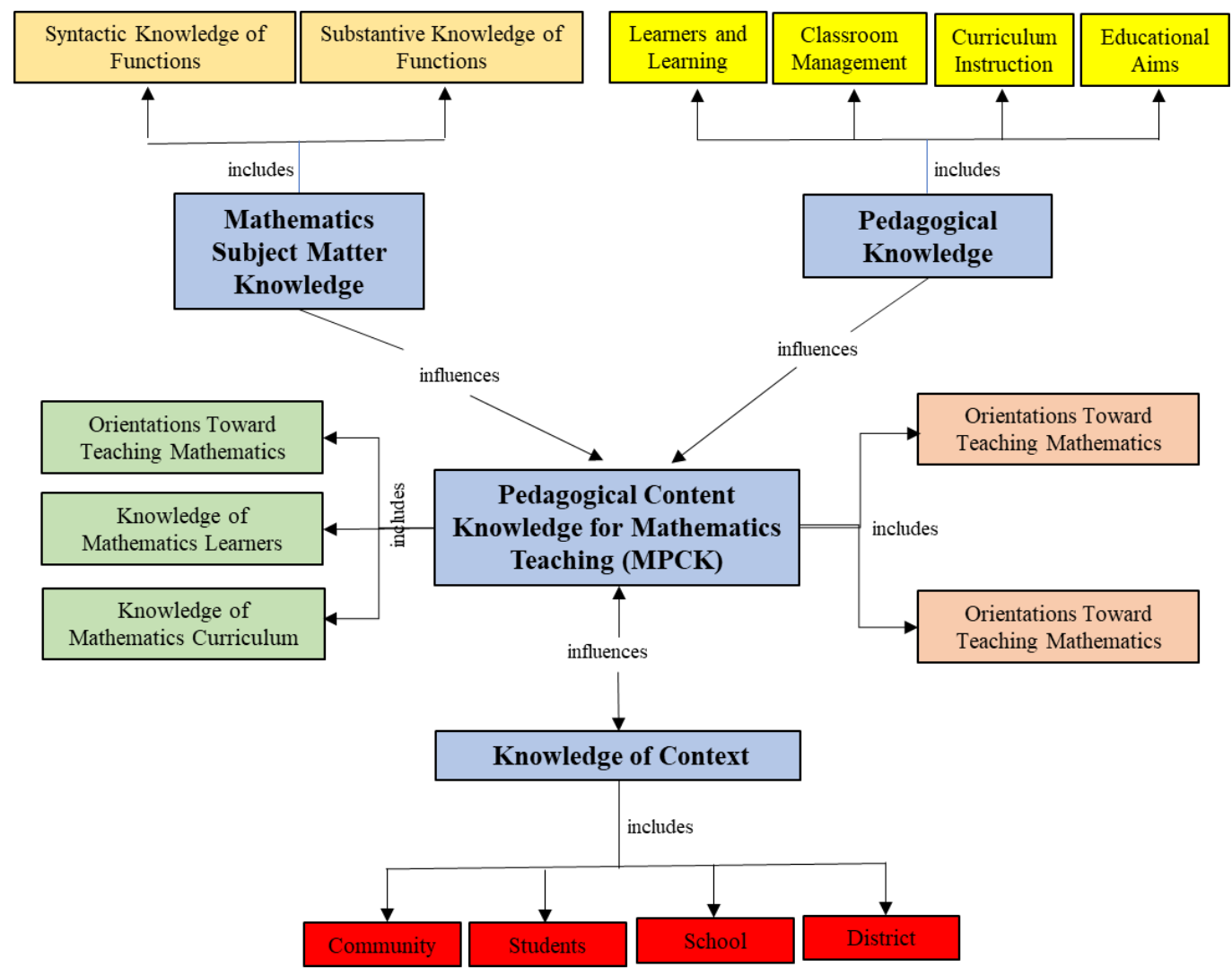

Figure 10. PCK model for teaching functions (Adapted from Grossman, 1990;

Magnusson et al., 1999, Abell, 2008)

\subsubsection{Theoretical perspectives about teachers' knowledge of functions}

Over the years the study of functions has received a substantial amount of attention which has seen mathematics education researchers embarking on studies that address different aspects of the subject. An inventory of studies has shown that when studying teachers' knowledge of functions, researchers have approached their studies from a variety of theoretical viewpoints on the concept of a function.

The dual nature of the concept of a function is one of the aspects that researchers have focussed on. The dual nature of the concept of a function suggests 
that a function can be viewed as a process or an object. A study conducted by Breidenbach et al. (1992) is an example of a research that viewed a function as a process or object. In their study they proposed a process and object view of a function. They posited that:

A process conception of function involves a dynamic transformation of quantities according to some repeatable means that, given the same original quantity, will always produce the same transformed quantity. The subject is able to think about the transformation as a complete activity beginning with objects of some kind, doing something to these objects, and obtaining new objects as a result of what was done.... A function is conceived of as an object if it is possible to perform actions on it, in general actions that transform it. (Breidenbach et al., 1992, p. 263).

Schwarz and Dreyfus (1995) developed a framework associated to functions in which they posited that knowledge of the concept of a function is connected to actions on objects and conservation of invariants under actions (O'Callaghan, 1998). This focus covers aspects associated with properties of functions. By action on objects it is implied to manipulate, compare and transform the objects in the graphical, tabular and algebraic forms. The objects change their essence and thus become objects of a new kind which is called representatives. Thus, new objects, new actions, and new links among the objects and actions of different settings could be created, but the function properties are invariant under actions

A two-dimensional framework for interpretation of linear functions was developed by Moschkovich et al. (1993). One dimensión of this framework focussed on the perspective from which a linear function was envisioned, which is processoriented and object oriented visión of a linear function. The other dimensión was with regards to the means of representation of linear functions with a focus on the most common symbolic representations (algebraic, graphical and tabular).

O'Callaghan (1998) investigated the impact of the Computer-Intensive Algebra (CIA) and traditional algebra curricula on students' understanding of the concept of a function. Computer-Intensive Algebra is a function-oriented curriculum that focuses on a problem-solving approach based on the modeling of realistic situations, an emphasis on conceptual knowledge, and the extensive use. This curriculum focused 
less on symbol manipulation skills and more on the conceptual understanding of the functional concept.

He proposed a function model, which consists of modeling, interpreting, translating and reifying. In his study, modeling referred to the ability to represent a problem situation using functions. It is a process entailing a transition from a problem situation to a mathematical representation of that situation. Interpreting, according to O'Callaghan, is a reverse procedure of the modeling process. Systems, symbols, tables and graphs are functions that have three core representations (Kaput, 1989). O'Callaghan (1988) defined translating as the ability to transfer from one representation of a function to another of three core representation systems. Reifying is the process of creating a mental object from procedures.

\subsection{PRE-SERVICE TEACHERS' CCK, SCK, KCT AND KCS OF THE CONCEPT OF A FUNCTION}

This section discusses pre-service teachers' common content knowledge (CCK), specialized content knowledge (SCK), knowledge of content and teaching (KCT), and Knowledge of content and students (KCS) in relation to the concept of a function. These knowledge domains are part of the categories that make up the mathematical knowledge for teaching (MKT) by Ball et al. (2008) on which this study is anchored (Figure 11).

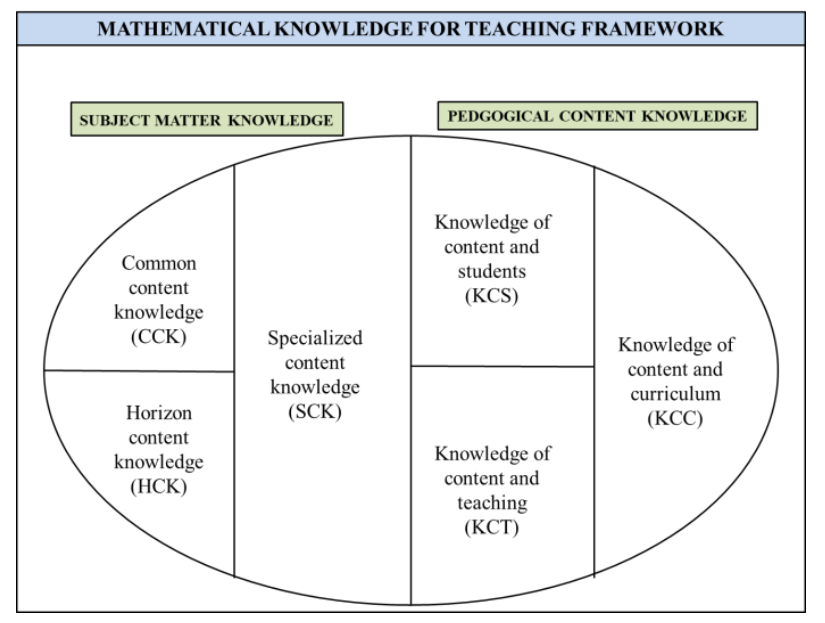

Figure 11. MKT framework (Hill et al., 2008, p. 377)

The first two form part of the subject matter knowledge (SMK) and the last two the pedagogical content knowledge (PCK) in Ball et al.'s framework. These knowledge 
domains will be elaborated in great detail because they serve the purpose for answering the research questions for the current study.

\subsubsection{Pre-service Teachers' Common Content Knowledge of the Function Concept}

Common content knowledge (CCK) of functions is essentially concerned with defining and identification of examples and non-examples of the concept. Ball et al. (2008, p. 399) have defined common content knowledge as "mathematical knowledge and skill used in settings other than teaching" ..., "the knowledge which any reasonably educated adult who uses mathematics ought to know and be able to do" (Nyikahadzoyi, 2015, p. 267) ..., the "knowledge that is used in the work of teaching in ways common with how it is used in many other professions or occupations that also use mathematics" (Ball et al., 2005, p. 377) and includes both procedural and conceptual knowledge. CCK is the knowledge that enables teachers to correctly solve problems in the students' curriculum or for themselves in their daily lives. Actually, teachers rely more on common content knowledge in their work.

According to Nyikahadzoyi (2015), as part of their CCK for the concept of a function, pre-service teachers are supposed to know and understand definitions and properties of functions, competently demonstrate knowledge of the connections between the function concept and other mathematical concepts, be able to identify relevant applications of functions in and outside mathematical contexts. Pre-service teachers should also be able to respond to their students' difficulties involving functions by identifying incorrect answers and inaccurate definitions and provide remedies. Research has also shown that pre-service teachers need to exhibit deep understanding of the univalence and arbitrariness of the function concept as the essential features or key characteristics of the concept (Freudenthal, 1983; Even, 1990; Lloyd etal., 2010; Nyikahadzoyi, 2015, Steele et al., 2013; Malambo, 2016). This is because pre-service teachers' ability to state the definition of a function does not explicitly confirm an understanding of the key features of that definition (Steele et al., 2013), but being able to demonstrate understanding of the univalence and arbitrariness charateristics of the function is vital since a mathematically valid definition of a function must include univalence and not exclude arbitrariness. In fact, Steele et al., (2013) conducted a study on developing pre- and in-service 
teachers' mathematical knowledge for teaching the concept of a function. Participants revealed positive development in the knowledge of definition of functions, selections of examples of functions and flexibility when moving between different representations of functions

Arbitrariness basically refers to the relationship between two sets on which a function is defined and the sets themselves. This means that the rule relating elements of the domain and those of the range does not need to be described by a regular expression or graph (Even, 1992). This entails that elements of the two sets need not necessarily be objects or numbers. Univalence is concerned with the mapping of elements from the domain to the range. The univalence nature of functions means that for each element in the domain there should be only one element in the range. This property allows for the one-to-one and many-to-one relationships but excludes the one-to-many relationship. Univalence can easily be evaluated on a graph.

For example, in a study aimed at analyzing prospective mathematics secondary teachers' common content knowledge of parabola and exponential functions, Ndlovu (2019) found that most of the participants committed procedural and conceptual errors when dealing with parabola and exponential functions and had weak CCK of parabola and exponential functions. This highlights the need for pre-service teachers to improve their CCK while in university. This is because teachers use more of their CCK when presenting lessons in class and it makes CCK a crucial knowledge domain for pre- and in-service teachers.

In another study related to teachers' CCK, Wilkie (2014) investigated upper primary teachers' mathematical knowledge for teaching functional thinking in algebra. Findings revealed that over two thirds of teachers had limited ability to teach functions and less than half were able to select appropriate examples for students' learning experiences. Similarly, Ma'rufi et al. (2018) conducted a study to investigate in-service secondary teachers' subject matter knowledge, pedagogical knowledge and knowledge of students in relation to the limit of a function. Findings revealed that teachers' knowledge of analyzing sources of students' misconceptions, difficulties and mistakes when dealing with the limit of a function was limited. Teachers were also unable to clear misconceptions held by students. In their attempts to clear misconcptions, they instead re-explained question completion procedures. 


\subsubsection{Pre-service Teachers' Specialised Content Knowledge of the Function Concept}

Specialised content knowledge (SCK) refers to the mathematical knowledge and skill unique to teaching which pre-service teachers use to develop their students' understanding of the function concept (Ball et al., 2008). Pre-service teachers require this special knowledge in order for them to decompress and unpack concepts related to functions in such a way that the content being taught is visible to and learnable by their students. Thus, mere solid grasp of mathematical material is not sufficient for pre-service teachers to effectively teach the function concept, but rather unique mathematical understanding and reasoning is key to making students understand and develop desired knowledge of the function concept (Ball et al., 2008).

Therefore, as part of their SCK, pre-service teachers must know different definitions of the function concept and should be able to easily decide the appropriate definition to use depending on the context because they are likely to encounter multiple definitions of the function concept in different books and other supplimetary materials (Cooney et al., 2011; Hatisaru \& Erba, 2015; Malambo, 2016; Nyikahadzoyi, 2015; Steele et al., 2013). According to Steele et al. (2013) "a class working on functions as numerical tables might find a definition focused on input and output to be useful, whereas a class exploring domains and ranges of composite functions might benefit from a set-mapping definition" (p. 455). Pre=service teachers must competently explain to their learners the important roles definitions hold in understanding functions and other mathematical concepts and must give simplified definitions without strictly defining functions in terms of the domain and range. Preservice teachers must also endeavor to link the function with other concepts, and treat it as a manipulative object.

Functions are usually represented in symbolic equations, graphs, tables, mappings, verbally, sets of ordered pairs and contextual situations (Lesh et al., 1987; Goldin, 2002; Cooney et al., 2010) and pre-service teachers ought to have the ability to effectively use these different representations in their explanations of the function concept and should also be able to translate between these representations (Steele et al., 2013). Actually, Chinnappan and Thomas (2001) investigated pre-service teachers' views about representations of functions. Findings revealed good knowledge of visual representations of fnctions while they had inadequate 
knowledge of symbolic representation of the concept. Further it was found that their pedagogical content knowledge was underdeveloped.

The symbolic and graphical forms of representation are common features of secondary school level of the function concept and seem to stimulate students' interest in learning the topic (Knuth, 2000). In their study, Thomas et al. (2010) used functional magnetic resonance imaging (fMRI) to investigate the role of algebraic and graphical representations in learning functions and found that participants had difficulties in understanding aspects of functions related to different representations.

Thus, pre-service teachers' fluent understanding of various representations of functions and ability to flexibly translate between them would enhance student understanding. For instance, in a study to analyze pre-service teachers' knowledge of linear function and slope, Tsao (2020) observed that students' comprehension of representations of linear functions is largely influenced by their perceptions about the concept. Results indicated that pre-service teachers had limited knowledge about moving between graphical and algebraic representations of slopes. They also had challenges in determining linear functions with perpendicular lines. Regarding preservice teachers' application of subject matter knowledge to pedagogical reasoning, Sanchez and LLinares (2003) studied the influence of pre-service teachers' mathematics content knowledge on their pedagogical reasoning when teaching functions. They found a relationship between content knowledge of functions and PCK in participants' instructional strategies. The study also revealed that participants were at different level of content knowledge of the function concept.

Basically, pre-service teachers must appreciate and conceieve functions as a procedure, process, object, or precept in order for them to effectively explain it to their learners by having a wide repertoire of neat examples to illustrate them. This can only happen if pre-service teachers know and understand the inherent weaknesses of these different representational forms of the function concept. Stermann et al. (2018) analysed pre-service teachers' diagnostic competences in judging task difficulties of graphs of functions. The study found that pre-service teachers developed their knowledge of students' misconceptions and concluded that pre-service teachers can improve their judgement when taught about PCK. In a similar study, Hofmann and Roth (2017) also ealier investigated pre-service teachers' 
diagnostic competences when dealing with graphs of functions. They revealed gaps in pre-service teachers' competences.

\subsubsection{Pre-service Teachers' Content Knowledge of the Function Concept and Teaching}

According to Ball and friends, the demands of teaching require knowledge at the intersection of content and teaching. This statement implies that for teaching to be effective pre-service teachers must possess good pedagogical skills and need to have good knowledge of mathematical content (in this case good knowledge of the function concept). Such knowledge enables teachers to select appropriate pedagogical strategies to suit the delivery of mathematical content to the level of their learners. They would choose relevant examples and practice activities that would scaffold their students to deep understanding of concepts. Ball et al. (2008) posits that pre-service teachers with a good blend of knowledge of mathematics and that of pedagogy excellently manage class activities by knowing when to pause for clarification from students, when to use students' remarks to emphasize a point and to build on the lesson and when to ask a question to further student learning.

As part of their KCT of the concept of a function, pre-service teachers should know different introductions for the topic of functions, definitions, explanations, examples, sequences of exercises, and representations, and adapt them to their lesson planning and actual instruction in class based on their adequacy and relevance to the needs of their students (Hatisaru \& Erba, 2015; Nyikahadzoyi, 2015). By indentifying their students' conceptions of the function concept, pre-service teachers would be able to make beneficial adjustments to their teaching.

\subsubsection{Teachers' Knowledge of Content of the Function Concept and Students}

Pre-service teachers require knowledge that combines knowledge about mathematics and knowledge about their students (Ball et al., 2008). As part of their $\mathrm{KCS}$ in relation to the concept of a function, pre-service teachers are required to know their students' conceptions, misconceptions and errors about the function concept, and put up intervention measures that would promote deep understanding of the concept while minimizing misconceptions. Key to this is the "teacher's ability to anticipate and resolve student errors and misconceptions, interpret incomplete student thinking, predict how students would handle specific tasks, and what students would find interesting and challenging" (Nyikahadzoyi, 2015). 
Pre-service teachers are expected to be aware of their students thought patterns, how they would handle class tasks, and know what students would find interesting (Hatisaru \& Erba, 2015; Nyikahadzoyi, 2015). Thus, pre-service teachers are expected to select examples that are predictive of their students' interest and exercises that would stimulate interest in their students. Pre-service teachers also need to predict if their students would find the class tasks easy or difficult. When explaining meanings and giving examples, pre-service teachers are supposed to use language to the comprehension levels of their students.

\subsection{CONCEPTUAL FRAMEWORK FOR THE STUDY}

The purpose of this study was to examine knowledge of functions of Zambian pre-service secondary school mathematics teachers in the area of functions. This study attempted to characterize the depth of Zambian pre-service mathematics teachrs' subject-matter and pedagogical content knowledge of the concept of a function in the secondary school curriculum. Specifically, the study assessed the levels of common content knowledge, specialized content knowledge and teachers' knowledge of student difficulties, errors and misconceptions rearding the function concept.

To this effect literature was reviewed to great detail to set the ground for the development of the project. Based on the review of the literature, a conceptual framework was developed based on the works of different scholars (Bair \& Rich, 2011; Ball et al., 2008; Dubinsky \& Wilson, 2013; Even, 1990; Lloyd et al., 2010; Malambo, 2016; Nyikahadzoyi, 2015; Shulman, 1986,1987; Steele et al., 2013). The conceptual framework for this study is displayed in Figure 12. This conceptual framework provided a context for the interpretation of the findings for this study. The framework also elaborated the relationships of concepts in this study.

The framework shows characteristics that pre-service teachers need to possess for them to be considered to reach the acceptable level of knowledge in each domain of knowledge. For example, demonstration of knowledge of definitions is a prerequisite for pre-service teachers' $\mathrm{CCK}$ while knowledge of application of these definitions to different situation entails SCK. Identifying student emerging errors, difficulties and misconception arising from their lack of knowledge of definitions is a pre-requisite for teachers' KCS. 


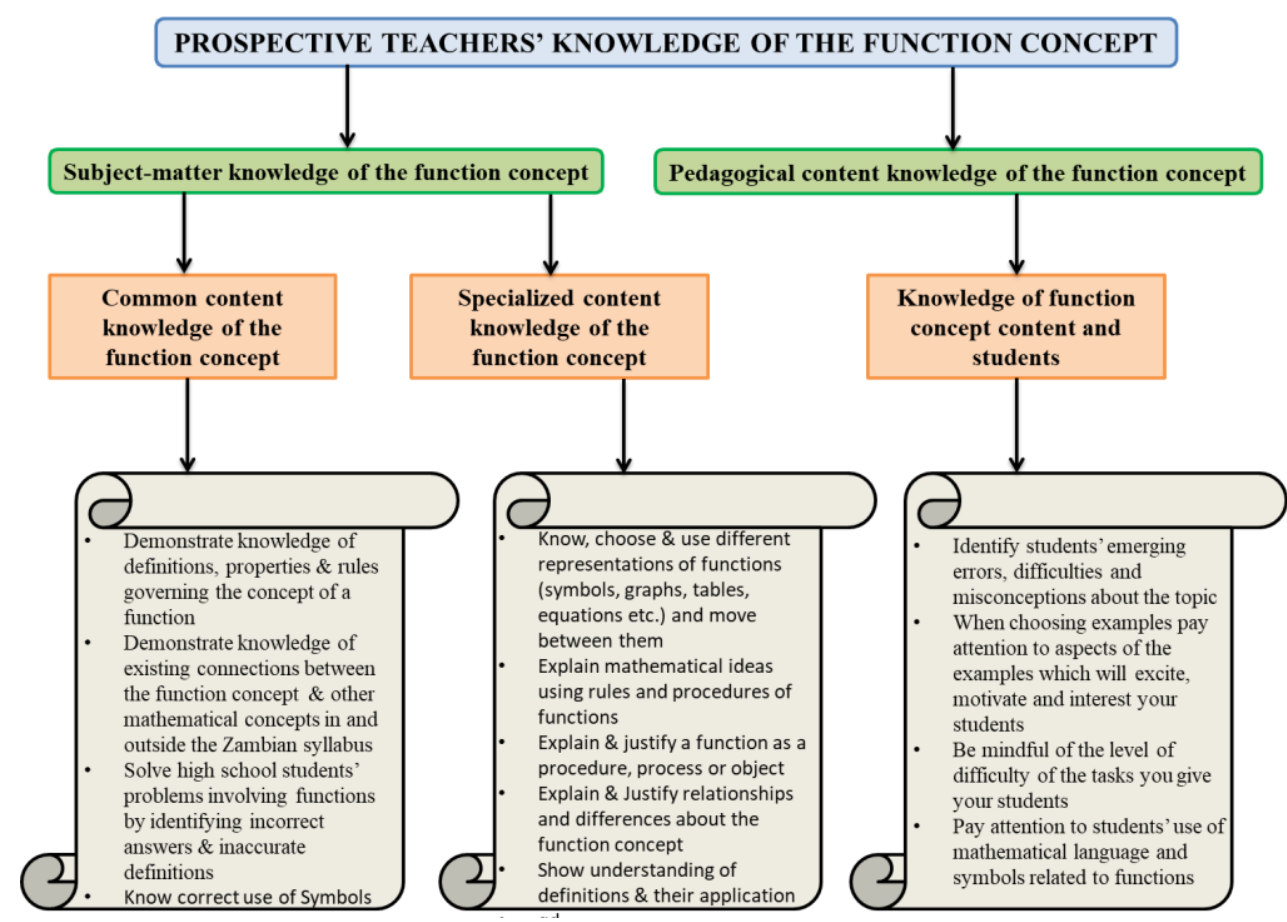

Figure 12. Conceptual framework for mathematics secondary teachers' knowledge of the function concept

\subsection{SUMMARY AND IMPLICATIONS}

Chapter 2 laid a strong and firm foundation for the methodological choices and decisions that were considered in this study, and for the interpretation of results that were obtained. The Chapter presented detatiled review of important frameworks for teacher knowledge that guided the development of the theoretical and conceptual frameworks for the study. Two of the most influential frameworks being Shulman's PCK (Shulman, 1986, 1987) and Hill et al.'s (2008) MKT. The entire study was actually anchored on the MKT framework for understanding the variables of analysis: CCK, SCK and KCS. Figure 12 gives a comprehensive visual representation of the concepts considered by the study and descritpions of CCK, SCK and KCS and how they related to the entire study are outlined.

Literature about MPCK perceptions related to mathematics was also reviewed in detatil. Perceptions influence teachers' confidence and beliefs about subject matter and are crucial for the development of teacher knowledge. From the literature it can be seen that none of the studies focused on pre- and in-service teachers' MPCK perceptions in relation to the concept of a function. This gap in literature needed to be filled by studies such as this one which focused on this knowledge domain. 
Chapter 2 then presented findings from various studies that focused on different aspects of the concept of a function. These studies were crucial in locating the current study in the literature. Some results from prior studies which investigated the concept of a function in relation to secondary school students revealed difficulties that participants faced with definition of the concept, inverse and composite functions, and dealing with different representations. These difficulties were largely sttributed to the teaching of the concept vis-à-vis teacher presentation of the concept. On the other hand findings from studies that investigated teacher knowledge of the function concept were presented. The general picture seemed to suggest that pre- and in-service teachers had weak knowledge of different aspects fo the concept. Other studies that were evaluated related directly to the use of the MKT in examing teacher knowledge of the function concept with some studies focusing on CCK and SCK. 


\section{Chapter 3: Research Design}

This chapter describes the research design and methodology adopted by this research to achieve the aims and objectives stated in Chapter 1 . The chapter opens with a detailed discussion of the philosophical considerations on which the entire study was anchored (section 3.1). Pragmatism was chosen as the philosophical lens that guided the investigation. Section 3.2 discusses the methodology used in the study, the stages by which the methodology was implemented, and the research design; section 3.3 details the participants in the study; section 3.4 lists all the instruments used in the study and justifies their use; section 3.5 outlines the procedure used and the timeline for completion of each stage of the study; section 3.6 discusses how the data were analysed; finally, section 3.7 discusses the ethical considerations of the research and its [potential] problems and limitations.

\subsection{PHILOSOPHICAL CONSIDERATIONS UNDERPINNING THIS STUDY}

Every research must have bases for its enquiry; it must be situated within particular philosophical or theoretical convictions to guide the study. These convictions, understood as 'research paradigms', are the set of beliefs, values and world views that researchers have in common regarding what is knowledge (ontology), how it can be ascertained (epistemology), and the procedures for studying it (methodology) (Johnson \& Onwuegbuzie, 2004).

This study was underpinned by the 'pragmatism' paradigm. In choosing pragmatism as a philosophical lens for this study, the researcher was cognizant of the logical contradictions and duality of data based on purist rigid interpretations of the main paradigms of (quantitatively oriented) positivism/post-positivism and (qualitatively oriented) constructivism. The positivist notion of a singular reality, the one and only truth that is out there waiting to be discovered by objective and valuefree inquiry underpins quantitative research methods. In contrast, the idea that there is no such thing as a single objective reality and that "subjective inquiry is the only kind possible to do" and for that reason constructivists favor qualitative research methods (Creswell \& Plano Clark, 2007; Erlandson et al., 1993, p. 11). Pragmatists 
are anti-dualist who hold that the purist schools of thought, positivism and constructivism have some commonalities in their approach to research and there are no ontological and epistemological differences between the two paradigms, hence the call for the convergence of quantitative and qualitative research methods (Yvonne, 2010; Hanson, 2008; Johnson \& Onwuegbuzie, 2004).

Teddlie and Tashakkori (2009) posit that for mixed methods research, pragmatism can be used as a guide not only for top-down deductive research design but also for grounded inductive or abductive research. It offers the chance to produce a "properly integrated methodology for the social sciences"' (Morgan, 2007, p. 73) in acknowledging the value of both quantitative and qualitative research methods and the knowledge produced by such research in furthering our understanding of society and social life. Pragmatism may thus enable researchers to enjoy the complexity and messiness of social life and revive a flagging sociological imagination.

The researcher was convinced that pragmatism would help go beyond just testing a particular idea or describing a status quo because it brushes aside the quantitative/qualitative divide by suggesting that in research the most fundamental question is whether the research has helped "to find out what [the researcher] want[s] to know" (Hanson, 2008, p. 109). Thus, pragmatists are less concerned about whether one uses quantitative methods or qualitative methods or both. What is pragmatically important is that the method(s) employed yield desirable results by adequately answering the posed research questions. This is the rationale for the researcher to utilize mixed methods approach in the current study.

Ontologically, pragmatism agrees with positivists/post-positivists on the existence of an external reality independent of our mind (Cherryholme, 1992). However, according to Teddlie \& Tashakkori (2009), pragmatists deny that truth regarding reality can actually be determined. Rather, pragmatists' choice of a particular explanation indicates that it is "better than another at producing anticipated or desired outcomes" (Cherryholmes, 1992, p. 15). Pragmatism as a world view sidesteps the contentious issues of truth and reality, accepts, philosophically, that there are singular and multiple realities that are open to empirical inquiry and orients itself towards solving practical problems in the "real world" (Cresswell \& PlanoClark, 2007, p. 20; Dewey, 1925; Rorty, 1999; Teddlie \& Tashakkori, 2010). Thus, pragmatism accords the researcher opportunities to be free of mental and practical 
constraints imposed by the "forced choice dichotomy between post positivism and constructivism" (Creswell \& Plano Clark, 2007, p. 27), and researchers do not have to "be the prisoner of a particular [research] method or technique" (Robson, 1993, p. 291).

\subsection{METHODOLOGY AND RESEARCH DESIGN}

The detailed methodology and design of this study are discussed in the following sub-sections. The choices and decisions taken are substantiated in this section of the study to show how they connect to the other parts of the investigation.

\subsubsection{Methodology}

This section details the mixed methods research design used in this study by focussing on the sequential explanatory mixed methods design and sampling techniques that suit the design. It also describes the data collection procedures for the two phases that were used and the analysis procedures employed. A visual representation of the data collection and analysis is provided to give a concise summary of the process. The strengths and weaknesses of using a sequential explanatory mixed methods approach are also outlined.

\subsubsection{Research Design}

To conduct research, educational researchers always draw from one of the three basic research methods: quantitative methods, qualitative methods or mixed methods (Creswell, 2003; Creswell \& Piano-Clark, 2007; Teddlie \& Tashakkori, 2009), mixed methods being a combination of quantitative and qualitative methods in a single study. The current study was underpinned by the mixed methods research design. Specifically, the study used the mixed methods sequential explanatory strategy (Creswell, 2003). In order to appreciate the choice of using the mixed methods design, it is important to have a clear overview and understanding of both quantitative methods and qualitative methods of inquiry.

Quantitative methods emphasise objective measurements and the statistical, mathematical, or numerical analysis of data collected through polls, questionnaires and surveys, or by manipulating pre-existing data using computational techniques. Quantitative research focuses on gathering numerical data and generalizing them across groups of people or to explain a particular Phenomenon (Babbie, 2010; Muijs, 
2010). It mainly deals with logic and objective stance. Quantitative methods have a wide range of advantages. One of the important advantages of quantitative research is that its results are based on a larger sample that is representative of the population and the results can be generalized more widely. With such strengths come the weaknesses of quantitative research methods. Creswell and Plano-Clark (2007, p. 9) claimed that quantitative research is "weak in understanding the context or setting in which people talk...the voices of participants are not directly heard in quantitative research. Further, quantitative researchers are in the background and their own personal biases and interpretations are seldom discussed".

Qualitative research, on the other hand, accords the researcher an opportunity to explore and explain phenomena as they occur in their natural setting. Denzin and Lincoln (2008) posited that

qualitative research involves the studied use and collection of a variety of empirical materials -case study; personal experience; introspection; life story; interview; artefacts; cultural texts and productions; observational, historical, interactional and visual texts-that describe routine and problematic moments and meanings in individuals' lives (p. 4).

In qualitative research, the researcher is actively involved in the research process by interacting with participants of the research and these researchers basically seek answers to questions that emphasize how and why social experience is created and given meaning. The researcher also doubles as an instrument of data collection. However, with its characteristic of producing rich descriptions of phenomena, qualitative research has some weaknesses. According to Cresswell and Plano-Clark (2007): "qualitative research is seen as deficient because of the personal interpretations made by the researcher, the ensuing bias created by this, and the difficulty in generalizing to a large group because of the limited number of participants studied" (p. 9).

Between quantitative and qualitative methods of enquiry sits the mixed methods approach to research. Upon realizing that the weaknesses of quantitative methods can be complemented by the strengths of qualitative methods and viceversa, it has increasingly become common practice in educational studies to employ mixed methods because mixed methods offer a "more complete picture by noting trends and generalizations as well as in-depth knowledge of participants' 
perspectives" (Creswell \& Plano-Clark, 2007, p. 33). Mixed methods approach has been described and defined in a number of ways but all stressing the fact that within a single study there is a stage or stages where both quantitative and qualitative methods are combined. Johnson et al. (2007) defined mixed methods research by saying that

Mixed methods research is the type of research in which a researcher or team of researchers combine elements of qualitative and quantitative research approaches (eg., use of qualitative and quantitative viewpoints, data collection, analysis, inference techniques) for the broad purpose of breadth and depth of understanding and corroboration (p. 123).

This implies that mixed methods are especially useful to answering questions that cannot adequately be addressed by either quantitative methods alone or qualitative methods alone. Creswell et al. (2002) included "concurrent" and "sequential" methods of collecting data in their description of mixed methods by positing that:

A mixed method study involves the collection and analysis of both quantitative and qualitative data in a single study in which data are collected concurrently or sequentialy. Either quantitative or qualitative data are given priority, and involve the integration of the data at one or more stages in the research process (p. 212).

For the purpose of this study, a more comprehensive definition of mixed methods study by Creswell and Plano-Clark (2007) was used:

Mixed methods research is a research design with the philosophical assumptions as well as methods of enquiry. As a methodology, it involves philosophical assumptions that guide the collection and analysis of data and the mixture of qualitative and quantitative in many phases in the research process. As a method, it focuses on collecting, analyzing, and mixing both quantitative and qualitative data in a single study or series of studies. Its central premise is that the use of quantitative and qualitative approaches in combination provides a better understanding of research problems than either approach alone (p. 5).

There are many variations or strategies that researchers employ in their studies to suit the purpose for which a study is conducted. For the current study the sequential 
explanatory strategy was used as it would help to adequately address the research problem.

\subsubsection{Sequential Explanatory Mixed Methods Research Design}

The mixed methods sequential explanatory research design consists of two phases within the same study and is "characterized by the collection and analysis of quantitative data in the first phase of research followed by collection and analysis of qualitative data in the second phase that builds on the results of the initial quantitative results and is typically used to explain and interpret quantitative results by collecting and analysing follow up qualitative data" (Creswell, 2017, p. 211). The sequential explanatory strategy can be very useful when unexpected results arise from a quantitative study (Morse, 1991) and therefore, the follow up qualitative data can be used to scrutinize these surprising results.

As the aim of this study was to have a holistic and detailed understanding of pre-service teachers' knowledge of the function concept and to provide in-depth explanation about the "why" questions regarding knowledge of the functions concept of these pre-service teachers, the selection of the mixed methods sequential explanatory design was ideal to address the research questions and to have a detailed and complete understanding of the research problem. The design provided the researcher with opportunities to explore the quantitative results obtained in Phase 1 (Figure 13) of the study from the MPCK survey, and the test on functions. This was followed by an in-depth analysis using qualitative interviews in the second phase. This approach is supported in literature by several authors who posit that usually quantitative data and their subsequent analysis provide a general understanding of the research problem. The qualitative data and their analysis refine and explain those statistical results by exploring participants' views in more depth (Rossman \& Wilson, 1985; Tahsakkori \& Teddlie, 1998; Creswell, 2003).

Creswell (2017) who based his arguments on Guba (1981) proposed six important factors to consider when conducting a sequential mixed methods study namely (i) rationale for the design, (ii) collection of quantitative and qualitative data, (iii) priority for the collection of quantitative and qualitative data, (iv) sequence of collecting the data, (v) matching data analysis to the research design and (vi) providing a visual model for the for the procedure. 
The rationale for using a sequential mixed methods research design has already been discussed and both quantitative and qualitative data were collected for that purpose. Priority is concerned with which type of data the researcher places more emphasis in the collection and analysis stages. For this study, emphasis was placed on qualitative data collection and analysis.

Sequence or implementation on the other side refers to which type of data is collected in the first and second phases respectively. For this study quantitative data were collected and analysed in Phase 1 and qualitative data were collected and analyzed in Phase 2 to gain in-depth understanding of the research problem and to give a detailed explanation of pre-service teachers' knowledge of the function concept.

The visual representation of the mixed methods sequential explanatory research design for this study was summarized in the model (Figure 13). In the first phase the MPCK survey and a test on functions were used to collect data for initial analysis. This was complemented by data collected via semi-structured interviews, vignettes and lesson plans in the second phase. The stages and all accompanying activities show how rigorous the quantitative and qualitative phases were. All procedures that were employed during the research process and the expected outcomes are indicated to ensure transferability and replication of the study to researchers that may intend to to so. 


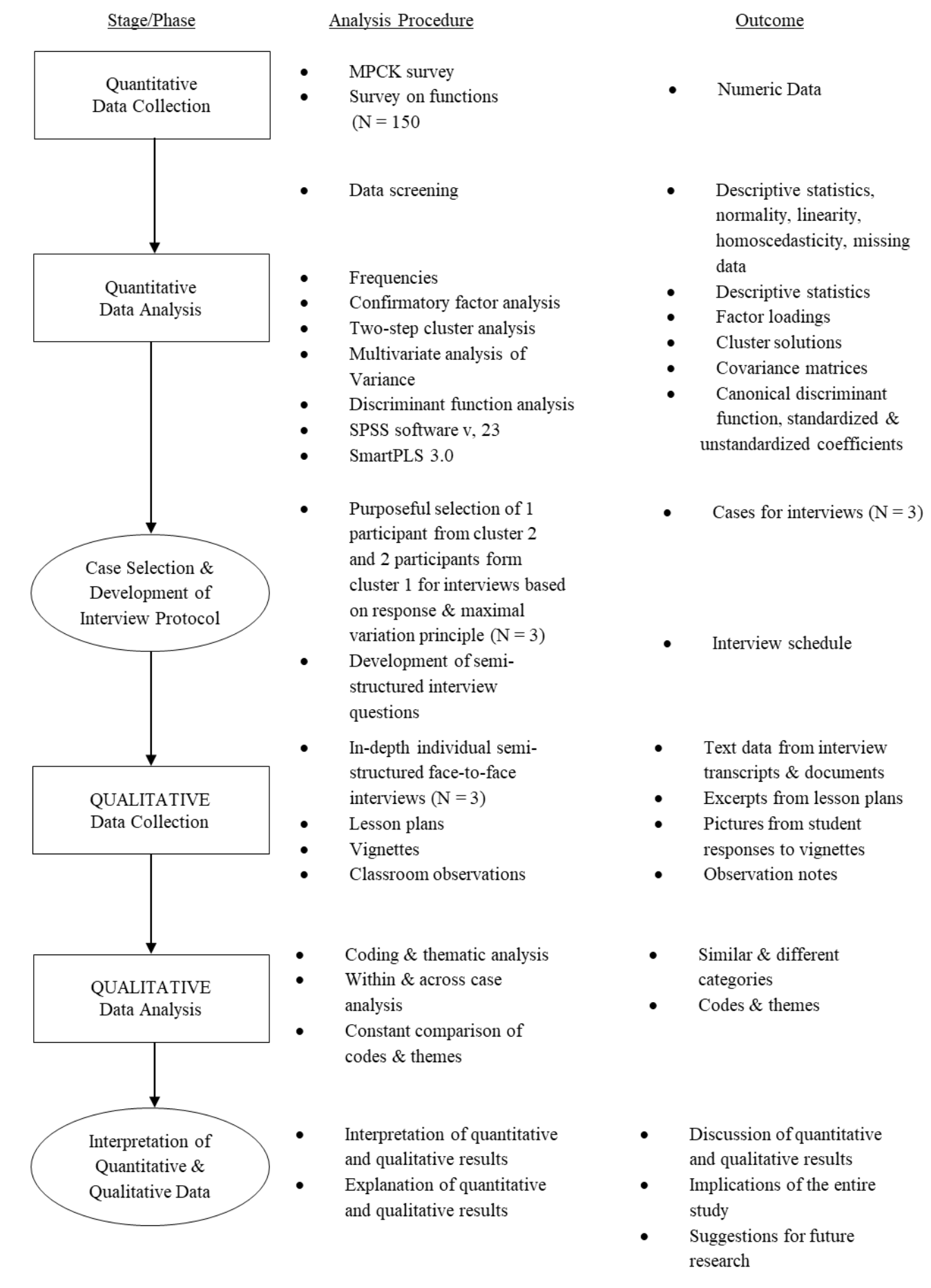

Figure 13. A visual representation of the sequential explanatory design procedure (adapted from Creswell, 2017, p. 2009)

\section{Strengths and weaknesses of the sequential explanatory design used in this study}

This design is not without its weaknesses. Generally, strengths and weaknesses of mixed methods designs have been extensively documented in literature (Creswell, 
2003, 2012; Ivankova et al., 2006; McGraw, 2019; Mena, 2019; Terrell \& Steven, 2012). Some of the advantages and disadvantages of this design are presented below.

\section{Strengths of the sequential explanatory design}

The major strengths of the sequential explanatory mixed methods design are, but not limited to

(a) Its straightforward nature which made it easy to move from one phase to the next

(b) The implementation of the design was easy because it only involved two clear and separate phases.

(c) Because of the separate phases, it was easy for the researcher to give a detailed description and report of the research process and its findings

(d) The researcher found this design useful when unexpected results arose from the quantitative phase of the study (Morse, 1991) which provided for the second phase (qualitative) to have an in-depth examination of the unexpected results.

\section{Weaknesses of the sequential explanatory design used in this study}

The major weaknesses of the sequential explanatory mixed methods design were, but not limited to

(a) Because the design involved two separate stages, the data collection period was very long as it involved collection and analysis of quantitative data before collection of data for the qualitative phase. At the time of qualitative data collection the participants had left the University for Various Schools in different parts of the country where they were going to do teaching practice. Thus, not all intended participants were accessed to participate in Phase 2.

(b) There were challenges in the quantitative phase of the study as some findings were not consistent with previous research. For example, this study found that there was no correlation between knowledge of teaching strategies and MPCK.

(c) At the time of collecting data for the qualitative phase some participants who had been purposefully selected to participate in Phase 2 had changed location and consequently declined to be part of the sample. 


\subsection{PARTICIPANTS}

The population for this study comprised pre-service teachers pursuing 4-year degree programs in secondary teaching leading to the award of Bachelor's degrees in mathematics education from public universities in Zambia. Specifically, the target population was that of students from the Faculties of Education in those universities. The sample was composed of male and female students who enrolled for a degree in mathematics education. The composition of participants was such that there were more male than female pre-service teachers who volunteered to participate in this study, hence the difference in the number of participants by gender (Table 2)". Twostep Cluster analysis was conducted to naturally group the participants according to their knowledge characteristics. Two Clusters were formed of which Cluster 1 was composed of 71 participants whereas Cluster 2 had 79. A detailed description of the two Clusters is presented in Chapter 4 of this Thesis.

Table 2. Characteristics of participants

\begin{tabular}{ccc}
\hline Characteristics & $\mathrm{N}$ & $\%$ \\
\hline Gender & 105 & 70 \\
Male & 45 & 30 \\
Female & & \\
Grade & 55 & 37 \\
$3^{\text {rd }}$ year & 95 & 63 \\
$4^{\text {th }}$ year & & \\
Cluster & 71 & 47 \\
Cluster 1 & 79 & 53 \\
Cluster 2 & &
\end{tabular}

\subsubsection{Sample and Sampling Techniques}

\section{Overview about sampling: General issues}

Sampling is a very important phase of a research process. It is basically the act, process, or technique of selecting a representative part of the population for the purpose of determining characteristics of the entire population. It is important to achieve a well-designed study that convincingly addresses the set research questions. However, sampling decisions that a researcher makes can guarantee failure of an otherwise strong study. For example, choosing a sample that is "unlikely to allow strong (internally valid and credible) conclusions related to the initial posed questions and unlikely to allow for the transfer the conclusions to other desired settings or populations" (Kemper et al., 2003, p. 275). 
Curtis et al. (2000) suggested six guidelines on which a sampling strategy should be based. In this study we highlight five of the guidelines which the researcher considered key to the success of the research. Curtis et al., contended that (a) the sampling strategy should stem logically from the conceptual framework as well as the research questions being addressed by the study. This item is concerned with ensuring that the sampling strategy is in line with the conceptual ideas that underlie the study and the employed sampling scheme should provide for a potentially valid means by which to answer the research questions under study; (b) the sample should generate a thorough database on the type of phenomena under study. This implies that the scope of the data that are to be collected should be adequate enough to help answer the research questions under study and the sampling scheme should sufficiently be focused to allow the researcher to gather data needed to answer the posed research questions; (c) the sample should at least allow the possibility of drawing clear inferences from the data and should also allow credible explanations. This guideline concerns issues of internal validity from both the quantitative and qualitative perspectives. Inferences from a quantitative point of view refers to the degree to which changes in the outcome variable can be attributed to the hypothesized cause rather than to other potential causal factors (Cook \& Campbell, 1979). From a qualitative perspective, credibility refers to the extent to which the researcher's reconstruction of reality are "credible to the constructors of the original multiple realities" (Lincoln \& Guba, 1985, p. 296); (d) the sampling strategy must be ethical. By this, it is implied that participants should give informed consent regarding their participation in the study. The researcher should also weigh the benefits and costs of the study to the participants and the researcher should provide absolute assurance to the participants that any promised confidentiality would be maintained; (e) the sampling plan should be feasible. This item is concerned with issues of whether the researcher can access all of the needed data and whether the sampling method chosen is congruent with the researcher's abilities.

\subsubsection{Two-Dimensional Mixed Methods Sampling Model}

Mixed methods studies require mixed methods sampling procedures in order to simultaneously increase inference quality (internal validity and trustworthiness) and generalizability/transferability of the study (Kemper et al., 2003). To this effect a probability sample would increase the generalizability/transferability aspects of the 
study while a purposive sample would increase the inference quality of the study. The two-dimensional mixed methods sampling model was developed by Onwuegbuzie and Collins (2017) to help mixed-methods researchers to identify an optimal sampling design and to classify mixed-methods studies in the extant literature with respect to their sampling strategies.

Onwuegbuzie and Collins (2017) posited that quantitative and qualitative samples in a mixed method study can portray a relationship which can either be identical, parallel, nested or multilevel and that this relationship plays a pivotal role in the success of a study. According to Onwuegbuzie and Collins (2017), an identical relationship denotes that exactly the same sample members participate in both the quantitative and qualitative phases of the investigation. A parallel relationship indicates that the samples for the quantitative and qualitative components of the inquiry are different but are drawn from the same underlying population. A nested relationship implies that the sample members selected for one phase of the study represent a subset of those participants chosen for the other phase of the research. A multilevel relationship involves the use of two or more sets of samples that are obtained from different levels of the study (i.e. different populations).

Thus, for the purpose of this study, a mixed method sequential sampling design using nested samples for the quantitative and qualitative components of the study was adopted to guide the sampling process. This was because nested samples would help the researcher to adequately address the research problem and provide answers for the posed research questions of the study.

\subsubsection{Mixed methods sequential sampling design: Nested samples technique}

A sampling design should fit the overall research design that underlies a study (Creswell, 2014). The research design used in the current study was the sequential explanatory mixed methods research design. In a sequential explanatory mixed methods research design, the quantitative phase is conducted first and the analysis and results are then used to inform the subsequent qualitative phase (Creswell, 2017). This entails that a suitable sampling design congruent to the overall research design must be used in order to achieve an elegant study. The current study utilised a mixed method sequential sampling design using nested samples for the quantitative and qualitative components of the study. According to some scholars (Kemper et al., 
2003; Johnson \& Onwuegbuzie, 2004), in sequential mixed methods studies, information from the first sample (derived from probability sampling procedures) is often required so as to draw the second sample (derived from purposive sampling procedures). As explained in the overview above, a nested relationship for this study implied that the sample members selected for the second phase (Qualitative) of the study represented a subset of those participants chosen for the first phase (Quantitative) of the research.

\section{Sampling for Phase 1}

The sample for this phase of the study constituted pre-service teachers whose major subject of study was mathematics. Cluster sampling was used to randomly select universities (clusters) from which participants were drawn to participate in the mathematical pedagogical content knowledge (MPCK) survey and the functions concept survey which was in form of a paper and pencil test. Participants were chosen using convenience sampling techniques to participate in both the MPCK survey and the test on functions. According to Gravetter and Forzano's (2012) study, convenience sampling is a non-probability method that is characterised by the choice of participants that are available, easy to obtain, and willing to participate in the study. Participants were then requested to respond to a MPCK survey with the aim of assessing their perceived MPCK knowledge of the concept of a function. A paper and pencil test was also administered to the sample to gather common content knowledge, specialized content knowledge and teachers' knowledge of content and students. A total of 150 pre-service teachers participated in Phase 1 of the study. Participation was purely voluntary and each participant registered to participate by signing a consent form which was provided.

\section{Sampling for Phase 2}

The sample for this phase also constituted pre-service teachers with a major in mathematics. The sample to participate in the interview constituted a sub-sample of three pre-service teachers who were purposefully selected from among those who wrote the test on functions and responded to the MPCK survey. A purposive sample was typically designed to pick a small number of cases that would yield the most information about the statistical findings of Phase 1. This was because it had the potential to lead to greater depth of information from a smaller number of carefully selected cases. Thus, it suited this phase of this study. 
The selection criterion that builds on extreme case sampling strategy (Creswell, 2012) was used. According to Teddlie and Yu (2007):

extreme or deviant case sampling, ... also known as 'outlier sampling' ... involves selecting cases near the 'ends' of the distribution of cases of interest. It involves selecting those cases that are the most outstanding successes or failures related to some topic of interest. Such extreme successes or failures are expected to yield especially valuable information about the topic of interest (p. 81).

Thus, for this study the strategy involved the selection of four cases that exhibited extreme features with a view to describing each case in detail. This implies that two participants were selected from among those whose test scores were high and the other two from among those whose test scores were low. However, one selected participant whose test score was high withdrew from the study leaving only three participants for phase 2 of the study. These cases yielded in-depth valuable information that helped in understanding Zambian pre-service teachers' knowledge of the function concept. Regarding the function concept, information collected using qualitative samples helped the researcher to "obtain in-depth understandings about the way things are, why they are that way, and how the participants in the context perceived them" (Gay \& Airasin, 2003, p. 13).

\subsection{INSTRUMENTS}

This section provides descriptions of the data collection tools that were employed in the study and how they were used. In total, the study used six data collection tools, all with a purpose of answering the posed research questions. The data collection tools that were employed included a mathematical pedagogical content knowledge survey, pencil and paper test on the concept of a function, semistuctured in-depth interviews related to the function concept, lesson plans, lesson observation sheets, and vignettes on functions. These instruments provided different types of data as explained by Creswell (2012). The types of data that were gathered included documents, observations, interviews and audiovisuals. Table 3 shows the types of data and their source.

Table 3. Types of data and their sources
Data type
Data source 


\begin{tabular}{|c|c|}
\hline $\begin{array}{l}\text { Documents } \\
\text { data }\end{array}$ & $\begin{array}{l}\text { These data were gathered from a pencil and paper test on the } \\
\text { concept of a function, a pedagogical content knowledge survey, } \\
\text { lesson plans, vignettes and a manual constituting definitions of } \\
\text { functions }\end{array}$ \\
\hline $\begin{array}{l}\text { Observations } \\
\text { data }\end{array}$ & $\begin{array}{l}\text { These data were collected from classroom teaching activities. Filed } \\
\text { notes were compiled based on each prospective teacher's classroom } \\
\text { teaching activity. }\end{array}$ \\
\hline $\begin{array}{l}\text { Interviews } \\
\text { data }\end{array}$ & Three interviews were transcribed to provide interview data \\
\hline $\begin{array}{l}\text { Audiovisual } \\
\text { data }\end{array}$ & $\begin{array}{l}\text { Lessons taught by prospective teachers were video-taped. These } \\
\text { became the source of audiovisual data }\end{array}$ \\
\hline
\end{tabular}

\subsubsection{Development of data collection instruments}

\section{Development and Validation procedure of the test on the concept of a function}

The pencil and paper test on the concept of a function was developed based on the revised Zambian senior secondary school mathematics curriculum (CDC, 2012). The test was developed for the purpose of measuring pre-service Zambian secondary mathematics teachers' CCK, SCK and KCS of the function concept. The test covered the entire topic paying particular attention to the objectives of the Zambian curriculum. The mathematics syllabus demands that after learning the topic all students should be able to define relations and functions, determine domain and range, determine objects and images, determine whether a relation is a function or not, distinguish types of functions, find inverses of one-to-one functions, represent functions using different representations, define composite functions and to solve problems involving functions. The development and validation procedure of the instrument was a two-stage process (Lynn, 1986). Following the views of Lynn, the two stages of content validity employed by the researcher were developmental stage and expert review/judgment stage. The implementation of the two stages was a sequential process.

\section{Stage 1: Development stage}

In the first content validation stage a comprehensive literature review in relation to the current study was conducted to identify items for inclusion in the 
instrument. An item pool was generated from which the first version of the instrument was constructed. The item pool consisted of test items from previous research on subject matter and pedagogical content knowledge of the function concept (Even, 1990; Malambo, 2016; Watson et al., 2018; Even, 1993; Leinhardt et al., 1990; You, 2010). The first version (pre-final version) comprised a total of twelve questions and 55 items.

In order to come up with the pre-final version of the instrument, two experts were involved. One is a professor of mathematics at a public university in Zambia and the other one is a professor of mathematics education at a public university in Spain. The criteria followed by the experts included selecting items based on the content objectives set out in the Zambian secondary school mathematics curriculum because the instrument was going to be administered to the Zambian sample. The experts were also availed the purpose and objectives of the current study and the Zambian senior secondary school mathematics syllabus.

\section{Stage 2: Expert review and Judgment stage}

At this point the second content validation stage was then incorporated. The stage involved recruitment of experts, face validation and content validation of the test. At this stage a Likert rating scale was developed for mathematics content experts to evaluate the entire instrument and rate each test item based on four indicators: (a) sufficiency; (b) clarity; (c) Coherence and (d) relevance (see appendix $\mathrm{H})$.

\section{Recruitment of experts for face and content validity evaluation of the instrument}

The recruitment process commenced with the identification and shortlisting of experts. To this effect, fifteen mathematics and mathematics education experts from universities, colleges of education and secondary schools were shortlisted for this exercise (Tabble 4). They were then contacted via e-mail requesting them to participate in the review. Ten out of fifteen experts responded with positive feedback while five were unable to participate citing various work related commitments. A set of documents was then e-mailed to the ten experts who showed willingness to participate in the validation process of the instrument. Each expert received (i) A letter of request, (ii) test paper, (iii) copy of instructions, (iv) item validation sheet, (v) Definitions of dimensions and (vi) senior secondary school mathematics 
curriculum. The experts were asked to evaluate the whole test and rate each test item.

Bio data of the experts are presented in Table 4.

Table 4. Academic Curriculum Vitae of experts

\begin{tabular}{|c|c|c|c|c|c|}
\hline Expert & $\begin{array}{l}\text { Highest academic } \\
\text { qualification }\end{array}$ & $\begin{array}{c}\text { Main area of } \\
\text { professional } \\
\text { expertise }\end{array}$ & $\begin{array}{c}\text { Years of } \\
\text { experience }\end{array}$ & $\begin{array}{l}\text { Current } \\
\text { position }\end{array}$ & Institution \\
\hline 1 & $\mathrm{MSc}$ & $\begin{array}{l}\text { Mathematics } \\
\text { Education }\end{array}$ & 11 & Lecturer & $\begin{array}{c}\text { Mukuba } \\
\text { University }\end{array}$ \\
\hline 2 & MSc & $\begin{array}{c}\text { Mathematics } \\
\text { Education }\end{array}$ & 4 & Lecturer & $\begin{array}{l}\text { Copperbelt } \\
\text { University }\end{array}$ \\
\hline 3 & MSc & Mathematics & 5 & Lecturer & $\begin{array}{l}\text { Rusangu } \\
\text { University }\end{array}$ \\
\hline 4 & $\mathrm{MSc}$ & $\begin{array}{c}\text { Mathematics } \\
\text { Education }\end{array}$ & 20 & $\begin{array}{c}\text { Head of } \\
\text { Department }\end{array}$ & $\begin{array}{l}\text { Chipata } \\
\text { college of } \\
\text { education }\end{array}$ \\
\hline 5 & $\mathrm{MSc}$ & $\begin{array}{l}\text { Mathematics } \\
\text { Education }\end{array}$ & 18 & $\begin{array}{l}\text { Senior } \\
\text { Lecturer }\end{array}$ & $\begin{array}{l}\text { Chipata } \\
\text { college of } \\
\text { education }\end{array}$ \\
\hline 6 & MSc & $\begin{array}{c}\text { Mathematics } \\
\text { Education }\end{array}$ & 20 & $\begin{array}{l}\text { Senior } \\
\text { Lecturer }\end{array}$ & $\begin{array}{l}\text { Chipata } \\
\text { college of } \\
\text { education }\end{array}$ \\
\hline 7 & BSc.ED & Mathematics & 12 & $\begin{array}{l}\text { Deputy } \\
\text { Head } \\
\text { teacher }\end{array}$ & $\begin{array}{c}\text { St. Monica's } \\
\text { secondary } \\
\text { school }\end{array}$ \\
\hline 8 & B.A. ED & Mathematics & 12 & $\begin{array}{c}\text { Head of } \\
\text { Department }\end{array}$ & $\begin{array}{c}\text { Chizongwe } \\
\text { Technical High } \\
\text { school }\end{array}$ \\
\hline 9 & MPhil & Mathematics & 12 & $\begin{array}{l}\text { Subject } \\
\text { teacher }\end{array}$ & $\begin{array}{l}\text { Lukanda } \\
\text { secondary } \\
\text { school }\end{array}$ \\
\hline 10 & B.A. ED & Mathematics & 11 & $\begin{array}{l}\text { Subject } \\
\text { teacher }\end{array}$ & $\begin{array}{l}\text { St. Raphael's } \\
\text { secondary } \\
\text { school }\end{array}$ \\
\hline
\end{tabular}

MPhil : Master of Philosophy

MSc: Master of Science

BSc.ED: Bachelor of Science with Education

B.A. ED: Bachelor of Arts with Education

Of the ten, six were Master's degree holders while four were Bachelor's degree holders. It can also be seen from Table 4 that three experts were university lecturers, three were Senior Lecturers at colleges of education for teacher training (with one Head of Department) and four were mathematics teachers in secondary schools (with one Deputy Headteacher and one Head of department). Of the six Master's degree holders, five hold a Master of Science in Mathematics Education, while one holds a Master of Science in Mathematics. Of the four Bachelor's degree holders, one holds a Bachelor of Science ibid while three hold a Bachelor of Arts with Education in mathematics. Table 4 also shows that eight experts had at least 11 years of 
professional experience in their main area of expertise. The other two had four and five years of professional experience respectively. It is also worth noting that at the time of engagement of the experts, one was pursuing a $\mathrm{PhD}$ in mathematics education and one was pursuing a MPhil in mathematics education.

\section{Face validity evaluation of the instrument}

In order to establish face validity of the instrument, the pre-final version was pilot tested on a sample of $1203^{\text {rd }}$ and $4^{\text {th }}$ year mathematics pre-service secondary teachers registered on four-year Bachelor of Science in mathematics education degree program. There was no time limit set in completing the exercise for the participants. The participants were asked to provide feedback in form of comments about comprehensibility and clarity of the test items, conformity of the test to the Zambian curriculum and any other general comments about the test.

\section{Content validity evaluation of the instrument}

In order to establish content validity of the instrument, ten mathematics education experts participated. One of the criteria for selecting participants was that the expert needed to have at least two years of practicing experience in their area of expertise. All the participants had recognized practicing experience. They were asked to rate each item for its clarity, coherence and relevance. The experts were also asked to rate groups of items for their conformity with a dimension they belonged to. The ratings were done using a four-point Likert scale ranging from (1) Does not meet the criteria, (2) Low level, (3) Moderate level, to (4) High level. Following expert ratings for each item, item-level content validity index (I-CVI) and scale-level content validity index (S-CVI) were calculated. CVI was the proportion of test items that were rated 3 or 4 (Waltz \& Bausell, 1983).

The content validation index (CVI), also known as proportion agreement, was then calculated for each item as an index of interrater agreement of the experts. To calculate the CVI usually two or more raters are asked to evaluate and rate test items. The CVI then becomes the proportion of raters in agreement about the item. For this study a four-point Likert scale was used to rate items of the test namely $1=$ Does not meet the criteria, $2=$ Low level, $3=$ Moderate level and $4=$ High level.

The CVI is not without weaknesses. Critics of CVI (Cohen, 1960; Waltz \& Bausell, 1983) have criticized the proportion agreement procedure for its lack of the 
"no agreement" value arguing that this is likely to inflate agreements purely due to chance. However, to overcome the occurrence of chance agreements Lynn (1986) proposed using more than five raters and a four-point Likert rating scale. This study met the threshold proposed by Lynn by using a four point Likert rating scale and employing ten experts to evaluate and rate the test items. For the instrument being developed in the current study, item-level content validity index of $\geq 0.80$ and scalelevel content validity index of $\geq 0.90$ were considered acceptable (Almanasreh et al., 2019; Cooper et al., 2010).

\section{Final version of test}

The final version of the test consisted of nine questions, all of which had subitems. In total, the test consisted of 35 items. Some questions in the test were open ended. This was to enable the researcher have in-depth understanding of pre-service teachers' knowledge of the function concept. All the questions in the test were taken from previous research studies. Only questions that met the requirements of the Zambian secondary school curriculum were included in the test. The validation process is shown in Figure 14.

\section{Item pool for the design of the instrument} The initial pool of 55 items from previous studies was created based on the scope and objectives Zambian secondary school curriculum

Generation of the pre-final version of the instrument This was done in consultation and agreement with two experts

Content Validity evaluation of the instrument This was done by ten experts with recognised experience in mathematics and mathematics education

Face Validity evaluation of the instrument This was done by a pilot test of the instrument on a sample of $1203^{\text {rd }}$ and $4^{\text {th }}$ year university students registered on a four year Bachelor of Science in mathematics education programme.

Final version of the instrument

Figure 14. Visual representation of the validation process 


\section{Results of the content validity evaluation of the instrument}

Item content validity index (I-CVI)

To evaluate content validity index for the clarity, coherence and relevance of each item (I-CVI), the number of experts who rated the item as 3 or 4 was divided by the total number of experts (Tables 5, 6, 7, 8). The CVI being mainly inter-ratter agreement with emphasis on the proportion of agreement by the ratters, there has been concern that agreements can be inflated merely by chance. To resolve this likely occurrence Lynn (1986) suggested that for five ratters or less, the I-CVI of 1.00 would be accepted as a cut-off. This means that all the five needed to agree on the validity of the item. However, for six or more ratters it was suggested that the ICVI of at least 0.78 would be the accepted cut-off. This criterion was used in this study as a guide to delete, revise or substitute items that failed to meet the minimum threshold. For the purpose of this study only items that recorded $\geq 0.80$ validity index were retained in the test. Comments from the ratters were also considered when deciding which items to delete from the test. If an item had good item validity but was considered vague by the ratters, it was deleted. Tables 5, 6 and 7 show the ICVI for the retained items.

Table 5. Item content validity index for the clarity, coherence and relevance of each test item

\begin{tabular}{cccccccc}
\hline Item & $\begin{array}{c}\text { Clarity } \\
\text { I-CVI }\end{array}$ & $\begin{array}{c}\text { Coherence } \\
\text { I-CVI }\end{array}$ & $\begin{array}{c}\text { Relevance } \\
\text { I-CVI }\end{array}$ & Item & $\begin{array}{c}\text { Clarity } \\
\text { I-CVI }\end{array}$ & $\begin{array}{c}\text { Coherence } \\
\text { I-CVI }\end{array}$ & $\begin{array}{c}\text { Relevance } \\
\text { I-CVI }\end{array}$ \\
\hline 1(a) & 1.00 & 1.00 & 0.80 & $4(\mathrm{~b})$ & 0.90 & 1.00 & 0.90 \\
2(a)(i) & 0.90 & 0.90 & 0.70 & $5(\mathrm{c})$ & 0.90 & 1.00 & 1.00 \\
2(b) & 0.80 & 0.80 & 0.80 & $6(\mathrm{a})$ & 0.80 & 1.00 & 1.00 \\
2(e) & 0.90 & 1.00 & 0.90 & $3(\mathrm{c})$ & 0.90 & 1.00 & 0.90 \\
$4(\mathrm{a})$ & 0.80 & 0.80 & 0.90 & $3(\mathrm{~d})$ & 0.90 & 1.00 & 1.00 \\
5(b) & 0.90 & 1.00 & 1.00 & $3(\mathrm{e})$ & 0.90 & 0.90 & 0.80 \\
8(b) & 0.90 & 0.80 & 0.70 & $5(\mathrm{~d})$ & 0.80 & 1.00 & 1.00 \\
1(b) & 0.90 & 0.90 & 0.90 & $6(\mathrm{c})$ & 0.90 & 0.80 & 0.80 \\
2(a)(ii) & 0.80 & 0.90 & 0.90 & $6(\mathrm{~d})$ & 0.80 & 0.80 & 0.70 \\
2(e) & 0.80 & 0.90 & 0.80 & $1(\mathrm{e})$ & 0.70 & 1.00 & 0.90 \\
\hline
\end{tabular}

Table 6. Item content validity index for the clarity, coherence and relevance of each test item continued

\begin{tabular}{cccccccc}
\hline Item & $\begin{array}{c}\text { Clarity I- } \\
\text { CVI }\end{array}$ & $\begin{array}{c}\text { Coherence I- } \\
\text { CVI }\end{array}$ & $\begin{array}{c}\text { Relevance } \\
\text { I-CVI }\end{array}$ & Item & $\begin{array}{c}\text { Clarity I- } \\
\text { CVI }\end{array}$ & $\begin{array}{c}\text { Coherence I- } \\
\text { CVI }\end{array}$ & $\begin{array}{c}\text { Relevance } \\
\text { I-CVI }\end{array}$ \\
\hline $2(\mathrm{c})$ & 0.90 & 1.00 & 0.90 & $11(\mathrm{~b})$ & 0.70 & 0.90 & 0.80 \\
$2(\mathrm{~d})$ & 0.80 & 0.90 & 0.90 & $3(\mathrm{e})$ & 0.90 & 1.00 & 0.90 \\
$2(\mathrm{~g})$ & 0.80 & 0.80 & 0.70 & $5(\mathrm{e})$ & 0.90 & 1.00 & 0.90 \\
$4(\mathrm{c})$ & 0.90 & 1.00 & 0.90 & $6(\mathrm{~b})$ & 0.80 & 0.90 & 0.90 \\
$5(\mathrm{a})$ & 0.90 & 0.80 & 0.70 & $1(\mathrm{c})$ & 0.90 & 1.00 & 1.00 \\
$2(\mathrm{e})$ & 0.80 & 1.00 & 1.00 & $1(\mathrm{~d})$ & 0.90 & 0.90 & 0.90 \\
$2(\mathrm{f})$ & 0.60 & 0.90 & 0.80 & $2(\mathrm{f})$ & 0.70 & 0.80 & 0.90 \\
\hline
\end{tabular}




\begin{tabular}{cccccccc}
\hline $4(\mathrm{~b})$ & 0.80 & 1.00 & 0.90 & $2(\mathrm{~g})$ & 0.80 & 1.00 & 0.80 \\
$4(\mathrm{~d})$ & 0.90 & 0.90 & 1.00 & $3(\mathrm{a})$ & 0.80 & 1.00 & 1.00 \\
$11(\mathrm{a})$ & 0.80 & 0.90 & 0.90 & $3(\mathrm{~b})$ & 0.90 & 0.90 & 0.80 \\
\hline
\end{tabular}

Table 7. Item content validity index for the clarity, coherence and relevance of each test item continued

\begin{tabular}{cccccccc}
\hline Item & $\begin{array}{c}\text { Clarity I- } \\
\text { CVI }\end{array}$ & $\begin{array}{c}\text { Coherence I- } \\
\text { CVI }\end{array}$ & $\begin{array}{c}\text { Relevance } \\
\text { I-CVI }\end{array}$ & Item & $\begin{array}{c}\text { Clarity I- } \\
\text { CVI }\end{array}$ & $\begin{array}{c}\text { Coherence I- } \\
\text { CVI }\end{array}$ & $\begin{array}{c}\text { Relevance } \\
\text { I-CVI }\end{array}$ \\
\hline $4(\mathrm{~d})$ & 0.90 & 1.00 & 1.00 & $9(\mathrm{a})$ & 0.80 & 0.80 & 0.80 \\
$7(\mathrm{a})$ & 0.90 & 1.00 & 0.80 & $9(\mathrm{~b})$ & 0.80 & 0.70 & 0.80 \\
$7(\mathrm{~b})$ & 0.90 & 0.90 & 0.90 & $9(\mathrm{c})$ & 0.90 & 0.90 & 0.90 \\
$12(\mathrm{a})$ & 0.90 & 1.00 & 0.90 & $10(\mathrm{a})$ & 0.90 & 1.00 & 0.90 \\
$12(\mathrm{~b})$ & 0.90 & 0.90 & 1.00 & $10(\mathrm{~b})$ & 0.90 & 0.90 & 0.90 \\
$12(\mathrm{c})$ & 0.90 & 1.00 & 0.90 & $11(\mathrm{a})$ & 0.90 & 1.00 & 0.90 \\
2(b) & 0.90 & 0.90 & 0.90 & $11(\mathrm{~b})$ & 0.90 & 0.80 & 0.90 \\
$8(\mathrm{a})$ & 0.80 & 0.90 & 0.90 & & & & \\
\hline
\end{tabular}

Table 8. Item content validity index for the sufficiency of test items

\begin{tabular}{|c|c|c|c|}
\hline Dimension & Sub-Dimension & Items & CVI \\
\hline \multirow{5}{*}{$\begin{array}{l}\text { Common } \\
\text { Content } \\
\text { Knowledge }\end{array}$} & Definitions of relations and functions & $\begin{array}{l}\text { 1(a), 2(a)(i), 2(b), 2(e), } \\
\text { 4(a), 5(b), 8(b) }\end{array}$ & 1.00 \\
\hline & Examples and non-examples of functions & 1(b), 2(a)(ii), 2(e),4(b) & 1.00 \\
\hline & Calculations involving inverse functions & $5(c), 6(a)$ & 1.00 \\
\hline & Calculations involving quadratic functions & $3(\mathrm{c}), 3(\mathrm{~d}), 3(\mathrm{e}), 5(\mathrm{~d})$ & 0.90 \\
\hline & Composite functions & $6(\mathrm{c}), 6(\mathrm{~d})$ & 0.80 \\
\hline \multirow{4}{*}{$\begin{array}{l}\text { Specialised } \\
\text { Content } \\
\text { Knowledge }\end{array}$} & $\begin{array}{l}\text { Explaining and justifying relationships and } \\
\text { differences between relations and functions }\end{array}$ & $\begin{array}{l}1(\mathrm{e}), 2(\mathrm{c}), 2(\mathrm{~d}), 2(\mathrm{~g},) \\
4(\mathrm{c}), 5(\mathrm{a})\end{array}$ & 1.00 \\
\hline & $\begin{array}{l}\text { Explanation and justification of examples and } \\
\text { non-examples of functions }\end{array}$ & $\begin{array}{l}2(\mathrm{e}), 2(\mathrm{f}), 4(\mathrm{~b}), 4(\mathrm{~d}) \\
11(\mathrm{a}), 11(\mathrm{~b})\end{array}$ & 0.90 \\
\hline & $\begin{array}{l}\text { Explanations and justifications of relationships } \\
\text { between the ranges and domains of functions }\end{array}$ & $3(\mathrm{e}), 5(\mathrm{e}), 6(\mathrm{~b})$ & 1.00 \\
\hline & $\begin{array}{l}\text { Producing and representing relations and } \\
\text { functions in different forms (symbolic, ordered } \\
\text { pairs, graphs, tables, equations) }\end{array}$ & $\begin{array}{l}\text { 1(c), 1(d), 2(f), 2(g), } \\
3(\mathrm{a}), 3(\mathrm{~b}), 4(\mathrm{~d}), 7(\mathrm{a}) \\
7(\mathrm{~b}), 12(\mathrm{a}), 12(\mathrm{~b}), 12(\mathrm{c})\end{array}$ & 0.90 \\
\hline $\begin{array}{l}\text { Pedagogical } \\
\text { Content } \\
\text { Knowledge } \\
\end{array}$ & $\begin{array}{l}\text { Identification of students' common difficulties, } \\
\text { misconceptions and errors }\end{array}$ & $\begin{array}{l}\text { 2(b), 8(a), 9(a), 9(b), } \\
\text { 9(c), 10(a), 10(b), 11(a), } \\
11(b)\end{array}$ & 0.80 \\
\hline
\end{tabular}

\section{Scale content validity index (S-CVI)}

The scale content validity is defined as the proportion of all individual items whose rating is 3 or 4 (Beck \& Gable, 2001; Walts \& Bausell, 1981). This implies that only those items who rated very highly would contribute to the content validity of the whole scale. In literature the acceptable threshold for scale content validity is 0.80 (Grant \& Davis, 1997; Polit \& Beck, 2004). Considering these requirements the S-CVI was calculated from all the items whose rating was 3 or 4 and found to be 
0.90. Thus, the instrument had acceptable I-CVI and S-CVI and was judged to be appropriate for use in data collection.

\section{M-PCK questionnaire}

As a data collection tool, a scale designed to measure pre-service mathematics teachers' perceptions related to their PCK which was developed by Bukova-Guzel et al. (2013) was adapted to the Zambian context for this study. Exploratory factor analysis for the original scale revealed five factors: Knowledge of Teaching Strategies (KTS), Knowledge of Mathematical Language and Symbols (KMLS), Knowledge of Misconceptions (KM), Knowledge of Learners (KL) and Knowledge of Curriculum (KC). Reliability analysis of the original scale was carried out twice, first with a sample size of 112 participants and the test-retest reliability was conducted with 78 participants. A result of the reliability analysis is presented in Table 9.

Table 9. Cronbach alpha reliability coefficients of factors of the original scale

\begin{tabular}{lccccccc}
\hline & $\mathrm{N}$ & $\mathrm{KTS}$ & $\mathrm{KMLS}$ & $\mathrm{KM}$ & $\mathrm{KL}$ & $\mathrm{KC}$ & Total \\
\hline $\begin{array}{l}\text { Cronbach alpha reliability } \\
\text { coefficient }\end{array}$ & 112 & 0.78 & 0.60 & 0.73 & 0.64 & 0.83 & 0.87 \\
\begin{tabular}{l} 
Test-retest reliability \\
\hline
\end{tabular} & 78 & 0.73 & 0.72 & 0.69 & 0.62 & 0.82 & 0.88 \\
\hline
\end{tabular}

\section{Confirmatory factor analysis results}

A confirmatory factor analysis (CFA) procedure was performed to determine the fit of the adapted scale to the Zambian context. This procedure was used because CFA models are usally context specific (Alhija, 2010) and produce fit indices that can be used for the purpose of deciding whether an adapted scale can be accepted for use in a particular context. In the case of the adapted MPCK scale for this study, CFA was conducted to find out if the factor structure of the original scale would be confirmed in the Zambian Sample or not. For this study, the structural equation modelling (SEM) using the partial least squares (PLS) modelling method was used to obtain the CFA model. The statistical software called SmartPLS version 3.0 was used for this purpose. Different fit indices which included the standardized root mean residual (SRMR), Chi-square value, Normed fit index (NFI) were obtained together with other exact fit measures d_ULS and d_G. These are dicussed in detail in this section. 


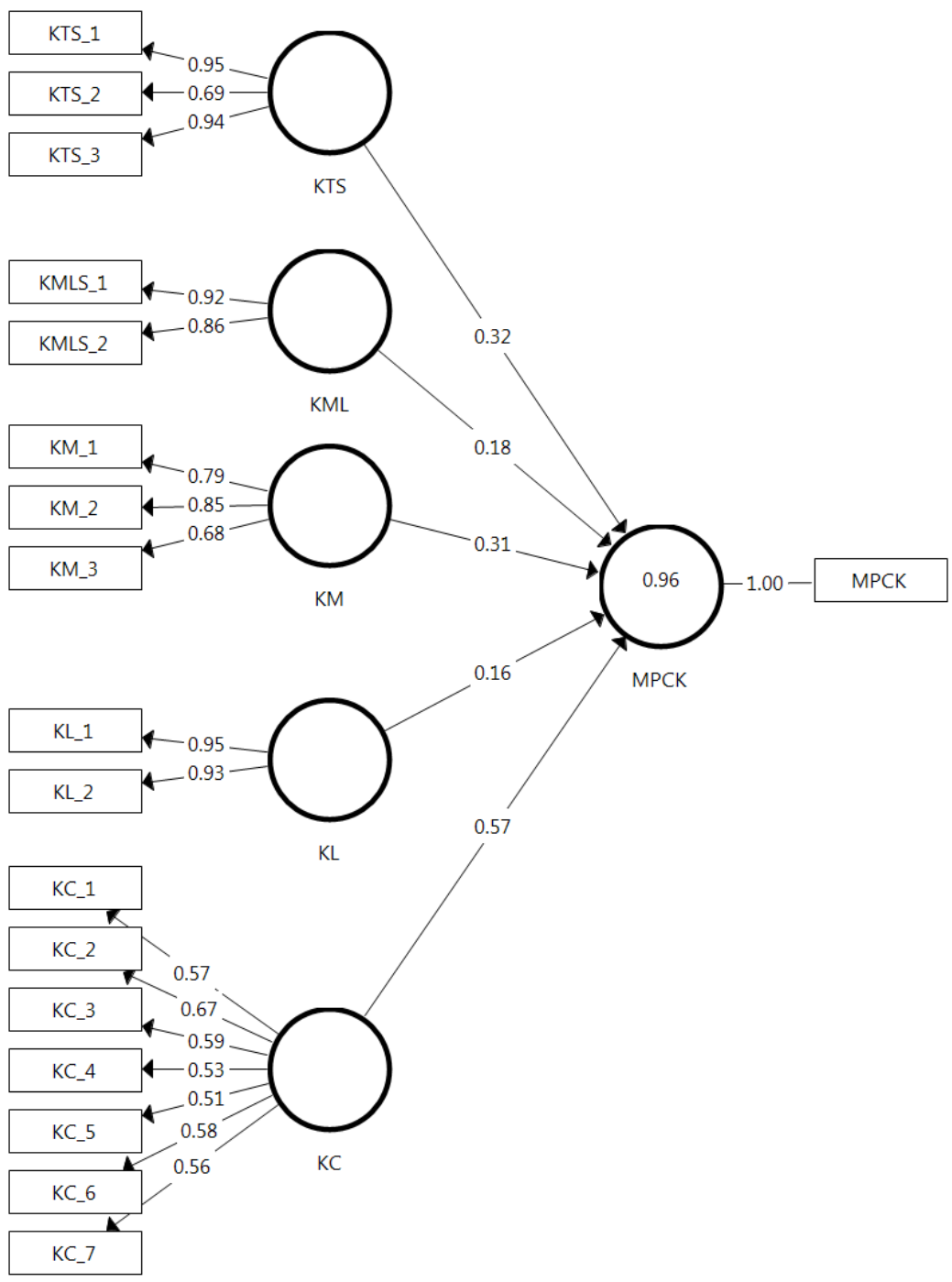

Figure 15. Confirmatory factor analysis model

When the target endogenous variable variance was examined for the latent variable MPCK (Figure 15), it was found that its coefficient of determination $\mathrm{R}^{2}$ was 0.959. This implied that all the five latent variables KTS, KMLS, KM, KL and KC accounted for $96 \%$ of the variation in MPCK. Examining the inner model for the path coefficient sizes and their significance, it can be seen that KC (0.57) had the strongest predictive effect on MPCK, followed by KTS (0.32), then KM (0.31), KMLS (0.18) and KL (0.16). The hypothesized path relationship between the five latent variables $\mathrm{KTS}, \mathrm{KM}, \mathrm{KMLS}, \mathrm{KL}$ and $\mathrm{KC}$ had a statistically significant hypothesized path relationship with MPCK. This was because each one of them had standardized path coefficients greater than the threshold of 0.1 . This means that KTS, $\mathrm{KM}, \mathrm{KMLS}, \mathrm{KL}$ and $\mathrm{KC}$ were all moderately strong predictors of MPCK. 
Table 10. Factor loadings of the MPCK components

\begin{tabular}{|c|c|c|c|c|c|}
\hline $\begin{array}{c}\text { Latent } \\
\text { variable }\end{array}$ & Indicators & Loadings & $\begin{array}{l}\text { Indicator } \\
\text { reliability }\end{array}$ & $\begin{array}{l}\text { Composite } \\
\text { reliability }\end{array}$ & AVE \\
\hline \multirow{3}{*}{ KTS } & KTS_1 & 0.95 & 0.9025 & \multirow{3}{*}{0.897} & \multirow{3}{*}{0.748} \\
\hline & KTS_2 & 0.69 & 0.4761 & & \\
\hline & KTS_3 & 0.94 & 0.8836 & & \\
\hline \multirow{2}{*}{ KMLS } & KMLS_1 & 0.92 & 0.8464 & \multirow{2}{*}{0.886} & \multirow{2}{*}{0.796} \\
\hline & KMLS_2 & 0.86 & 0.7396 & & \\
\hline \multirow{3}{*}{ KM } & KM_1 & 0.79 & 0.6241 & \multirow{3}{*}{0.818} & \multirow{3}{*}{0.601} \\
\hline & KM_2 & 0.85 & 0.7225 & & \\
\hline & KM_3 & 0.68 & 0.4624 & & \\
\hline \multirow{2}{*}{ KL } & KL_1 & 0.95 & 0.9025 & \multirow{2}{*}{0.941} & \multirow{2}{*}{0.889} \\
\hline & KL_2 & 0.93 & 0.8649 & & \\
\hline \multirow{7}{*}{$\mathrm{KC}$} & KC_1 & 0.57 & 0.3249 & \multirow{7}{*}{0.773} & \multirow{7}{*}{0.328} \\
\hline & KC_2 & 0.67 & 0.4489 & & \\
\hline & KC_3 & 0.59 & 0.3481 & & \\
\hline & KC_4 & 0.53 & 0.2809 & & \\
\hline & KC_5 & 0.51 & 0.2601 & & \\
\hline & KC_6 & 0.58 & 0.3364 & & \\
\hline & KC_7 & 0.56 & 0.3136 & & \\
\hline
\end{tabular}

\section{Indicator reliability}

It is always important to check individual reliability of each indicator in the model. Hulland (1999) suggested a reliability of 0.4 or more as acceptable and stressed that a reliability of 0.7 or more was even better. Analysing table 10, it can be seen that all the indicators of the latent variables KTS, KMLS, KL and KM had indicator reliability ranging from 0.4624 to 0.9025 which were within the acceptable cutoffs. However, the latent variable $\mathrm{KC}$ had six of its indicators with reliability below the acceptable minimum of 0.4 . Only one indicator had reliability greater than 0.4 .

\section{Internal consistency reliability}

Internal consistency has commonly been measured using Cronbach's alpha. This has presented challenges such that some scholars suggested the use of composite reliability in PLS-SEM as a preferred measure of internal consistency (Bagozzi \& Yi, 1988; Hair et al., 2012; Hair et al., 2014). A composite reliability of at least 0.7 is preferred but a minimum of 0.6 would be acceptable to achieve internal 
consistency. Examining the Table 10, it can be seen that all the latent variables KTS, KMLS, KL, KM and KC had composite reliability greater than 0.7. Thus, all the latent variables recorded high internal consistency.

\section{Convergent validity}

Convergent validity is established by considering the Average Variance Extracted (AVE) of each latent variable and an AVE of 0.5 and higher is acceptable (Bagozzi \& Yi, 1988; Henseler et al., 2009). The latent variables KTS, KMLS, KL and KM all had AVE higher than the acceptable minimum of 0.5. However, the variable $\mathrm{KC}$ had the $\mathrm{AVE}$ of 0.328 which was far below the minimum. This could have been caused by the poor indicator reliability of the indicators of $\mathrm{KC}$. Despite the AVE being low the items were included in the scale because they were very important to the measurement of the stated constructs.

\section{Discriminant validity}

Discriminant validity referred to how variance in the indicators was able to explain variance in the latent variables (Hamdan et al., 2011). Table 11 shows indices of the Fornell-Larcker criterion for checking discriminant validity. Fornell and Larcker (1981) proposed that discriminant validity can be achieved by finding the square root of the AVE of each latent variable. According to Fornell-Larcker (1981) and Chin (1998), if correlation values of other latent variables were less than the square root of the AVE then discriminant validity was achieved. Examining Table 12, it can be seen that all the latent variables except $\mathrm{KC}$ had the AVE values larger than the correlations in their columns. Discriminant validity was also checked using the HTMT to resolve the challenge presented by the latent variable $\mathrm{KC}$.

Table 11. Fornell-Larcker criterion for checking discriminant validity

\begin{tabular}{lcccccc}
\hline & KC & KL & KM & KMLS & KTS & MPCK \\
\hline KC & $\mathbf{0 . 5 7 3}$ & & & & & \\
KL & 0.060 & $\mathbf{0 . 9 4 3}$ & & & & \\
KM & 0.158 & 0.314 & $\mathbf{0 . 7 7 5}$ & & & \\
KMLS & 0.302 & 0.126 & 0.322 & $\mathbf{0 . 8 9 2}$ & $\mathbf{0 . 8 6 5}$ & \\
KTS & 0.235 & 0.064 & 0.267 & 0.355 & 0.605 & $\mathbf{1 . 0 0 0}$ \\
MPCK & 0.752 & 0.336 & 0.594 & 0.581 & & \\
\hline
\end{tabular}

Table 12. Correlations of latent variables

\begin{tabular}{lcccccc}
\hline & KC & KL & KM & KML & KTS & MPCK \\
\hline KC & 1.000 & & & & & \\
KL & 0.060 & 1.000 & & & & \\
KM & 0.158 & 0.314 & 1.000 & & & \\
\hline
\end{tabular}




\begin{tabular}{lllllll}
\hline KML & 0.302 & 0.126 & 0.322 & 1.000 & & \\
KTS & 0.235 & 0.064 & 0.267 & 0.355 & 1.000 & \\
MPCK & 0.752 & 0.336 & 0.594 & 0.581 & 0.605 & 1.000 \\
\hline
\end{tabular}

Table 13. Heterotrait-Monotrait Ratio (HTMT)

\begin{tabular}{lccccc}
\hline & KC & KL & KM & KML & KTS \\
\hline KC & & & & & \\
KL & 0.195 & & & & \\
KM & 0.353 & 0.421 & & & \\
KML & 0.400 & 0.164 & 0.433 & & \\
KTS & 0.321 & 0.075 & 0.358 & 0.451 & \\
MPCK & 0.916 & 0.355 & 0.726 & 0.660 & 0.671 \\
\hline
\end{tabular}

The Heterotrait-Monotrait (HTMT) ratio for determining discriminant validity is said to be more efficient. Henseler et al. (2015) proposed that the HTMT ratio of less than 1.0 met the threshold for the establishment of discriminant validity. From Table 13 all the constructs had their HTMT ratios below 1.0. Thus, discriminant validity was achieved. However, other scholars proposed even a lower threshold with Gold et al. (2001) and Teo et al. (2008) proposing a 0.90 threshold. A threshold of 0.85 was suggested by Kline (2011)

Table 14. Adjusted model: summary of adjusted model indices

\begin{tabular}{lcc}
\hline & Saturated model & Estimated model \\
\hline SRMR & 0.094 & 0.094 \\
d_ULS & 1.500 & 1.500 \\
d_G & 0.983 & 0.983 \\
Chi-square & 453.499 & 453.499 \\
NFI & 0.605 & 0.605 \\
\hline
\end{tabular}

Table 14 shows the adjusted model fit indices. One of the most important indices for determining a good model fit is the standardized root mean residual (SRMR) which is responsible for measuring the approximate model fit by taking into consideration the difference between the observed correlation matrix and the model implied correlation matrix (Garson, 2016, p. 68). The SRMR of less than 0.8 has been recommended to show good model fit (Hair et al., 2014; Hu and Bentler, 1998). However, it has been observed that "a lenient SRMR cut of point of less than 0.10 " has been accepted in some instances (Garson, 2016, p. 68). Analysing Table 14, it can be seen that the SRMR index for the estimated model was 0.094 which falls short of the "less than" 0.08 cutoff but is within the lenient 0.10 cutoff. Another index which is used to establish good model fit is the normed fit index (NFI) which must be above 0.9 for a good fit. In the case of the model under discussion the NFI 
was 0.605 which is lower than the cutoff. It was considered because other fit indices were strong enough.

\section{Vignettes}

Part of the purpose for this study was to characterize pre-service teachers' pedagogical content knowledge of the function concept. This was to be accomplished by understanding pre-service teachers' content knowledge of functions and students (KCS). Pre-service teachers' content knowledge of functions and students in the context of this study referred to teachers' knowledge of secondary school students' misconceptions, conceptions, errors and difficulties related to the concept of a function. For this purpose teachers' KCS was assessed using vignettes. According to Jeffries and Maeder (2011, p. 162) vignettes are "a specific type of short, descriptive story that describes a problem related to course content in order to stimulate discussion". Thirteen vignettes designed to assess pre-service teachers' PCK about inverse and composite functions were adapted from Karahasan (2010). Vignettes have been widely used to study pre-service teachers' instructional knowledge of mathematics (Kerschen et al., 2017; Lindmeier et al., 2020; Martin et al., 2020; Max, 2017; Polly \& Casto, 2019; Polly et al., 2019; Sahidinet al., 2019; Smith et al., 2020; Wilkerson et al., 2018) by understanding how they respond to scenarios that occur in classrooms during the teaching and learning process. These scenarios would present themselves as student responses to questions and tasks, questions posed by students as they seek clarification and solution to their class exercises and homework tasks.

Of the thirteen, one vignette was adapted from Ebert (1993). To determine the face and content validity of the vignettes and their suitability to the Zambian context with special reference to the Zambian senior secondary mathematics curriculum, ten experts who validated the test on functions were asked to check the validity. The experts strongly agreed on eight out of the thirteen vignettes as fitting the Zambian context. Thus, the eight vignettes were retained to form the final version of the instrument (see Appendix D) with one vignette modified based on expert advice. The first four vignettes were about inverse functions while vignettes 5 to 8 were about composite functions. The vignettes on inverse and composite functions were consistent with lesson plans which also focused on inverse and composite functions. The two instruments were designed to assess pre-service teachers' KCS of the function concept. 


\section{Interview protocol}

The interview was developed to collect in-depth data following participants' responses to test items in the functions survey. Three interviews were conducted. Each interview was conducted for the duration of one hour. The interview protocol was pilot tested with two pre-service teachers who did not participate in the main interview, before using it with the three selected pre-service teachers. The reasons for piloting the interview protocol was to ensure that (i) the questions were not vague, (ii) the interview would be carried out in a timely manner, (iii) testing the recording devices and ascertaining their quality. After the interview the two participants were invited to give their views about any aspect of the interview including the questions (wording and clarity) asked during the interview.

\section{Lesson plan}

Pre-service teachers were asked to use the lesson plan format that was provided by the mathematics department of the school. That was the format every teacher in the department was using for uniformity purposes. A meeting to discuss the lesson plan format and other issues related to the teaching was convened by the researcher. All the five pre-service teachers were present at the meeting and consented to participate in this phase of the study. Three items were discussed namely (i) lesson plan format, (ii) teaching activity and (iii) content to be taught. The adopted lesson plan format contained subtitles like topic, sub-topic, and duration of the lesson in minutes, grade level, expected learning outcomes, rationale for the lesson, learners' pre-requisite knowledge and skills, and teaching and learning materials/resources. The lesson was to be taught through three stages namely lesson introduction, lesson development and lesson evaluation. The duration for each lesson would be 80 minutes.

The pre-service teachers were advised to prepare detailed lesson plans that were learner centered in which tasks for both the teacher and the learner were to be clearly outlined and to select examples that would arouse learner interest. During the meeting pre-service teachers were advised to choose the sub-topics they would teach. They unanimously chose to teach inverse and composite functions. They claimed that inverse and composite functions were key concepts that were the most examined by Examinations Council of Zambia. One pre-service teacher said that these were his favourites. All the five pre-service teachers agreed to prepare and submit three lesson 
plans and to implement them in class by way of teaching. It was agreed that their lesson teaching activities would be video recorded. Pre-service teachers were given three weeks to prepare lesson plans and gather the necessary teaching and learning resources they would use during the lesson teaching activity. They were also asked to submit lesson plans before the actual teaching for checking.

\subsection{PROCEDURE AND TIMELINE}

This section outlines the procedure across and within the techniques used in this study for collecting and recording data. This included how, when (in what order) and where the instruments were administered and how the data was recorded. Rationalization for the procedures used is included. Since the study was done in two stages, a timeline for the completion of each stage is explained.

This study used a mixed methods sequential explanatory study. This naturally meant that data was collected in two phases. Phase 1 characterized quantitative data collection in which the MPCK survey and the functions survey (pencil and paper test) were administered to 150 pre-service teachers. The two instruments were administered on different days. The first to be administered was the MPCK survey followed by the functions survey. Both instruments were administered in the third week of February 2019. The instruments were administered during lecture hours. The lecturers involved granted permission to collect data during leture hours because that was the most suitable period to access all the participants at the same time.

Regarding administration of the MPCK survey, the objectives of the research were explained to the participants. Participants were also given instructions on how to use the survey. They were categorically told that they were expressing their level of agreement with the statements in the Likert scale contained in the survey. Participants were allowed to complete the survey within one hour. In the case of the paper and pencil functions survey, it was also administered in the lecture room. Unlike the MPCK survey this instrument was to be completed in 2 hour 30 minutes. The researcher explained to the participants who consented to sit for the test that it was not part of their coursework. It was also explained that the aim was not to obtain correct answers but to examine pre-service teachers' knowledge. To this effect they were told to answer the questions in great detail. In instances where they were unable to answer a particular question they were advised to write down the reason for their 
failure. They were also advised to seek clarifications on questions they did not understand. For the purpose of this exercise, answer sheets were distributed to each participant. This included sheets of graph paper for questions that needed to be answered on graph paper.

Phase 2 was accomplished in May 2019. This phase targated five participants but two withdrew from the research for personal reasons. Thus, only three preservice teachers participated in this phase. The phase involved classroom observation of teaching activities of participants, semi-strctured interviews as follow-up to answers in the functions survey, and administration of vignettes on inverse and composite functions.

The data collection for this phase was spread across three weeks from third week of May 2019 to first week of June 2019. Each instrument was administered in a different week. In the first of the three weeks, semi structured interviews were conducted for each participant. Each interview lasted for at least one hour 20 minutes. In the second week, vignettes were administered. The duration for answering vignettes was 3 hours. Observation of lessons went on for the three weeks of the data collection period. The researcher sought permission from the school administration to involve students in the research activities.

Each of the observed lessons was taught for duration of 80 minutes. This was because the school where the participants were doing their teaching practice only had 80 minutes lessons on the time table. All the lessons were video recorded. Before the lessons both the teacher and the students were made aware that the researcher would attend the lessons and record all activities during the lessons. The school observation sheet was also used to assess the lessons.

\subsection{ANALYSIS}

This section presents the data analysis procedures that were used in this research. In particular, both quantitative and qualitative analysis procedures are discussed. First, a discussion about quantitative data analysis procedures is presented followed by that of the qualitative analysis. 


\subsubsection{Analysis of quantitative data}

To analyze quantitative data, Statistical Package for Social Science (SPSS) version 23 was used to conduct a Two-step Cluster analysis for the categorization of participants into groups based on their CCK, SCK and KCS. A one-way Multivariate analysis of Variance was also conduncted followed by a Discriminant function Analysis. A confirmatory factor analysis was also conducted using Smart-PLS version 3.0 to obtain fit indices of the adapted MPCK scale.

\subsubsection{Analysis of qualitative data}

Data collected using the test on functions, vignettes, and lesson plans were analysed using a framework adapted from Ebert (1993) which she used to assess preservice teachers' subject-matter knowledge and pedagogical content knowledge related to the function concept and graphs. In her study Ebert suggested that teachers' knowledge about teaching occurs through lesson planning, teaching using simulations and development of conceptual explanations while reflecting on one's teaching. Eleven pre-service teachers were each assigned five vignettes about functions and graphs to answer. The vignettes comprised problems secondary school students faced when learning functions and graphs. The vignettes were designed to assess pre-service teachers' ability to identify, diagnose and explain secondary school students' misconceptions in the content area of functions and graphs. Ebert claimed that teachers' pedagogical knowledge mainly manifested in their ability to use appropriate analogies, select suitable examples, use different representations, offer detailed demonstrations and offer convincing explanations about functions and graphs (1993, p.9). The analysis framework used by Ebert (1993) was a modification of Thompson's 1991 framework which was used to study teacher's conceptions of mathematics teaching.

Thompson's framework proposed three levels: L evel 0, Level 1, and Level 2 at which teachers' knowledge of mathematics was to be charaterised. In this study Ebert's ideas were adapted to the analysis framework because it fitted the context of the study. The framework (see Table 15) was used to analyse both subject-matter and pedagogical content knowledge for this investigation. Level 0 meant that the preservice teacher possessed inadequate subject-matter and pedagogical content knowledge while Level 1 meant that he/she possessed good subject-matter and pedagogical content knowledge of functions. Level 2 meant that the pre-service 
teacher possessed strong subject-matter and pedagogical content knowledge of the function concept. The features of each knowledge level are presented in Table 15. Features of pre-service teachers' common content knowledge, specialised content knowledge, and knowledge of content and students are presented in detail in the Table 15.

Pre-service teachers' common content knowledge of the function concept was characterised as being inadequate at Level 0. At this level of their common content knowledge they are not able to demonstrate knowledge of definitions of function concepts and were unable to show knowledge of properties and rules that govern the concept of a function. At this level pre-service teachers are not able to demonstrate knowledge of existing connections between the function concept and other mathematical concepts in the curriculum. They instead treat all concepts as isolated thereby facing difficulties in their understanding of the syllabus content. Thus, they face difficulties in solving secondary school level problems involving functions by failing to identify incorrect answers and inaccurate definitions offered by their students. They also exhibit difficulties in their explanation of the correct use of symbols used when learning functions and the use of correct mathematical language related to the function concept.

At Level 1 pre-service teachers are able to define functions and begin to show good knowledge of rules and properties that govern the function concept but their knowledge of application of the rules, properties and definitions is still very limited. They begin to show their ability to connect existing function concepts with other mathematical concepts and start solving secondary school students' problems involving functions by confidently identifying incorrect answers and inaccurate definitions. At this level pre-service teachers are able to explain correct use of symbols (notation) to their students.

At Level 2 pre-service teachers are able to demonstrate strong knowledge of definitions, properties \& rules governing the concept of a function by being able to effectively apply it to different situations. At this level pre-service teachers have the ability to see existing connections between the function concept and other mathematical concepts in the curriculum and able to apply their knowledge of this to different situations. They no longer see concepts as being unrelated. Thus, they solve secondary school students' problems involving functions by identifying and 
diagnosing incorrect answers and inaccurate definitions. They use their knowledge of patterns within function concepts to demonstrate the connectedness of concepts and clearly explain correct use of symbols and mathematical language with justification.

Regarding their specialised content knowledge, pre-service teacher knowledge is characterised as inadequate at Level 0 . At this level they have difficulties in conceptually explaining mathematical ideas using rules and procedures of functions. They show very little understanding of definitions of different aspects of functions and have difficulties in explaining and justifying a function as a procedure, process and object, and they have difficulties in explaining and justifying relationships and differences of concepts involving the function concept like inverse and composition of functions. Pre-service teachers at this level have difficulties to choose and use different representations of functions and move between them. They have difficulties translating functions from tabular form to graphs or from equations to graphs or from symbols to other forms. Thus, they have difficulties to effectively work with symbols, graphs, tables, and equations involving functions.

At Level 1 pre-service teachers' specialized content knowledge is good. At this level they are now able to explain mathematical ideas in a coordinated manner using rules and procedures of functions. Pre-service teachers are able to recognise patterns related to the function concept and are able to explicitly explain and justify a function as a procedure, process and object. They are also able to explain with justification all existing relationships and differences of aspects of the function concept. Their understanding of definitions of functions is now good and their ability to apply definitions to different situations and provide alternative definitions is improved at this level. They know, choose and use different representations of functions, and can smoothly translate between symbols, graphs, tables, and equations as well as giving justifications for their step-by-step work.

At Level 2 pre-service teachers have strong specialised content knowledge of the function concept. They are now able to confidently explain mathematical ideas using rules and procedures of functions with deep understanding. They have strong understanding of definitions of functions and their applications. They are able to use patterns to explain and justify a function as a procedure, process and object. Thus, they now know, choose and use different representations of functions (symbols, graphs, tables, equations etc.) and move between them. They are able to conceptually 
explain and justify relationships and differences about the function concept. Table 15 shows a summary of the characterization of pre-service teachers' common content knowledge and their specialised content knowledge levels of the function concept.

Table 15. Framework for analysing pre-service teachers' CCK and SCK

\begin{tabular}{|c|c|c|}
\hline \multirow[b]{2}{*}{ Level } & \multicolumn{2}{|c|}{ Key features } \\
\hline & Common content knowledge of functions & $\begin{array}{l}\text { Specialized content knowledge of } \\
\text { functions }\end{array}$ \\
\hline $\begin{array}{c}\text { Level } 0 \\
\text { Inadequate }\end{array}$ & $\begin{array}{l}\text { - Not able to demonstrate knowledge of } \\
\text { definitions, properties \& rules governing } \\
\text { the concept of a function } \\
\text { - Not able to demonstrate knowledge of } \\
\text { existing connections between the } \\
\text { function concept and other mathematical } \\
\text { concepts } \\
\text { - Have difficulties to solve high school } \\
\text { students' problems involving functions } \\
\text { by failing to identify incorrect answers } \\
\text { and inaccurate definitions } \\
\text { Have difficulties to know and explain } \\
\text { correct use of symbols (notation) to } \\
\text { students }\end{array}$ & $\begin{array}{l}\text { Have difficulties in explaining } \\
\text { mathematical ideas using rules and } \\
\text { procedures of functions } \\
\text { - Have difficulties in explaining and } \\
\text { justifying a function as a procedure, } \\
\text { process and object } \\
\text { Have difficulties in explaining and } \\
\text { justifying relationships and } \\
\text { differences about the function } \\
\text { concept } \\
\text { Show little understanding of } \\
\text { definitions of a function and their } \\
\text { applications } \\
\text { Have difficulties to choose and use } \\
\text { different representations of } \\
\text { functions (symbols, graphs, tables, } \\
\text { equations etc.) and move between } \\
\text { them }\end{array}$ \\
\hline $\begin{array}{c}\text { Level } 1 \\
\text { Good }\end{array}$ & $\begin{array}{l}\text { - Show knowledge of definitions, } \\
\text { properties \& rules governing the concept } \\
\text { of a function } \\
\text { - Show knowledge of existing } \\
\text { connections between the function } \\
\text { concept and other mathematical } \\
\text { concepts } \\
\text { - Solve high school students' problems } \\
\text { involving functions by identifying } \\
\text { incorrect answers and inaccurate } \\
\text { definitions } \\
\text { Know and explain correct use of } \\
\text { symbols (notation) to students }\end{array}$ & $\begin{array}{l}\text { Explain mathematical ides using } \\
\text { rules and procedures of functions } \\
\text { - } \quad \begin{array}{l}\text { Explain and justify a function as a } \\
\text { procedure, process and object }\end{array} \\
\text { - } \quad \begin{array}{l}\text { Explain and justify relationships } \\
\text { and differences about the function } \\
\text { concept }\end{array} \\
\text { - Show understanding of definitions } \\
\text { of a function and their applications } \\
\text { Know, choose and use different } \\
\text { representations of functions } \\
\text { (symbols, graphs, tables, equations } \\
\text { etc.) and move between them }\end{array}$ \\
\hline $\begin{array}{l}\text { Level } 2 \\
\text { Strong }\end{array}$ & $\begin{array}{l}\text { Demonstrate and apply knowledge of } \\
\text { definitions, properties \& rules governing } \\
\text { the concept of a function to different } \\
\text { situations } \\
\text { - } \\
\text { Demonstrate and apply knowledge of } \\
\text { existing connections between the } \\
\text { function concept and other mathematical } \\
\text { concepts to different situations } \\
\text { - Solve high school students' problems } \\
\text { involving functions by identifying and } \\
\text { diagnosing incorrect answers and } \\
\text { inaccurate definitions } \\
\text { - Know, explain and justify correct use of }\end{array}$ & $\begin{array}{l}\text { Explain and justify relationships } \\
\text { and differences about the function } \\
\text { concept } \\
\text { - Show understanding of definitions }\end{array}$ \\
\hline
\end{tabular}


Concerning their knowledge of functions content and students, pre-service teachers' knowledge is inadequate at Level 0 . At this level pre-service teachers have difficulties in identifying students' emerging errors, difficulties and misconceptions about the function concept. They find it difficulties to diagnose students' emerging errors and misconceptions about the function concept and usually when choosing examples, they are not able to pay attention to aspects of examples that would excite, motivate and interest the students. They are also not able to mind the level of difficulty of the tasks that they assign to their students. Similarly, at this level preservice teachers are not able to pay attention to students' use of mathematical language and symbols related to functions.

At Level 1 pre-service teachers possess good knowledge of the function concept and begin to identify students' emerging errors, difficulties and misconceptions about the function concept and when choosing examples they partially pay attention to aspects of the examples that will excite, motivate and interest the students. At this level pre-service teachers are partially mindful of the level of difficulty of the tasks that you assign to students and are partially able to pay attention to students' use of mathematical language and symbols related to functions.

At Level 2 pre-service teachers' knowledge of the functions content and students is considered to be strong. At this level they are able to easily identify and diagnose students' emerging errors, difficulties and misconceptions about the function concept. They also demonstrate their ability to easily diagnose students' emerging errors and misconceptions about the function concept and pay attention to aspects of the examples that would excite, motivate and interest the students when choosing examples during lesson preparation. Pre-service teachers at this level are mindful of the level of difficulty of the tasks that they assign to students and pay attention to students' use of mathematical language and symbols related to functions. A summary of the characterization of pre-service teachers' knowledge of functions content and students is shown in Table 16. 
Table 16. Framework for analysing pre-service teachers' KCS

\begin{tabular}{|c|c|}
\hline \multirow{2}{*}{ Level } & Key features \\
\hline & Knowledge of functions content and students \\
\hline Level 0 & $\begin{array}{l}\text { - Have difficulties in identifying students' emerging errors, difficulties and } \\
\text { misconceptions about the function concept } \\
\text { - Find difficulties to diagnose students' emerging errors and misconceptions about the } \\
\text { function concept } \\
\text { - When choosing examples, not able to pay attention to aspects of the examples that will } \\
\text { - } \quad \text { Not able to mind the level of difficulty of the tasks that you assign to students } \\
\text { - Not able to pay attention to students' use of mathematical language and symbols } \\
\text { related to functions }\end{array}$ \\
\hline Level 1 & $\begin{array}{l}\text { - Identify students' emerging errors, difficulties and misconceptions about the function } \\
\text { concept } \\
\text { - When choosing examples partially pay attention to aspects of the examples that will } \\
\text { - } \quad \text { Partially mindful of the level of difficulty of the tasks that you assign to students } \\
\text { - Partially able to pay attention to students' use of mathematical language and symbols } \\
\text { related to functions }\end{array}$ \\
\hline Level 2 & $\begin{array}{l}\text { - Able to easily identify and diagnose students' emerging errors, difficulties and } \\
\text { misconceptions about the function concept } \\
\text { - Able to easily diagnose students' emerging errors and misconceptions about the } \\
\text { function concept } \\
\text { - Able pay attention to aspects of the examples that will excite, motivate and interest the } \\
\text { - } \text { students when choosing examples during lesson preparation } \\
\text { - Able to be mindful of the level of difficulty of the tasks that you assign to students } \\
\text { functions }\end{array}$ \\
\hline
\end{tabular}

\subsubsection{Trustworthiness of qualitative results}

There is a general consensus among quantitative, qualitative and mixed methods researchers that research needs to demonstrate high levels of quality. The research community demands that not only should research be trustworthy but should also be rigorous and relevant (Bryman et al., 2008; Mandal, 2018; Merriam, 2009; Kidder \& Judd, 1986). However, there is a disagreement on the evaluation criteria between quantitative and qualitative researchers. This is largely because quantitative and qualitative research differs in nature, purpose, approach and philosophical views. Proponents of quantitative research contend that the criteria for evaluating the quality of research must include reliability, internal validity, external validity, construct validity and generalizability (Bryman et al., 2008; Mandal, 2018; Merriam, 2009).

Qualitative researchers, on the other hand, emphasise that trustworthiness and rigor needed to be upheld in every qualitative research. Trustworthiness is the equivalent of validity in quantitative research (Creswell \& Miller, 2000) while rigor basically refers to the actual process of coming up with the results. Research is also 
evaluated based on how relevant it is to a particular field. Trustworthiness and its importance to qualitative research has extensively been discussed by researchers (Creswell, 2014; Creswell \& Miller, 2000; Gibbs, 2007; Gay et al., 2006; Lincoln et al., 2011). Lincoln and Guba (1985) proposed four criteria for evaluating the trustworthiness of qualitative research. Instead of internal validity, external validity, reliability and objectivity, Lincoln and Guba proposed credibility, transferability, dependability and confirmability respectively. Lincoln and Guba's criteria have been widely employed in qualitative research across different fields since it was first introduced. Mixed methods researchers opted to use a combination of quantitative and qualitative quality evaluation strategies and emphasised the research need to demonstrate rigor (Bryman et al., 2008).

Credibility: Credibility is simply the extent to which the research process can be believd. It seeks to establish whether standard procedure for a chosen qualitative approach was followed when conducting a particular study. It also seeks to establish whether the researcher provided justifications for selecting a particular approach, giving convincing reasons for not opting to use other existing variations of a particular qualitative approach. In fact, Polit and Beck (2014) argued that credibility stands out as the most important criterion for establishing quality of a study.

Transferability: According to Polit and Becker (2014), refers to the applicability of the study to other settings or situations. Transferability seeks answers to questions like "to what extent are results of a particular study important to other situations?" According to Amankwaa (2016), transferability of a study can be justified by providing a detailed description of the subjects studied, the location where the study was conducted and the context in which the study was conducted. Bitsch (2005) emphasized that subjects needed to be purposively sampled for transferability to be achieved. The descriptions given needed to be very clear and highly informative.

Dependendability: According to Polit and Becker (2014), and Bitsch (2005), dependability is concerned with issues related to how stable research data is over a period of time with respect to conditions under which a study was conducted. Dependability can be accomplished by triangulation; peer review and keeping a good audit trail (Ary et al., 2010). For example, a study conducted to investigate preservice teachers' attitudes toward integration of technology in mathematics 
instruction may be similar from time to time. However, in a study seeking to diagnose a mathematics curriculum for Zambian students, conditions would most likely change over time.

Confirmability: Is concerned with extent to which research results are consistent and the degree to which these results could be replicated by other researchers (Poliy \& Becker, 2014). This could be achieved by keeping a good audit trial methodological and analysis processes at every stage of the study.

To ensure quality of research findings, Creswell (2014) proposed eight validity strategies that would help the researcher check and establish credibility of their findings. The credibility strategies include triangulation, member checking, rich and thick description, researcher reflectivity, peer debriefing, prolonged time in the field, use of external auditor and negative or discrepant information

\section{Triangulation}

Triangulation is the use of multiple data sources or research methods in order to have an in-depth understanding of phenomena under study (Carter et al., 2014; Noble \& Heale, 2019; Patton, 1999; Yin, 2003). One of the advantages of triangulation is minimising biases by using a combination of methods, theories for rich data analysis and interpretation (Noble \& Heale, 2019).

For qualitative research, there are four types of triangulation namely triangulation of theories which refers to the use of multiple theoretical frameworks to enrich data interpretation, (2) methodological triangulation which refers to the use of multiple data collection methods like observations, interviews and surveys, (3) data triangulation which refers to issues related to participants, space and period of time for data collection, (4) investigator triangulation which encourages using more than one researcher in the same study to bring different viewpoints and comprehensive understanding of the phenomena under study (Creswell, 2007; Denzin, 1978; Patton, 1999). In this study triangulation was achieved by using multiple data collection tools: functions test, MPCK questionnaire, lesson plans, interviews, vignettes and observations. Because this study is a mixed methods study, quantitative and qualitative approaches were used.

The study also recruited the second corder in the data analysis stage. This was aimed at reducing researcher biases when analysing the data. The recruited corder 
was oriented to the instruments and procedures to be used during data analysis. The two corders then analyzed the data independently and came together to compare and discuss the analysis results for possible inconsistencies. Where inconsistencies manifested an agreement was reached on the best posible results to be included in the study.

\section{Member checking}

Member checking refers to the process of requesting feedback from participants about the results that emerged from the data they provided (Creswell, 2014; Guba, 1981; Merriam, 2009). Member checking is regarded as the most important way of establishing credibility of the research results which every researcher is encouraged to go through as it helps in noticing misrepresentations of the data collected and biases that may be prevalent in the results (Creswell, 2014; Lincoln \& Guba, 1985; Maxwell, 2005; Onwuegbuzie \& Leech, 2007). This means that after all the data analysis has been performed and the interpretation completed, the final results, emerging themes, descriptions are sent back to the participants for them to check if they are indeed a representation of the data they provided.

It is important to note that it is not the raw data that is used for member checking (Creswell, 2014; Lincoln \& Guba, 1985). At this stage the key informants may reject or accept the findings as a correct representation of the data they provided. This process is important in the eradication of inconsistencies and misunderstandings of the data. For the current study a compilation of major findings emanating from interviews, observations and questionnaires was given to the participants who participated at all stages of the data collection process for verification of the accuracy of the findings. The informants were allowed one week to check through the results. Thereafter a meeting was organised where they were asked to give their feedback and any other comments they could have about the quality of the results.

\section{Rich and thick description}

By providing rich and thick description the researcher endeavors to fit his own research context to other contexts in order to ensure transferability of the study (Creswell, 2014; Li, 2004; Lincoln \& Guba, 1981, 1985). According to Creswell (2014), Shenton (2004) and Merriam (2009), rich and thick description of all stages of the research process enables the reader of the final output to determine the extent 
to which replication of the study can be possible and a determination of how true the results are. The researcher provides an explicitly detailed description of the context of the study, data collection and analysis procedures and explains the research design in great detail for the reader to comprehend and compare with other research settings. In this study, the researcher gave a detailed account of the methods used, data collection tools, types of data collected using these tools, analysis techniques used and why, and a detailed interpretation of the results.

\section{Researcher reflectivity}

As the researcher is a tool for qualitative data collection (Lincoln \& Guba, 2000), self-reflection presents an opportunity for the researcher to conduct a critical self-assessment and provide a honest narrative of how his own background, assumptions, perceptions, biases and interests influenced the entire research process to arrive at interpretations and conclusions about the data (Creswell, 2014; Merriam, 2009). The researcher of the current study has been a high school teacher of mathematics in Zambia for fourteen years.

During this period he has worked as a part-time lecturer of mathematics education in a college of education and a university offering teacher education. This ensured that the researcher was very familiar to the context of the study and had a very good understanding of both teacher education and secondary school education offered in Zambia. It was therefore easy for the researcher to orient the participants of the research by clearly explaining the objectives of the research needed to accomplish and the need for some of their lessons to be observed in the classroom. This was because some of the participants were reluctant to have their lessons videotaped.

Out of the 150 participants, eight pre-service teachers applied to have their teaching practice in the school where the researcher works. The researcher requested the school administration to accept the eight pre-service teachers as they were subjects of the research project for the researcher. However, only five out of the eight were accepted. The researcher was pleased to meet the pre-service teachers and developed a good rapport with each one of them. During the course of the school term the researcher called for a meeting for the five pre-service teachers in which he requested them to participate in a lesson plan and classroom teaching activity. Two declined citing personal reasons while the other three expressed interest in the idea. 
The three were later oriented about how the activity was to be carried out. It was easy to organize them because at the time the researcher and the pre-service teachers were colleagues who belonged to the mathematics department in the school and spent a lot of time together.

\section{Peer debriefing}

Peer debriefing involves subjecting the study to an external person for review or examination (Creswell, 2014). This process could be done by the colleague (maybe a fellow doctoral student) who is familiar with the knowledge domain in which the study is located. The peer debriefer would examine the entire study and ask questions related to every stage of the study and its findings. This ensures that the interpretations are not only from the researcher but views of another person. By so doing, aspects not well covered in the study are highlighted: such things as ambiguous themes, unclear strategies and many others. For this study the researcher shared and discussed all the stages of the study with another doctoral student for feedback. The supervisor also provided useful feedback concerning the methodology used in the study, instruments for data collection, strategies for data analysis and interpretation of results. This is supported by the views of Merriam (2009) who contended that by virtue of every member dissertation committee reading and commenting on the contents of the dissertation, peer debriefing is accomplished.

\section{Prolonged time in the field}

Spending prolonged time in the research site enables the researcher to gain indepth understanding of the participants and setting (Creswell, 2014; Guba 1981). By establishing a strong rapport with the participants the researcher would discover participants' unusual characteristics and their perception of reality. For this study the researcher spent three months with the participants during their teaching experience in the school where the researcher is a permanent employ. The more time the researcher spent with the participants the more comfortable the participants became to disclose information. This served as the most interactive phase of this study for the researcher. In fact, Miles and Huberman contended that information gathered at the entry stage in the field is weaker than that gathered towards the end of the study. 


\section{Use of external auditor}

The role of an external auditor is to provide an audit trail of the entire research process with the aim of objectively assessing the research project at the end of the study (Creswell, 2014). The auditor assesses how accurate the transcriptions were, the level at which raw data was collected, recorded, analysed and interpreted. The external auditor is unlike the peer examiner. While the peer examiner is an individual familiar with the researcher, the external auditor is not familiar with either the project or the researcher. To accomplish external auditing the researcher requested a Senior Education Standards Officer (SESO) for mathematics in the Ministry of General Education (Zambia) to audit the entire study. The auditor holds a Master's degree in mathematics education and has over twenty years of professional practicing experience.

\section{Negative case analysis}

Negative case analysis refers to a situation where the researcher encounters information that is contradictory to his expectations (Bitsch, 2005; Creswell, 2014). The researcher is expected to analyse such data and report them. By reporting negative data the credibility of the study is enhanced and the rigor improved. Such data could also provide alternative explanations that could accord the researcher room to reformulate the research questions.

\subsection{ETHICS AND LIMITATIONS}

This section outlines the ethical considerations and limitations of the research. Ethical issues are discussed followed by limitations that were experienced.

\subsubsection{Ethical considerations}

Ensuring high ethical standards in research is mandatory because good ethical practices during the research process would increase the quality and validity of the obtained results. Ethical issues include confidentiality and anonymity of participants. Another important eithical issue is that of voluntary participation and informed consent. Researchers need to inform their participants about the objectives of the research they would be participating in and to assure them of the confidentiality of data they give, and anonymity of their identity (Creswell, 2017; Gay, 2011; Connelly, 2014). In fact, informed consent by paerticipants is an essential requirement of a research process. It is also important to consider the site in which 
the research would be conducted because this is the place where participants would be found. The site should be "respected by gaining permission before entering it" (Creswell, 2017, p. 23).

To accomplish these ethical requirements, a letter seeking permission to conduct research was written to institutions that were selected for data collection. Permission was sought through the Registrar and the Head of Mathematics Education Department respectively. The course lecturers for MSE third and fourth year co-horts were informed about the $\mathrm{PhD}$ project and the need for data collection from their students. The researcher was then introduced to the students on the appointed date. The researcher explained to the students about the objectives of the project and assured those that would volunteer to participate of the confidentiality of the data they would give out, and anonymity of their personal identity.

The researcher also informed the potential participants that the research was purely for academic purposes and would have no bearing on their coursework. $\mathrm{He}$ also advised them that they were free to withdral their participation from the research without prior notice and at any stage of the research process. In terms of data reporting, it is ethical to ensure that "data is reported honestly, without changing or altering the findings to satisfy certain predictions or interest groups" (Creswell, 2017, p. 24). To this effect, transcripts of interviews were referred back to the interviewees to confirm that their views were not altered during the transcription stage. Most importantly, backups of interviews were retained by the researcher and participants' answer booklets, in the case of the test on functions and vignettes were not disposed off. Journal publications (Marban \& Sintema, 2020; Sintema \& Marban, 2020) emanating from the data were also shared by participants and institutions where the research took place.

\subsubsection{Limitations}

This study was limited to pre-service teachers pursuing their bachelor's degrees in mathematics education because these were being prepared to be mathematics teachers in secondary schools. This study could not investigate all mathematics preservice teachers in the sampled universities. Thus, the study was limited to mathematics pre-service teachers who were in their third and fourth years of their studies. 
Only 150 pre-service teachers participated in the study. Selection of participants was based on the purpose of the study. Considering that participation in the study was purely voluntary, this restricted the number of participants. A dependent sample may also have excluded partcipants that could have added to the richness of the data. Some potential participants did not find their participation in the study useful because they had other academic obligations that contributed directly to the final mark of their degree. The researcher would have loved a larger sample but to the aforementioned limitations. It is encouraging to note that 150 participants was representative. 


\section{Chapter 4: Results}

This chapter presents results of the study pertaining to pre-service secondary mathematics teachers' knowledge of the concept of a function. The results reported relate to pre-service teachers' CCK, SCK and KCS. The Chapter is organised in such a way that it reports about quantitative (section 1.1) and qualitative (section 0) results of the research. Quantitative results are organised based on research questions related to pre-service teachers' MPCK and subject matter knowledge of the concept of a function. The results also referred to the correlative relationship between the MPCK sub-factors and subject matter knowledge of the concept of a function. Qualitative results are organised based on research questions relating to pre-service teachers' CCK, SCK and KCS. This section reports results via excerpts from pre-service teachers' responses to test items from the functions survey, vignettes on inverse and composite functions, lesson plans and semi-structured interviews. Finally, the Chapter concludes with a summary of all the results reported in the thesis.

\subsection{QUANTITATIVE RESULTS}

This section portrays results from the MPCK survey and pencil and paper test. MPCK is reported in terms of pre-service teachers' KTS, KMLS, KM, KL and KC whereas subject matter knowledge is reported in terms of CCK, SCK and KCS. The section reports on the two Clusters formed for pre-service teachers' knowledge of a function by focusing on the profiles of participants in each Cluster before concluding with a correlative relationship of pre-service teachers' MPCK and subject Matter knowledge of the concept of a function.

\subsubsection{MPCK results}

This section presents results pertaining to pre-service teachers' self-concept about their MPCK. Profiles of participants in each Cluster are presented together with the correlations of their MPCK sub-factors with the mean scores in the functions survey. 
Table 17. Results of the auto-clustering for the two-step cluster analysis

\begin{tabular}{ccccc}
\hline $\begin{array}{c}\text { Number of } \\
\text { Clusters }\end{array}$ & $\begin{array}{c}\text { Schwarz's } \\
\text { Bayesian Criterion } \\
\text { (BIC) }\end{array}$ & BIC Change ${ }^{\mathrm{a}}$ & $\begin{array}{c}\text { Ratio of BIC }_{\text {Changes }^{\mathrm{b}}} \\
\text { Batio of Distance } \\
\text { Measures }^{\mathrm{c}}\end{array}$ \\
\hline 1 & 907.94 & -118.97 & 1.000 & 2.39 \\
2 & 788.97 & -3.32 & .03 & 1.79 \\
4 & 785.65 & 33.64 & -.28 & 1.29 \\
5 & 819.29 & 44.13 & -.31 & 1.30 \\
6 & 863.43 & 52.44 & -.44 & 1.06 \\
7 & 915.87 & 54.12 & -.46 & 1.33 \\
8 & 969.99 & 60.60 & -.51 & 1.26 \\
9 & 1030.59 & 64.61 & -.54 & 1.13 \\
10 & 1095.19 & 66.44 & -.56 & 1.01 \\
11 & 1161.63 & 66.52 & -.56 & 1.02 \\
12 & 1228.15 & 66.72 & -.56 & 1.14 \\
13 & 1294.87 & 68.40 & -.58 & 1.09 \\
14 & 1363.27 & 69.36 & -.58 & 1.03 \\
15 & 1432.63 & 69.68 & -.59 & 1.00 \\
\hline
\end{tabular}

a. The changes are from the previous number of clusters in the table.

b. The ratios of changes are relative to the change for the two cluster solution.

c. The ratios of distance measures are based on the current number of clusters against the previous number of clusters.

We see from Table 17 that the two-step auto clustering revealed a two cluster solution as the optimal number of clusters that best profiled the data. The BIC values were minimized and the change in them between adjacent numbers of clusters and the largest ratio of distances was for two clusters. The predictor importance of knowledge dimension to the formation of the clusters was $\mathrm{SCK}=1.74, \mathrm{CCK}=1.00$ and $\mathrm{KCS}=0.77$ and the ratio of large cluster to small cluster was 1.08 which was good.

Table 18. Cluster distribution

\begin{tabular}{cccc}
\hline & & $\mathrm{N}$ & \% of Total \\
\hline \multirow{3}{*}{ Cluster } & 1 & 71 & 47.3 \\
& 2 & 79 & 52.7 \\
& Total & 150 & 100 \\
\hline
\end{tabular}

The cluster distribution (Table 18) shows the composition of the clusters. Clusters 1 and 2 contained 72 and 79 subjects respectively which translate to 47.3 and 52.7 percent of the total number of participants. The cluster quality was 0.4 which is fair. 
Table 19. Cluster profiles of pre-service teachers

TEST

\begin{tabular}{|c|c|c|c|c|c|c|c|c|c|c|c|c|c|}
\hline & & \multicolumn{2}{|c|}{ KTS } & \multicolumn{2}{|c|}{ KMLS } & \multicolumn{2}{|c|}{$\mathbf{K M}$} & \multicolumn{2}{|c|}{ KL } & \multicolumn{2}{|c|}{ KC } & \multicolumn{2}{|c|}{ SCORE } \\
\hline & & ean & $\begin{array}{l}\text { Std. } \\
\text { Dev. }\end{array}$ & Mean & $\begin{array}{l}\text { Std. } \\
\text { Dev. }\end{array}$ & Mean & $\begin{array}{l}\text { Std. } \\
\text { Dev. }\end{array}$ & Mean & $\begin{array}{l}\text { Std. } \\
\text { Dev. }\end{array}$ & Mean & $\begin{array}{l}\text { Std. } \\
\text { Dev. }\end{array}$ & Mean & $\begin{array}{l}\text { Std. } \\
\text { Dev. }\end{array}$ \\
\hline & & 3.48 & .89 & 3.82 & .98 & 3.48 & .92 & 3.44 & .83 & 3.83 & .72 & 41.23 & 10.56 \\
\hline & 2 & 4.35 & .60 & 4.70 & .35 & 4.34 & .49 & 4.50 & .49 & 4.49 & .39 & 55.80 & 14.73 \\
\hline
\end{tabular}

Table 19 shows the cluster profiles of the Zambian mathematics pre-service teachers based on their Mathematical Pedagogical Content Knowledge (MPCK) factors and results of the pencil and paper test on the concept of a function. The MPCK factors that were used to form the clusters are Knowledge of Teaching Strategies (KTS), Knowledge of Mathematical Language and Symbols (KMLS), Knowledge of Misconceptions (KM), Knowledge of Learners (KL) and Knowledge of Curriculum (KC).

Cluster 1 is basically composed of pre-service teachers with low levels of knowledge across all the MPCK factors when compared with their counterparts in Cluster 2. Pre-service teachers in Cluster 1 also performed below average in the achievement test on functions posting a mean performance of $41.23 \%$ with a standard deviation of 10.56. Those in Cluster 2 posted a mean performance of $55.80 \%$ with standard deviation of 14.73 . A very interesting global picture is building from these initial results.

Pre-service teachers who performed below average in the achievement test also recorded lower scores their Mathematical Pedagogical Content Knowledge (MPCK) factors. This implies that pre-service teachers with low performance in subject matter are more likely to experience difficulties in their classroom teaching because they have also exhibited low levels of mathematics PCK skills. Pearson's principle moment correlation analysis (Table 21) has revealed significant correlations between Pedagogical Content Knowledge (MPCK) factors and performance in the achievement test. The students who scored highly in the achievement test also posted high MPCK skills. These are pre-service teachers who are likely to have high selfesteem during their interactions with students in their future classes. 
Table 20. Results of the independent samples t-test of pre-service teachers' PCK by

Cluster

\begin{tabular}{cccccccc}
\hline Factor & Cluster & N & Mean & Std. Dev. & T & df & Sig. \\
\hline \multirow{2}{*}{ KTS } & Cluster 1 & 71 & 3.48 & .89 & -7.09 & 148 & .000 \\
& Cluster 2 & 79 & 4.35 & .60 & & & \\
\multirow{2}{*}{ KMLS } & Cluster 1 & 71 & 3.82 & .98 & -7.51 & 148 & .000 \\
& Cluster 2 & 79 & 4.71 & .35 & & & \\
\multirow{2}{*}{ KM } & Cluster 1 & 71 & 3.48 & .92 & -7.20 & 148 & .000 \\
& Cluster 2 & 79 & 4.34 & .49 & & & \\
KL & Cluster 1 & 71 & 3.44 & .83 & -9.58 & 148 & .000 \\
& Cluster 2 & 79 & 4.50 & .49 & & & \\
\multirow{2}{*}{ KC } & Cluster 1 & 71 & 3.83 & .72 & -7.10 & 148 & .000 \\
\multirow{2}{*}{ MPCK } & Cluster 2 & 79 & 4.49 & .39 & & & \\
& Cluster 1 & 71 & 41.23 & 10.56 & -6.90 & 148 & .000 \\
& Cluster 2 & 79 & 55.80 & 14.72 & & & \\
\hline
\end{tabular}

Table 20 shows the independence samples t-test results for the mean differences of pre-service teachers' knowledge based on clusters. The results revealed that there was a significant difference between clusters in pre-service teachers' mathematical pedagogical knowledge factors and mean performance in the functions achievement test scores. The results further show that the two clusters were dissimilar based on the factors that were used to form them.

Table 21. Correlations between MPCK sub-factors

\section{KTS KMLS KM KL $\quad$ KC $\quad$ MPCK Test Score}

\begin{tabular}{ccccccc}
\hline KTS & $\mathrm{R}$ & 1.00 \\
& $\mathrm{P}$ & & & & & \\
KMLS & $\mathrm{R}$ & $.388^{* *}$ & & & & \\
& $\mathrm{P}$ & .000 & & & & \\
\hline $\mathrm{KM}$ & $\mathrm{R}$ & $.450^{* *}$ & $.386^{* *}$ & & & \\
& $\mathrm{P}$ & .000 & .000 & & & \\
\hline $\mathrm{KL}$ & $\mathrm{R}$ & $.311^{* *}$ & $.298^{* *}$ & $.341^{* *}$ & & \\
\hline $\mathrm{KC}$ & $\mathrm{P}$ & .000 & .000 & .000 & & \\
\hline $\mathrm{K}$ & $\mathrm{R}$ & $.325^{* *}$ & $.290^{* *}$ & $.328^{* *}$ & $.399^{* *}$ & \\
\hline MPCK & $\mathrm{P}$ & .000 & .000 & .000 & .000 & \\
\hline
\end{tabular}




\begin{tabular}{lcccccccc} 
& $\mathrm{p}$ & .000 & .000 & .000 & .000 & .000 & & \\
\hline \multirow{2}{*}{ Test Score } & $\mathrm{r}$ & .134 & $.291^{* *}$ & $.196^{*}$ & $.380^{* *}$ & $.318^{* *}$ & $.375^{* *}$ & 1.00 \\
& $\mathrm{p}$ & .103 & .000 & .016 & .000 & .000 & .000 & \\
\hline
\end{tabular}

$* * \mathbf{p} \leq 0.01$ (2-tailed).

$* \mathbf{p} \leq 0.05$ (2-tailed).

Table 21 shows the results of Pearson's product-moment correlation analysis. This analysis was conducted to examine the relationship between MPCK sub-factors and the test scores of pre-service secondary mathematics teachers. As depicted from Table 6, there was a significant positive correlation between KMLS, KM, KL, KC and test scores obtained from the functions pencil and paper test. Although these correlations were positively significant, KMLS $(\mathrm{r}=.291, \mathrm{p}=.000)$ and KM $(\mathrm{r}=$ $.196, \mathrm{p}=.016)$ posted weak correlations with the test scores while KL $(\mathrm{r}=.380, \mathrm{p}=$ $.000)$ and $\mathrm{KC}(\mathrm{r}=.318, \mathrm{p}=.000)$ were moderately correlated with test scores. This implies that pre-service teachers with high MPCK self-concept performed better in the functions pencil and paper test that those with low MPCK self-concept. However, the correlation between KTS $(r=.134, p=.103)$ and test score was not significant. This implies that the level of KTS was not related to one's performance in mathematics. Thus, if a pre-service teacher had high level of KTS it does not necessarily mean that their knowledge of the function concept would be high.

\subsubsection{Functions survey results}

This section presents pre-service teachers' knowledge profiles of the concept of a function by detailing their CCK, SCK and KCS by Cluster. Their CCK was presented in terms of KDRF, CIQCF and KASERF while SCK was presented in terms of KDRRF, EJRRDF, EJEF and EJRDRF. Their KCS was analysed in terms of KSDME.

Table 22. Performance profiles of pre-service mathematics teachers by cluster for each knowledge dimension

\begin{tabular}{cccccc}
\hline Cluster & Cluster size & $\begin{array}{c}\text { Overall } \\
(35 \text { items })\end{array}$ & $\begin{array}{c}\text { Common } \\
\text { content } \\
\text { knowledge } \\
(15 \text { items })\end{array}$ & $\begin{array}{c}\text { Specialized } \\
\text { content } \\
\text { knowledge } \\
(13 \text { items })\end{array}$ & $\begin{array}{c}\text { Knowledge of } \\
\text { content and } \\
\text { students } \\
(7 \text { items })\end{array}$ \\
\hline 1 & $72(48 \%)$ & $12.94(3.72)$ & $14.93(3.82)$ & $11.96(3.63)$ & $11.93(3.71)$ \\
2 & $78(52 \%)$ & $19.11(4.60)$ & $23.13(5.64)$ & $17.56(4.38)$ & $16.65(3.80)$ \\
\hline
\end{tabular}


Table 22 shows the average performance of prospective teachers across the two clusters. It can be seen from Table 22 that prospective teachers in cluster two performed better than their counterparts in Cluster 1. Although there was a performance difference between the two clusters, general performance was very low in CCK, SCK and KCS with Cluster 2 posting the best performance of $23.13 \%$ in CCK and the least being $11.93 \%$ in KCS in Cluster 1. It can also be argued that Cluster 1 was comprised of prospective teachers with low CCK, SCK and KCS (Figure 16) when compared with their counterparts in Cluster 2.

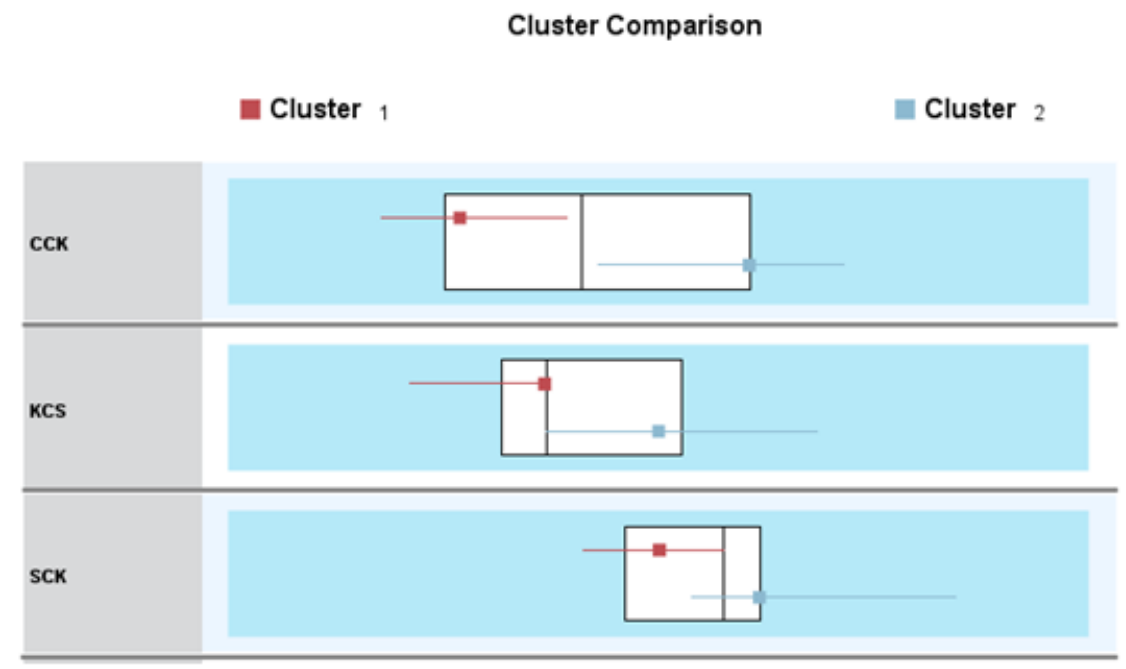

Figure 16. Cluster comparison of prospective mathematics secondary teachers' performance

Table 23. Knowledge profiles of prospective Zambian mathematics teachers based on their CCK, SCK and KCS

\begin{tabular}{ccccccccc}
\hline \multirow{2}{*}{ Dimension } & \multicolumn{2}{c}{ Mean } & \multicolumn{2}{c}{ Minimum } & \multicolumn{2}{c}{ Maximum } & \multicolumn{2}{c}{ Std } \\
\cline { 2 - 10 } & Cluster & Cluster & Cluster & Cluster & Cluster & Cluster & Cluster & Cluster \\
& 1 & 2 & 1 & 2 & 1 & 2 & 1 & 2 \\
\hline CCK & 14.83 & 23.14 & 7 & 12 & 24 & 35 & 3.75 & 5.64 \\
SCK & 11.90 & 17.56 & 0 & 11 & 18 & 26 & 3.62 & 4.38 \\
KCS & 11.85 & 16.65 & 6 & 11 & 18 & 25 & 2.63 & 3.80 \\
\hline
\end{tabular}

Table 23 shows the minimum and maximum scores for each knowledge domain by cluster. The minimum CCK score for the two clusters was 7\% (Cluster 1) while the maximum CCK score was 35\% (Cluster 2). As for SCK, Cluster 1 posted the minimum score of $0 \%$ while $26 \%$ was the maximum score from cluster 2 . The minimum KCS score was $6 \%$ (Cluster 1) while the maximum KCS score was $25 \%$ (cluster 2). 
Table 24. Performance profiles of prospective mathematics teachers by cluster for the constructs of knowledge domains

\begin{tabular}{ccccccccc}
\hline \multirow{2}{*}{ Sub-Dimension } & \multicolumn{2}{c}{ Mean } & \multicolumn{2}{c}{ Minimum } & \multicolumn{2}{c}{ Maximum } & \multicolumn{2}{c}{ Std } \\
\cline { 2 - 9 } & Cluster & Cluster & Cluster & Cluster & Cluster & Cluster & Cluster & Cluster \\
& 1 & 2 & 1 & 2 & 1 & 2 & 1 & 2 \\
\hline KDRF & 5.66 & 7.15 & 2 & 4 & 8 & 10 & 1.79 & 1.32 \\
KASERF & 2.38 & 3.55 & 1 & 2 & 4 & 6 & .88 & 1.16 \\
CIQCF & 6.79 & 12.44 & 4 & 5 & 13 & 19 & 1.68 & 4.29 \\
EJRDRF & 3.65 & 4.15 & 0 & 2 & 6 & 6 & 0.93 & 1.01 \\
EJEF & 1.10 & 2.26 & 0 & 0 & 3 & 5 & .45 & 1.38 \\
EJRRDF & 1.65 & 3.56 & 0 & 0 & 4 & 6 & 1.27 & 1.31 \\
KDRRF & 6.65 & 10.65 & 0 & 4 & 10 & 17 & 2.26 & 3.72 \\
KSDME & 11.85 & 16.65 & 6 & 11 & 18 & 25 & 2.63 & 3.80 \\
\hline
\end{tabular}

CCK was further analysed in terms of teacher's knowledge about definitions of relations and functions (KDRF), calculations involving inverse, quadratic \& composite functions (CIQCF) and teacher's knowledge about appropriate selection of examples and non-examples of relations and functions (KASERF). Cluster 2 prospective teachers performed better than those in Cluster 1 in term of KDRF, CIQCF and KASERF. A maximum score of 19\% (CIQCF) was recorded and a minimum score of $1 \%$ (KASERF) for clusters 2 and 1 respectively (Table 24).

SCK was analysed in terms of different representations of relations \& functions (KDRRF), explanations and justifications of relationships between the ranges and domains of functions (EJRRDF), explanation and justification of examples and nonexamples of functions (EJEF) and explaining and justifying relationships and differences between relations and functions (EJRDRF). Both clusters 1 and 2 recorded a minimum score of $0 \%$ in EJEF and EJRRDF. Pre-service teachers' KDRRF of $17 \%$ was the maximum for all the four sub-dimensions of SCK. KCS was further analysed in terms of Knowledge of students' difficulties, misconceptions \& errors (KSDME). The maximum KSDME score was $25 \%$ while the minimum was $6 \%$ (Table 24).

To further understand prospective teachers' knowledge of the function concept, a one-way between-subjects multivariate analysis of variance (MANOVA) was conducted and a follow-up discriminant function analysis (DFA) to the significant MANOVA. In the MANOVA test (Table 25), the clusters derived from the two-step cluster analysis procedure formed the independent variable while the three MKT knowledge domains CCK, SCK and KCS were the dependent variables. The 0.05 level of significance was set as a priori for the analysis. Comparison of the 
prospective teachers' performance in the CCK, SCK and KCS knowledge domains across the clusters signified their knowledge of the function concept.

Table 25. Between levels of cluster effects of prospective secondary mathematics

\begin{tabular}{ccccccc}
\multicolumn{7}{c}{ teachers' knowledge of the function concept } \\
\hline \multirow{2}{*}{ Group } & $\begin{array}{c}\text { Test } \\
\text { factor }\end{array}$ & Df & $\begin{array}{c}\text { Mean } \\
\text { square }\end{array}$ & F & sig & $\begin{array}{c}\text { Observed } \\
\text { power }\end{array}$ \\
\hline \multirow{3}{*}{ Cluster } & CCK & 1 & 2566.687 & 110.019 & .000 & 1.000 \\
& SCK & 1 & 1191.826 & 73.259 & .000 & 1.000 \\
& KCS & 1 & 859.480 & 79.116 & .000 & 1.000 \\
\hline
\end{tabular}

Table 25 shows the univariate analysis results of prospective secondary mathematics teachers' performance across all the three knowledge domains CCK, SCK and KCS in each cluster. As can be seen in the table, there was a statistically significant difference $(\mathrm{p}<.05)$ in the prospective teachers' CCK, SCK and KCS of the function concept

Table 26. Multivariate analysis of prospective secondary mathematics teachers' knowledge of the function concept between clusters

\begin{tabular}{ccccccc}
\hline & Box's M & Sig & $\begin{array}{c}\text { Wilk's } \\
\text { Lambda }\end{array}$ & Sig & \multicolumn{2}{c}{ Log Determinants } \\
\cline { 5 - 7 } Cluster & 23.880 & .001 & .551 & .000 & 6.026 & 7.334 \\
\hline
\end{tabular}

Analysing Table 26, we see that there is a significant difference in the CCK, SCK and KCS scores of prospective secondary mathematics teachers justified by a significant Wilk's lambda of $0.55, \mathrm{p}<0.001$. There was a statistically significant difference between the covariance matrices of clusters 1 and 2 with a significant Box's $M$ value of $23.88, \mathrm{p} \leq 0.001$. The DFA generated only one discriminant function. This could have been due to the fact that only two clusters were being used in the analysis. To check the robustness of the DFA we considered the log determinants of the two clusters and Table 6 shows that the log determinants do not differ greatly which confirms the robustness of the DFA.

Table 27. Test of equality of cluster mean scores for prospective secondary mathematics teachers' knowledge of the function concept

\begin{tabular}{lccccc}
\hline & $\begin{array}{c}\text { Wilk's } \\
\text { lambda }\end{array}$ & F & df1 & df2 & Sig \\
\hline CCK & .572 & 110.019 & 1 & 147 & .000 \\
SCK & .667 & 73.259 & 1 & 147 & .000 \\
KCS & .650 & 79.116 & 1 & 147 & .000 \\
\hline
\end{tabular}


Table 27 shows results of the test of equality of cluster mean scores for prospective secondary mathematics teachers' knowledge of the function concept. Examining Table 7, it can be seen that the Wilk's lambda is statistically significant for all the independent variables $(\mathrm{p}<0.05)$ using the F-test. Following a rule of thumb which states that the smaller the Wilk's lambda the more important the independent variable to the discriminant function, common content knowledge $(\mathrm{CCK})$ is the most important factor in discriminating between prospective teachers in Cluster 1 and those in Cluster 2.

Table 28. Standardized and unstandardized canonical discriminant function coefficients

\begin{tabular}{ccc}
\hline Knowledge domain & Standardized coefficients & Unstandardized coefficients \\
\hline CCK & .748 & .155 \\
SCK & -.023 & -.006 \\
KCS & .372 & .113 \\
\hline
\end{tabular}

Table 28 shows standardized and unstandardized discriminant function coefficients. The purpose for which these coefficients are used is similar to that of beta weights in regression analysis. Standardized coefficients are used to indicate the relative importance of the independent variable in predicting the dependent variable. Thus, the higher the absolute value of the standardized coefficient the greater the discriminating ability. Just like unstandardized regression coefficients in regression analysis, the unstandardized coefficients in this study were used to construct the prediction equation for classification of new cases.

\subsection{QUALITATIVE RESULTS}

Results in this section are presented in accordance to the main research questions contained in Chapter 1 of this thesis. In-depth responses of pre-service teachers from all the instruments are are presented. Detailed answers related to questions concerning their CCK, SCK and KCS are outlined in this section. The section structure is such that it first presents results about participants' CCK before delving into their SCK and cocluding with their KCS.

\subsubsection{Pre-service mathematics teachers' common content knowledge}

Pre-service teachers' CCK was presented using excerpts of their responses from the functions survey and semi-structured interviews. The question which was being answered in this section is: 


\section{What level of proficiency of common content knowledge of the concept of a function do Zambian pre-service mathematics teachers possess?}

To answer the question three cases are presented: Teacher X, Teacher $\mathrm{Y}$ and Teacher Z. their responses are portrayed in sequence with the first being Teacher X.

The case of Teacher $X$

Item 1(a)(i)

Define a relation

The definition of a relation offered by Teacher X (Figure 17) was considered a valid one because it constituted key words that clarify what a function is. By stating that a relation is a rule and the rule associates elements of two sets,

(a) ir) A telation is a rofe thet associates efoments

Figure 17. Excerpt of Teacher X's answer to item 1(a)(i)

Teacher $\mathrm{X}$ demonstrated strong understanding of what a relation is. The definition establishes a relationship between two sets and the relationship was strictly defined by a specific rule. During the interview Teacher X still demonstrated good understanding of the definition of a relation by giving an example similar to the one he gave in the test. His answer was at level 2. Key knowledge features for level 2 are outlined in Table 15 of Chapter 3.

Interviewer: How would you define a relation to your students?

Teacher X: A relation, maybe to make our pupils understand, is simply a mapping of two sets. It is a connection between the elements of one set to that of the second set.

Interviewer: $\mathrm{Ok}$

Teacher X: [Long pause] ... Maybe if you have a set that has the first five natural numbers as maybe the first set. Now if we square this particular set to get another set. Maybe the first elements will be $\{1,2,3,4,5\}$ as my first set. We are talking about a relation "is a square of ". This means that in the second set I will get 1 , then 4 , and so on. The "square of" is a relation that makes a bond between the two sets.

Interviewer: somebody said that a relation is a statement between two sets. Would you qualify that definition?

Teacher X: Aah not really. Unless you go on to explain what kind of a statement it is. I wouldn't qualify it. 
Ítem 1(a)(ii)

Give one example of a relation

Following his definition (Figuer 18) of a relation Teacher $\mathrm{X}$ gave two examples that justified that a relation is a rule. By stating that " $\mathrm{A}$ is a factor of $\mathrm{B}$ ", the phrase "a factor of" act as a rule in this example and the phrase "square of" acts as a rule in the relation "P is a square of Q". His ability to give an example was deemed to be level 1-2.

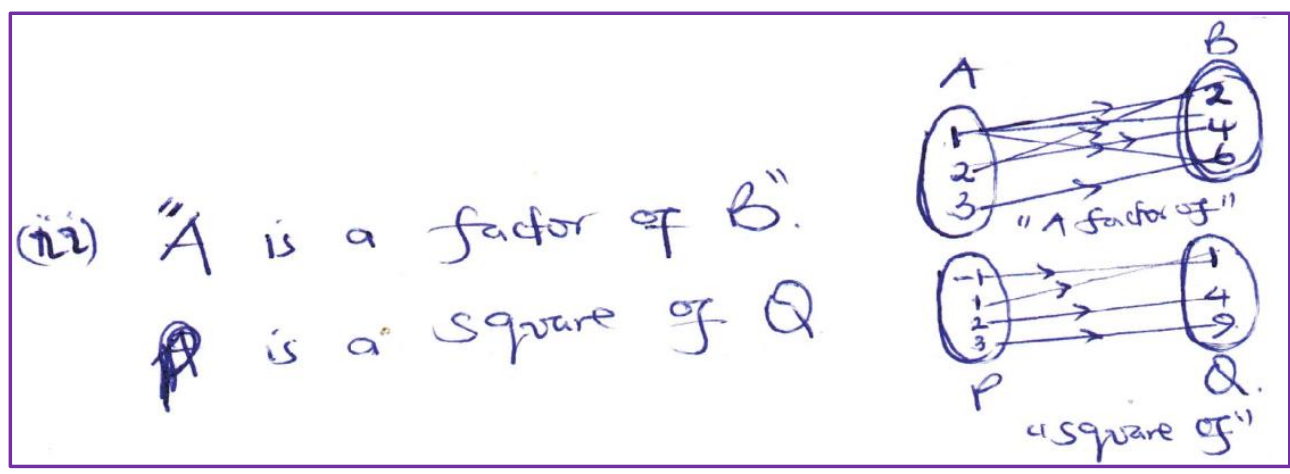

Figure 18. Excerpt of Teacher X's answer to item 1(a)(ii)

Item 1(b)(i)

Define a function

This item was aimed at assessing the pre-service teacher's knowledge of the features or characteristics of a function that give it a complete description or definition.

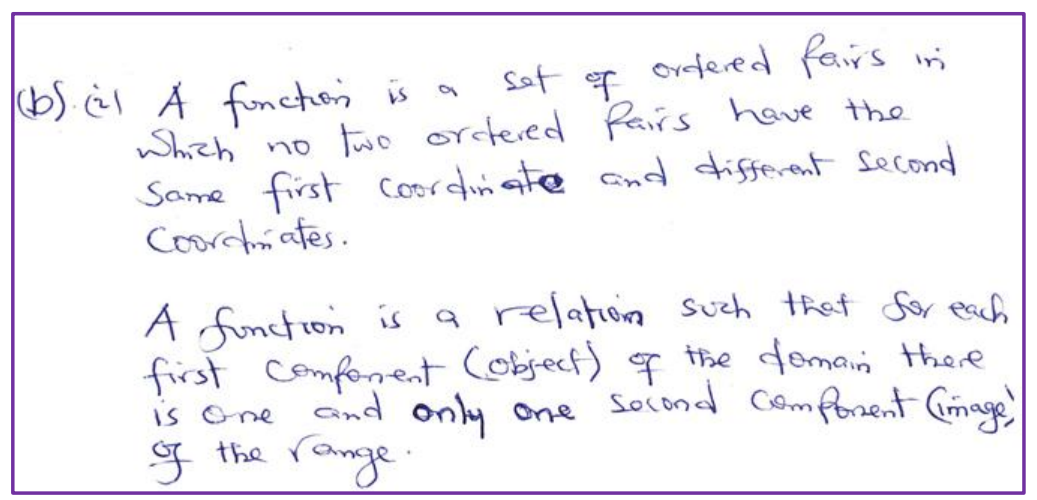

Figure 19. Excerpt of Teacher X's answer to item 1(b)(i)

The teacher was expected to demonstrate the arbitrary and univalence characteristic of a function. Even (1990, p. 528) explained that the arbitrariness of a function denoted "the relationship between the two set on which the function was 
defined and the sets themselves ... which means that the two sets do not need to be defined on specific set of objects, in particular, the sets do not need to be sets of numbers". Secondly, the teacher needed to demonstrate knowledge of the univalence nature of a function. The univalence of a function states that "for each element in the domain there be only one element (image) in the range" (Even, 1990,p. 530).

Analyzing Teacher X's answer (Figure 19) to this question, it can be seen that the first paragraph of his answer refers to the arbitrariness of a function because the teacher did not suggest that a function is an object or indeed a number. However, Teacher $\mathrm{X}$ was expected to exemplify his definition so as to demonstrate a clear understanding of the arbitrariness of a function. Examples in most cases demonstrate understanding and justification of a viewpoint. In his second paragraph Teacher X demonstrates the univalence characteristic of a function.

This paragraph demonstrates Teacher X's understanding of a function as taught in secondary schools in Zambia and as it is defined in Mathematics textbooks approved by the Curriculum Development Centre (CDC) in Zambia. The overreliance on the univalence of a function, with little or no emphasis on the arbitrary nature of a function has created gaps in secondary school students' understanding of the function concept. During the interview Teacher $X$ still demonstrated gaps in the arbitrariness of a function but showed knowledge of the univalence by claiming that a function is a one-to-one. His response has been rated Level 1.

Interviewer: How would you define a function?

Teacher X: A function, maybe, in simpler terms is a relation but it is a special relation because maybe it is one-to-one kind of relation.

Item 1(b)(ii)

Give one example of a function

This item was aimed at assessing Teacher X's ability to exemplify the definition given in part (i) of question one of the survey on functions. The example given (fgure 20) demonstrates Teacher X's reliance on the univalence of a function rather than its arbitrariness. This in part is as a result of the curriculum materials designed for use in Zambian secondary schools. The teacher managed to give an example of a function. However, it would have been better to give an example which 
refers to both the arbitrariness and univalence of a function. His example has been rated level 1.

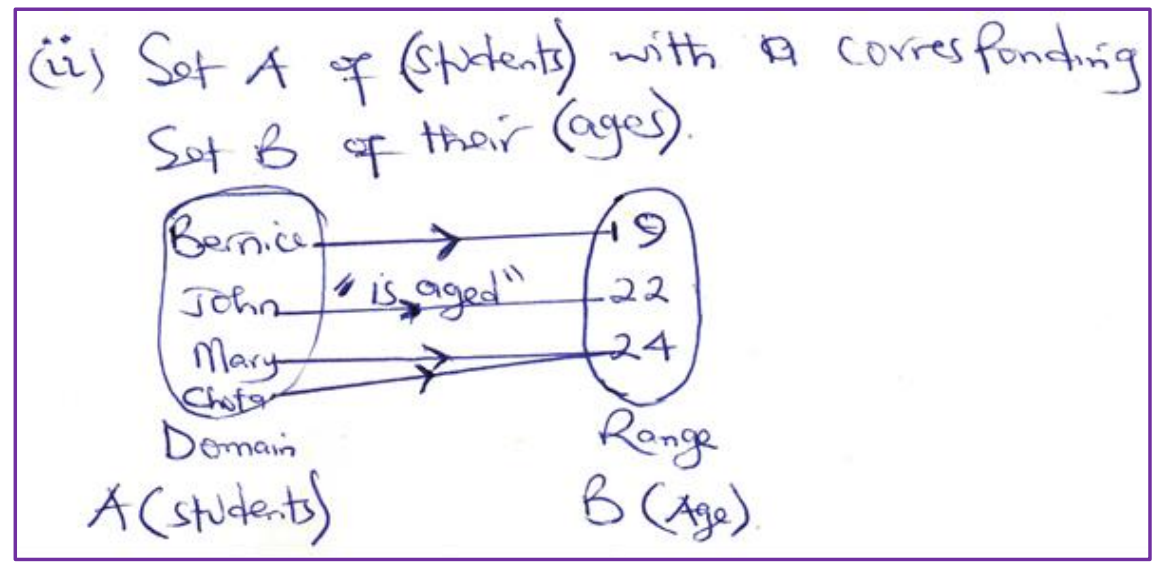

Figure 20. Excerpt of Teacher X's answer to item 1(b)(ii)

Item 1(e)

In each of the cases below (Figure 21), state whether the figure represents a function or not. Justify your answers.

This question was intended to assess pre-service teachers' application of their understanding of the definition of a function. Key to answering this question was the teachers' application of the arbitrariness and univalence of a function and application of the "vertical line test" to ascertain whether the given figure was a function or not.

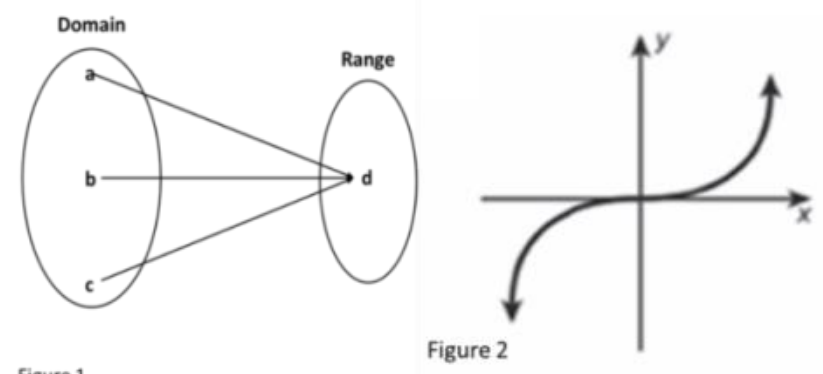

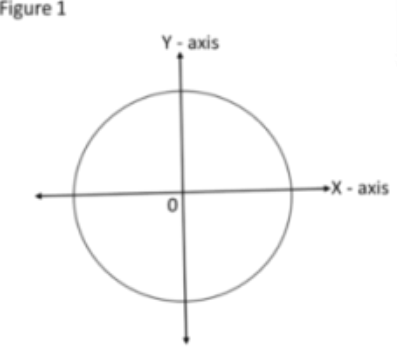

Figure 3

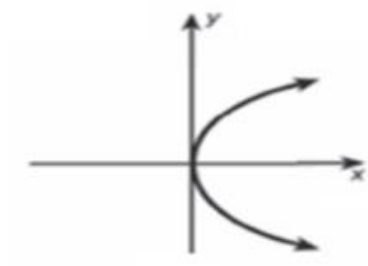

Figure 4

Figure 21. Graphs of functions and non-functions 
Also by being able to determine which of the figures contained functions the teacher would be in a strong position to easily give his secondary school students examples and non-examples of functions.

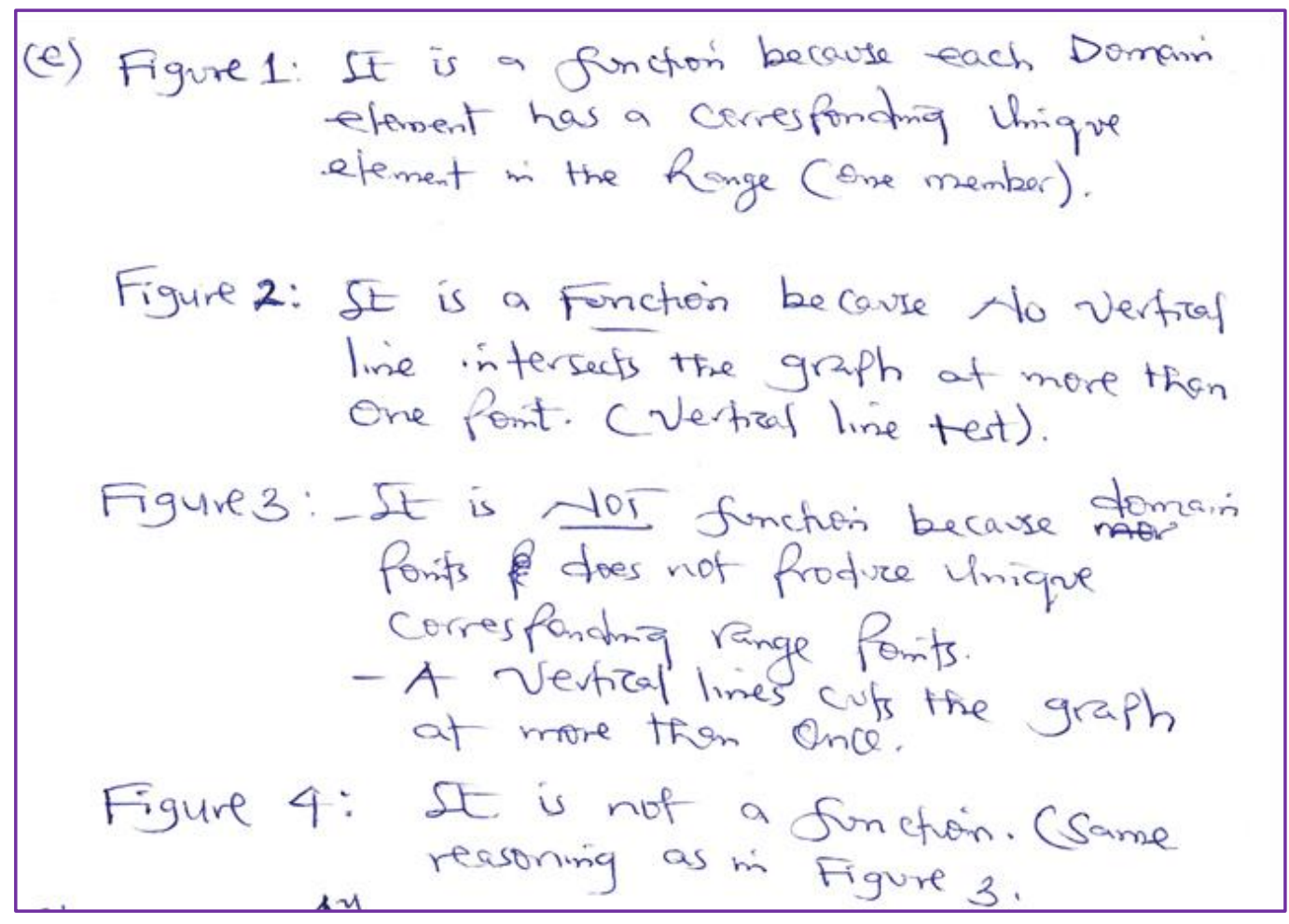

Figure 22. Excerpt of Teacher X's answer to item 1(e)

This question was well answered by Teacher X. In his determination of whether or each of the figures represented a function (see Figure 22), teacher $X$ relied on the univalence property of a function and the vertical line test. In determining Figure 1 as a function Teacher $\mathrm{X}$ used the univalence property by stating that each element of the domain had a unique corresponding element in the range. The concepts of domain and range were correctly used by Teacher X. In qualifying the graph in Figure 2 to be a function Teacher $\mathrm{X}$ used the vertical line test. He stated that if a vertical line is drawn to intersect the graph, it would not intersect the graph at more than one point. Figure 2 passed the vertical line test and thus was deemed to be a function.

As for Figure 3 Teacher $\mathrm{X}$ used the concept of domain and range by stating that it was not a function because the domain points did not produce unique corresponding range points. However, Teacher $\mathrm{X}$ did not state which points in particular he was referring to. It would have been easier for Teacher $X$ to use the vertical line test in examining Figure 3. Even in a secondary school classroom 
situation the vertical line test would have been easily understood that using the ideas of domain and range. Students can be left wondering as to which domain points or range points the teacher was referring to since on the graph no specific points are indicated for reference. Teacher $\mathrm{X}$ determined that the graph in Figure 4 was not a graph of a function.

He made the determination based on the reasons he used to determine that Figure 3 was not a function. As in Figure 3, Teacher X could easily have relied on the vertical line test. In the case of Figure 4 a vertical line drawn through the graph would intersect the graph at two points. Thus, the graph in this Figure failed the vertical line test. To justify his reasoning behind the answers he gave in this question.

Teacher X was given a worksheet (Figure 23) which had similar situations to confirm his answers to this item. He demonstrated knowledge of application of definitions to the figures. However, in some cases he could not fully use the definition of a function to help in determining which was a function.

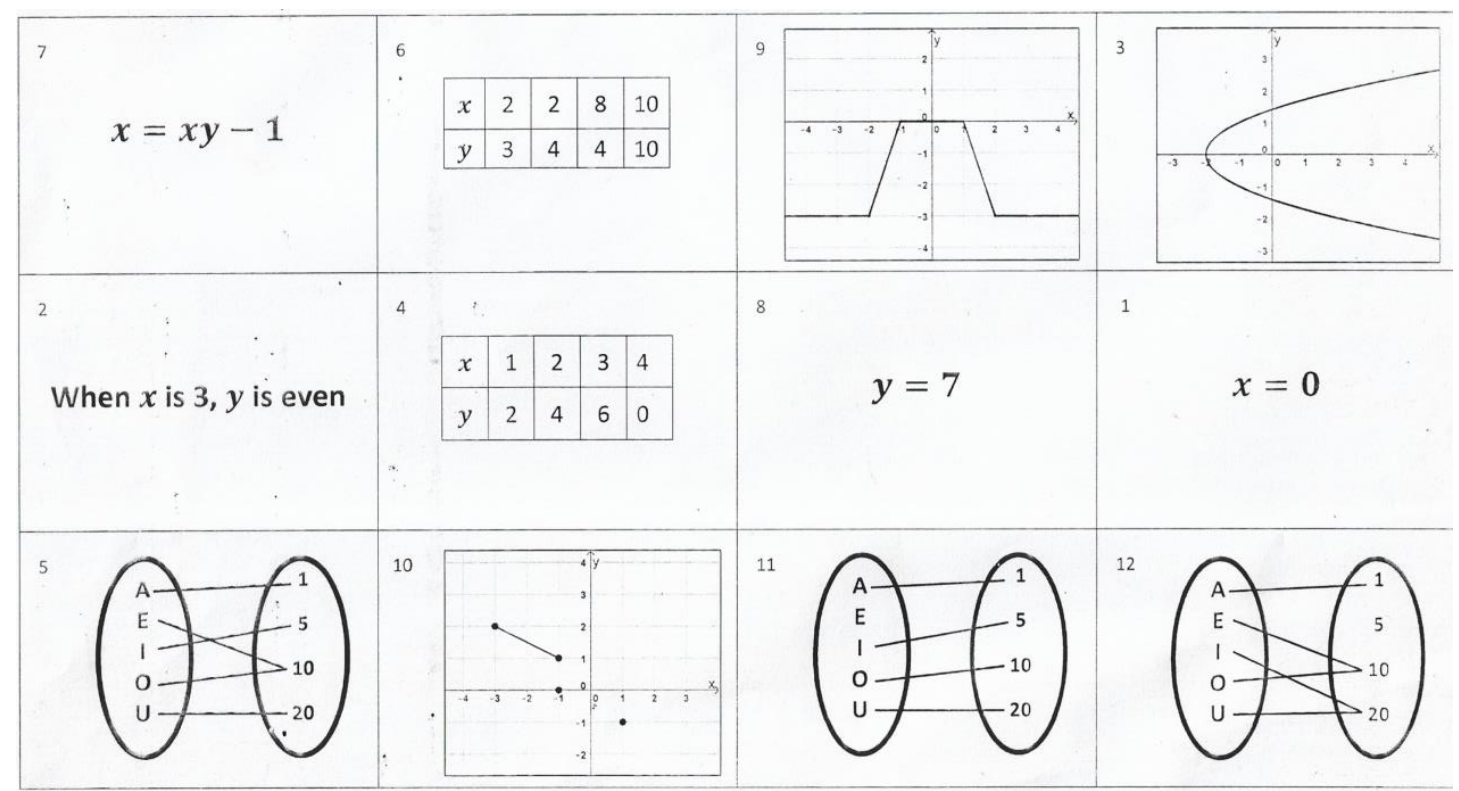

Figure 23. Cards showing graphs of functions

Interviewer: The worksheet you have been given has is similar to question 1(e). For each figure on the worksheet, determine which is a function and which is not and couple your answer with an explanation.

Teacher X: I will start with 10. [Long pause] ... 10 is like a piecewise kind of function. It is not a continuous function.

Interviewer: But can we call it a function:

Teacher X: If it is not continuous. Maybe as piecewise it maybe a function. But if it 
was continuous I wouldn't say it was a function.

Interviewer: Ok. Let us move to the next one.

Teacher $\mathbf{X}$ : we can go to 3 . For 3 probably I will say it is not a function going by the vertical line test. This is because if I draw a vertical line I will have a single point having two corresponding points. So, it won't be a one-to-one function. It is not a function.

Interviewer: $\mathrm{Ok}$

Teacher X: Then we are going to 1 . This one says $\mathrm{x}=0$. I will say this is a function because this is simply a straight line. It is the y-axis.

Interviewer: $\mathrm{Ok}$

Teacher X: Equally for 8. It is just a straight line. It is a function. If you use a vertical or horizontal line test in this case then it also qualifies to be a function.

Interviewer: $\mathrm{Ok}$

Teacher X: We go to 7. I don't know whether it could be the equation of a curve or a circle. But given more time I would determine the kind of curve. From the snapshot you would say it is not a function because it might be a circle or something similar.

Interviewer: $\mathrm{Ok}$

Teacher X: For number 2, when $\mathrm{x}$ is $3, \mathrm{y}$ is even. [Long pause] ... I think it is a function. As for 9 it is a continuous function. I would say it is not a function. If we use the horizontal line test it will use a single input to produce two outputs.

Interviewer: Alright

Teacher X: We can go to 11 . Eleven is a function. I think the relation is a one-toone function because each element is mapped to a distinct element.

Interviewer: What about the input "E"? how do you treat "E"?

Teacher X: [Long pause] ... Oh "E" is hanging [laughs] ... Here I am not sure.

Interviewer: This situation is similar to 12 . Let us go to 12 . There is one output which is not mapped. How would you address this situation?

Teacher X: I think it is a function because each of the elements from the first set is having a corresponding element on the other set.

Interviewer: in your definition of a functions the emphasis is on inputs.so even if there is no element in the first set corresponding to " 5 " twelve remains a function. Would you use the same reasoning to answer 11 ?

Teacher X: Maybe if we borrow the fact that each input should have a unique output. Since one element "E" is not having an output or it is not linked [laughs] that is why I am saying that I am not sure whether it is a function or not

Interviewer: Ok let us leave it there. Which one is the next?

Teacher X: let us go to 5 . This one I would say is a function.

Interviewer: Is it by your definition?

Teacher X: Laughs .... Yes by definition because each input is having an output 
which is unique.

Interviewer: What about 4?

Teacher X: I just looked at 4. Pause ... if we consider $\mathrm{x}$ as a set of inputs and $\mathrm{y}$ a set of outputs, from just a glance you can say it is a function because each input has a distinct output.

Interviewer: what about 6?

Teacher X: If you look at 6 as well, comparing the two sets I would say it is not a function because of the last element which maps 10 onto 10. It is not producing any output..

Interviewer: Ok let us move away from this. Have you ever heard about the univalence of a function?

Teacher X: Not really.

Interviewer: Ok we will not discuss this. Would you define a one-to-one function as you eould define it for your students in class?

Teacher X: [Long pause] ... like we said earlier on it is simply some kind of relation where an input has a unique output.

Teacher X's responses in the test and in the interview were given a combined rating of level 1 .

Item 2(c)

Use the graph of $f(x)=-2 x^{2}-x+8$ to solve $f(x)=2$

This item required the pre-service teacher to graphically solve for $\mathrm{x}$. Recognizing that this problem could be solved algebraically; the question was instructive about a particular method. Upon inspecting the graph, it was observed that Teacher X did not give actually the answer to this item. There was no evidence on the graph that was indicative of a response to this item. Teacher $\mathrm{X}$ was asked during the interview to give reasons why he did not answer the question.

Interviewer: when I was checking your answer booklet I noticed that you did not answer item 2(c) which required you to solve the equation $f(x)=2$ using the graph of $f(x)=-2 x^{2}-x+8$. Would you explain the reasons why you did not answer this question?

Teacher X: Maybe I did not see it.

Interviewer: Now you have the opportunity. How would you explain the procedure of answering such a question to your students?

Teacher X: If it is using a graph, [we know that] the graph of $f(x)=-2 x^{2}-x+8$ is already drawn. We will need to draw the line for the graph of $f(x)=2$. The solution will be where the two graphs meet. So, we need to identify the $\mathrm{x}$-values where the 
two graphs are meeting.

The answers to this question both from the test and interview were rated level 1.

Item 2(d)

Complete the square for $f(x)=-2 x^{2}-x+8$ and hence determine the turning point of $f$.

This item was aimed at assessing skills, the first was teacher X's knowledge of solving a quadratic equation by completing the square method. By this teacher X's ability to follow all the steps involved in completing the square of a quadratic function were tested. Secondly, teacher X's knowledge of the stationary points of the graph of a quadratic function using completing the square method were tested. In this case, if the quadratic equation $a x^{2}+b x+c=0$ is written in the form $a\left[\left(x+\frac{b}{2 a}\right)^{2}-\frac{b^{2}}{4 a^{2}}\right.$ $\left.+\frac{c}{a}\right]$, the stationary point (maximum or minimum) occurs at the point where $\left(x+\frac{b}{2 a}\right)^{2}$ $=0$ or $x=-\frac{b}{2 a}$.

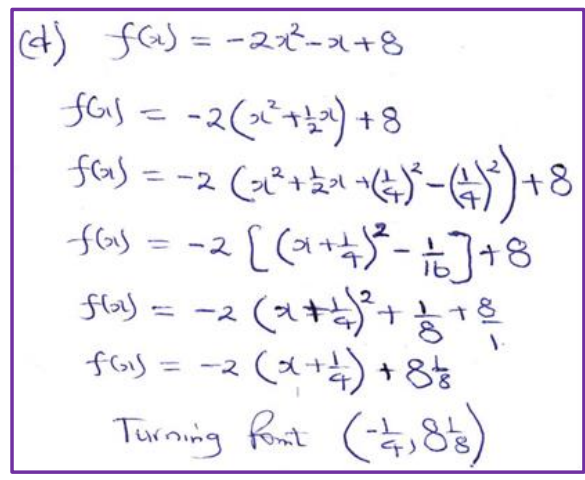

Figure 24. Excerpt of Teacher X's answer to item 2(d)

Analyzing Teacher X's work (Figure 24) it can be seen that he has very good knowledge about completing the square of a quadratic function. In his calculations Teacher X showed all essential steps. However, in the step that is second from the last he omitted the exponent 2 which during the interview he admitted was merely an error out of carelessness. The second aspect of this item was concerned with determination of the turning point of the graph of the given quadratic function. Teacher X correctly determined the turning point $\left(-\frac{1}{4}, 8 \frac{1}{8}\right)$ but it is not clear how he arrived at $-\frac{1}{4}$. By merely moving from $+\frac{1}{4}$ to $-\frac{1}{4}$ without justifying the change of 
sign from positive (+) to negative (-) could suggest that he was merely using rote memory of the steps involved in completing the square. Teacher $\mathrm{X}$ was expected to state that the turning point of the graph of the given function occurred at the point where $\left(\mathrm{x}+\frac{1}{4}\right)^{2}=0$, which simplified to $\mathrm{x}=-\frac{1}{4}$ upon solving for $\mathrm{x}$.

Interviewer: Generally is it important to teach completing the square?

Teacher X: It is very important. Firstly, when coming to graphing, certain aspects come out [like] the turning point which will help a learner to graph a function. Secondly, it is also important because we assume [that] these learners will advance in their education. There are so many [areas] where completing the square is used. So, this knowledge is not just at that particular level but will go on in other areas of mathematics.

The answers to this item were given a combined rating of level 2.

Item 3(a)

Define a one-to-one function in your own words

This item was assessing Teacher X's knowledge of a one-to-one function. To demonstrate knowledge of the definition the teacher was expected, as a bare minimum, to state that for a one-to-one function each member of the domain has a unique corresponding member of the range. And of course the reverse is also true. To further demonstrate full knowledge the teacher was expected to state that for a function to be one-to-one it needed to pass both the vertical line test and the horizontal line test..

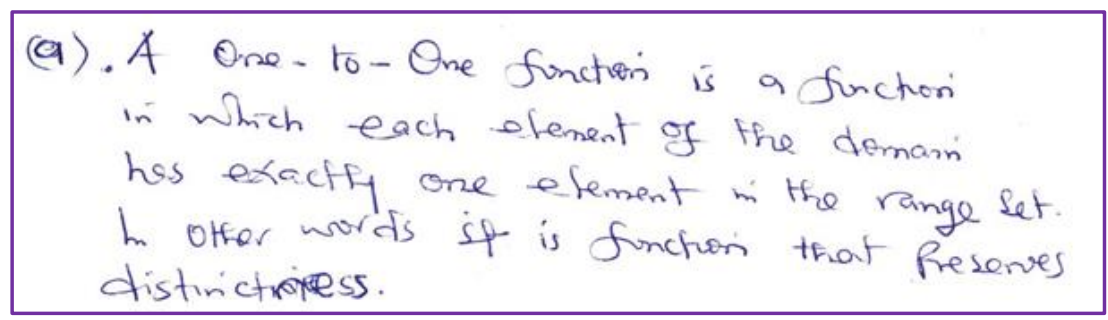

Figure 25. Excerpt of Teacher X's answer to item 3(a)

Analyzing Teacher X's answer (Figure 25) to this question we can see that that he used the concept of the domain and range in his definition which was commendable. His definition also emphasized uniqueness of the correspondence between members of the domain and those of the range. However, he does not mention that the function has to pass the vertical line test and the horizontal line test. 
The emphasis of uniqueness or distinctiveness in his definition implied that Teacher $\mathrm{X}$ was aware that a one-to-one function was different from a many-to-one function. Thus, to render clarity about the mix up that can arise as a result of a many-to-one function it was important for Teacher $\mathrm{X}$ to refer to the vertical line test and the horizontal line test for a function to be one-to-one.

Item 3(b)

A mathematics textbook shows the following graphs as examples of one-to-one functions (Figure 25). Is the textbook correct in this regard? Explain.

This item (see graphs in Figure 26) was aimed at assessing Teacher X's knowledge of using graphs to determine whether or not a given graph was a function.

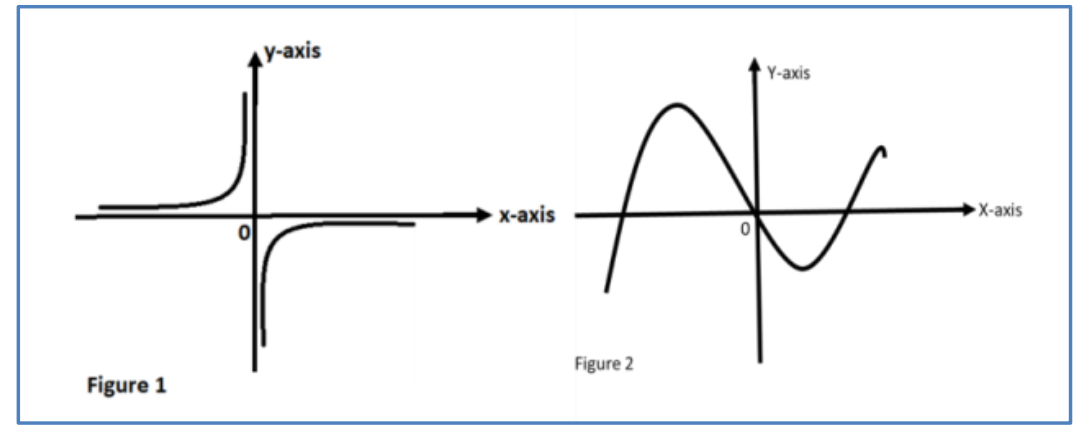

Figure 26. Graphs of functions and non-functions

In answering this question it was important for him to refer to the vertical line test and the horizontal line test. The former would have helped in determining that the given graph was a function while the latter test would have helped to establish that the function is one-to-one.

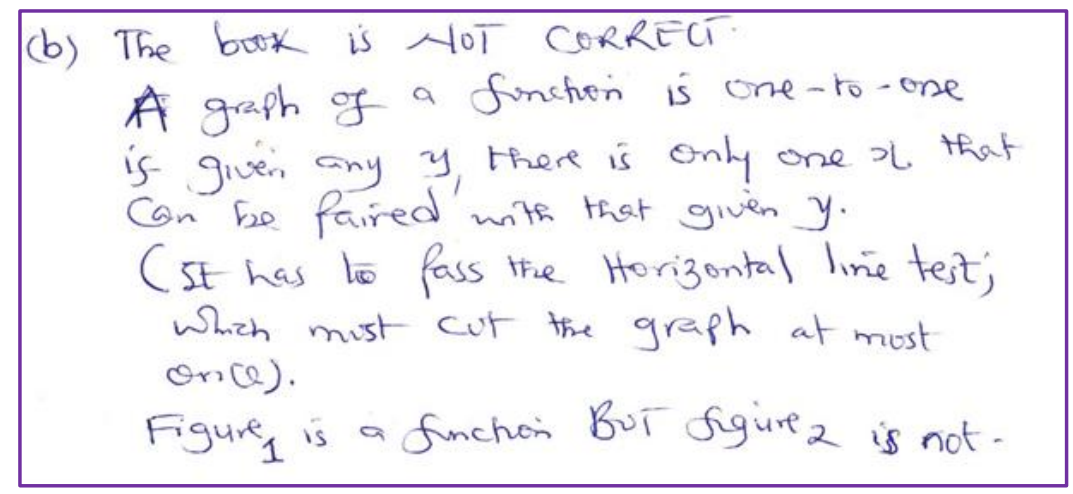

Figure 27. Excerpt of Teacher X's answer to item 3(b)

Analyzing Teacher X's answer (Figure 27) it can be seen it was too harsh of him to claim that the textbook was "not correct". This can be seen from the last 
sentence in his answer where he concluded that "Figure 1 is a function. But Figure 2 is not". When I examined these sentences, I found that Teacher X probably meant to state that that Figure 1 was a one-to-one function while Figure 2 was not. Thus, it would have been fair for him to state that the textbook was not entirely correct. It was partly correct (the case of Figure 1) and was partly wrong (the case of Figure 2). He correctly used the horizontal line test to determine that the graph in Figure 2 was not a one-to-one function. However, the most appropriate way could have been first use the vertical line test to establish that the two graphs were graphs of functions. Then employ the horizontal line test to determine which of the two was one-to-one before concluding whether the textbook was correct or not. Thus, stating whether the textbook was correct or not should have logically been the last thing to do. His answer was rated level 0 .

Item 4(b)

Let $h(x)=x^{2}+1$ for $-2 \leq \mathrm{x} \leq 2$ and $f(x)=x^{2}+1$ for $0 \leq \mathrm{x} \leq 2$.

Define an inverse function.

The inverse function is one of the key concepts related to functions. It is actually one of the most examined concepts in the Zambian curriculum. Teacher X's understanding of this concept was assessed by asking him to define the inverse function. Using concepts of domain and range, Teacher $\mathrm{X}$ was expected to state in his definition that if a function $g$ relates members of the domain to corresponding members of the range then the inverse functions would relate members of the range to their corresponding members the domain.

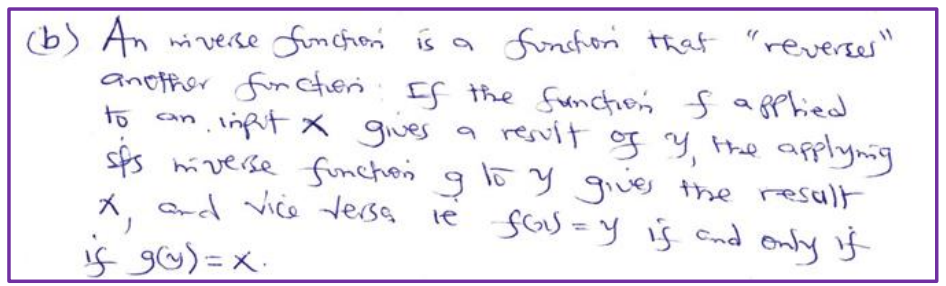

Figure 28. Excerpt of Teacher X's answer to item 4(a)

Analyzing the answer given by Teacher X (Figure 28), it can be seen that his definition seems to imply the inverse of a function though clarity was needed. For example Teacher $\mathrm{X}$ states that the inverse reverses another function. This is not very clear. The definition becomes clearer when he exemplifies it using $\mathrm{x}$ as the input and $\mathrm{y}$ as the output with $\mathrm{g}$ being the function that maps $\mathrm{y}$ back to $\mathrm{x}$. teacher $\mathrm{x}$ could have 
further mentioned that the process of mapping $\mathrm{x}$ onto $\mathrm{y}$ and using $\mathrm{g}$ to map $\mathrm{y}$ back to $\mathrm{x}$ requires that the function be a one-to-one function. Thus, the univalence of a function must be applicable. Making reference to the univalence or one-to-one characteristic of a function could have made his case even stronger. However, his answer was to a large extent an illustrative explanation. But because this definition was likely to be used in a secondary school classroom, it was important for teacher X to include every key concept in his definition. Thus, his answer was rated level 1.

\section{Item 4(c)}

Let $h(x)=x^{2}+1$ for $-2 \leq \mathrm{x} \leq 2$ and $f(x)=x^{2}+1$ for $0 \leq \mathrm{x} \leq 2$. Find an expression for $f^{-1}(\mathrm{x})$ and specify the domain of $f^{-1}$.

This item was assessing Teacher X's knowledge of the step-by-step procedure of finding an expression of the inverse of a given function. Secondly, his ability to state the domain from the derived expression for the inverse was also tested.

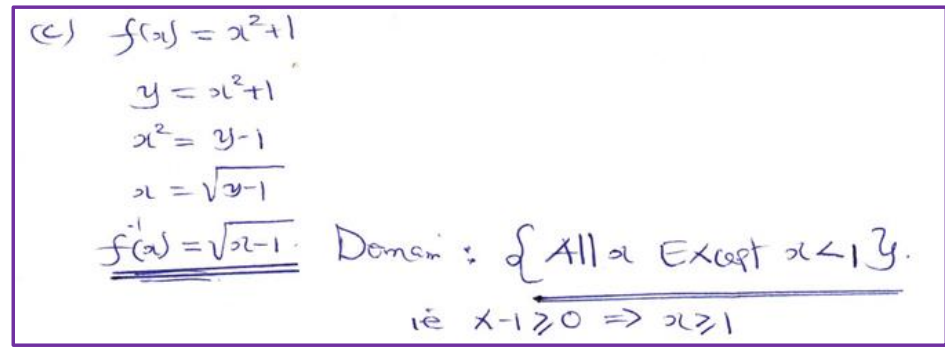

Figure 29. Excerpt of Teacher X's answer to item 4(b)

Strictly analyzing the answers provided for this question (Figure 29), it can be seen that Teacher $\mathrm{X}$ correctly found the expression for the inverse of the function $f(\mathrm{x})$. However, before introducing the variable $\mathrm{y}$ he was supposed to say "let $\mathrm{f}(\mathrm{x})=\mathrm{y}$ then $y=x^{2}+1$ ". Such a step in the calculation would not leave a secondary school student wondering how $\mathrm{f}(\mathrm{x})$ suddenly changes to $\mathrm{y}$.

As for the domain of $f^{1}(\mathrm{x})$ Teacher $\mathrm{X}$ was supposed to pay attention to two important things. Firstly, he was supposed to realize that since the domain of $f(x)$ was restricted its range was also restricted. Secondly, by relying on the definition of the inverse of a function asked earlier he was supposed to be alert to the relationship between the range of the function $\mathrm{f}(\mathrm{x})$ and the domain of its inverse.. This, however, was not the case with Teacher $\mathrm{X}$. By stating that the domain of $f^{1}$ was "all $\mathrm{x}$ except $\mathrm{x}$ $<1$ " or indeed " $x-1 \geq 0$ implying that $x \geq 1$ " he did not employ the definition of 
the inverse function. He also did not make use of the fact that the range of the given function was in fact the domain of its inverse. Thus, in wring the domain of $f^{1}$ Teacher $\mathrm{X}$ disregarded the restriction in the domain of $\mathrm{f}(\mathrm{x})$. his answer to this item was rated level 1.

Item $4(\mathrm{~d})$

Let $h(x)=x^{2}+1$ for $-2 \leq \mathrm{x} \leq 2$ and $f(x)=x^{2}+1$ for $0 \leq \mathrm{x} \leq 2$. Determine the range of $h$.

Figure 30 shows the answer to part (d) of question 4. Analyzing the answer Teacher $X$ correctly stated that the range of $h(x)$ was equal to the domain of its inverse.

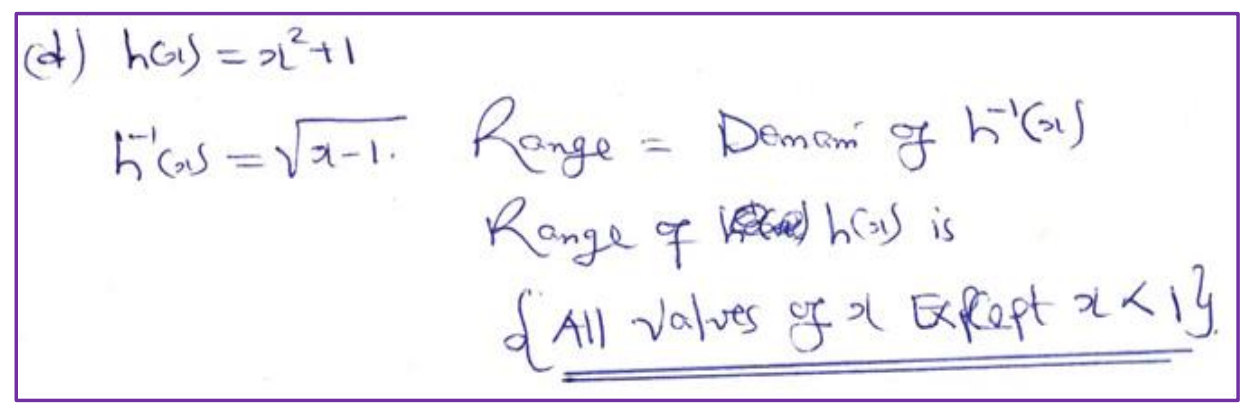

Figure 30. Excerpt of Teacher X's answer to item 4(c)

He approached the question by first finding the inverse of $h(x)$ and used it to determine its domain. This approach was good. Teacher $\mathrm{X}$ would also have found the domain of the inverse of $h(x)$ graphically. Actually, a graphical approach could have better demonstrated his ability to work with different representations of functions in coming up with the answer. Otherwise, the approach used to answer the question was a valid one. Thus, his answer was rated level 1.

Item 5(a)

Given that $g(\mathrm{x})=\frac{3}{2 \mathrm{x}+1}$ and $z: \mathrm{x} \rightarrow \mathrm{x}^{2}-2 \mathrm{x}$, find the value of $g^{-1}(-5)$

This item was aimed at assessing the pre-service teacher's combined knowledge of finding the expression for the inverse of a function and evaluating the inverse when given the input. This combined skill would demonstrate thorough understanding of the inverse function concept. 
Analyzing Teacher X's answer (Figure 31), it can be seen that he demonstrated very good knowledge of the combined skills required to work out this problem. As expected, Teacher $\mathrm{X}$ initially found the expression for the inverse of function $g(\mathrm{x})$ probably because he knew that it was impossible to evaluate the inverse function in the absence of the expression in which $(-5)$ would be substituted. In finding the numerical value of the function $g^{-1}(\mathrm{x})$, Teacher $\mathrm{X}$ performed a correct substitution and a correct calculation. Thus, Teacher $\mathrm{X}$ demonstrated strong knowledge of the inverse function. The combined knowledge is also essential when teaching functions in secondary school because it is always examined in national examinations in Zambia. Thus, it was important to assess it. His response was rated level 1.

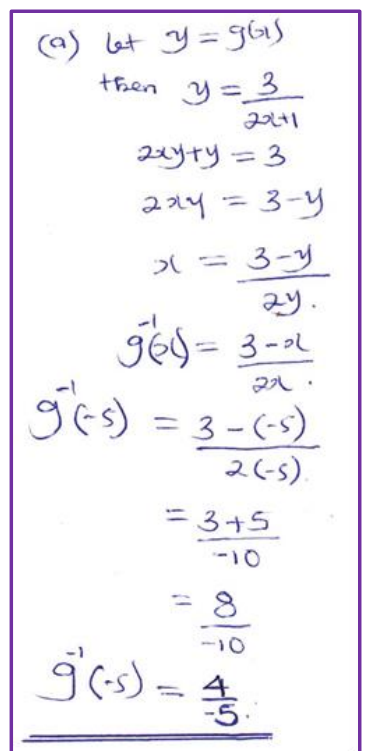

Item 5(c)

Figure 31. Excerpt of Teacher X's answer to item 5(a)

Given that $g(\mathrm{x})=\frac{3}{2 \mathrm{x}+1}$ and $z: \mathrm{x} \rightarrow \mathrm{x}^{2}-2 \mathrm{x}$, an expression for $(z \circ g)(\mathrm{x})$ where $z o$ $g$ denotes the composite function of $z$ and $g$.

This item was assessing one of the key aspects of the concept of a function. Composition of functions is a key concept bot at secondary school and tertiary school levels of education in Zambia. This item was also aimed at appreciating how the preservice teacher understood notation used for the composition of functions in view of process-conception, $z(g(x))$, of a function and the object-conception, $z o g$, of a function (Watson and Harel, 2013, p. 157). This item required the object-conception in which the function $g(\mathrm{x})$ was acting as the object of the function $z(\mathrm{x})$. Analyzing Teacher X's answer (Figure 32) to this question gave a clear indication that he 
understood notation for composite function, in particular, the object conception of the composite function.

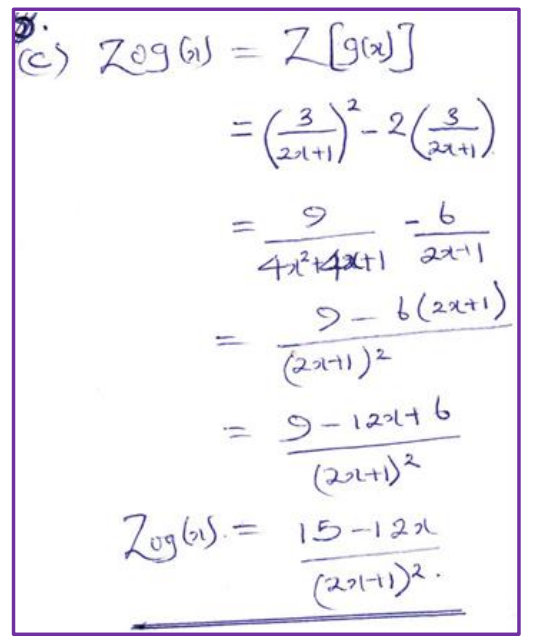

Figure 32. Excerpt of Teacher X's answer to item 5(c)

However, he exhibited some unnecessary simplifications and careless errors the process of finding the expression for the composition of $z$ and $g$. in the third step of his work it was unnecessary to simplify $(2 x+1)^{2}$ to obtain $4 x^{2}+4 x+1$ because he didn't need this expression anyway. Such unnecessary simplifications can cause confusion in a classroom situation as the teacher would be forced to factorize the expression to get back to the initial expression $(2 x+1)^{2}$. Secondly, the simplification of the expression $9-6(2 x+1)$ to obtain $9-12 x+6$ exhibited a careless error. The error affected the final expression for the composite function. Thus, it can be concluded that Teacher $\mathrm{X}$ understood the notation and procedure for finding the composition of two function but carelessness errors and unnecessary simplifications affected his proficiency in getting to the correct answer. His answer was rated level 2.

Item 5(c)

Given that $g(\mathrm{x})=\frac{3}{2 \mathrm{x}+1}$ and $z: \quad \mathrm{x} \rightarrow \mathrm{x}^{2}-2 \mathrm{x}$, evaluate $\left(g \circ g^{-1}\right)(-5)$ where -5 belongs to the domain of $g^{-1}$.

This item required the pre-service teacher to first find the composition of the function $g(x)$ and its inverse $g^{-1}(x)$ and then evaluate the composite resultant composite function. 


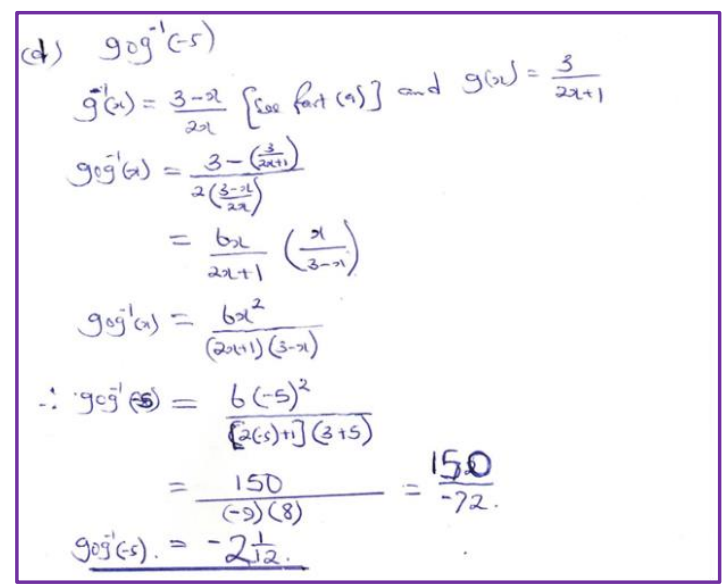

Figure 33. Excerpt of Teacher X's answer to item 5(d)

Analyzing Teacher X's answer (Figure 33), it can be seen that he had no knowledge of the rule of thumb that governs the composition of a function and its inverse. It is a general rule that if the function $g(\mathrm{x})$ and its inverse $g^{-1}(\mathrm{x})$ have their domains and ranges on the set of real numbers, then $g \circ g^{-1}=\mathrm{x}$ and $g^{-1} \circ g=\mathrm{x}$. with this in mind Teacher $\mathrm{X}$ could easily have stated the $g \circ g^{-1}(-5)$ without attempting to perform any calculations. However, in his work Teacher X recalled that he already found the expression for the inverse of the function $g(\mathrm{x})$. But his work on finding the expression for $g \circ g^{-1}$ was characterized by conceptual errors thereby yielding an incorrect expression for $g \circ g^{-1}$. This in turn affected his evaluation of the composite function $g \circ g^{-1}(-5)$. It was clear from the onset in his work on this question that teacher X lacked pre-requisite knowledge about the composition of a function and its inverse. Lack of such basic knowledge would affect his teaching in future. Thus, his answer was rated level 0 .

Interviewer: Is there any other way you could have worked out question 5(d)?

Teacher X: The composition of a function and its inverse....there must be a fundamental result to this [laughs]. So, $g\left[g^{-1}(x)\right]$ should be $x$. so, I don't know why I worked it out that way in the test.

Interviewer: Finally, you talked about vertical and horizontal line tests. Do you think it is important to teach these tests to students?

Teacher X: Usually we rely on definitions and we try to emphasise from that [perspective], and we think learners will determine functions from definitions. When we include these tests it will become clearer on how to check the graphs. It becomes easier to learners to use.

\section{The case of Teacher $Y$}

Item 1(a)(i)

Define a relation 
This item was assessing Teacher Y's ability to provide a meaningful and valid definition of a relation as it relates to the concept of a function. The teacher was supposed to establish two important things in his definition; (i) that a relation is a rule and (ii) that it links or associates or connects elements/members of two sets.

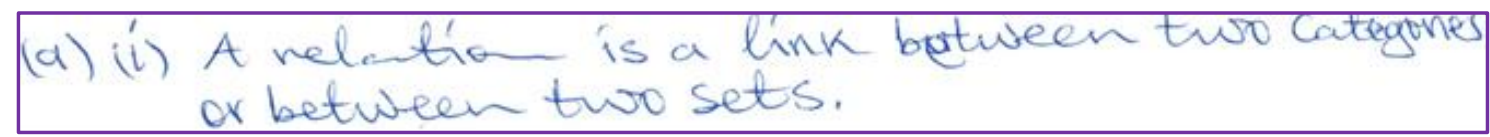

Figure 34. Excerpt of Teacher Y's answer to item 1(a)(i)

Teacher Y's definition (Figure 34) satisfies the second requirement but fall short of the first. This is because a relation is not in itself a link as purported by Teacher $Y$. it is a rule that links members of two sets. The answer provided by Teacher Y shows gaps in his conception of what a relation is. If taught this way in secondary school it has the potential to create misconceptions among secondary school students. During the interview he was asked for the same definition. His answer was still inadequate.

Interviewer: In the test on functions you defined a relation as a link between two sets. In justifying your answer, would you please define a relation as you can teach it to your students?

Teacher Y: Ok. My simple understanding of a relation is a connection between things or objects and those things could be living or non-living, but there is a connection. For example, you can have a group of teachers being related to their schools and many other things. In short, I can say that a relation is simply a statement that connects things.

His response during the interview still revealed some gaps in his knowledge of definitions. By stating that a relation was simply a statement was ambiguous and too general. Similarly, to define it as merely being a connection was incomplete. Teacher $\mathrm{Y}$ does not seem to realize that in a statement that defines a relation there is a rule. It is that rule that is actually a relation. The example he gave during the interview was also short of meaning. He stated that teachers would be related to their schools but how the said relationship would be defined was missing in his example. His combined answer from the test and interview was rated level 1.

Ítem 1(a)(ii)

Give one example of a relation 
The aim of this item was to assess Teacher Y's knowledge of examples and non-examples of relations. Ability to exemplify definitions plays a key role in the teaching of mathematics. Analyzing Teacher Y's answer (Figure 35) shows that though his definition was incomplete or vague, he had good knowledge of examples of relations. The phrase "is a father of" is a rule that probably associates a set of fathers with a set of children. Thus, the example was considered to be appropriate.

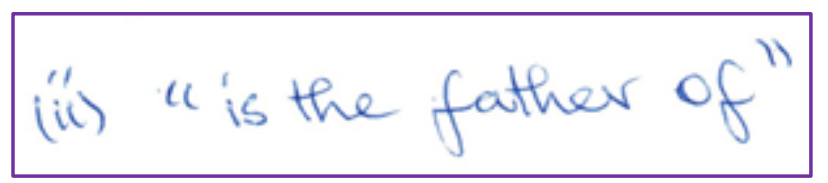

Figure 35. Excerpt of Teacher Y's answer to item 1(a)(ii)

Item 1(b)(i)

Define a function

This item was designed to assess the Teacher Y's knowledge of the features or characteristics of a function that give it a complete and valid definition. It required the teacher to demonstrate the arbitrary and univalence characteristic of a function.

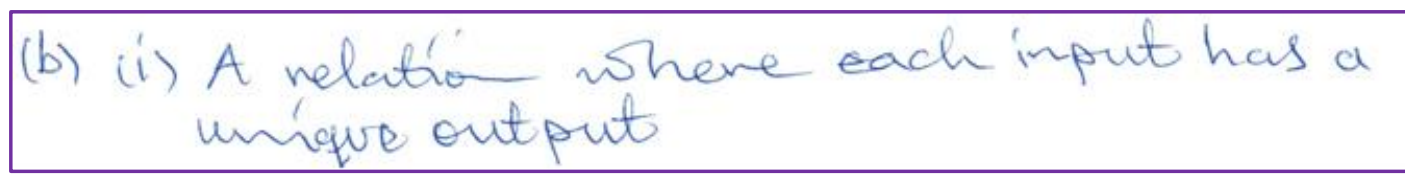

Figure 36. Excerpt of Teacher Y's answer to item 1(b)(i)

The definition presented by Teacher Y (Figure 36) correctly conceptualized a function as a relation where each input produced a unique output. This definition emphasized the univalence of a function with an object-conception perception more than it addressed the arbitrary nature of a function. According to Even (1990, p. 528), the arbitrariness of a function denoted "the relationship between the two sets on which the function was defined and the sets themselves ... which means that the two sets do not need to be defined on specific sets of objects, in particular, the sets do not need to be sets of numbers". The univalence of a function states that "for each element in the domain there be only one element (image) in the range" (Even, 1990,p. 530). During the interview Teacher Y repeated that in a function every input has a unique output. 


\section{Interviewer: Define a function}

Teacher Y: My understanding of a function is more of ... [stammers] ... what can I say ... [pauses] ... it comes from a relation except it has certain properties which not every relation may possess. So we are saying that a function is a in which inputs have unique outputs. So I see a relation as being a sub set of a function. We can say that not every relation is a function but evey function is a relation.

Thus, the combined answer from the test and interview was rated level 1.

Item 1(b)(ii)

Give one example of a function

This item was aimed at assessing Teacher Y's knowledge of examples of functions. Particularly it was asking teacher $\mathrm{Y}$ to exemplify the definition he gave in part (i). Teacher $\mathrm{Y}$ was not restricted as to the form of the example to give (see Figure 37). The example could have been graphical or algebraic or even both as a matter of emphasis. He chose the function $f: x \rightarrow x^{2}$ which represents a quadratic function. It would have been more insightful for the teacher to include a sketch of a quadratic function. Otherwise, his choice of an example was appropriate to address the question. It was rated level 1.

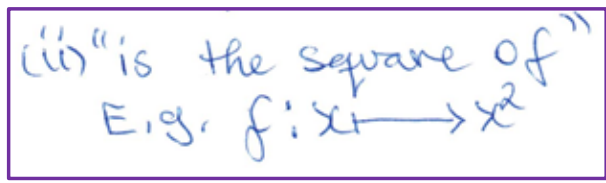

Figure 37. Excerpt of Teacher Y's answer to item 1(b)(ii)

Item 1(e)

In each of the cases below (Figure 38), state whether the figure represents a function or not. Justify your answers.

This question intended to assess pre-service teachers' application of their understanding of the definition of a function. Key to answering this question was the teachers' application of the arbitrary and univalence characteristics of a function. Further the application of the "vertical line test" to ascertain whether the given figure was a graph of a function or not. Also by being able to determine which of the figures contained functions the teacher would be in a strong position to easily give his secondary school students examples and non-examples of functions. 


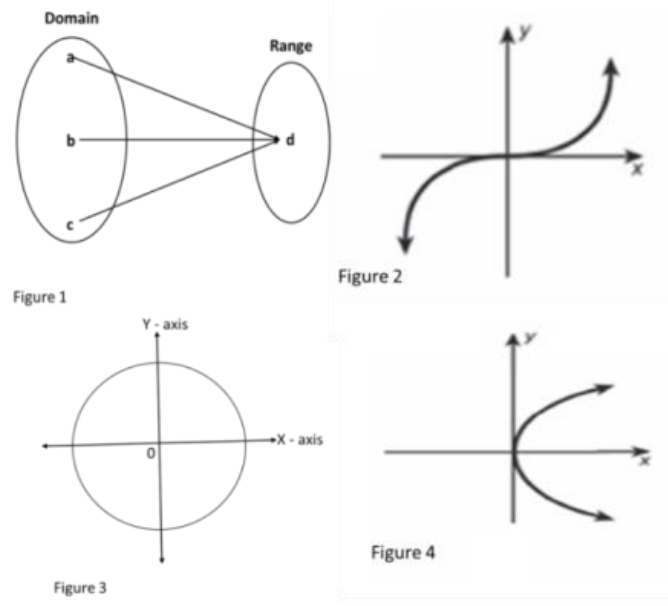

Figure 38. Examples of graphs of functions and non-functions

Analyzing Teacher Y's answers (Figure 39), it can be seen that he relied on the univalence of a function in determining which of the four figures contained a function. He did not in any of the cases use the vertical line test which I think is one of the most common approaches whenever a graph of a function is used. Figure 1 contained an arrow diagram which was showing a association of the members of the domain to those of the range. In this case it was not sensible to use the vertical line test. Rather the univalence characteristic was best suited for this situation and Teacher $\mathrm{Y}$ correctly observed that each member of the domain had a unique corresponding member of the range.

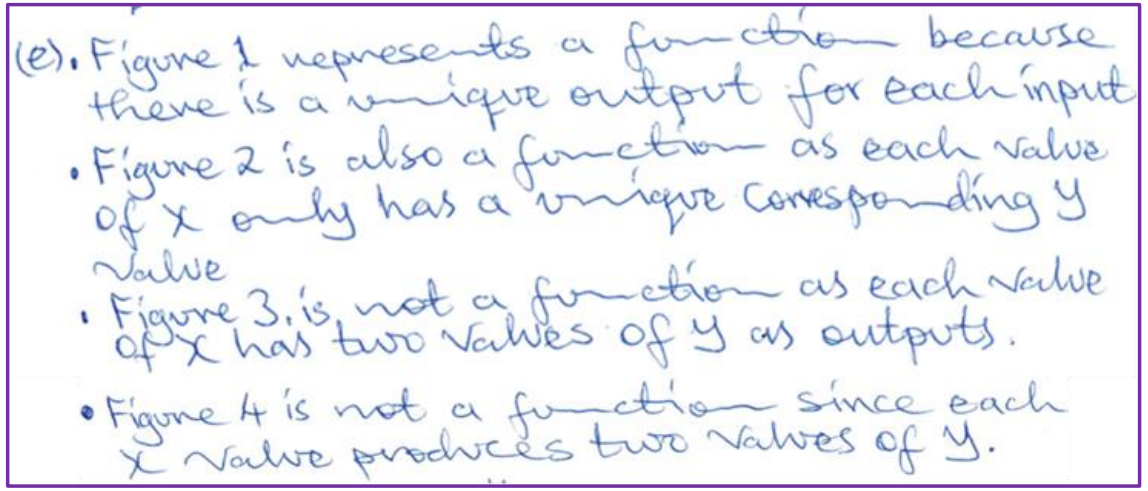

Figure 39. Excerpt of Teacher Y's answer to item 1(e)

For Figure 2, Teacher Y correctly deemed the graph a function claiming that "each value of $\mathrm{x}$ only has a unique corresponding y value". However, since there were no values of $\mathrm{x}$ and $\mathrm{y}$ indicated on the coordinate plane on which the graph was drawn it would have been good for Teacher $\mathrm{Y}$ to use the vertical line test. This is because if a teacher starts talking about values of $\mathrm{x}$ and $\mathrm{y}$ on a sketch that does not 
show any values, it would be confusing for secondary school students. For Figures 3 and 4, Teacher Y correctly claimed that they were not function because each value of $\mathrm{x}$ on either graph corresponded to two values of $\mathrm{y}$. as in the case of Figure 2, teacher $\mathrm{Y}$ could have used the vertical line test because no values were indicated on all the graphs.

During the interview he was asked to determine functions from a given number of cards (see Figure 40) in order to justify his reasoning for the answers he gave in this question. He was also asked about the vertical line test and how it would help determine whether a figure was a function or not.

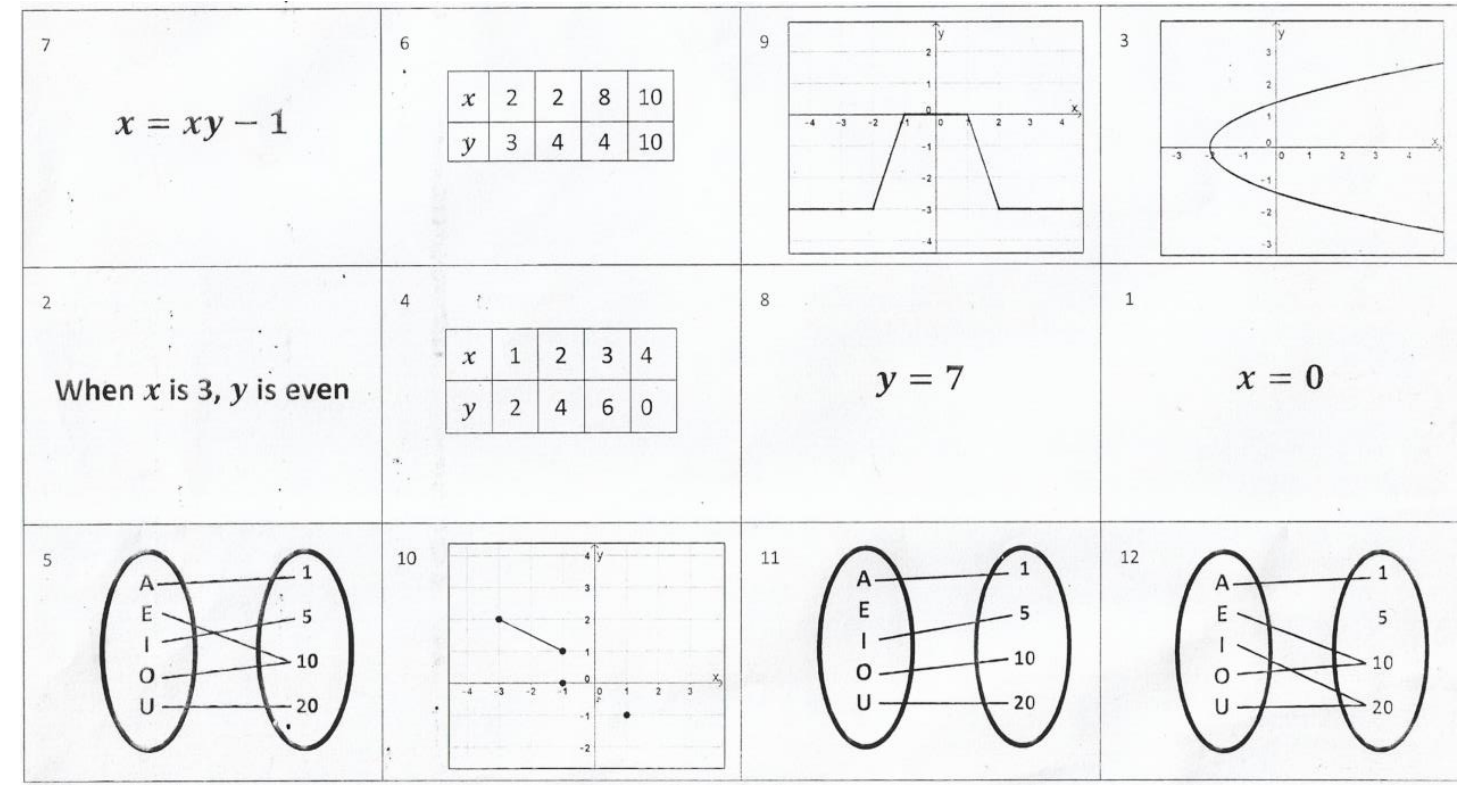

Figure 40. Cards showing examples of functions and non-functions

Interviewer: In the questionnaire that you responded to, question 1(e) asked you to state whether what was in the figure was a function or not. Related to that, there is this worksheet on which you have figures labeled 1 to 12 . Would you determine which of these is a function or not? Explain.

Teacher Y: 1 is a function though its gradient is undefined. So we are going to ... [pauses]... it's the $y$-axis as a matter of fact. It is $x=0$, it is a function.

Interviewer: Ok. What about 2 ?

Teacher Y: 2 is a function and it is of the form $\mathrm{y}=2 \mathrm{x}$ since when $\mathrm{x}$ is $3 \mathrm{y}$ is even. This is the only time we are going to have $\mathrm{y}$ being even when $\mathrm{x}$ is 3 . So we just needed to multiply 3 by 2 .

Interviewer: Ok. What about 3 ?

Teacher $\mathbf{Y}$ : it is a function though not a one-to-one function. It is actually a hyperbolic function in my view. So since it is not a one-to-one function it may not 
actually have an inverse.

Interviewer: what about 4 ?

Teacher Y: 4 is a function though the gradients are differing over certain regions.

When we restrict the domain it comes out clearly as a function.

Interviewer: Ok. What about 5?

Teacher Y: 5 is a function. It is easy for people to easily get confused that it is not a function because of the inputs. Assuming that A, E, I, O, U are inputs, that's the assumption I have made, then it is a function. Because every for input we are getting a unique output.

Interviewer: $\mathrm{Ok}$.

Teacher Y: 6 is maybe a function. I was trying to test this one whether it is really a function by trying to find a gradient and I found that over some certain regions the gradient is different. So am saying that it may be a function. It is possible to have it as a function where we are going to have the gradients different over certain regions. But again may not be a function because what we have here is how the numbers are related and it may not be very consistent considering the way the numbers are coming out

Interviewer: $\mathrm{Ok}$.

Teacher Y: Yes because I tried to test this one by trying to look for the gradient where I found that over certain regions the gradient is different. So it may be a function or it may not be a function.....

Teacher Y: 7 is a function but then it is only going to be defined if from the domain we remove the value of $\mathrm{x}$ because if we have $\mathrm{x}$ there then it is going to make this function to be undefined.

Interviewer: $\mathrm{Ok}$.

Teacher Y: Yes so it comes out when we are trying to make y the subject of the formula then we are going to have $\mathrm{y}$ equals $\mathrm{x}$ plus 1 , everything over $\mathrm{x}\left(y=\frac{x+1}{x}\right)$. And there we are going to exclude the values of $\mathrm{x}$ being zero. So we say that $\mathrm{x}$ should not be equal to zero.

Interviewer: What about 8 ?

Teacher Y: 8 is a function with gradient equal to zero.

Interviewer: Ok.

Teacher Y: Yes. So, this one is a straight line parallel to the $\mathrm{X}$-axis. So, it is a function......

Teacher Y: 9 is a function and as a matter of fact it is a one-to-one function because whenever we draw our vertical lines there we know that it will not cut the point at only one point.

Interviewer: what about 10?

Teacher Y: 10 becomes a function [pause] it is a function although over certain regions it is a discrete part but it is still a function, Yes that is in my view. It is a 
function.

Interviewer: what about 11 ?

Teacher Y: 11 is a function just like 5 and this one is a one-to-one function.

Interviewer: Ok.

Teacher Y: Yes. 12 is also a function. The reasoning would be the same as that in 5 .

Interviewer: Let me take you back to 11 .

Teacher Y: Ok.

Interviewer: assuming that $\mathrm{A}, \mathrm{E}, \mathrm{O}, \mathrm{I}, \mathrm{O}$ are the domain like you suggested, E seems not to have an output in the range. How do you explain this?

Teacher Y: Ooh ok [laughs]. Ok I think it doesn't have a unique output so we disqualify it. I did not notice this particular one.

Interviewer: then for 12 , the output 5 is not linked to any input. How do you explain this one as well?

Teacher Y: [Long pause]...this was also an oversight. In 11 we can just restrict the inputs. We remove $\mathrm{E}$. if we remove $\mathrm{E}$ it qualifies to be a function. But if we keep $\mathrm{E}$ it will not qualify to be a function.

Interviewer: what about 12 ? How do we deal with the 5?

Teacher Y: it not a function.

Interviewer: but looking at the definition you gave me earlier on, you said that for a function each input has a unique output.

Teacher Y: Laughs......ok. All the inputs have outputs

Interviewer: Do they fit your definition?

Teacher Y: Yes they do though the 5 is confusing me. But I think since mathematics is about definitions, going by the definition this one will qualify to be a function..

His combined response from the test and the interview was rated level 1.

Item 2(c)

Use the graph of $f(x)=-2 x^{2}-x+8$ to solve $f(x)=2$

This item required the pre-service teacher to graphically solve for $x$. Recognizing that this problem could be solved algebraically; the question was instructive about a particular method. Upon inspecting the graph it was observed that Teacher $Y$ found that when $f(x)=2, x=1.55$. During the interview he was asked to justify his answer; considering the answer in the test and his views during the interview, his responses were rated level 1.

Interviewer: when you used the graph of $f(x)=-2 x^{2}-x+8$ to solve $f(x)=2$ you found the value of $x$ to be 2 . Could you please explain how you arrived at this answer?

Teacher Y: prior to part (c) we already sketched the graph of the function $f(x)=$ $2 x^{2}-x+8$. So here we have technically been asked to find the solution of two 
graphs. This is actually their point of intersection. So, this one means that we need to come up with the graphs of $f(x)=2$ and $f(x)=-2 x^{2}-x+8$ and where they intersect, then those values of $\mathrm{x}$ become our solution set.

Item 2(d)

Complete the square for $f(x)=-2 x^{2}-x+8$ and hence determine the turning point of $f$.

This item was aimed at assessing two skills, the first was Teacher Y's knowledge of solving a quadratic equation by completing the square method. By this, Teacher Y's ability to follow all the steps involved in completing the square of a quadratic function were tested. Secondly, Teacher Y's knowledge of the stationary points of the graph of a quadratic function using completing the square method were tested. In this case, if the quadratic equation $a x^{2}+b x+c=0$ is written in the form $\mathrm{a}\left[\left(\mathrm{x}+\frac{\mathrm{b}}{2 \mathrm{a}}\right)^{2}-\frac{\mathrm{b}^{2}}{4 \mathrm{a}^{2}}+\frac{\mathrm{c}}{\mathrm{a}}\right]$, the stationary point (maximum or minimum) occurs at the point where $\left(x+\frac{b}{2 a}\right)^{2}=0$ or $x=-\frac{b}{2 a}$.

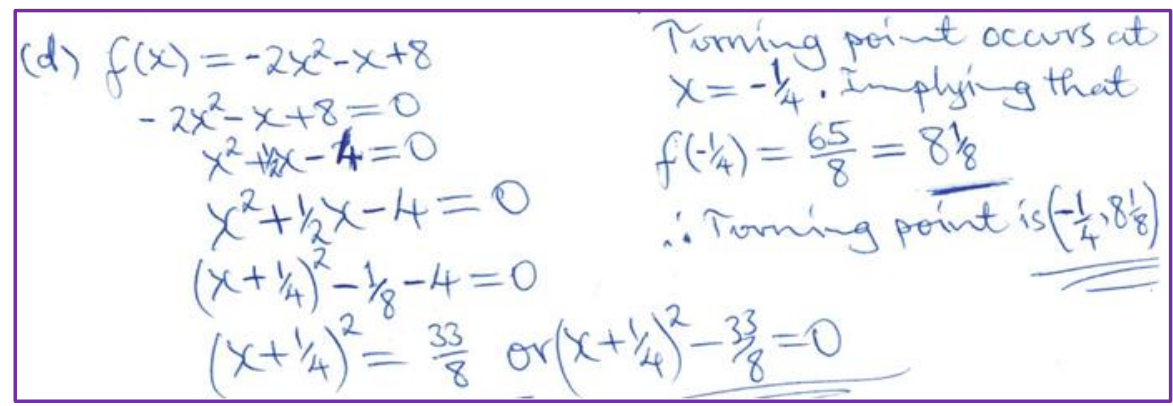

Figure 41. Excerpt of Teacher Y's answer to item 2(d)

Analyzing Teacher Y's work (Figure 41), it can be seen that he had ideas about completing the square but some assumptions he considered misguided his work. By substituting 0 for $\mathrm{f}(\mathrm{x})$ in the original function he confused a quadratic function for a quadratic equation (step 2). By maintaining the zero in subsequent steps of his work implied that Teacher $Y$ was not completing the square of the quadratic function $f(x)=$ $-2 x^{2}-x+8$, but rather he was solving the quadratic equation $-2 x^{2}-x+8=0$. Thus, from the onset his work was erroneous. It showed that Teacher Y had no knowledge of the difference between a quadratic function and a quadratic equation. However, he managed to obtain the correct value of $\mathrm{x}$ at the stationary point and used this value to obtain the value of $\mathrm{f}(\mathrm{x})$. from the work presented by Teacher $\mathrm{Y}$ it was clear that there was a mix-up of concepts even though he managed to find the correct coordinates of the turning point. This gap in knowledge could be a source of misconceptions in his 
future classroom. During the interview he was asked about the importance of teaching "completing the square" to Zambian secondary school students.

Interviewer: in your opinion, do you think it is important to teach completing the square?

Teacher Y: it is very important as you can see question (d) does not only end at completing the square but there is a part where we needed to determine the turning point of $f(x)$. by complketing the square you can easily determine the turning point. Secondly, we teach completing the square method as part of the students' preparation for higher education because we expect a good number of them to proceed to tertiary education. If they can't complete the square university mathematics becomes tricky for them.

His combined answers from the interview and the test were rated level 1.

Item 3(a)

Define a one-to-one function in your own words

This item was designed to assess Teacher Y's ability of defining a one-to-one function. To demonstrate knowledge of this definition the teacher was expected, as a bare minimum, to state that for a one-to-one function each member of the domain has a unique corresponding member of the range. And of course the reverse is also true. To further demonstrate full knowledge the teacher was expected to state that for a function to be one-to-one it needed to pass both the vertical line test and the horizontal line test.

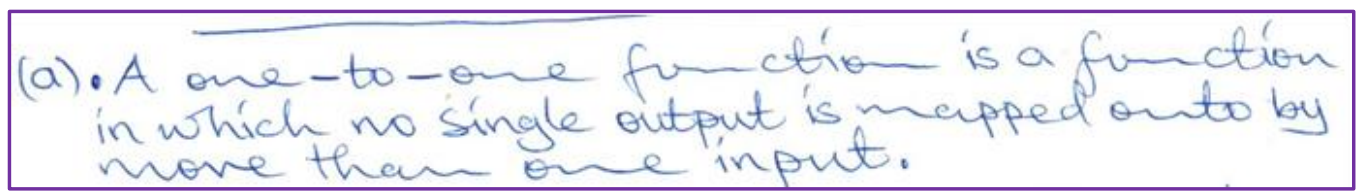

Figure 42. Excerpt of Teacher Y's answer to item 3(a)

Examining Teacher Y's answer (Figure 42), it can be seen he had knowledge of one-to-one functions. His answer implies that a member of one set is mapped onto only one member of the corresponding set. This suggests that he understood a oneto-one function. However, Teacher Y did not make reference to the need for the function to pass both the vertical line test and the horizontal line test. It was going to be very insightful of him to make that reference. During the interview Teacher Y was 
asked about one-to-one functions, vertical and horizontal line tests, and the univalence of a function.

Interviewer: Have you ever heard anything about the univalence of a function?

Teacher Y: Hesitates.....no, not yet. I may not have input on it because I do not have much information

Interviewer: Ok. Then you are in good position to define a one-to-one function.

Teacher Y: Yes. Of course for every input it has only one output and every output is related only to one input and that becomes a one-to-one function.

Interviewer: Do you think it would have been appropriate to teach the vertical and horizontal line tests to secondary school students in Zambia? In answering this question justify your answer.

Teacher Y: It is extremely important because they are very handy ways of determining whether a graph is a one-to-one function and if it actually is a function

The combined responses were rated level 1.

Item 3(b)

A mathematics textbook shows the following graphs as examples of one-to-one functions (Figure 43). Is the textbook correct in this regard? Explain.

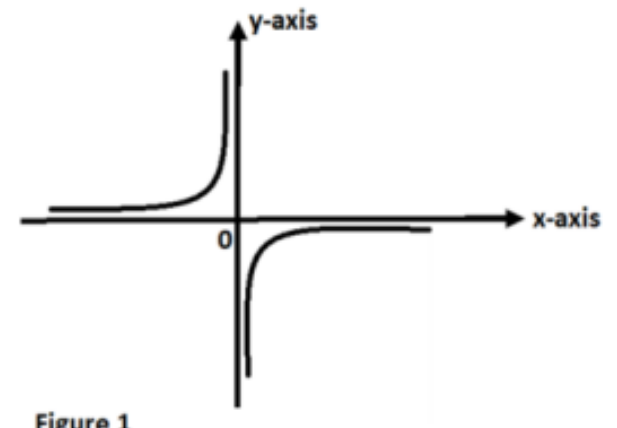

Figure 1

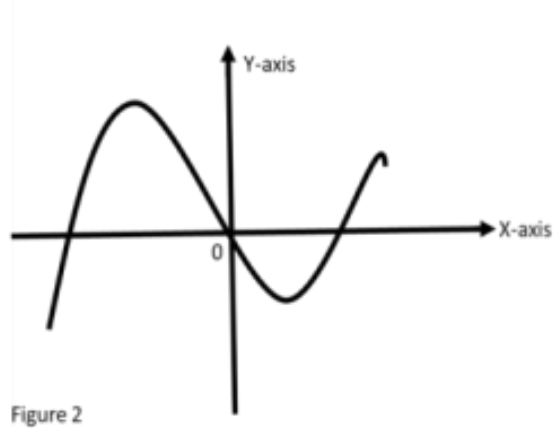

Figure 2

Figure 43. Textbook examples of functions and non-functions

This item was designed to assess Teacher Y's knowledge of using graphs to determine whether or not a given graph was a function. In answering this question it was important for him to refer to the vertical line test and the horizontal line test. The former would help in determining that the given graph was a function while the latter test would help to establish that the function is one-to-one. 


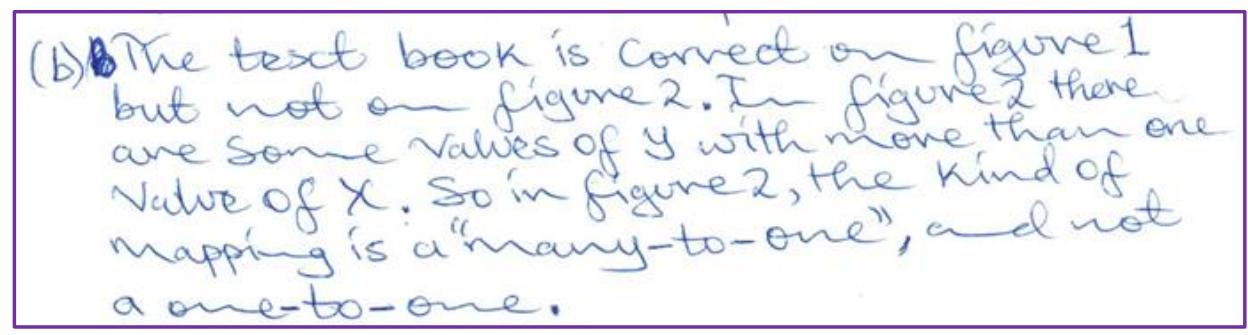

Figure 44. Excerpt of Teacher Y's answer to item 3(b)

Teacher $\mathrm{Y}$ was right to judge the textbook based on individual figures (see Figure 44). By indicating that the book was right regarding Figure 1 and was wrong regarding Figure 2 was a demonstration that one cannot discredit a book based on one mistake. Teacher Y was also notably able to distinguish between a one-to-one function from a many-to-one function. This was one of the key expectations of all the pre-service teachers. Thus, Teacher Y exhibited good knowledge of a one-to-one function. The answer to this item was rated level 1.

Item 4(b)

Let $h(x)=x^{2}+1$ for $-2 \leq \mathrm{x} \leq 2$ and $f(x)=x^{2}+1$ for $0 \leq \mathrm{x} \leq 2$.

Define an inverse function.

The inverse function is one of the key concepts and one of the most examined concepts in the Zambian curriculum. Teacher Y's understanding of this concept was assessed by asking him to define the inverse function. Using concepts of domain and range, Teacher $\mathrm{Y}$ was expected to state in his definition that if a function $\mathrm{g}$ relates members of the domain to corresponding members of the range then the inverse functions would relate members of the range to their corresponding members the domain.

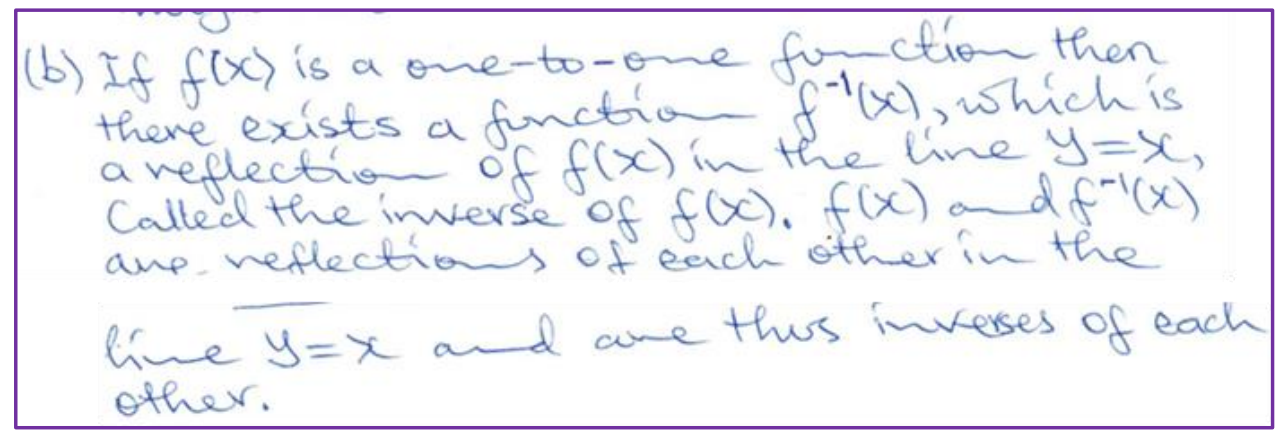

Figure 45. Excerpt of Teacher Y's answer to item 4(b) 
Teacher Y used ideas of geometry to define the inverse function (see Figure 45). By defining it this way probably he had the graphical representation of a function in mind. However, he could still have explicitly stated that if a function $f(x)$ and its inverse $f^{1}(\mathrm{x})$ were reflections of each other in the line $\mathrm{x}=\mathrm{y}$ the relation is that $f^{1}(\mathrm{x})$ can be mapped back onto $f(\mathrm{x})$. Interestingly Teacher $\mathrm{Y}$ started by noting that the initial function is one-to-one which was key to his definition because for a function to have an inverse it must be a one-t-one function. Although the definition offered cannot easily be grasped by secondary school students it provides a good picture about inverse functions. Using domain and range concept in his definition would preferably have made it clearer. The answer rated level 1.

Item 4(c)

Let $h(x)=x^{2}+1$ for $-2 \leq \mathrm{x} \leq 2$ and $f(x)=x^{2}+1$ for $0 \leq \mathrm{x} \leq 2$. Find an expression for $f^{-1}(\mathrm{x})$ and specify the domain of $f^{-1}$.

This item was assessing Teacher Y's knowledge of the step-by-step procedure of finding an expression of the inverse of a given function. Secondly, his ability to state the domain from the derived expression for the inverse was also tested.

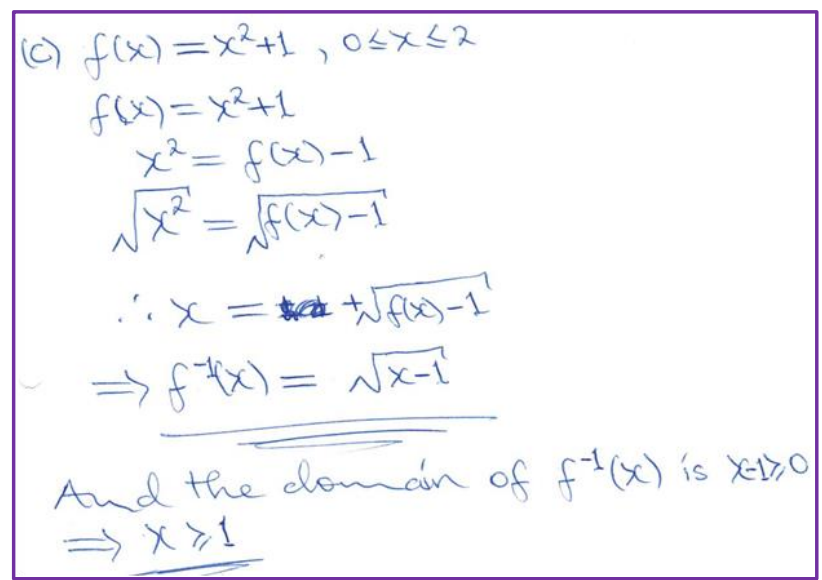

Figure 46. Excerpt of Teacher Y's answer to item 4(c)

Teacher Y seems conversant with the steps involved in finding the expression for the inverse of a function. However, a closer look at his work (Figure 46) revealed that he kept ' $f(\mathrm{x})$ ' throughout his work. It would have been more ideal to let $f(\mathrm{x})=\mathrm{y}$ in the second step and work with the variable y throughout his work. This is because curriculum materials in Zambia always use $\mathrm{x}$ and $\mathrm{y}$ as the working variables because at some stage one is required to swap the two variables as procedure for finding the 
inverse. It was also important for Teacher $\mathrm{Y}$ to realize that the range of $f(\mathrm{x})$ was actually the domain of its inverse. Recalling the definition of the inverse and recognizing the restriction provided in the question would have been very helpful. Otherwise Teacher Y has good knowledge of the procedure for finding the inverse of a function. Thus, his answer was rated level 1 .

Item $4(\mathrm{~d})$

Let $h(x)=\mathrm{x}^{2}+1$ for $-2 \leq \mathrm{x} \leq 2$ and $f(x)=\mathrm{x}^{2}+1$ for $0 \leq \mathrm{x} \leq 2$. Determine the range of $h$.

Figure 47 shows the answer to part (d) of question 4. Analyzing the answer, teacher $\mathrm{Y}$ had it in mind that the range of $\mathrm{h}(\mathrm{x})$ was equal to the domain of its inverse. He approached the question by the range of $\mathrm{h}(\mathrm{x})$ and used it to determine its domain. This he did by creating a table which was a good approach because table are one of the representations of a function. Teacher Y demonstrated his ability to work with different representations of functions in coming up with the answer. Otherwise, the approach used to answer the question was a valid one.

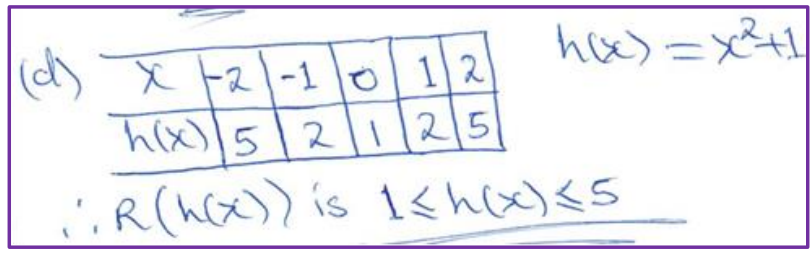

Item 5(a)

Figure 47. Excerpt of Teacher Y's answer to item 4(d)

Given that $g(x)=\frac{3}{2 x+1}$ and $z: x \rightarrow x^{2}-2 x$, find the value of $g^{-1}(-5)$

This item was designed to assess Teacher Y's combined knowledge of finding the expression for the inverse of a function and evaluating the inverse when given an input. This combined skill would demonstrate thorough understanding of the inverse function concept.

Teacher $\mathrm{Y}$ found this question easy (see Figure 48). From the onset he knew that he needed to first find the expression for the inverse of the function $g(\mathrm{x})$ because it was going to be an impossible task to evaluate $g^{-1}(-5)$ without the expression for the inverse. Thus, he correctly found the expression for the inverse and made a correct substitution to find the numerical value of $g^{-1}(-5)$. Thus, teacher $\mathrm{Y}$ 
demonstrated that he had good combined knowledge necessary for evaluating the inverse function. His answer was rated level 1.

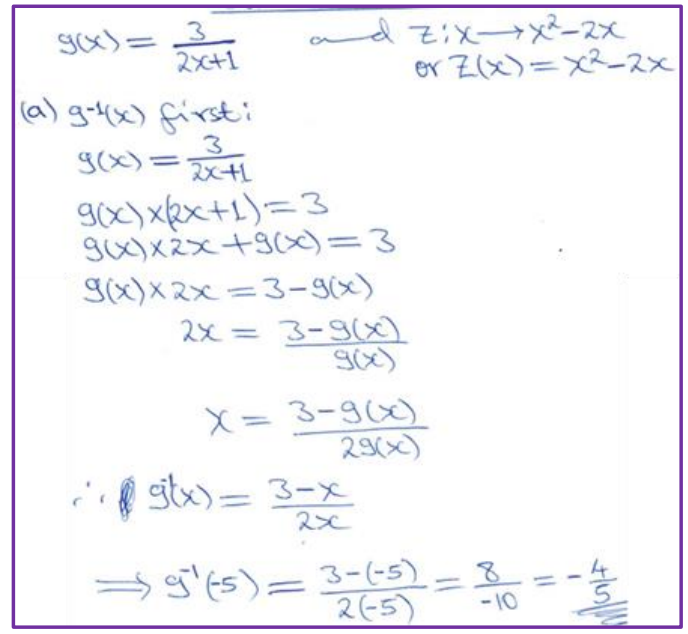

Figure 48. Excerpt of Teacher Y's answer to item 5(a)

Item 5(c)

Given that $g(\mathrm{x})=\frac{3}{2 \mathrm{x}+1}$ and $z: \mathrm{x} \rightarrow \mathrm{x}^{2}-2 \mathrm{x}$, an expression for $(z \circ g)(\mathrm{x})$ where $z o$ $g$ denotes the composite function of $z$ and $g$.

This item was designed to assess Teacher Y's knowledge of finding the composition of two functions. Composition of functions is a key concept both at secondary school and tertiary levels of education in Zambia. This item would also reveal Teacher Y's understanding of notation used for the composition of functions in view of process-conception, $z(g(x))$, of a function and the object-conception, $z \circ g$, of a function (Watson AND Harel, 2013, p. 157). This item required the objectconception in which the function $g(\mathrm{x})$ was acting as the object of the function $z(\mathrm{x})$.

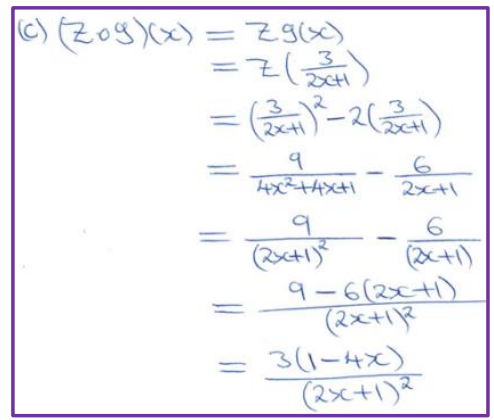

Figure 49. Excerpt of Teacher Y's answer to item 5(c) 
Examining Teacher Y's answer (Figure 49), it is clear that he was using the object conception of a function when working out this problem. Teacher $\mathrm{Y}$ also demonstrated that he had good knowledge of finding the composition of two function as evidenced by the flow of the work presented in Figure....... However, he included a very unnecessary expansion of $(2 x+1)^{2}$ which gave $4 x^{2}+4 x+1$. He did not need this it would complicate his work when looking for the lowest common multiple of $(2 x+1)^{2}$ and $(2 x+1)$. This can be seen in step 5 where he reverted back to $(2 x+1)^{2}$. Unnecessary expansions like this can be a source of misconceptions and confusion in a classroom situation. Thus, they should be avoided as much as possible. Thus, his answer to this item was rated level 0 .

Item $5(\mathrm{~d})$

Given that $g(x)=\frac{3}{2 x+1}$ and $z: \quad x \rightarrow x^{2}-2 x$, evaluate $\left(g \circ g^{-1}\right)(-5)$ where -5 belongs to the domain of $g^{-1}$.

This item required the pre-service teacher to first find the composition of the function $g(\mathrm{x})$ and its inverse $g^{-1}(\mathrm{x})$ and then evaluate the composite resultant composite function.

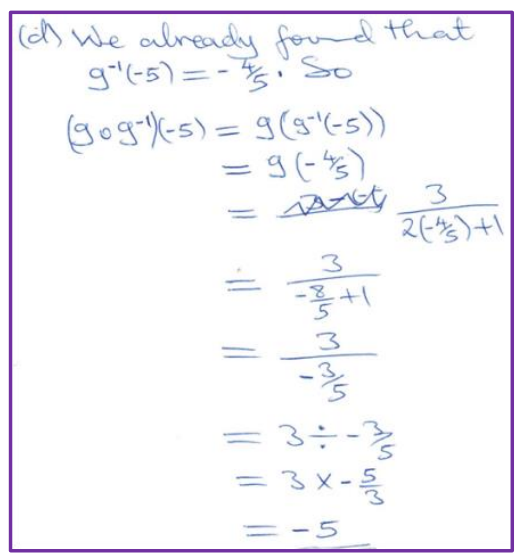

Figure 50. Excerpt of Teacher Y's answer to item 5(d)

Analyzing Teacher Y's answer (Figure 50), it can be seen that he did not demonstrate knowledge of the rule of thumb that governs the composition of a function and its inverse. It is a general rule that if the function $g(\mathrm{x})$ and its inverse $g^{-}$ ${ }^{1}(\mathrm{x})$ have their domains and ranges on the set of real numbers, then $g \circ g^{-1}=\mathrm{x}$ and $g^{-1}$ 
$o g=\mathrm{x}$. with this in mind Teacher Y could easily have stated the $g \circ g^{-1}(-5)$ without attempting to perform any calculations.

By writing $\left(g \circ g^{-1}\right)(-5)$ Teacher $Y$ implied that he first needed to find an expression for the composition of $g$ and $g^{-1}$ before finding the numerical value of the composite function $g o g^{-1}(-5)$. However, having already found $g^{-1}(-5)$ earlier, Teacher $\mathrm{Y}$ in his presentation decided to workout $g\left[g^{-1}(-5)\right]$. Suggestively, had he stuck with his earlier intention of first finding the expression for the composition of $g$ and $g^{-1}$, Teacher Y could have found that $g \circ g^{-1}=\mathrm{x}$. this then could have easily helped to evaluate the given function. His approach also worked very well to solve the problem and demonstrated his knowledge of evaluating composition of functions. During the interview Teacher $\mathrm{Y}$ was asked if there was an alternative way of working out this question.

Interviewer: Go to your solution to question 5(d). could there have been another way of looking at it?

Teacher Y: Another way could have been where we could have worked out $g\left(g^{-1}\right)$. We find that particular expression. After finding $g\left(\mathrm{~g}^{-1}\right)$ then in that expression we come and put (-5) where there is $\mathrm{x}$ and we are hoping that the answer should come out the same.

Interviewer: Do you know that the composition of a function and its inverse is always $\mathrm{x}$ ?

Teacher Y: It was just a slip. One thing to note here is that in the Zambian syllabus now we have composition of functions which was previously restricted to additional mathematics and it is very important to teach that concept you have brought up. It should be emphasized. Oh yah I now realize.

Considering his answer in the test and his views during the interview, his responses were rated level 1 .

\section{The case of Teacher $Z$}

Item 1(a)(i)

Define a relation

This item was designed to assess Teacher Z's ability to provide a meaningful and valid definition of a relation as it relates to the concept of a function. The teacher was supposed to establish two important things in his definition; (i) that a relation is a rule and (ii) that it links or associates or connects elements/members of two sets. 


\section{(a) (i) A relation is a mathematical stafement that expresses a relationship between two sets.}

Figure 51. Excerpt of Teacher Z's answer to item 1(a)(i)

The answer provided by Teacher Z (Figure 51) was not adequate to carter for a complete and valid definition of a relation. In a mathematical statement there must be a key phrase that will indicate a relationship. Teacher $\mathrm{Z}$ was supposed to explicitly state that a relation is a 'rule' that relates or connects or associates or links two sets. Merely stating that it is a 'mathematical statement' is vague and renders the definition invalid. During the interview Teacher $\mathrm{Z}$ did not state that a relation is a rule. Instead he now stated that is was a link between two variables as opposed to a rule that links two sets.

Interviewer: would you clarify the definition you gave in the test of what a relation really is?

Teacher Z: Umh.... Basically a relation is a link between two variables. For example, I can say that we have variables in one set and variables in the other set. So, you look at the relationship that is there. The link that is linking one variable from the first set to the other set.

Considering Teacher Z's answer in the test and his views during the interview about this definition, his answer has been rated level 0 .

Ítem 1(a)(ii)

Give one example of a relation

This item was designed to assess Teacher Z's ability to exemplify a definition. It was aimed at confirmation whether the teacher actually understood the definition he gave in part (i). The teacher correctly gave the example of a relation (Figure 52) but could have stated that the rule in this case is "is greater than". Usually it is not the entire statement that is a relation. There is always a phrase that acts as a rule.

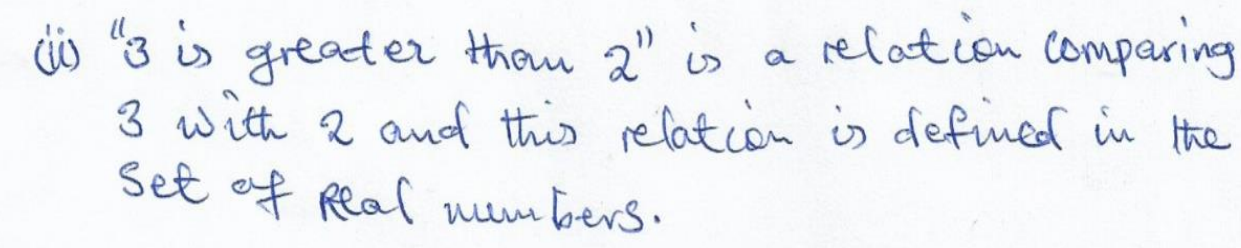

Figure 52. Excerpt of Teacher Z's answer to item 1(a)(ii) 
Item 1(b)(i)

Define a function

This item was designed to assess Teacher Z's knowledge of the features or characteristics of a function that give it a complete and valid definition. It required the teacher to demonstrate the arbitrary and univalence characteristic of a function.

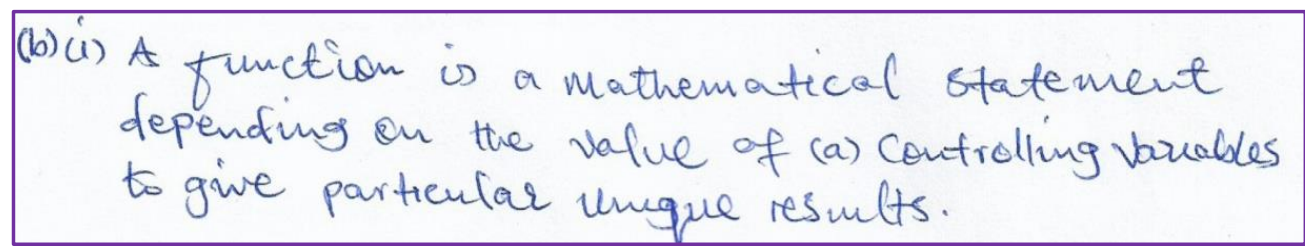

Figure 53. Excerpt of Teacher Z's answer to item 1(b)(i)

The definition provided was vague (see Fifure 53). The phrase 'is a mathematical statement depending on the value of the controlling variable' signified doubt about his statement. Of course there has to be a unique relationship between two sets but the uniqueness is not explained. Teacher $\mathrm{Z}$ was in a way bringing out ideas of univalence of a function but it was unclear whether he actually was talking about univalence. Also by saying 'unique results' it is not clear exactly what he was referring to. Thus, the definition could not be accepted to be valid. During the interview Teacher $\mathrm{Z}$ gave a definition of a function which was not different from the one he gave for a relation. He however gave an example of a function in form of an equation as a function. The definition was unsatisfactory but the example defined a function.

Interviewer: would you clarify the definition you gave in the test of what a function really is?

Teacher $\mathbf{Z}$ : a function is a relationship that is linking the first variables to the other ones. For example, you can have, let's say in the first set, you have values like $\{1,2$, $3\}$, then in the other set you have, let's say $\{2,4,6\}$. So, the function is that there is a relationship that is linking the values from the first set to the other set. Maybe we can have an equation $\mathrm{y}=2 \mathrm{x}$ which becomes a function.

Interviewer: How would you distinguish a relation from a function?

Teacher Z: A function is a relation and a relation cannot be a function

By stating that a relation cannot be a function Teacher $\mathrm{Z}$ was contradicting himself because he already stated that a function is a relation which meant that some relations are actually functions. He seemed not too sure about his understanding of 
definitions of functions and relations and their point of departure. His answer was rated level 0 .

Item 1(b)(ii)

Give one example of a function

The example by Teacher $\mathrm{Z}$ implied a function (see Figure 54). It appears the teacher intended to write it as $f: \mathrm{x} \rightarrow 3 \mathrm{x}-5$. If his intention was to use $f(\mathrm{x})$ in his example he could have written it as $f(\mathrm{x})=3 \mathrm{x}-5$. Inappropriate use of symbols could be as a result of carelessness and can be a serious cause of misconception in a classroom setup. Mathematics is an exact science which demands correct use of symbols and language. If a teacher's use of mathematical language and symbols is sloppy, even the students under the tutelage of such a teacher are likely to exhibit similar gaps in knowledge. The example given here was rated level 1.

$$
\begin{aligned}
& \text { (ii) } f(x) \longrightarrow 3 x-5 \text { where } x \text { is the coutrolling } \\
& \text { variable. }
\end{aligned}
$$

Item $1(\mathrm{e})$

Figure 54. Excerpt of Teacher Z's answer to item 1(b)(ii)

In each of the cases below (Figure 55), state whether the figure represents a function or not. Justify your answers.

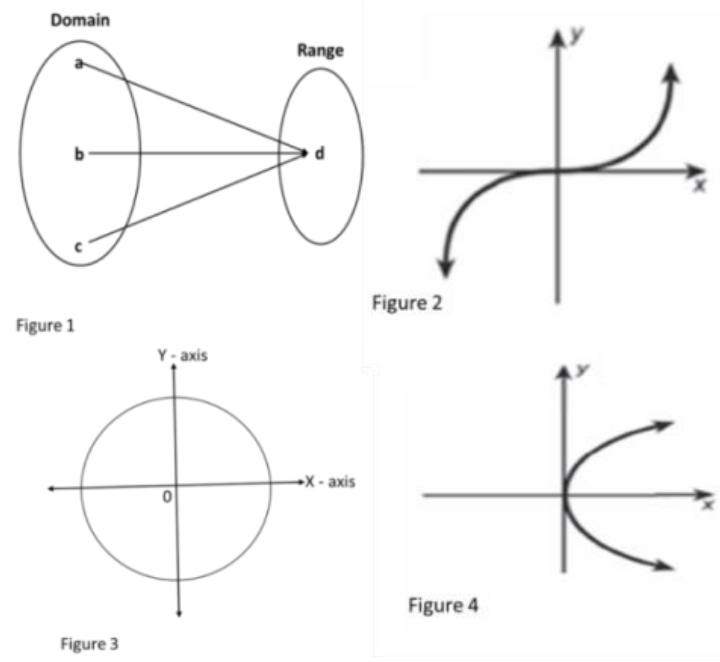

Figure 55. Functions and non-functions

This question designed to assess pre-service teachers' application of their understanding of the definition of a function and his ability to give examples and 
non-examples of functions. Key to answering this question was the teachers' application of the arbitrary and univalence characteristics of a function. Further the application of the "vertical line test" to ascertain whether the given figure was a graph of a function or not. Also by being able to determine which of the figures contained functions the teacher would be in a strong position to easily give his secondary school students examples and non-examples of functions.

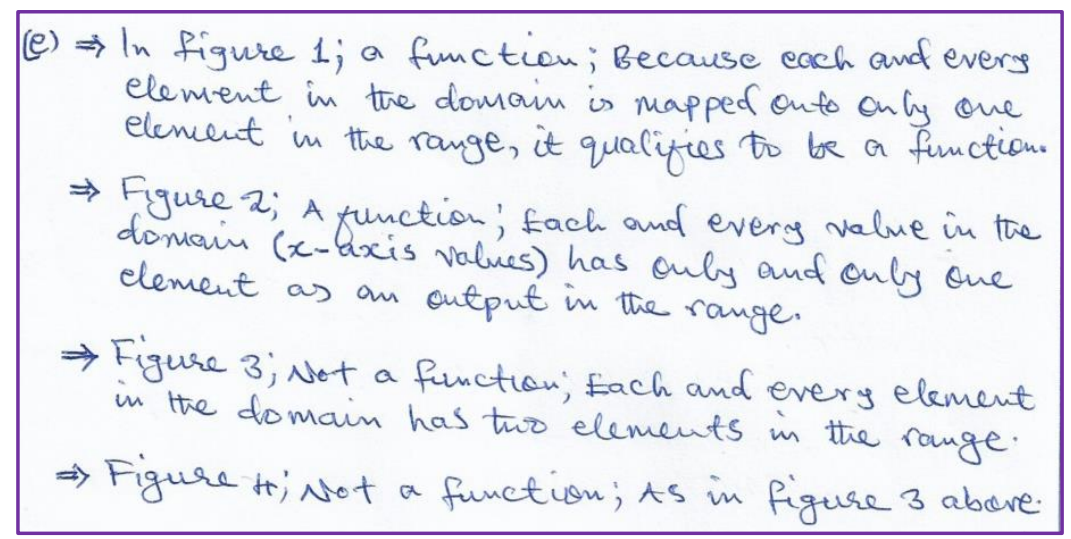

Figure 56. Excerpt of Teacher Z's answer to item 1(e)

Teacher $\mathrm{Z}$ indicated that Figures 1 and 2 were functions because each and every element in the domain was mapped onto one element in the range (see Figure 56). It is clear that he was using the object conception of a function. In Figure 1 it was indicated clearly that there was a domain and range. So it was okay for him to refer to domain and range in his answer. However, the graph in Figure 2 was not showing the domain and range though teacher $\mathrm{Z}$ assumed that the $\mathrm{x}$ and $\mathrm{y}$ axes were the domain and range respectively.

It would have been good for him to use the vertical line test to determine Figure 2. Teacher $\mathrm{Z}$ again used the concept of domain and range to determine that Figures 3 and 4 were not functions. As already stated the vertical line test would have been more appropriate for these situations and could be easy to comprehend by learners. During the interview Teacher Z was presented a worksheet (Figure 57) that contained similar situations as this question. He was asked to determine with a reason which figures were functions and which were not. 


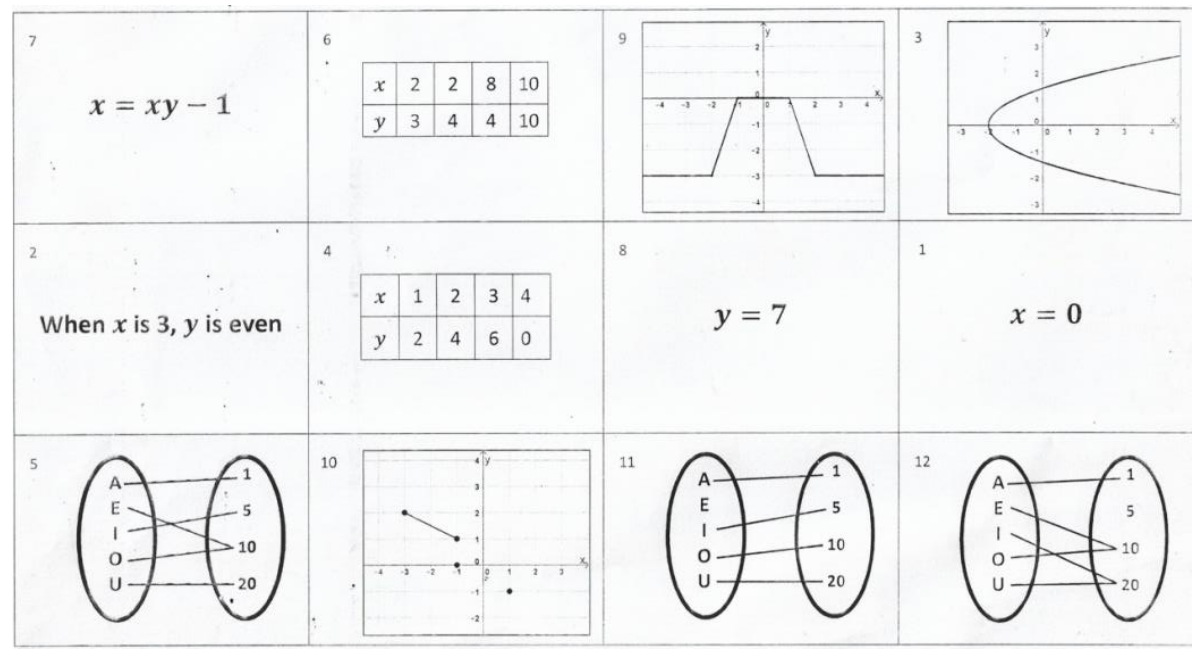

Figure 57. Cards showing graphs of functions

Interviewer: consider the figures on the worksheet you have been given. Determine which of the figures represents a function and explain your reasons.

Teacher Z: I will start with 6.6 is not a function because we have two values of $\mathrm{x}$ having two different values of $y$.

Interviewer: $\mathrm{Ok}$

Teacher $\mathbf{Z}$ : 4 is a function because each value of $\mathrm{x}$ has a unique corresponding value of $y$.

Interviewer: $\mathrm{Ok}$

Teacher $\mathbf{Z}$ : we now go to 11 . It is a function because each letter in the domain has got a unique element in the range.

Interviewer: How do you explain "E”?

Teacher Z: Let's say we have a function $y=\frac{x-2}{x}$, so Zero will not have a corresponding element in the y but these others will have corresponding elements.

Interviewer: $\mathrm{Ok}$

Teacher $\mathbf{Z}$ : Let's go to 5 . It is not a function because we have two letters corresponding to one.

Interviewer: $\mathrm{Ok}$

Teacher Z: In 7 each of $x$ will have one corresponding value of $y$.

Interviewer: so, is it a function or not?

Teacher Z: Yes it is.

Interviewer: $\mathrm{Ok}$

Teacher $\mathbf{Z}$ : Number 3 is a function because each values of $\mathrm{x}$ will have a unique corresponding value of $\mathrm{y}$.

Interviewer: Alright, next?

Teacher Z: We go to number 10. It is not a function because we have (-1) here which can be $(-1,0)$ and also $(-1)$ is giving us a positive 1 . So, you are going to have two values. It is not a function.

Interviewer: $\mathrm{Ok}$

Teacher Z: Number 2 is a function because we are saying that when $\mathrm{x}$ is 3 then $\mathrm{y} y$ is even. Meaning that it will give a unique output.

Interviewer: Suppose you have $(3,6),(3,8),(3,10)$ and so on?

Teacher Z: oh ok, I think in that sense it is doesn't qualify to be a function.

Interviewer: What did you say about number 1 and number 8 ?

Teacher Z: [Long silence] umh these ones I am not sure.

Interviewer: Have you ever heard about the univalence of a function?

Teacher Z: No

Interviewer: Ok. Then we cannot discuss it 
The combined responses to the item in the test and the one during the interview have been rated level 1 .

Item 2(c)

Use the graph of $f(x)=-2 x^{2}-x+8$ to solve $f(x)=2$

This item was designed to assess Teacher Z's knowledge of using graphs to solve quadratic equations. When the graph of $f(\mathrm{x})=-2 \mathrm{x}^{2}-\mathrm{x}+8$ was inspected, it was observed that Teacher $\mathrm{Z}$ drew a horizontal broken line at the point $f(\mathrm{x})=2$, extending it on either side of the point until it intersected the graph of $f(\mathrm{x})=-2 x^{2}-x$ +8 . The broken line intersected the graph at two points. Then he picked the $x$ coordinates of those points of intersection as the solutions of the equation (see Figure 58). It was clear that Teacher $\mathrm{Z}$ had good knowledge of solving quadratic equations using the graphical method. During the interview Teacher $\mathrm{Z}$ was asked to explain how he would teach secondary school students how to solve the equation $f(\mathrm{x})=2$

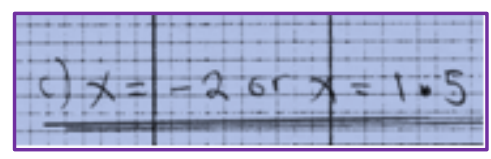

Figure 58. Excerpt of Teacher Z's answer to item 2(c)

Interviewer: You were asked to solve the equation $f(x)=2$. How would you explain this to your [secondary school] students?

Teacher Z: When you look at graphs of polynomials for example, you will be given an equation like the one you have been given $f(x)=-2 x^{2}-x+8$. In this case the value of $\mathrm{y}$ was 2 . So, you look at the point where the graph of $f(\mathrm{x})=-2 x^{2}-x+8$ is going to cut the line $\mathrm{y}=2$. Then you pick the values of $\mathrm{x}$ at that point.

Considering the answer given in the test and the explanation during the interview, this item received a rating of level 1.

Item 2(d)

Complete the square for $f(x)=-2 x^{2}-x+8$ and hence determine the turning point of $f$.

This item was designed to assess two skills, the first was Teacher Z's knowledge of solving a quadratic equation by completing the square method. By this, Teacher Z's ability to follow all the steps involved in completing the square of a quadratic function were examined. Secondly, Teacher Z's knowledge of the stationary points of the graph of a quadratic function using completing the square 
method were examined. In this case, if the quadratic equation $a x^{2}+b x+c=0$ is written in the form $\mathrm{a}\left[\left(\mathrm{x}+\frac{\mathrm{b}}{2 \mathrm{a}}\right)^{2}-\frac{\mathrm{b}^{2}}{4 \mathrm{a}^{2}}+\frac{\mathrm{c}}{\mathrm{a}}\right]$, the stationary point (maximum or minimum) occurs at the point where $\left(x+\frac{b}{2 a}\right)^{2}=0$ or $x=-\frac{b}{2 a}$.

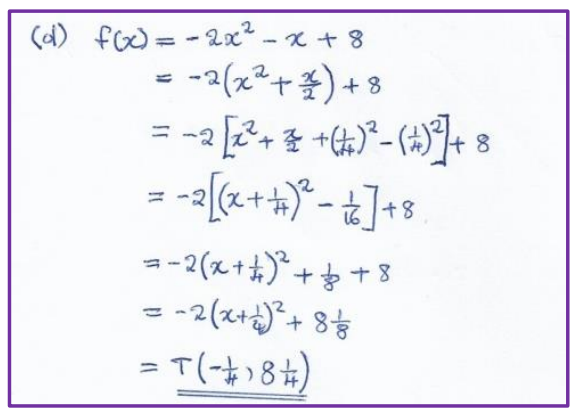

Figure 59. Excerpt of Teacher Z's answer to item 2(d)

Analyzing Figure 59, it is obvious that Teacher $\mathrm{Z}$ exhibited very good knowledge of solving quadratic functions using by completing the square. He followed al the steps involved. However, it could have been better for him to state that the turning point for the function $f(x)=-2 x^{2}-x+8$ occurred at the point $\left(x+\frac{1}{4}\right)^{2}$ $=0$ which simplified to $\mathrm{x}=-\frac{1}{4}$. The turning point $\mathrm{T}\left(-\frac{1}{4}, 8 \frac{1}{4}\right)$ incorrect and teacher $\mathrm{Z}$ was asked during the interview to justify the turning point.

Interviewer: Can you justify the answer you obtained for the turning point of the function $f(x)=-2 x^{2}-x+8$ ?

Teacher $\mathbf{Z}$ : When you look at the turning point you are looking at where the curve is going to turn.

Interviewer: Is it important for someone to know how to complete the square for them to sketch the graph of a function?

Teacher Z: No. it is not that important because you can also use other methods to determine the turning point. This is because we are looking at the best way for pupils to understand how to determine the turning point. I feel that completing the square method is not the simplest way.

The combined responses to this item were rated level 1 .

Item 3(a)

Define a one-to-one function in your own words

This item was designed to assess Teacher Z's ability of defining a one-to-one function. To demonstrate knowledge of this definition the teacher was expected, as a bare minimum, to state that, for a one-to-one function each member of the domain has a unique corresponding member of the range. And of course the reverse is also true. To further demonstrate full knowledge the teacher was expected to state that for 
a function to be one-to-one it needed to pass both the vertical line test and the horizontal line test. The definition in Figure 60 was a valid one. Teacher $\mathrm{Z}$ was expected to also refer to the vertical line test and the horizontal line test. The two test would help in instances where one is given the graph of a parabola which opens to either the left or the right. The vertical line test would help determine such a graph as not being a function and thus there would be no reason to proceed with ascertaining the one-to-one property.

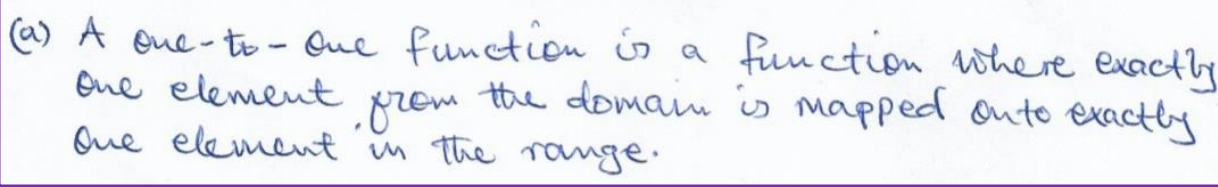

Figure 60. Excerpt of Teacher Z's answer to item 3(a)

During the interview Teacher $\mathrm{Z}$ confirmed his earlier definition given during in the test by emphasizing that one element from one set will correspond to only one element in the other set. His combined response to this item was rated level 1.

Interviewer: Would you define a one-to-one function?

Teacher Z: Umh... a one-to-one function is a function where each value in the first set corresponds to exactly one value in the other set. For example, we can have a list of say $\{a, b, c\}$ and this other side we have three elements, and each element from the first set is uniquely mapped to one element on the other set.

Item 3(b)

A mathematics textbook shows the following graphs as examples of one-to-one functions (Figure 61). Is the textbook correct in this regard? Explain.

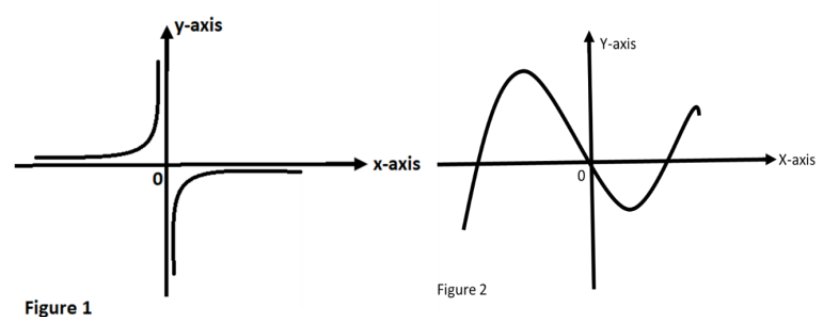

Figure 61. Functions and non-functions

This item (see graph in Figure 61) was designed to assess Teacher Z's knowledge of using graphs to determine whether or not a given graph was a function. In answering this question (Figure 62) it was important for him to refer to the 
horizontal line test as it would help to establish that the function is one-to-one. Teacher $\mathrm{Z}$ used the concept of domain and range when the horizontal line test would have been the most appropriate. Using domain and range Teacher $\mathrm{Z}$ correctly observed that Figure 1 was not a one-to-one function while Figure two was a one-toone function. It was expected of Teacher $\mathrm{Z}$ to mention that one of the Figures contained a many-to-one function. Thus, his answer to this question was rated level 1.

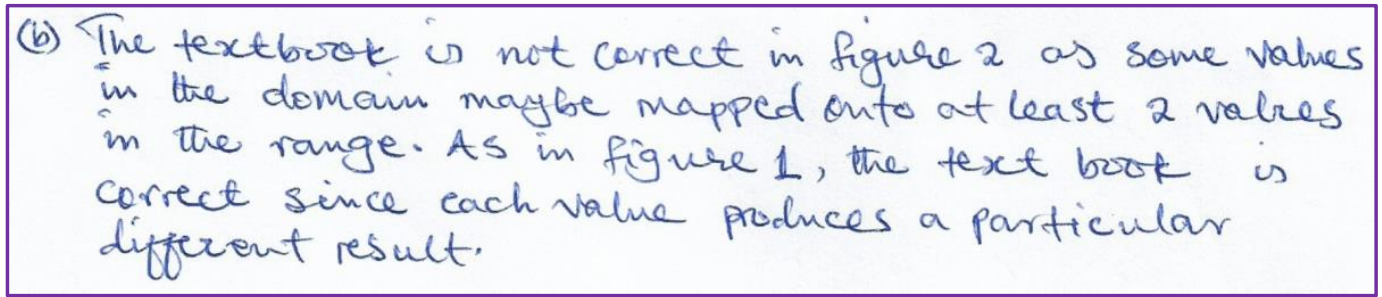

Item 4(b)

Figure 62. Excerpt of Teacher Z's answer to item 3(b)

Let $h(x)=x^{2}+1$ for $-2 \leq \mathrm{x} \leq 2$ and $f(x)=x^{2}+1$ for $0 \leq \mathrm{x} \leq 2$.

Define an inverse function.

This item was designed to assess Teacher Z's understanding of the definition of the inverse concept. Using concepts of domain and range, Teacher $\mathrm{Z}$ was expected to state in his definition that if a function $\mathrm{g}$ relates members of the domain to corresponding members of the range then the inverse functions would relate members of the range to their corresponding members the domain.

(b) An inverse function is a function that maps the elements in the range back onto the elements in

Figure 63. Excerpt of Teacher Z's answer to item 4(b)

Teacher $\mathrm{Z}$ used the object conception to answer this question (see Figure 63). By using the domain and range concept he correctly identified the inverse function as one which would map member of the range back onto the domain. In this sense it was necessary to implicitly state that each member of the range is mapped onto a a corresponding unique member of the domain. Teacher Z's definition was considered to be valid. Thus, his answer was rated level 1.

Item 4(c)

Let $h(x)=x^{2}+1$ for $-2 \leq \mathrm{x} \leq 2$ and $f(x)=x^{2}+1$ for $0 \leq \mathrm{x} \leq 2$. Find an expression for $f^{-1}(\mathrm{x})$ and specify the domain of $f^{-1}$. 
This item was designed to assess Teacher Z's knowledge of the steps involved in finding an expression of the inverse of a given function. The item also examined his ability to find the domain of the derived expression for the inverse function. Analyzing Teacher Z's work (Figure 64), it can be seen that he was knowledgeable about the procedure for finding the expression for the inverse of a function. This was seen from his step-by-step working of the problem. In specifying the domain of $f(\mathrm{x})$ $=\mathrm{x}^{2}+1$ it was important for Teacher $\mathrm{Z}$ to know that the domain of $f(\mathrm{x})=\mathrm{x}^{2}+1$ was restricted. Thus, considering the relationship of the range of a function with the domain of its inverse was vital for specifying the domain of $f^{-1}(\mathrm{x})$. His answer was rated level 1 .

$$
\begin{array}{rlr|}
\hline \text { (c) } f(x)=x^{2}+1 & x-1<0 \\
\text { let } f(x)=y & x<1 \\
y=x^{2}+1 & \text {. the domain is all } \\
x^{2}=y-1 & \text { values of } x \text { greater } \\
x=\sqrt{y-1} & \text { than one. } \\
\therefore f^{-1}(x)=\sqrt{x-1} &
\end{array}
$$

Item $4(\mathrm{~d})$

Figure 64. Excerpt of Teacher Z's answer to item 4(c)

Let $h(x)=\mathrm{x}^{2}+1$ for $-2 \leq \mathrm{x} \leq 2$ and $f(x)=\mathrm{x}^{2}+1$ for $0 \leq \mathrm{x} \leq 2$. Determine the range of $h$.

This item was designed to assess Teacher Z's ability to find the range of a given function. The analysis of Teacher Z's answer (see Figure 65) brought in an interesting perspective. Ordinarily he was expected to use the concept of domain and range. But he opted to use concepts of calculus. In particular he opted to use differentiation. Firstly, he substituted the loser bound of the domain of the function $h(x)=x^{2}+1$ to obtain $h(-2)=5$ which he used as the upper bound of the range. Using his knowledge of calculus he then differentiated the function $h(x)=x^{2}+1$ with respect to $x$ to obtain $\frac{d h}{d x}=2 x+1$. Considering that at the turning point of a quadratic function $\frac{\mathrm{dh}}{\mathrm{dx}}=0$, he solve for $\mathrm{x}$ and obtained $\mathrm{x}=-\frac{1}{2}$. He then substituted 
$\mathrm{x}=-\frac{1}{2}$ into the original function to obtain $h(\mathrm{x})=\frac{5}{4}$, the lower bound of the range. He finally obtained the range $\frac{5}{4} \leq \mathrm{x} \leq 5$.

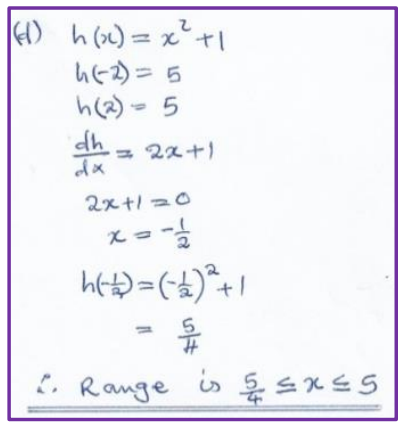

Figure 65. Excerpt of Teacher Z's answer to item 4(d)

During the interview he was asked he arrived at $\frac{d h}{d x}=2 x+1$ after differentiating $h(x)=x^{2}+1$. He was asked to justify his answer as well as the process which seemed erroneous. His answer both in the test and during the interview was rated level 0 .

Interviewer: can you explain with justification how you arrived at $\frac{\mathrm{dh}}{\mathrm{dx}}=2 \mathrm{x}+1$ from the differentiation of $\mathrm{h}(\mathrm{x})=\mathrm{x}^{2}+1$ ?

Teacher Z: I just thought this was the best approach for me to answer the question.

Item 5(a)

Given that $g(x)=\frac{3}{2 x+1}$ and $z: x \rightarrow x^{2}-2 x$, find the value of $g^{-1}(-5)$

This item was designed to assess Teacher Z's combined knowledge of finding the expression for the inverse of a function and evaluating the inverse when given an input. This combined skill would demonstrate thorough understanding of the inverse function concept.

Teacher $\mathrm{Z}$ omitted a (+1) in the denominator and ended up working with the function $g(x)=\frac{3}{2 x}$ instead of $g(x)=\frac{3}{2 x+1}$ (see Figure 66). Because the purpose of this question was to assess conceptual knowledge, Teacher Z's work was analyzed based on the function $g(x)=\frac{3}{2 x}$. 


$$
\text { (a) } \begin{gathered}
g(x)=\frac{3}{2 x} \\
\text { let } g(x)=y \\
\Rightarrow y=\frac{3}{2 x} \\
\Rightarrow 2 x y=3 \\
x=\frac{3}{2 y} \\
\therefore g^{-1}(x)=\frac{3}{2 x} \\
\text { ond } g^{-1}(5)=\frac{3}{10} \\
\hline
\end{gathered}
$$

Figure 66. Excerpt of Teacher Z's answer to item 5(a)

Examining Teacher Z's work, it was observed that he had good knowledge of finding an expression of the inverse of a function and he was able to evaluate the inverse at $x=5$ instead of $x=-5$. The erroneous work presented by Teacher $Z$ was purely out of carelessness. Much as he demonstrated knowledge of evaluating the inverse of a function, it was important for him to use the given function. This is because there was a particular skill that the given function was assessing. Otherwise, using a different function and again using $\mathrm{x}=5$ instead of $\mathrm{x}=-5$ was too much a mistake. He was asked during the interview why he used a different function and a different value of $\mathrm{x}$. He said that he mistakenly omitted (+1). Thus his answer was rated level 1 based on his understanding of the concept.

Item 5(c)

Given that $g(\mathrm{x})=\frac{3}{2 \mathrm{x}+1}$ and $z: \mathrm{x} \rightarrow \mathrm{x}^{2}-2 \mathrm{x}$, an expression for $(z \circ g)(\mathrm{x})$ where $z o$ $g$ denotes the composite function of $z$ and $g$.

The purpose of this item was to assess Teacher Z's knowledge of composition of functions. It can be seen from his work (Figure 67) that the composition of $g(x)$ and $z(\mathrm{x})$ using $g(\mathrm{x})$ as the input followed by $z(\mathrm{x})$. He demonstrated this by using arrows which was impressive considering that other students worked out the same question algebraically. This shows that he was comfortable using different approaches in finding composition of functions. Thus, his answer was rated level 1. 


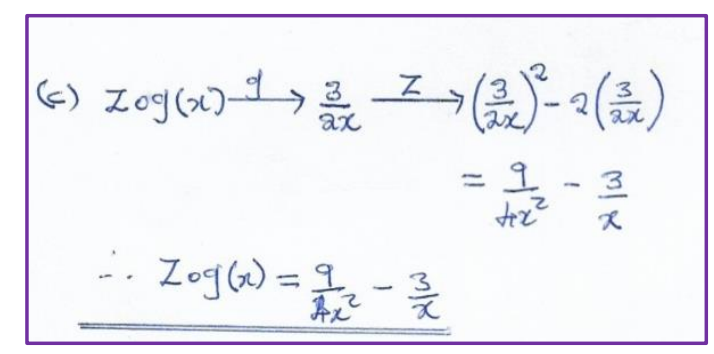

Item 5(d)

Figure 67. Excerpt of Teacher Z's answer to item 5(c)

Given that $g(\mathrm{x})=\frac{3}{2 \mathrm{x}+1}$ and $z: \quad \mathrm{x} \rightarrow \mathrm{x}^{2}-2 \mathrm{x}$, evaluate $\left(g \circ g^{-1}\right)(-5)$ where -5 belongs to the domain of $g^{-1}$.

Analyzing Teacher Z's answer (Figure 68), it can be seen that he demonstrate knowledge of the rule of thumb that governs the composition of a function and its inverse. It is a general rule that if the function $g(\mathrm{x})$ and its inverse $g^{-1}(\mathrm{x})$ have their domains and ranges on the set of real numbers, then $g \circ g^{-1}=\mathrm{x}$ and $g^{-1} \circ g=\mathrm{x}$. with this in mind Teacher $\mathrm{Z}$ was easily able to state the value $g \circ g^{-1}(-5)$ without attempting to perform any calculations. During the interview he was asked to comment on his answer. His answer was rated level 2.

Interviewer: Do you have any comments about your answer to 5(d)

Teacher $\mathbf{Z}$ : This case is similar to what I was teaching someone just before I wrote the test. So, I didn't waste time on this one because I knew that $g \circ g^{-1}=\mathrm{x}$.

Interviewer: Do you know the horizontal and vertical line tests?

Teacher Z: Aah.... No

$$
\begin{aligned}
& \text { (d) } g \circ g^{-1}(-5) \\
& \Rightarrow \operatorname{gog}^{-1}(-5)=-5 \\
& \text { Since } \operatorname{gog}^{-1}(x)=x
\end{aligned}
$$

Figure 68. Excerpt of Teacher Z's answer to item 5(d)

\subsubsection{Pre-service mathematics teachers' specialized content knowledge}

Pre-service teachers' SCK is presented via excerpts from their responses to the functions suvey and justification of these responses through views from the semistructured interviews. In characterizing their proficiency in SCK answers to the following question are presented: 


\section{What level of proficiency of specialized content knowledge of the concept of a function do Zambian pre-service mathematics teachers possess?}

The presentation of results follows a sequence which begins with Teacher X's answers, then Teacher $\mathrm{Y}$ and concludes with Teacher $\mathrm{Z}$.

\section{The case of Teacher $X$}

Item 1(c)

Is there a difference between a function and a relation? Explain your view.

This item was designed to assess Teacher X's knowledge of a relation and characteristics that qualifies a relation to be a function. Teacher $\mathrm{X}$ was expected to know that generally a function is also a relation with special characteristics.

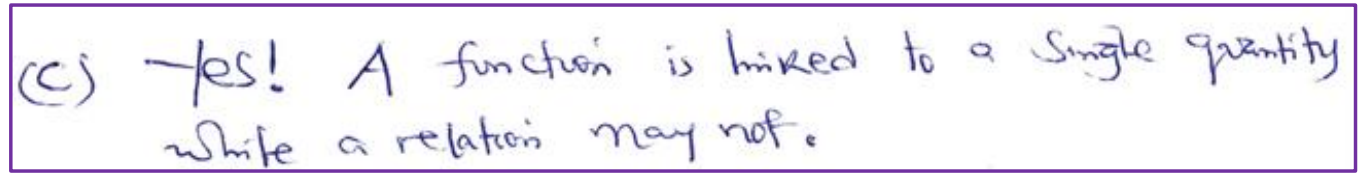

Figure 69. Excerpt of Teacher X's answer to item 1(c)

Analyzing his answer (Figure 69), it can be seen that Teacher X's answer was vague. Firstly, he correctly stated that there was indeed a difference between a relation and a function but his explanation in support of his assertion was unclear. By stating that a function is linked to a single quantity it was not clear what he was trying to say. This is because a function is always an association between two sets called inputs and outputs. The association between inputs and outputs is such that every input is related to not more than one output, otherwise, it would be a relation. Thus, Teacher X's definition lacked clarity and it was difficulty to assume that by merely stating that 'a function is linked to one output' he implied that each input is related to not more than one output. This answer was rated level 1.

Item $1(\mathrm{~d})$

How are functions and equations related to each other?

This item was designed to assess Teacher X's knowledge of a function and that of an equation. He was also expected to acknowledge that functions and equations are not essentially the same though they may be related to each other in some way. 


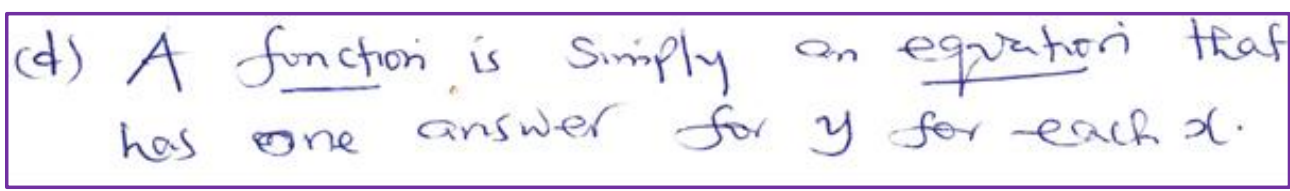

Figure 70. Excerpt of Teacher X's answer to item 1(d)

Teacher X's explanation was vague (see Figure 70). This is because a function is not "simply an equation that has one answer for $\mathrm{y}$ for each $\mathrm{x}$ ". A function is an expression of the relationship between two sets in which a member of the first set has a unique corresponding member of the second set. An equation on one hand is a statement of equality of two quantities. The equal sign is the most important feature used to identify an equation while this may not be the case with a function. In the absence of an equal sign a statement cannot qualify to be called an equation. A typical scenario is that one can use arrows to write down a function but arrows cannot be used to write down an equation. Thus, to loosely call a function an equation was a sloppy consideration of what a function really is. What Teacher $\mathrm{x}$ was supposed to highlight is that an equation can be used to define a function and probably could have used an equation in two variables to exemplify his explanations. In using an equation to define a function lays the similarity between the two. Otherwise, to know the similarity one has to understand the differences more. This answer was inadequate and was therefore rated level 0.

Item 1(f)

Draw a graph of a function that passes through the points $\mathrm{X}$ and $\mathrm{Y}$ in the figure below (see Figure 71). Are there other functions which pass through the points $X$ and $\mathrm{Y}$ ? if yes, draw the graph of such a function. If no such other function exists,

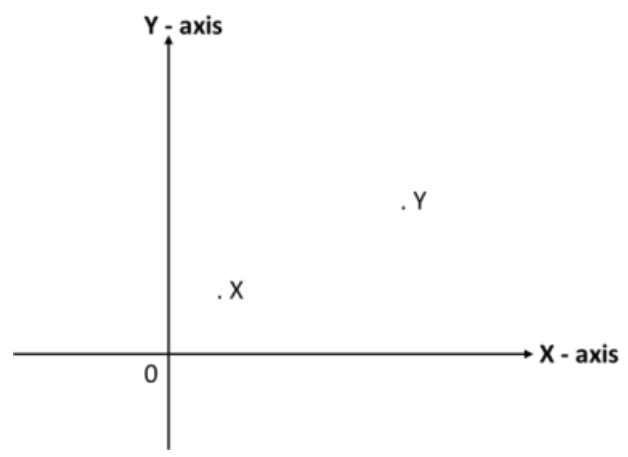

Figure 71. Cartesian plane showing positions of the points $\mathrm{X}$ and $\mathrm{Y}$ 
This item was designed to assess Teacher X's knowledge of expressing functions graphically which is part of his ability to work with different representations of functions. To demonstrate this knowledge he was expected to draw at least two graphs. Analyzing his answer (Figure 72), it can be seen that Teacher X demonstrated good knowledge of graphs of functions. This was shown by drawing two types of graphs where one was a graph of a linear function and the other two were graphs of quadratic functions. By observation it is clear that all the three graphs can pass the vertical line test for determination of whether they are functions or not. This answer was rated level 2.

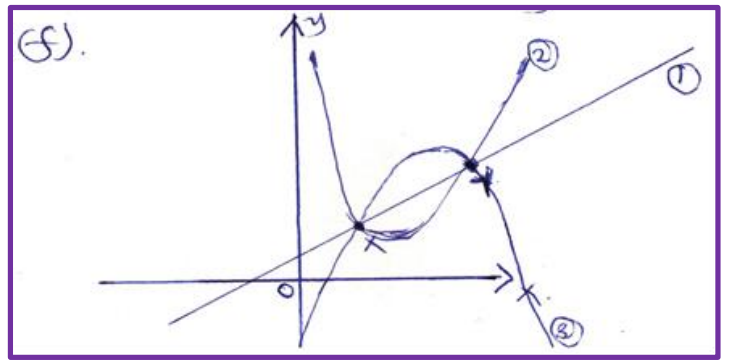

Item 2(a)

Figure 72. Excerpt of Teacher X's answer to item 1(f)

Represent the function $g: \mathrm{x} \rightarrow|\mathrm{x}|$ whose domain is $\{\mathrm{x}:-3 \leq \mathrm{x} \leq 2$, and $\mathrm{x} \in Z\}$ on a Cartesian plane

This item was designed to assess Teacher X's knowledge of drawing continous and descret functions. In answering this question the key aspect was for Teacher $\mathrm{X}$ to decide from the onset the kind of a graph he was drawing. The clue to this was hidden in the domain of $g(\mathrm{x})$. The domain of $g(\mathrm{x})$ was a closed interval on the set of integers. This was a descrete interval with integers $-3,-2,-1,0,1,2$ which will produce specific out puts using the function $g(\mathrm{x})$.

Teacher X corrrectly found the range of the function $g(\mathrm{x})$ using a table of values (Figure 73) and was able to tap from his knowledge of moving between different representations of functions. In this case he was able to move from the tabular representation of an absolute value function to the graphical representation of the function. However, Teacher X showed gaps in knowledge of how a graph of a function with a descrete domain differed from the one with a continous domain. Teacher X was expected to know that the plotted points of a descrete function are not 
supposed to be connected by either a straight line or a smooth curve. Connection of points is an indication that a particular graph is a continous function.

Thus, while the ploting of the points was correctly done, the resultant graph was incorrectly drawn because Teacher $\mathrm{X}$ did not need to connect the plotted points with a line. Teacher $\mathrm{X}$ failed to use the domain to determine whether or not he was asked to draw a descrete or continous function. He was asked to justify his answer during the interview. The answer to this question was rated level 0. However during the interview Teacher $\mathrm{X}$ realised the mistake he made in the test.

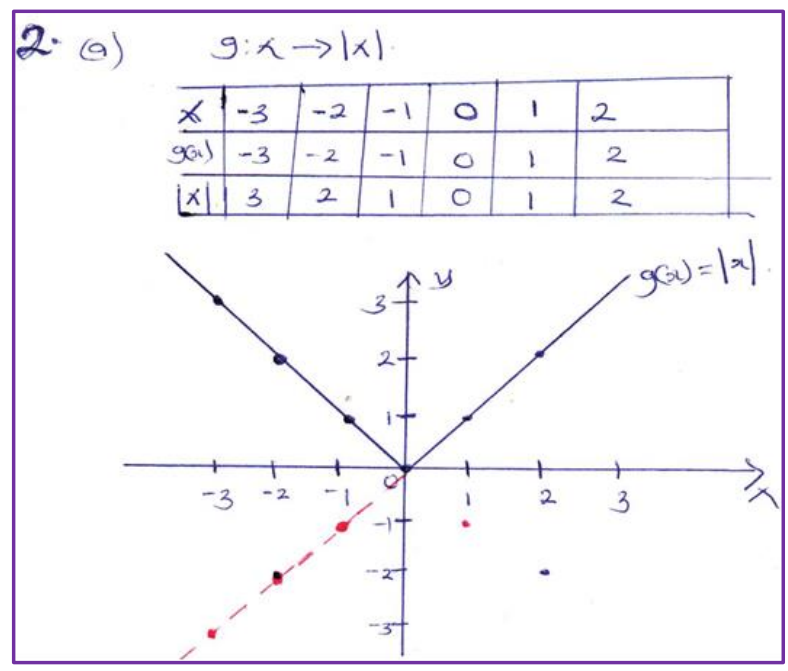

Figure 73. Excerpt of Teacher X's answer to item 2(a)

Interviewer: there is this interesting situation in 2(a) where you were asked to draw the graph of the function $\mathrm{g}(\mathrm{x})$. I observed that you connected the plotted points with a straight line. In justifying your answer explain why you connected the points.

Teacher X: I think that maybe they were not supposed to be connected because I think I did not see the other condition. They are saying that $\mathrm{x}$ is an integer. So, if they were integers then probably they will not be continuous. So, I was just supposed to show the dots because if it comes out as a straight line we are including values that are not integers. So, the key factor in answering this question was the condition " $\mathrm{x}$ is an integer".

Item 2(b)

Answer this question on a sheet of graph paper provided. The table below shows corresponding values of the objects and images of a function $f(x)=-2 x^{2}-x+8$. Taking $2 \mathrm{~cm}$ to represent 1 unit on the $\mathrm{x}$-axis for $-3 \leq \mathrm{x} \leq 2$ and $1 \mathrm{~cm}$ to represent 1 unit on the $\mathrm{y}$-axis, draw the graph of $f(x)=-2 x^{2}-x+8$. 
Table 29. $\mathrm{X}$ and $\mathrm{Y}$ values of the function function $f(x)=-2 x^{2}-x+8$

\begin{tabular}{|c|c|c|c|c|c|c|c|c|c|}
\hline$X$ & -3 & -2 & -1 & -0.5 & 0 & 0.5 & 1 & 2 & 3 \\
\hline$f(x)$ & -7 & 2 & 7 & 8 & 8 & 7 & 5 & -2 & -13 \\
\hline
\end{tabular}

This item was designed to assess knowledge of flexibility between different representations of functions, particularly his ability to draw a graph of a quadratic function when given a table of values representing a function and its image or a domain and a range. It was assumed that Teacher $\mathrm{X}$ already knew how to draw the $\mathrm{XY}$-plane and how to locate ' $1 \mathrm{~cm}$ to 1 unit' on the graph paper. In a nutshell, he was being assessed on his ability to draw a graph of a function following specific instructions. Analyzing Teacher X's graph (Figure 74), it was observed that he correctly drew and labeled the XY-plane. He then correctly plotted all the given points. It was also observed that he correctly connected the points on with a smooth curve. By correctly drawing the graph of $f(x)=-2 x^{2}-x+8$ Teacher $\mathrm{X}$ demonstrated that not only did he understand different representations of functions but he can flexibly move between then. This represented his good specialized content knowledge of the function concept. This answer was rated level 1. 


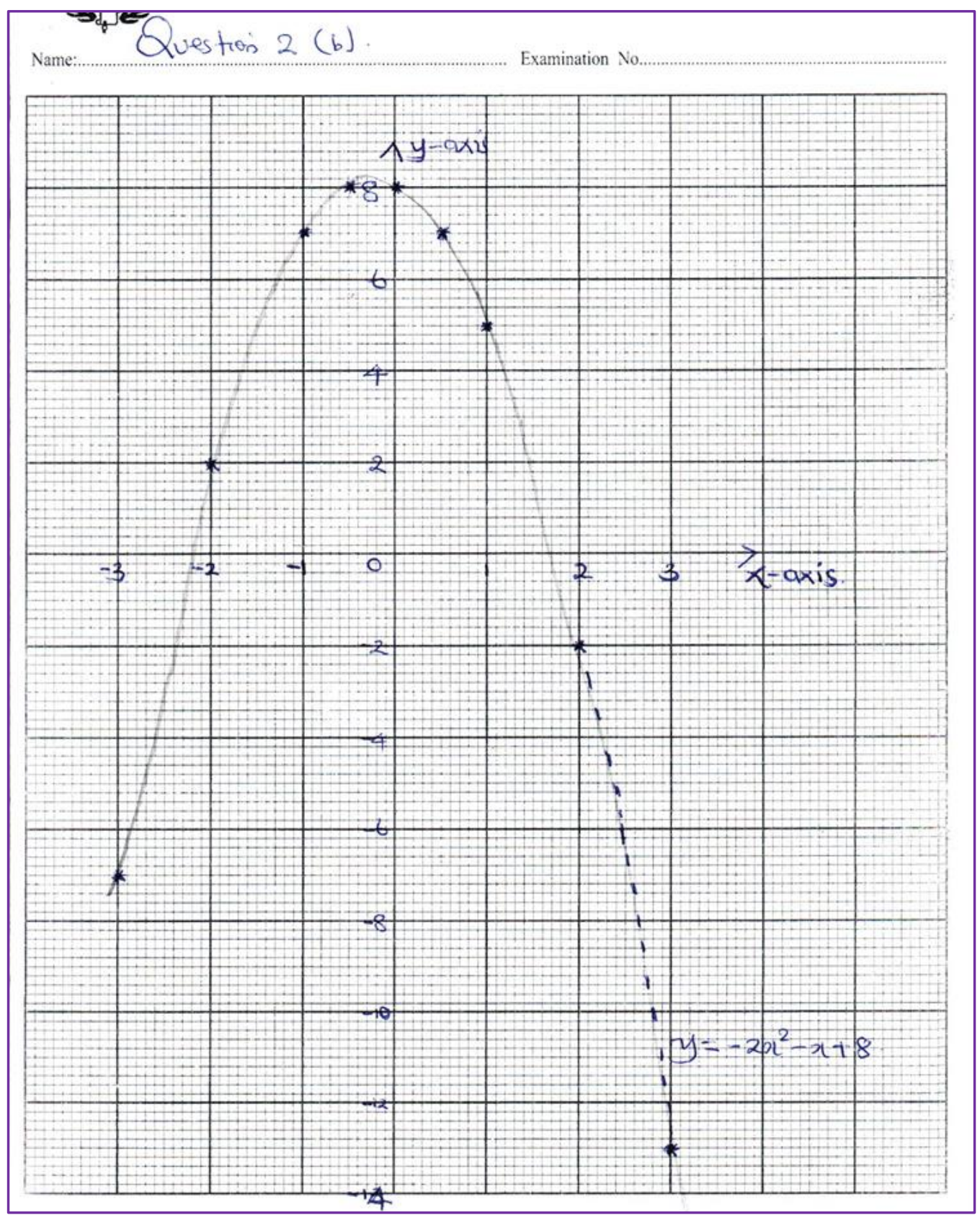

Figure 74. Excerpt of Teacher X's answer to item 2(b)

Item 2(e)

State the maximum value of $f(x)=-2 x^{2}-x+8$ and explain how this value relates to the range of the function $f$.

This item was designed to assess Teacher X's ability to use a graph of a quadratic function to identify the maximum value of the function. All he needed to know was that the maximum value of a parabola is the y-coordinate of the turning point of the graph. Thus, Teacher $\mathrm{X}$ correctly found the maximum value of the 
function $f(x)=-2 x^{2}-x+8$ (see Figure 75) and gave a valid explanation of how it relates to the range. The answer to this question was rated level 1.

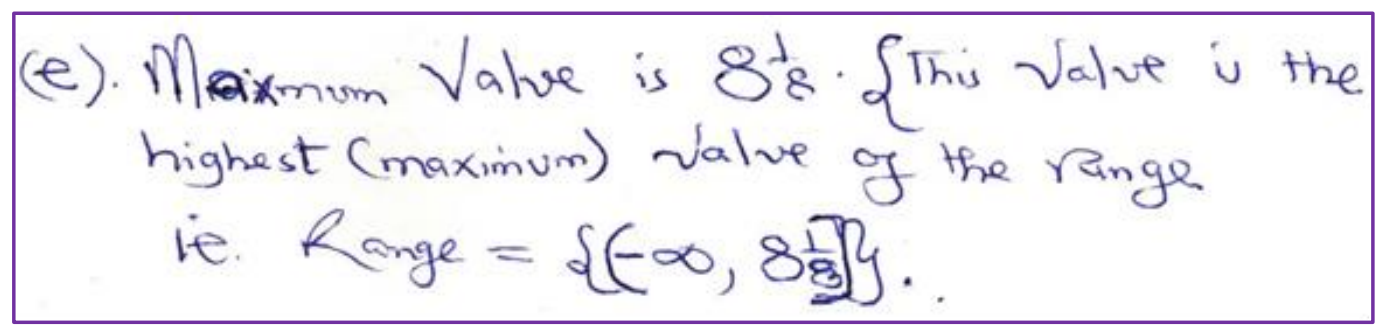

Item 3(c)

Figure 75. Excerpt of Teacher X's answer to item 2(e)

The figure below (Figure 76) is a graph of a function $f(x)=a x^{2}+b x+c$. state whether $a, b$ and $c$ are positive, negative or zero. Explain your decision.

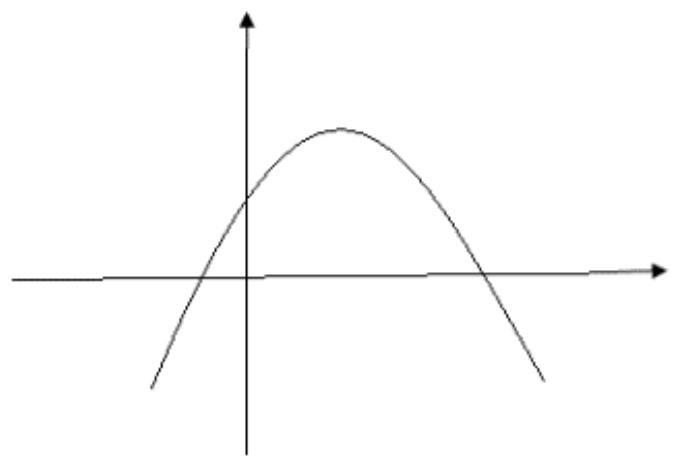

Figure 76. Graph of the function $f(x)=a x^{2}+b x+c$

The aim of asking this question was to assess the participants' knowledge of graphs of functions. For this purpose the graph of a quadratic function (parabola) was used. For a participant to fully answer this question he needed to have very good knowledge of the features of the graph of a quadratic function. The respondent needed to know that for the function $f(x)=a x^{2}+b x+c$, the value of " $a$ " is positive (i.e $a>0)$ if and only if the parabola opens upwards and it is negative $(a<0)$ if and only if it opens downwards. In other word the value of "a" is positive if the parabola has a minimum turning point and it is negative if the parabola has a maximum turning point. To determine whether " $b$ " was positive or negative, the participants were expected to employ the principle of the first derivative at the stationary point which states that "at the stationary point (maximum or minimum), the first derivative $\mathrm{f}^{\prime}(\mathrm{x})$ of the function $\mathrm{f}(\mathrm{x})=a \mathrm{x}^{2}+\mathrm{bx}+\mathrm{c}$ is equal to zero. That is, $\mathrm{f}^{\prime}(\mathrm{x})=2 \mathrm{ax}+\mathrm{b}$ implies that $2 a x+b=0$. Thus, solving for $b$ gives $b=-2 a x$. Since the parabola under 
consideration opens downwards, the value of "a" is negative, making " $b$ " to be positive. A rule of thumb could also be applied which states that if the y coordinate of the turning point is positive, then " $\mathrm{b}$ " is also positive. "c" is basically the $y$ intercept of the graph.

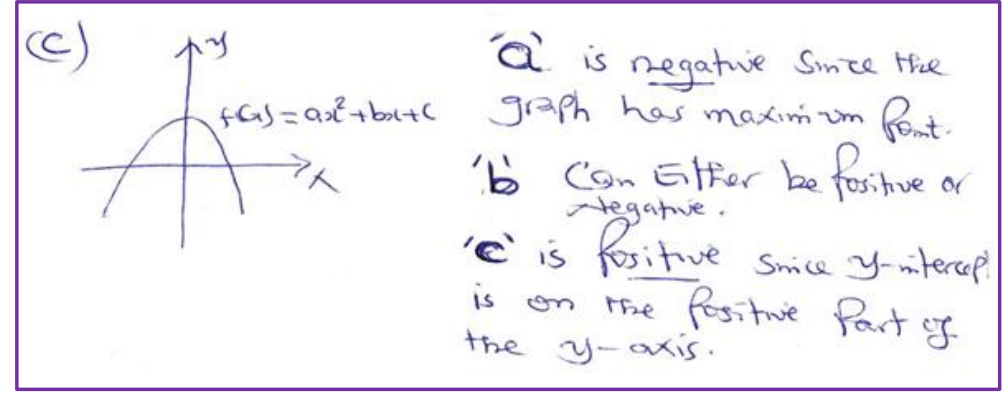

Figure 77. Excerpt of Teacher X's answer to item 3(c)

Analyzing Teacher X's answers (Figure 77) to this item, it can be seen that he correctly determined that "a" was negative because the given graph had a maximum turning point. He also correctly determined that "c" was also positive since the yintercept of the graph was in the positive region of the $y$-axis of the coordinate plane. However, Teacher X could not explicitly determine the sign of " $b$ ". he was of the view that " $b$ " can either be positive or negative which was rather vague. Teacher $\mathrm{X}$ could have used the first derivative principle to determine the sign of " $b$ " or he could have used the rule of thumb as aforementioned.

Interviewer: In question 3(c) you were asked to determine the signs of "a", "b" and "c". would you explain why you in your answer they were determined as "a" being negative, "b" positive or negative and "c" positive?

Teacher X: I thought so because of some common features when you draw graphs of quadratic functions. If you look at the value of "a", [it] is a coefficient of $x^{2}$. So, this one determines whether the graph will face upwards or downwards in terms of whether it is positive or negative. So, if you have a positive one then it will have a minimum value. That analysis can only be done if [one has] done a lot of sketching of these graphs. The function $f(x)=\mathrm{a} x^{2}+\mathrm{b} x+\mathrm{c}$ has a minimum turning point. Therefore, the value of "a" should be negative.

Interviewer: What about " $b$ "?

Teacher X: "b" will have no effect on the nature of the graph. So, it can either be positive or negative. What really has an impact is "a", which determines whether it will have a maximum turning point or a minimum turning point. So, "b" will have no effect. 
The combined answer from the test and the interview was rated level 0-1.

Item 4(a)

Let $h(\mathrm{x})=\mathrm{x}^{2}+1$ for $-2 \leq \mathrm{x} \leq 2$ and $f(\mathrm{x})=\mathrm{x}^{2}+1$ for $0 \leq \mathrm{x} \leq 2$. State two differences between $f$ and $h$.

This item was designed to assess Teacher X's conceptual differences between the functions $h(\mathrm{x})$ and $f(\mathrm{x})$ with special consideration of their respective domains. It was not meant for Teacher $\mathrm{X}$ to give merely any visible differences but the differences needed to be conceptual.

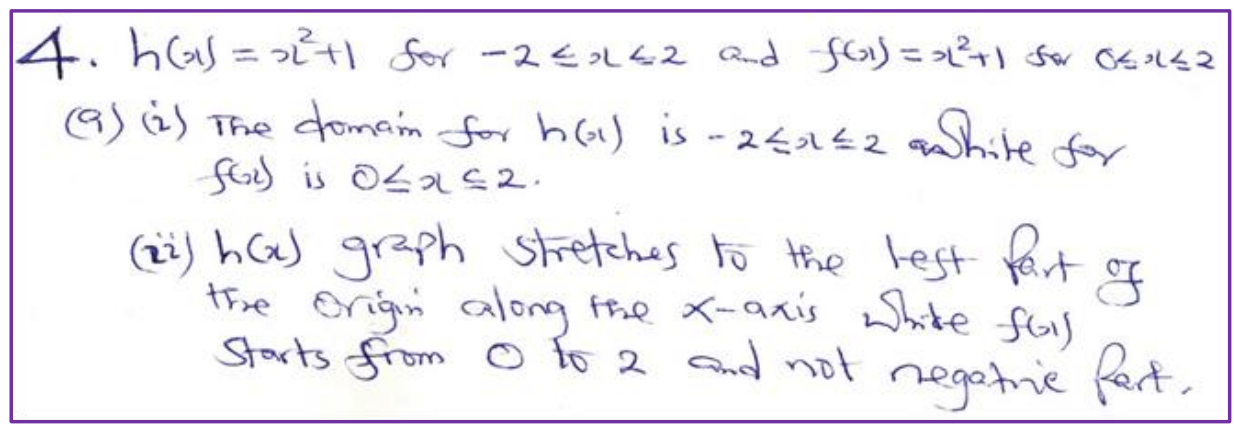

Figure 78. Excerpt of Teacher X's answer to item 4(a)

Analyzing Teacher X's answer (Figure 78), it can be seen the differences he gave fell short of being conceptual. The two differences by Teacher $\mathrm{X}$ were mere descriptions of what was stated in the question. For example, the question states that the domain of $h(\mathrm{x})$ is $-2 \leq \mathrm{x} \leq 2$ and that of $f(\mathrm{x})$ is $0 \leq \mathrm{x} \leq 2$. Thus, stating this as a difference was tantamount to restating part of the question. Even though there was no restriction on what kind of differences one needed to state, the differences stated by Teacher $\mathrm{X}$ were invalid. Among the conceptual differences that Teacher $\mathrm{X}$ was expected to state were (i) $f(\mathrm{x})=\mathrm{x}^{2}+1$ was a one-to-one function while $h(\mathrm{x})=\mathrm{x}^{2}+1$ was a many-to-one function and (ii) following this, the inverse of $f(\mathrm{x})=\mathrm{x}^{2}+1$ exists while the inverse of $h(x)=x^{2}+1$ did not exist. Had teacher X drawn the two graphs he could have checked this using the horizontal line test. Teacher X was asked during the interview to think about other differences apart from the obvious ones he stated. He could not reason beyond what he stated in the test. As such, his answer was rated level 0.

Interviewer: Would you justify your answers to question 4(a)?

Teacher X: What I discovered was I looked at the two functions were exactly the same. 
The difference I realized was the domain. One was ranging from $-2 \leq x \leq 2$ [and] the other $0 \leq \mathrm{x} \leq 2$. [This is] because if I am to draw the two functions, one will stretch from $(-2)$ to 2 on the $\mathrm{x}$-axis but the other one will start from 0 to 2 . I think that is the major difference.

Interviewer: Did you draw:

Teacher X: No I didn't.

Interviewer: Don't you think that by restricting the domain of $\mathrm{f}(\mathrm{x})$ it becomes a one-toone function?

Teacher X: For $\mathrm{f}(\mathrm{x})$ the other part will be chopped. When you restrict the domain it will be a one-to-one and it has an inverse.

Item $4(\mathrm{e})$

Determine the relationship between the range of $h$ and the domain of $f^{-1}$.

Teacher X correctly determined the relation between the range of $h(\mathrm{x})$ and the domain of $f^{-1}$. This item was basically designed to see if Teacher $\mathrm{X}$ could easily notice the relationship. Thus, his answer to this question was valid. Teacher $\mathrm{X}$ was asked to clarify his answer during the interview. His answer (Figure 79) and his interview explanation was rated level 1.

$$
\text { (e) Domain of } f^{-1} \text { and Range of } h \text { are EQUAL }
$$

Figure 79. Excerpt of Teacher X's answer to item 4(e)

Interviewer: What is your comment about question 4(e)?

Teacher X: I concluded that the domain of the inverse of the function $h(x)$ and the range of the function were equal.

Interviewer: Why did you think that they were equal?

Teacher X: From the preliminary questions before coming to this [one], part "c" was asking to find the inverse of $\mathrm{f}(\mathrm{x})$ then at the same time determine the domain. So, I discovered that the domain was all values except $x<1$. Then the range of the function $f(x)$ is equal to the domain of the inverse of that function. So, that is the test I used.

Item 5(b)

Given that $g(x)=\frac{3}{2 x+1}$ and $z: x \rightarrow x^{2}-2 x$, state with justification, two domains on which the function $\mathrm{z}: \mathrm{x} \rightarrow \mathrm{x}^{2}-2 \mathrm{x}$ has an inverse.

This item was designed to assess Teacher X's ability to use his knowledge of one-to-one functions combined with the knowledge of inverse functions. Since the 
function $z: \mathrm{x} \rightarrow \mathrm{x}^{2}-2 \mathrm{x}$ will produce quadratic graph, he was expected to know that for a quadratic graph to have an inverse, its domain needed to be restricted on either side of the origin of the XY-plane on which it is drawn. There are several ways by which this question can be approached and Teacher $\mathrm{X}$ had the freedom to tap from any approach. One of them could have involved a sketch of the graph of $z: \mathrm{x} \rightarrow \mathrm{x}^{2}-$ $2 \mathrm{x}$. then using the graph to determine the domain. Another could have involved algebraic simplifications like Teacher $\mathrm{X}$ did in his approach. Teacher $\mathrm{X}$ opted to first find the expression for the inverse of the function $z: x \rightarrow x^{2}-2 x$ and then used it to come up with two domains (see Figure 80). His approach was valid and the two domains stated were valid. Thus, his answer was rated level 1.

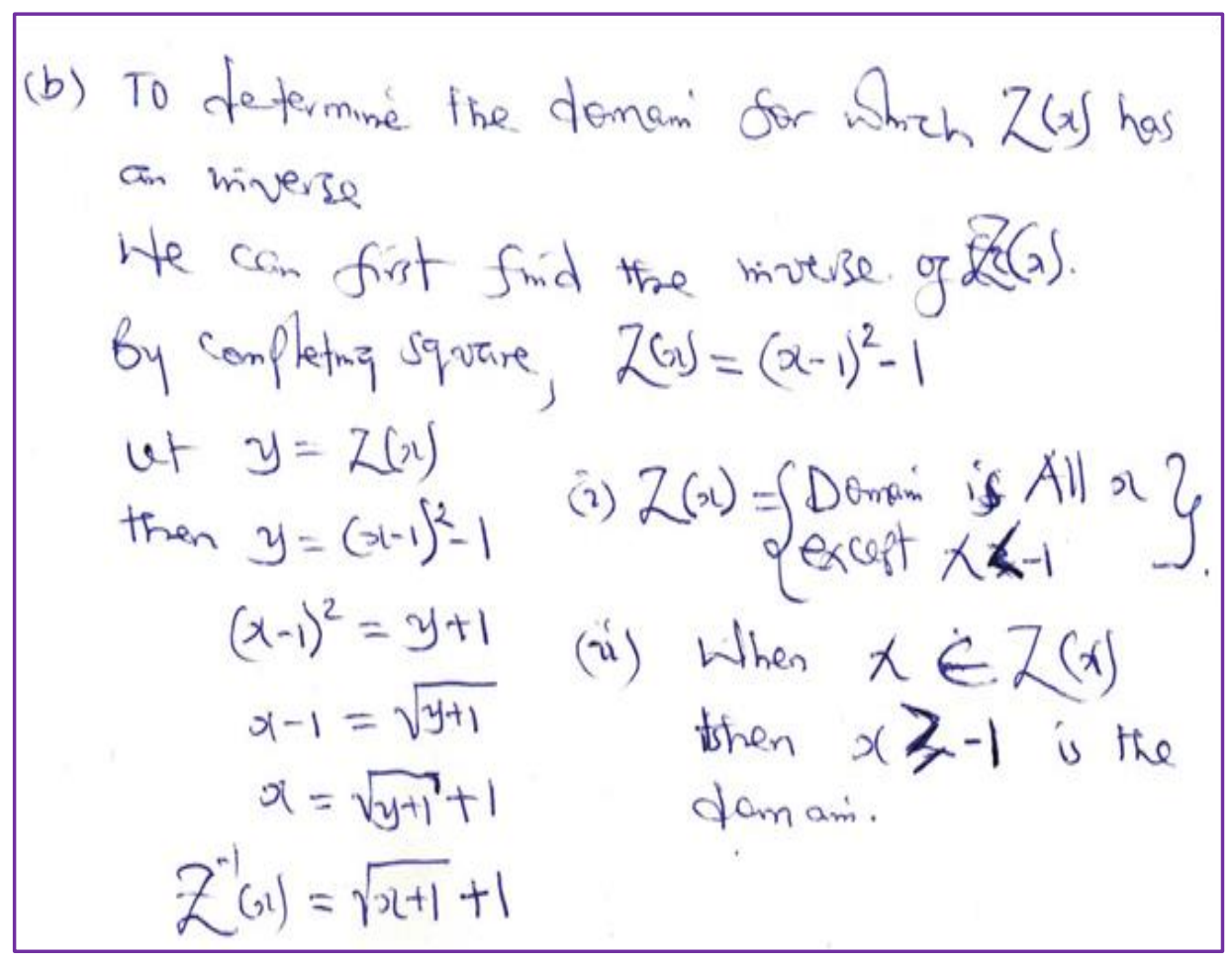

Figure 80. Excerpt of Teacher X's answer to item 5(b) 
Item 9

Consider the three figures below and answer the questions that follow.

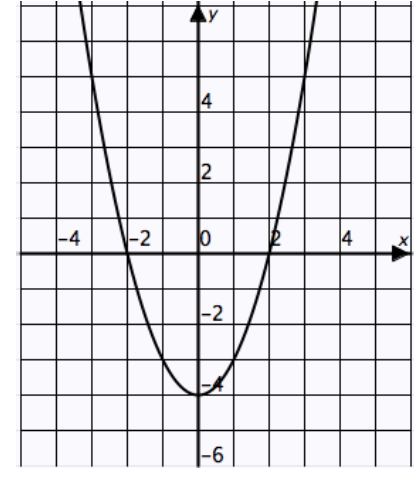

Figure A

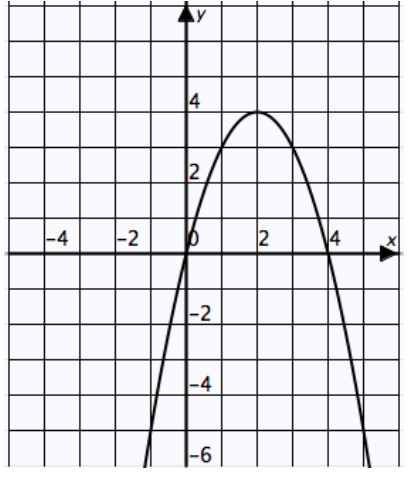

Figure B

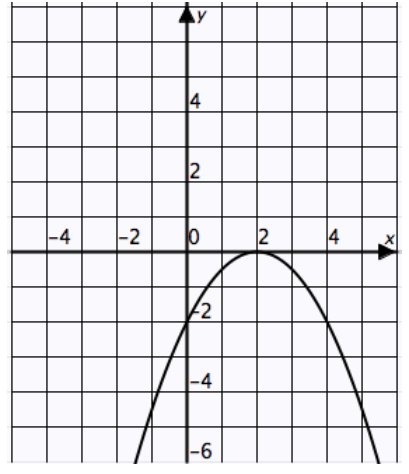

Figure C

This item was designed to assess Teacher X's level of knowledge of analyzing graphs of quadratic functions. The key features that Teacher $\mathrm{X}$ was expected to bring out when analyzing the given graphs included (but were not limited to) using the general form $f(\mathrm{x})=\mathrm{ax}^{2}+\mathrm{bx}+\mathrm{c}$ where $\mathrm{a}, \mathrm{b}$ and $\mathrm{c}$ are constants and $\mathrm{a} \neq 0, \mathrm{x}$ and $\mathrm{y}$ intercepts of the graph, stationary (minimum and maximum) points, axes of symmetry and the nature of roots of the quadratic functions.

Item 9(a)

Indicate the features that are common to graphs A and B but not to graph $\mathrm{C}$.

$$
\begin{aligned}
& \text { P.(a)-A and B have two distinet roofs whis? } \\
& C \text { has a refeated root. } \\
& \text { (ie) } A \text { and } B \text { cots the } x \text {-axis at turs foints } \\
& \text { white } C \text { just at one fonit. }
\end{aligned}
$$

Item 9 (b)

Figure 81. Excerpt of Teacher X's answer to item 9(a)

Indicate the features that are common to graphs $\mathrm{B}$ and $\mathrm{C}$ but not to graph $\mathrm{A}$.

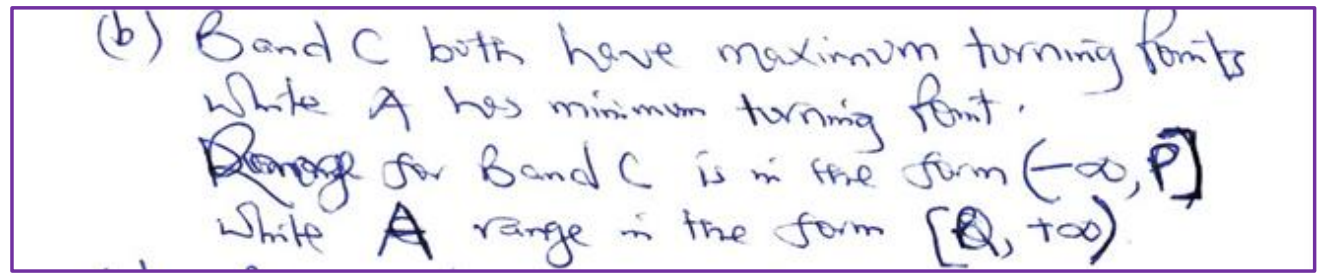

Figure 82. Excerpt of Teacher X's answer to item 9(b) 
Item 9(c)

Indicate the features that are common to graphs $\mathrm{A}$ and $\mathrm{C}$ but not to graph $\mathrm{B}$.

(c) - both Aand $c$ have $y$-intercepts in the negative
fart of the $y$-axis.

Figure 83. Excerpt of Teacher X's answer to item 9(c)

Here are the three equations for the functions A, B and C. You might want to use them.
A. $\mathrm{y} \square \mathrm{x}^{2} \square 4$
B. $\mathrm{y} \square 4(\mathrm{x} \square 2)^{2}$
C. $\mathrm{y} \square \square \frac{1}{2}(\mathrm{x} \square 2)^{2}$

Teacher $\mathrm{X}$ distinguished figures $\mathrm{A}, \mathrm{B}$ and $\mathrm{C}$ in terms of the nature of roots and the $\mathrm{X}$-intercepts (Figure 81). Teacher $\mathrm{X}$ observed that in Figures $\mathrm{A}$ and $\mathrm{B}$ there existed distinct roots because the graphs intersect the $\mathrm{x}$-axis at two distinct points, while the graph of the function in Figure $\mathrm{C}$ intersected the $\mathrm{x}$-axis at only one point. Teacher $\mathrm{X}$ also observed that a major difference between graphs of quadratic functions in Figures $\mathrm{B}$ and $\mathrm{C}$ was that they had maximum turning points while the graph in Figure A had a minimum turning point (see Figure 82). However, he could not explain why in figure A the parabola opens upwards while in the other two figures the parabolas open downwards (see Figure 83) and possibly relate this to the coefficient of $\mathrm{x}^{2}$ in the general form $f(\mathrm{x})=\mathrm{ax}^{2}+\mathrm{bx}+\mathrm{c}$. It can be seen from the explanations advanced by this Teacher $\mathrm{X}$ that there are gaps in his specialized content knowledge as he was not thoroughly able to work with different representations. His answer to this question was rated level 0.

\section{The case of Teacher $Y$}

Item $1(\mathrm{c})$

Is there a difference between a function and a relation? Explain your view.

This item was designed to assess Teacher Y's knowledge of a relation and characteristics that qualifies a relation to be a function. Teacher $\mathrm{Y}$ was expected to know that generally a function is also a relation with special characteristics. 


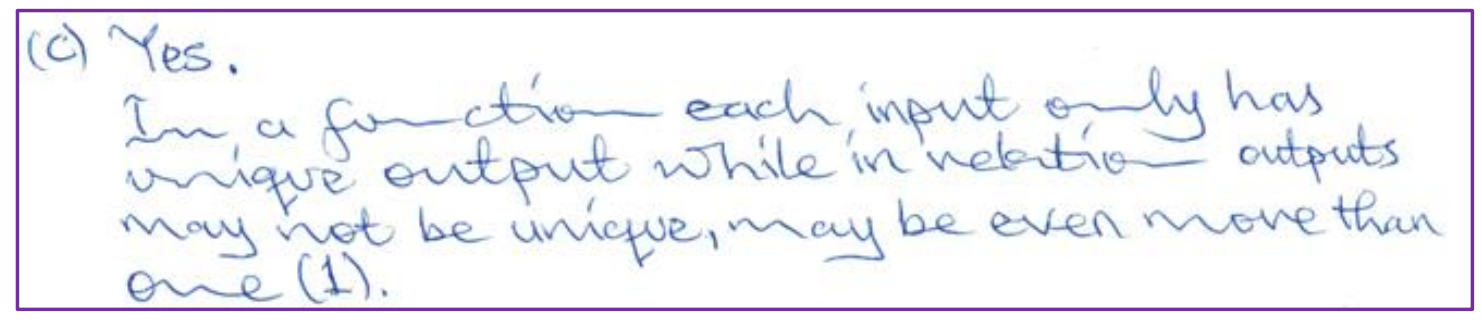

Figure 84. Excerpt of Teacher Y's answer to item 1(c)

Teacher Y claimed that there existed differences between relations and functions (see Figure 84). He stated one key difference by claiming that for a function each element in the set of inputs corresponds to a unique element in the set of outputs while for a relation this may not be the case. The difference advanced by Teacher $\mathrm{Y}$ was accepted as a valid difference between a relation and a function. This answer was rated level 1.

Item $1(\mathrm{~d})$

How are functions and equations related to each other?

This item was designed to assess Teacher Y's knowledge of a function and that of an equation. He was also expected to acknowledge that functions and equations are not essentially the same though they may be related to each other in some way.

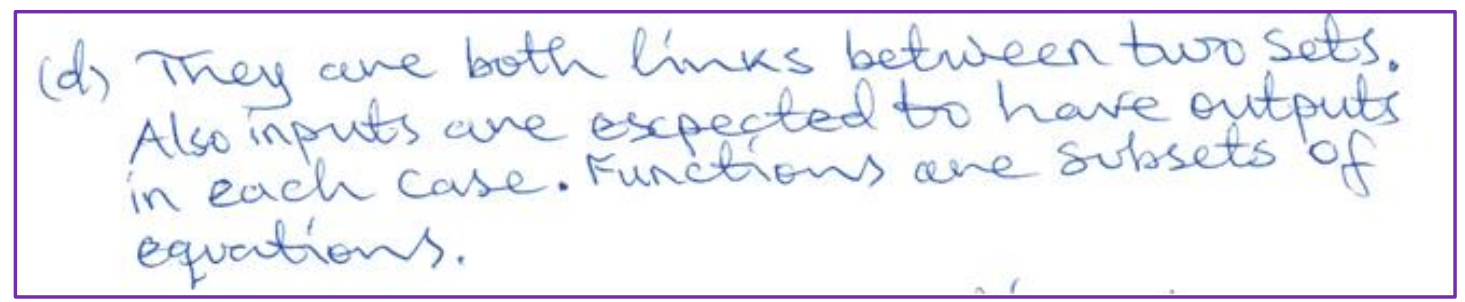

Figure 85. Excerpt of Teacher Y's answer to item 1(d)

Analyzing Teacher Y's answer (Figure 85), it can be seen that he establishes a relationship between functions and equations by stating that both of them link two sets and that with functions a set of inputs is expected to have a set of outputs. The same applies to equations. It was not clear what he meant by claiming that functions were subsets of equations. Teacher $\mathrm{Y}$ was expected to acknowledge that a function is an expression of the relationship between two sets in which a member of the first set has a unique corresponding member of the second set. An equation on one hand is a 
statement of equality of two quantities. It is not always true that in an equation every input would produce a unique output but this is always the case with functions. It would have been worth noting by Teacher $\mathrm{Y}$ that an equation can be used to define a function. Teacher Y's answer to this question was rated level 1.

Item 1(f)

Draw a graph of a function that passes through the points $\mathrm{X}$ and $\mathrm{Y}$ in the figure below. Are there other functions which pass through the points $\mathrm{X}$ and $\mathrm{Y}$ ? if yes, draw the graph of such a function. If no such other function exists, explain why.

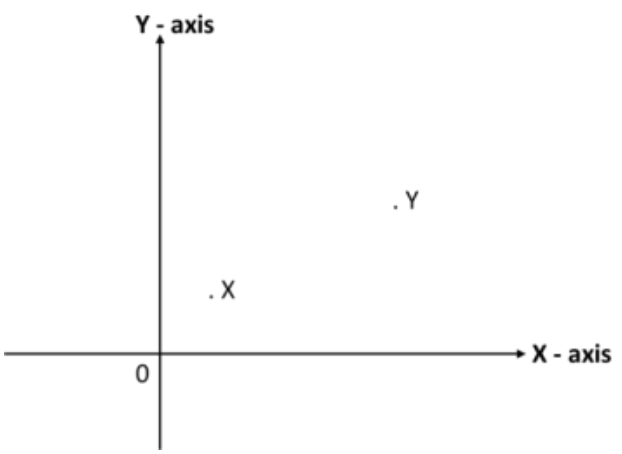

Figure 86. XY-Plane showing the points $\mathrm{X}$ and $\mathrm{Y}$

This item (Figure 86) was designed to assess Teacher Y's knowledge of graphs of functions. In particular, his ability to draw different graphs passing through the same points was tested. Analyzing his answer, Teacher Y drew three different graphs passing through the points $\mathrm{x}$ and $\mathrm{y}$. He drew a the graph of a linear function and two graphs of quadratic functions (see Figure 87). by this Teacher Y demonstrated good knowledge of drawing graphs when given specific constraints. Thus, his answer to this question was accepted as being valid and was rated level 1.

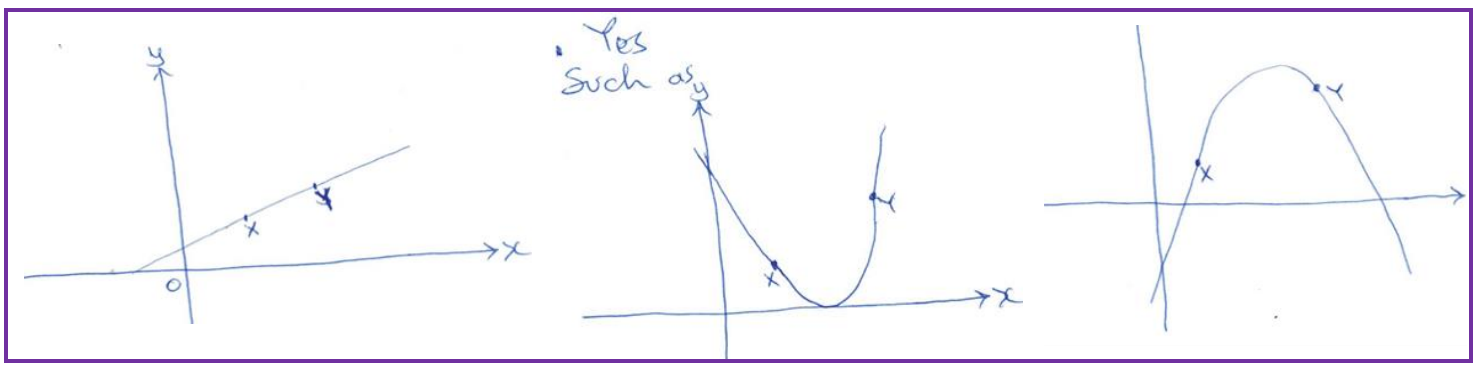

Item 2(a)

Figure 87. Excerpt of Teacher Y's answer to item 1(f)

Represent the function $g: \mathrm{x} \rightarrow|\mathrm{x}|$ whose domain is $\{\mathrm{x}:-3 \leq \mathrm{x} \leq 2$, and $\mathrm{x} \in Z\}$ on a Cartesian plane 
This item was designed to assess Teacher Y's knowledge of drawing the graph of an absolute value function. In answering this question the key aspect was for Teacher Y to decide from the onset whether he was drawing a continous or descrete graph. The clue to this was dependant on the domain of $g(\mathrm{x})$. The domain of $g(\mathrm{x})$ was a closed interval on the set of integers. This was a descrete interval with integers -3 , $2,-1,0,1,2$ which would produce descrete outputs using the function $g(\mathrm{x})$.

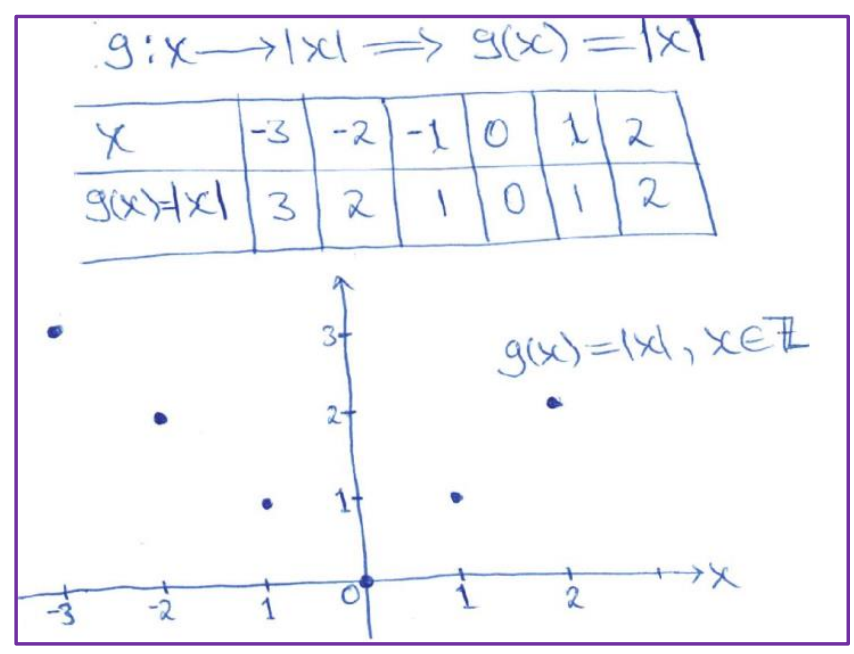

Figure 88. Excerpt of Teacher Y's answer to item 2(a)

This was an easy one for Teacher Y. He knew that he was dealing with a descrete domain and thus, he correctly found the range of the function using a table of values. It was clear that Teacher $\mathrm{Y}$ was knowledgeable about different representation of functions as evidenced by the ease with which he moved from tabular to graphical representation. Teacher Y correctly plotted points on the XYplane which was accurately drawn. Realizing that he was working with a discrete domain, Teacher Y did not connect the plotted points with either a straight line or a smooth curve. His graph (Figure 88) was accepted as being a valid answer to the posed question. Teacher Y was asked to justify his answer during the interview.

Interviewer: When you look at your solutions to question 2(a), you did not connect the plotted points with either a smooth curve or a straight line. What were your reasons for that?

Teacher $\mathbf{Y}$ : this is because the values of $\mathrm{x}$ were exclusively given as to come from the set of integers.. so it is only the values of $x$ coming from the set of integers that should have outputs and if that be the case then we expect to have outputs only 
integers. So the restriction as to why I did not connect came in because of the $\mathrm{x}$ coming from the set of integers. If however, $x$ was every real number then we would have considered every number between -3 and 2 inclusive. So I did not connect because I wanted outputs to be discrete

Teacher Y's answer to this question was a demonstration of good understanding of the concept and his views during the interview confirmed his good understanding. As such, his answer to this question wasn rated level 2.

Item 2(b)

Answer this question on a sheet of graph paper provided. The table below shows corresponding values of the objects and images of a function $f(x)=-2 x^{2}-x+8$. Taking $2 \mathrm{~cm}$ to represent 1 unit on the $\mathrm{x}$-axis for $-3 \leq \mathrm{x} \leq 2$ and $1 \mathrm{~cm}$ to represent 1 unit on the y-axis, draw the graph of $f(x)=-2 x^{2}-x+8$.

Table 30. Corresponding values of $\mathrm{x}$ and $\mathrm{f}(\mathrm{x})$

\begin{tabular}{|c|c|c|c|c|c|c|c|c|c|}
\hline$X$ & -3 & -2 & -1 & -0.5 & 0 & 0.5 & 1 & 2 & 3 \\
\hline$f(x)$ & -7 & 2 & 7 & 8 & 8 & 7 & 5 & -2 & -13 \\
\hline
\end{tabular}

This item was designed to assess Teacher Y's ability to draw a quadratic graph when given domain values and range values. He was also being assessed on how well he can translate instructions to a graph paper. For example, his ability to interpret the phrase " $2 \mathrm{~cm}$ to represent 1 unit" was also tested. Teacher Y correctly drew and labeled the XY-plane (see Figure 89) and correctly plotted the $\mathrm{x}$ and $\mathrm{f}(\mathrm{x})$ values from the table. He then connected the plotted points with a smooth curve and correctly labeled it $f(x)=-2 x^{2}-x+8$. Teacher Y demonstrated good knowledge of drawing graphs and his answer was considered to be valid and it was consequently rated level 1. 


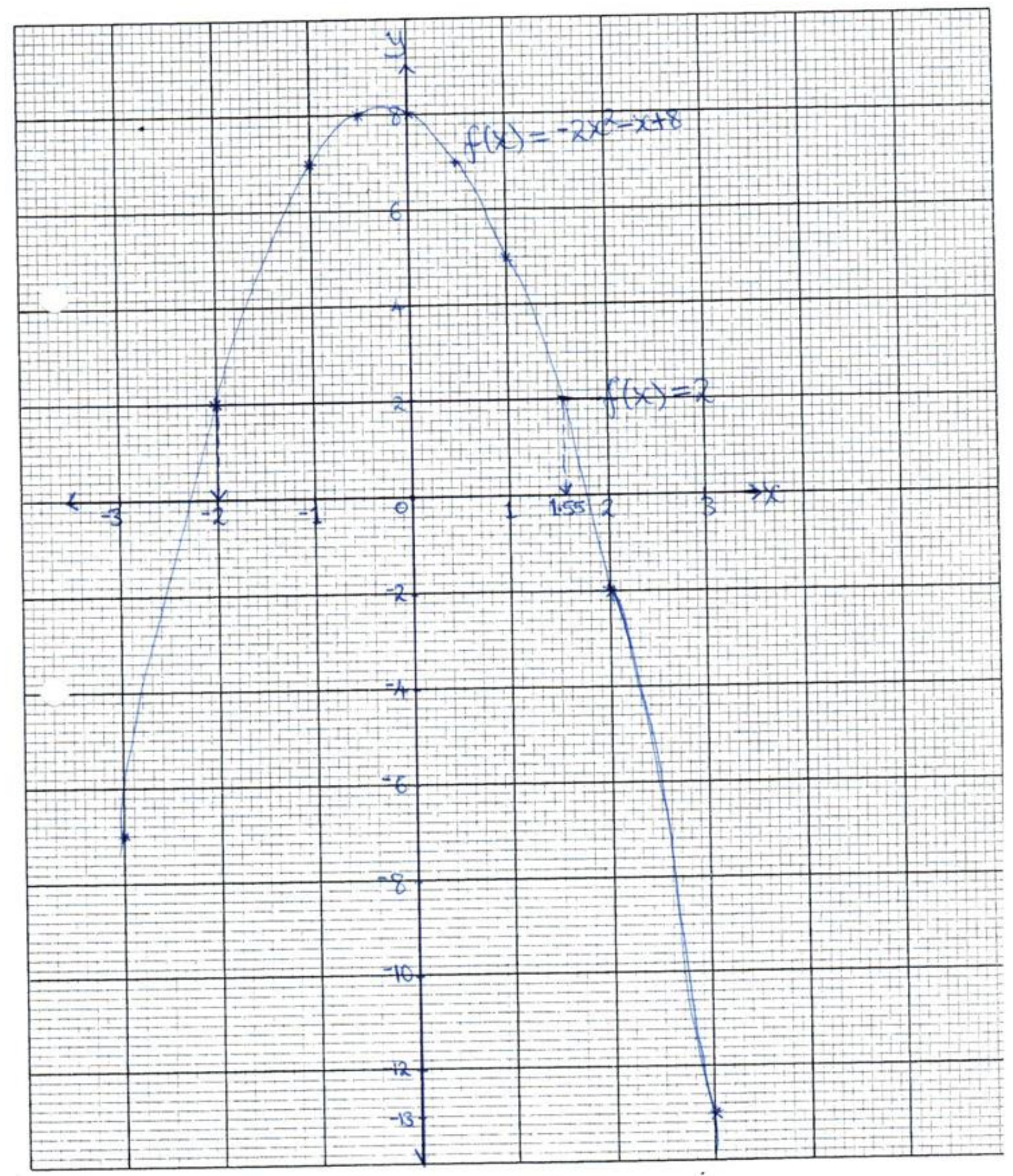

Figure 89. Excerpt of Teacher Y's answer to item 2(b)

Item 2(e)

State the maximum value of $f(x)=-2 x^{2}-x+8$ and explain how this value relates to the range of the function $f$.

This item was designed to assess Teacher Y's ability to find the maximum value of a quadratic function by inspecting the drawn graph and to relate the value to 
the range of the function. Teacher Y correctly used the graph of $f(x)=-2 x^{2}-x+8$ to identify the maximum value. In his case the maximum value of was the y-coordinate of the turning point of the function $f(x)=-2 x^{2}-x+8$ (see Figure 90). He explained that the relationship between the maximum value of $f(x)=-2 x^{2}-x+8$ and the range is that the maximum value was the highest value of the range of the function. This was a valid reason especially that he was using the graph to generate his answers. His answer was rated level 1 .

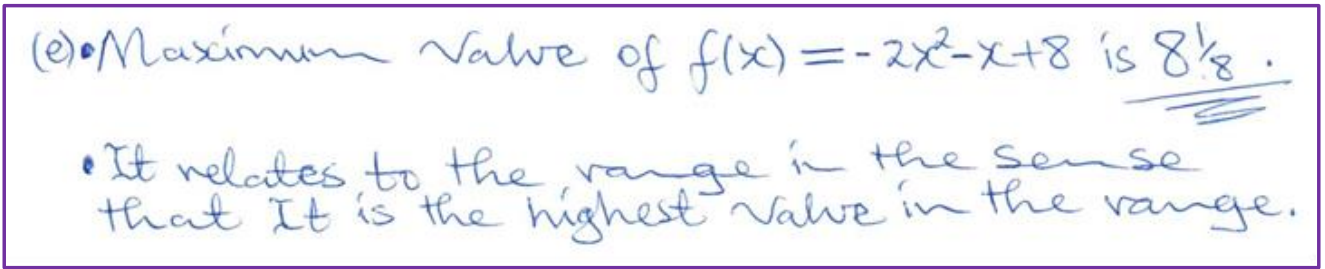

Figure 90. Excerpt of Teacher Y's answer to item 2(e)

Item 3(c)

The figure below (Figure 91) is a graph of a function $f(x)=a x^{2}+b x+c$. state whether $a, b$ and $c$ are positive, negative or zero. Explain your decision.

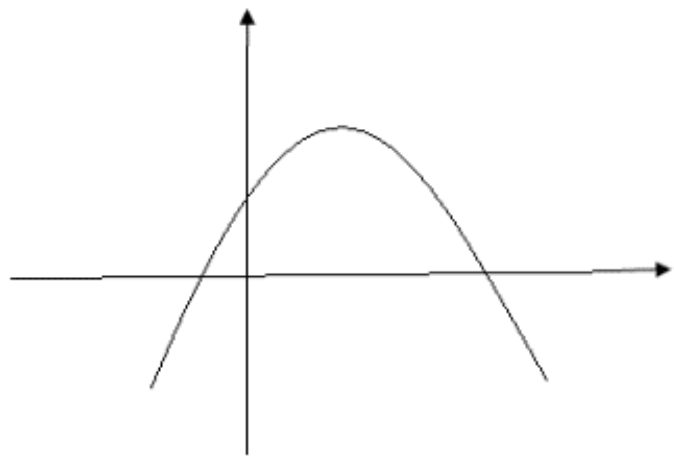

Figure 91. Graph of $f(x)=a x^{2}+b x+c$

This item was designed to assess Teacher Y's knowledge of graphs of functions. For this purpose the graph of a quadratic function (parabola) was used (Figure 91). For Teacher $\mathrm{Y}$ to comprehensively answer this question he needed to have very good knowledge of the features of the graph of a quadratic function. Teacher $Y$ needed to know that for the function $f(x)=a x^{2}+b x+c$, the value of " $a$ " was positive (i.e a $>0$ ) if and only if the parabola opened upwards and it was negative $(a<0)$ if and only if it opened downwards. In other word the value of "a" 
was positive if the parabola had a minimum turning point and it was negative if the parabola had a maximum turning point.

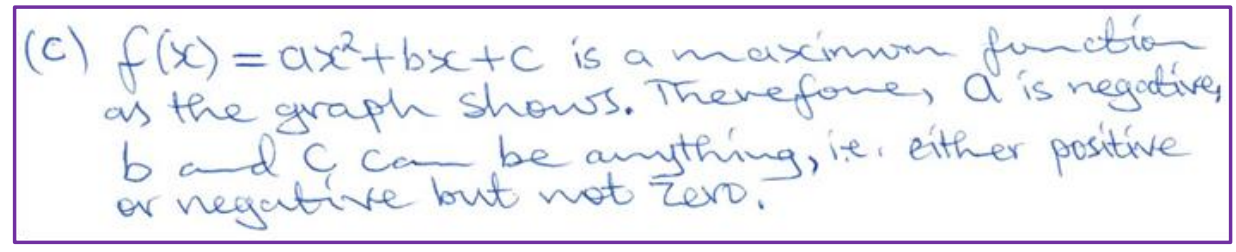

Figure 92. Excerpt of Teacher Y's answer to item 3(c)

Analyzing Teacher Y's answer (Figure 92), he correctly stated that "a" was negative because the graph had a maximum turning point. Regarding the signs of " $b$ " and "c" Teacher Y explained that they would either be positive or negative but not zero. This reasoning was vague as he did not sufficiently justify his explanation.

To determine whether " $b$ " was positive or negative, Teacher $Y$ was expected to use the principle of the first derivative at the stationary point which states that "at the stationary point (maximum or minimum), the first derivative, $\mathrm{f}^{\prime}(\mathrm{x})$, of the function $\mathrm{f}(\mathrm{x})=\mathrm{ax}^{2}+\mathrm{bx}+\mathrm{c}$ was equal to zero. That is, $\mathrm{f}^{\prime}(\mathrm{x})=2 \mathrm{ax}+\mathrm{b}$ implies that $2 \mathrm{ax}+\mathrm{b}=$ 0 . Thus, solving for $b$ gives $b=-2 a x$. Since the parabola under consideration opens downwards, the value of "a" is negative, making "b" to be positive. A rule of thumb could also be applied which states that if the y coordinate of the turning point is positive, then "b" is also positive. "c" was basically the y-intercept of the graph and since it lays in the positive region of the y-axis it was positive. During the interview Teacher $\mathrm{Y}$ was asked to justy his answers to question 3(c). his answer was not elaborate enough and was rated level 0 .

Interviewer: In your answer to question 3(c) you stated that "a" was negative while "b" and "c" would either be positive or negative. Would you please justify your answer?

Teacher Y: We know that the function $f(\mathrm{x})=\mathrm{ax}^{2}+\mathrm{bx}+\mathrm{c}$ is a graph of a parabolic function whose turning point is a maximum. The value of "a" does tell us whether the graph has a maximum or minimum. So, once we know that it is a maximum function we know the value of "a" has to be negative. From what we can see from the graph, it is a maximum function because it has a maximum point as it faces downwards. So "a" is automatically negative. "c" in this case is the y-intercept. In this particular case "c" is automatically positive because we can clearly see where the graph intersects the y-axis. As for "b" it still stands that it can be positive or negative. So allow me to modify the answer that I wrote in the test. We can say tha 
"a" is strictly negative, "c" is positive because it is the y-intercept and "b" can either be positive or negative.

Item 4(a)

Let $h(\mathrm{x})=\mathrm{x}^{2}+1$ for $-2 \leq \mathrm{x} \leq 2$ and $f(\mathrm{x})=\mathrm{x}^{2}+1$ for $0 \leq \mathrm{x} \leq 2$. State two differences between $f$ and $h$.

This item was designed to assess Teacher Y's ability to find differences between two functions if their domains have been restricted. The differences which were being sought in this case were conceptual differences not ordinary and obvious ones. To state that their domains were different and hence their ranges would also be different was an obvious observation with little conceptual application (see Figure 93). Teacher $Y$ was expected to draw the graphs of $h(x)=x^{2}+1$ for $-2 \leq x \leq 2$ and $f(\mathrm{x})=\mathrm{x}^{2}+1$ for $0 \leq \mathrm{x} \leq 2$ and use them to find some differences.

There were no restrictions on the approach to be used and the conceptual differences to be stated but Teacher $\mathrm{Y}$ could among other differences stated that (i) $h(\mathrm{x})=\mathrm{x}^{2}+1$ for $-2 \leq \mathrm{x} \leq 2$ was a many-to-one function while $f(\mathrm{x})=\mathrm{x}^{2}+1$ for $0 \leq \mathrm{x}$ $\leq 2$ was a one-to-one function (ii) $h(\mathrm{x})=\mathrm{x}^{2}+1$ for the domain $-2 \leq \mathrm{x} \leq 2$ did not have an inverse while $f(\mathrm{x})=\mathrm{x}^{2}+1$ for the domain $0 \leq \mathrm{x} \leq 2$ had an inverse. These are among the key differences between $h(\mathrm{x})$ and $f(\mathrm{x})$. Thus, Teacher Y's answers were not valid for this question. Teacher Y was asked to justify his answers. Considering the answer he gave in the test and his views during the interview, he was given a rating of level 0 on this one.

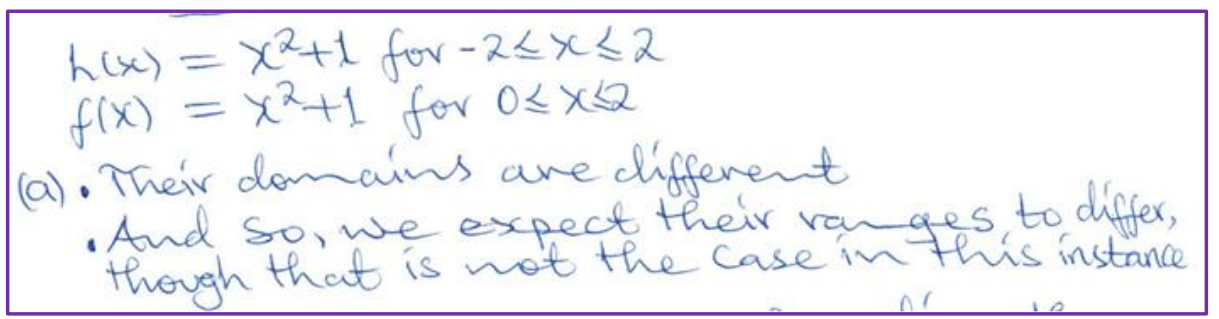

Figure 93. Excerpt of Teacher Y's answer to item 4(a)

Interviewer: In question 4(a) you were asked to find the difference between the functions $\mathrm{f}(\mathrm{x})$ and $\mathrm{h}(\mathrm{x})$. would you please justify your answer?

Teacher Y: probably the point where I should be allowed to go a little deeper is on point number 2, because for domains being different it is easier for us to see. Now we are saying that we expect the ranges to differ depending on the function that you are dealing with. However, in this case looking at the function that we are dealing 
with $\mathrm{x} 2+1$, so the values from [pause] -2 to 0 will give the same outputs as the domain from 0 to 2 because $\mathrm{x}$ is squared.

Interviewer: And still on this one. Did you try to sketch the two functions? Would we say by restricting the domain of $\mathrm{f}(\mathrm{x})$ we are making it a one-to-one function?

Teacher Y: Of course, yes, yes. It was just a restriction.

Interviewer: Do you think that $\mathrm{h}(\mathrm{x})$ is many-to-one while $\mathrm{f}(\mathrm{x})$ is one-to-one?

Teacher Y: That is true Sir. That is very true because you are going to have two values of $\mathrm{x}$ mapping onto one value of $\mathrm{y}$. definitely it comes out to be a many-to-one function.

Interviewer: Does it make sense to conclude that $f(x)$ has an inverse while $h(x)$ does not?

Teacher Y: It makes sense yes because for a function to have an inverse it is supposed to be one-to-one.

Item 4(e)

Determine the relationship between the range of $h$ and the domain of $f^{-1}$.

This item was designed to assess Teacher Y's ability to determine the relationship between the domain and range of two functions. According to Teacher $Y$ (see Figure 94), the range of $h$ and the domain of $f^{-1}$ both had minimum value of 1 . The essential relationship that Teacher $\mathrm{Y}$ was expected to state was that the range of $h$ was equal to the domain of $f^{-1}$. His answer was rated level 0 .

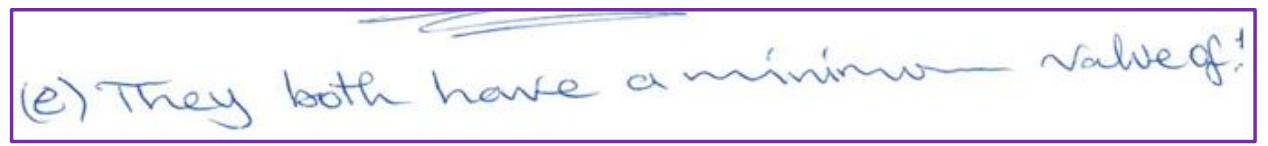

Figure 94. Excerpt of Teacher Y's answer to item 4(e)

Item 5(b)

Given that $g(x)=\frac{3}{2 x+1}$ and $z: x \rightarrow x^{2}-2 x$, state with justification, two domains on which the function $\mathrm{z}: \mathrm{x} \rightarrow \mathrm{x}^{2}-2 \mathrm{x}$ has an inverse.

This item was designed to assess Teacher Y's ability to determine two domains on which the given function had an inverse. Firstly, Teacher Y stated that for the function $z: \mathrm{x} \rightarrow \mathrm{x}^{2}-2 \mathrm{x}$ to have an inverse it needed to be a one-to-one function (Figure 95). This reasoning by Teacher $\mathrm{Y}$ was valid and key to determining the required domains and thus it justified the two domains that he gave. Thus his answer was considered valid and was rated level 1 . 


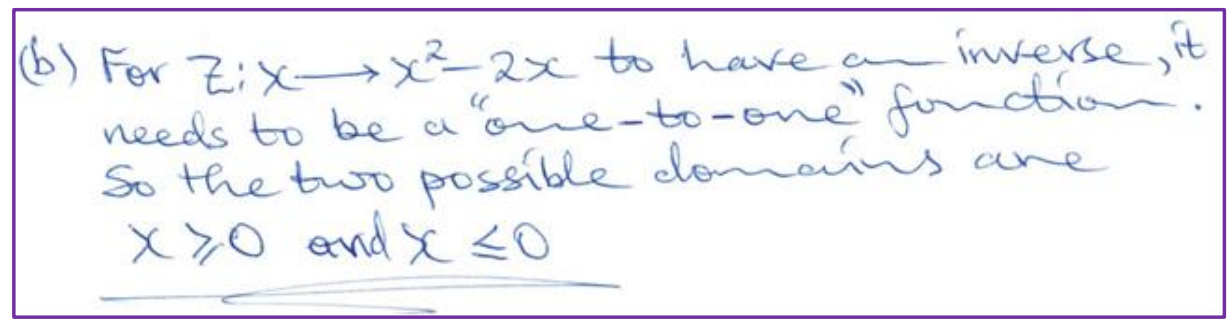

Item 9

Figure 95. Excerpt of Teacher Y's answer to item 5(b)

Consider the three figures below and answer the questions that follow.

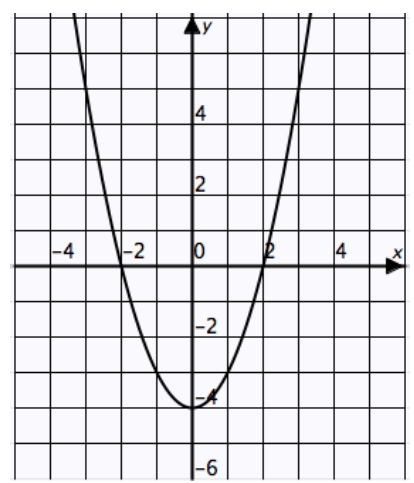

Figure A

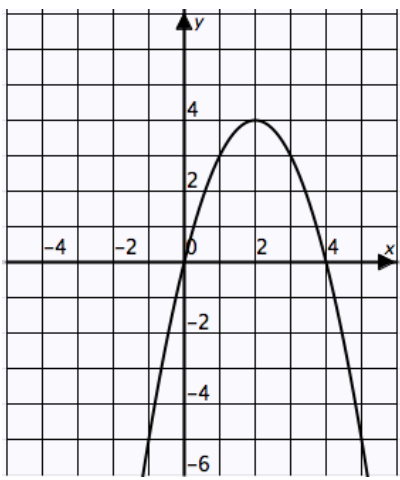

Figure B

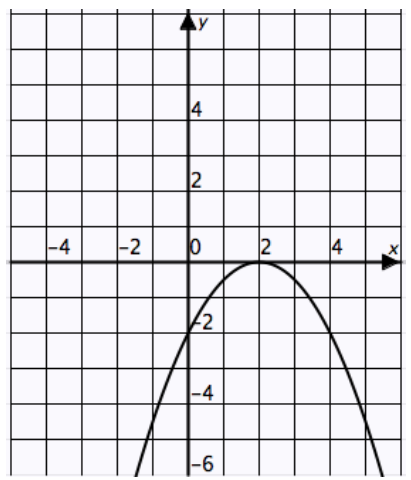

Figure C

This item was designed to assess Teacher Y's level of knowledge of analyzing graphs of quadratic functions. The key features that Teacher Y was expected to bring out when analyzing the given graphs included (but were not limited to) using the general form $\mathrm{f}(\mathrm{x})=\mathrm{ax} \mathrm{x}^{2}+\mathrm{bx}+\mathrm{c}$ where $\mathrm{a}, \mathrm{b}$ and $\mathrm{c}$ are constants and $\mathrm{a} \neq 0, \mathrm{x}$ and $\mathrm{y}$ intercepts of the graph, stationary (minimum and maximum) points, axes of symmetry and the nature of roots of the quadratic functions.

Item 9(a)

Indicate the features that are common to graphs A and B but not to graph C.

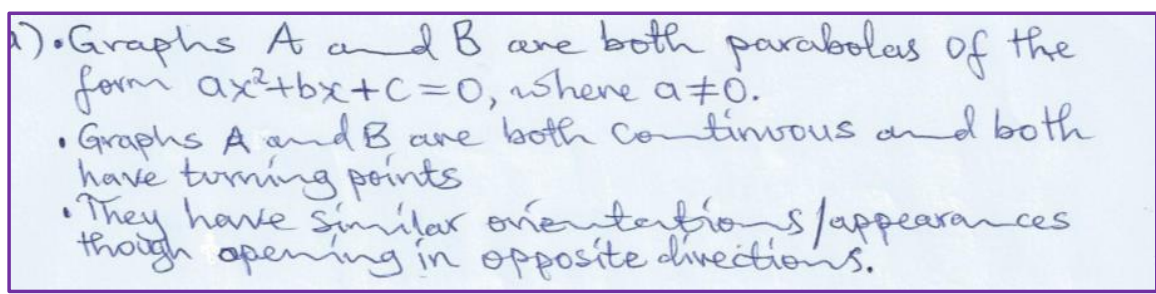

Figure 96. Excerpt of Teacher Y's answer to item 9(a) 
Item 9(b)

Indicate the features that are common to graphs $\mathrm{B}$ and $\mathrm{C}$ but not to graph $\mathrm{A}$.

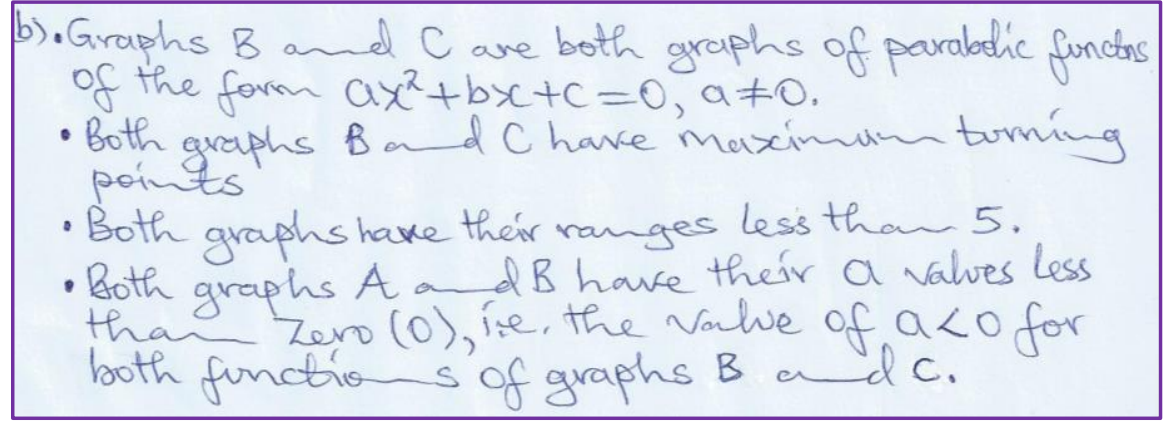

Item $9(\mathrm{c})$

Figure 97. Excerpt of Teacher Y's answer to item 9(b)

Indicate the features that are common to graphs $\mathrm{A}$ and $\mathrm{C}$ but not to graph $\mathrm{B}$.

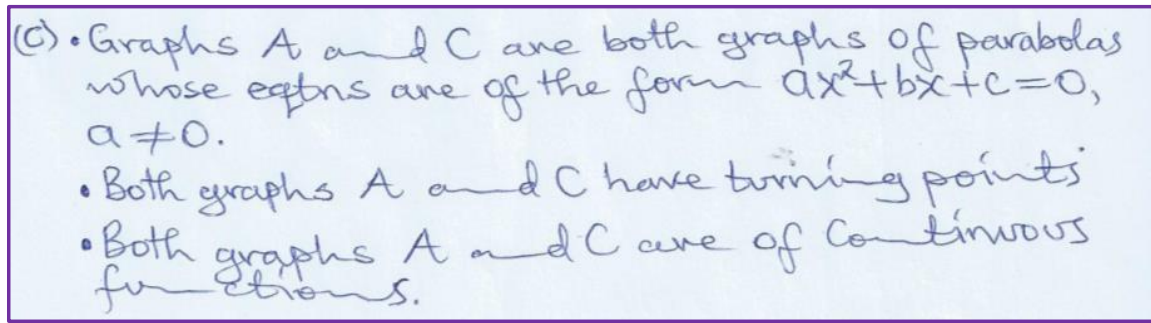

Figure 98. Excerpt of Teacher Y's answer to item 9(c)

Here are the three equations for the functions A, B and C. You might want to use them.
A. $\mathrm{y} \square \mathrm{x}^{2} \square 4$
B. $\mathrm{y} \square 4(\mathrm{x} \square 2)^{2}$
C. $\mathrm{y} \square \square \frac{1}{2}(\mathrm{x} \square 2)^{2}$

Teacher $\mathrm{Y}$ distinguished figures $\mathrm{A}, \mathrm{B}$ and $\mathrm{C}$ in terms of the nature of the nature of their turning points and continuity. He explained why in figure A the parabola opens upwards while in the other two figures the parabolas open downwards and possibly related this to the coefficient of $x^{2}$ in the general form $f(x)=a x^{2}+b x+c$. It can be seen from the explanations advanced by this teacher that there are gaps in his specialized content knowledge as he was not thoroughly able to work with different representations. His answer to this question was rated level 0. 


\section{The case of Teacher $Z$}

Item 1(c)

Is there a difference between a function and a relation? Explain your view.

This item was designed to assess Teacher Z's knowledge of differences between a relation and a function. Teacher $\mathrm{Z}$ was expected to know that generally a function is also a relation with special characteristics.

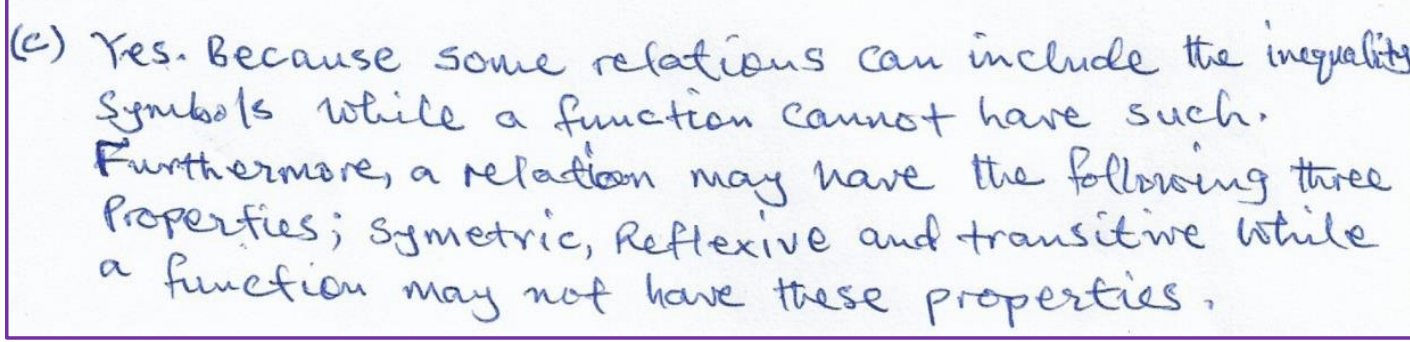

Figure 99. Excerpt of Teacher Z's answer to item 1(c)

Teacher $\mathrm{Z}$ correctly stated that there were differences between relations and functions (see Figure 99). He supported his claim by focusing on properties of a relation that may not hold for a function. He stated that a relation can be expressed using an inequality symbol while this may not be the case with functions. He further stated that typically a relation may be symmetric, reflexive and transitive while these maybe be absent in a function. As there were no restrictions on which differences one would state, Teacher Z's answers were accepted as valid for this question. However, Teacher $\mathrm{Z}$ was also supposed to explicitly state that a function is a relation in which each member of the domain corresponded to a unique member of the range if he uses the concept of domain and range which is common in Zambian curriculum materials. His answer was rated level 1.

Item $1(\mathrm{~d})$

How are functions and equations related to each other?

This item was designed to assess Teacher Z's knowledge of a function and that of an equation. He was also expected to acknowledge that functions and equations are not essentially the same though they may be related to each other in some way. 
(d) Functions are refoted to each other as they both have
a variable. In the first, (a) confrolling vareable(5)
existis) on which the function depends. In the lafter,
(a) variables) exist(s) which con only have (a) specific
value(s).

Figure 100. Excerpt of Teacher Z's answer to item 1(d)

Teacher $\mathrm{Z}$ claimed that functions and equations were related in the sense that both of them are expressed using variables (Figure 100). He claimed that functions have a controlling variable on which the depend although he did not clarify what he meant by a controlling variable. As regards equations Teacher $\mathrm{Z}$ claimed that they have a variable which can only have specific values. Teacher Z's answer lacks clarity and cannot be entirely accepted. One of the relationships he was expected to mention was that sometimes functions can be expressed using an equal sign which is always present in an equation. Thus, an equation can be used to define a function. His answer was inadequate and was rated level 0.

Item 1(f)

Draw a graph of a function that passes through the points $\mathrm{X}$ and $\mathrm{Y}$ in the figure below (Figure 101). Are there other functions which pass through the points $\mathrm{X}$ and $\mathrm{Y}$ ? if yes, draw the graph of such a function. If no such other function exists,

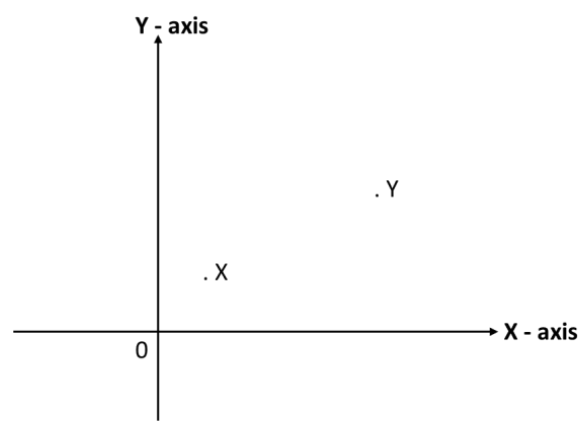

Figure 101. XY-Plane showing points X and Y

This item was designed to assess Teacher Z's knowledge of graphs of functions. In particular he was assessed on his ability to draw graphs based on given constraints. In this case he was expected to draw graphs that passed through two predetermined points. Teacher $\mathrm{Z}$ drew two graphs that passed through points $\mathrm{x}$ and $\mathrm{y}$. the first which was also obvious was the graph of a linear function and the second 
was a graph of a quadratic function. By drawing the two graphs (Figure 102), Teacher $\mathrm{Z}$ demonstrated that he had knowledge of drawing graphs when given restrictions. His answer was valid and was rated level 2.

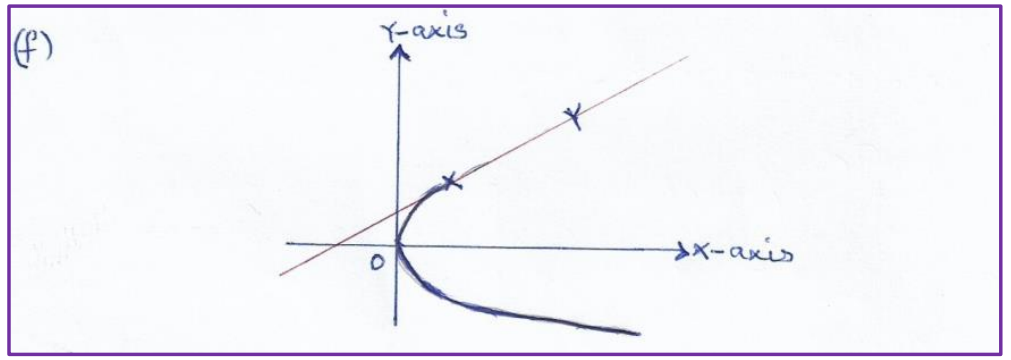

Item 2(a)

Figure 102. Excerpt of Teacher Z's answer to item 1(f)

Represent the function $g: \mathrm{x} \rightarrow|\mathrm{x}|$ whose domain is $\{\mathrm{x}:-3 \leq \mathrm{x} \leq 2$, and $\mathrm{x} \in Z\}$ on a Cartesian plane

This item was designed to assess Teacher Z's knowledge of drawing continous and descret functions. In answering this question the key aspect was for Teacher $\mathrm{Z}$ to decide from the onset the kind of a graph he was drawing. The clue to this was hidden in the domain of $g(\mathrm{x})$, which in this case, was a closed interval on the set of integers. This was a descrete interval with integers $-3,-2,-1,0,1,2$ which would produce specific out puts using the function $g(\mathrm{x})$.

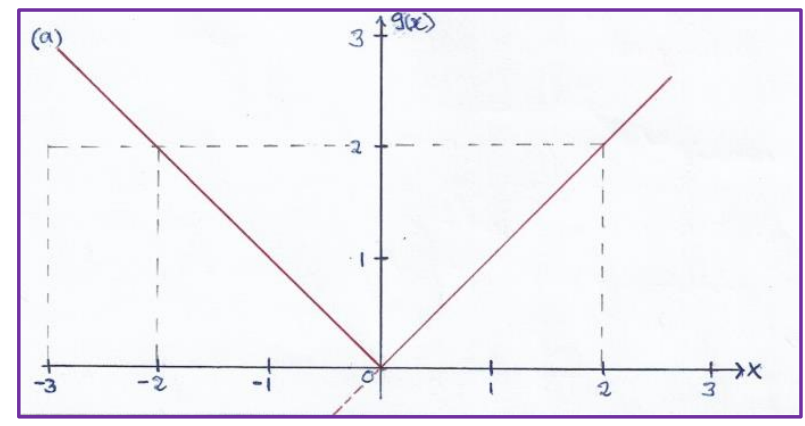

Figure 103. Excerpt of Teacher Z's answer to item 2(a)

Teacher Z correctly drew and labeled the XY-plane, and he correctly plotted the domain and range points of the absolute value function (see Figure 103). However, he did not analyze and properly interpret the domain of $g: \mathrm{x} \rightarrow|\mathrm{x}|$ to help him ascertain whether or not he was supposed to connect the plotted points of the function. As a result he incorrectly connected the plotted points. This was a 
demonstration that Teacher $\mathrm{Z}$ lacked knowledge of discrete functions. Had he noticed earlier that the given domain was discrete he could have considered not connecting the plotted points. Further, he lacked knowledge of the difference between discrete and continuous functions which is very important if he has to teach graphs of functions adequately to his future secondary school learners. Thus, Teacher $\mathrm{Z}$ presented an invalid answer. During the interview Teacher $\mathrm{Z}$ was asked to justify his answer. His answer to this question was rated level 0.

Interviewer: Would you give justification for your answer to 2(a)? why did you connect the plotted points?

Teacher Z: I just wanted to see how it was going to come out

Item 2(b)

Answer this question on a sheet of graph paper provided. The table below shows corresponding values of the objects and images of a function $f(x)=-2 x^{2}-x+8$. Taking $2 \mathrm{~cm}$ to represent 1 unit on the $\mathrm{x}-$ axis for $-3 \leq \mathrm{x} \leq 2$ and $1 \mathrm{~cm}$ to represent 1 unit on the $\mathrm{y}$-axis, draw the graph of $f(x)=-2 x^{2}-x+8$.

Table 31. Relationship between $\mathrm{X}$ and $\mathrm{f}(\mathrm{x})$

\begin{tabular}{|c|c|c|c|c|c|c|c|c|c|}
\hline$X$ & -3 & -2 & -1 & -0.5 & 0 & 0.5 & 1 & 2 & 3 \\
\hline$f(x)$ & -7 & 2 & 7 & 8 & 8 & 7 & 5 & -2 & -13 \\
\hline
\end{tabular}

This item was designed to assess Teacher Z's knowledge of drawing graphs of quadratic functions. This being a key concept in the secondary school curriculum in Zambia, Teacher $\mathrm{Z}$ was assessed on his ability to move between different representations of functions, in this case he moved from tabular to graphical representation.

Analyzing the graph presented by Teacher Z (Figure 104), it can be seen that he correctly drew and labeled the XY-plane. The given points were also correctly plotted with a smooth cur connecting them except for the y-coordinate of the maximum point of the parabola. He was asked during the interview to justify the maximum point in view of the given function Teacher $\mathrm{Z}$ demonstrated good knowledge of drawing graphs of quadratic functions. This was attributed to the fact that this type of graph is usually the major graph taught at secondary school and there is considerable attention given to it at university level in Zambia. His answer was rated level 1. 


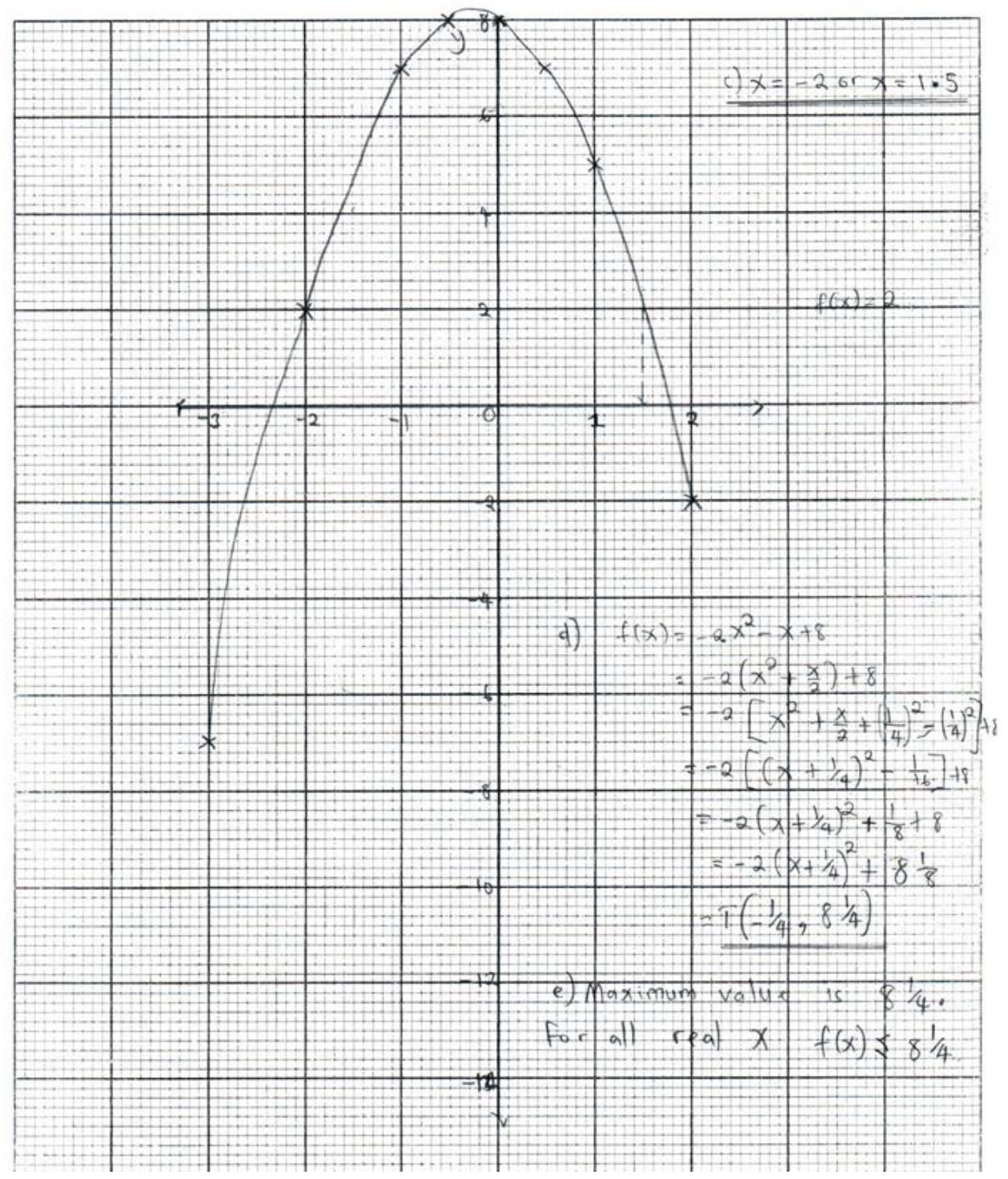

Figure 104. Excerpt of Teacher Z's answer to item 2(b)

\section{Item 2(e)}

State the maximum value of $f(x)=-2 x^{2}-x+8$ and explain how this value relates to the range of the function $f$.

This item was designed to assess Teacher Z's ability to use the graph of a quadratic function to determine the maximum value and give a sound explanation about its relationship to the range of the function. Analyzing Teacher Z's work (Figure 105), it can be seen that the maximum value which he stated was incorrect. This was due to errors committed as he was completing the square of the function $(x)$ $=-2 x^{2}-x+8$. During the interview he was asked about how the earlier error affected 
his answer at this stage. He said that it was just a mistake and his answer was rated level 0 .

$$
\begin{aligned}
& \text { (e) Maximum value is } 8 \frac{1}{4} \text {. } \\
& \text { For all real } x \quad f(x) \leq 8 \frac{1}{4}
\end{aligned}
$$

Figure 105. Excerpt of Teacher Z's answer to item 2(e)

Item 3(c)

The figure below (Figure 106) is a graph of a function $f(x)=a x^{2}+b x+c$. state whether $\mathrm{a}, \mathrm{b}$ and $\mathrm{c}$ are positive, negative or zero. Explain your decision.

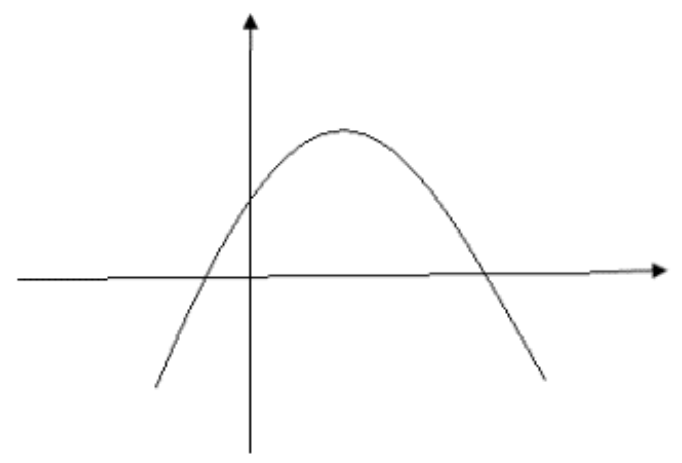

Figure 106. Graphical representation of $\mathrm{f}(\mathrm{x})=\mathrm{ax} \mathrm{x}^{2}+\mathrm{bx}+\mathrm{c}$

The reason for asking this question was to assess Teacher Zs' knowledge of graphs of functions. For this purpose the graph of a quadratic function (parabola) was used. For Teacher $\mathrm{Z}$ to comprehensively answer this question he needed to have good knowledge of the features of the graph of a quadratic function. He needed to know that for the function $f(x)=a^{2}+b x+c$, the value of "a" was positive (i.e a $>0$ ) if and only if the parabola opened upwards and it was negative $(a<0)$ if and only if it opened downwards. In other words the value of "a" was positive if the parabola had a minimum turning point and it was negative if the parabola had a maximum turning point. To determine whether " $b$ " was positive or negative, Teacher $\mathrm{Z}$ expected to use the principle of the first derivative at the stationary point which states that "at the stationary point (maximum or minimum), the first derivative $\mathrm{f}^{\prime}(\mathrm{x})$ of the function $f(\mathrm{x})$ $=a x^{2}+b x+c$ is equal to zero. That is, $f^{\prime}(x)=2 a x+b$ implies that $2 a x+b=0$. Thus, solving for $b$ gives $b=-2 a x$. Since the parabola under consideration opens 
downwards, the value of "a" is negative, making " $b$ " to be positive. A rule of thumb could also be applied which states that if the y coordinate of the turning point was positive, then "b" was also positive. "c" is basically the y-intercept of the graph.

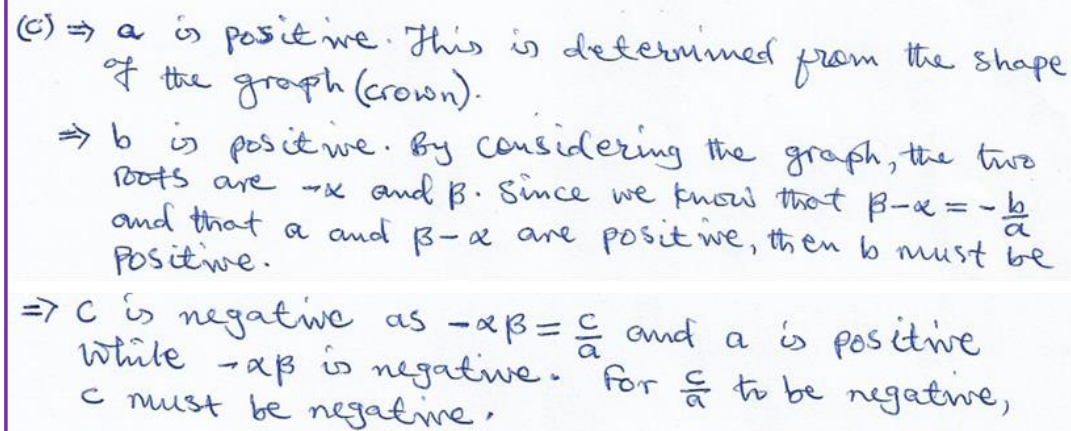

Figure 107. Excerpt of Teacher Z's answer to item 3(c)

Teacher Z stated that "a" was positive because the graph of the function $f(\mathrm{x})=$ $a x^{2}+b x+c$ opened downwards See Figure 107). He used the nature of roots of the given function to determine the sign of " $b$ " and established that it was also positive. According to Teacher $\mathrm{Z}$, "the two roots of the function were $-\alpha$ and $\beta$. Since $\beta-\alpha=-\frac{b}{a}$ and that "a" and $\beta-\alpha$ were positive, it followed that "b" was also positive". He further stated that "c" was negative because $-\alpha \beta=\frac{c}{a}$ and "a" was positive while $-\alpha \beta$ was negative. During the interview he was asked to clarify his reasoning for determining "a" as positive and "c" to be negative. Considering the mistakes made in the test which he corrected during the interview, Teacher Z's answer was rated level 1.

Interviewer: Would you please justify your answers to 3(c)?

Teacher $\mathbf{Z}$ : The graph has a maximum value so the value of "a" should be negative. When you look at "c" we are looking at [the point] where this curve will cut the $y$ axis. So, when you look at the way it is, "c" wil be positive/

Interviewer: But in the test you stated that "a" was positive and "c" was negative Item 4(a)

Teacher Z: Laughs..... that was just a mistake

Let $h(\mathrm{x})=\mathrm{x}^{2}+1$ for $-2 \leq \mathrm{x} \leq 2$ and $f(\mathrm{x})=\mathrm{x}^{2}+1$ for $0 \leq \mathrm{x} \leq 2$. State two differences between $f$ and $h$.

This item was designed to assess Teacher Z's ability to analyze given quadratic functions and identify conceptual differences between then. In this case he was expected to go beyond the information contained in the question. According to 
Teacher Z, the functions $h(x)$ and $f(x)$ have different domains and so they will have different ranges (see Figure 108). The different domains were part of the information contained in the question and thus do not qualify to be stated as conceptual differences. The domains actually would have been used as a clue to answering the question. Teacher $\mathrm{Z}$ could have drawn the graphs of $h(x)$ and $f(x)$ to have a visual analysis of the two functions. It would have been visible to him that $h(x)$ was a many-to-one function while $f(x)$ was a one-to-one function. Thus $h(x)$ had no inverse on the domain $-2 \leq \mathrm{x} \leq 2$ while $f(x)$ had an inverse on the domain $0 \leq \mathrm{x} \leq 2$. Thus, Teacher $\mathrm{Z}$ exhibited gaps in the analysis of the given functions and so his answer was not valid. During the interview Teacher $\mathrm{Z}$ was asked to explain more about his answers.

$$
\begin{aligned}
& \text { (a) } \Rightarrow \text { Their domain is different } \\
& \Rightarrow \text { Their range will also be different }
\end{aligned}
$$

Figure 108. Excerpt of Teacher Z's answer to item 4(a)

Interviewer: the answers to item 4(a) were not satisfactory. Would you explain more?

Teacher Z: When I looked at the functions that we [were] given, they were the same. The only thing that [changed] was the domain. That is the reason I stated those two differences.

Interviewer: Did you try to draw the graphs of the two functions?

Teacher Z: No I didn't, but when I draw the graph of the second [function] it will be like a subset of the other graph.

Interviewer: Don't you think that one of them has an inverse while the other does not?

Teacher Z: Yah, yes

Here Teacher Z didn't sound confident in agreeing with one function being invertible. He actually seemed lost with the whole situation which demonstrated a serious gap in knowledge. Consequently, his answer was rated level 0.

Item $4(\mathrm{e})$

Determine the relationship between the range of $h$ and the domain of $f^{-1}$.

This item was designed to assess Teacher Z's ability to identify relationships between the range of $h$ and the domain of $f^{-1}$. However, he did not answer this question. He was asked during the interview why he did not answer the question and whether he could answer it during the interview. Considering his answer during the interview, he was rated level 0 on this question. 
Interviewer: You did not answer 4(e). Explain why you left it unanswered.

Teacher Z: Umh.... It was difficult for me. I didn't understand it very well.

Item 5(b)

Given that $g(x)=\frac{3}{2 x+1}$ and $z: x \rightarrow x^{2}-2 x$, state with justification, two domains on which the function $\mathrm{z}: \mathrm{x} \rightarrow \mathrm{x}^{2}-2 \mathrm{x}$ has an inverse.

This item was designed to assess Teacher Z's ability find domains on which a quadratic function has an inverse. There exists many domains on either side of the origin of the XY-plane on which the function $\mathrm{z}: \mathrm{x} \rightarrow \mathrm{x}^{2}-2 \mathrm{x}$ has an inverse. It was upto him to stae only two of them. Analyzing his answer (Figure 109), it looked an incomplete and invalid answer. To this effect he was asked to clarify his answer during the interview. His answer to this question was rated level 0.

$$
\text { (b) hef } \begin{aligned}
z(x) & =x^{2}-2 x=y \\
y & =x^{2}-2 x
\end{aligned}
$$

Item 9

Figure 109. Excerpt of Teacher Z's answer to item 5(b)

Consider the three figures below and answer the questions that follow.

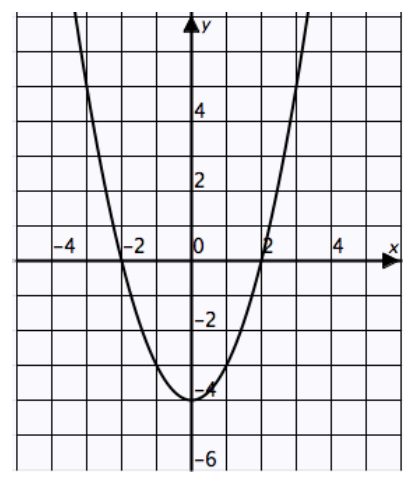

Figure A

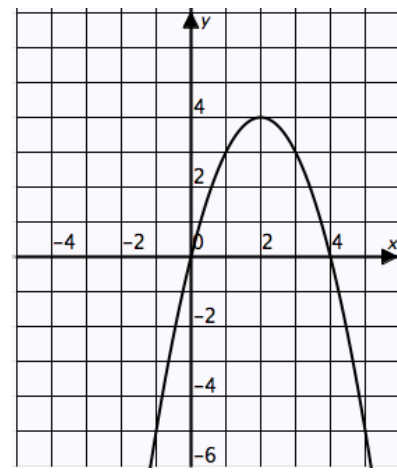

Figure B

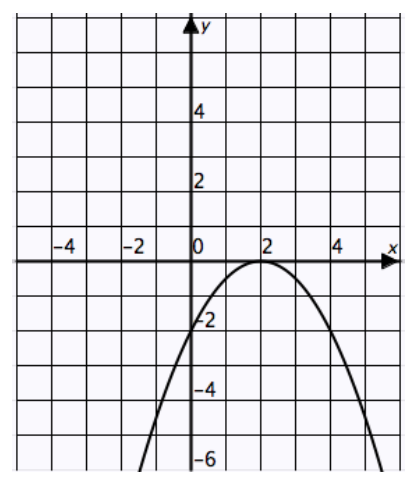

Figure C

This item was designed to assess Teacher Z's level of knowledge of analyzing graphs of quadratic functions. The key features that Teacher $\mathrm{Z}$ was expected to bring out when analyzing the given graphs included (but were not limited to) using the general form $f(x)=a x^{2}+b x+c$ where $a, b$ and $c$ are constants and $a \neq 0, x$ and $y$ intercepts of the graph, stationary (minimum and maximum) points, axes of symmetry and the nature of roots of the quadratic functions. 
Item 9(a)

Indicate the features that are common to graphs A and B but not to graph C.

$$
\begin{aligned}
& \text { (a)-Craphs } A \text { and } B \text { cut the } x \text {-axis at tros points } \\
& \text { - the distence between the roots in A and B is } \\
& \text { H units }
\end{aligned}
$$

Item 9(b)

Figure 110. Excerpt of Teacher Z's answer to item 9(a)

Indicate the features that are common to graphs $\mathrm{B}$ and $\mathrm{C}$ but not to graph $\mathrm{A}$.

Item $9(\mathrm{c})$

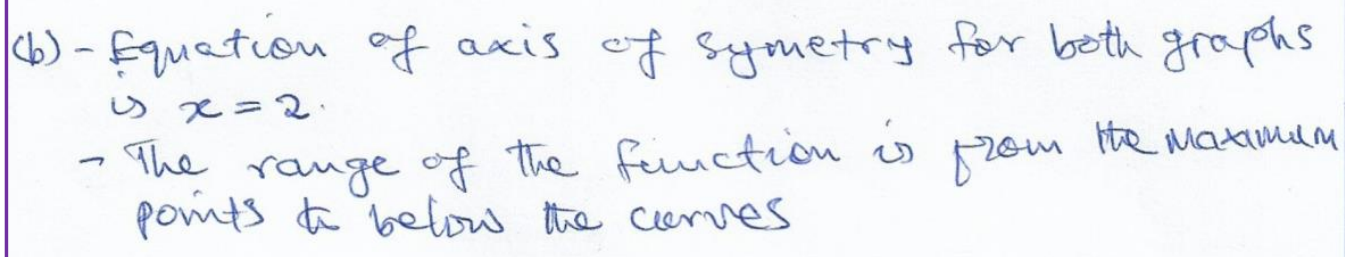

Figure 111. Excerpt of Teacher Z's answer to item 9(b)

Indicate the features that are common to graphs $\mathrm{A}$ and $\mathrm{C}$ but not to graph $\mathrm{B}$.

(c) The two graphs pass through the point $(2,0)$.

Figure 112. Excerpt of Teacher Z's answer to item 9(c)

Here are the three equations for the functions A, B and C. You might want to use them.
A. $\mathrm{y} \square \mathrm{x}^{2} \square 4$
B. $\mathrm{y} \square 4(\mathrm{x} \square 2)^{2}$
C. $\mathrm{y} \square \square \frac{1}{2}(\mathrm{x} \square 2)^{2}$

Teacher $\mathrm{Z}$ brought out different aspects of the distinction between graphs. In part (a) he concentrated more of the x-intercepts and to some extent on the symmetry of the graphs in figures A and B. It might have been good for this participant to talk also about the nature of the root as his mere mention of the roots was not enough to explain the difference. In part (b) Teacher $Z$ stated the axis of symmetry of the graphs in figures B and C. Symmetry in this situation was one of the key features that 
would help draw a distinction. For Teacher $\mathrm{Z}$ it was also important to state the nature of the turning point of the given graphs which was omitted. In part (c) Teacher Z stated the x-intercept as the major difference. He could also have talked about the $y$ intercept which the first student talked about. As such, his answer was rated level 1.

\subsubsection{Pre-service mathematics teachers' knowledge of functions concept content and students}

Pedagogical Content Knowledge (PCK) of pre-service teachers was investigated mainly through their Knowledge of Content and Students (KCS). To understand their level of KCS, three instruments were used namely pencil and paper test on functions, vignettes and lesson plans. I acknowledge that in the MKT framework by Ball et al. (2008) lesson plans and actual teaching would be categorized under teacher's Knowledge of Content and Teaching (KCT). However, this study sought to understand the kind of content teachers prepared for their students and how they would communicate it.

Thus, for the purpose of this study lesson plans and classroom teaching were imbedded in teacher's KCS. Vignettes demonstrated how teachers anticipated, identified and diagnosed students' misconceptions, errors and difficulties when presented with hypothetical situations. Lesson plans and actual teaching activity demonstrated how teachers packaged content and unpacked it in class using suitable teaching strategies. For this reason it was important to include lesson plans and classroom teaching activities. This provided a holistic and in-depth picture of preservice teachers' knowledge of the function concept. Lesson plans, classroom teaching activities and vignettes were used to answer the following question.

\section{What level of proficiency of knowledge of content and students of the concept of a function do Zambian pre-service mathematics teachers possess?}

Lesson plans, classroom teaching activities and vignettes were analyzed for each of the three teachers that participated in the qualitative phase of the study.

\section{The case of Teacher $X$}

\section{Summary of teacher $X$ 's lesson plan on inverse functions}

The lesson plan was prepared for a grade 11 class comprised of 52 students (30 boys and 22 girls). It would be taught in 80 minutes. The rationale set out by the teacher for teaching inverse functions was that students "would learn how to find the inverse of a function and the lesson would create critical thinking in learners". As 
pre-requisite knowledge, students were expected to possess knowledge about "mappings, and that of changing subject of the formula". The expected outcomes were that students should be able to (a) define and find the inverse of a function, (b) use the inverse function to find the domain. Teacher $\mathrm{X}$ only planned to use a duster and board rule as his teaching aids for the lesson (see Figure 113).

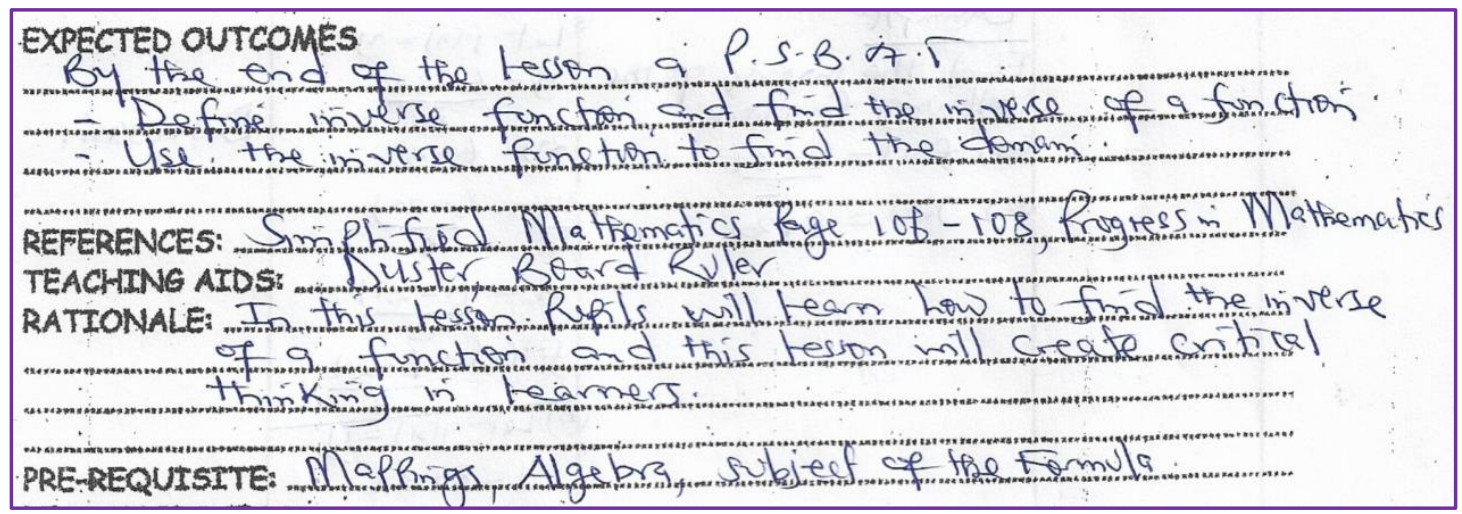

Figure 113. Excerpt LP1 of Teacher X's lesson plan on inverse functions

Teacher X planned to introduce the lesson by posing a question to the students for discussion as a way to recap on the previous lesson. The teacher would ask the learners to evaluate a function and to find a value(s) for which a given function would be undefined (see Figure 114).

\begin{tabular}{|c|c|c|c|}
\hline STAGETTIME & TEACHERS ACTIVITY & PUPILS ACTIVDTY & METHODS USEO \\
\hline $\begin{array}{l}\text { Tritroductori } \\
\text { (Smins). }\end{array}$ & $\begin{array}{l}\text { Give a recal on the } \\
\text { Revious lesson. } \\
\text { Givin a function } \\
f(x)=\frac{3 x-1}{x-1} \text {, find } \\
(a) f(z) \text { (b) the value of } \\
x \text { for when the } \\
\text { fanction will be lindef }\end{array}$ & $\begin{array}{l}\text { Effected Answers } \\
\text { (a) } \begin{aligned} f(2) & =\frac{3(2)-1}{2-1} \\
& =\frac{6-1}{1} \\
f(2) & =5\end{aligned} \\
\text { ped. }\end{array}$ & ions \\
\hline
\end{tabular}

Figure 114. Excerpt LP2 of Teacher X's lesson plan on inverse functions

The teacher would then develop the lesson by giving the definition of the inverse of a function and the symbol used to denote inverse functions. The teacher believed that defining the inverse of a function at this stage would build a firm connection between what students learnt in the previous lesson to what they were currently learning. The teacher would give a definition from the reference book he used to prepare the lesson (Figure 115). 


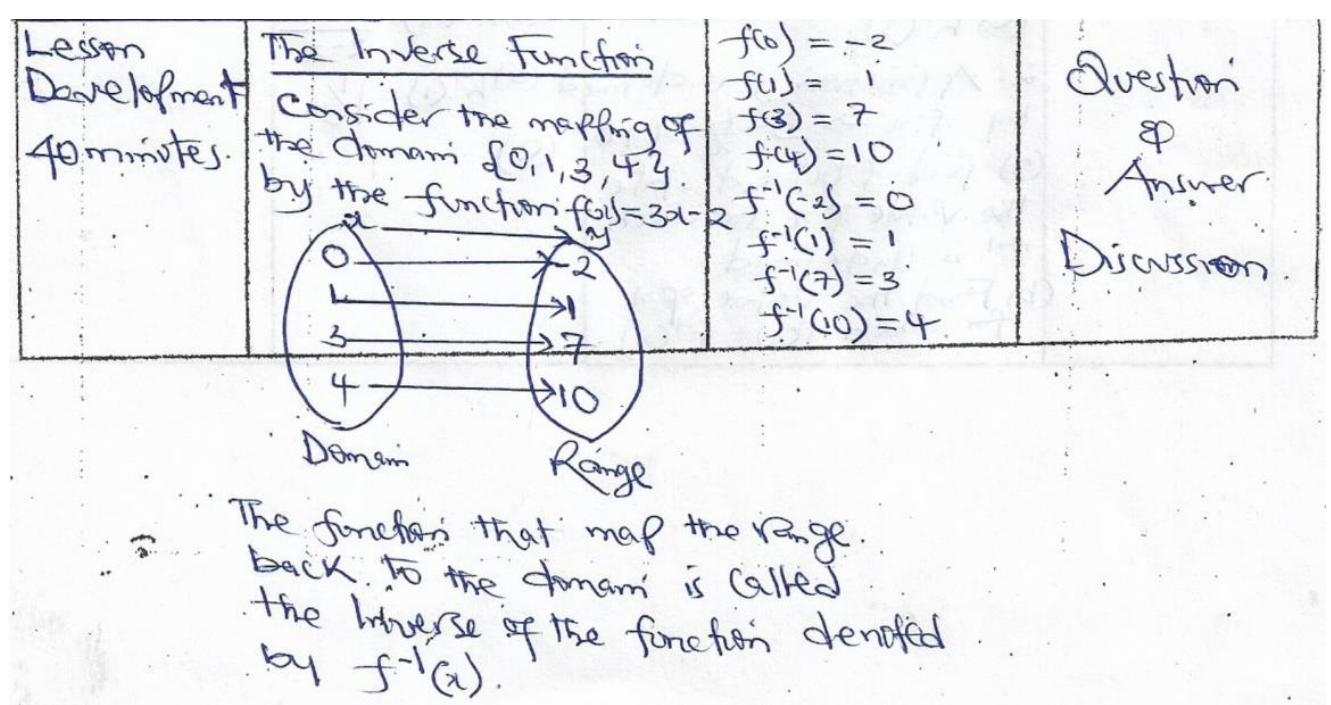

Figure 115. Excerpt LP3 of Teacher X's lesson plan on inverse functions

The teacher would then proceed to give two examples on finding the inverse of a function together with expected solutions to the example questions (Figure 116). Since the methods used to develop the lesson would be discussion method and question and answer method, students would be expected to find the same answer provided by the teacher with a step by step procedure of arriving at the answers.

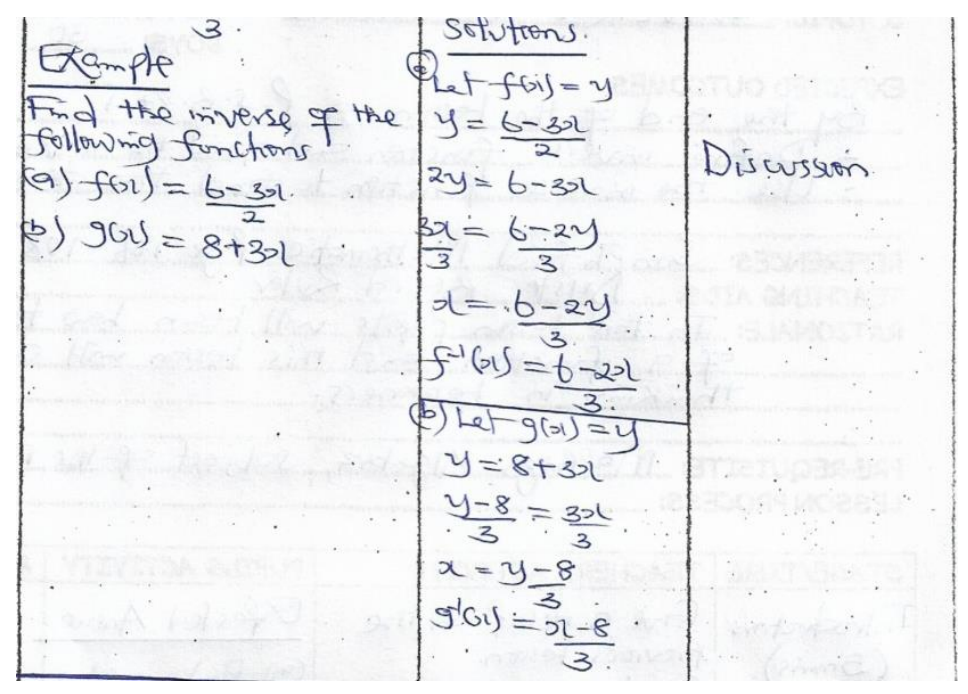

Figure 116. Excerpt LP4 of Teacher X's lesson plan on inverse functions

The teacher would winds up the lesson by giving students a 30 minutes class exercise and homework activity based on the day's lesson. It was hoped that students would consolidate their understanding of inverse functions by practice tasks given through the class exercise and homework. Teacher X concludes by telling students what they will learn in the next lesson 
Summary of teacher X's actual classroom teaching of the lesson on inverse functions

Teacher $\mathrm{X}$ began the lesson by greeting his students and briefly recapped on the previous lesson on domain and range of functions by stating that

"Good morning...... Last time I was here we discussed how to find the range of a function when you are given the domain. So today we will go a step further to look at how to find the inverse of a function......."

The teacher then asked his students to define the inverse of a function. Two students (a boy and a girl) attempted to define the inverse of a function. Without telling the students whether their definitions were correct or not the teacher went on to find the range of the function $\mathrm{f}(\mathrm{x})=3 \mathrm{x}-2$ whose domain was $\{0,1,3,4\}$. He substituted every element of the domain in the function to obtain the range. $\mathrm{He}$ carried out all the calculations by himself and involved the students by asking them questions throughout the steps. He illustrated this using the arrow diagram below.

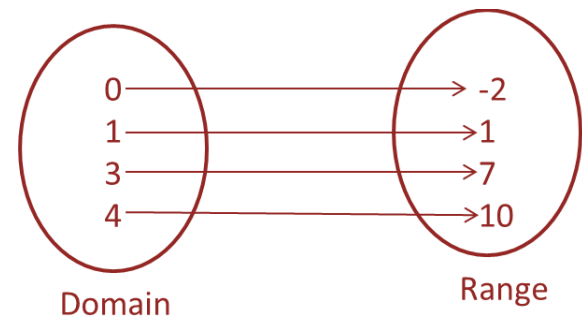

He explained that the function which would map elements of the range back to the domain was called the inverse of the function $\mathrm{f}$. He then demonstrated a step-by-step procedure for finding the inverse of the function $f(x)=3 x-2$ as follows

$f(x)=3 x-2$

Let $f(x)=y$, where there is $f(x)$ in the function replace it with $y$. So, we shall have

$y=3 x-2$, then make $x$ the subject of the formula to obtain

$y+2=3 x$, here he explained that when $(-2)$ crosses the equal sign it changes its sign to $(+2)$

He then said dividing both sides of $y+2=3 x$ by 3 we obtain

$$
\mathrm{x}=\frac{\mathrm{y}+2}{3}
$$

He then explained that the symbol for the inverse was $\mathrm{f}^{-1}$ and told the students that to finally write down the inverse of the given function replace $y$ with $\mathrm{x}$ to obtain

$$
\mathbf{f}^{-1}(\mathbf{x})=\frac{\mathbf{x}+\mathbf{2}}{3}
$$


He explained that the obtained inverse function would map every element of the range back to the domain. He went ahead to map elements of the range to the domain.

He then wrote two functions for students to find the inverse and invited a boy and a girl to find the inverse respectively.

\section{Examples}

Find the inverse of the functions

(a) $f(x)=\frac{6-3 x}{2}$

(b) $g(x)=8+3 x$

The boy correctly worked out example (a) to obtain

$\mathbf{f}^{-1}(x)=\frac{6-2 x}{3}$

He also correctly worked out the second example to obtain

$\mathbf{g}(\mathbf{x})=\frac{\mathbf{x}-\mathbf{8}}{\mathbf{3}}$

The teacher then gave the following task as class work (Figure 117). As the students were working out the problems the teacher went round checking what his students were doing, responding to individual student questions as they arose. This according to the teacher was aimed at ensuring that all students were actually focused on the given task. When all the students finished finding solutions to the given task the teacher quickly marked their work and invited selected students to showcase their answers on the chalk board.

\section{Task}

1. The function $h$ is defined by $h: x \rightarrow \frac{2 x-1}{x-3}, x \neq 3$. Find
(a) $h^{-1}(x)$
(b) $\mathrm{h}^{-1}(-1)$
(c) $h^{-1}(3)$

2. A function $\mathrm{f}$ is defined by $\mathrm{f}: \mathrm{x} \rightarrow 5-\frac{6}{\mathrm{x}}, \mathrm{x} \neq 0$. Find

(a) $f^{1}$ and state the value of $x$ for which $f^{1}$ is undefined

(b) the value of $x$ for which $f(x)=f^{-1}(x)$

Figure 117. Teacher X's class exercise on iverse functions

A boy was the first to work out question 1(a). As he worked out the problem he reached a stage containing the equation $x y-3 y=2 x-1$. He then said that to group 
like terms the term $2 \mathrm{x}$ would cross the equal sign to the left and the term (-3y) would also cross the equal sign to the right to obtain $\mathrm{xy}-2 \mathrm{x}=3 \mathrm{y}-1$. The last two stages of the calculation involved replacing the variable $\mathrm{y}$ with the variable $\mathrm{x}$ when introducing $\mathbf{h}^{-1}(\mathbf{x})$. The student did not give a reason for this replacement. Neither did the teacher.

$$
\begin{aligned}
& x=\frac{3 y-1}{y-2} \\
& \mathbf{h}^{-1}(\mathbf{x})=\frac{\mathbf{3 x}-\mathbf{1}}{\mathbf{x}-\mathbf{2}}
\end{aligned}
$$

\section{Summary of teacher $X$ 's lesson plan on composite functions}

This was also an 80 minutes lesson prepared for the same Grade 11 class that was taught inverse functions. In this lesson students would be expected to define and evaluate composite functions with a performance level of at least $75 \%$ being satisfactory. Teacher $\mathrm{X}$ did not state pre-requisite knowledge required for his learners to learn composite function but did indicate that the rationale for teaching composite functions was to "create critical thinking in the learners" (see Figure 118). A duster and a ruler were the only teaching aids Teacher $\mathrm{X}$ deemed suitable for this lesson.

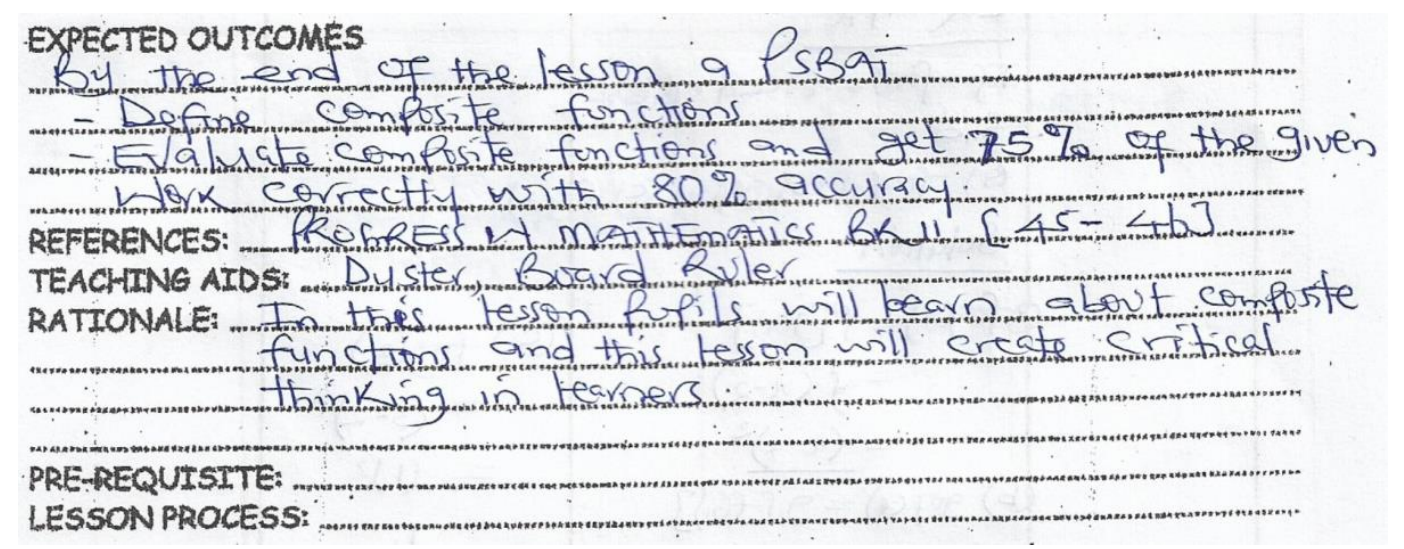

Figure 118. Excerpt LP5 of Teacher X's lesson plan on composite functions

Teacher $\mathrm{X}$ would introduce the lesson by revisiting work covered in the previous lesson and would then link it to the current lesson (see Figure 119). To accomplish this Teacher $\mathrm{X}$ would present and workout a question on inverse functions, being the subtopic which was learnt in the previous lesson. In developing the lesson, Teacher $\mathrm{X}$ would proceed to present an example of a composite function without explicitly giving a definition of what a composite function really is (Figure 
120). Meanwhile, one of the expected outcomes of the lesson is for students to define the composite function.

\begin{tabular}{|c|c|c|c|}
\hline STAGE TXME & TEACHERS ACTIVITY & PUPILS ACTIVITY & METHODS USEO \\
\hline $\begin{array}{l}\text { Iritroduction } \\
5 \text { minutes. }\end{array}$ & $\begin{array}{l}\text { Give a recap on the } \\
\text { Previous lesson. } \\
\text { Gruen a function } \\
f(x)=\frac{3 x+1}{2} \text {, find } \\
\begin{array}{ll}\text { (a) } f^{-1}(x) & \text { (b) } f^{-1}(5)\end{array}\end{array}$ & $\begin{array}{l}\text { Exrecfed Arinel } \\
\text { (a) } f^{-1}(x)=\frac{2 x-1}{3} \\
\text { (b) } f^{-1}(5)=3\end{array}$ & $\begin{array}{l}\text { Question } \\
\text { and } \\
\text { Answer. }\end{array}$ \\
\hline
\end{tabular}

Figure 119. Excerpt LP6 of Teacher X's lesson plan on composite functions

The teacher would develop the lesson further by explaining and showing students how to denote composite function. He would then present another example before proceeding to give a class exercise and homework activity. The teacher would conclude by highlighting what would be covered in the next lesson. An extract of the example which is similar to the task given in the class exercise and homework is presented below.

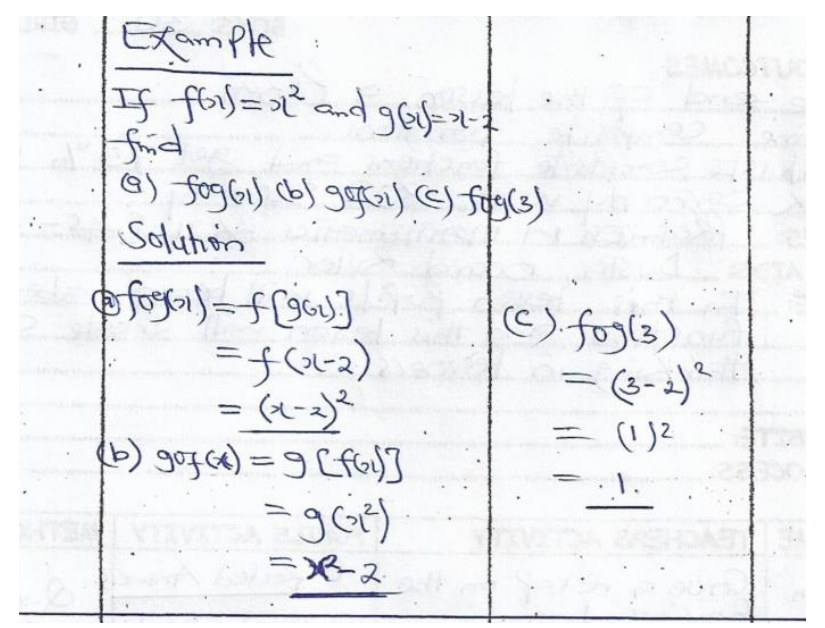

Figure 120. Excerpt LP7 of Teacher X's lesson plan on composite functions

\section{Summary of Teacher X's actual classroom teaching activity of the lesson on composite functions}

The teacher greeted his students and introduced the lesson by posing the following question which was answered to his satisfaction by a student.

Teacher: What is a composite function?

Student answer: A composite function is a combination of two functions

The teacher went further to explain that composition of functions can involve two or more functions. To further consolidate his explanation, he demonstrated the concept 
of composite functions by finding the composition of the functions $f: x \rightarrow 2 x-3$ and $\mathrm{g}: \mathrm{x} \rightarrow \mathrm{x}+2$. He progressed as follows

$$
\begin{aligned}
\mathrm{f}(4) & =2(4)-3 \\
& =8
\end{aligned}
$$

In the above work the teacher did not demonstrate how to find $g[f(x)]$ and how to eventually use it to evaluate $\mathrm{g}[\mathrm{f}(4)]$. At this stage he used the arrow diagram to explain that it could be assumed that a machine acts on the number 4 to give out the number 5 . Then it acts on the number 5 to give out a 7 . The same reasoning was applied to the variable $\mathrm{x}$ until he realized that when the machine acted on the expression $2 \mathrm{x}-3$ the output for $\mathrm{g}[\mathrm{f}(\mathrm{x})]$ was not readily available to complete the explanation because he did not find it early in his calculations.

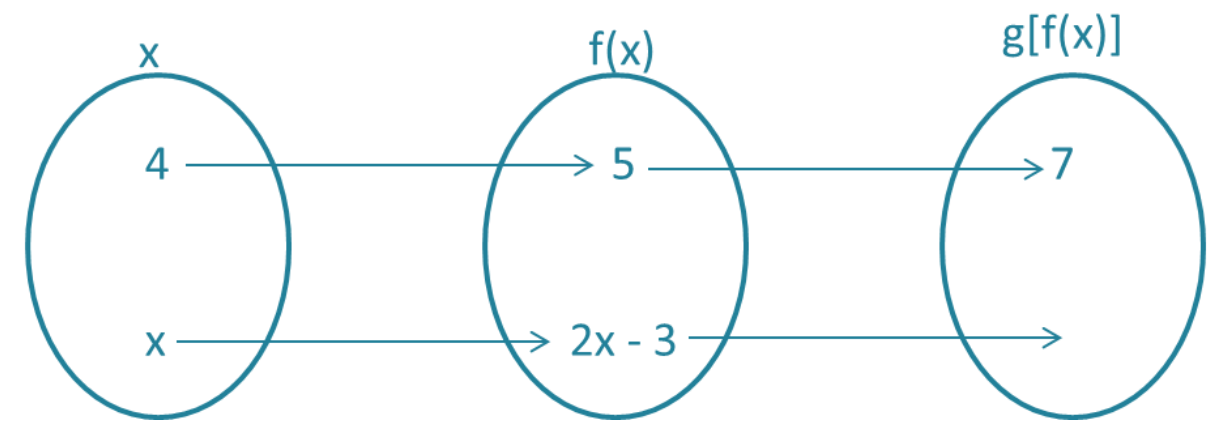

Then teacher then began to find the expression for the function $g[f(x)]$. At this stage the teacher carried out the manipulations without necessarily involving his students and correctly found $g[f(x)]=2 x-1$. The teacher then presented an example on composition of functions which he worked out by himself. The teacher concluded the lesson by giving a class exercise. He went round marking and helping students that encountered difficulties.

\section{Teacher X's responses to vignettes}

Vignette 1

You have been discussing the concept of inverse functions in class. You pose the following question in class.

Determine the inverse $\left(f^{-1}(x)\right)$ of a function $f(x)=x-4$.

Five different solutions come out from the class. 
(i) $\quad f^{-1}(\mathrm{x})=\frac{1}{\mathrm{x}-4}$

(ii) $\quad f^{-1}(\mathrm{x})=\frac{1}{\mathrm{x}}-4$

(iii) $f^{-1}(\mathrm{x})=-\mathrm{x}-4$

(iv) $f^{-1}(\mathrm{x})=-\mathrm{x}+4$

(v) $\quad f^{-1}(\mathrm{x})=\mathrm{x}+4$

The different answers reveal that the class is confused.

What is the problem in each solution (if there exists)?

Explain how you would respond to these comments and clear up confusion during a class.

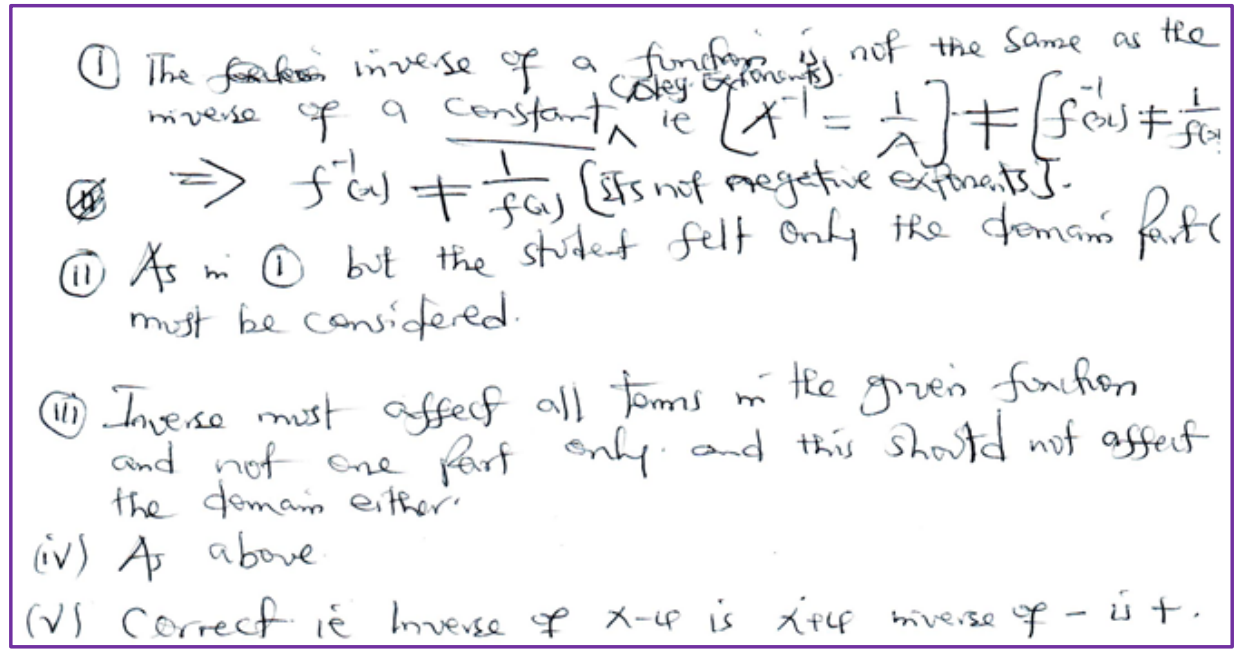

Figure 121. Teacher X's response to vignette 1

This vignette was centered on teacher's ability to understand inverse function notation and how it caused misconceptions by conflicting with concepts in arithmetic (multiplicative inverse) and negative exponents when dealing with indices and exponential functions. The teacher demonstrated superior understanding of inverse function notation and explained how it differed from multiplicative inverse in arithmetic (Figure 121). This helped the teacher to spot defects in the reasoning of the students in the solutions presented. The teacher was equally able to recognize the correct answer. Considering the clarity of concepts in the teacher's explanations, his response to this vignette was rated Level 2.

Vignette 2

A student said the inverse of the function $(x)=x^{2}$ is $f(x)=\sqrt{x}$.

Is the student right? If you think that the student is correct explain why? 
If you think the student is incorrect explain where the error lies and how you would respond to these comments and clear up confusion in lass.

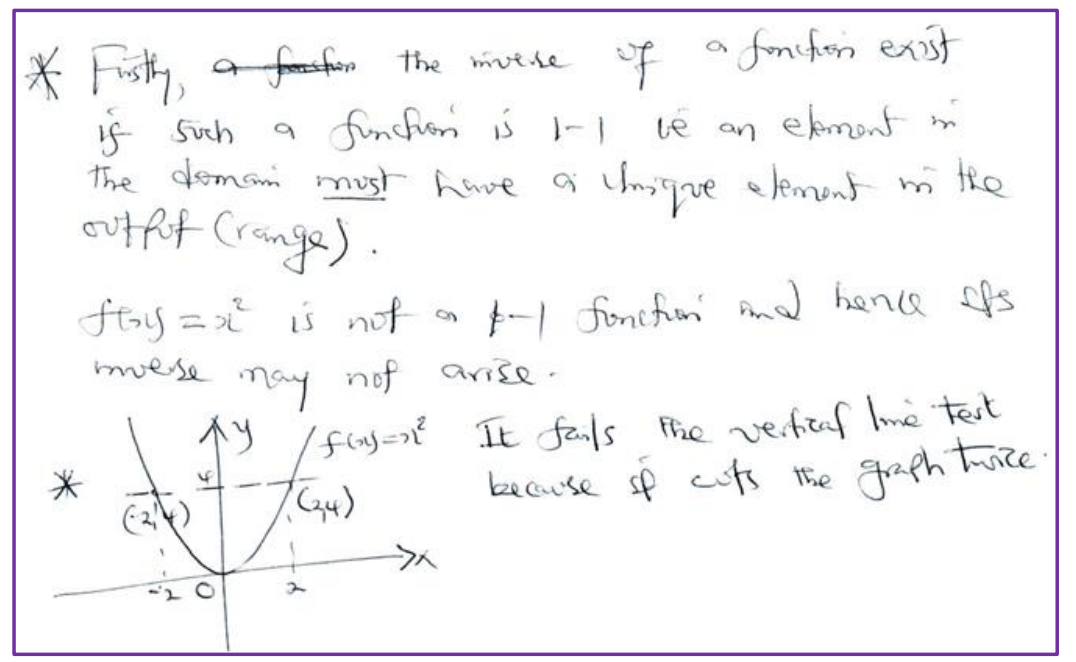

Figure 122. Teacher X's response to vignette 2

This vignette was meant to assess the teacher's ability to demonstrate knowledge of existence of inverse functions and to highlight conditions under which such a function can exist. The teacher explained that for a function to have an inverse it must be a one-to-one function (Figure 122). He used the concepts of domain and range to emphasize this point. However, he seems to confuse the horizontal line test for testing that a function is one-to-one with a vertical line test for testing whether a particular graph is a function. By using a graph (different representation) to explain existence of inverse of a function the teacher demonstrated high order understanding of the inverse function concept and conditions related to its existence. Thus, his explanations were rated Level 1-2.

Vignette 3

A teacher gave the definition of the inverse function and explained it on the board to his/her students. However, some of the students stated that they did not understand it completely. The teacher then gave the following example to the students.

If you think of a school bus as a function which takes you from home to school in the morning, then the school bus that takes you back from school to home is the inverse of the first function.

* What do you think of this example?

Can the example cause students to misunderstand any points in the definition? 
* If exists, please explain these points. If you were to explain the inverse function by using a real life example, what will be your example?

Explain how you will use it in class.

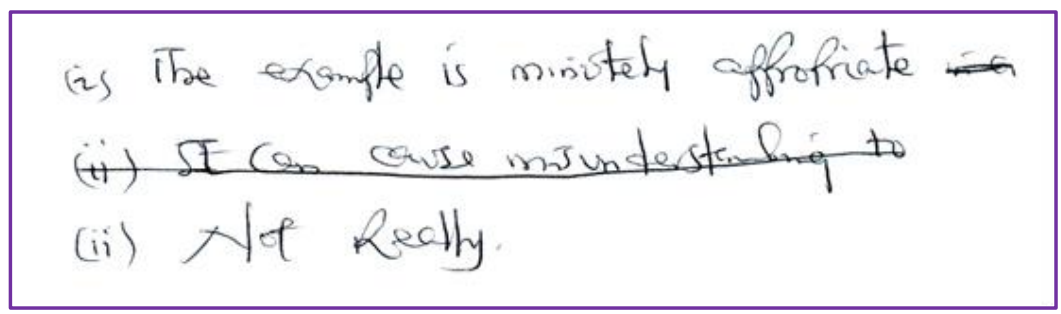

Figure 123. Teacher X's response to vignette 3

This vignette was aimed at assessing the teacher's understanding of the inverse function definition and how he can explain it to make his students comprehend it. It also sought to assess the teacher's ability to understand and employ analogies in his teaching. The teacher found the given analogy to be appropriate for use in defining the inverse of a function and stated that it would not cause misunderstanding among the students (see Figure 123). However, the teacher could not give his own real life example of how he would emphasize the definition of the inverse function. He did not either elaborate how he would handle the confusion arising from his students' failure to comprehend a formal definition of the inverse function. That showed limited understand regards teacher's use or real life situations to define function concepts. Thus, his response to this vignette was rated Level 0.

\section{Vignette 4}

You have been discussing the concept of inverse functions in class. You pose the following problem in class.

If $f(2 x+1)=2 x-1$, find $f(3 x)$ and $f(x)$ and explain the steps of your solution.

The students solved the question correctly as follows:

$$
\begin{aligned}
& \left.\begin{array}{l}
y=2 x+1 \\
x=2 y=1 \\
x-1=2 y \\
y=\frac{x-1}{2}
\end{array}\right\} f(\mathrm{x})=2 \cdot \frac{\mathrm{x}-1}{2}=\mathrm{x}-2 \text { then } f(\mathrm{x})=3 \mathrm{x}-2 \\
& f(x)+2 \Rightarrow f(x)=f(3 x)=3(f(x)+2) \Rightarrow f(3 x)=3 f(x)+4
\end{aligned}
$$

After the solution made, teacher wants from the student to explain what she did in the step indicated by *. She said "I have to get $f(x)$ so that I could calculate $f(3 x)$. 
For getting $f(x)$ I made the necessary calculation as you did in our previous examples".

Further, teacher wants from the students to explain what she did in the $f(x)+2=x$ step. She said that "we have to single out $\mathrm{x}$ from the equation as you did in our previous examples". However, she couldn't explain what she did.

What should teacher do to make his/her students understand the case?

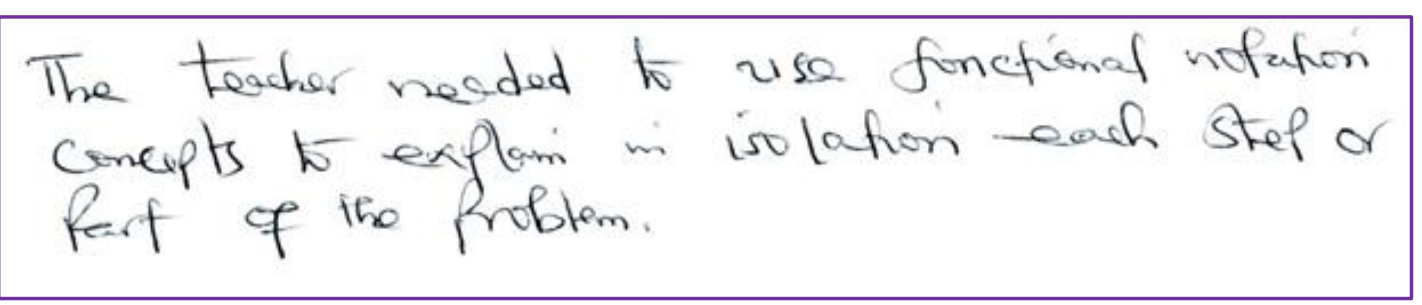

Figure 124. Teacher X's response to vignette 4

In this vignette, the teacher was expected to notice that two concepts were involved in the solution by the student. Thus, the main purpose of this vignette was to see if the teacher would recognize that concepts related to inverse functions were combined to concepts related to composite functions. The teacher, however, could not recognize this and concentrated on the use of "notation in each step" of the solution (see Figure 124). The teacher did not demonstrate understanding of this vignette. Hence, his explanation was rated Level 0.

\section{Vignette 5}

This vignette exemplified the definition of a composite function using a real life situation. The vignette was calling on the teacher's understanding of the definition(s) and how a teacher can move between theoretical to practical or real life examples in explaining a concept.

A teacher gave the definition of a composite function and explained it on the board to his/her students. However, some of his/her students stated that they did not understand it completely.

Then the teacher gave the following example to the students.

In order to clean and dry your clothes in a laundry we use two machines, washing machine and Dryer, respectively. Dry \& wash(clothes).

Dry[Wash(clothes) $]=$ Dry[cleaned and wet clothes $]=$ dried and cleaned clothes. Combination of these machines works can be considered as a composition of functions. 
What do you think of this example? Can this example cause to misunderstand any points in the definition? If exists, please explain these points. If you were to explain the composite function by using a real life example, what will be your example? Explain how you will use it in class.

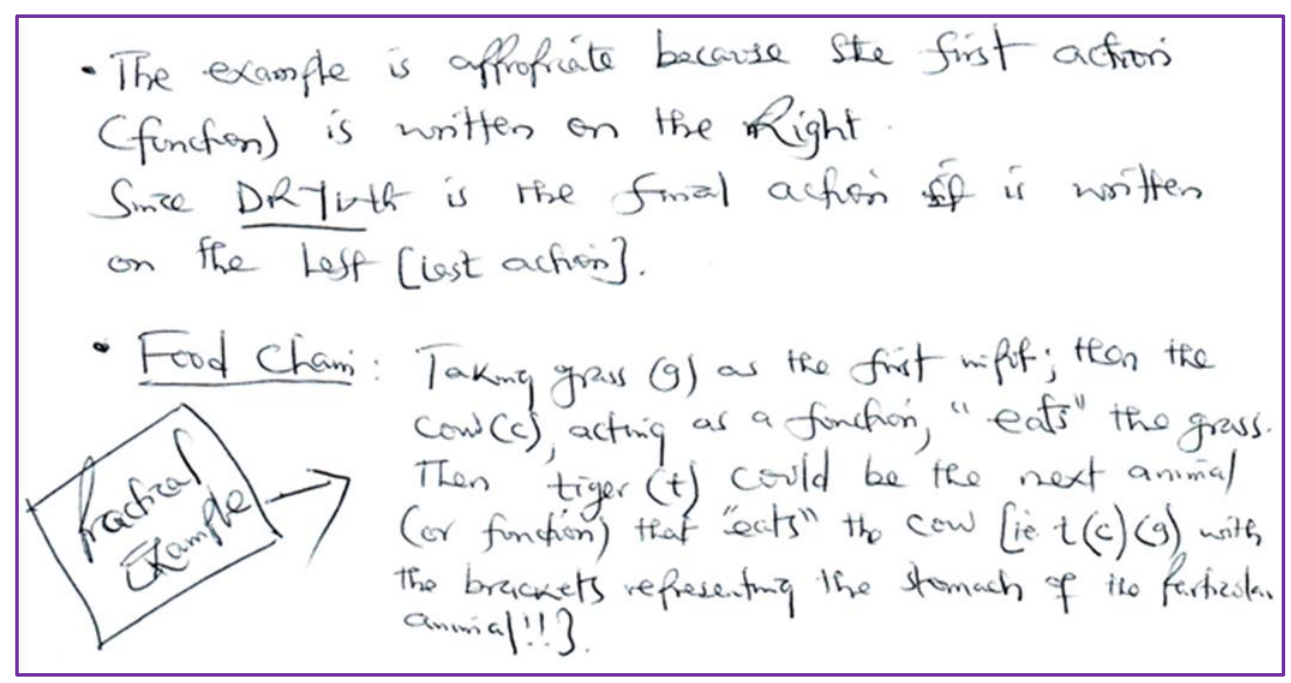

Figure 125. Teacher X's response to vignette 5

The teacher demonstrated understanding of the definition of composite functions by stating that the given real life example was appropriate in providing an alternative explanation regarding the definition (see Figure 125). The teacher was also able to breakdown parts of the given analogy and showed how they combined to fit the definition of composite functions. The real life example given by the teacher was a true reflection of a composite function. It showed good understanding of using analogies to explain mathematical concepts and epitomized the importance analogies play in teaching function concepts. This response to vignette 5 was rated Level 1.

Vignette 6

This vignette was basically testing the understanding of composite function definition and how composite functions differ from ordinary functions. The vignette required the students to also distinguish the composite function $f[g(\mathrm{x})]$ from ordinary multiplication of algebraic terms $f(\mathrm{x}) \cdot g(\mathrm{x})$. 


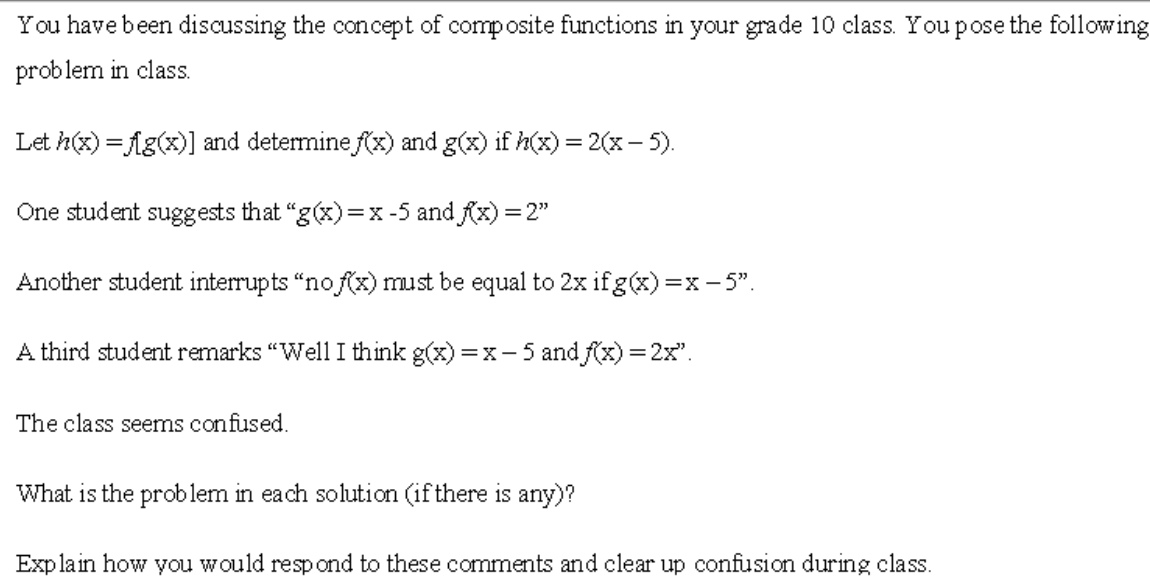

The teacher correctly states that $f(\mathrm{x})=2$ in the first response is incorrect whereas $g(\mathrm{x})=(\mathrm{x}-5)$ is correct. The teacher also explicitly states that the second and third responses were correct (see Figure 126). The teacher does did refer to the definition of composite functions and made no attempt in identifying the misconception the first student exhibited when he assumed that $h(\mathrm{x})$ was equal to $\mathrm{f}(\mathrm{x}) \cdot \mathrm{g}(\mathrm{x})$. He rather relied on the understanding that $f(\mathrm{x})$ needed to be a function of $\mathrm{x}$ just like $g(\mathrm{x})$ was a function of $\mathrm{x}$. In his attempt to clear the confusion the teacher relied on the definition of composite functions without explicitly demonstrating how he understood the definition and how it applied to the situation.

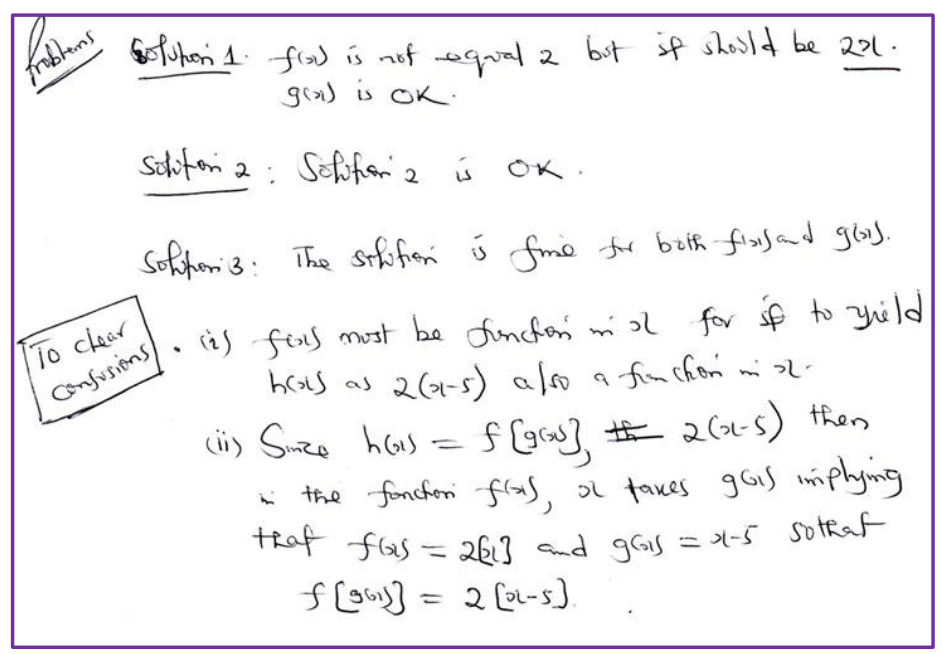

Figure 126. Teacher X's response to vignette 6

The teacher did not use different representation of function to clear the confusion in class and did not use other examples either. Since the teacher was able to identify the error in the first response and correctly stated that $f(x)$ was supposed to be $2 \mathrm{x}$ but did not explicitly demonstrated how the confusion was largely related to 
lack of understanding of the definition of composite functions and did not even use or mention different representations and how to use them to understand the definition, the response to vignette 6 was rated Level 0-1.

\section{Vignette 7}

This vignette was meant to show the importance of the order in which the functions were taken when simplifying composite functions. It was trying to demonstrate that commutative law in arithmetic operations was not applicable to operations on composite functions. When combining two or more functions order in which the composition is written must be respected.

You have been discussing the concept of composite functions in class. You pose the following problem.

Determine the composite function $(f \circ g)(x)$ if $f(x)=x+3$ and $g(x)=x^{2}+6$.

One student answers the problem as " $\left(\mathrm{fog}_{\mathrm{o}}\right)(\mathrm{x})=(\mathrm{x}+3)^{2}+6$ ".

Another student answered the problem as " $(\mathrm{fog})(\mathrm{x})=(\mathrm{x}+3)\left(\mathrm{x}^{2}+6\right)$ ".

A third student answered it as " $\left(f_{\circ} g\right)(x)=x^{2}+9$ ".

For each of the incorrect solutions;

What is the source of the mistake? (Show and explain how they may have found the solution).

Explain how you would respond to these comments and clear up confusion during a class.

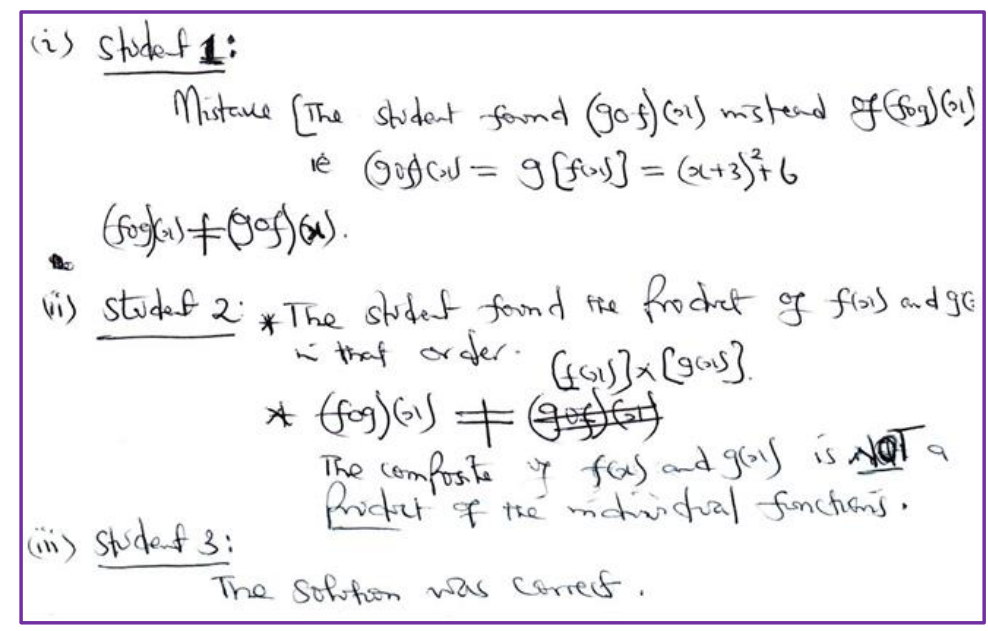

Figure 127. Teacher X's response to vignette 7

Teacher X was able to identify mistakes made by the first and second students in their work. In the answer given by the first student, Teacher $\mathrm{X}$ was able to highlight that order of operations when applied to composite functions was 
important. Though not stated explicitly Teacher $X$ demonstrated that the commutative law of arithmetic was applicable to operations on functions (see Figure 127). He showed it by stating that fog $(\mathrm{x})$ was not equal to $\operatorname{gof}(\mathrm{x})$. In the answer given by the second student, teacher $X$ categorically stated that the "composition of $f(x)$ and $\mathrm{g}(\mathrm{x})$ is NOT a product of the individual functions". In this vignette the teacher showed good understanding of the meaning of the composition of functions and how it differs from a product of two functions. He also showed how order is important when combining two functions. Though he did not explain how he would resolve students' misconceptions that would arise in the vignette he demonstrated good conceptual understanding. Thus, the response was rated Level 1.

Vignette 8

This vignette presented a situation where one of the functions involved in the composition was a constant function. In such situations misconceptions occur when students resort to finding products of given functions as their composition. This vignette, therefore, was trying to bring out the teacher's ability to recognize possible errors and misconceptions that would arise when finding the composition of two functions where one was a constant function.

A student asked the following question.

$$
\begin{aligned}
& \text { Let } f(x)=4, g(x)=2 \text { and } h(x)=x+3 . \text { Evaluate the following } \\
& \begin{aligned}
\text { a. } & \left(f_{\circ} g\right)(7) \\
\text { b. } & \left(g_{\circ} h\right)(x) \\
\text { c. } & \left(h_{\circ} f\right)(x) \\
\text { d. } & \left(h_{\circ} f\right)(3)
\end{aligned}
\end{aligned}
$$

Student's answer is the following:

$$
\begin{aligned}
& \text { a. } f(x)=4 \text { and } g(x)=2 \text {, then }\left(f_{\circ} g\right)=(4.2)=8,\left(f_{\circ} g\right)(7)=56 \\
& \text { b. }\left(g_{0} h\right)(x)=2 x+3 \\
& \text { c. }\left(h_{o f}\right)(x)=7 \\
& \text { d. }\left(h_{\circ}\right)(5)=32
\end{aligned}
$$

What is the source of the mistake? (show and explain how they may have found this solution).

Explain how you would respond to these comments and clear up confusion during a class. 


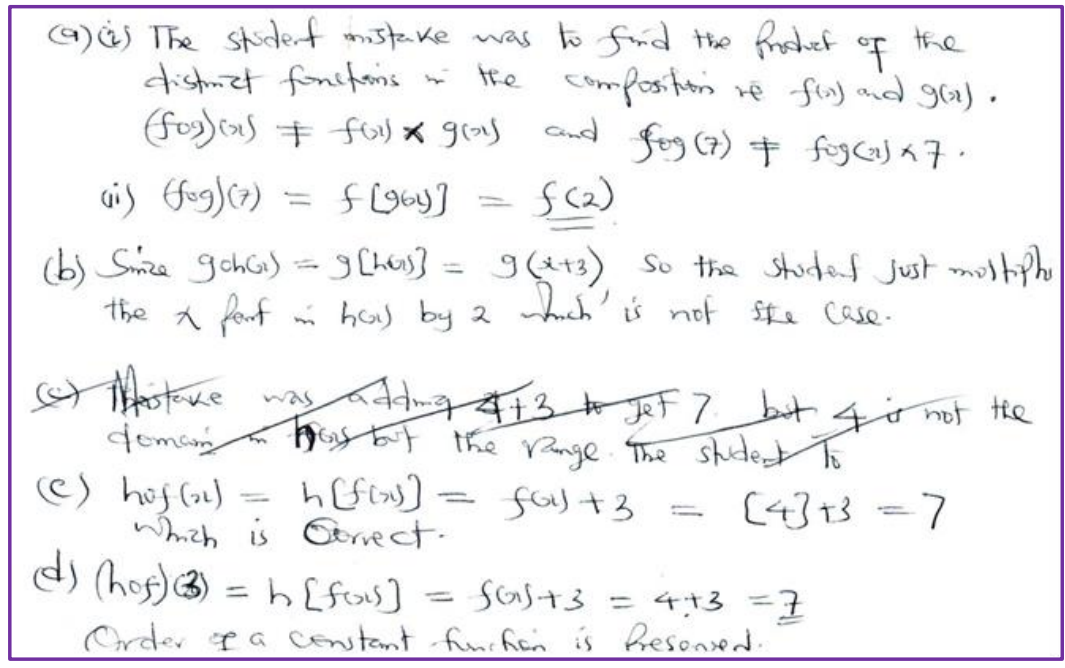

Figure 128. Teacher X's response to vignette 8

The teacher demonstrates very good understanding of the demands of this vignette (see Figure 128). He clearly stated in his explanation of the mistake made in the first answer that composition of functions did not mean the product of distinct functions by arguing that $\left(f_{\circ} g\right)(x) \neq f(x) \times g(x)$ and $\left(f_{\circ} g\right)(x) \neq\left(f_{\circ} g\right)(x) \times 7$. Similarly, the teacher identified the error committed in the solution for the second question by stating that $\left(\mathrm{g}_{\mathrm{o}}\right)(\mathrm{x})=\mathrm{g}[\mathrm{h}(\mathrm{x})]$ which does not imply multiplication. However, the student multiplied the functions $\mathrm{g}(\mathrm{x})$ and $\mathrm{h}(\mathrm{x})$. The teacher nods the answer provided for part (c) and corrects the mistake made in the solution for part (d) by giving an explanation. Thus, it was seen in the teacher's responses that he demonstrated his ability to correctly identify student mistakes and proving correct solutions but he did not attempt to explain in detail how to clear the confusion to avoid reoccurrence of similar mistakes. This meant that the teacher still had difficulties in providing conceptual explanations and justifications that would help his students avoid making similar mistakes. Thus, his solutions to this vignette were rated Level 1.

\section{Test on functions}

Item 6

Arthur, Ruth, Ian, Naomi and Liz discussed what a function is. Read each of the students' ideas about functions and write your response to it.

This item was designed to assess Teacher X's knowledge of learners' views about what a function is. It accorded him an opportunity to analyze a variety of answers from different learners and provide insight about how valid the learners' 
views were. Through this the teacher would identify his learners' misconceptions about a function and how he would provide remedy to some of their flawed understanding.

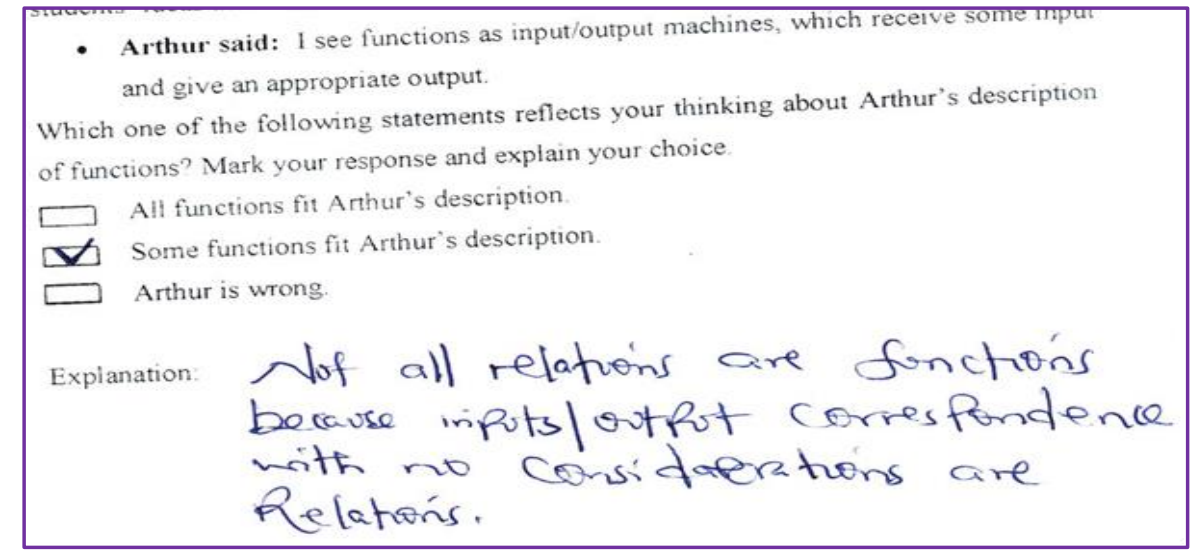

Figure 129. Excerpt of Teacher X's answer to item 6(a)

In his analysis of Arthur's views about a function, Teacher X claimed that it was not entirely true as not all the functions would fit Arthur's description (see Figure 129). In explaining his claim Teacher $X$ contented that functions use input/output correspondence but not all correspondence would describe a function. There are several relations that could fit the input/output correspondence but fall short of being called functions because according to Teacher $\mathrm{X}$, a function must have some consideration. He was not clear which consideration but probably could have meant each input corresponding to a unique output. He was asked during the interview to explain what he meant by "consideration" in the context of functions.

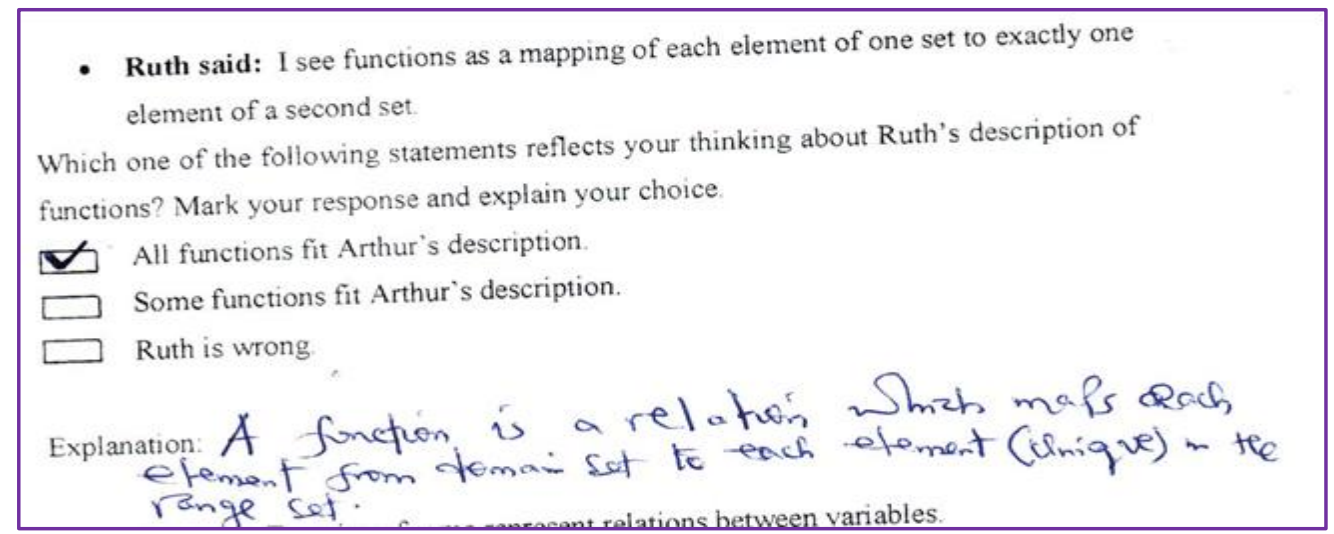

Figure 130. Excerpt of Teacher X's answer to item 6(b)

In his analysis of Ruth's description, Teacher X stated that all functions could be described as a mapping of each element in one set to exactly one element of the 
second set (see Figure 130). He justifies this by using the concept of domain and range with uniqueness in the correspondence of the two as being key. Thus, Teacher $\mathrm{X}$ provide a sound conceptual analysis to Ruth's description of a function and it was considered to be valid.

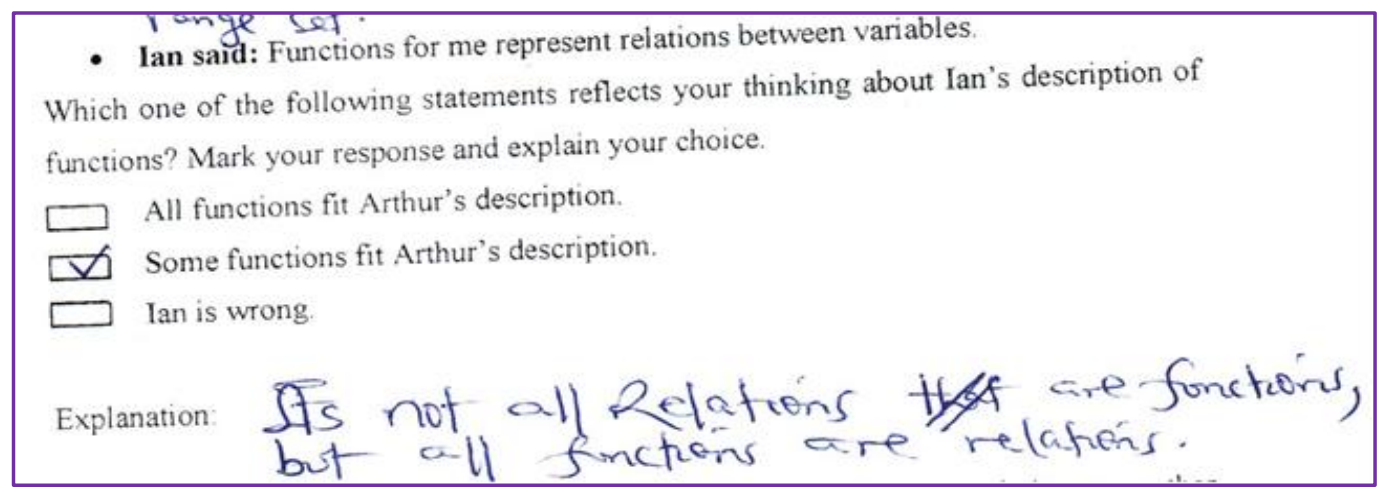

Figure 131. Excerpt of Teacher X's answer to item 6(c)

Ian described all functions to be relations and Teacher $\mathrm{X}$ partially agreed with Ian by admitting that some functions fitted Ian's description (see Figure 131). He explains his stance by stating that actually all functions are considered to be relations between variables but not all relations can be considered to be functions. Thus, functions can be used to define a relation but not all relations can be used to define functions. For a relation to be called a function the relation must establish a unique association between variables.

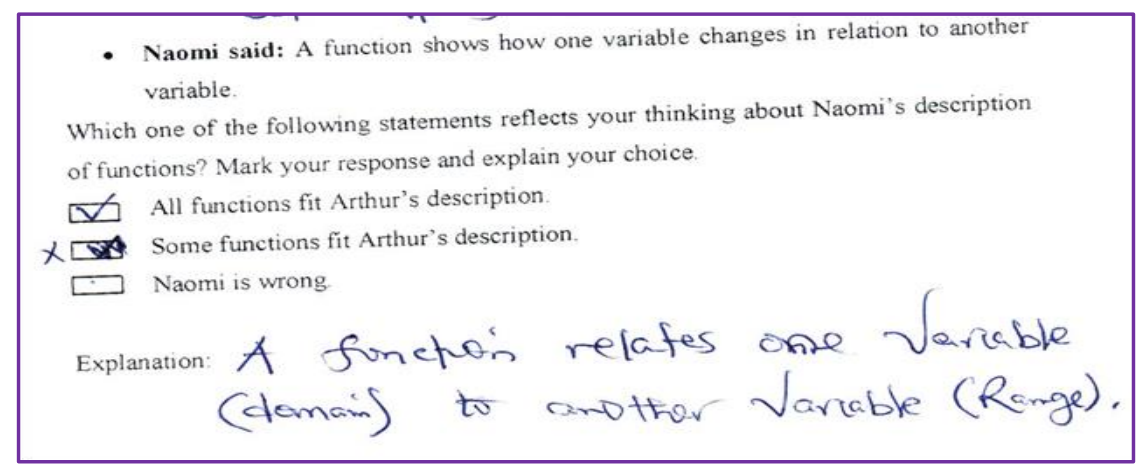

Figure 132. Excerpt of Teacher X's answer to item 6(d)

Analyzing Naomi's description of functions, Teacher X agreed with Naomi that all functions show how one variable changes in relation to another variable (see Figure 132). He backed this by stating that a function related one variable from the domain to another variable the range. However it is not in all cases that the relationship between two variables must result in change of one of them. The 
essential concept about functions is that a function links or connects or associates or relates a member of one set to a unique member of the second set. If that association results in change of the second variable does not make it a universal characteristic of a function because some associations between two variables may not cause any changes. Thus Teacher X was asked to clarify his explanation.

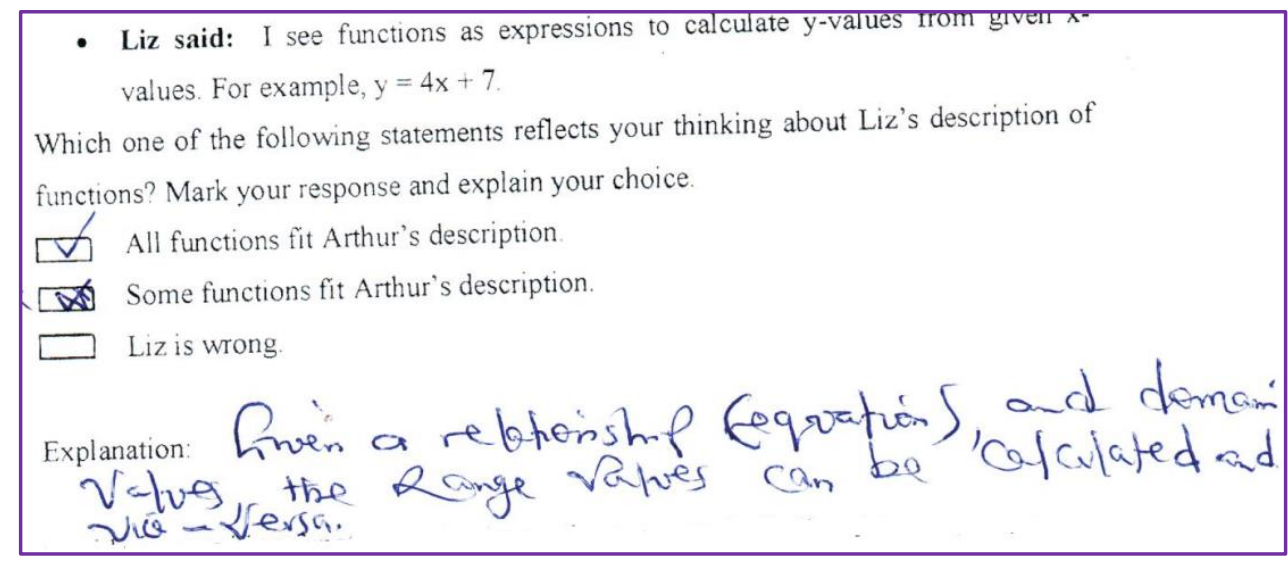

Figure 133. Excerpt of Teacher X's answer to item 6(e)

In analyzing Liz's answer, Teacher $\mathrm{X}$ agreed with Liz that functions are expressions used to calculate y-values from x-values (see Figure 133). They contend that an equation $y=4 x+7$ is a good example to justify their claim. Teacher $X$ went on to explain that "given a relationship (equation) and domain values, the range values can be calculated and vice-versa". Teacher X's explanation seems to suggest that equations and functions are the same and can be used to mean the same thing. His explanation was flawed and lacked knowledge of the relationship between functions and equations. Of course equations can be used to define functions but that does not make them to be the same.

Item 7

Could you provide a function so that its graph goes through $(0,2)$ and the value of $y$ increases as $x$ increases? For example:

One student's response to this problem was as follows:

"No. To do so you would need to know another point on the graph." 
Item 7(a)

Is the answer correct?

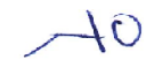

Item 7(b)

What do you think the student is thinking about the equation and graph?

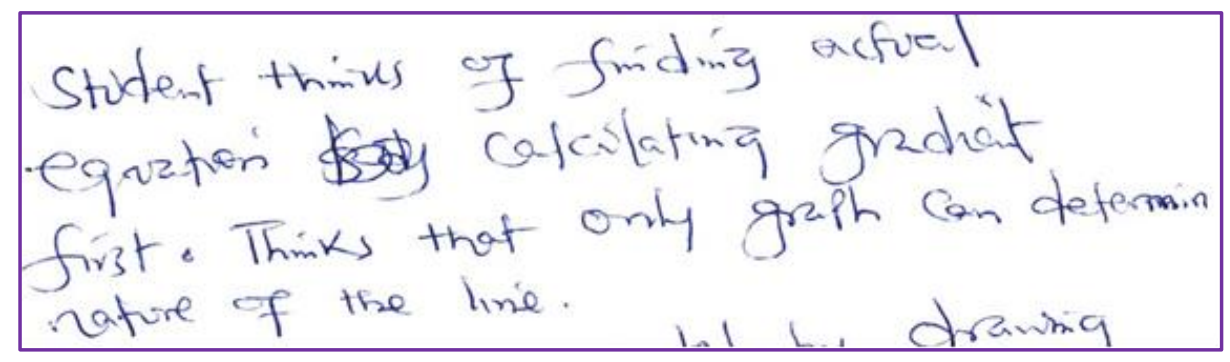

Figure 134. Excerpt of Teacher X's answer to item 7(b)

This item was designed to assess Teacher X's ability to resolve students' difficulties in drawing graphs of functions. He correctly observed that the student had limited knowledge of graphs when he/she said to draw a function that passes through the point $(0,2)$ one needed to know a second point (see Figure 134). He highlighted that the student was probably thinking in terms of obtaining the equation of a straight line by first calculating the gradient. However, Teacher X could also have anticipated that maybe the student was also thinking about a linear function which can easily be drawn by connecting two points. This was the reason he was talking about a second point

Item 7(c)

If you think the student has misconceptions with respect to the equation and graph, how would you assist this student?

This item was designed to assess Teacher X's knowledge of learner misconceptions and his ability to anticipate, identify and resolve them. To assist the learner eliminate the misconception Teacher $X$ (in Figure 135) suggested that increasing and decreasing functions passing through the point $(0,2)$ could be drawn so that he could be assisted to visualize that increasing functions can be drawn without necessarily having a second point. Teacher X's response to this question was valid as it would help the student to understand and clear misconception. 


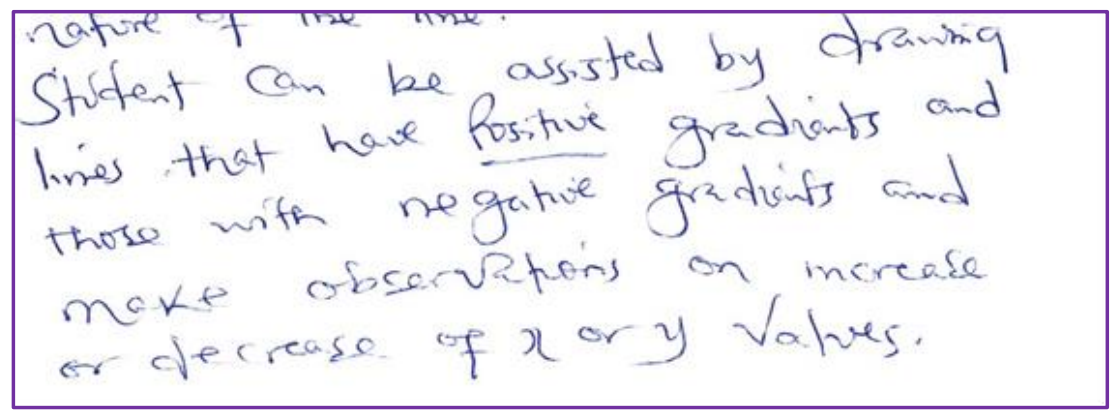

Figure 135. Excerpt of Teacher X's answer to item 7(c)

Item 8

A student is asked to give an example of a graph of a function that passes through the points A and B (See Figure 1). The student gives the following answer (see Figure 2). When asked if there is another answer the student says "No"

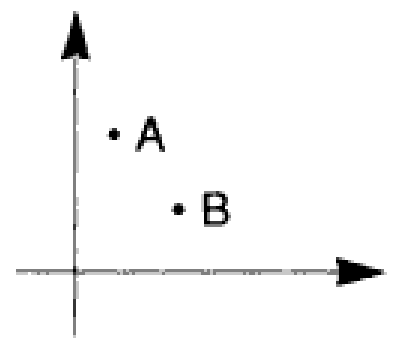

Figure 1

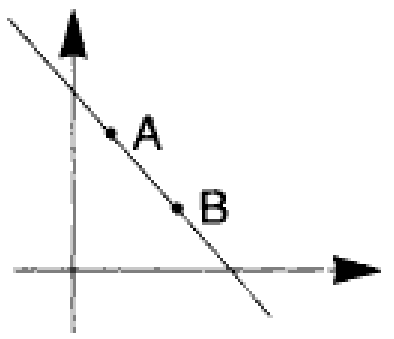

Figure 2

Item $8(a)$

If you think the student is right, explain why.

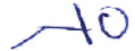

Item $8(b)$

If you think the student is wrong, how many functions which satisfy the condition can you find? Explain.

This item was designed to assess Teacher X's knowledge of learners' difficulties with graphs. In this case he was assessed on his ability to identify functions that can be drawn passing through two given points. He correctly determined that the student had limited knowledge about how many functions could 
be drawn that passed through the points $\mathrm{A}$ and $\mathrm{B}$. teacher $\mathrm{X}$ explained by drawing three graphs of functions that passed through points $\mathrm{A}$ and $\mathrm{B}$, a linear function and two quadratic functions. By drawing these functions (Figure 136), Teacher $X$ demonstrated that not only did he know that there were more than one function that could be drawn passing through A and B but he could actually draw them.

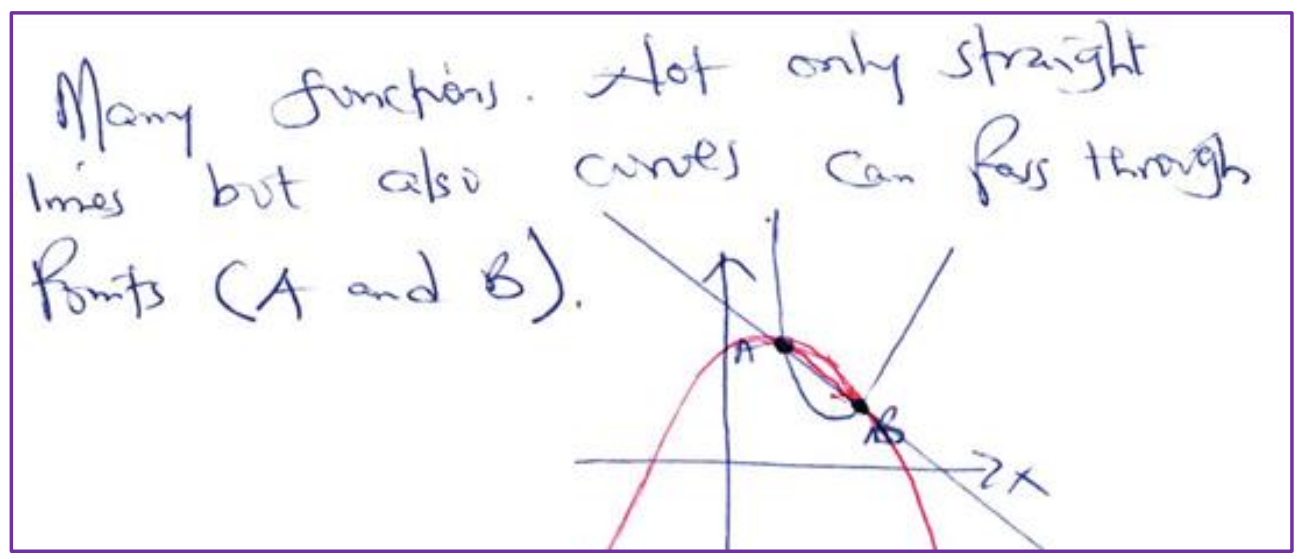

Figure 136. Excerpt of Teacher X's answer to item 8(b)

\section{The case of teacher $Y$}

Summary of teacher Y's lesson plan on inverse functions

Teacher Y prepared the lesson for a Grade 11 class comprising 11 girls and 27 boys. After completion of the lesson students would be expected to define the inverse of a given function and to solve questions involving inverse functions. As prerequisite knowledge for learning inverse functions, teacher $\mathrm{Y}$ would expect his students to already be "aware of functions" with a chalk board as the only teaching aid to be used during the lesson (see Figure 137). His rationale for teaching the topic would be for students to "think critically and apply the inverse function concepts in other topics".

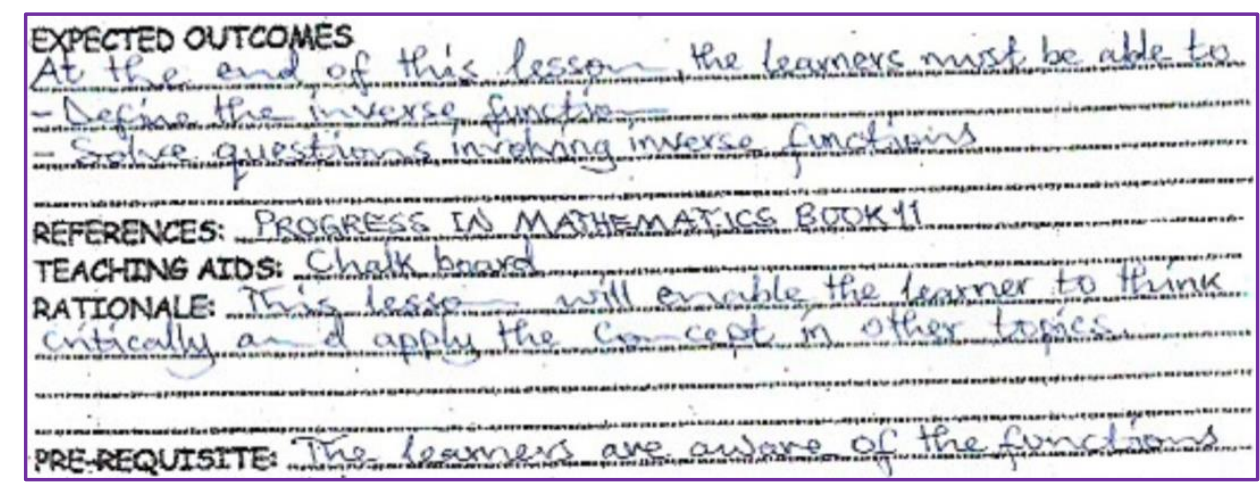

Figure 137. Excerpt LP8 of Teacher Y's lesson plan on inverse functions 
Teacher Y would introduce the lesson by asking students to define the inverse of a function for which an expected definition would be given by the students (see Figure 138). As a key feature of the definition, teacher $\mathrm{Y}$ would expect students to state that the inverse function would "reverse the mapping of the original function". He would exemplify the definition by giving an illustration of how to map the original function to its inverse.

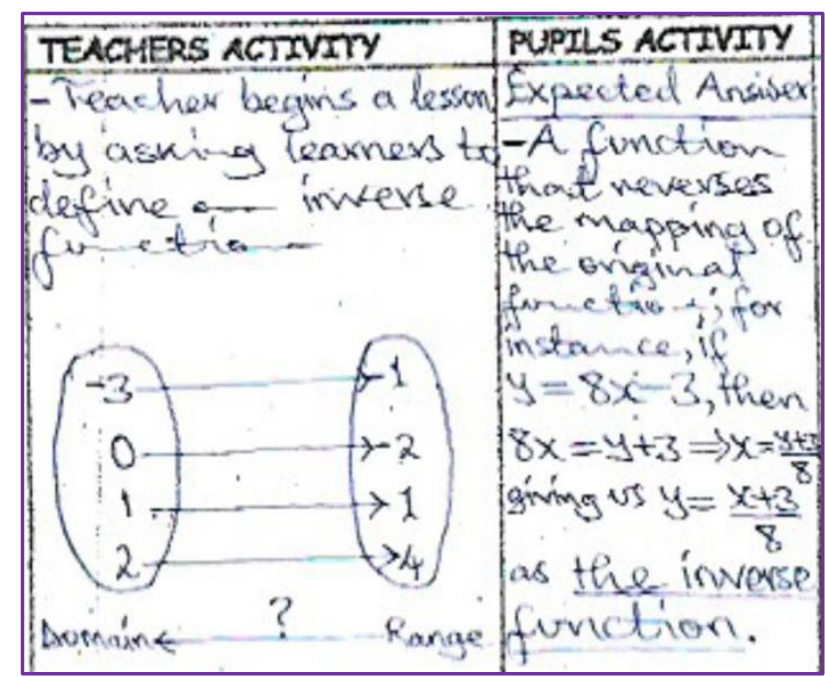

Figure 138. Excerpt LP9 of Teacher Y's lesson plan on inverse functions

The teacher would develop the lesson by presenting two examples on how to find inverse functions and how to carry out calculations involving inverse functions (see Figure 139). The emphasis would likely be on the procedural aspect of how to come up with the inverse when given any function.

\begin{tabular}{|c|c|}
\hline EXAMPLES: & EXPECTED ANS \\
\hline 1. Given that & $\oint f(x)=2 x-5$ \\
\hline$f(x)=\frac{x-1}{2}$ & $y=2 x-5$ \\
\hline - Calculate & $y+5=2 x$ \\
\hline (a) $f^{-1}(x)$ & $\frac{y+5}{2}=x$ \\
\hline (b) $f^{-1}(-4)$ & $\Rightarrow x=\frac{y+5}{2}$ \\
\hline * & $\therefore f^{-1}(x)=\frac{x+5}{2}$ \\
\hline
\end{tabular}

Figure 139. Excerpt LP10 of Teacher Y's lesson plan on inverse functions 
Teacher $\mathrm{Y}$ would involve students in the lesson by asking then questions during the course of the lesson and by responding to their questions. After presentation of examples, teacher Y would assess students' understanding by giving them a class exercise which he would mark and provide feedback and concluding by revising the class exercise with the students. Teacher Y's lesson would not include homework or any practical lab work on inverse functions.

\section{Teacher Y's responses to vignettes}

\section{Vignette 1}

You have been discussing the concept of inverse functions in class. You pose the following question in class.

Determine the inverse $\left(f^{-1}(x)\right)$ of a function $f(x)=x-4$.

Five different solutions come out from the class.

$$
f^{-1}(\mathrm{x})=\frac{1}{\mathrm{x}-4}
$$

(vii) $f^{-1}(\mathrm{x})=\frac{1}{\mathrm{x}}-4$

(viii) $f^{-1}(\mathrm{x})=-\mathrm{x}-4$

(ix) $f^{-1}(\mathrm{x})=-\mathrm{x}+4$

(x) $\quad f^{-1}(\mathrm{x})=\mathrm{x}+4$

The different answers reveal that the class is confused.

What is the problem in each solution (if there exists)?

Explain how you would respond to these comments and clear up confusion during a class.

This vignette was centered on teacher's ability to understand inverse function notation and how it caused misconceptions by conflicting with concepts in arithmetic (multiplicative inverse) and negative exponents when dealing with indices and exponential functions. In his comments on the mistakes in the solutions presented in the vignettes by the student, the teacher started by correctly finding the inverse of the given function. From the teacher's diagnosis of the mistakes made by students it was clear that the student did not understand notation of inverse functions. According to the teacher, the -1 in the function notation was regarded as an exponent. To this effect he found that in the first and second solutions the students was merely finding the multiplicative inverses of $\mathrm{x}-4$ and the variable $\mathrm{x}$ respectively. He noticed that in the third and fourth solutions the student was finding the additive inverse of the 
variable $\mathrm{x}$ and $\mathrm{x}-4$ respectively. The teacher then claimed that in the last solution the student found the additive inverse of the constant 4 . This is despite the last solution being exactly the same as the teacher's solution. The teacher did not give the last solution a careful consideration for him not to notice that the last solution by the student was correct.

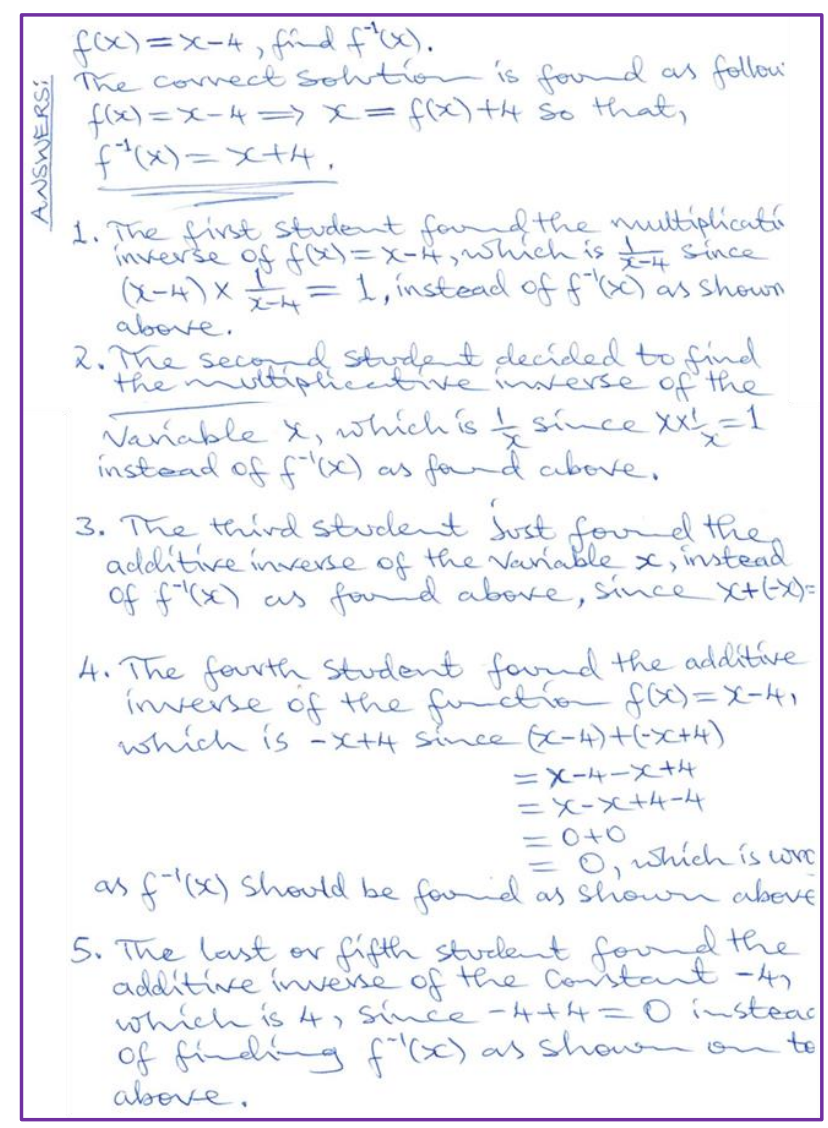

Figure 140. Teacher Y's response to vignette 1

However, the teacher provided a good and detailed analysis of the errors in the first four solutions (Figure 140). Unfortunately he did not provide any explanation about how he would help his students clear the confusion arising from misunderstanding inverse function notation. For demonstrating understanding of the student misconception the teacher's response to this vignette was rated Level 1.

Vignette 2

A student said the inverse of the function $(x)=x^{2}$ is $f(x)=\sqrt{x}$.

Is the student right? If you think that the student is correct explain why?

If you think the student is incorrect explain where the error lies and how you would respond to these comments and clear up confusion in lass. 


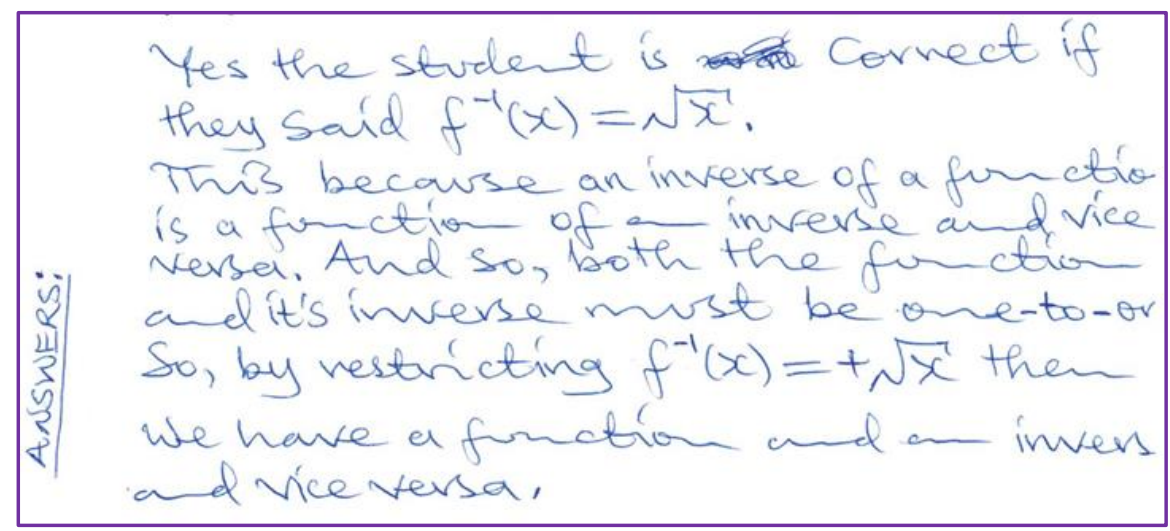

Figure 141. Teacher Y's response to vignette 2

This vignette was meant to assess the teacher's ability to demonstrate knowledge of existence of inverse functions and to highlight conditions under which a function can exist. Teacher $\mathrm{Y}$ correctly highlighted that for the function to have an inverse it must be one-to-one (see Figure 141). However, the teacher did not recognize that the given function $\mathrm{f}(\mathrm{x})=\mathrm{x}^{2}$ did not satisfy the one-to-one condition as the domain was not restricted. The teacher's conceptual understanding of the given problem was erroneous when he agreed that the inverse of the function $f(x)=$ $x^{2}$ was $\sqrt{x}$. The teacher could have used a graphical method of ascertaining that the function $\mathrm{f}(\mathrm{x})=\mathrm{x}^{2}$ was not one-to-one. Thus, the lack of conceptual understanding and failure to explain how he would help clear misconceptions surrounding such situations earned the teacher a rating of Level 0.

\section{Vignette 3}

A teacher gave the definition of the inverse function and explained it on the board to his/her students. However, some of the students stated that they did not understand it completely. The teacher then gave the following example to the students.

If you think of a school bus as a function which takes you from home to school in the morning, then the school bus that takes you back from school to home is the inverse of the first function.

What do you think of this example?

* Can the example cause students to misunderstand any points in the definition?

* If exists, please explain these points. If you were to explain the inverse function by using a real life example, what will be your example?

* Explain how you will use it in class. 


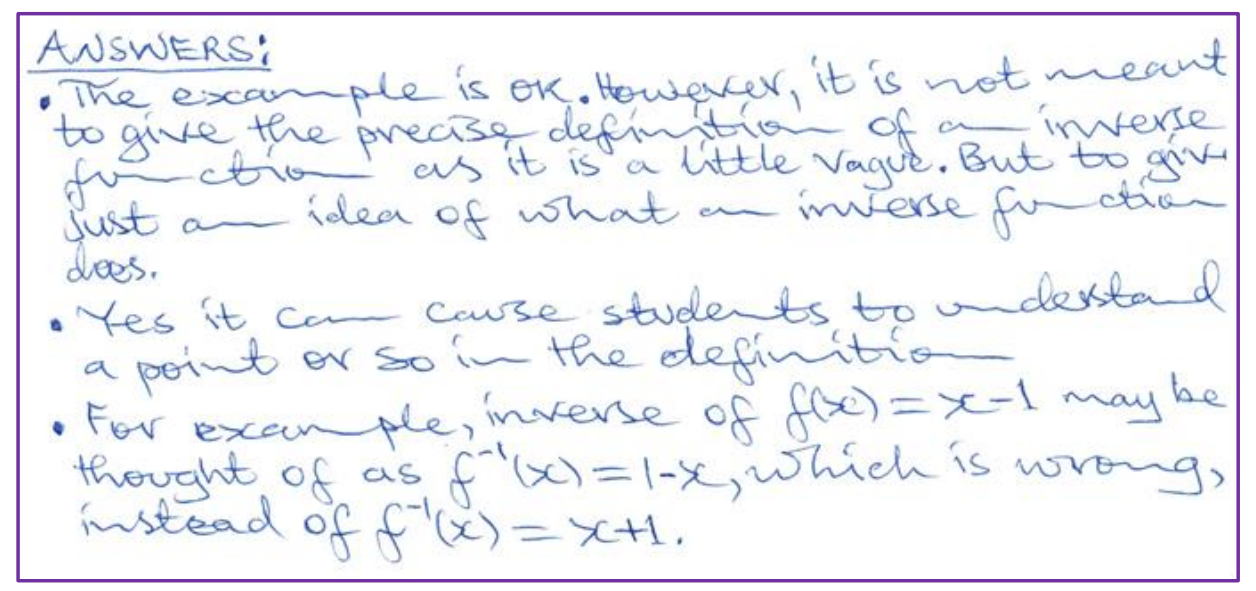

Figure 142. Teacher Y's response to vignette 3

This vignette was aimed at assessing the teacher's understanding of the inverse function definition and how he can explain it to make his students comprehend it. It also sought to assess the teacher's ability to understand and employ analogies in his teaching. The teacher agreed that the analogy which was used to define the inverse of a function would help students understand the definition of the inverse of a function because it gives a gives an idea of the definition (see Figure 142). However, the teacher argued that the analogy was a little vague and it fell short of a precise mathematical meaning of the inverse function concept. He backed his reasoning by contending that if one was asked to find the inverse of the function $f(x)=x-1$ using the reasoning in the analogy, they would give the answer as $f^{-1}(x)=x+1$ which is incorrect. Thus, the teacher demonstrated understanding of using analogies in teaching mathematical concepts and by giving an alternative example he demonstrated knowledge of different representations which is high order mathematical reasoning. Thus, his response to this vignette was rated Level 1-2.

Vignette 4

You have been discussing the concept of inverse functions in class. You pose the following problem in class.

If $f(2 x+1)=2 x-1$, find $f(3 x)$ and $f(x)$ and explain the steps of your solution.

The students solved the question correctly as follows:

$$
\begin{aligned}
& \left.\begin{array}{l}
y=2 x+1 \\
x=2 y=1 \\
x-1=2 y \\
y=\frac{x-1}{2}
\end{array}\right\} \underbrace{f(\mathrm{x})=2 \cdot \frac{\mathrm{x}-1}{2}=\mathrm{x}-2}_{*} \text { then } f(\mathrm{x})=3 \mathrm{x}-2 \\
& f(x)+2 \Rightarrow f(x)=f(3 x)=3(f(x)+2) \Rightarrow f(3 x)=3 f(x)+4
\end{aligned}
$$


After the solution made, teacher wants from the student to explain what she did in the step indicated by *. She said "I have to get $f(x)$ so that I could calculate $f(3 x)$.

For getting $\mathrm{f}(\mathrm{x})$ I made the necessary calculation as you did in our previous examples".

Further, teacher wants from the students to explain what she did in the $f(x)+2=x$ step. She said that "we have to single out $\mathrm{x}$ from the equation as you did in our previous examples". However, she couldn't explain what she did.

What should teacher do to make his/her students understand the case?

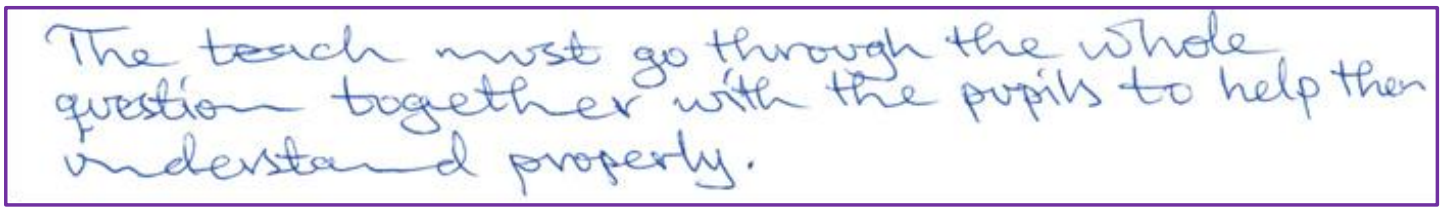

Figure 143. Teacher Y's response to vignette 4

In this vignette, the teacher was expected to notice that two concepts were involved in the solution by the student. Thus, the main purpose of this vignette was to see if the teacher will recognize that concepts related to inverse functions were combined to concepts related to composite functions. The teacher only advised that it was important to go through the entire example with the students (Figure 143). This response is very inadequate to respond to the requirements of the vignette. The teacher did not provide any reasons for such a brief comment. Thus, his response to the vignette was rated Level 0.

\section{Vignette 5}

A teacher gave the definition of a composite function and explained it on the board to his/her students. However, some of his/her students stated that they did not it completely.

Then the teacher gave the following example to the students.

In order to clean and dry your clothes in a laundry we use two machines, washing machine and Dryer, respectively. Dry \& wash(clothes).

Dry[Wash(clothes) $]=$ Dry[cleaned and wet clothes $]=$ dried and cleaned clothes Combination of these machines works can be considered as a composition of functions.

What do you think of this example? Can this example cause to misunderstand any points in the definition? If exists, please explain these points. If you were to explain 
the composite function by using a real-life example, what will be your example? Explain how you will use it in class.

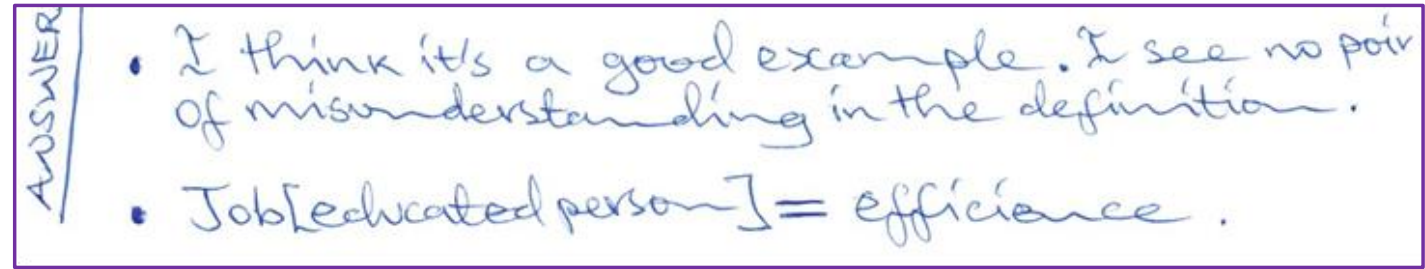

Figure 144. Teacher Y's response to vignette 5

This vignette exemplified the definition of a composite function using a real life situation. The vignette was calling on the teacher's understanding of the definition(s) and how a teacher can move between theoretical to practical or real life examples in explaining a concept. Teacher $\mathrm{Y}$ found the analogy suitable for teaching definition of composite functions (see Figure 144). He also did not see anything about the analogy that would cause misunderstanding of the concept related to the definition of composite functions. However, the example the teacher provided was not good enough as it lacked detail. It was not a well thought example to fit the definition of composite functions. Thus, his response to the vignette was rated Level 0 .

\section{Vignette 6}

You have been discussing the concept of composite functions in the $10^{\text {th }}$ grade class. You pose the following problem in class.

Let $h(x)=f[g(x)]$ and determine $f(x)$ and $g(x)$ if $h(x)=2(x-5)$.

One student suggests that " $\mathrm{g}(\mathrm{x})=\mathrm{x}-5$ and $\mathrm{f}(\mathrm{x})=2$ "

Another student interrupts "no $\mathrm{f}(\mathrm{x})$ must be equal to $2 \mathrm{x}$ if $\mathrm{g}(\mathrm{x})=\mathrm{x}-5$ ".

A third student remarks "Well I think $g(x)=x-5$ and $f(x)=2 x "$.

The class seems confused.

What is the problem in each solution (if there is any)?

Explain how you would respond to these comments and clear up confusion during class. 


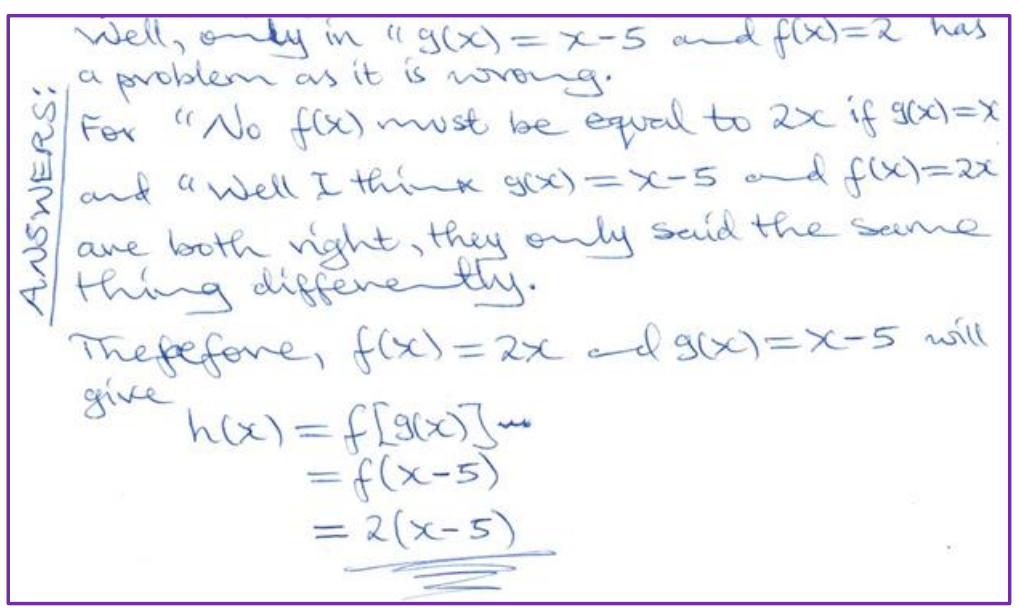

Figure 145. Teacher Y's response to vignette 6

This vignette was basically testing the understanding of composite function definition and how composite functions differ from ordinary functions. The vignette required the students to also distinguish the composite function $f[g(\mathrm{x})]$ from ordinary multiplication of algebraic terms $f(\mathrm{x}) \cdot g(\mathrm{x})$. Teacher $\mathrm{Y}$ argued that $\mathrm{f}(\mathrm{x})=2$ was incorrect and said that the correct one was $f(x)=2 x$ (see Figure 145). He went on to verify his claim by finding the composition of $\mathrm{f}(\mathrm{x})$ and $\mathrm{g}(\mathrm{x}), \mathrm{He}$, however, did not give reasons as to why $\mathrm{f}(\mathrm{x})=2$ was incorrect. Neither did he offer an explanation about how he would help students to avoid similar misconceptions. His response was not conceptual and thus received a rating of Level 0 .

\section{Vignette 7}

You have been discussing the concept of composite functions in class. You pose the following problem in class.

Determine the composite function $(f \circ g)(x)$ if $f(x)=x+3$ and $g(x)=x^{2}+6$.

One student answers the problem as " $\left(f_{\circ} g\right)(x)=(x+3)^{2}+6 "$ ".

Another student answered the problem as $\left(f_{\circ} g\right)(x)=(x+3)\left(x^{2}+6\right) "$.

A third student answered it as $\left(f_{\circ} g\right)(x)=x^{2}+9$ ".

For each of the incorrect solutions

What is the source of the mistake? (show and explain how they may have found the solution).

Explain how you would respond to these comments and clear up confusion during a class. 


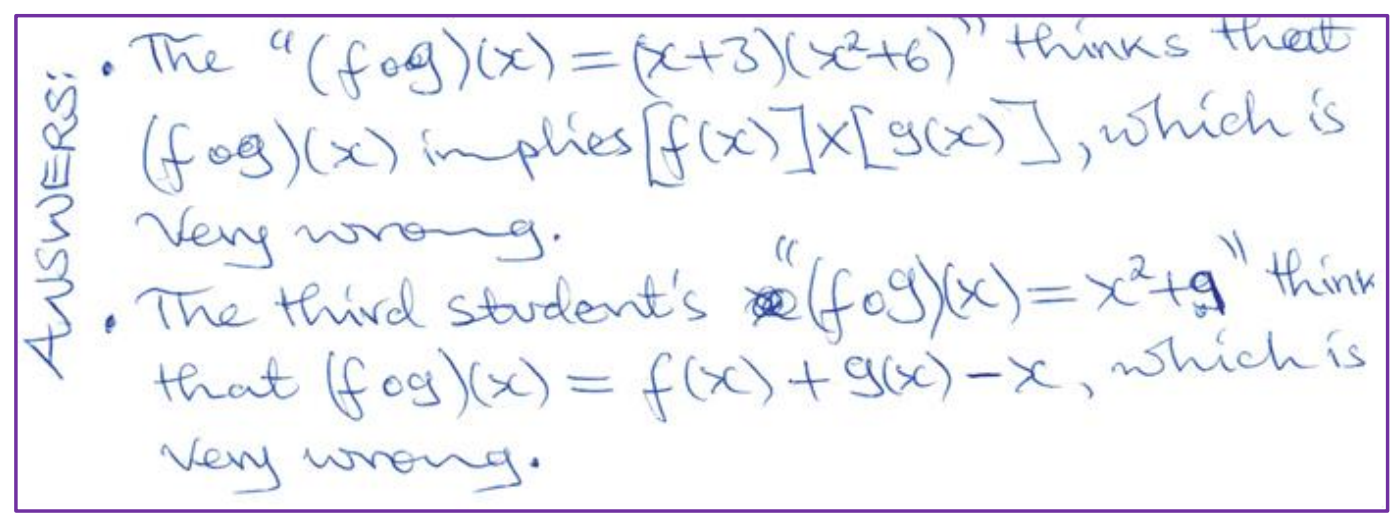

Figure 146. Teacher Y's response to vignette 7

This vignette was meant to show the importance of the order in which the functions were taken when simplifying composite functions. It was trying to demonstrate that the order of operations in arithmetic operations was not applicable to operations on composite functions. When combining two or more functions order in which the composition is written must be respected. Teacher Y claimed that all three student responses exhibited lack of knowledge of the composite function notation $(f \circ g)(x)$. He claimed that the first student assumed that ( $\left.f_{\circ g}\right)(x)$ was equal to $\mathrm{f}(\mathrm{x})$ multiplied by $\mathrm{g}(\mathrm{x})$ which was incorrect while the third student assumed that $\left(f_{\circ} g\right)(x)$ was equal to $f(x)+g(x)-x$ which was also incorrect reasoning (see Figure 146). He, however, did not provide convincing reasons why the third solution was wrong and he did not offer an explanation on how such misconceptions would be avoided by his students. His response was rated Level 0.

Vignette 8

A student asked the following question.

Let $f(x)=2$, and $h(x)=x+3$. Evaluate the following
7. $\left(f_{\circ} g\right)(7)$
8. $(g \circ h)(x)$
9. $(h \circ f)(x)$
10. $\left(h_{o} f\right)(3)$

Student's answer is the following:
e. $f(x)=4$ and $g(x)=2$, then $\left(f_{\circ g}\right)=(4.2)=8,\left(f_{\circ} g\right)(7)=56$
f. $\left(g_{0 h}\right)(x)=2 x+3$
g. $($ hof $)(x)=7$
h. $\left(h_{\text {of }}\right)(5)=32$ 
What is the source of the mistake? (show and explain how they may have found this solution).

Explain how you would respond to these comments and clear up confusion during a class.

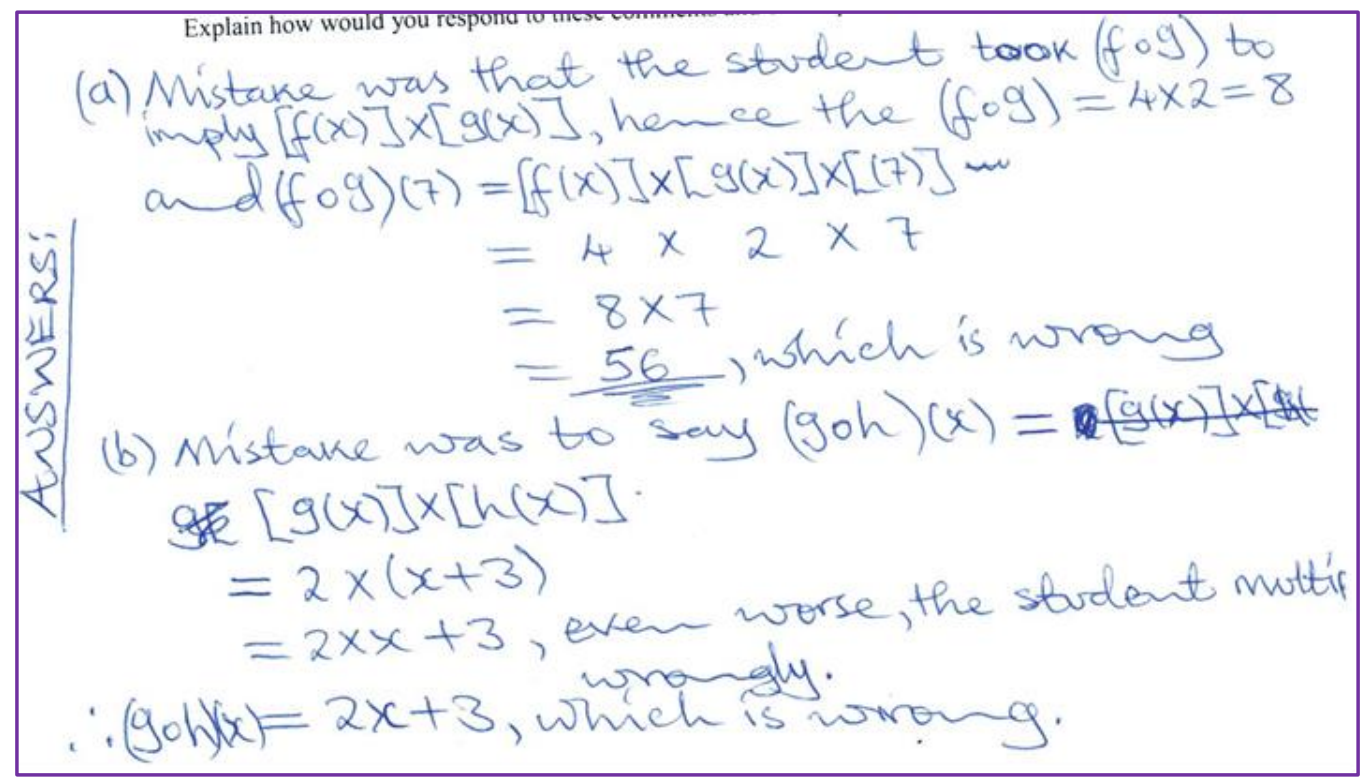

Figure 147. Teacher Y's response to vignette 8

This vignette presented a situation where one of the functions involved in the composition was a constant function. In such situations misconceptions occur when students resort to finding products of given functions as their composition (see Figure 147). This vignette, therefore, was trying to bring out the teacher's ability to recognize possible errors and misconceptions that would arise when finding the composition of two functions where one was a constant function.

Teacher $\mathrm{Y}$ claimed that the sources of mistakes committed were misunderstanding of the meaning of notation used for composite functions. The students assumed that composition of two functions implied multiplication of the functions. For parts (a) and (b) the students thought that $\left(f_{\circ} g\right)(x)=f(x) \times g(x)$ and $\left(g_{\circ} h\right)(x)=g(x) \times h(x)$ respectively. He contended that part (c) was correctly solved. For part (d) Teacher Y claimed that the students assumed that $(\mathrm{hof})(5)=[\mathrm{h}(\mathrm{x}) \times$ $f(x)](5)$. The student would find the product of $h(x)$ and $f(x)$ as the first step and then substitute 5 for $\mathrm{x}$ in the final step which was erroneous (see Figure 148). To clear confusion and misconception, Teacher Y proposed using laws of indices as one of the good ways of ensuring that students understood the concepts. His response to this vignette was rated Level 1. 
(c) Thene was that $(h \circ f)(x)$ was taken to imply that $(f \theta h)(x)=f[h(x)]$

$$
\begin{aligned}
(h \circ f)(x) & =h[f(x)] \\
& =h(4) \\
& =4+3
\end{aligned}
$$

So $=7$, which is cornect.

So, part (c) was not a mistake.

(d) The mistake here is that the stadent tor

$(h \circ f)(5)$ to imply that

$$
\begin{aligned}
(h \circ f)(5) & =\{h[f(x)]\}(5) \\
& =\{[h(x)] \times[f(x)]\}(5) \\
& =[(x+3) \times(4)](5) \\
& =(4 x+12)(5) \\
& =4 \times 5+12 \\
& =20+12 \\
& =32
\end{aligned}
$$

The way to vespond is to show that

(a) $f(x)=4 \Rightarrow f(x)=4 x^{\circ}$ and lly $g(x)=2 x^{0}$, using indices. So that $(f \circ g)(7)=f[g(x)](7)=f\left[2 \times(7)^{0}\right]=f(2)=4 \times(2)^{0}=4$

(b) $(g \circ h)(x)=g[h(x)]=g(x+3)=2(x+3)^{0}=2 \times 1=2$

(c) This is correct as it is.

(d) $(h \circ f)(5)=h[f(5)]=h\left[4 \times(5)^{0}\right]=h[4 \times 1]=h(4)$

$$
\begin{aligned}
& =4+3 \\
& =7 \\
& \hline
\end{aligned}
$$

Figure 148. Teacher Y's response to vignette 8 continued

\section{Test on functions}

Item 6

Arthur, Ruth, Ian, Naomi and Liz discussed what a function is. Read each of the students' ideas about functions and write your response to it. 
This item was designed to assess Teacher Y's knowledge of learners' views about what a function is. It accorded him an opportunity to analyze a variety of answers from different learners and provide insight about how valid the learners' views were. Through this the Teacher would identify his learners' misconceptions about a function and how he would provide remedy to some of their flawed understanding.

According to Teacher Y, Arthur was wrong to perceive functions as input/output machines which receive an input and give an appropriate output (see Figure 149). He claimed that the input/output conception best describes relations and functions are just a subset of relations. If Teacher $\mathrm{Y}$ insisted that functions were subjects of relations, it follows that some of them would actually be perceived according to Arthur's description. It seems Teacher Y did not critically consider Arthur's description.

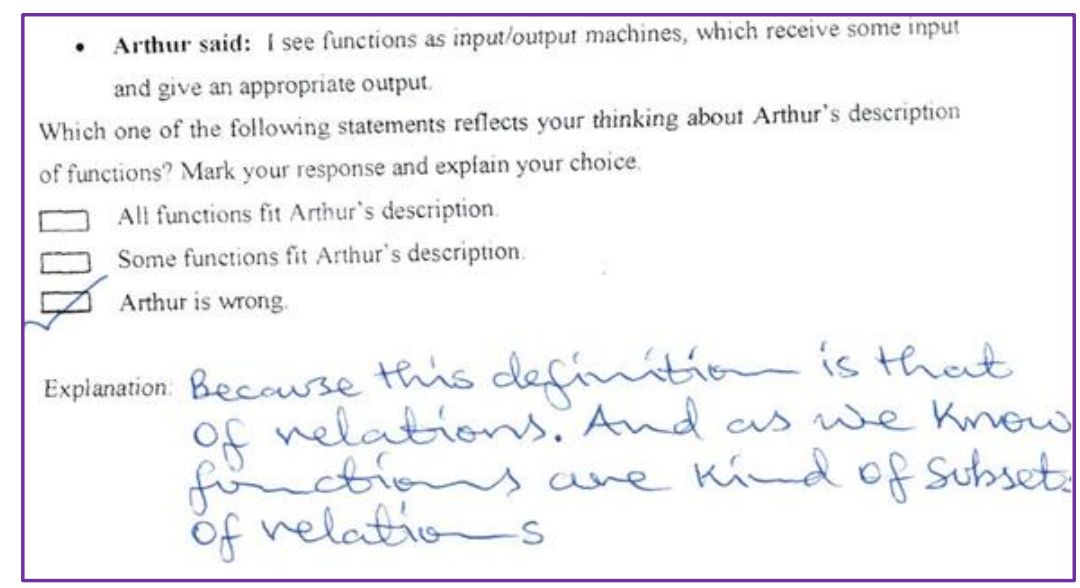

Figure 149. Teacher Y's answer to item 6(a)

Considering Ruth's description of functions, Teacher Y explained that a function can either be one-to-one or many-to-one and thus describing it as a "mapping of each element of one set to exactly one element of a second set" was the most appropriate way of defining it (see Figure 150). Teacher Y's explanation was a demonstration of a strong understanding of what a function is and he was able to match Ruth's description to his own understanding of the definition. 


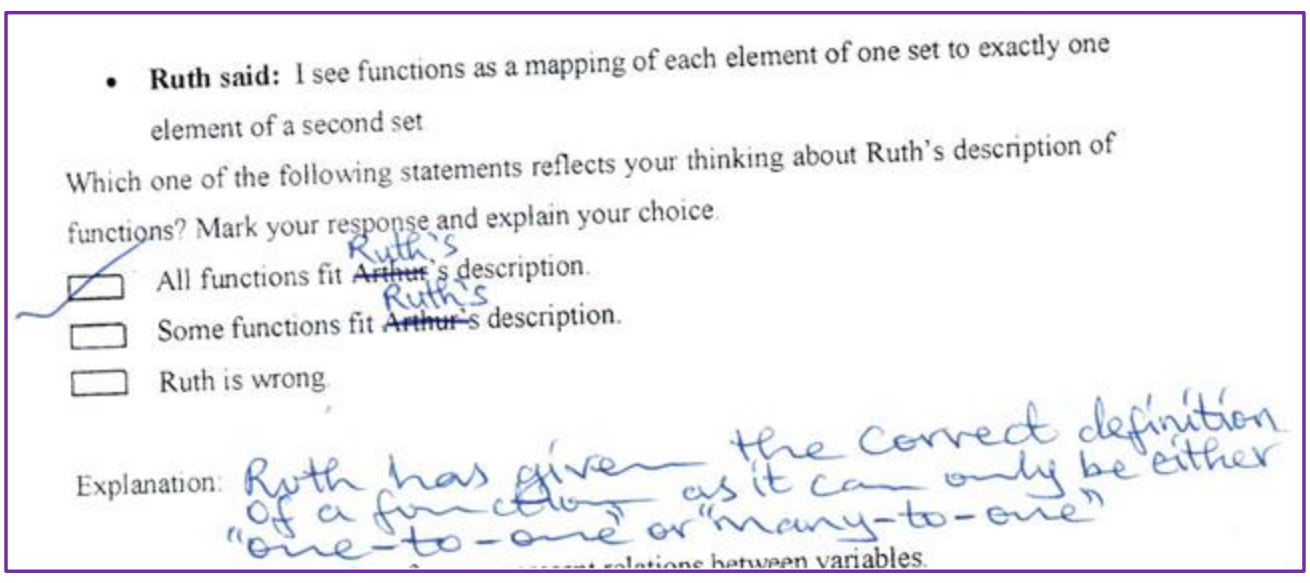

Figure 150. Teacher Y's answer to item 6(b)

In his analysis of Ian's description of functions (Figure 151), Teacher Y stated that to say that functions represented relations between variables was merely giving a general description which was more appropriate for describing relations. As such Teacher Y explained that Ian's description only encompassed some functions but not all. Here Teacher Y could have explained further how only some functions fit Ian's description. He could have stated some characteristics of functions which prevented them from explicitly being described as relations between variables.

- Ian said: Functions for me represent relations between vanaoles

Which one of the following statements reflects your thinking about Ian's description of functions? Mark your response and explain your choice.

All functions fit Arthitrs description.

Some functions fit Afthuts sescription.

lan is wrong

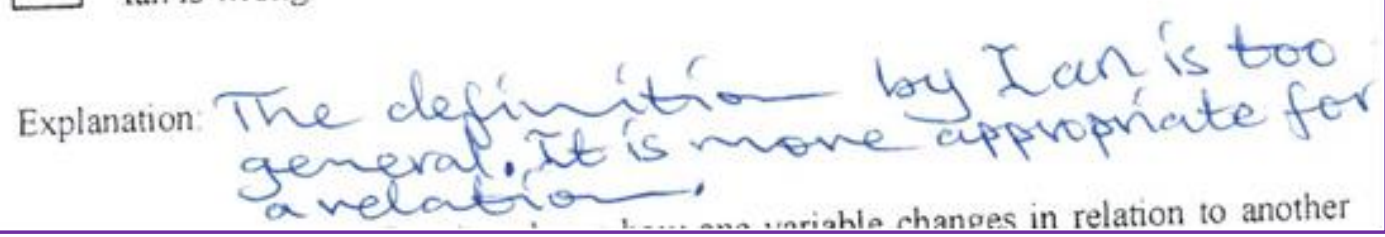

Figure 151. Teacher Y's answer to item 6(c)

Analyzing Naomi's description (Figure 152), Teacher Y stated that Naomi's description of functions was wrong because it referred to relations not functions. $\mathrm{He}$ did not give any detailed explanation why he thought that way. In this case Teacher $Y$ did not demonstrate comprehensive understanding of Naomi's description. Merely stating that it was wrong because it described relations, was not adequate to convince anyone. 


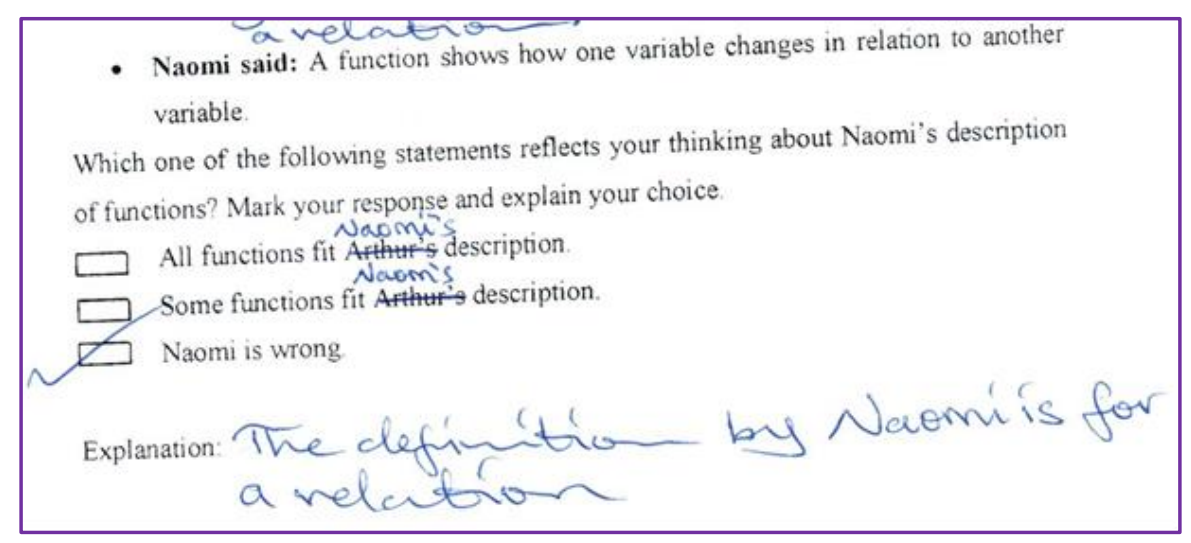

Figure 152. Teacher Y's answer to item 6(d)

In his analysis of Liz's description of functions (Figure 153), Teacher Y explained that $y=4 x+7$ was a function but her description was appropriate for a relation. Thus, he stated that only some functions would fit Liz's description. Again Teacher Y did not provide detailed explanations about how Liz's description would best describe a relation. Lack of detailed explanations would imply gaps in knowledge. Thus, it was important for Teacher $\mathrm{Y}$ to comprehensively support his claims.

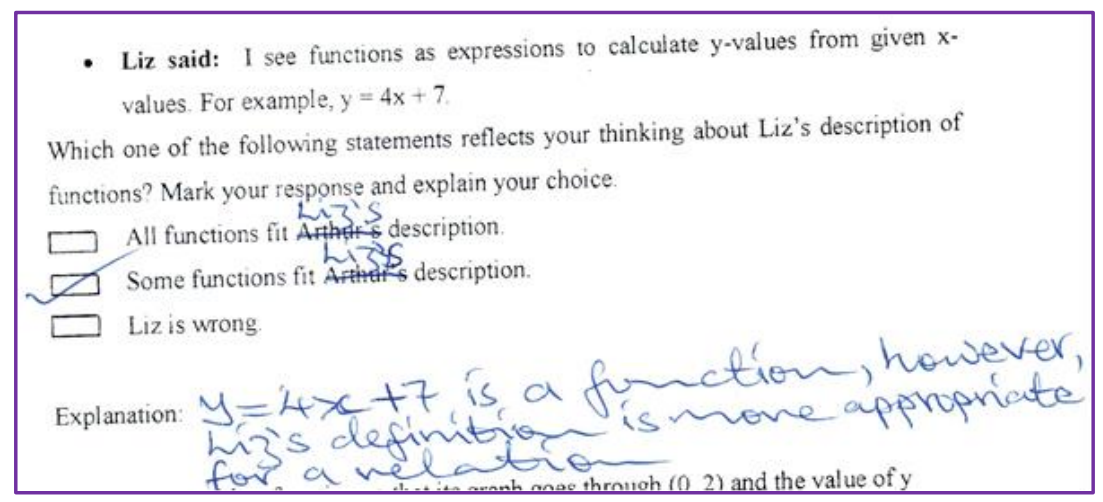

Figure 153. Teacher Y's answer to item 6(e)

\section{Item 7}

Could you provide a function so that its graph goes through $(0,2)$ and the value of $\mathrm{y}$ increases as $\mathrm{x}$ increases? For example:

One student's response to this problem was as follows:

"No. To do so you would need to know another point on the graph."

This item was designed to assess Teacher Y's ability to resolve students' difficulties in drawing graphs of functions. 
(a) Is the answer correct? What do you think the student is thinking about the equation and graph? The stoudert

c) If you think the student has misconceptions with respect to the equation and graph,

how would you assist this student?

Bu

3iv (

waves.

Figure 154. Teacher Y's answer to items 7(a), 7(b) and 7(c)

Teacher Y stated that the student was not correct to say that to draw a graph that passes through the point $(0,2)$ another point on the graph was needed (see Figure 154). He claimed that the student was probably thinking about plotting the graph of an equation. He suggested that this kind of misconception could best be resolved by using a table of values to draw a particular graph. Teacher Y may be suggesting that once the student is allowed to see how a table of values would generate a graph, it would be clearer to the student to appreciate the given situation in this question.

Item 8

A student is asked to give an example of a graph of a function that passes through the points A and B (See Figure 1). The student gives the following answer (see Figure 2). When asked if there is another answer the student says "No"

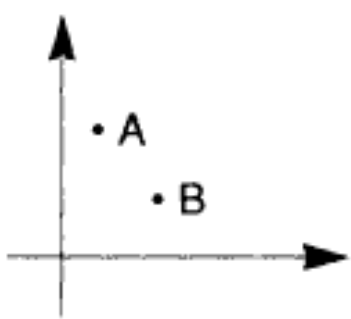

Figure 1

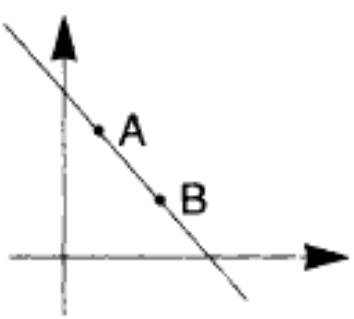

Figure 2

Item 8(a)

If you think the student is right, explain why.

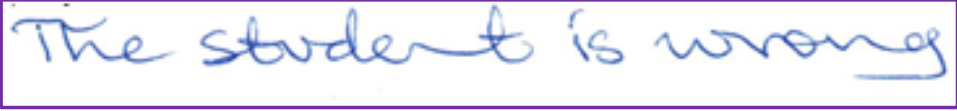

Figure 155. Teacher Y's answer to item 8(a) 
If you think the student is wrong, how many functions which satisfy the condition can you find? Explain.

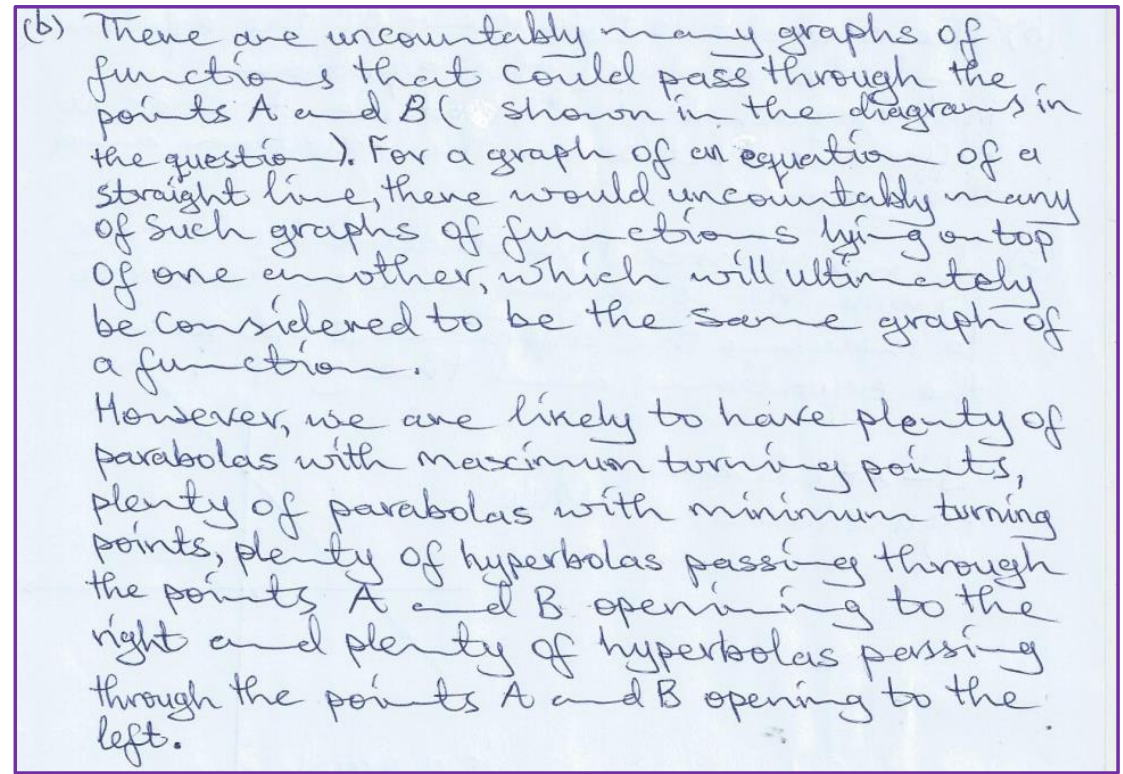

Figure 156. Teacher Y's answer to item 8(b)

This item was designed to assess Teacher Y's knowledge of learners' difficulties with graphs. In this case he was assessed on his knowledge of students' ability to identify functions that can be drawn passing through two given points (see Figure 156). Here Teacher $Y$ just stated that the student was wrong without any explanations to support his statement. He was asked during the interview to justify his statement and why he did not answer the second part of the question.

Interviewer: I observed that you did not answer item $8(\mathrm{~b})$ in the test. Why did you leave it unanswered?

Teacher Y: Umh..... let me answer it right now.

Teacher Y then answered the question. Analyzing his answer, it can be seen that he demonstrated good knowledge of drawing graphs especially when given restrictions of where the graphs needed to pass. He showed this by stating different types of graphs that can be drawn like hyperbolas.

\section{The case of teacher $Z$}

\section{Summary of teacher Z's lesson plan on inverse functions}

This 80 minutes lesson would be taught to 40 grade 11 students (17 girls and 23 boys). As a rationale for teaching inverse functions, Teacher $\mathrm{Z}$ would like his 
students to apply inverse function concepts to other mathematics topics. The teacher did not state teaching aids to be used during the lesson but would expect students to have "knowledge in making subjects of the formula" as their pre-requisite knowledge. The expected outcomes were that (a) students should be able to distinguish a relation from the inverse of a function and (b) define the inverse of a function.

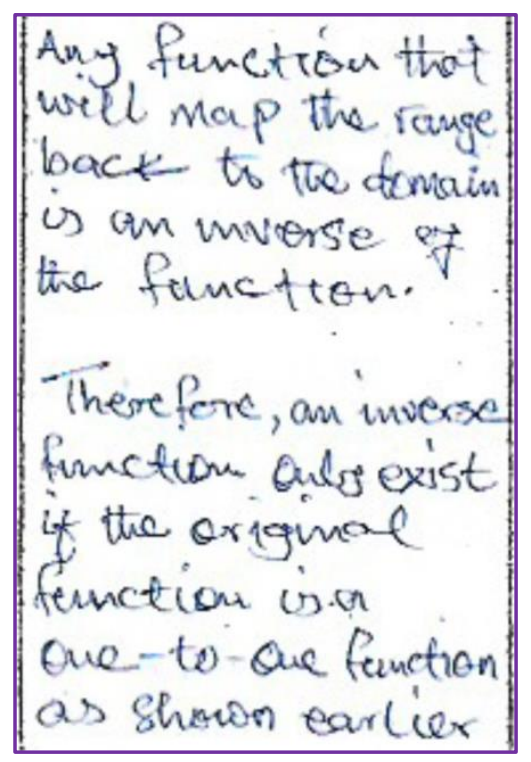

Figure 157. Excerpt LP11 of Teacher Z's lesson plan on inverse functions

Teacher Z would introduce the day's lesson by revising previous work taught then connect to the present lesson. The teacher would then present an example before offering the definition of the inverse function (see Figure 157). In his definition the teacher would rely on the concepts of domain and range by stressing that the inverse of a function maps the range back to the domain. He would then note that the "inverse function only exists if the original function is a one-one function". Teacher $\mathrm{Z}$ would then present two examples for which he included expected answers from his students (see Figure 158). He would end the lesson by giving a class exercise. In the example the teacher justifies that the function $\mathrm{f}(\mathrm{x})=\mathrm{x}^{2}$ is not a function because two members of the domain would be mapped onto one member of the range. Thus, this function is not a one-to-one function. Throughout his presentation, correct notation for inverse functions was used. 


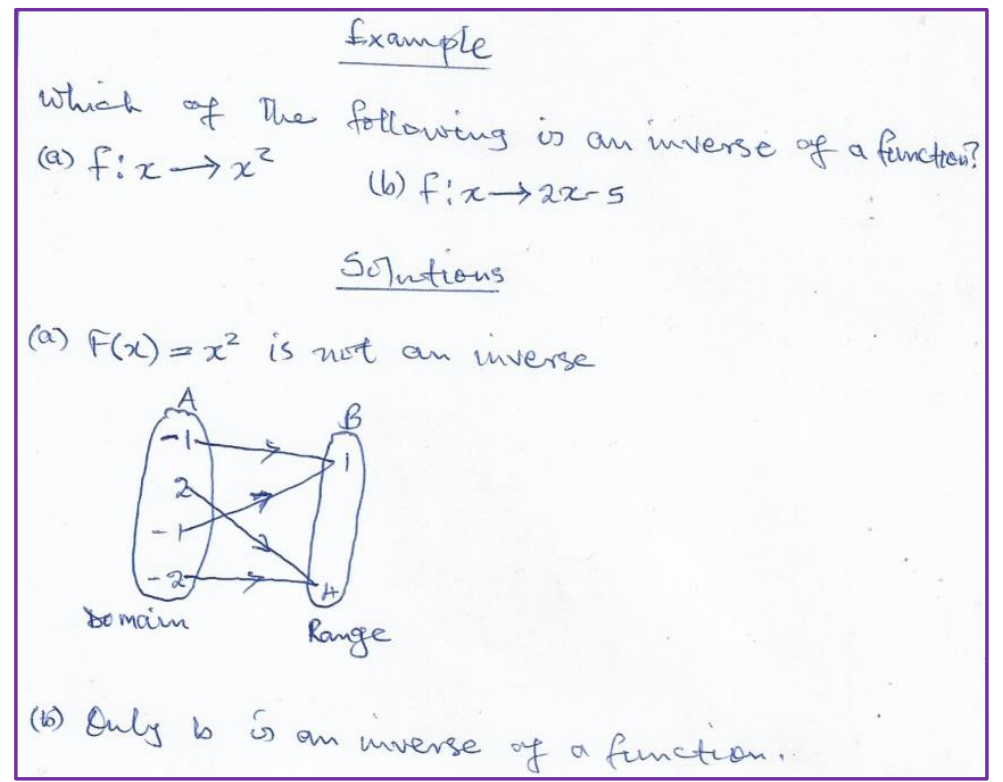

Figure 158. Excerpt LP12 of Teacher Z's lesson plan on inverse functions

Summary of teacher Z's actual classroom teaching activity of the lesson on inverse functions

Teacher $\mathrm{Z}$ introduced the lesson on inverse functions by posing the following question to his students

Teacher: what is the inverse of a function?

With students unable to respond to the question the teacher told the students that "we know that a function is a mapping" which can be

\section{One-to-many}

\section{Many-to-one}

\section{Many-to-many}

\section{One-to-one}

Of these which one qualifies to be the inverse of the function? Students responded with different answers which seemed to be guessed answers

\section{First attempt: Many-to-one}

\section{Second attempt: Many-to-many}

\section{Third attempt: One-to-one}

The teacher then defined the inverse function as "a function that will reverse the order of coordinates of the ordered pairs". He then illustrated the inverse function using an example 


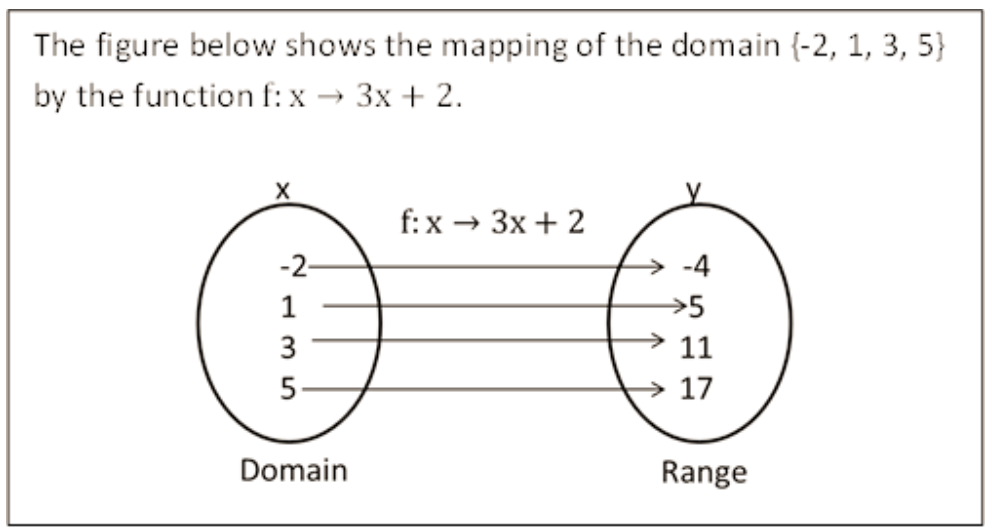

The teacher then explained to the students that the inverse of the given function can be used to map every element of the range back to the domain. He then stated that the function $\mathrm{f}: \mathrm{x} \rightarrow 3 \mathrm{x}+2$ can also be written as $\mathrm{y}=3 \mathrm{x}+2$. No explanation for the change was given. He then stated that when $x$ is made the subject of the formula the result is called the inverse. Thus to make $x$ the subject in $y=3 x+2$, "the left hand side becomes the right hand side and the right hand side becomes the left hand side to obtain $3 x+2=y$ ". then make two to cross the equal sign and then divide both sides by 3 to obtain $\mathrm{x}=\frac{\mathrm{y}-2}{3}$. Then write down the inverse by replacing $\mathrm{y}$ with $\mathrm{x}$ to obtain $\mathbf{f}^{-1}(\mathbf{x})=\frac{\mathbf{x}-\mathbf{2}}{3}$.

The teacher only mentioned about notation for the inverse when he encountered the need to use it in the final stage of his calculations. He then asked students to find the inverse of the functions (a) $x=\frac{2 x-7}{-2}$ and $f(x)=6 x-4$. After discussing the two examples with his class with full participation of the students the teacher gave a class exercise and marked all the books and helped individual students that faced difficulties with exercise questions.

\section{Summary of teacher Z's lesson plan on composite functions}

This lesson would be taught in 80 minutes to 40 grade 11 students (17 girls and 23 boys). The teacher did not include teaching aids as he planned for this lesson. $\mathrm{He}$ stated that for students to understand composite functions they would need to have knowledge of substitution and that of subject of the formula. The rationale for teaching composite functions is for students to "apply the concept in other topics like calculus and probably in other subjects and in real life situations". The expected outcomes would be for students to "be able to solve problems involving the composite of functions with less difficulty". As an introduction to the lesson, 
Teacher $\mathrm{Z}$ would briefly revise work on inverse functions, being the topic which was taught in the previous lesson (see Figure 159).

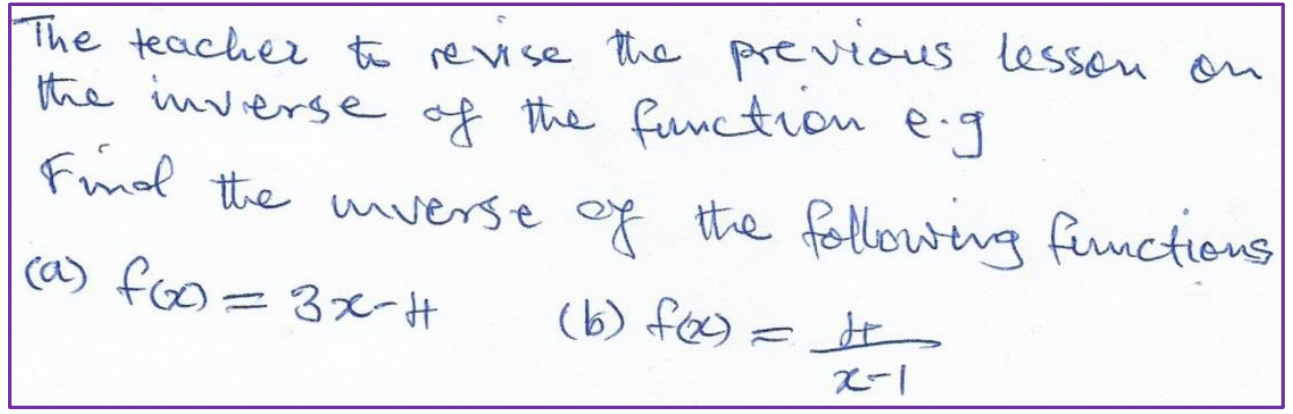

Figure 159. Excerpt LP13 of Teacher Z's lesson plan on composite functions

Then teacher would then build on to the introduction by asking students what they know about composition of functions. Upon receiving answers from students, he would then define a composite function as "a function that is a combination of two or more functions". He would then proceed to give two examples about composite functions (see Figure 160). For the first example Teacher $\mathrm{Z}$ illustrates the solution using a diagram. He would then give a class exercise to conclude the lesson. No concluding remarks are indicated in the lesson plan as the lesson ends with a class exercise.

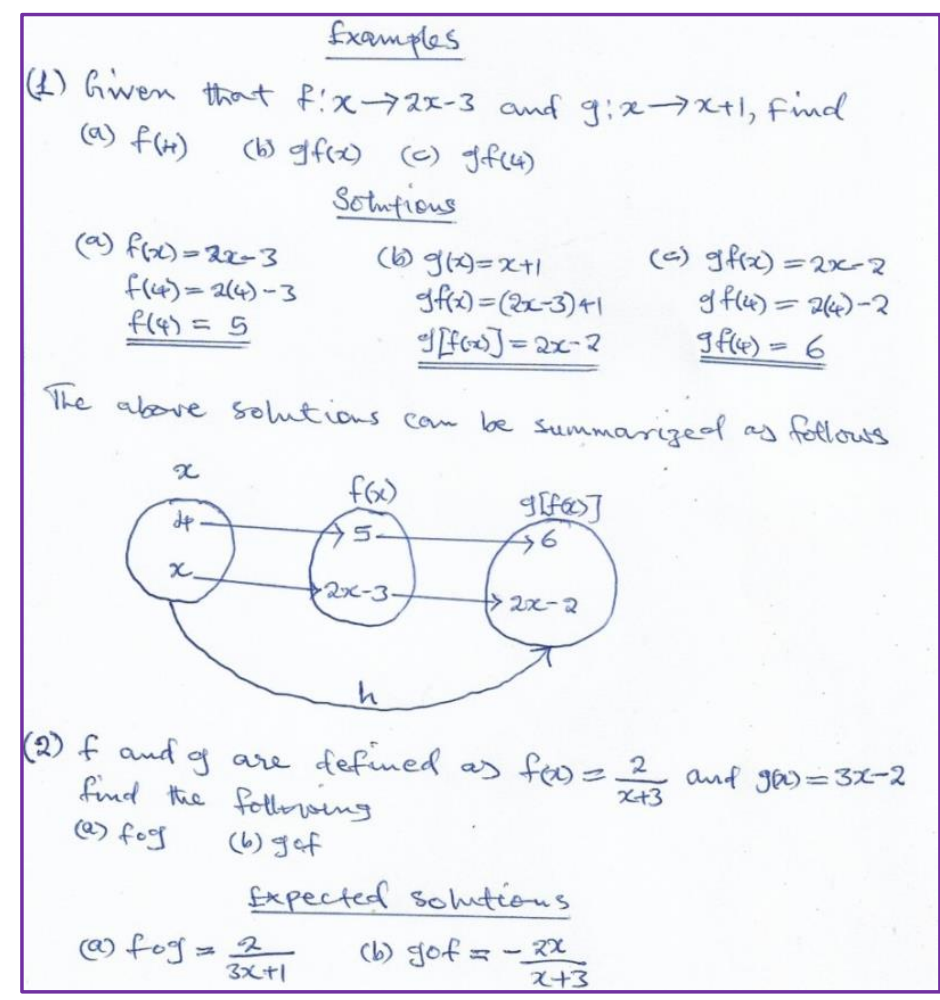

Figure 160. Excerpt LP14 of Teacher Z's lesson plan on composite functions 
Summary of teacher Z's actual classroom teaching activity of the lesson on composite functions

Teacher Z introduced the day's lesson by reminding students what they learnt in the previous lesson on inverse functions. He then asked two students (a boy and a girl) to find the answer to the following introductory task

Find the inverse of the following functions
(a) $f(x)=3 x-2$
(b) $f(x)=\frac{4}{x-1}$

The boy managed to find the inverse without difficulty while the girl had difficulties with the last two stages which involved the introduction of $\mathrm{f}^{-1}(\mathrm{x})$ and replacement of $\mathrm{y}$ with $\mathrm{x}$. The teacher also kept using the phrase "when y crosses the equal to sign it changes its sign" throughout his teaching. The teacher corrected the errors committed by the girl. He then switched to the day's main business by asking students what they understood by composite function. He received the following responses

First response: "it is an expression of $\mathrm{f}(\mathrm{g})$ "

Second response: "A function with a combination of different functions"

Teacher $\mathrm{Z}$ then told the students that the answers they gave were both partly correct and he went on to define the composite function as "a combination of two or more functions". He stated that the composition of functions $f$ and $g$ was denoted by $\mathrm{f}^{\mathrm{o}} \mathrm{g}$ or $\mathrm{f}[\mathrm{g}]$ or $\mathrm{fg}$. And that notation needed not confuse them. Teacher $\mathrm{Z}$ then presented the following example allowing students' participation by answering questions while he found solutions to the problems.

\section{Given that the functions $f$ and $g$ are defined by $\mathrm{f}: \mathrm{x} \rightarrow \mathrm{x}-3$ and $\mathrm{g}: \mathrm{x} \rightarrow \mathrm{x}+1$ respectively. Find}
(a) $F(4)$
(b) $g^{\circ} \mathrm{f}$
(c) $f^{\circ} g$

He explained how to find solutions to (b) emphasizing that for the function $g^{o}$ $\mathrm{f}$ they need to imput the function $\mathrm{f}$ into $\mathrm{g}$ by substituting $\mathrm{x}$ with the function $\mathrm{f}$. he told the students that the same reasoning is applied to example (c). while students seemed to have understood how to find $\mathrm{g}{ }^{\mathrm{o}} \mathrm{f}$, the overall impression was that finding $\mathrm{f}^{\mathrm{o}} \mathrm{g}$ was difficult. The teacher struggled to make them understand as he kept referring to examples (a) and (b). the teacher then presented the second example before giving 
students a class exercise. He concluded the lesson by highlighting the main points of the day's lesson with special emphasis on the notation.

\section{Teacher Z's responses to vignettes}

\section{Vignette 1}

You have been discussing the concept of inverse functions in class. You pose the following question in class.

Determine the inverse $\left(f^{-1}(x)\right)$ of a function $f(x)=x-4$.

Five different solutions come out from the class.

$$
\begin{array}{ll}
\text { (xi) } & f^{-1}(\mathrm{x})=\frac{1}{\mathrm{x}-4} \\
\text { (xii) } & f^{-1}(\mathrm{x})=\frac{1}{\mathrm{x}}-4 \\
\text { (xiii) } & f^{-1}(\mathrm{x})=-\mathrm{x}-4 \\
\text { (xiv) } & f^{-1}(\mathrm{x})=-\mathrm{x}+4 \\
\text { (xv) } & f^{-1}(\mathrm{x})=\mathrm{x}+4
\end{array}
$$

The different answers reveal that the class is confused.

What is the problem in each solution (if there exists)?

Explain how you would respond to these comments and clear up confusion during a class.

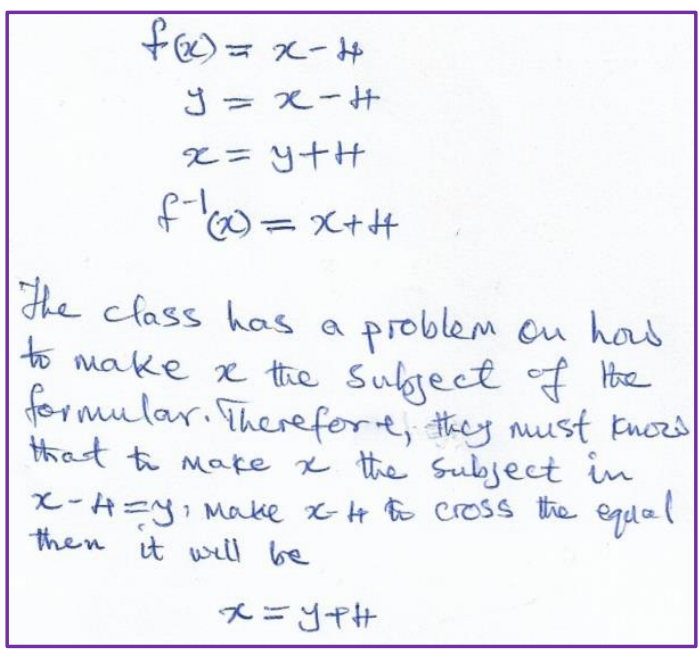

Figure 161. Teacher Z's response to vignette 1

This vignette was centered on teacher's ability to understand inverse function notation and how it caused misconceptions by conflicting with concepts in arithmetic (multiplicative inverse) and negative exponents when dealing with indices and exponential functions. According to Teacher Z, the student's error was as a result of 
his/her inability to "make $\mathrm{x}$ the subject of the formula" Teacher $\mathrm{Z}$ demonstrated how he hoped the student would proceed to make $\mathrm{x}$ the subject. He makes reference to adding the additive inverse of (-4) as "making -(4) to cross the equal to sign" (see Figure 161). This type of language would easily cause misunderstanding because using correct mathematical language and symbols enhances understanding of concepts. The teacher did not also provide ways of clearing confusion created in the class. As such his responses to the vignette were rated Level 0.

\section{Vignette 2}

A student said the inverse of the function $(x)=x^{2}=\sqrt{x}$.

Is the student right? If you think that the student is correct explain why?

If you think the student is incorrect explain where the error lies and how you would respond to these comments and clear up confusion in lass.

Figure 162. Teacher Z's response to vignette 2

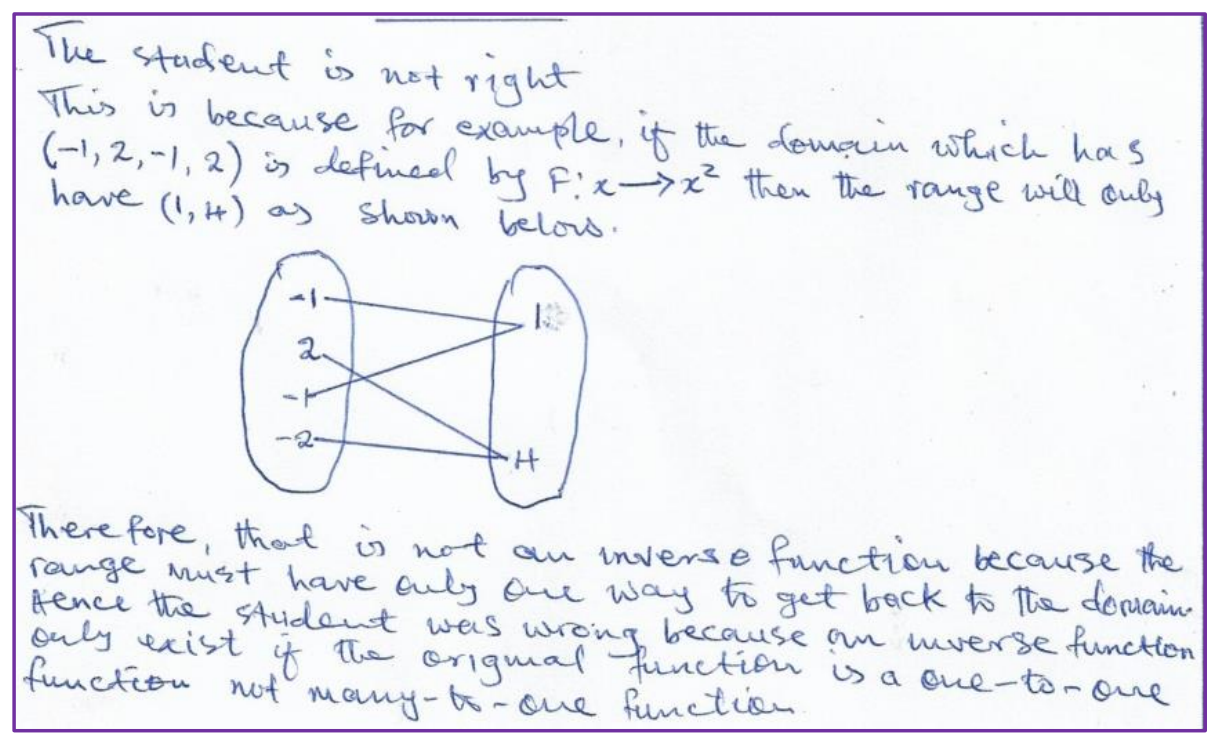

This vignette was meant to assess the teacher's ability to demonstrate knowledge of existence of inverse functions and to highlight conditions under which a function can exist. The teacher stated that for a function to have an inverse it must be a "one-to-one" which was not the case with the given function (Figure 162). Thus, $\sqrt{\mathrm{x}}$ is not the inverse of $f(\mathrm{x})=\mathrm{x}^{2}$. He used different representation to emphasis his point. He used the concept of domain and range on an arrow diagram to demonstrate that the function was not a one-to-one. Thus, his response to this vignette was rated Level 2. 


\section{Vignette 3}

A teacher gave the definition of the inverse function and explained it on the board to his/her students. However, some of the students stated that they did not understand it completely. The teacher then gave the following example to the students.

If you think of a school bus as a function which takes you from home to school in the morning, then the school bus that takes you back from school to home is the inverse of the first function.

* What do you think of this example?

* Can the example cause students to misunderstand any points in the definition?

* If exists, please explain these points. If you were to explain the inverse function by using a real life example, what will be your example?

* Explain how you will use it in class.

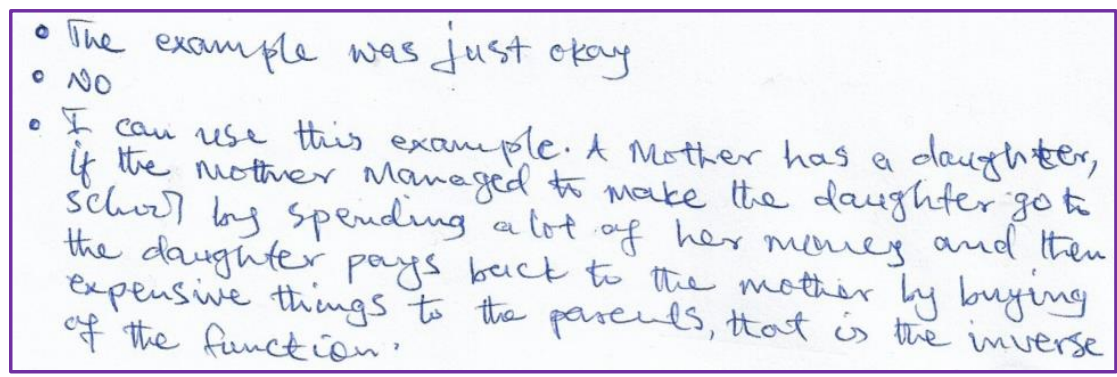

Figure 163. Teacher Z's response to vignette 3

This vignette was aimed at assessing the teacher's understanding of the inverse function definition and how he can explain it to make his students comprehend it. It also sought to assess the teacher's ability to understand and employ analogies in his teaching. Teacher $\mathrm{Z}$ approved the example to be appropriate and that it would not cause misunderstanding among the students (Figure 163), he went on to give an analogy that he thought would help explain the inverse of a function. The given analogy was somewhat vague because it talks about two different variables (money spent educating a daughter and money spent buying expensive things). His analogy seems quite complicated for students to relate to. His response was rated Level 0-1.

Vignette 6

You have been discussing the concept of composite functions in the $10^{\text {th }}$ grade class. You pose the following problem in class.

Let $h(x)=f[g(x)]$ and determine $f(x)$ and $g(x)$ if $h(x)=2(x-5)$. 
One student suggests that " $\mathrm{g}(\mathrm{x})=\mathrm{x}-5$ and $\mathrm{f}(\mathrm{x})=2$ "

Another student interrupts "no $f(x)$ must be equal to $2 x$ if $g(x)=x-5$ ".

A third student remarks "Well I think $g(x)=x-5$ and $f(x)=2 x "$.

The class seems confused.

What is the problem in each solution (if there is any)?

Explain how you would respond to these comments and clear up confusion during class.

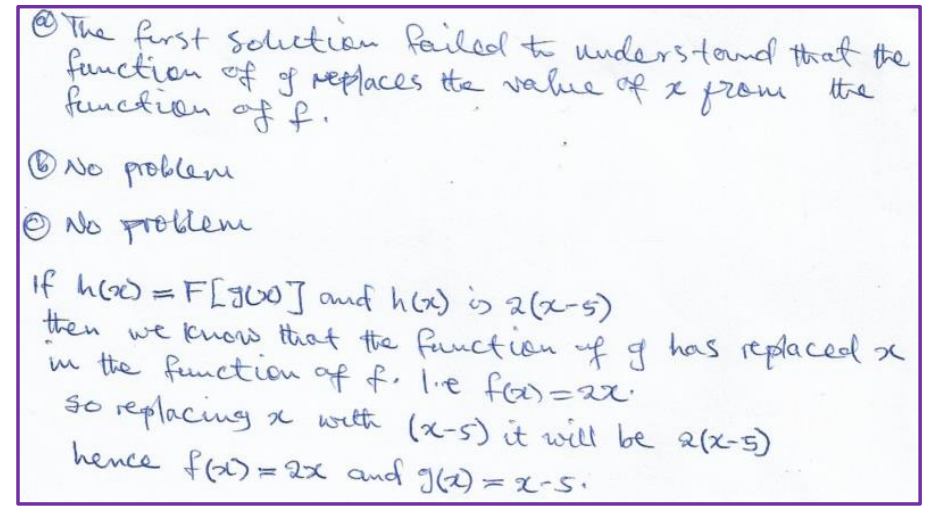

Figure 164. Teacher Z's response to vignette 6

This vignette was basically testing the understanding of composite function definition and how composite functions differ from ordinary functions. The vignette required the students to also distinguish the composite function $f[g(\mathrm{x})]$ from ordinary multiplication of algebraic terms $f(\mathrm{x}) \cdot g(\mathrm{x})$. Teacher $\mathrm{Z}$ stated that solutions to parts (b) and (c) were correct while the solution to part (a) was incorrect (see Figure 164). His explanation for errors in part (a) seemed to suggest that the student did not understand the definition of composite function. The teacher did not explicitly talk about the definition but his explanation was suggestive of that reasoning. In his explanation to clear confusion the teacher attempted to solve the given problem in a way that was less convincing and conceptually lacking. The manner in which he brings in $2 \mathrm{x}$ without justification left a conceptual gap. Thus, his response was rated Level 1.

Vignette 7

You have been discussing the concept of composite functions in class. You pose the following problem in class.

Determine the composite function $\left(f_{\circ} g\right)(x)$ if $f(x)=x+3$ and $g(x)=x^{2}+6$. 
One student answers the problem as " $\left(f_{\circ} g\right)(x)=(x+3)^{2}+6 "$.

Another student answered the problem as $\left.\left(f_{\circ} g\right)(x)=(x+3) x^{2}+6\right) "$.

A third student answered it as $\left(f_{\circ} g\right)(x)=x^{2}+9$ ".

For each of the incorrect solutions

What is the source of the mistake? (show and explain how they may have found the solution).

Explain how you would respond to these comments and clear up confusion during a class.

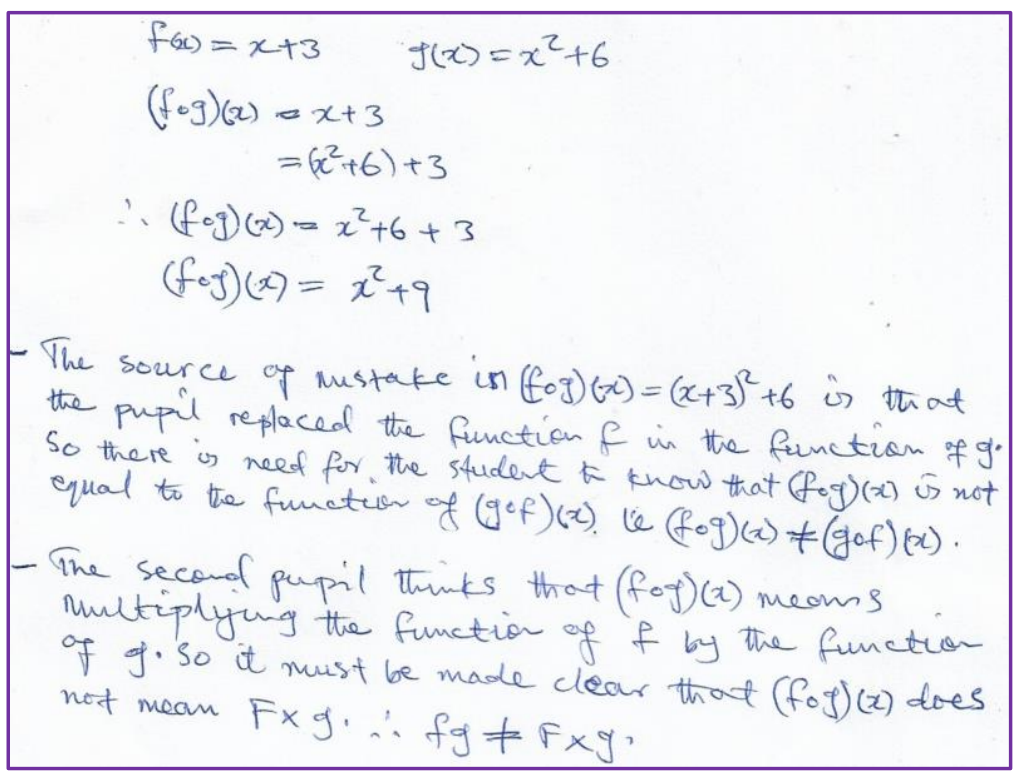

Figure 165. Teacher Z's response to vignette 7

This vignette was meant to show the importance of the order in which the functions were taken when simplifying composite functions. It was trying to demonstrate that the order of operations in arithmetic operations was not applicable to operations on composite functions. When combining two or more functions order in which the composition is written must be respected. Teacher $\mathrm{Z}$ started by working out the given problem to find the composition (Figure 165). He went to state that in the first solution the mistake was for the student to assume that $\left(f_{\circ} g\right)(x)=\left(g_{0} f\right)(x)$. in the second solution teacher $\mathrm{Z}$ explained that the mistake arose from the assumption that $\left(f_{\circ} g\right)(x)$ implied $f(x)$ multiplied by $g(x)$ which was incorrect. Teacher $\mathrm{Z}$ showed knowledge of the sources of misconception for the solutions in this vignette but did not explain how such misconceptions would be avoided in future. His response was rated Level 1. 


\section{Test on functions}

Item 6

Arthur, Ruth, Ian, Naomi and Liz discussed what a function is. Read each of the students' ideas about functions and write your response to it.

This item was designed to assess Teacher Z's knowledge of learners' views about what a function is. It accorded him an opportunity to analyze a variety of answers from different learners and provide insight about how valid the learners' views were. Through this the Teacher would identify his learners' misconceptions about a function and how he would provide remedy to some of their flawed understanding.

In his analysis of Arthur's description of functions (Figure 166), Teacher Z agreed with Arthur that functions are input/output machines, which receive some input and give an appropriate output. He further explained that a value of the controlling variable is inserted as an input to give an output. Teacher $\mathrm{Z}$ did not consider how relations would also fit Arthur's description. This is because in a oneto-many relation an input can also give an output. Thus, Arthur's description fits some relations. Secondly, not all functions may fit Arthur's description because a function is basically a correspondence between two sets where an element of one set has a unique corresponding element of the second set. This correspondence will not always be defined in terms of input/output correspondence.

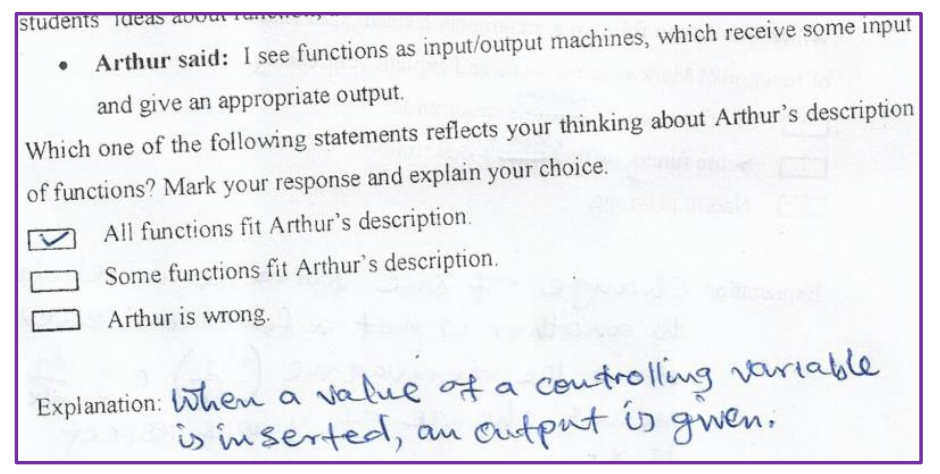

Figure 166. Excerpt of Teacher Z's answer to item 6(a)

Ruth described functions as a mapping of each element of one set to exactly one element of the second set. Teacher Z stated that Ruth's description fitted all functions and used the concept of domains and ranges to emphasis his views (Figure 167). He stated that in view of domain and range of a function, one element from the 
domain (first set) is mapped to one and only one element in the range (second set). Teacher Z's explanation was valid.

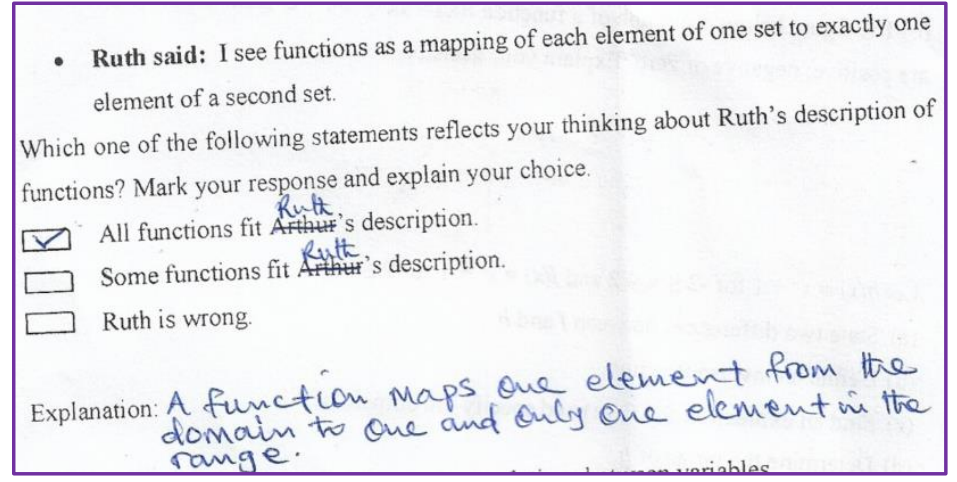

Figure 167. Excerpt of Teacher Z's answer to item 6(b)

In his analysis of Ian's description, Teacher Z stated that Ian was wrong to conceive functions as representing relations between variables (Figure 168). He explained that a function may only have one variable called the controlling variable. He probably argued that functions contain only one variable to mean that a function, unlike a relation, has a unique variable of the second set linked to a variable of the first set. His explanation was brief and not elaborate to convince Ian that his description was incorrect.

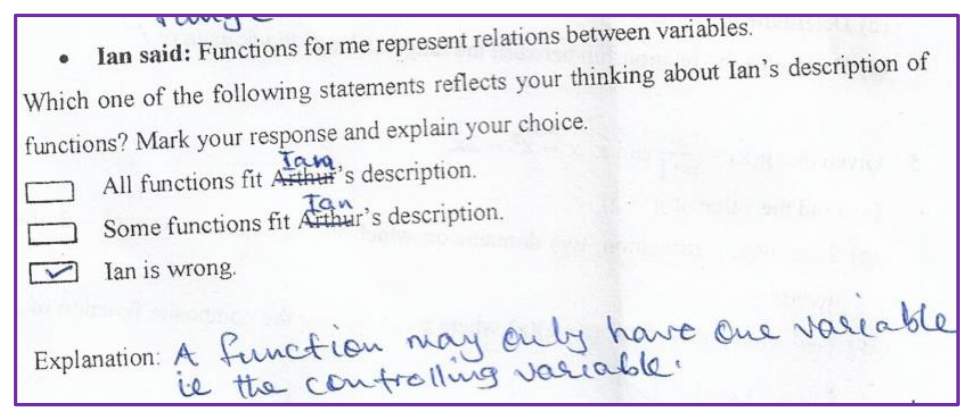

Figure 168. Excerpt of Teacher Z's answer to item 6(c)

Naomi stated that functions show how "one variable changes in relation to another variable". In analyzing Naomi's conception of a function, Teacher Z stated that Naomi was wrong to conceive functions in that manner, arguing that change "of one variable in relation to another is not a function" (Figure 169). He stated that the change purported by Naomi implied a derivative $\frac{d y}{d x}$ which meant change of $\mathrm{y}$ with respect to $\mathrm{x}$. teacher $\mathrm{Z}$ did not give Naomi's description a wide consideration because 
if for instance, Naomi used an equation in two variables to define a function, a change in one variable would trigger a change in the other variable.

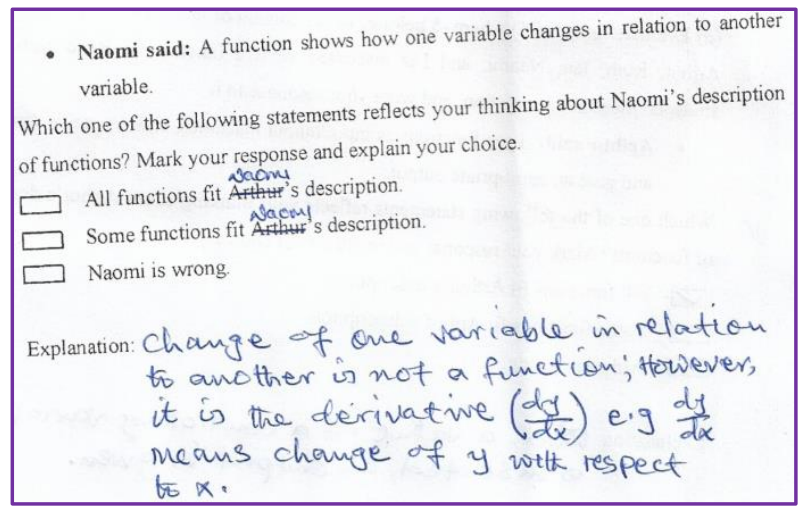

Figure 169. Excerpt of Teacher Z's answer to item 6(d)

Considering Liz's description of functions Teacher $\mathrm{Z}$ agreed with Liz that some functions could be viewed as expressions to calculate $\mathrm{y}$-values from given $\mathrm{x}$ values (see Figure 170). He explained that this is because it was not always the case that variables will be given in terms of $\mathrm{x}$ and $\mathrm{y}$, and it is not always the case that a function would require one to find the value of y. Teacher Z's explanation about Liz's description of functions was valid.

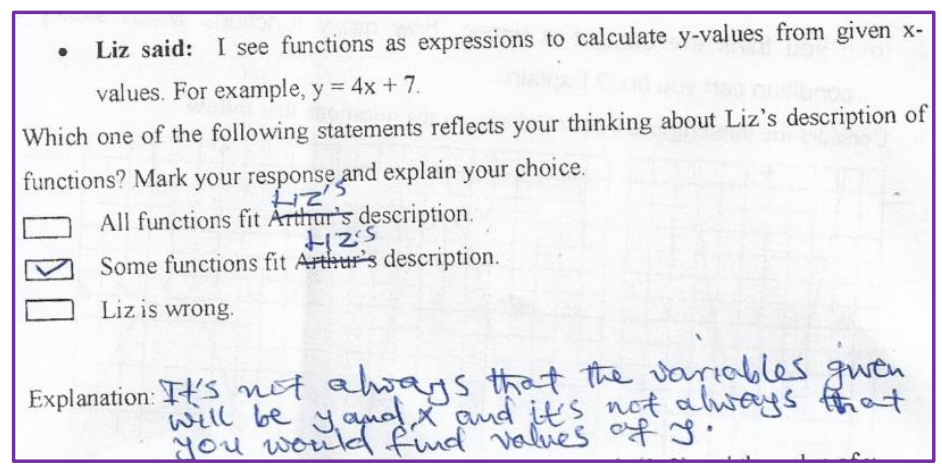

Item 7

Figure 170. Excerpt of Teacher Z's answer to item 6(e)

Could you provide a function so that its graph goes through $(0,2)$ and the value of $\mathrm{y}$ increases as $\mathrm{x}$ increases? For example:

One student's response to this problem was as follows:

"No. To do so you would need to know another point on the graph."

This item was designed to assess Teacher Z's ability to resolve students' difficulties in drawing graphs of functions. Teacher $\mathrm{Z}$ stated that the student was not 
correct to say that a second point was needed to draw an increasing graph that passed through the point $(0,2)$. He claimed that the student was probably thinking that the graph should have an equation of the form $y=m x+c$. he suggest that the student could be assisted by exposing him/her to other types of functions like cubic functions (see Figure 171).

(a) Is the answer correct? No

(b) What do you think the student is thinking about the equation and graph? $\Rightarrow$ the student thution and graph,

(c) If you think the student has misconceptions with respect to the equ

how would you assist this student? other types of functions e.g cubric functions By subjecting the sifudent to other the

Figure 171. Excerpt of Teacher Z's answer to items 7(a), 7(b) and 7(c)

Item 8

A student is asked to give an example of a graph of a function that passes through the points A and B (See Figure 1). The student gives the following answer (see Figure 2). When asked if there is another answer the student says "No"

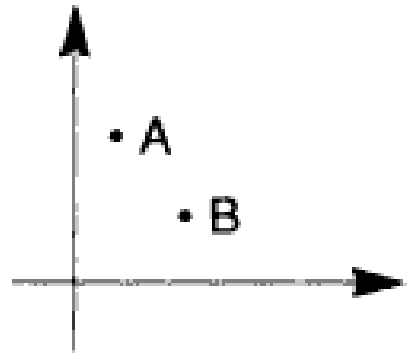

Figure 1

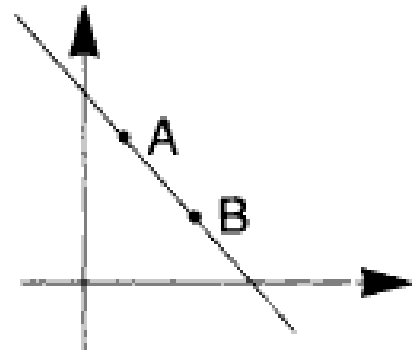

Figure 2

Item 8(a)

If you think the student is right, explain why.

Item 8(b)

If you think the student is wrong, how many functions which satisfy the condition can you find? Explain.

This item was designed to assess Teacher Z's knowledge of learners' difficulties with graphs. In this case he was assessed on his ability to identify functions that can be drawn passing through two given points. Analyzing the response by the student (Figure 172), Teacher $\mathrm{Z}$ stated that an infinite number of 
functions can be drawn which would pass through points $\mathrm{A}$ and $\mathrm{B}$ and that the graphs would have different amplitudes. Teacher $\mathrm{Z}$ would have exemplified his explanation by drawing a few graphs for the student to see visual representations of what he was talking about.

(b) There are infinity of functions whose graphs may pass through the two geven pouts as the graphs of the functions may have different amplitudes.

Figure 172. Excerpt of Teacher Z's answer to item 8(b) 



\section{Chapter 5: Analysis}

This Chapter contains a full discussion, interpretation and evaluation of the results with reference to the evalutated literature. The outcomes of this study were tied to the review of literature, objectives and rationale. The Chapter starts with discussion of quantitative results (section 5.1) and then devlves into a discussion of qualitative results (section 5.2). The discussion of results in the entire Chapter is tied to the research objctes set in Chapter 1 of this study.

\subsection{DISCUSSION OF QUANTITATIVE RESULTS}

This section provides a detailed interpretation of results obtained from quantitative analysis. The researcher first discusses pre-service teachers' MPCK. A discussion about subject matter knowledge follows before concluding with the correlational relationship between MPCK factors and subject matter knowledge.

\subsubsection{Mathematical Pedagogical Content Knowledge perceptions of pre-service teachers}

The Mathematical Pedagogical Content knowledge (MPCK) perceptions of pre-service teachers were discussed in terms of their self-perceived Knowledge of Teaching Strategies (KTS), Knowledge of Mathematical Language and Symbols (KMLS), Knowledge of Misconceptions (KM), Knowledge of Learners (KL) and Knowledge of Curriculum (KC). The way an individual teacher perceives mathematics subject-matter and the methods by which it is taught has a huge bearing on how well they would actually comprehend the subject (Akkaya, 2016; Bjerke \& Solomon, 2019; Karakus, 2018).

A teacher needs to have strong knowledge of teaching strategies relevant to the teaching of mathematics (You, 2006). In the context of this study of the function concept, teacher's knowledge of instructional strategies included but not limited to the teacher's ability to select and integrate appropriate teaching approaches and techniques in the teaching of functions. The teacher also needs to possess advanced skills necessary for the assessment and evaluation of their secondary school students' conceptual understanding of functions and academic performance. In light of this 
knowledge the teacher is expected to conduct effective delivery of functions subjectmatter.

To examine their knowledge of teaching strategies, participants of this study were categorized in clusters (see Table 3 in Chapter 4) according to their average scores in the KTS domain. Pre-service teachers in Cluster 1 perceived themselves to have low Knowledge of Teaching Strategies with a mean score of 3.48 and standard deviation of .89 compared to their counterparts in Cluster $2(\bar{X}=4.35, \mathrm{SD}=.60)$ which represented a significant difference $[\mathrm{t}(148)=-7.09, \mathrm{p}<.05]$ in their selfperceived knowledge of teaching strategies (Table 4). This entails that pre-service teachers in Cluster 2 are more likely to exhibit confidence in their selection and use of different teaching strategies when teaching functions in secondary school compared to those in Cluster 1.

However, a global examination of pre-service teachers' KTS in both clusters 1 and 2 revealed a rather unsatisfactory picture. Overall, pre-service teachers in both clusters posted low knowledge of teaching strategies. It is expected that they would experience challenges in either their assessment or evaluation of the students or both. They are also likely to face challenges with the selection and implementation of suitable approaches for teaching the function concept. There is need for them to have good KTS skills because it will positively impact on their confidence and self-esteem in their future mathematics classrooms.(Kilic, 2018; Lin \& Rowland, 2016; Lui \& Bonner, 2016; Strayer et al., 2018).

A bivariate analysis of pre-service teachers' KTS and knowledge of the concept of a function (Table 21) showed that there was no significant relationship between the two $(\mathrm{r}=.134, \mathrm{p}=.103)$. This result was highly unexpected and contradicts the views of You (2006) stated ealier. Pre-service teachers in this study had teaching practice experience and were expected to appreciate the connection between knowledge of subject matter and instructional strategies. But probably teaching experience played its part in this situation because teaching practice is usually for a period of three months. This could be a short period for them to fully realize the relationship betwteen KTS and subject matter knowledge. Otherwise there is evidence of a positive relationship between KTS and subject matter knowledge in literature (Duran \& Usak, 2015; Goe, 2007; Handa, 2011; Mason \& Davis, 2013). It is therefore important for teacher education providers to prepare pre-service teachers 
to develop a relationship between the mathematics subject matter they learn in university and teaching it in secondary school (Handa, 2011)

As regards Knowledge of Mathematical Language and Symbols (KMLS), every teacher ought to have very good command of mathematical language for effective communication of mathematical concepts to the students. Every teacher also needs to know all the symbols for each topic of mathematics, how to write them, how to correctly pronounce them, what they mean and how to use them. Failure to have this kind of knowledge would mean ineffective communication between the teacher and his/her learners (Sajka, 2003).

The concept of a function is such one topic where use of symbols or notation ought to be strictly adhered to. Failure to correctly use suitable language would result into gross misunderstanding of the concepts by the learners. Equally, incorrect use of notation would translate to misrepresentation of function concepts. Thus, every teacher is supposed to integrate appropriate language of functions in teaching function concepts using correct notation prescribed in the topic. For example, a teacher is supposed to correctly identify the notations $f(x), f^{-1}(x), f[g(x)]$, fog as denoting a function, its inverse and the composition of two functions respectively. Similarly, a teacher must be able to correctly explain the representations $f(x)=2 x-5$ and $f(\mathrm{x}) \rightarrow 2 \mathrm{x}-5$. Teachers should be able to properly explain such symbolic language verbally.

While it was evident from Table 4 that there was a significant difference between pre-service teachers' Knowledge of Mathematical Language and Symbols between Cluster 1 and Cluster 2 [t(148) $=-7.51, \mathrm{p}<.05]$, the overall performance was still low. However, Table 3 shows that pre-service teachers in Cluster $1(\bar{X}=$ $3.83, \mathrm{SD}=.98)$ comprised pre-service teachers with lower KMLS than those in Cluster $2(\bar{X}=4.70, \mathrm{SD}=.35)$. The pre-service teachers perceived their KMLS to be low which implies that they had low confidence in using correct mathematical language and appropriate symbols. This was likely to negatively affect their ability to explain concepts on functions effectively. With limited knowledge of symbols related to the function concept the teacher would find it challenging when teaching the topic (Huang \& Kulm, 2012; Kontorovich, 2017; Paoletti, 2020; Sajka, 2003). Pre-service teachers need to take interest in the use of appropriate mathematical language and use of symbols. This seems not to be the case with pre-service teachers 
who participated in this study as evidenced from the low KMLS scores. This is in spite of mathematics being full of symbols and strict language.

There is research evidence that secondary school students have a lot of misconceptions about various mathematics concepts (Egodawatte, 2011; Koklu \& Topcu, 2012; Luneta, 2015; Neidorf et al., 2020; Ojose, 2015). The function concept is one such concept characterized by high levels of misconceptions from both teachers (Aziz 7 Kurniasih, 2019; Kontorovich, 2017; Ozkan \& Unal, 2009; Teoh et al., 2018) and secondary school students (Alajmi, 2019; Dorko \& Weber, 2014; Elia et al., 2007; Koklu \& Topcu, 2012). Thus, it is important for mathematics pre-service teachers to be aware of the common misconceptions and to be able to anticipate them and to have knowledge of how best these misconceptions can be resolved.

Pre-service teachers in the two clusters posted moderate mean scores about their knowledge of learner misconceptions with teachers in Cluster $1(\bar{X}=3.48, \mathrm{SD}=$ .93 ) recording lower scores than those in cluster $2(\bar{X}=4.34, \mathrm{SD}=.49)$. These scores were statistically different $[\mathrm{t}(148)=-7.51, \mathrm{p}<.05]$. With this, it was clear that preservice teachers in Cluster 1 would have more challenges in identifying and/or resolving their learners' misconceptions related to the concept of a function during their classroom discourse. This would affect their confidence in the classroom as they are likely to have difficulties to answer learners' questions that would border on misconceptions. This finding is consistent with prior research findings which revealed that teaching mathematics concepts was highly influenced by the teacher's confidence (Newton et al.,2012) and this largely contributed to the determination of pre-service teacher preparedness to embark on a teaching career Gresham (Elmahdi \& Fawzi, 2019).

Considering pre-service teachers in Cluster 2, they are expected to teach with more confidence and be able to exhibit good knowledge of identifying and resolving misconceptions arising from their students. Their knowledge of teaching functions will benefit from the increased confidence, self-esteem and ability to clear confusion in the classroom arising from misconception of functions concepts.

The perceived knowledge of misconceptions of pre-service teachers who participated in this study presents challenges for their future classrooms if nothing is done about it. Particularly, they need to increase their awareness about various 
aspects of the function concept that would give rise to misconceptions and they also need to develop skills that would enable them to effectively resolve their learners' misconceptions, errors and mistakes. Ability to identify and clear misconception would result in increased self-confidence and increased conceptual understanding of the function concept on the part of their students.

Knowledge of learners (KL) refers to teacher's overall knowledge about each of the students he/she is handling in class. In the context of the function concept this refers to the teacher having knowledge of the learner's previous knowledge of mathematics that would facilitate learning functions concepts. The teacher also needs to have knowledge of the learners' individual differences for him/her to structure his instruction in a manner that benefits all his students.

By having good knowledge of his/her learners, the teacher would be able to anticipate difficulties students are likely to encounter when learning the function concept. This would include, to a large extent, misconceptions that students would have from their prior knowledge which would conflict with the new knowledge of concepts related to functions.

Results of this study have revealed that pre-service teachers who participated in the study showed differences in their self-perceived knowledge of learners. Preservice teachers in Cluster 1 showed lower knowledge levels of learners $(\bar{X}=3.44$, $\mathrm{SD}=.83)$ than those in Cluster $2(\bar{X}=4.50, \mathrm{SD}=.49)$. It can be concluded from these results that pre-service teachers in Cluster 2 are more likely to anticipate difficulties their students are likely to face when learning functions than those in cluster one because the difference in knowledge between them is significant enough $[\mathrm{t}(148)=-9.58, \mathrm{p}<.05]$ to support this claim (Elia et al., 2007; Huang \& Kulm, 2012; Paoletti, 2020).

It is important for pre-service teachers to have very good knowledge of the Zambia secondary school mathematics curriculum (KC). This is because in the four years of their university education they receive training on the implementation of the curriculum. The teaching process is a principle aspect of curriculum implementation. It is important for pre-service mathematics teachers to know that the Zambian mathematics syllabus is outcome based. For each topic in the syllabus general and specific outcomes are stated aimed at meeting the aspirations of the Zambian 
education system (CDC, 2012) in the promotion of equity and inclusiveness in mathematics education.

As part of their knowledge of curriculum, pre-service teachers are expected to gain awareness of important elements of the Zambian mathematics curriculum like its purpose and objectives. They are expected to have sound knowledge of the instructional tools suitable for teaching functions as one of the key concepts in the Zambian mathematics curriculum and how to appropriately use these instructional tools to maximize learning in the classroom.

Pre-service teachers are also expected to be aware of assessment tools that would help them assess and evaluate curriculum materials they use for instruction. They are expected to demonstrate knowledge of the horizontal and vertical knowledge of the function concept in relation to other topics in the syllabus.

It was revealed in this study that a significant difference in the curriculum knowledge levels of pre-service teachers in cluster one and those in Cluster 2 [t(148) $=-7.10, \mathrm{p}<.05]$ existed. Pre-service teachers in Cluster 1 recorded lower mean scores in curriculum knowledge $(\bar{X}=3.83, \mathrm{SD}=.72)$ compared to their counterparts in Cluster $2(\bar{X}=4.49, \mathrm{SD}=.39)$. This implies that pre-service teachers in Cluster 1 perceived themselves to have inadequate knowledge of the Zambian mathematics curriculum. It is important for them to familiarize themselves with the objects of the curriculum for them to effectively and successfully implement the said curriculum. It is in the curriculum that the function concept is defined for Zambian secondary school students, and lack of full understanding of the curriculum would lead to inadequate coverage of the topic much to the detriment of the students. Further, universities should introduce a course that exclusively deals with the Zambia secondary school mathematics curriculum. A course that would inform pre-service teachers about curriculum goals and expected outcomes in order for them to position themselves for the task of teaching that is ahead. It would increase pre-service teachers' awareness about the curriculum. Currently there seems to be a gap between pedagogical courses in university and curriculum implementation on the ground.

\section{Summary of pre-service mathematics teachers' perceptions of mathematics}

Perception is referred to as the act of being aware of and making sense of a mathematical concept a person would encounter in the course of learning (Acil, 
2011). The way pre-service teachers perceive concepts in mathematics, including the concept of a function, has a lot to do with their previous experiences with the subject because "individuals learn through perception" (Gokdag, 2008 cited in BukovaGuzel et al., 2013). Thus, pre-service teachers' learning of mathematics can be immensely supported by constantly examining their perceptions (Bukova-Guzel et al., 2013) and formulating learning materials that respond to their needs.

A close analysis of the pre-service mathematics teachers that participated in this study brought about two categories of teachers in relation to their MPCK perceptions. Cluster 1 comprised pre-service teachers who perceived themselves weak in all MPCK components (KTS, KMLS, KM, KL, KC). Interestingly this group of teachers recorded a low mean score in a pencil and paper test on functions as compared to those in cluster 2 who exhibited strong perceptions of the MPCK knowledge domains (Table 3).

A picture created in Table 3 suggests that Cluster 1 consisted of pre-service teachers who were weak on the knowledge of their learners. Meaning that these preservice teachers would most likely face challenges identifying and diagnosing learner misconceptions, errors, difficulties and mistakes related to the function concept compared to those in Cluster 2. This would be coupled with their weak knowledge of using appropriate mathematical language and symbols related to the function concept and they would not be confident in their implementation of the mathematics curriculum because their awareness of the curriculum was weak. Pre-service teachers in Cluster 2 would have less of these challenges because their profiling related to the MPCK factors is much better.

Teachers in Cluster 2 had strong knowledge of teaching strategies and assessment methods to enable then teach the function concept compared to those in Cluster 1. Thus, it can be seen from the data in Table 3 that when a teacher has weak perceptions of mathematics subject-matter and pedagogical content knowledge, their mastery and overall knowledge about a particular mathematics concept is affected. The functions survey which was administered in form of a pencil and paper test contained mathematics and pedagogical items which were examining domains closely related to components of the MPCK survey.

An analysis of Table 3 revealed that pre-service teachers in Cluster 2 performed better than those in Cluster 1. This was attributed to their high confidence 
of mathematics subject-matter and pedagogical content knowledge exhibited through their responses to the MPCK survey items. The performance of pre-service teachers in the functions survey reflected their common content knowledge specialized content knowledge and their knowledge of content and students related to the function concept. This will be discussed in detail in the next section. However, it is worth stating that perceptions of pre-service teachers who took part in this study were well correlated to the performance in the mathematics test given. This has a lot of implications for teacher training in Zambia and those implications and suggestions for improvement will be detailed in the Chapter 6 .

Thus, it can be seen from the foregoing that Zambian pre-service teachers exhibited gaps in their perception of both subject-matter and pedagogical content knowledge which opens up lines of research that would bridge this gap and areas where colleges of education and universities can revise their current course packages with the aim of responding to the challenges presented by pre-service teachers through results of this study.

The results of this study regarding pre-service teachers' perception to teach mathematics were consistent with previous research findings (Bursal \& Paznokas, 2006; Duru, 2011; Hine \& Thai; 2018; Rosas \& West, 2011) who found that preservice teachers' confidence levels in their readiness to teach mathematics were not adequate but not high enough to meet the required standard. They concluded that teachers were not well prepared to teach mathematics. Bursal and Paznokas (2006) in their study on mathematics anxiety and pre-service elementary teachers' confidence to teach mathematics and science found that pre-service teachers whose perceptions to teach mathematics were clouded with high anxiety had low confidence.

Hine and Thai (2018) investigated pre-service teachers' self-perceptions of their preparedness to teach secondary school mathematics via mathematical pedagogical content knowledge, mathematical knowledge for teaching and mathematics subject-matter knowledge. Results of this study revealed that preservice teachers had low confidence in their pedagogical content knowledge to teach upper secondary mathematics and needed more training. Duru (2011) investigated pre-service teachers, perceptions about the concept of a limit of the same partial functions in its graphical and symbolic forms. Findings revealed conceptual misconceptions and low confidence on the part of pre-service teachers. 


\subsubsection{Subject-matter and pedagogical content knowledge levels of secondary mathematics pre-service teachers}

This discussion puts into perspective subject-matter and pedagogical content knowledge levels of pre-service secondary mathematics teachers' knowledge of the function concept vis-à-vis their Common Content Knowledge, Specialized Content Knowledge and Knowledge of Content and Students. Subject-Matter Knowledge was discussed in terms of Common Content Knowledge and Specialized Content Knowledge while Pedagogical Content Knowledge was discussed in terms of Knowledge of Content and Students.

To fully appreciate pre-service teachers' Common Content Knowledge, it was further discussed based on their knowledge about definitions of concepts involving relations and functions (KDRF), calculations involving inverse, quadratic and composite functions (CIQCF), and knowledge about the appropriate selection of examples and non-examples of relations and functions (KASERF).

Specialized Content Knowledge was further discussed with reference to preservice teachers' ability to work with different representations of relations and functions (KDRRF), explanations and justifications of relationships between the ranges and domains of functions (EJRRDF), and their explanations and justifications of examples and non-examples of functions (EJEF). SCK was also discussed in relation to pre-service teachers' explanations and justification of relationships and differences between relations and functions (EJRDRF). On the other hand, preservice teachers' Knowledge of Content and Students was further discussed in relation to their Knowledge of Students' Difficulties, Misconceptions and Errors (KSDME).

Table 32 shows the overall results of pre-service teachers' performance in the functions survey. These results accounted for a combined performance in CCK, SCK and KCS. Overall performance of pre-service teachers in this survey revealed that the majority performed poorly with 91 pre-service teachers (61 from cluster 1 and 30 from cluster 2) scoring below the pass mark of 50 percent. This translated to 61 percent of the 150 pre-service teachers failing to reach the minimum pass mark. This implied that 61 percent of the pre-service teachers who participated in this study exhibited poor common content knowledge, specialized content knowledge and knowledge of content and students related to the function concept. 
Table 32. Final results of pre-service teachers' performance in the MPCK functions survey

\begin{tabular}{cccc}
\hline Classification & Cluster 1 & Cluster 2 & Total \\
\hline Fail (0-49) & 61 & 30 & $\mathbf{9 1}(61 \%)$ \\
Fair (50-69) & 9 & 33 & $\mathbf{4 2}(28 \%)$ \\
Good (70-79) & 1 & 11 & $\mathbf{1 2}(8 \%)$ \\
Very Good (80-100) & 0 & 5 & $\mathbf{5 ( 3 \% )}$ \\
Total & $\mathbf{7 1}$ & $\mathbf{7 9}$ & $\mathbf{1 5 0}$ \\
\hline
\end{tabular}

These findings coincide with other prior research findings which noted poor subject-matter knowledge and pedagogical content knowledge of pre-service and inservice mathematics teachers related to the concept of a function (Sajka, 2003; Hatisaru \& Erbas, 2017; Even, 1993; Aksu \& Kul, 2016; Nyikahadzoyi, 2015; Malambo, 2016, 2019; Karahasan, 2010; Tasdan \& Koyunkaya, 2017). However, some previous studies revealed contrary results (Steele et al., 2013) by observing positive development of teacher knowledge related to teaching the function concept.

\section{Common Content Knowledge}

The functions survey comprised 35 items in total. Of the 35 items, 15 items were designed to assess pre-service teachers' Common Content Knowledge of the function concept. Generally, the average performance of pre-service teachers in this knowledge domain was low. However, taking a comparative perspective we see that pre-service teachers in Cluster 2 had a better average performance $(\bar{X}=23.13, \mathrm{SD}=$ 5.64) than those in Cluster $1(\bar{X}=14.93, \mathrm{SD}=3.82)$. This was also evident when analyzing the minimum and maximum raw scores from the two clusters. Cluster 1 posted a minimum score of 7 marks in CCK compared to Cluster 2 whose minimum score was 12 marks.

This implied that pre-service teachers in Cluster 1 had more challenges with definitions involving relations and function. They also had gaps in their knowledge about definitions of concepts involving relations and functions, calculations involving inverse, quadratic and composite functions, and knowledge about the appropriate selection of examples and non-examples of relations and functions.

Findings of this study regarding CCK of pre-service teachers were consistent with the findings of Sajka (2003) who revealed pre-service teachers' limited understanding of functions by observing inappropriate use of symbols in learning functional equations. However, some previous studies revealed results that were not 
consistent with certain aspects of CCK in this study. In their study, McCulloch et al., (2019) recorded positive development of pre-service teachers' knowledge of definitions involving function concepts contrary to the findings of this study. Similarly, Steele et al. (2013) revealed positive development of pre-service teachers' knowledge of definitions of functions and selection of examples. As regards inverse functions, Paolleti et al., (2018) revealed positive results of pre-service teachers' knowledge of inverse functions.

\section{Specialized Content Knowledge}

Specialized Content Knowledge was assessed using 13 items from the 35 item functions survey. Results detailed the level pre-service teachers' knowledge of working with different representations of relations and functions (KDRRF), explanations and justifications of relationships between the ranges and domains of functions (EJRRDF), and their explanations and justifications of examples and nonexamples of functions (EJEF). Pre-service teachers' explanations and justification of relationships and differences between relations and functions (EJRDRF) were also assessed.

Pre-service teachers generally did not perform well in the SCK domain which meant that their KDRRF, EJRRDF, EJEF and EJRDRF levels were low (with $\bar{X}=$ 11.96, $\mathrm{SD}=3.63$ for Cluster 1 and $\bar{X}=17.56, \mathrm{SD}=4.38$ for Cluster 2). In fact, their level of CCK was higher than that of SCK. Although SCK will be assessed in detail case wise in the next section, it is worth concluding that pre-service teacher participants had difficulties with different representations of functions. This finding is consistent with the findings of Aziz et al. (2018) and Hitt (1998). The former whose study on pre-service teachers' knowledge of differences between functions and quadratic equations revealed gaps in knowledge in their description and interpretations of those differences. They could not flexibly move between different representations. The latter revealed in his study that pre-service teachers particularly exhibited difficulties with different representations of functions.

They also had problems with concepts related to domain and range of functions by exhibiting gaps in their knowledge of understanding domain and range of functions and how these concepts can help in defining functions and relations, and applying the knowledge to other contexts. This result is consistent with the findings of Aziz and Kurniasih (2019) whose study about pre-service teachers' knowledge of 
domain and range of functions revealed that participants exhibited difficulties in defining the two concepts and using facts related to them when solving problems on functions. Thus, Aziz and Kurniasih (2019) concluded that pre-service teachers had general lack of understanding of concepts related to domain and range of functions. This emerged as a problem for participants of this study in both clusters as preservice teachers in clusters 1 and 2 recorded a minimum score of zero marks in EJRRDF.

Pre-service teachers also manifested difficulties in their explanation and justification of concepts involving functions and could therefore not make a good selection of examples and non-examples of functions for their learners contrary to the findings of Steele et al. (2013). This was evident in the EJEF minimum score of zero marks by pre-service teachers in both clusters 1 and 2 . To this effect, they could hardly explain and justify differences between functions and relations.

\section{Knowledge of Content and Students}

Pre-service teachers' knowledge of content and students was assessed through their Knowledge of students' Difficulties, Misconceptions and Errors (KSDME). It is important for teachers to understand secondary school students' difficulties and errors as they learn functions. This is because secondary school students encounter serious difficulties and commit numerous errors as they learn function concepts especially in their quest to correctly use symbols related to the topic (Saraiva and Teixeira, 2009). Defined as a systematic pattern of errors manifested in secondary school students' conceptions of mathematical concepts (Smith et al., 1993), misconceptions are a common feature in secondary school students' work on the concept of a function and it is essential for teachers to anticipate, identify and resolve these misconceptions.

In this study, pre-service teachers' knowledge of content and students in relation to the concept of a function was assessed using 7 items from a 35 item functions survey. In general, performance across clusters revealed that pre-service teachers in cluster $2(\bar{X}=16.65, \mathrm{SD}=3.80)$ performed better than those in cluster 1 $(\bar{X}=11.93, \mathrm{SD}=3.71)$ although a combined analysis revealed a low overall knowledge level for this knowledge domain. 
This low knowledge level was coupled with a minimum score of 6 marks which implied that pre-service teachers would have difficulties in resolving secondary school students' difficulties with function concepts. These pre-service teachers would most likely have difficulties in identifying their students' misconceptions and later on resolve them. The low level of KSDME further implies that pre-service teachers would not easily detect errors and mistakes in their secondary school students' calculations involving functions thus, contributing to the gap in students' knowledge of the function concept.

Results of this study concerning pre-service teachers' KSDME were consistent with findings of previous research with a similar focus (Kilic, 2011; Tanisli \& Kose, 2013). Kilic (2011) used interviews, observations and written documents to investigate pre-service teachers' knowledge of secondary school students' sources of misconceptions and conceptual errors, difficulties in understanding mathematical concepts, and suitable ways of eliminating such misconceptions and difficulties. Their study revealed that pre-service teachers had difficulties not only in identifying misconceptions and errors but also coming up with procedures and mathematically acceptable rules of eliminating them.

Similarly, Tanisli and Kose (2013) conducted a study to examine pre-service teachers' knowledge and ability to predict students' misconceptions and difficulties, which in turn would reveal their own (pre-service teachers) subject-matter knowledge and misconceptions. Findings of this study revealed that pre-service teachers had insufficient knowledge of students' misconceptions and difficulties. It was also revealed that pre-service teachers had misconceptions in relation to algebra.

\section{Summary of pre-service teachers' CCK, SCK and KCS}

It has been shown using quantitative analysis that pre-service teachers who participated in this study had low subject-matter and pedagogical content knowledge of the functions. Although a cluster comparison of the pre-service teachers' level of CCK, SCK and KCS shows that Cluster 2 pre-service teachers were a step above their colleagues in Cluster 1, a holistic consideration of their level of knowledge in the three domains (CCK, SCK, KCS) revealed gaps in their understanding of basic concepts. 
For example, their incomplete knowledge of definitions of concepts involving functions was a clear indication of pre-service teachers' inadequate common content knowledge. This is despite overwhelming research evidence emphasizing the need to have good knowledge of definitions because definitions help in explaining concepts and their relationships (Mark, 1990; Star et al., 2005). Participants of this study also revealed insufficient SCK through low levels of knowledge on particular indicators that were used to measure SCK. Notwithstanding the evidence in the literature supporting knowledge of using different representations as an indicator of specialized content knowledge of functions, pre-service teachers in this study exhibited gaps in their knowledge of different representations of functions (algebraic, tabular, graphical). It has also been detailed in this chapter that pre-service teachers had insufficient knowledge of functions content and students. By posting low levels of knowledge of learner misconceptions, pre-service teachers demonstrated the need to learn more about anticipation, identification and resolution of learner misconceptions.

\subsection{DISCUSSION OF QUALITATIVE RESULTS}

This section presents the interpretation of results based on the domains of teachers' knowledge that were being investigated. The discussion focused on three cases: Teacher $\mathrm{X}$. Teacher $\mathrm{Y}$ and Teacher $\mathrm{Z}$ that were selected for the qualitative phase of the study. Teacher $X$ was an extreme case selected from Cluster 1 . He scored $80 \%$ in the test of functions and emerged as an interesting case to explore further. Teachers $\mathrm{Y}$ and $\mathrm{Z}$ were selected from Cluster 2. Teacher Y's performance was average (54\%) while that of Teacher $\mathrm{Z}$ was below average (42\%). This was because the sampling was based on median and extreme case selection. Thus, this sample was representative of the performance fo all participants. In interpreting the results this Chapter dicusses CCK, then SCK and finally KCS in that order. A summary of the results is presented at the end.

\subsubsection{Common Content Knowledge}

During the quantitative analysis phase Common Content Knowledge was analysed based on pre-service teachers' knowledge about definitions of relations and functions, calculations involving inverse, quadratic and composite functions, and their knowledge about appropriate selection of examples and non-examples of 
relations and functions. Based on the mean scores obtained in the functions survey, it was observed that the general picture that emerged depicted knowledge gaps in preservice teachers. Interestingly, Common Content Knowledge was the most important factor in discriminating between pre-service teachers in clusters 1 and 2. This was largely because when teachers teach in classrooms they use more content knowledge than other domains of knowledge.

Thus, after discovering through mean scores that pre-service teachers had insufficient Common Content Knowledge of the function concept, the researcher decided to have an in-depth understanding of what exactly contributed this situation. This was done by analyzing answers to the functions survey of three pre-service teachers who participated in this study.

\section{Pre-service mathematics teacher's knowledge about definitions of relations and functions}

The first indicator that was used to assess pre-service teachers' Common Content Knowledge was their knowledge of definitions of different concepts related to functions. Their knowledge of definitions was generally inadequate and incomplete in many cases. This finding supported the views of Chesler (2012) who observed that teachers had problems with definitions of functions.

Considering the definition of a relation, Teacher $\mathrm{Z}$ could not fully define a relation. He omitted key words/phrases that constituted a concise definition and this affected his level of understanding of concepts that relied on the definition. Teacher $\mathrm{Y}$ gave an acceptable definition but it was Teacher $\mathrm{X}$ who gave a complete definition of a relation and supported it with appropriate examples during the interview. Teacher $\mathrm{Z}$ could not, however, adequately justify his definition. This was in spite of previous research studies emphasizing the importance of mastering and understanding definitions of concepts for their correct application to areas in mathematics that demand their use (Byrnes \& Wasik, 1991; Malambo, 2016; Perry, 1991).

Pre-service teachers also showed deficiencies in their definitions of a function and how it differed from a relation. Lack of full understanding of the definition of a function was manifested in their failure to answer certain question in the survey. Most evident was when all the three pre-service teachers could not determine some figures to be functions or not during the interviews. When presented with a 
worksheet during the interview which contained twelve figures of which they were to determine which ones were functions, pre-service teachers had difficulties determining some figures. Figures 1, 2, 3, 8, 10, 11 and 12 presented situations which brought out emerging gaps by all the three pre-service teachers' knowledge of the definition of a function.

Teacher $\mathrm{X}$ had difficulties in applying the definition of a function to determine whether or not figures 10, 11 and 12 were functions. He was confused by the situations presented in Figure 11. He could not strictly relate Figure 11 to the definition of a function that he gave earlier in the interview. He also could not confidently tell whether Figure 10 was a function or not. These are typical situations where teachers tend to transfer their gaps in knowledge to the students they teach. This was evidence that Teacher $\mathrm{X}$ was not fully aware of the definition of a function.

Teacher Y exhibited similar gaps as Teacher X. Teacher Z on the other hand could hardly tell whether or not figures $1,8,11$ and 12 were functions. In fact he outrightly stated that he had no ideas to help him determine figures 1 and 8. It was clear that he lacked a comprehensive understanding of the definition. This suggested that all the three teachers could have difficulties defining other concepts related to the concept of a function. Thus, even though all of them had difficulties in this task, Teacher X had more knowledge than the other two teachers and Teacher Z exhibited more deficiencies in his knowledge of definition of a function.

The pre-service teachers also did not adequately define and justify their definition of an inverse of a function. Beyond stating that an inverse function reverses the range back to the domain, nothing was said about it. Their definitions were either informal or very weak to account for comprehensive understanding of inverse functions. This presented a challenge for them in establishing relationships that existed between domains and ranges of inverse functions. Teacher $X$ and Teacher $\mathrm{Y}$ were moderately elaborate in their definitions compared to Teacher $\mathrm{Z}$. This could be attributed to the fact that they were drawn from different clusters. Teacher $\mathrm{Z}$ was drawn from Cluster 1 in which the general performance was lower than that of Cluster 2. Teacher Y was also selected from Cluster 1 while Teacher X was chosen from Cluster 2.

It was also evident in the way they handled questions on composite functions that they lacked full knowledge of the definition of the concept. The questions of 
composite functions required that they comprehensively understood what composition of two or more functions meant before attempting to answer the questions. Lack of knowledge of definitions affected their answers on some of the questions on composite functions.

This is consistent with the findings of Jojo, Brijlall \& Maharaj (2011) who noted pre-service teachers' lack of comprehensive knowledge of composite functions. On a positive note, pre-service teachers demonstrated good knowledge of the definition of a one-to-one function but they could not exemplify their definitions to justify their understanding, it was evident that they had some gaps in their knowledge of one-to-one functions. However, this helped them in the identification of one-to-one functions and to work out problems in the survey which required knowledge of one-to-one functions

It has been elaborated here that the general picture about pre-service teachers' knowledge of definitions was not generally good. In all cases pre-service teachers seemed to suggest that the definition of a function and that of a one-to-one function can be used interchangeably. This is consistent with previous research which noted that is was common for pre-service teachers to confuse the definition of a function with that of a one-to-one function (Leinhardt et al., 1990; Markovits et al., 1986).

It is important for them to develop their understanding of different concepts related to the function concept. This is because good understanding of definitions sets a solid ground for easy understanding of other concepts. When definitions are fully understood, the teacher will be able to relate and contextualize the rules and procedures governing the concept.

The results concerning definitions of function concepts in this study are consistent with previous studies that (Byrnes \& Wasik, 1991; Malambo, 2016; Malambo, 2019; Perry, 1991) who emphasized pre-service teachers need for complete knowledge of definition of relations and functions. It has also been observed that none of the definitions given by pre-service teachers adequately addressed both the univalence and arbitrariness properties of functions. This is in spite of previous research emphasizing the need to include both properties as a sure way of validating definitions (Even, 1990; Lloyd et al., 2010; Malambo, 2016; Nyikahadzoyi, 2015) 
Generally, pre-service teachers in this study based their definitions on the univalence property. However, the interviews revealed that even though their definitions seemed to suggest use of the univalence property, the pre-service teachers did not actually understand what univalence meant. The arbitrariness property was not used by pre-service teachers in this study to validate their definitions. This contributed to them not to be rated at Level 2 with regards to their knowledge of definitions. They needed to understand that in mathematics every concept needs to be fully defined as a starting point to understanding it. Failure to fully define concepts explains a weak conceptual background.

\section{Pre=service teachers' knowledge of calculations involving inverse, quadratic \& composite functions}

The second predictor of pre-service teachers' Common Content Knowledge for this study was concerned with their knowledge of calculations involving inverse, quadratic and composite functions. Prior research has showed studies focusing on inverse functions (Even, 1992; Kontorovich, 2017; Karahasan, 2010; Paoletti, 2020; Wasserman, 2017). There is also evidence from literature of studies on composite functions (Kontorovich, 2017; Karahasan, 2010) and quadratic functions (Huang \& Kulm, 2012; Ubah \& Bansilal, 2018).

Generally, pre-service teachers' Common Content Knowledge related to their calculations involving inverse, composite and quadratic functions was below desirable levels. It was characterized by unnecessary errors while performing calculations. This led to incorrect answers mainly due to carelessness.

When carrying out calculations involving inverse functions, pre-service teachers could easily make the substitution of $y$ for $f(x)$ but unnecessary factorization could mess up the process. When following their work there were signs of good understanding of how to find the inverse of a given function but errors due to carelessness affected their final answers in some cases. This is consistent to the findings of Even (1992) who observed that pre-service teachers exhibited mathematical difficulties when performing calculations involving inverse functions.

Even (1992) further observed that in some cases pre-service teachers either showed naïve understanding of inverse functions or had poor knowledge of how inverse function concepts related. For instance, Teachers $\mathrm{X}, \mathrm{Y}$ and $\mathrm{Z}$ easily found the inverse of a function in one of the items of the functions survey but could not 
convincingly state the domain of that inverse. Thus, pre-service teachers demonstrated insufficient knowledge of calculations involving inverse functions (Kontorovich, 2017; Karahasan, 2010; Paoletti, 2020) by their lack of meaningful connections between inverse function concepts (Wasserman, 2017). In fact, Kontorovich, (2017) found that participants of his study could not adequately understand and contextually interpret the polysemous symbol of the superscript (-1) which is used to denote inverse functions.

Pre-service teachers showed below average knowledge of composite functions. They showed lack of comprehensive understanding of the notation and the sequence of executing the function in a composition. For instance, when they were asked to find the expression for $z o g$, they were able to do it with ease. However, when asked to find the value of $\left(g_{o} g^{-1}\right)(-5)$ gaps in the understanding of the concept emerged. The pre-service teachers showed that they did not have a desirable level of working with composite function and this was one of the emerging signs that they were not fully prepared to teach secondary school mathematics on aspects of the function concept.

Teacher $\mathrm{X}$ approached the problem by first attempting to find an expression for the composition of the function $g(x)$ and its inverse $g^{-1}(\mathrm{x})$ before evaluating the resultant expression at (-5). In the process of performing the calculations he erred and consequently could not arrive at the desired answer. This was a clear demonstration of lack of comprehensive knowledge of calculations involving composite functions.

It was a similar situation with Teacher $\mathrm{Y}$ who opted to first find $g^{-1}(-5)$ before finally finding a composition of $g(\mathrm{x})$ and $g^{-1}(-5)$. Although Teacher $\mathrm{Y}$ was able to arrive at the correct answer using this approach, it was also obvious that he had gaps in his understanding of rules and principles that guided the composition of a function and its inverse. In this situation it was not the correct answer that was very important, rather it was the teacher's ability to recognize that the value of $\left(g \circ g^{-1}\right)(-5)$ could be found without attempting to perform any calculations. This was the significant gap in knowledge that emerged from the work of Teacher $\mathrm{X}$ and Teacher $\mathrm{Y}$ when answering this question.

The situation was better off for Teacher $\mathrm{Z}$ who showed solid understanding of what exactly the question required. He quickly realized that the principle guiding the composition of a function and its inverse could be used to evaluate the problem. By 
stating that $\left(g_{o} g^{-1}\right)(\mathrm{x})=\mathrm{x}$, Teacher $\mathrm{Z}$ demonstrated his strong knowledge of calculations involving composition of functions. It easily followed from his reasoning that $\left(g_{\circ} g^{-1}\right)(-5)=-5$. As stated earlier, Teacher $Y$ managed to arrive at the correct answer but still showed gaps in his understanding because he failed to employ the most desired thinking process.

The thinking process involved whenever a teacher is carrying out mathematical calculations matters more than arriving at the correct answer using any other means. This result supports the findings of Kontorovich (2017) who observed that apart from incorrect use of symbols, pre-service teachers generally had difficulties with composition of functions to the extent that some would even confuse composition of functions with ordinary multiplication of two terms or expressions.

The pre-service teachers in this study showed good knowledge of quadratic functions. This was largely due to the fact that the senior secondary school mathematics syllabus in Zambia has a very wide and comprehensive coverage of quadratic equations and quadratic functions. Thus, it was assumed that the good performance was motivated by their secondary school background. The only instance in the survey where pre-service teachers encountered calculations involving quadratic functions was when they were asked to complete the square for the function $f(x)=-2 x^{2}-x+8$.

Notwithstanding their strong background on quadratic functions, their work was characterized by errors in some cases. Teacher $\mathrm{X}$ and Teacher $\mathrm{Y}$ were able to provide very detailed and conceptually sound calculations. However, minor errors were detected in the calculations performed by Teacher Z. Otherwise, the teachers demonstrated good understanding of quadratic functions and that they could teach this concept with satisfaction in secondary school.

While this study has showed that pre-service teachers who participated had desirable knowledge of calculations involving quadratic functions, previous studies presented results that were not consistent with the current findings (Huang \& Kulm, 2012; Ubah \& Bansilal, 2018). In the first study, Huang and Kulm (2012) reported that pre-service teachers' knowledge of representations of quadratic functions were inadequate which made their overall knowledge of quadratic functions to be weak. In the other study, Ubah and Bansilal (2018) found that the insufficient knowledge of 
quadratic functions exhibited by pre-service teachers rendered them not ready to teach secondary school concepts on quadratic functions.

\section{Pre-service teachers' knowledge of appropriate selection of examples and non-examples of relations and functions.}

It is important for pre-service teachers to have good knowledge of selection of appropriate examples for their learners. This is because good examples increase the chances of their students grasping concepts related to functions. This study included items aimed at assessing pre-service teachers' ability to select examples and to give counter examples. In every case where they were asked to define a relation or a function, pre-service teachers were also asked to give at least one example supporting the definition. Items which required pre-service teachers to determine functions from given figures were also opportunities for them to demonstrate their ability to select appropriate examples for their students.

Their selection of examples of functions was generally good though in some cases it was below average. They were all able to give examples of a relation in the survey and were also able to justify their examples during the interviews except for Teacher $\mathrm{Z}$ who was not very confident about his responses during the interview. They were also presented with figures containing graphs purported to have been extracted from a mathematics textbooks. They were asked to review the graphs in relation with one-to-one functions. Their attention to detail in responding to this task was impressive. They were able to determine that one figure was a one-to-one function while the other was not and they concluded that the textbook was correct on one figure and incorrect on the other.

Pre-service teachers faced some difficulties when they were presented with figures in the functions survey and during the interview to determine which ones were functions. They were able to correctly determine most of the figures but showed complete lack of knowledge about few other figures. This was the only instance where gaps in their knowledge were emergent. Otherwise, they had good knowledge of selecting examples of functions. It is expected that the participants will have little problems in choosing good examples for their future students. 


\subsubsection{Specialized Content Knowledge}

SCK was analysed in terms of different representations of relations and functions, explanations and justifications of relationships between the ranges and domains of functions, explanation and justification of examples and non-examples of functions and explaining and justifying relationships and differences between relations and functions.

\section{Pre-service teachers knowledge of different representations of relations \& functions}

Pre-service teachers' ability to translate between different representation of functions was analysed in detail in this study. This study examined pre-service teachers' knowledge of different representation by focusing on graphs, algebraic symbols, ordered pairs and tabular expression (Aziz \& Kurniasih, 2019). However, previous studies on different representations of functions have exclusively focused on symbolic representations (Dorko \& Weber, 2014; Ozkan \& Unal, 2009) as a way of having a deeper understanding of different modes in which functions can be represented. Other researchers sought to understand the function concept by having in-depth understanding of the graphical representations of the concept (Cho, 2013; Cho \& Moore-Rosso, 2014; Martinez-Planell et al., 2015). This study included all the different representations in its assessment of teacher knowledge of functions.

Results of this study have showed that in some instances the three pre-service teachers had low knowledge of different representations of functions. The pre-service teachers demonstrated that they had strong knowledge and flexibility of translating from ordered pairs to graphical representation when they were asked to draw the graph of the quadratic function $\mathrm{f}(\mathrm{x})=-12 \mathrm{x}^{2}-\mathrm{x}+8$ using a given table of ordered pairs.

All the three pre-service teachers were able to draw the graph without problems and were able to conceptually explain the procedure to be followed when drawing the graph. The teachers showed desirable skills and ability of translating between ordered pairs and graphical representation. This implied that they were ready to teach secondary school functions related to graphing quadratic from a given set of ordered pairs. This was also attributed to the knowledge they acquired at secondary school. This is because in the Zambian senior secondary school mathematics syllabus 
different representations of the concept of a function are focused mainly on translating from ordered pairs to graphical representations.

However, pre-service teachers in this study showed gaps in knowledge when translating from symbolic to graphical representations. Particular reference is made to the answers they gave when asked to draw the graph of the absolute value function $\mathrm{g}: \mathrm{x} \rightarrow|\mathrm{x}|$ with the domain from the set of integers. This question was inadequately answered. Pre-service teachers lacked knowledge of drawing functions whose domains come from the set of integers.

Pre-service teachers drew graphs of continuous functions with all plotted points connected with a straight line. Teacher $\mathrm{X}$ and Teacher $\mathrm{Z}$ did not know that the graph of the absolute value function whose domain was from the set of integers was discontinuous. Thus, the two pre-service teachers correctly plotted points on the coordinate plane and also connected the plotted points with a straight line. This result was supporting the findings of previous researchers who found deficiencies in pre-service teachers' knowledge of different representations of the concept of a function (Aziz \& Kurniasih, 2019; Gagatsis \& Shiakalli, 2004; Hitt, 1998).

Aziz and Kurniasih (2019) observed that pre-service teachers' had weak knowledge of different representations of domain and range of the concept of a function. Similarly, Gagatsis and Shiakalli (2004) reported pre-service teachers showed low levels of mathematical problem solving due to low ability of translating from one representation to another in relation to the function concept. They attributed this lack of knowledge to inadequate secondary school teaching of the concept.

Although evidence from literature shows that teachers and students have varied difficulties with different representations of functions (Elia et al., 2007; Gagatsis \& Shiakalli, 2004; Hitt, 1998), it is teacher knowledge that is crucial because if the knowledge gaps observed in this study were transferred to the students it would be more damaging. The inconsistencies exhibited by secondary school students and their lack of knowledge of definitions can easily be corrected if pre-service teachers improved their abilities to translate between different representations of functions.

In spite of the difficulties faced by Teacher $\mathrm{X}$ and Teacher $\mathrm{Z}$ when graphing the absolute value function $\mathrm{g}: \mathrm{x} \rightarrow|\mathrm{x}|$, Teacher Y showed very good understanding of the requirements of the question. He did not connect the plotted points on the 
coordinate plane and when asked to justify his answer he backed it with a strong reason. Thus, it was evident that unlike Teachers $\mathrm{X}$ and $\mathrm{Z}$, Teacher $\mathrm{Y}$ had good knowledge of both translations from ordered pairs to graphical representations and drawing graphs of absolute value functions on restricted domains. It was clear from the results that pre-service teachers' knowledge of different representations of functions was not at a desirable level and needed improvements before being released to go and teach in secondary school.

\section{Pre-service teachers' knowledge of explanations and justifications of relationships between the ranges and domains of functions}

Pre-service teachers' knowledge of domain and range was a very important aspect of this study because good knowledge of the concept of domain and range would help in learning and comprehensively understanding concepts related to inverse functions (Arnold, 2004). It has also been observed that a strong knowledge foundation of domain and range would result in pre-service teachers solid understanding of linear transformations (Dorko \& Weber, 2014).

In this study pre-service teachers showed low knowledge of domain and range, failing to offer valid explanations with good justifications in some cases. During interviews all participants were given a worksheet containing figures of functions and non-functions. In their determination and justifications of their answers, preservice teachers relied more on the concept of domain and range. Unfortunately, they were not sure of how to apply the concept in some cases. They often used the definition of one-to-one functions in relation to the concept of domain and range but still could not apply it correctly. This result is convergent with the findings of Aziz and Hurniasih (2019) whose study found that pre-service teachers had difficulties in validly and consistently defining the concept of domain and range of functions. This result was also consistent with Aziz and Kurniasih (2019) when they found that preservice teachers' written answers to tasks fail short of desired understanding of domain and range of functions.

Participants also showed lack of understanding of domain and range when responding to questions in the survey that sought an explanation of the relationship between the range of one function with the domain of the inverse of the other function. Teacher $\mathrm{X}$ was able to explain the relationship while the other two participants struggled to make sense of the requirements of the question. What came 
out was the aspect of confusing concepts of domain and range, similar to the findings of Ozkan and Unal (2009). Ozkan and Unal (2009) reported that pre-service teachers had misconceptions of domain and range of functions and often mixed up these two concepts. This negatively affected their understanding of inverse functions (Arnold, 2004) because these concepts are highly related. Pre-service teachers in this study were able to find the inverse of a given function with less difficulty but could not easily find the domain of the inverse.

Thus, pre-service teachers needed to improve their knowledge of domain and range by working on their understanding of how the two concepts relate and how they relate with other concepts like inverse and composite functions. This would guarantee solid knowledge of the entire topic on concept of a function. Graduating from university with insufficient knowledge of the function concept would create challenges in the way they would teach related secondary school concepts.

\section{Pre-service teachers' knowledge of explanation and justification of examples and non-examples of relations functions}

This indicator of Specialized Content Knowledge was assessed mainly during the interviews when participants were asked to define different concepts and were also asked to exemplify their definitions with valid and justified reasons. Generally, their ability to justify their knowledge of examples and non-examples of functions was good. However, Teacher $\mathrm{Z}$ could not adequately explain and justify his views in some cases. He insufficiently explained and justified examples of a relation as observed from his responses to items in the survey on functions and during the interview when he was specifically called upon to justify his responses in the survey.

His lack of explanation emerged as a concern especially that secondary school teaching is anchored on the teacher's ability to explain concepts convincingly and to justify each step in the procedure used to arrive at a particular answer. In his examples he was expected to strongly relate to the given definition but that aspect was missing. He would give an incomplete definition of a relation and couple it with a fairly good example. But when asked to justify the relationship between the lacking definition and the given example he failed to offer a convincing explanation.

Otherwise, Teacher $\mathrm{X}$ and Teacher $\mathrm{Y}$ were able to easily explain and justify examples related to functions. Responses to the items in the functions survey and their views during the interviews were evident of a solid ability to conceptually 
justify their given examples. In the survey on functions they were asked to give examples of relations and functions and they were able to justify their choice of examples during the oral interviews. This showed that they had desired knowledge which would help them when selecting examples for their secondary school students.

\section{Pre-service teachers' knowledge of explaining and justifying relationships and differences between relations and functions}

Knowledge of relationships and differences between relations and functions was very low for the participants of this study. Some participants could not define a relation as well as a function and consequently had difficulties in explaining existing differences and relationships between the two concepts. Others were able to define relations and functions but could not offer any satisfactory explanation relating to the differences and relationships between the two concepts. In the Zambian mathematics syllabus the concept of a function is built from analyzing relations in general. Thus it is important for pre-service teachers to have a clear understanding of the relationships and differences between the two concepts.

When asked to explain the difference between a relation and a function, Teacher $\mathrm{X}$ and Teacher $\mathrm{Y}$ used a one-to-one function definition to distinguish the two. This was not adequate because a one-to-one function is just one of the types of functions and so it could not entirely be used to explain the difference between relations and functions. However, Teacher $\mathrm{Z}$ seemed not to have any valid difference between the two concepts. His response was that "... a function is a relation but a relation is not a function ...". This was a demonstration of a huge gap in knowledge. This was not surprising as Teacher $\mathrm{Z}$ was unable to give a valid definition of a relation earlier in the interview and neither was he able to do so in the survey.

The participants were expected to draw on their knowledge of definitions of relations and functions in answering this question. But since their knowledge of definitions was not at the desired level it affected their understanding of other concepts related to functions. They were expected to make reference to one-to-many relations, many-to-one functions in their justification of the possible differences. But the general conception they were bringing out seemed to suggest that anything which was not a one-to-one function was actually a relation.

Teacher $\mathrm{X}$ and Teacher $\mathrm{Y}$ were able to state that "every function is a relation but not all relations are functions". However they could not give thorough 
explanations for a clear cut difference or relationship between the two concepts. Their lack of ability to explain and justify differences and relationships between these concepts has the potential to affect their teaching in future. Many secondary school sstudents would love to know the difference especially that they will be taught relations and later build on to learn functions. Thus, if the difference would not be well explained it will be difficult for these learners to fully comprehend the topic and such a situation can affect students' ability to learn the remaining aspects of the function concept.

\subsubsection{Knowledge of Content and Students}

Knowledge of Content and Students is one of the vital requirements for a teacher if quality and effective implementation of the mathematics curriculum is to be achieved. This is because effective teaching of mathematics is heavily dependent on the teacher's understanding of subject-matter and his/her understanding of the students. In the absence of these two aspects no meaningful learning can take place. In this study, pre-service teachers' Knowledge of Content and Students was examined through their Knowledge of Students' difficulties, misconceptions and errors. To this effect different instruments that included lesson plans, vignettes, classroom observation and a survey on functions were used to gain in-depth knowledge about this aspect of Pedagogical Content Knowledge.

\section{Pre-service teachers' Knowledge of Students' Difficulties, Misconceptions \& Errors}

All the participants used lesson plans as tools for planning and implementing the lesson. Examination of a lesson plan informs us about how inclusive the lesson would be and how interactive and beneficial it would be to the students. Lesson plans for all the three pre-service teachers were lacking in some areas. It was observable from all the lesson plans that the lesson was going to be less interactive on the part of the learners. They were mostly centered on the explanations by the teacher. This kind of lessons which place the teacher in the center of all activities would make it difficult for him to identify his students' misconceptions about the lesson.

The lesson plans did not include teaching and learning aids that would motivate students to participate fully in the lesson. All lesson plans stated duster, chalk board and ruler as teaching/learning aids. The aids do not inspire the learner because they are always supposed to be carried by the teacher. The teachers were supposed to 
include audio-visual aids that students can interact with as individuals or in small groups for effective learning to occur. The positive aspect was that learning outcomes and the rationale for the lesson were clearly stated which indicated that the teacher was aware of what he wanted to achieve at the end of the lesson. The anticipated cognitive entry characteristics were also well accounted for by stating pre-requisite knowledge for learning inverse and composite functions.

The examples which were selected for the students mostly based on the procedure to follow when finding expressions for inverses of functions. In all the three cases emphasis during the lesson was on the procedure for finding inverse functions and very limited application of the inverse function was taught. Notwithstanding the importance of knowing these procedures, it is important for students to be exposed to situations that require application of inverse functions. Students are supposed to relate inverse function concepts to real life situations in their immediate environment, something which did not happen during the lesson.

During observation of the lesson on inverse functions it was found that the only instances when learners would participate actively was when the teacher paused a question to confirm a stage as he worked out problems on the board. There were two instances when Teacher $\mathrm{X}$ and Teacher $\mathrm{Y}$ invited students to work out a problem on the board. This good gesture was not beneficial to the rest of the students who did not get the chance to do so themselves.

Group work was not used at any time during the lesson in spite of its wellknown advantage of allowing all the students to actively participate in the lesson. The pre-service teachers also did not attempt to explain notation associated with inverse functions in detail to the students. This was despite documented evidence that both teachers and students had difficulties in understanding and interpreting the polysemous symbol of superscript (-1) when teaching and learning inverse functions (Kontorovich, 2017).

The lessons did not include any homework or take-home assignment for the students to go and practice what they just learnt either. Homework could have been a very good opportunity for the teacher to give tasks that included application of the inverse function concept. It was seen during class observation of the lesson that some students did not fully understand what was taught and this was down to the fact that they were not accorded the opportunity to fully participate in the lesson. The lack of 
involvement of students during lessons confirms why students continue to have problems with inverse function concepts

Lessons on composite functions were executed in a similar fashion as those for inverse functions. Again no group work was used for the students to interact among themselves and benefit from what they knew. The teachers did not take time to explain and clear confusion that comes with notation used to denote composite functions. It has been reported in literature (Kontorovich, 2017) that pre-service teachers and students have a tendency of confusing composition of functions and multiplication. It was evident during lesson observation that some students were confused about this. Teacher $\mathrm{X}$ tried to explain the difference but it was not well understood among the students.

Overall, the lesson plan preparation and actual implementation of the planned activities was average. Lesson plans lacked some important features and the teaching was not learner centered because most of the work was done by the teacher with students only limited to answering few questions. This was attributed to the low knowledge levels of subject matter that were observed from the participants. This is consistent with other studies that found inconsistencies in pre-service teachers' subject matter and pedagogical content knowledge of inverse and composite functions (Even, 1992; Kontorovich, 2017; Karahasan, 2010; Wasserman, 2017). In all the presentations of inverse and composite functions there was little or no use of different representations of functions. Pre-service teachers were supposed to use different representations because these have been seen to be challenging to students and teachers (Gagatsis \& Shiakalli, 2004; Hitt, 1998).

Vignettes were administered specifically to assess pre-service teachers' ability to identify and resolve confusion among students resulting from their misconceptions related to inverse and composite functions. In some cases it involved working out the problems before identifying the misconceptions which confused the students.

A common observation about participants' responses to vignettes was that they were able to work out the given problems in a bid to identify the misconceptions that caused confusion among students. Thus, they were able to identify the misconception and its source. However none of the pre-service teachers was able to give specific response to the comments by students. For example, pre-service teachers were able to notice that students had misconceptions about composite functions. The students 
were confusing composite functions with ordinary multiplication (Kontorovich, 2017) but were not able to explain the conceptual difference between the two concepts. This could mean lack of conceptual knowledge on the part of the teacher.

Another notable example was concerned with composition of constant functions. Teacher $\mathrm{X}$ was able to identify student misconceptions but his explanation about resolving the misconception was inadequate. This implied that it was not enough to just identify the misconception. It is more important to clear the purported misconceived concepts.

In the case of inverse functions the notable example which brought out teacher's inability to clear a misconception required the teacher to explain a concept by way of giving an example. The three pre-service teachers were unable to give good examples to make the students understand the concept of inverse functions. This meant that the teacher's knowledge of selection of examples was not good.

Furthermore, the pre-service teachers were unable to explain how to resolve the identified misconceptions. The lack of specific comments regarding students' wrong conceptions created a gap in the knowledge of pre-service teachers. This is because in a classroom situation, which is what the vignettes were depicting, it is important for a teacher to satisfactorily respond to student comments about the content. Teacher comments help in making students understand concepts.

Pre-service teachers were not able to resolve the misconceptions that they identified in each of the vignettes. The teacher's inability to resolve misconceptions implies that students would not have learnt anything and they would probably carry their misconceptions to their next level.

The inability by the teacher to resolve the misconceptions by way of clearing confusions among students could have meant that the teacher also had a misconception in the problems posed by students or he had insufficient content knowledge about the problems. This reflects well on the views of researchers in previous research that teachers and students have difficulties with the concept of a function (Gagatsis \& Shiakalli, 2004; Hitt, 1998) although they face different difficulties.

The vignettes on inverse and composite functions revealed that pre-service teachers had difficulties in teaching aspects of the concept of a function. Secondly, it 
showed that pre-service teachers had insufficient knowledge of concepts related to the function concept. This is consistent with previous research which documented different problems that pre-service teachers faced with the function concept (Huang \& Kulm, 2012; Ubah \& Bansilal, 2018).

In the survey on functions three questions were based on teachers' content knowledge and students. There were different responses from the three pre-service teachers on their definition of a function, a result which was consistent with the view of Paoletti (2020) that pre-service teachers had limited knowledge of meaning of functions. This was worrying because teachers are supposed to have a common understanding of a function for them not to confuse the students. The three preservice teachers were doing their teaching practice at the same school and yet had different conceptions of the definition of a function. This meant that if some of the conceptions of the function concept were incorrect, as the case turned out to be, a good fraction of students under the tutelage of these teachers benefited less.

When one student said that he/she saw functions as "input/output machines which receive an input to give out an appropriate output", Teacher X claimed that this view did not fit all functions but it was fitting for all relations because the input/output correspondence without restrictions simply defined a relation and not every relation is a function. This explanation seemed elaborate and conceptually convincing to the student. Teacher $\mathrm{Y}$ out rightly judged the view to be wrong stating that the view was fit for a relation. Teacher $\mathrm{Z}$ on the other hand claimed that all functions fit in the student's view. This scenario presented an opportunity to the teachers to actually tackle a real classroom situation. Teacher X's response was comprehensive while Teacher Z's response was inadequate and would not completely help the student change his view. The fact that all the three pre-service teachers qualified the student's view of a function at different levels shows the gaps in the pre-service teachers' view of a function.

In three other similar cases the pre-service teachers were in disagreement as to whether the views of the students (i) all functions fit the student conception of a function, (ii) some functions fit the student conception of a function and (iii) the students were actually wrong in their conception of a function. Interesting their explanations also differed in some instances. This was a clear indication that preservice teachers had their own difficulties with the concept of a function (Even, 
1992). It was expected of the pre-service teachers to have a common view of the definition of a function in relation to the given situations and to give conceptual justifications to back their conceptions. This was partly an indication that these teachers were not fully prepared to teach secondary school concepts on functions because they needed to improve their understanding of the concept before embarking on teaching (Ubah \& Bansilal, 2018).

The three pre-service teachers were also presented with situations that were focused on their knowledge of students' misconceptions related to different representations of functions. They were all able to identify the mistakes in the students' conceptions but were not comprehensive in their explanations about the thinking process of the student and did not fully demonstrate solutions that would completely solve the misconception. Teacher X, however, was able to back his explanations with graphs which were very good. The other two pre-service teachers relied more on theoretical explanations, which were not enough to resolve the misunderstanding. The lack of including graphs in explaining to the student suggests insufficient knowledge of different representation by the pre-service teachers (Cho \& Moore-Rosso, 2014; Huang \& Kulm, 2012; Martinez-Planell et al., 2015).

\section{Summary of CCK, SCK and KCS of Teachers X, Y and Z}

Pre-service teachers' CCK, SCK and KCS were not at a high level though it was good in some instances. There were cases where they failed to deal with very basic concepts like evaluating the inverse of the composition of two functions. Gaps in the CCK were mainly evident in their lacking definitions and lack of appropriate examples and errors in their calculations involving inverse, quadratic and composite functions.

Their inability to provide valid explanations and justification of their answers in many instances meant that their SCK was not at a desirable level. This is because a teacher should endeavor to justify their work in class at all times failure to which students always lose out. Their KCS was inadequate in some cases as pre-service teachers were not able to resolve student misconceptions related to inverse and composite functions when responding to vignettes and they also could not adequately deal with student misunderstanding of situations related to different representations of functions. Thus, it was evident that pre-service teachers in Cluster 2 had slightly higher knowledge levels of CCK, SCK and KCS as could be seen from the 
quantitative results and the qualitative analysis of Teacher $\mathrm{X}$ who was drawn from Cluster 2. However, all pre-service teachers need to improve in some areas of their knowledge of the concept of a function. Otherwise, they are not fully prepared to teach secondary school concepts related to functions. 



\section{Chapter 6: Conclusions}

This sequential explanatory mixed methods study has characterized pre-service secondary mathematics teachers' Subject Matter Knowledge and Pedagogical Content Knowledge regarding the concept of a function. The level of proficiency of their Subject Matter Knowledge was assessed through looking at their Common Content Knowledge and Specialized Content Knowledge while that of Pedagogical Content Knowledge was assessed through their knowledge of content of the function concept and students. The study also examined pre-service teachers' Mathematical Pedagogical Content Knowledge perceptions about mathematics using the MPCK entry survey.

The major intention of this study was to make a valuable contribution to the field of mathematics education in Zambia regarding the level of CCK, SCK and KCS of secondary mathematics pre-service teachers. Secondly, it was intended by this study to contribute knowledge on the improvement of mathematics teacher education by providing empirical evidence about difficulties pre-service teachers face with content knowledge of the concept of a function and their challenges in teaching the concept. Thirdly, the study intended to highlight mathematics pre-service teachers' MPCK perception by bringing out the relationships with subject matter knowledge. These intentions were actualized by accomplishing the stated purpose and objectives of the study.

\subsection{OVERVIEW ABOUT RESEARCH OBJECTIVES}

The study projected a general objective which was broken down into three specific objectives. The following discusses how the results of this study related to the objectives:

- The general objective of this study was to describe the subject matter and pedagogical content knowledge levels of pre-service secondary school mathematics teachers concerning the topic of functions. 
Regarding this objective, quantitative results provided a general description of pre-service teachers' pedagogical and subject matter knowledge of the concept of a function. The analysis of these results led the researcher to conclude that the level of pedagogical and subject matter knowledge of pre-service teachers who participated in the study was generally low. This being the case there is need for teacher education providers to pay extra attention to the pedagogical development of preservice teachers. Thus, the general objective of the study was achieved.

In the case of specific objectives the following was concluded:

- The first specific objective was to characterize the depth of preservice secondary school mathematics teachers' Common Content Knowledge, Specialized Content Knowledge and Mathematical Pedagogical Content Knowledge of functions.

Pre-service teachers' knowledge was mainly characterized in terms of KDRF, KASERF, CIQCF, EJRDRF, EJEF, EJRRDF, KDRRF and KSDME. Based on the results, it was concluded that pre-service teachers in Clusters 1 and 2 who participate in the study exhibited challenges when explaining and justifying examples of functions. This was especially evident in their responses to items in the functions survey. Majority of pre-service teachers could hardly explain and justify existing relationships and connections between domain and range of a function. The details of these gaps in knowledge are further explained in detail in the overview of their CCK, SCK and KCS. Pre-service teachers need to improve in the three domains of knowledge to avoid challenges when teaching secondary school concepts about the concept of a function. This objective was achieved.

- The second was to provide descriptions of pre-service secondary school mathematics teachers' Common Content Knowledge, Specialized Content Knowledge and Knowledge of Content and Students of the function concept.

In-depth descriptions of participants' CCK, SCK and KCS were provided based on the three cases that were sampled for the second phase of the investigation. All the three participants mainly had average pedagogical and subject matter knowledge of the concept of a function. In some items that called for concepts like arbitrariness of functions, they seemed to have no knowledge. Teacher X exhibited better knowledge than Teachers $\mathrm{Y}$ and $\mathrm{Z}$. This was largely attributed to the fact that 
he performed extremely well in the test with a score of $80 \%$ in Cluster 2 while the other two were drawn from Cluster 1 with average scores. It can be argued that descriptions of knowledge possessed by participants suggested that they needed to improve their CCK, SCK and KCS in order to comfortably teach the topic under investigation in secondary school. This objective was achieved.

- The third was to compare the level of knowledge of functions of Zambian pre-service secondary school mathematics teachers with findings from similar studies carried out in Zambia and abroad.

Throughout the analysis of the results comparisons were made with other related prior studies. It was concluded that participants of the current investigation had difficulties with inverse and composite functions similar to those of pre-service teachers who were investigated in previous studies (Even, 1992; Kontorovich, 2017; Paoletti, 2020; Wasserman, 2017). Participants of this study also had difficulties when dealing with quadratic functions and translation between different representations of functions similar to pre-service teachers in previous studies (Cho \& Moore-Rosso, 2014; Cho, 2013; Gagatsis and Shiakalli, 2004; Gaisman, \& McGee, 2015; Huang \& Kulm, 2012; Martinez-Planell et al., 2015; Ubah \& Bansilal, 2018). It was evident from this study that participants exhibited difficulties dealing with domain and range of functions a similar manner as those who participated in previous studies (Dorko \& Weber, 2014; Ozkan \& Unal, 2009). In achieving this object this study was not alienated from previous research. Detailed comparison with previous studies is detailed in Chapter 5 of this thesis.

\subsection{OVERVIEW ABOUT METHODOLOGICAL CHOICES AND DECISIONS FOR THE STUDY}

All choices and decisions related to the methodology used in this study were taken based on two factors, namely (i) the nature of the problem which was being studied and (ii) the depth that was intended to understand the problem. These two factors dictated the choice of methods and decisions in their application.

Firstly, it was planned to conduct an in-depth study about pre-service teachers' knowledge of concept of a function. Quantitative data alone was not going to provide an in-depth understanding of the research problem and to adequately collect data that would help to sufficiently answer the research questions. Based on the nature of the research problem and what the study intended to achieve it was decided to use a 
mixed methods sequential explanatory research design (Creswell, 2014). The researcher was cognizant of the availability of philosophical world views of positivism/post positivism (supporting quantitative research) and constructivism (supporting qualitative research) (Creswell \& Plano Clark, 2007),

Ii was decided to locate the study in the pragmatic world view. This study needed to use both quantitative and qualitative approaches for deeper understanding of the problem and for richer findings, thus, pragmatism was a preferred paradigm to support it. This was because pragmatism recognizes that positivism and constructivism have ontological and epistemological commonalities and can complement each other during the research process (Hanson, 2008; Yvonne, 2010).

The choice for adopting pragmatism was influenced by the views of Teddlie and Tashakkori (2009), and Morgan (2007) that it (pragmatism) is the most suitable philosophical lens to guide mixed methods studies. They argued that pragmatism guides a mixed methods design to produce a well-integrated methodology because of the value it attaches to quantitative and qualitative approaches to research. Thus, the mixed methods sequential explanatory research design used in this study was a good fit in the pragmatism paradigm.

In choosing the mixed methods sequential explanatory research design, the investigator was cognizant of the other methods of conducting a mixed methods study like exploratory sequential design, convergent parallel design, embedded design, multistage design and transformative design (Creswell, 2017). Among the reasons for choosing the explanatory sequential design was that it is not complicated to implement because of the two stages that are implemented in sequence. Secondly, the investigator wanted to first have a wider understanding of the research problem, which meant that he needed a large sample which could only be accomplished by collect quantitative data. Then use the qualitative phase to explain the initial results.

This prompted the researcher to choose appropriate sampling techniques which were in conformity with the explanatory sequential design. He used nested sampling where the second sample was a sub-sample of the first. Three cases were selected from the initial sample to participate in the second phase of the study. Triangulation was employed at different stages of the study including instruments, data collection and analysis procedures. All these reflected triangulation. 


\subsection{OVERVIEW OF PRE-SERVICE SECONDARY MATHEMATICS TEACHERS' MPCK PERCEPTIONS}

A global consideration of MPCK perceptions gave an average level of preservice teachers' confidence in teaching mathematics. Clusters 1 and 2 had average scores that were not high enough. The low scores would affect their confidence to teach secondary school concepts involving function concepts. There was also a significant correlation between pre-service teachers' performance in the functions survey and each of the MPCK factors. This implied that pre-service teachers whose subject matter knowledge and pedagogical content knowledge of the function concept was low also had low perceptions about their ability to teach the function concepts. Thus, such teachers were likely to have low confidence about their teaching and their anxiety will be high.

Teacher Knowledge of Misconceptions (KM) plays a very important role in a mathematics classroom. This knowledge equips the teacher with skills to anticipate the wrong conceptions that students would have about function concepts and be able to clear all misconceptions. Results revealed that pre-service teachers in Cluster 2 showed more confidence in their abilities to anticipate, identify and clear any conceptual confusion that would arise due to misconceptions than their colleagues in cluster 1. Considering the composition of the clusters, the results showed that a bigger number of pre-service teachers would confidently resolve students' misconceptions because Cluster 2 had more members (79 members) than Cluster 1 (71 members).

Pre-service teachers in Cluster 1 had the least confidence in their knowledge of learners (KL). Knowledge of Learners was one of the focal areas of this study. The investigator is of a considered view that it is non-negotiable for a teacher to know his/her learners' characteristics if teaching would be inclusive. The number of preservice teachers who were more confident was slightly larger (Cluster 2) but the difference was not much larger than those that were less confident. The overall picture about this construct was not very good and needed great improvement. Results also indicated that pre-service teachers in Cluster 2 were more confident about their knowledge of curriculum (KC) than those in Cluster 1. It was noted in the results that knowledge of curriculum materials was crucial to the teaching process. Teaching involves implementation of the national curriculum and knowledge of the 
curriculum is highly sought for. Thus, it can be concluded that the overall picture about pre-service teachers' MPCK perceptions was not desirable. Pre-service teachers need to be up in confidence about all aspects of teaching mathematics especially the concept of a function because it is widely regarded to be a central concept in mathematics at all levels of education.

\subsection{OVERVIEW OF PRE-SERVICE SECONDARY MATHEMATICS TEACHERS' COMMON CONTENT KNOWLEDGE (CCK)}

As stated in Chapter 5, CCK was assessed through pre-service teachers' knowledge of definitions of relations and functions (KDRF), calculations involving inverse, quadratic and composite functions (CIQCF) and appropriate selection of examples and non-examples of relations and functions (KASERF). Compared to SCK and KCS, pre-service teachers in clusters 1 and 2 performed well in CCK. Mean scores for overall CCK were higher than those for SCK and KCS in both clusters. This means that they had good knowledge of CCK than SCK and KCS. Their knowledge of selecting examples for students was the weakest in the CCK domain for both clusters although pre-service teachers in Cluster 2 had better knowledge about this than those in Cluster 1.

Majority of students exhibited lack of knowledge of the difference between a relation and a function. It was also observed that while definition of a function was not particularly a big problem for pre-service teachers, quite a good number of them were not able to give a valid definition of a relation. This actually contributed to most of them failing to distinguish between a relation and a function. While some of them were able to define one-to-one functions, it was difficult for many to define an inverse of a function. In fact, even in their definition of a function they referred more to a one-to-one function than the actual definition of a function. Gaps in their knowledge of definitions affected their knowledge of calculations because they could not apply definitions to solve some problems.

Regarding knowledge of calculations involving inverse, quadratic and composite functions, numerous procedural, conceptual and carelessness errors were present in pre-service teachers' responses to the function survey. Majority of preservice teacher lacked the ability to correctly find the expression for the inverse of a function. It was also observed that while a good number were able to find the composition of two functions, some of them were unable to correctly evaluate 
composite function especially in situations which included constant functions. In few cases errors due to inability to correctly add or subtract were noticed and some included unnecessary factorisations which turned out to complicate some stages of their work.

Their knowledge of selection of examples and non-examples of functions and relations was good with majority of pre-service teachers able to give conceptually valid examples. They were able to exemplify their definitions of relations and functions even in cases where the actual definition was not valid. Majority of them were also able to give examples of one-to-one functions and they were also able to identify functions from situations which were graphically presented. However, in their knowledge of examples and non-examples of functions, pre-service teachers were not able to use the vertical and horizontal line tests in determining functions from graphs. In fact, during interviews it was revealed that all participates lacked knowledge of vertical and horizontal line tests. Teacher $\mathrm{X}$ who attempted to use the two concepts confused them. He lacked knowledge of the difference between the two and what they were used for. Thus, he could not correctly apply either test in determining functions. All participants showed lack of knowledge of the univalence and arbitrariness properties of functions. They stated that they have never heard about these properties. While the univalence property was noticed in their definitions, they could not explain during interviews.

\subsection{OVERVIEW OF PRE-SERVICE SECONDARY MATHEMATICS TEACHERS' SPECIALIZED CONTENT KNOWLEDGE (SCK)}

Pre-service teachers did not perform at a high level in their specialized content knowledge. Their level of SCK was not at a desirable level. While some were operating at a very good level, majority of the pre-service teachers showed low level of this type of knowledge. With the lowest score of zero in their ability to smoothly translate between different representations, their knowledge of different representations of functions was low.

Some of them could not translate from tabular to graphical form. They did not accurately draw a quadratic graph from a given table of values for $x$ and $f(x)$. Majority of the pre-service teachers failed to meaningfully analyze graphs of quadratic functions to bring out conceptual differences. Some even failed to explain the relationship between the range of a function and the maximum point of the graph 
of a quadratic function, while majority of pre-service teacher were able to draw arrow diagrams to represent domain and range, they were unable to adequately explain and justify these concepts. Very few of them were able to solve quadratic equations using graphs and to justify the procedures used. Majority pre-service teachers were more comfortable with algebraic representation of a function as opposed to the graphical representation.

While their knowledge of selection of examples and non-examples of relations and functions was desirably good, pre-service teachers' ability to explain and justify the stages involved in solving these examples was inadequate. For example, some of them were able to find the turning point of a quadratic function using completing the square method but could not explain with justification all the steps involved and they were unable to even state the relationship between completing the square and the stationary point of a quadratic function. It was this lack of justification of one's examples that indicated a lot of gaps in their SCK. Ability to explain and justify one's own examples showed the difference between knowing procedures of solving and understanding the concept while solving. Procedure can easily be memorized but conceptual understanding, which was being sought, can largely be demonstrated through explaining and justifying every step of an example.

Majority of pre-service teachers were not able to state the difference between range and domain of a function. This also affected their ability to define inverse functions. For one to sufficiently define inverse functions, he/she needed to fully understand the existing relationship and difference between the two, during the interviews pre-service teachers struggled in their justifying of some of the answers they wrote in their response to the function survey. Teacher X and Teacher $\mathrm{Y}$ were not able to adequately explain their answer to the problem $\mathrm{g}\left(\mathrm{g}^{-1}\right)(-5)$. The problem was involving evaluation of the composition of a function and its inverse. While Teacher $\mathrm{Z}$ was able to easily state the answer without solving, which is what was being sought, he could not go beyond stating the answer.

Thus, their SCK was not good enough and they need to improve their ability to explain every step of their solutions to problems, giving valid conceptual reasons for each step. To teach secondary school concepts related to functions effectively, preservice teachers need to improve their explanations. This is because some of their work seemed to indicate memorized procedures other than mastery of concepts. 


\subsection{OVERVIEW OF PRE-SERVICE SECONDARY MATHEMATICS TEACHERS' KNOWLEDGE OF CONTENT AND STUDENTS (KCS)}

Regarding their KCS, pre-service teachers were able to identify mistakes from students' work and in some cases were able to offer alternative correctly solved solutions. However, they were not able to resolve identified misconceptions. For the few that were administered vignettes that depicted classroom situations, they were unable to clear confusions among students that caused misconception despite being asked to do so. This was an observed gap in knowledge for resolving misconceptions. When a teacher identifies misconceptions it is important to clear it. Identification is not enough. Students need to be guided on the correct conception to prevent future occurrences of the same.

Regarding situations where they needed to judge the appropriateness and correctness of definitions of functions given by students, their judgments were characterized by disagreements. This implied that some of them either did not understand definitions or they had misconceived ideas about definitions. This was evident even from their perceptions about implementation of the mathematics curriculum. Their knowledge of the curriculum was low and this was reflected in their KCS. Since vignettes present situations which enable us to see how a teacher would explain concepts to students in class, their inability to clear misconception within the vignettes reflected low levels of KCS. This has the potential to negatively impact on their ability to teach in a real classroom.

For the pre-service teachers that prepared lesson plans, important components of a lesson plan like pre-requisite knowledge of learners were omitted in some cases. Definitions were also not adequately catered for in the lesson plans. The lesson plans mostly displayed the role of the teacher with very little involvement of the learners. This was observed during the implementation of the lesson plans in class. Much of the talking and writing was done by the teacher. There were no instances in all the observed lessons where students were made to work in small groups or to manipulate any objects in class. They were limited to answering few questions from the teacher. This meant that over $80 \%$ of the learners did not actively participate during learning time. There is need for massive improvement before going out to teach. 


\subsection{NEW AND UNIQUE CONTRIBUTION OF THIS STUDY TO EXISTING KNOWLEDGE ABOUT MATHEMATICS EDUCATION}

The major contribution of this study to mathematics education literature is that MPCK perceptions about mathematics among Zambian pre-service teachers are highly related to their level of subject matter knowledge as well as their pedagogical content knowledge. This was evident from cluster analysis results. Pre-service teachers in Cluster 1 were found to have low confidence about the MPCK. It was eventually revealed that their level of subject matter knowledge related to their CCK and SCK was also low. Interestingly, but not surprising, was that even their KCS was low.

While there are several studies that have previously examined pre-service teachers' knowledge of the function concept, many exclusively focused on Subject Matter Knowledge (Arnold, 2004; Aziz \& Kurniasih, 2019; Boyce \& Lamberg, 2020; Dorko \& Weber, 2014; Gaisman, \& McGee, 2015; Huang \& Kulm, 2012; Kontorovich, 2017; Malambo, 2016, Malambo et al., 2019; Wasserman, 2017; Martínez-Planell et al., 2015; Karahasan, 2010). These studies have contributed immensely to difficulties faced by pre- and in-service teachers when learning functions. They have highlighted pre-service teachers' difficulties with domain and range, inverse functions, quadratic functions and different representations of functions.

Other studies focused exclusively on Pedagogical Content Knowledge (Aksu \& Kul, 2016; Hatisaru, 2013; Karahasan, 2010; Tasdan, 2019; Tasdan \& Koyunkaya, 2017; Ubah \& Bansilal, 2018). These studies focused on the teaching aspect of preservice teachers in relation to the function concept. They brought out pedagogical inadequacies and instructional inconsistencies for pre-service teachers approaches to teaching the concept of a function. Few other studies focused on both pedagogical content knowledge and subject matter knowledge (Even, 1993).

However, there has been lack of studies in literature that considered examining pre-service teachers' MPCK perceptions in relation to their Subject matter knowledge and their knowledge of teaching in relation to the concept of a function. This study, though not exhaustive of this line of research, brought a new perspective and new arguments about pre-service teachers' knowledge of the function concept. The investigator is of a strong and considered view that a well-rounded and effective 
teacher should have high confidence (perceptions), strong subject matter (content) knowledge and strong knowledge of teaching strategies and approaches (pedagogy) to effectively teach function concepts. The focus of this study has not received considerable attention in previous studies in spite of its importance in fully understanding pre-service teachers' knowledge related to the concept of a function. The researcher is of the view that examining pre-service teachers' knowledge should begin from appreciating their perceptions about phenomena being studied because their perceived knowledge can greatly influence new knowledge.

\subsection{IMPLICATIONS OF THE STUDY}

This study has highlighted pre-service mathematics teachers' level of Common Content Knowledge, Specialized Content Knowledge, and their Knowledge of Content and Students regarding the concept of a function. The study also highlighted pre-service teachers' Pedagogical Content Knowledge perceptions about mathematics and how their perceptions influenced their pedagogical practices. The findings of the study have implications for mathematics teacher education in Zambia. The findings also have policy implications for secondary school education and teacher professional development in Zambia, and for related future studies.

\subsubsection{Implication for mathematics teacher education}

Results of this study have revealed that pre-service mathematics teachers have low levels of Common Content Knowledge, Specialized Content Knowledge, and Knowledge of Content and Students. It has also been revealed that there exists a link between Subject-Matter Knowledge (CCK, SCK) and Pedagogical Content Knowledge (KCS). KCS improves instructional quality of mathematics teachers (Ünver, Özgür, and Güzel, 2020; Wildgans-Lang et al., 2020; Yang et al., 2020) Thus, mathematics teacher education providers in Zambian colleges of education and universities are urged to design educational courses that are aimed at addressing secondary school mathematics. The said courses should have special focus on the concept of a function because it is a central topic in secondary school mathematics and in advanced university mathematics.

Introducing a course that specifically focuses on secondary school mathematics would help bridge the gap that exists between advanced university mathematics and secondary school mathematics. It would also help in the preparation of pre-service 
teachers on the actual curriculum they are trained to implement after leaving university.

Teacher educators should also design professional development programmes for in-service mathematics teacher aimed at updating teachers on the new developments in mathematics subject-matter and new pedagogical developments. By designing continuous professional development (CPD) programmes for secondary school teachers, teacher educators will be strengthening the link between schools and universities. This is because universities train teachers to work in schools and they must ensure a strong connection. There is need to organize CPDs on graphs of functions with emphasis on translation from one representation of functions to another. This is because effective CPDs have been viewed to be essential to improving teaching and learning in schools and have had a positive impact on teacher training by promoting inquiry and justification of mathematics concepts (Borko, 2004; Choppin et al., 2020; Ekawati et al., 2020; Jackson et al., 2020; Nite \& Bicer, 2020). Pre-service teachers who participated in this study showed weak knowledge of different representation of functions.

There is also need for teacher educators to give increased attention to what preservice teachers know about learner misconceptions and how to resolve the misconceptions. This would improve their pedagogical content knowledge in terms of KCS. Increased peer teaching in universities would help in adequately preparing pre-service teachers for their practicum and eventual careers as teachers. In relation to this, teacher educators should help their trainees develop confidence in teaching mathematics especially concepts involving functions because the function concept has been seen to improve problem solving abilities of teachers.

\subsubsection{Implications for further studies}

This study was very extensive in understanding the research problem and finding answers to the posed research questions but the researcher recognizes that it was not exhaustive about pre-service teachers' knowledge of the concept of a function. Much still need to be done in studying pre-service teachers' knowledge of the function concept in relation to their subject matter knowledge and their pedagogical content knowledge. Thus, the study only acts as a springboard for many lines of research in mathematics teacher education in Zambia and abroad. 
In terms of pedagogical content knowledge the study concentrated of teachers' knowledge of content and students (KCS) from the mathematics knowledge for teaching framework (Ball et al., 2008). This was because the investigator considered KCS a very important domain of pedagogical content knowledge. In the researcher's view, a teacher with good subject matter knowledge and good knowledge of his students' misconceptions, difficulties and errors is well placed to effectively teach mathematics. Secondly, a teacher with positive perceptions of mathematics as a subject will teach mathematical concepts with confidence. This was the reason this study focused on subject matter knowledge and KCS.

It would also be beneficial to see studies purely focused on teaching strategies suitable for teaching the concept of a function. The integration of technology in teaching functions would be very interesting. The country needs studies aimed at technology integration in teaching the function concept. This is because prior studies in this area (Sintema \& Phiri, 2018) have revealed that teacher knowledge of integration of technology in teaching mathematics in Zambia are low. Thus, there is urgent need for research in this area in Zambia.

One of the interesting lines of research would be to examine pre- and in-service teachers' subject matter and pedagogical content knowledge of different representations of functions. There is need to conduct such a study in Zambia in order to validate earlier studies like the current study and to bring up new evidence about teacher knowledge. This is because although knowledge of different representations was part of the focus of this study it was not widely investigated. This study focused on many other aspects of the concept of a function which made it difficult to dwell on one aspect. Researchers in Zambia should conduct in-depth studies on aspects of the function concept like inverse, composite, knowledge definitions, and domain and range. Detailed studies on the proposed aspects would provide a wide and deeper understanding of pre-service teachers' knowledge of the concept of a function.

Another proposed line of research would be to consider investigating secondary school students' difficulties when learning the concept of functions. Do Zambian secondary school students understand notation used to denote inverse and composite functions? Can Zambian secondary school students translate from one representation of functions to another? Can Zambian secondary school students 
meaningfully define the concept of a function? Do Zambian secondary school students fully understand the concept of domain and range?

These questions beg some answers from local researchers. Answers to these questions would greatly contribute to the improvement of pedagogical strategies used in teaching the function concept. Research aimed at answering these questions would trigger a reconceptualization of approaches in teaching mathematics in Zambia. Research on secondary school students would inform teacher education providers on the best way to structure mathematics teacher education programmes in a way that would respond to needs to students in secondary schools.

\subsubsection{Policy implications for secondary school education and teacher professional development in Zambia}

Recent performance analysis for Grade 12 Ordinary level mathematics and Additional mathematics results by the Examinations Council of Zambia (ECZ) recorded concerns about Grade 12 students' poor performance in examination questions involving functions. The $2017 \mathrm{ECZ}$ report noted that poor performance by candidates in functions emerged as one of the problem areas that contributed to the overall poor performance in mathematics at Grade 12 level. Table 33 shows that 1,189 candidates who sat the Grade 12 mathematics national examinations scored zero in mathematics paper 1 and this figure shot up to 5,588 in paper 2 of the same examination. In Additional mathematics paper 1, 79 candidates scored zero while the number of candidates scoring zero reduced to 29 in additional mathematics paper 2.

Table 33. Zambian national examinations results for Grade 12 mathematics and Additional mathematics

\begin{tabular}{|c|c|c|c|c|}
\hline $\begin{array}{c}\text { Year or } \\
\text { Examination }\end{array}$ & \multicolumn{2}{|c|}{ Subject } & $\begin{array}{c}\text { No. of students } \\
\text { who sat }\end{array}$ & $\begin{array}{l}\text { No. of students } \\
\text { who scored zero }\end{array}$ \\
\hline \multirow{4}{*}{2017} & \multirow{2}{*}{ Mathematics } & Paper 1 & 132,530 & 1189 \\
\hline & & Paper 2 & 132,530 & 5588 \\
\hline & Additional & Paper 1 & 4,823 & 79 \\
\hline & Mathematics & Paper 2 & 4,823 & 29 \\
\hline
\end{tabular}

Results of this study have important implications for secondary school mathematics education in Zambia. The Ministry of Education through the Curriculum Development Centre (CDC) should identify the concept of a function as a key concept in the mathematics senior syllabus and make a deliberate policy for teachers in secondary schools to emphasise its teaching. This is because functional 
thinking features in almost all mathematics topics and should be emphasized for students to see patterns in mathematics and to improve their reasoning.

The concept of a function is present in a number of major topics in the Zambia senior secondary school syllabus like trigonometry, algebra, calculus and linear programming. It would be difficult for secondary school students to learn and understand trigonometric functions, limits and optimization if they lack basic knowledge of the function concept. There is empirical evidence suggesting that knowledge of the function concept improves problem solving abilities of both teachers and students (Gagatsis \& Shiakalli, 2004; Hitt, 1998). Thus, if there is a deliberate policy placing the function concept in the centre of mathematical development in Zambia, students would improve their problem solving skills.

Results of this study can also be used as a starting point for teacher professional development aimed at improving the teaching of mathematics in Zambia. The Zambian government through the Teaching Council of Zambia (TCZ) instructed that teaching licenses would not be renewed without evidence of any professional development programmes undertaken by the teachers. Thus, this study provides tasks with proven methodologies that can be used for mathematics teacher professional development; especially that part of the focus of this study was teachers' knowledge of mathematics content and students.

Professional development programmes in the form of lesson studies involving different representations of functions would be good because this is one of the most difficult aspects of functions that has been researched in this study. Teacher knowledge of different representations was found to be weak in this study and other studies (Aziz \& Kurniasih, 2019; Elia et al., 2007). Professional development in other aspects like domain and range, inverse, and composition of functions would be beneficial to teachers because teacher knowledge of these concepts is insufficient and needs to be improved to trigger high achievement of learners.

\subsection{LIMITATIONS OF THE STUDY}

This study was not without limitations. The study was limited by a number of factors that included researcher's inexperience with mixed methods research, potential researcher biases and a few others. 
The first limitation was concerning the researcher's inexperience in conducting mixed methods research. The researcher is not an advanced user of mixed methods research approaches and this was a limitation to the implementation of the methodology. Researcher bias was also a limitation to this study in some ways. The researcher has beliefs about mathematics and the research topic that could have been a limitation to the study. His mathematics background and beliefs may have influenced the choice of the mathematical pedagogical content knowledge perceptions survey and contents of the functions survey. A robust validation process for these instruments mitigated this influence.

Considering that the sequential explanatory mixed methods approach used in this research comprised two phases (quantitative and qualitative) which were implemented in a sequence, the researcher could have been a limitation to data collection and analysis processes of the second phase (qualitative). The researcher is naturally and primarily a data collection instrument and a data analysis instrument in qualitative research. His beliefs and background can potentially be a limitation to the effect that his beliefs and background would unintentionally affect the data collection and analysis stages of research process.

During the sampling stage of the study the researcher faced a challenge of maintaining the participants who volunteered to participate in the quantitative and qualitative phases of the data collection stage of the study. A total of 150 pre-service teacher consented to participate in phase 1 of the study. Out of this number, four preservice teachers were selected to participate in phase 2 of the study. However, one participant withdrew from taking part in phase 2 and it was difficult to replace him. Phase 2 had to proceed with the remaining three participants. This was a limitation to the study because the four participants were initially selected on purpose.

\subsection{SUMMARY OF THE RIGOR CRITERIA FOR THE STUDY}

The merit, quality or worth of any research which adopts qualitative, quantitative or mixed methods approaches is easily established by assessing its rigor (Creswell, 2017; Henry, 2015; Krefting, 1991; Lincoln \& Guba, 1985). It has increasingly become important and mandatory to conduct evidence based and rigorous research that can be trusted based on its methodological rigor. To ensure rigor of quantitative inquiry, researchers have largely relied on established 
standardized procedures of validity, reliability and objectivity while qualitative investigators rely on credibility to ensure trustworthiness of qualitative inquiry (Creswell, 2017; Henry, 2015).

To establish methodological rigor of this study, the researcher adopted and implemented Guba's (1981) model for trustworthiness of qualitative and quantitative research as expounded in Krefting (1991). Guba's (1981) model has been used widely in educational research and underwent revisions (Lincoln, 1995; Lincoln \& Guba, 1985). According to Krefting (1991), Guba (1981) proposed and described four criteria for evaluating research which fitted both quantitative and qualitative approaches, and could thus fit mixed methods research because it incorporates both quantitative and qualitative approaches in a single study. The four criteria proposed by Guba (1981) were truth value, applicability, consistency and neutrality (Krefting, 1991). Figure 173 shows a visual representation of Guba's (1981) model for trustworthiness which was used in this study to ensure methodological rigor of its qualitative and quantitative phases.

\subsubsection{Guba's (1981) model of trustworthiness}

The call for quality and rigorous research among the research community implied that there was need for standards on which research processes were to be evaluated. To respond to this call, Guba (1981) proposed (i) Truth value, (ii) Applicability, (iii) Consistency and (iv) Neutrality as the criteria by which research quality and worth was to be evaluated (Krifting, 1991) and he provided working definitions for both qualitative and quantitative approaches for the application of these criteria. A detailed explanation of how this model was applied to the current study is provided in Chapter 3, section 3.4.1 for the quantitative phase and section 3.6.3. for the qualitative phase. Guba's model was the appropriate fit for this study because of its tendency to define rigor criteria from the perspectives of both qualitative and quantitative research.

In these criteria, to strengthen the 'credibility' of the research, researchers should focus on prolonged engagement, persistent observation, triangulation, peer debriefing, negative case analysis, and member checking. 


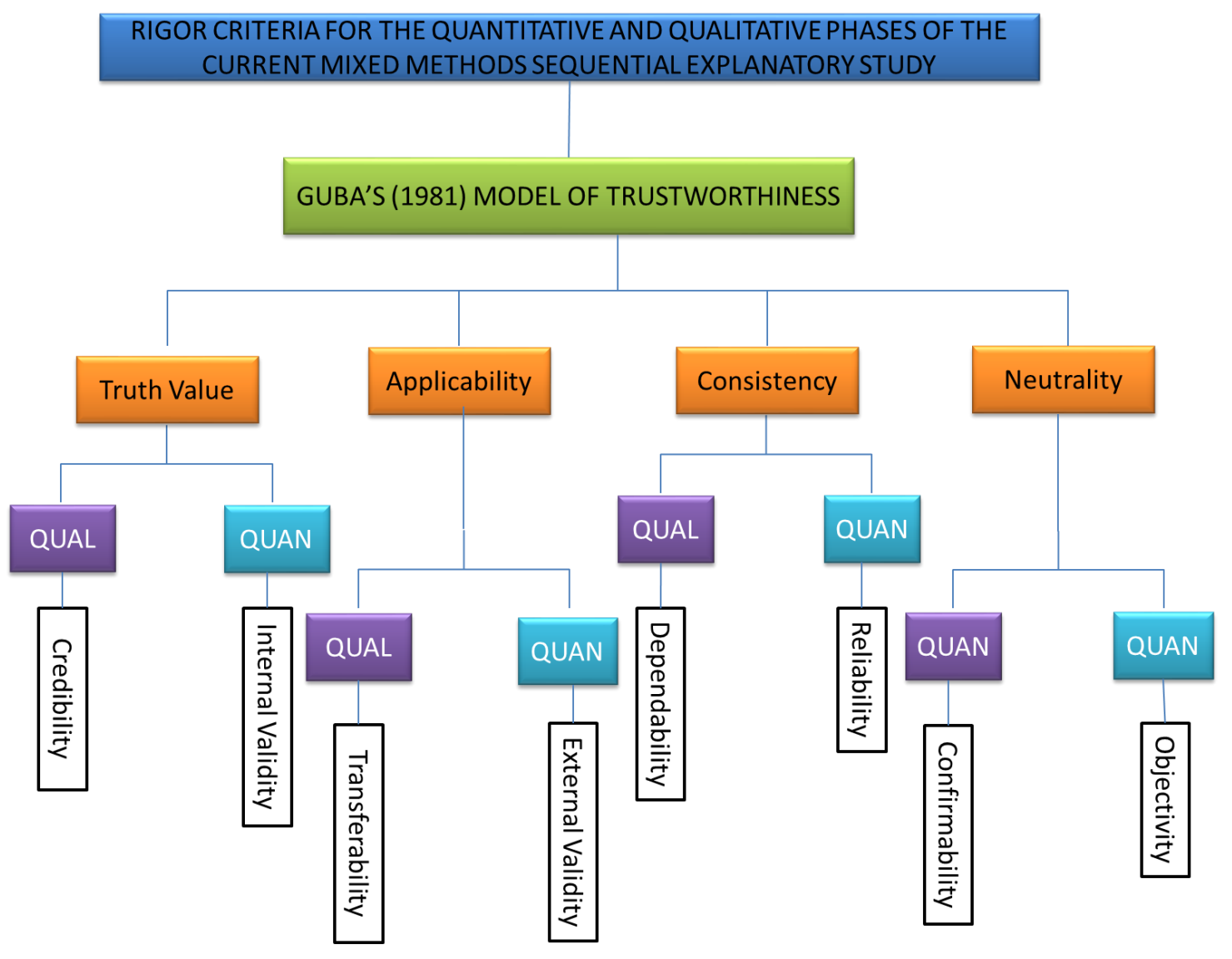

Figure 173. Framework for the rigor criteria of the current study

\section{Truth value}

Truth value of any research refers to the ability of the researcher to establish confidence of the research findings regardless of the research design adopted (Krefting, 1991). Quantitative researchers ensure the truth value of their research by basically considering the validity of the instruments used to collect data that give rise to the results. In particular, researchers are expected to take care of the threats to internal and external validity of the study. In the case of qualitative studies, the researcher establishes the credibility of the study.

The sequential mixed methods approach which was used in the current study demanded that truth value for both quantitative and qualitative phases be established. It can be seen from Chapter 3 that the research design was explained in detail with a visual representation provided (Figure 12). The context of the study was extensively highlighted and how the research instruments fitted the local context of Zambia. Participants of the study were also adequately described to the extent that a reader 
would have confidence in the study. In the quantitative phase the validity of all data collection instruments was extensive and rigorous.

To ensure truth value of the quantitative phase and to mitigate threats to internal validity, all data collection instruments were extensively validated. The pencil and paper test was subject to validation in which both face and content validation were established and detailed in Chapter 3. Experts were invited to rate items of the instrument based on their clarity, coherence and relevance. In doing so the item content validity index (I-CVI) for each item and the scale content validity index (S-CVI) for the entire instrument were established. This was done to ensure that the study reflected and assessed the concept and constructs of interest as advocated by Thorndike (1997). Item content validity index of at least 0.80 was used as cut-off for retaining an item in the final version of the instrument. As regards scale content validity, it was found to be 0.90 . This ensured that the instrument was valid for use in the study.

Regarding the adapted MPCK scale, a confirmatory factor analysis (CFA) was conducted to ensure that the instrument was a good fit to the Zambian context. The researcher favoured the CFA approach because of its ability to produce models that are usually context specific (Alhija, 2010) and the procedure also produces fit indices that can be used for the purpose of deciding whether an adapted scale can be accepted for use in a particular context. For this purpose, the structural equation modeling (SEM) using the partial least squares (PLS) modeling method was used to obtain the CFA model using SmartPLS version 3.0 where different fit indices which included the standardized root mean residual (SRMR), Chi-square value, Normed fit index (NFI) were obtained together with other exact fit measures d_ULS and d_G (Table 14). These indices are presented in detail in Chapter 3.

For the qualitative phase of the study, truth value was established by considering the credibility of the research process. In Chapter 3 the researcher provided reasons and justifications for complimenting the quantitative phase with qualitative inquiry which was to have an in-depth understanding of the research problem. Being one of the most important criterion for establishing the quality of the study (Polit \& Beck, 2014), credibility was given considerable attention in this study. The researcher achieved this by engaging in member checking, peer debriefing, providing rich and thick descriptions of the data, incorporation of negative results 
and researcher self-reflection of the entire research process. These aspects of credibility are explained in great detail in Chapter 3 of this study.

\section{Applicability}

Applicability basically refers to the extent or degree to which results of the study can be generalized to other contexts (Creswell 2003; Krefting, 1991). The ability to generalize or apply research findings to other settings is very important for replication of research. It enables other researchers to replicate existing research to their own contexts. Generalization of research findings is common and highly pronounced among quantitative researchers although qualitative researchers refer to transferability (Creswell, 2017; Guba, 1981; Lincoln \& Guba, 1985). It has been emphasized that quantitative researchers achieve applicability of research findings by minimizing threats to external validity. Selection bias was observed as the greatest threat to external validity of this study. The study target pre-service who were university students and participation in the study was voluntary.

Research has revealed that volunteer samples and student samples are problematic in some ways (Rosenthal and Rosnow, 1975). To reduce biases that could have been caused by volunteering, the researcher asked all participants to briefly explain why they decided to volunteer in the study. Most of them explained that the research would enable them to learn something new. In the case of problems presented by student samples that include inability to generalize to populations that may not be predominantly that of students, this did not cause a significant threat to the generalizability of the findings of this study. Considering that undergraduate curricula in Zambian universities are similar with students learning similar content, findings of a study involving students from one university can be generalized to other students in other universities.

Since research instruments were thoroughly validated and consisted of items based on the secondary school mathematics curriculum in Zambia, results of this study could be generalized to other contexts within Zambia. This does not mean that findings can easily been generalized to international contexts because other countries may be following different curricula at both secondary and tertiary levels of education. Nevertheless, comparative studies can be conducted at international level. In the same vain the qualitative phase of the study can be transferable to other 
settings within the Zambian context considering that the research design, instruments and the sample were described in details.

\section{Consistency}

Consistency refers to the ability to obtain similar findings when the study is replicated with the same participants or in very similar contexts (Krefting, 1991). Consistency was assessed using different criteria for the quantitative and qualitative phases of this study because of its mixed methods approach. For the quantitative phase consistency was established using the reliability criterion (Ivankova, 2004; Krefting, 1991; Sandelowski, 1986) while dependability was used to assess the consistency of the qualitative phase (Field \& Morse, 1985; Guba, 1981; Krefting, 1991). Both reliability and dependability of the data are well explained in Chapter 3 of this thesis. For the quantitative phase of this study reliability was established using indicator reliability which measured the reliability of each indicator for the latent variables under study. The latent variables KTS, KMLS, KL and KM had indicator reliability ranging from 0.4624 to 0.9025 (Hulland, 1999) which was within the accepted cut-off (refer to Chapter 3 for details). However, the latent variable $\mathrm{KC}$ had six of its indicators with reliability below the acceptable minimum of 0.4. Internal consistency was also measured using composite reliability (Bagozzi \& Yi, 1988; Hair et al., 2012; Hair et al., 2014). It was found that all the latent variables KTS, KMLS, KL, KM and $\mathrm{KC}$ had composite reliability greater than 0.7. This was an indication that the data was reliable and would produce consistent results if replicated.

For the qualitative phase dependability was achieved via triangulation; peer review and keeping a good audit trail (Ary et al., 2010) as evidenced in Chapter 3. With regards to triangulation, for example, multiple data sources and research methods were used in order to have an in-depth understanding of phenomena under study (Carter et al., 2014; Noble \& Heale, 2019; Patton, 1999; Yin, 2003). Methodological triangulation which refers to the use of multiple data collection methods like observations, interviews and surveys was implemented in the qualitative phase of this study. For this particular study triangulation was achieved by using multiple data collection tools: functions test, MPCK questionnaire, lesson plans, interviews, vignettes and observations. 


\section{Neutrality}

Neutrality refers to the researcher's ability to free one's research from any research biases regarding the procedures followed when conducting the study and findings of the study. It is important that no biases are reflected in any part of the study (Krefting, 1991; Sandelowski, 1986). The quantitative phase of this study used objectivity as a criterion for establishing neutrality of the study (Guba, 1981). In this regard the reliability and validation procedures of all research instruments were rigorously established (Refer to Chapter 3) using objectively scientific procedures like confirmatory factor analysis. These procedures were not in any way influenced by the researcher. Rereliability coefficients and validity indices were purely obtained based on the data obtained from participants. Thus, results of the study are all supported by these data. With regards to the qualitative phase of this study, neutrally was established by confirmability (Lincoln \& Guba, 1985). In particular, prolonged time in the research site enabled the researcher to gain in-depth understanding of the participants and setting (Creswell, 2014; Guba 1981), thereby reducing bias. Additionally, by establishing the truth value and applicability of the study, the researcher demonstrated lack of bias in this study. 


\section{Bibliography}

Acil, E. (2011). Ilkogretim ogretmenlerinin etkinlik algisi ve uygulanisina iliskin gorusleri [Yayınlanmamıs Yuksek Lisans Tezi, Gaziantep Universitesi].

Abell, S. K. (2008). Twenty years later: Does pedagogical content knowledge remain a useful idea?. International Journal of Science Education, 30(10), 1405-1416. https://doi.org/10.1080/09500690802187041

Airasian, P. W., \& Gay, L. R. (2003). Educational research: Competencies for analysis and application ( $7^{\text {th }}$ ed.) . Prentice Hall.

Alrwaished, N., Alkandari, A., \& Alhashem, F. (2017). Exploring In- and PreService Science and Mathematics Teachers' Technology, Pedagogy, and Content Knowledge (TPACK): What Next? Eurasia Journal of Mathematics, Science and Technology Education, 13(9), 61136131. https://doi.org/10.12973/eurasia.2017.01053a

Akkaya, R. (2016). Research on the development of middle school mathematics preservice teachers' perceptions regarding the use of technology in teaching mathematics. EURASIA Journal of Mathematics, Science and Technology Education, 12(4), 861-879. https://doi.org/10.12973/eurasia.2016.1257a

Akkoc, H. (2008). Pre-service mathematics teachers' concept images of radian. International Journal of Mathematical Education in Science and Technology, 39(7), 857-878. https://doi.org/10.1080/00207390802054458

Aksu, Z., \& Kul, Ü. (2016). Exploring Mathematics Teachers' Pedagogical Content Knowledge in the Context of Knowledge of Students. Journal of Education and Practice, 7(30), 35-42.

Alajmi, A. H. (2019). Twelfth Grade Kuwaiti Students' Identification of Domain and Range in Graphical Representation of Function and the Meaning they Ascribe to them. Journal of Educational and Psychological Studies [JEPS], 13(3), 576591. http://doi.org/10.24200/jeps/vol13iss3pp576-591

Alhija, F. A. N. (2010). Factor analysis: An overview and some contemporary advances. International encyclopedia of education, 3, 162-170.

Almanasreh, E., Moles, R., \& Chen, T. F. (2019). Evaluation of methods used for estimating content validity. Research in Social and Administrative Pharmacy, 15(2), 214-221. https://doi.org/10.1016/j.sapharm.2018.03.066

Amankwaa, L. (2016). Creating protocols for trustworthiness in qualitative research. Journal of Cultural Diversity, 23(3). 121-127.

Aminah, N., Waluya, S. B., Rochmad, R., Sukestiyarno, S., Wardono, W., \& Adiastuty, N. (2020). Analysis of Technology Pedagogic Content Knowledge Ability for Junior High School Teacher: Viewed TPACK Framework. In Advances in Social Sciences, Education and Humanities Research (Vol.429, pp. 257-260): International Conference on Agriculture, Social Sciences, Education, Technology and Health (ICASSETH 2019). Atlantis Press.

Arnold, S. (2004). Investigating Functions: Domains and Ranges. Australian Senior Mathematics Journal, 18(1), 59-64. 
Ary, D., Jacobs, L. C., Sorensen, C., \& Razavieh, A. (2010). Introduction to research in education (8th ed.). Cengage Learning.

Aziz, T. A., Pramudiani, P., \& Purnomo, Y. W. (2018). Differences between quadratic equations and functions: Indonesian pre-service secondary mathematics teachers' views. Journal of Physics: Conf. Ser. 948012043. http://doi.org10.1088/1742-6596/948/1/012043

Aziz, T. A., \& Kurniasih, M. D. (2019). External representation flexibility of domain and range of function. Journal on Mathematics Education, 10(1), 143156

Babbie, Earl R. (2010). The Practice of Social Research (12th ed.). Wadsworth publishing.

Bagozzi, R. P., \& Yi, Y. (1988). On the evaluation of structural equation models. Journal of Academy of Marketing Science, 16(1), 74-94. https://doi.org/10.1007/BF02723327

Bair, S. L., \& Rich, B. S. (2011). Characterizing the development of Specialised Mathematical Content Knowledge for teaching in Algebraic Reasoning and number Theory. Mathematical Thinking and Learning, 13(4), 292-321. http://doi.org/10.1080/10986065.2011.608345

Ball, D. L., \& Wilson, S. M. (1990). Knowing the subject and learning to teach it: Examining assumptions about becoming a mathematics teacher. Research Report No. 90-7. Michigan State University.

Ball, D. L. (1991). Research on teaching mathematics: Making subject-matter knowledge part of the equation. In J. Brophy (Ed.), Advances in research on teaching, (vol. 2, 1-48). JAI Press Inc.

Ball, D. L., Hill, H. C., \& Bass, H. (2005). Knowing mathematics for teaching: Who knows mathematics well enough to teach third grade, and how can we decide? American Education, 29(3),

14-22.

http://hdl.handle.net/2027.42/65072

Ball, D. L., Thames, M .H., \& Phelps, G. (2008). Content Knowledge for Teaching: What makes it Special? Journal of teacher education, 59(5),389-407. https://doi.org/10.1177/0022487108324554

Ball, L. D., \& Mc Diarmid, G. W. (2010). The subject matter preparation of teachers. In W. R. Houston (Ed.), Handbook for Research on Teacher Education (pp. 437-449). Macmillan,

Bastürk, S. (2009). Investigating teaching practice course according to student teachers' opinions, Elementary Education Online, 8(2), 439-456.

Bates, A. B., Latham, N., \& Kim, J. A. (2011). Linking pre-service teachers' mathematics self-efficacy and mathematics teaching efficacy to their mathematical performance. School Science and Mathematics, 111(7), 325-333.

Bell, J. (2014). Doing Your Research Project. A guide for first time researchers (6th ed.). McGraw-Hill Education.

Beswick, K., \& Goos, M. (2012). Measuring pre-service primary teachers' knowledge for teaching mathematics. Mathematics Teacher Education and Development, 14(2), 70-90. 
Bitsch, V. (2005). Qualitative research: A grounded theory example and evaluation criteria. Journal of agribusiness, 23, 75-91. http://dx.doi.org/10.22004/ag.econ.59612

Bjerke, A. H., \& Solomon, Y. (2019). Developing self-efficacy in teaching mathematics: Pre-service teachers' perceptions of the role of subject knowledge. Scandinavian Journal of Educational Research, 64(5), 692-705. http://doi.org/10.1080/00313831.2019.1595720

Bloch, I. (2003). Teaching Functions in a Graphic Milieu: What Forms of Knowledge enable Stidents to Conjecture and prove? Educational Studies in Mathematics, 52(1), 3-28. https://doi.org/10.1023/A:1023696731950

Blömeke, S., Busse, A., Kaiser, G., König, J., \& Suhl, U. (2016). The relation between content-specific and general teacher knowledge and skills. Teaching and Teacher Education, 56, 35-46. http://doi.org/10.1016/j.tate.2016.02.003

Borko, H. (2004). Professional development and teacher learning: Mapping the terrain. Educational researcher, 33(8), 3-15. https://doi.org/10.3102/0013189X033008003

Borko, H., Eisenhart, M., Brown, C. A., Underhill, R. G., Jones, D., \& Agard, P. C. (1992). Learning to teach hard mathematics: Do novice teachers and theirinstructors give up too easily? Journal for Research in Mathematics Education, 23(3), 194-222. http://doi.org/10.2307/749118

Breidenbach, D., Dubinsky, E., Hawks, J., \& Nichols, D. (1992). Development of the process conception of function. Educational studies in mathematics, 23(3), 247-285. https://doi.org/10.1007/BF02309532

Breslich, E.R. (1928). Developing functional thinking in secondary school mathematics. In National Council of Teachers of Mathematics (Eds.), The third year book (pp. 42-56). Little and Ives.

Brown, A. L., Myers, J., \& Collins, D. (2019). How pre-service teachers' sense of teaching efficacy and preparedness to teach impact performance during student teaching. Educational Studies, $\quad 45(1), \quad 1-21$. https://doi.org/10.1080/03055698.2019.1651696

Bryman, A., Becker, S., \& Sempik, J. (2008). Quality criteria for quantitative, qualitative and mixed methods research: A view from social policy. International journal of social research methodology, 11(4), 261-276. https://doi.org/10.1080/13645570701401644

Budayasa, I. K., \& Juniati, D. (2018). Pedagogical Content Knowledge: Teacher's Knowledge of Students in Learning Mathematics on Limit of Function Subject. In Journal of Physics: Conference Series (Vol. 954, No. 1, p. 012002). IOP Publishing.

Bukova-Güzel, E., Cantürk-Günhan, B., Kula, S., Özgür, Z., \& Elçí, A. N. (2013). Scale development for pre-service mathematics teachers' perceptions related to their pedagogical content knowledge. South African Journal of Education, 33(2), 1-21. https://doi.org/10.15700/saje.v33n2a690 
Bursal, M., \& Paznokas, L. (2006). Mathematics anxiety and preservice elementary teachers' confidence to teach mathematics and science. School Science and Mathematics, 106(4), 173-180. $\quad$ https://doi.org/10.1111/j.19498594.2006.tb18073.x

Byrnes, J. P., \& Wasik, B. A. (1991). Role of conceptual knowledge in mathematical

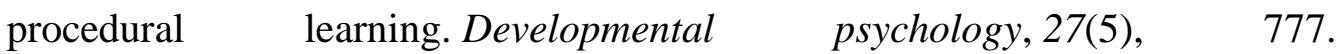
https://psycnet.apa.org/doi/10.1037/0012-1649.27.5.777

Cantley, I., O’Meara, N., Prendergast, M., Harbison, L., \& O’Hara, C. (2020). Framework for analysing continuity in students' learning experiences during primary to secondary transition in mathematics. Irish Educational Studies, 113. https://doi.org/10.1080/03323315.2020.1779108

Carrillo, J., Climent, N., Contreras, L. C., \& Muñoz-Catalán, M. D. C. (2013). Determining specialised knowledge for mathematics teaching. In Proceedings of the CERME, (Vol. 8, pp. 2985-2994).

Chai, C. S., Jong, M., \& Yan, Z. (2020). Surveying Chinese teachers' technological pedagogical STEM knowledge: a pilot validation of STEM-TPACK survey. International Journal of Mobile Learning and Organisation, 14(2), 203-214. https://doi.org/10.1504/IJMLO.2020.106181

Chai, C. S., Tan, L., Deng, F., \& Koh, J. H. L. (2017). Examining pre-service teachers' design capacities for web-based 21 st century new culture of learning. Australasian Journal of Educational Technology, 33(1), 1-20. https://doi.org/10.14742/ajet.3013

Chen, W. (2017). Knowledge convergence among pre-service mathematics teachers through online reciprocal peer feedback. Knowledge Management \& ELearning: An International Journal,9(1), 1-18. https://doi.org/10.34105/j.kmel.2017.09.001

Cherryholmes, C. H. (1992). Notes on pragmatism and scientific realism. Educational researcher, 21(6), 13-17. https://doi.org/10.3102/0013189X021006013

Chesler, J. (2012). Pre-Service Secondary Mathematics Teachers Making Sense of Definitions of Functions. Mathematics Teacher Education and Development, 14(1), 27-40.

Chinnappan, M., \& Thomas, M. O. J. (2001). Prospective teachers' perspectives on function representations. In Proceedings of the 24th annual conference of the Mathematics Education Research Group of Australasia (pp. 152-162).

Cho, Y. D. (2013). College Students' Understanding of the Domain and Range of Functions on Graphs. [Doctoral thesis, State University of New York at Buffalo]

Cho, P., \& Moore-Russo, D. (2014). How Students Come to Understand the Domain and Range for the Graphs of Functions. Proceedings of the Joint Meeting of the PME 38 and PME-NA 36 (Vol. 2, pp. 281-288). Vancover: International Group for the Psychology of Mathematics Education. 
Clark, K. (2019). History and pedagogy of mathematics in mathematics education: History of the field, the potential of current examples, and directions for the future. In Eleventh Congress of the European Society for Research in Mathematics Education. Freudenthal Institute; ERME.

Clement, L. L., (2001). What Do Students Really Know about Functions?. Mathematics Teacher, 94(9). 745-748.

Cohen, J. (1960). A coefficient of agreement for nominal scales. Educational and psychological measurement, 20(1), 37-46. https://doi.org/10.1177/F001316446002000104

Connelly, L. M. (2014). Ethical considerations in research studies. Medsurg Nursing, 23(1), 54-56.

Cook, T. D., Campbell, D. T., \& Day, A. (1979). Quasi-experimentation: Design \& analysis issues for field settings (Vol. 351). Houghton Mifflin.

Cooper, S., Cant, R., Porter, J., Sellick, K., Somers, G., Kinsman, L., \& Nestel, D. (2010). Rating medical emergency teamwork performance: development of the Team Emergency Assessment Measure (TEAM). Resuscitation, 81(4), 446452. https://doi.org/10.1016/j.resuscitation.2009.11.027

Costa, D. A. D. (2020). Knowledge to Teach and Knowledge for Teaching in Teacher Education Research. Pedagogical Research, 5(3), em0059, http://doi.org/10.29333/pr/7936

Creswell, J. W., \& Miller, D. L. (2000). Determining validity in qualitative inquiry. Theory into practice, 39(3), 124-130.

Creswell, J. W. (2003). Research design: Qualitative, quantitative, and mixed methods approaches (2nd ed.). Sage Publications.

Creswell, J. W., \& Plano-Clark, V. L. (2007). Designing and conducting mixed methods research. Sage Publications.

Creswell, J. W. (2012). Educational Research Planning, Conducting, and Evaluating Qualitative and Quantitative Research (4th ed.). Pearson Education.

Creswell, J. W. (2014). Research design: Qualitative, quantitative and mixed methods approaches. Sage Publications.

Creswell, J. W., \& Creswell, J. D. (2017). Research design: Qualitative, quantitative, and mixed methods approaches. Sage publications.

Creswell, J. W., \& Clark, V. L. P. (2017). Designing and conducting mixed methods research. Sage publications.

Cunningham, R.F. (2005). Algebra teachers' utilization of problems requiring transfer between algebraic, numeric, and graphic representations. School Science and Mathematics, 105(2), 73-81. https://doi.org/10.1111/j.19498594.2005.tb18039.x

Curtis, S., Gesler, W., Smith, G., \& Washburn, S. (2000). Approaches to sampling and case selection in qualitative research: examples in the geography of health. Social science \& medicine, 50(7-8), 1001-1014. https://doi.org/10.1016/S02779536(99)00350-0 
Dalal, M., Archambault, L., \& Shelton, C. (2017). Professional Development for International Teachers: Examining TPACK and Technology Integration Decision Making. Journal of Research on Technology in Education, 49(3-4), 117-133. https://doi.org/10.1080/15391523.2017.1314780

Davis, B., \& Simmt, E. (2006). Mathematics-for-teaching: An ongoing investigation of the mathematics that teachers (need to) know. Educational studies inmathematics, 61(3), 293-319. https://doi.org/10.1007/s10649-006-2372-4

Demana, F., Schoen, H.L., \& Waits, B. (1993). Graphing in the K-12 curriculum: The impact of the graphing calculator. In T.A. Romberg, E. Fennema \& T.P. Carpenter (Eds.), Integrating research on the graphical representation of functions (pp. 11-39). Erlbaum.

Denzin, N. K. (1978). Triangulation: A case for methodological evaluation and combination.In N. K. Denzin (Ed.), Sociological methods: A Sourcebook (pp. 339-357). Mc Graw-Hill.

Denzin, N. K., \& Lincoln, Y. S. (2008). The discipline and practice of qualitative research. In N. Denzin, \& Y. Lincoln (Eds.), Collecting and interpreting qualitative materials (Vol. 3). Sage Publications.

Dewey, J. (1925). Experience and nature. Kessinger Publishing.

Dorko, A., \& Weber, E. (2014). Generalising calculus ideas from two dimensions to three: How multivariable calculus students think about domain and range. Research in Mathematics Education, 16(3), 269-287. https://doi.org/10.1080/14794802.2014.919873

Dreyfus, Tommy, \& Eisenberg, T. (1982). Intuitive Functional Concepts: A Baseline Study on Intuitions. Journal for Research in Mathematics Education 13(5), 360-380. http://doi.org/10.2307/749011

Dumbisky, E., \& Wilson, R. T. (2013). High School Students' Understanding of the Function Concept. The Journal of Mathematical Behavior, 32(1), 83-101. https://doi.org/10.1016/j.jmathb.2012.12.001

Dunham, P. H., \& Osborne, A. (1991). Learning how to see: Students' graphing difficulties. Focus on Learning Problems in Mathematics, 13(4), 35-49.

Duran, M., \& Usak, M. (2015). Examining the pedagogical content knowledge of science teachers who have different teaching experience about acids and bases. Oxidation Communications, 38(1A), 540-557.

Duru, A., \& Koklu, O. (2011). Middle school students' reading comprehension of mathematical texts and algebraic equations. International Journal of Mathematical Education in Science and Technology,42(4), 447-468. https://doi.org/10.1080/0020739X.2010.550938

Ebert, C. L. (1993). An assessment of prospective secondary teachers' pedagogical content knowledge about functions and graphs. A Paper presented at the American Educational Research Association. https://eric.ed.gov/?id=ED366580

Egodawatte, G. (2011). Secondary school students' misconceptions in algebra. [Unpublished Doctoral Thesis, University of Toronto]. http://hd1.handle.net/1807/29712 
Eisenberg, T.A., \& Dreyfus, T. (1991). On the reluctance to visualize in mathematics. In W. Zimmerman \& S. Cunningham (Eds.), In W. Zimmermann \& S. Cunningham. Visualization in teaching and learning mathematics (pp. 25-37). Mathematical Association of America

Ekawati, R., Wintarti, A., \& Kurniasari, I. (2020). Integrating the hypothetical learning trajectory with realistic mathematics to in-service teachers' professional development. In International Conference on Research and Academic Community Services (ICRACOS 2019). Atlantis Press.

Ekmekci, A., Papakonstantinou, A., Parr, R., \& Shah, M. (2019). Teachers' knowledge, beliefs, and perceptions about mathematics teaching: How do they relate to teachers' technological pedagogical content knowledge? In M. L. Niess, H. Gillow-Wiles, \& C. Angeli (Eds.), Handbook of Research on TPACK in the Digital Age (pp. 1-23). IGI Global.

Elia, I., Panaoura, A., Eracleous, A., \& Gagatsis, A. (2007). Relations between secondary pupils' conceptions about functions and problem solving in different representations. International Journal of Science and Mathematics Education, 5(3), 533-556. https://doi.org/10.1007/s10763-006-9054-7

Elmahdi, I., \& Fawzi, H. (2019). Pre-service Teachers' Perception of Readiness to Teach in Light of Teachers' Standards. American Journal of Educational Research, 7(4), 304-308. http://doi.org/10.12691/education-7-4-1

Erlandson, D. A., Harris, E. L., Skipper, B. L., \& Allen, S. D. (1993). Doing naturalistic inquiry: A guide to methods. Sage Publications.

Even, R. (1990). Subject matter knowledge for teaching and the case of functions. Educational studies in mathematics, 21, 521 - 544. https://doi.org/10.1007/BF00315943

Even, R. (1992). The inverse function: Prospective teachers' use of "undoing". International Journal of Mathematical Education in Science and Technology, 23(4), 557-562. https://doi.org/10.1080/0020739X.1992.10715689

Even, R. (1993). Subject matter knowledge and pedagogical content knowledge: Prospective teachers and the concept of a function. Journal for Research in Mathematics Education, 24(2), 94-116. http://doi.org/10.2307/749215

Even, R., \& Trosh, D. (1995). Subject matter knowledge and knowledge about students as sources of teacher presentations of the subject matter. Educational studies in mathematics, 29(1), 1-20. https://doi.org/10.1007/BF01273897

Even, R. (1998). Factors involved in linking representations of functions. Journal of Mathematical Behavior, 17(1), 105-121. https://doi.org/10.1016/S07323123(99)80063-7

Fennema, E., \& Franke, M. L. (1992). Teachers' knowledge and its impact. In D. Grouws (Ed.), Handbook of research on mathematics teaching and learning (pp. 147-164). Macmillan Publishing Company.

Fornell, C. G., \& Larcker, D. F. (1981). Evaluating structural equation models with unobservable variables and measurement error. Journal of Marketing Research, 18(1), 38-50. https://doi.org/10.1177/002224378101800104 
Gagatsis, A., \& Shiakalli, M. (2004). Ability to translate from one representation of the concept of a function to another and mathematical problem solving. An International Journal of Experimental Educational Psychology, 24(5), 645657. https://doi.org/10.1080/0144341042000262953

Garson, G. D. (2016). Partial least squares: regression \& structural equation models Asheboro. Statistical Associates Publishing.

Gay, L. R., \& Airasian, P. (2003). Educational research: Consequences for analysis and applications (7th ed.). Pearson Education

Gay, L. R., Mills, G. E., \& Airasian, P. (2006). Educational research: Competencies foranalysis and application. Merrill Greenwood.

Gay, L. R. Mills, G. E., \& Airasian, P.(2012). Educational research: Competencies for analysis and application (10th ed.). Pearson Education.

Gibbs, G. R. (2007). The naure of qualitative analysis (pp. 1-9). In Analyzing Qualitative Data. Sage Publications.

Goe, L. (2007). The link between teacher quality and student outcomes: A research synthesis. National Comprehensive Center for Teacher Quality.

Gökdağ, D. (2008). Etkili iletişim. In U. Demiray (Ed.), Etkili Illetişim. Pegem Akademi Yayıncılık.

Gold, A. H., Malhotra, A., \& Sergas, A. H. (2001). Knowledge management: an organizational capabilities perspective. Journal of Management Information Systems, 18(1), 185-214. https://doi.org/10.1080/07421222.2001.11045669

Goldin, G. A. (2002). Representation in mathematical learning and problem solving. In L. D. English (Ed.). Handbook of international research in mathematics education (pp. 197-218). Erlbaum.

Grant, J. S., \& Davis, L. L. (1997). Selection and use of content experts for instrument development. Research in nursing \& Health, 20(3), 269-274. https://doi.org/10.1002/(SICI)1098-240X(199706)20:3<3C269::AIDNUR9>3E3.0.CO;2-G

Gravetter, F. J., \& Forzano, L. B. (2012). Research Methods for the Behavioral Sciences (4th ed.). Linda schreiber-Ganster.

Gresham, G. (2009). An examination of mathematics teacher efficacy and mathematics anxiety in elementary pre-service teachers. The Journal of Classroom Interaction, 44(2), 22-38. http://www.jstor.org/stable/23869610

Grossman, P. L. (1990). The making of a teacher: Teacher knowledge and teacher education. Teachers College Press.

Grossman, P. L., Wilson, S. M., \& Shulman, L. S. (1989). Teachers of substance: Subject matter knowledge for teaching. Profesorado, Revista de Currículum y $\begin{array}{llll}\text { Formación del Profesorado, } & 9(2), & 1-25 .\end{array}$ https://recyt.fecyt.es/index.php/profesorado/article/view/42833

Guba, E. G. (1981). Criteria for assessing the trustworthiness of naturalistic inquiries. Ectj, 29(2), 75. https://doi.org/10.1007/BF02766777

Guba, E. G., \& Lincoln, Y. S. (1981). Effective evaluation: Improving the usefulness of evaluation results through responsive and naturalistic approaches. JosseyBass. 
Hair J. F., Sarstedt, M., Pieper, T. M., \& Ringle, C. M. (2012). The use of partial least squares structural equation modeling in strategic management research: a review of past practices and recommendations for future applications, Long Range planning, 5(6), 320-340. https://doi.org/10.1016/j.lrp.2012.09.008

Hair Jr, J. F., Hult, G. T. M., Ringle, C., \& Sarstedt, M. (2016). A primer on partial least squares structural equation modeling (PLS-SEM). Sage publications.

Hair Jr, J. F., Sarstedt, M., Hopkins, L., \& Kuppelwieser, V. G. (2014). Partial least squares structural equation modeling (PLS-SEM). European business review. 26(2), 106-121. http://doi.org/10.1108/EBR-10-2013-0128

Handa, Y. 2011. What does understanding mathematics mean for teachers? Relationship as a metaphor for knowing (Studies in curriculum theory series). Routledge.

Hanson, B. (2008). Wither qualitative/quantitative? Grounds for methodological convergence. Quality \& Quantity,42(1), 97-111. https://doi.org/10.1007/s11135-006-9041-7

Harel, G., \& Wilson, S. (2011). The state of high school textbooks. Notices of the AMS, 58(6), 823-826.

Harel, G., Selden, A., \& Selden, J. (2006). Advanced mathematical thinking: Some PME perspectives. In Handbook of research on the psychology of mathematics education (pp. 147-172). Brill Sense.

Harris, J. B., Phillips, M., Koehler, M. J., \& Rosenberg, J. M. (2017). TPCK/TPACK research and development: Past, present, and future directions. Australasian Journal of Educational Technology, 33(3), 1-8. https://doi.org/10.14742/ajet.3907

Hart, K. M., Brown, M. L., Kuchemann, D. E., Kerslake, D., Ruddock, G., \& McCartney, M. (1981). Children's understanding of mathematics: 11-16 ( $\mathrm{p}$. 212). John Murray.

Hatisaru V. \& Erbas A. K. (2017). Mathematical Knowledge for Teaching the Function Concept and Student Learning Outcomes. International Journal of Science and Mathematics Education, 15(4), 703-722. http://doi.org/10.1007/s10763-015-9707-5

Hennissen, P., Beckers, H., \& Moerkerke, G. (2017). Linking practice to theory in teacher education: A growth in cognitive structures. Teaching and Teacher Education, 63, 314-325. http://doi.org/10,1016/j.tate.2017.01.08

Henry, P. (2015). Rigor in qualitative research: Promoting quality in social science research. Research Journal of Recent Sciences, 4, 25-28.

Henseler, J., Ringle, C. M., \& Sarstedt, M. (2015). A new criterion for assessing discriminant validity in variance-based structural equation modeling. Journal of the Academy of Marketing Science, 43(1), 115-135. https://doi.org/10.1007/s11747-014-0403-8

Henseler, J., Ringle, C. M., \& Sinkovics, R. R. (2009). The use of partial least squares path modeling in international marketing. In R. R. Sinkovics \& P. N. Ghauri (Eds.), Advances in International Marketing (Vol. 20, pp. 277-320). Emerald Group Publishing Limited. 
Hill, H. C., Schilling, S. G., \& Ball, D. L. (2004). Developing measures of teachers' mathematics knowledge for teaching. The Elementary School Journal, 105(1), 11-30. https://doi.org/10.1086/428763

Hill, H. C., Rowan, B., \& Ball, D. L. (2005). Effects of teachers' mathematical knowledge for teaching on student achievement. American Educational Research Journal, 42(2), 371-406. https://doi.org/10.3102/00028312042002371

Hill, H. C., Sleep, L., Lewis, J. M., \& Ball, D. L. (2007). Assessing teachers' mathematical knowledge: What knowledge matters and what evidence counts. In F. K. Lester (Ed.), Second Handbook of Research on Mathematics Teaching and Learning, (Vol. 1, pp. 111-155). Information Age.

Hine, G., \& Thai, T. (2019). Pre-service mathematics teachers' self-perceptions of readiness to teach secondary school mathematics. Mathematics Teacher Education and Development, 21(2), 64-86. https://researchonline.nd.edu.au/edu_article/236/

Hitt, F. (1998). Difficulties in the articulation of different representations linked to the concept of a function. The Journal of Mathematics Behavior, 17(1), 123134. https://doi.org/10.1016/S0732-3123(99)80064-9

Hofmann, R., \& Roth, J. (2017). Assessment of students' thinking when working with graphs of functions-Promoting pre-service teachers' diagnostic competence. Proceedings of the $10^{\text {th }}$ Congress of the European Society for Research in Mathematics Education (CERME 10), DCU Institute of Education and ERME. https://hal.archives-ouvertes.fr/hal-01949273/

Holmes, V. L. (2012). Depth of teachers' Knowledge: Frameworks for Teachers' Knowledge of Mathematics. Journal of STEM education: Innovations \& Research, 13(1), 55-71.

Hu, L. T., \& Bentler, P. M. (1998). Fit indices in covariance structure modeling: Sensitivity to underparameterized model misspecification, Psychological Methods, 3(4), 424-453. http://doi.org/10.1037/1082-989X.3.4.424

Huang, R., \& Kulm, G. (2012). Prospective middle grade mathematics teachers' knowledge of algebra for teaching. The Journal of Mathematics Behavior, 31(4), 417-430. https://doi.org/10.1016/j.jmathb.2012.06.001

Hulland, J. (1999). Use of partial least squares (PLS) in strategic management research: A review of four recent studies. Strategic management journal, 20(2), 195-204. https://doi.org/10.1002/(SICI)1097-0266(199902)20:2<195::AIDSMJ13>3E3.0.CO;2-7

Isiksal, M., \& Cakiroglu, E. (2011). The nature of prospective mathematics teachers' pedagogical content knowledge: the case of multiplication of fractions. Journal of Mathematics Teacher Education, 14(3), 213-230. https://doi.org/10.1007/s10857-010-9160-x

Ivankova, N. V., Creswell, J. W., \& Stick, S. L. (2006). Using mixed-methods sequential explanatory design: From theory to practice. Field methods, 18(1), 3-20. https://doi.org/10.1177\%2F1525822X05282260 
Jeffries, C., \& Maeder, D. W. (2005). Using vignettes to build and assess teacher understanding of instructional strategies. Professional Educator, 27, 17-28. https://eric.ed.gov/?id=EJ728478

Jeffery, T. D., Hobson, L. D., Conoyer, S. J., Miller, K. E., \& Leach, L. F. (2018). Examining EC-6 Pre-Service Teachers' Perceptions of Self-Efficacy in Teaching Mathematics. Issues in the Undergraduate Mathematics Preparation of School Teachers: The Journal, 5, 1-10. https://eric.ed.gov/?id=EJ1189604

Johnson, R. Burke, Anthony, J. Onwueghuzie, and Lisa, ATurner, 2007. Toward a defition of mixed methods research. Journal of Mixed Methods Research 1(2): 112-133. https://doi.org/10.1177/1558689806298224

Johnson, R. B., \& Onwuegbuzie, A. J. (2004). Mixed methods research: A research paradigm whose time has come. Educational researcher, 33(7), 14-26. https://doi.org/10.3102/0013189X033007014

Jojo, Z. (2019). Students' conceptual understanding of cubic functions in differential calculus. In J. Naidoo \& R. Mudaly (Eds.), Proceedings of the $25^{\text {th }}$ Annual National Congress of the Association for Mathematics Education South Africa (Vol. 1, pp. 117-125). Association for Mathematics Education of South Africa.

Kaput, J. J. (1989). Supporting Concrete Visual Thinking in Multiplicative Reasoning: Difficulties and Opportunities. Focus on Learning Problems in Mathematics, 11(1), 35-47. https://eric.ed.gov/?id=EJ389505

Karahasan, B. (2010). Pre-service secondary mathematics teachers' pedagogical content knowledge of composite and inverse functions [Doctoral Dissertation, Middle East Technical University]. http://citeseerx.ist.psu.edu/viewdoc/download?doi=10.1.1.632.7944\&rep=rep1 $\underline{\text { \&type }=\mathrm{pdf}}$

Karakus, F. (2018). An Examination of Pre-Service Teachers' Technological Pedagogical Content Knowledge and Beliefs Using Computer Technology in Mathematics Instruction. Issues in the Undergraduate Mathematics Preparation of School Teachers: The Journal3. 1-13. https://eric.ed.gov/?id=EJ1199683

Kemper, E. A., Stringfield, S., \& Teddlie, C. (2003). Mixed methods sampling strategies in social science research. In A. Tashakkori \& C. Teddlie (Eds.), Handbook of mixed methods in social and behavioral research (pp. 273-296). Sage Publications.

Kerschen, K., Shelton, R., \& Wilkerson, T. L. (2017). Developing pre-service teachers' understanding of effective mathematical teaching practices using vignettes. In M. J. Mohr-Schroeder \& J. N. Thomas (Eds.), Proceedings of the $116^{\text {th }}$ annual convention of the School Science and Mathematics Association (Vol. 4, pp. 44-50). SSMA.

Kidder, L., \& Judd, C. (1986). Research methods in social science. CBS College Publishmg.

Kilic, H. (2011). Pre-service secondary mathematics teachers' knowledge of students. Turkish Online Journal of Qualitative Inquiry, 2(2), 17-35. 
Kilic, H., Dogan, O., Tun, S. S., \& Arabaci, N. (2018). Supporting preservice teachers' in-the-moment noticing. In E. Bergqvist, M. Osterholm, C. Granberg, $\&$ L. Sumpter (Eds.), Proceedings of the 42nd Conference of the International Group for the Psychology of Mathematics Education (Vol. 3, pp. 203-210). PME.

Kim, S. (2018). Technological, Pedagogical, and Content Knowledge (TPACK) and Beliefs of Pre-service Secondary Mathematics Teachers: Examining the Relationships. Eurasia Journal of Mathematics, Science and Technology Education, 14(10), em1590. http://doi.org/10.29333/ejmste/93179

Kline, R. B. (2011). Principles and practice of structural equation modeling (93rd ed), Guilford Press.

Koehler, M., \& Mishra, P. (2009). What is technological pedagogical content knowledge (TPACK)? Contemporary issues in technology and teacher education, 9(1), 60-70. https://www.learntechlib.org/p/29544/

Koklu, O., \& Topcu, A. (2012). Effect of Cabri-assisted instruction on secondary school students' misconceptions about graphs of quadratic functions. International Journal of Mathematical Education in Science and Technology, 43(8), 999-1011. https://doi.org/10.1080/0020739X.2012.678892

Kontorovich, I. (2017). Students' confusions with reciprocal and inverse functions. International Journal of Mathematical Education in Science and Technology, 48(2), 278-284. https://doi.org/10.1080/0020739X.2016.1223361

Knuth, E. J. (2000). Student understanding of the Cartesian connection: An exploratory study. Journal for Research in Mathematics Education, 31(4), 500507. http://doi.org/10.2307/749655

Krefting, L. (1991). Rigor in qualitative research: The assessment of trustworthiness. American journal of occupational therapy, 45(3), 214-222. https://doi.org/10.5014/ajot.45.3.214

Kulm, G. (2008). Teachers' mathematics knowledge. School Science and Mathematics, 108(1), 2-4.

Lappan, G., \& Ferrini-Mundy, J. (1993). Knowing and doing mathematics: A new vision for middle grades students. The Elementary School Journal, 93(5), 625641. https://doi.org/10.1086/461744

Lee, Y., Capraro, R. M., \& Capraro, M. M. (2018). Mathematics Teachers' Subject Matter Knowledge and Pedagogical Content Knowledge in Problem Posing. International Electronic Journal of Mathematics Education, 13(2), 7590. http://doi.org/10.12973/iejme/2698

Leinhardt, G., \& Smith, D. (1985). Expertise in mathematics instruction: Subject matter knowledge. Journal of Educational Psychology, 77(3), 247-271. https://psycnet.apa.org/doi/10.1037/0022-0663.77.3.247

Leinhardt, G., Zaslavsky, O., \& Stein, M. S. (1990). Functions, graphs and graphing: Tasks, learning, and teaching. Review of Educational Research, 60(1), 1-64. https://doi.org/10.3102\%2F00346543060001001 
Lesh, R., Post, T., \& Behr, M. (1987). Representations and translations among representations in mathematics learning and problem solving. In C. Janiver (Ed.), Problems of representation in the teaching and learning of mathematics, 21, (33-40). Erlbaum.

Li, D. (2004). Trustworthiness of think-aloud protocols in the study of translation processes. International Journal of Applied Linguistics, 14(3), 301-313. https://doi.org/10.1111/j.1473-4192.2004.00067.x

Lin, F. L., \& Rowland, T. (2016). Pre-service and in-service mathematics teachers' knowledge and professional development. In A. Gutierrez, G. Leder, \& P. Boero (Eds.), The second handbook of research on the psychology of mathematics education (pp. 481-520). Sense Publishers.

Linchevsky, L., Vinner, S., \& Karsenty, R. (1992). To be or not to be minimal? Student teachers' views about definitions in geometry. In W. Geeslin \& K. Graham (Eds), Proceedings of the $16^{\text {th }}$ PME Conference (Vol. 2, pp. 4855). University of New Hampshire.

Lincoln, Y. S., Lynham, S. A., \& Guba, E. G. (2011). Paradigmatic controversies, contradictions, and emerging confluences, revisited. The Sage handbook of qualitative research, 4, 97-128.

Lincoln, Y., \& Guba, E. G. (2000). Paradigmatic controversies, contradictions and emerging confluences (pp. 163-188). In N. K. Denzin, \& Y. S. Lincoln (Eds), The Handbook of qualitative research (2nd ed., pp. 1065-1122), Sage Publications.

Lincoln, Y. S., \& Guba, E. G. (1985). Naturalistic inquiry. Sage Publications.

Lloyd, G. M., Beckmann, S., Zbiek, R. M., \& Cooney, T. J. (2010). Developing essential understanding of functions for teaching mathematics in grades 9-12. National Council of Teachers of Mathematics.

Lui, A. M., \& Bonner, S. M. (2016). Preservice and inservice teachers' knowledge, beliefs, and instructional planning in primary school mathematics. Teaching and Teacher Education, 56, 1-13. https://doi.org/10.1016/j.tate.2016.01.015

Luneta, K. (2015). Understanding students' misconceptions: an analysis of final Grade 12 examination questions in geometry. Pythagoras, 36(1), 1-11. https://hdl.handle.net/10520/EJC172894

Lynn, M. R. (1986). Determination and quantification of content validity. Nursing research. 35, 382-385. https://psycnet.apa.org/doi/10.1097/00006199$\underline{198611000-00017}$

Ma, L. (1999). Knowing and teaching elementary mathematics: Teachers' understanding of fundamental mathematics in China and the United States. Erlbaum.

Ma'rufi, I., \& Juniati, D. (2018). Pedagogical Content Knowledge: Teacher's Knowledge of Students in Learning Mathematics on Limit of Function. Journal of Physics, Conf, Ser, 954 012002. https://doi.org/10.1088/1742$\underline{6596 / 954 / 1 / 012002}$ 
Males, L. M. (2017). Using video of peer teaching to examine grades 6-12 preservice teachers' noticing. In E. Schack, M. Fisher, \& J. Wilhelm (Eds.). Teacher noticing: bridging and broadening perspectives, contexts, and frameworks (pp. 91-109). Springer.

Magnusson, S., Krajcik, J., \& Borko, H. (1999). Nature, sources, and development of pedagogical content knowledge for science teaching. In J. Gess-Newsome \& N. Lederman (Eds.), Examining pedagogical content knowledge: The construct and its implications for science education (pp. 95-132). Kluwer Academic Publishers.

Malambo, P. (2016). Exploring Zambian Mathematics Student Teachers' Content knowledge of Functions and trigonometry for Secondary School. [Doctoral Dissertation, University of Pretoria, South Africa]. http://hdl.handle.net/2263/52943

Malambo, P., Van Putten, S., Botha, J. J., \& Stols, G. H. (2019). Dysfunctional functions: the case of Zambian mathematics education students. Eurasia Journal of Mathematics, Science and Technology Education, 15(1), em1651. https://doi.org/10.29333/ejmste/99510

Mandal, P. C. (2018). Trustworthiness in qualitative content analysis. International Journal of Advanced Research and Development,3(2), 479-485. http://www.advancedjournal.com

Marbán, J. M., \& Sintema, E. J. (2020). Pre-service secondary teachers' knowledge of the function concept: A cluster analysis approach. JRAMathEdu (Journal of Research and Advances in Mathematics Education), 5(1), 38-53. https://doi.org/10.23917/jramathedu.v5i1.9703

Markovits, Zvia, Eylon, B. S., \& Bruckheimer, M. (1988). "Difficulties Students Have with the Function Concept." In A. Coxford \& A. Shulte (Eds.), The Ideas of Algebra, K-12 (pp. 48-60), 1988 Yearbook of the National Council of Teachers of Mathematics.

Marks, R. (1990). Pedagogical content knowledge: From a mathematical case to a modified conception. Journal of Teacher Education, 41(3), 3-11. https://doi.org/10.1177/002248719004100302

Martin, W. G., Smith, W. M., \& Mohr-Schroeder, M. J. (2020). Transforming secondary mathematics teacher preparation programs. In W. G. Martin, B. R. Lawrer, A. E. Lischka, \& W. M. Smith (Eds.), The Mathematics Teacher Education Partnership: The Power of a Networked Improvement Community to Transform Secondary Mathematics Teacher Preparation. Information Age Publishing.

Martínez-Planell, R., Trigueros Gaisman, M., \& McGee, D. (2015). Student understanding of directional derivatives of functions of two variables. In Proceedings of the $37^{\text {th }}$ Annual meeting of the North american chapter of the international group for the psychology of mathematics education. Michigan State University. https://eric.ed.gov/?id=ED584220 
Martínez-Planell, R., Gaisman, M. T., \& McGee, D. (2015). On students' understanding of the differential calculus of functions of two variables. The Journal of Mathematical Behavior, 38, 57-86. http://dx.doi.org/10.1016/j.jmathb.2015.03.003

Mason, J., \& Davis, B. (2013). The importance of teachers' mathematical awareness for in-the-moment pedagogy. Canadian Journal of Science, Mathematics and Technology Education, 13(2): 182-197.

Matos, J. M. (2020). Construing Professional Knowledge of Secondary School Teachers of Mathematics: A Historical Perspective. Pedagogical Research, 5(3), em0058. http://doi.org/10.29333/pr/7898

Max, B. (2017). Pre-service secondary mathematics teachers' conceptualizations of equity: Access and power as seen through vignette responses: PSMTs' conceptualizations of equity. School Science and Mathematics, 117(7-8), 286294. https://doi.org/10.1111/ssm.12246

McCulloch, A., Lovett, J., \& Edgington, C. (2019). Designing to Provoke Disorienting Dilemmas: Transforming Preservice Teachers' Understanding of Function Using a Vending Machine Applet. Contemporary Issues in Technology and Teacher Education, 19(1), 4-22. https://www.learntechlib.org/p/177835

Mena, J. (2019). Teachers' Beliefs Towards Blended Learning in Higher Education: A Mixed-Methods Study. In Learning Technology for Education Challenges: 8th International Workshop, LTEC 2019 (Vol. 1011, p. 177), Springer.

Merriam, S. B. (2009). Qualitative research A Guide to Design and Implementation (2nd ed.). Jossey-Bass.

Ministry of Education (1996). Educating our Future: National policy on Education (pp. 67-89). Zambia Educational Publishing House.

Ministry of Education (1977). Educational Reform: Proposals and Recommendations. Zambia Educational Publishing House.

Ministry of Education (1992). Focus on Learning. Zambia Education Publishing House.

Ministry of Education (2013a). “O” level Mathematics Syllabus (Grades 10 t0 12), Zambia Curriculum Development Centre.

Ministry of Education. (2013b). Zambia Education Curriculum Framework. Lusaka: Zambia. Curriculum Development Centre.

Mishra, P., \& Koehler, M.J. (2006). Technological pedagogical content knowledge: A framework for teacher knowledge. Teachers College Record, 108(6), 10171054. https://www.learntechlib.org/p/99246/?nl=1

Mohr, M. J. (2008). Mathematics knowledge for teaching: The case of preservice teachers. In G. Kulm (Ed.), Teacher knowledge and practice in middle grades mathematics (pp. 19-43). Sense Publishers. 
Moore-Russo, D. (2008). Use of definition construction to help teachers develop the concept of slope. In O. Figueras, J. L. Cortina, S. Alatorre, T. Rojano, \& A. Sepulveda (Eds.), Proceedings of the Joint Meeting of International Group for the Psychology of Mathematics Education and the North American Group for the Psychology of Mathematics Education(Vol. 3, pp. 407-414). http://citeseerx.ist.psu.edu/viewdoc/download?doi=10.1.1.688.897\&rep=rep1\& type $=$ pdf\#page $=436$

Morgan, D. L. (2007). Paradigms lost and pragmatism regained. Journal of Mixed Methods Research, 1(1), 48-76. https://doi.org/10.1177/2345678906292462

Morgart, E. C. (2019). Developing elementary pre-service teachers' mathematical knowledge for teaching: Engaging in an adapted lesson study cycle. [Doctoral Dissertation The Pennsylvania State University]. PennState Electronic Theses Dissertations for Graduate School.. https://etda.libraries.psu.edu/catalog/16893eum193

Morse, J. M. (1991). Approaches to qualitative-quantitative methodological triangulation. Nursing Research 40:120-23.

Moschkovich, J. (1993). Aspects of understanding: On multiple perspectives and representations of linear relations and connections among them. In T. A. Romberg, E. Fennema \& T. P. Carpenter (Eds.), Integrating research on the graphical representation of functions (pp. 69-100), Erlbaum.

Moss, D. L., Boyce, S., \& Lamberg, T. (2019). Representations and Conceptions of Variables in Students' Early Understandings of Functions. International Electronic Journal of Mathematics Education, 15(2), em0564. http://doi.org/10.29333/iejme/6257

Muijs, D. (2010). Doing quantitative research in education with SPSS. Sage Publications.

Mulenga, I. M., \& Luangala, J. R. (2015). Curriculum Design in Contemporary Teacher Education: What Makes Job Analysis a Vital Preliminary Ingredient? International Journal of Humanities Social Sciences and Education, 2(1), 3951.

http://citeseerx.ist.psu.edu/viewdoc/download?doi=10.1.1.679.2294\&rep=rep1 $\underline{\text { \&type }=\mathrm{pdf}}$

National Council of Teachers of Mathematics (1991). Professional standards for teaching mathematics. Reston.

National Council of Teachers of Mathematics. (2000). Principles and standards for school mathematics. Reston.

Ndlovu, Z. (2019). An analysis of pre-service mathematics secondary teachers'common content knowledge of parabola and exponential functions. In J. Naidoo \& R. Mudaly (Eds.), Proceedings of the $25^{\text {th }}$ Annual National Congress of the Association for Mathematics Education of South Africa (Vol. 1, pp. 222-231). University of Kwazulu-Natal. 
Neidorf, T., Arora, A., Erberber, E., Tsokodayi, Y., \& Mai, T. (2020). An introduction to student misconceptions and errors in physics and mathematics. In Student Misconceptions and Errors in Physics and Mathematics (Vol. 9, pp. 1-10). IEA Research for Education (A series of in-depth Analyses Based on Data of the International Association for the Evaluation of Education Achievement. Springer.

Newton, K. J., Leonard, J., Evans, B. R., \& Eastburn, J. A. (2012). Preservice elementary teachers' mathematics content knowledge and teacher efficacy. School Science and Mathematics, 112(5), 289-299. https://doi.org/10.1111/j.1949-8594.2012.00145.x

Nieuwenhuis, J. (2014a). Introducing qualitative research. In K. Maree (Ed.), First steps in research (14th ed., pp. 46-68). Van Schaik Publishers.

Nieuwenhuis, J. (2014b). Qualitative research designs and data gathering technique. In K. Maree (Ed.), First steps in research (14th ed., pp. 69-97). Van Schaik Publishers.

Nite, S. B., \& Bicer, A. (2020). Online Mathematics Teacher Professional Development. In P. Wachira \& S. Keengwe (Eds.), Handbook of Research on Online Pedagogical Models for Mathematics Teacher Education (pp. 203215). IGI Global.

Noble, H., \& Heale, R. (2019). Triangulation in research, with examples. Evid Based Nurs, 22(3), 67-68. http://dx.doi.org/10.1136/ebnurs-2019-103145

Nyikahadzoyi, M. R. (2015). Teachers' Knowledge of the Concept of a Function: A Theoretical Framework. International Journal of Science and Mathematics Education, 13(2), 261-283. https://doi.org/10.1007/s10763-013-9486-9

Ojose, B. (2015). Students' misconceptions in mathematics: Analysis of remedies and what research says. Ohio Journal of School Mathematics, 72, 30-34. http://hdl.handle.net/1811/78927

O'Callaghan, B. R. (1998). Computer-intensive algebra and students' conceptual knowledge of functions. Journal for research in mathematics education, 21-40. http://doi.org/10.2307/749716

Onwuegbuzie, A. J., \& Leech, N. L. (2007). Sampling designs in qualitative research: Making the sampling process more public. Qualitative Report, 12(2), 238-254. https://eric.ed.gov/?id=EJ800181

Onwuegbuzie, A. J., \& Collins, K. M. T. (2007). A typology of mixed methods sampling designs in social science research. The Qualitative Report 12(2), 281316. https://eric.ed.gov/?id=EJ800183

Onwuegbuzie, A. J., \& Collins, K. M. (2017). The Role of Sampling in Mixed Methods-Research. KZfSS Kölner Zeitschrift für Soziologie und Sozialpsychologie, 69(2), 133-156. https://doi.org/10.1007/s11577-017-0455-0

Ostermann, A., Leuders, T., \& Nückles, M. (2018). Improving the judgment of task difficulties: Prospective teachers' diagnostic competence in the area of functions and graphs. Journal of Mathematics Teacher Education, 21(6), 579605. https://doi.org/10.1007/s10857-017-9369-z 
Ouvrier-Buffet, C. (2006). Exploring mathematical definition construction processes. Educational Studies in Mathematics, 63(3), 259-282. https://doi.org/10.1007/s10649-005-9011-3

Özkan, E. M., \& Ünal, H. (2009). Misconception in Calculus-I: Engineering students' misconceptions in the process of finding domain of functions. Procedia-Social and Behavioral Sciences, 1(1), 1792-1796. https://doi.org/10.1016/j.sbspro.2009.01.317

Paoletti, T., Stevens, I.E., Hobson, N.L., Moore, K.C., \& LaForest, K.R. (2018). Inverse function: Pre-service teachers' techniques and meanings. Educational Studies in Mathematics, 97(1), 93-109. https://doi.org/10.1007/s10649-0179787-y

Paoletti, T. (2020). Reasoning about relationships between quantities to reorganize inverse function meanings: The case of Arya. The Journal of Mathematical Behavior, 57, 100741. https://doi.org/10.1016/j.jmathb.2019.100741

Patton, M. Q. (1999). Enhancing the quality and credibility of qualitative analysis. Health services research, 34(5), 1189-1208.

Pazuch, V., \& Ribeiro, A. J. (2017). Conhecimento profissional de professores de matemática e o conceito de função: uma revisão de literatura. Educação Matemática Pesquisa, 19(1). 465-496. http://dx.doi.org/10.23925/19833156.2017v19i1p465-496

Polit, D. F., \& Beck, C. T. (2010). Essentials of nursing research: Appraising evidence for nursing practice. (7th ed.). Williams \& Wilkins.

Polly, D., \& Casto, A. R. (2019). Blended Learning in Mathematics: Examining Vignettes From Elementary and Middle Schools. In T. L. Heafner, R. Hartshome, R. Thripp (Eds.), Handbook of Research on Emerging Practices and Methods for K-12 Online and Blended Learning (pp. 272-291). IGI Global.

Polly, D., Pinter, H. H., \& Casto, A. R. (2019). Practice-Based Approaches to Mathematics Education: Vignettes and Experiences. In T. E. Hodges \& A. C. Baum (Eds.), Handbook of Research on Field-Based Teacher Education (pp. 451-470). IGI Global.

Pournara, C., Hodgen, J., Adler, J., \& Pillay, V. (2015). Can improving teachers' knowledge of mathematics lead to gains in learners' attainment in Mathematics?. South African Journal of Education, 35(3). http://dx.doi.org/10.15700/saje.v35n3a1083

Robson, C. (1993). Real world research. Blackwell.

Romberg, T. A., Carpenter, T. P. \& Fennema, E. (1993). Towards a common research perspective. In T. A. Romberg, T. P. Carpenter, \& E. Fennema (Eds.), Toward a common research perspective. Integrating research on the graphical representation of functions (pp. 1-9). Erlbaum.

Ronau, R. N., Rakes, C. R., Bush, S. B., Driskell, S. O., Niess, M. L., \& Pugalee, D. K. (2014). A survey of mathematics education technology dissertation scope and quality. American Educational Research Journal,51(5), 974-1006. https://doi.org/10.3102/0002831214531813 
Ronau, R. N., Webb, D. C., Peters, S. A., Mohr-Schroeder, M. J., \& Stade, E. (2020). Mathematical preparation of secondary mathematics teacher candidates. In W. G. Martin, B. R. Lawler, A. E. Lischka, \& W. M. Smith (Eds.), The Mathematics Teacher Education Partnership: The Power of a Networked Improvement Community to Transform Secondary Mathematics Teacher Preparation (Vol. 4). Information Age Publishing.

Rossman, G. B., and B. L. Wilson. (1985). Number and words: Combining quantitative and qualitative methods in a single large-scale evaluation study. $\begin{array}{lllll}\text { Evaluation } & \text { Review } & 9 & \text { (5), }\end{array}$ https://doi.org/10.1177/0193841X8500900505

Rorty, R. M., \& Rorty, R. (1999). Philosophy and social hope. Penguin UK.

Sahidin, L., Budiarto, M. T., \& Fuad, Y. (2019). Developing Vignettes to Assess Mathematical Knowledge for Teaching Based Conceptual. International Journal of Instruction, 12(3), 651-664. https://eric.ed.gov/?id=EJ1220235

Sahidin, L., Budiarto, M. T., \& Fuad, Y. (2019). What Construct of Mathematical Knowledge for Teaching do Mathematics Teachers Need? (A Theoretical Framework and Conceptualization in Geometry). In Advances in Social Science, Education and Humanities Research (Vol. 227): 1st International Conference on Advanced Multidisciplinary Research (ICAMR 2018). Atlantis Press.

Sajka, M. (2003). A secondary school student's understanding of the concept of function-A case study. Educational Studies in Mathematics, 53(3), 229-254. https://doi.org/10.1023/A:1026033415747

Sánchez, V., \& Llinares, S. (2003). Four student teachers' pedagogical reasoning on functions. Journal of mathematics teacher education,6(1), 5-25. https://doi.org/10.1023/A:1022123615355

Sánchez-Jiménez, E. (2020). The Methodology of Mathematics and the Emergence of a Proto Discipline. Pedagogical Research, 5(3). http://doi.org/10.29333/pr/8201

Sandelowski, M. (1986). The problem of rigor in qualitative research. Advances in nursing science 8(3), 27-37. https://doi.org/10.1097/00012272-198604000$\underline{00005}$

Saraiva, M. J., \& Teixeira, A. M. (2009). Secondary school students' understanding of function via exploratory and investigative tasks. Quaderni di Ricerca in Didattica, 4(19), 74-83.

Scheiner, T., Montes, M. A., Godino, J. D., Carrillo, J., \& Pino-Fan, L. R. (2019). What makes mathematics teacher knowledge specialized? Offering alternative views. International Journal of Science and Mathematics Education, 17(1), 153-172. https://doi.org/10.1007/s10763-017-9859-6

Schilling, Hill \& Ball, (2008). Unpacking Pedagogical Content Knowledge: Conceptualizing and measuring teachers' topic-specific knowledge of students. Journal for Research in Mathematics Education, 39(4), 372-400.

Schwarz, B., \& Dreyfus, T. (1995). New actions upon old objects: A new ontological perspective on functions. Educational studies in mathematics, 29(3), 259-291. https://doi.org/10.1007/BF01274094 
Selden, A. \& Selden, J. (1992). Research perspectives on conceptions of functions: Summary and overview. In G. Harel \& E. Dubinsky (Eds.), The concept of function: Aspects of epistemology and pedagogy (pp. 1- 16). Mathematical Association of America.

Shenton, A. K. (2004). Strategies for ensuring trustworthiness in qualitative research projects. Education for information, 22(2), 63-75. http://doi.org/10.3233/EFI$\underline{\text { 2004-22201 }}$

Shulman, L. S. (1986). Those who understand: Knowledge growth in teaching. Educational Researcher, 15(2), 4-14. https://doi.org/10.3102/0013189X015002004

Shulman, L. (1987). Knowledge and teaching: Foundations of the new reform. Harvard Educational Review, 57(1), 1-23. https://doi.org/10.17763/haer.57.1.j463w79r56455411

Sierpinska, A. (1992). On Understanding the Notion of Function. In G. Harel \& E. Dubinsky (Eds.). The Concept of Function: Aspects of Epistemology and Pedagogy (pp. 25-58). Mathematical Association of America,

Simon, M. (1993). Prospective elementary teachers' knowledge of division. Journal for Research in Mathematics Education, 24(3), 233-254.

Sintema, E. J., \& Phiri, P. A. (2018). An Investigation of Zambian Mathematics Student Teachers' Technological Pedagogical Content Knowledge (TPACK). Journal of Basic and Applied Research International, 24(2), 70-77.

Sintema, E. J., \& Marbán, J. M. (2020). Pre-service secondary teachers' mathematical pedagogical content knowledge self-concept related to their content knowledge of functions and students. International Electronic Journal of Mathematics Education, 15(3), em0598. https://doi.org/10.29333/iejme/8327

Smith III, J. P., Disessa, A. A., \& Roschelle, J. (1994). Misconceptions reconceived: A constructivist analysis of knowledge in transition. The journal of the learning sciences, 3(2), 115-163. https://doi.org/10.1207/s15327809j1s0302_1

Somayajulu, R. B. (2012). Building Pre-Service Teacher's Mathematical Knowledge for Teaching of High School Geometry [Doctoral Dissertation, The Ohio State University]. Electronic Theses and Dissertations Center. http://rave.ohiolink.edu/etdc/view?acc_num=osu1348805530

Sowder, J. T., Phillip, R. A., Armstrong, B. E., \& Schappelle, B. (1998). Middlegrade teachers' mathematical knowledge and its relationship to instruction: A research Monograph. State University of New York Press.

Spyrou, P., \& Zagorianakos, A. (2010). Greek students' understandings of the distinction between function and relation. Research in Mathematics Education, 12(2), 163-164. https://doi.org/10.1080/14794802.2010.496988

Steele, M. D., Hillen, A. F., \& Smith, M. S. (2013). Developing mathematical knowledge for teaching in a methods course: the case of function. Journal of Mathematics Teacher Education, 16(6), 451-482. https://doi.org/10.1007/s10857-013-9243-6 
Stein, M.K., Baxter, J., \& Leinhardt, G. (1990). Subject-matter knowledge and elementary instruction: A case from functions and graphing. American Educational Research Journal, 27(4), 639-663. https://doi.org/10.3102/00028312027004639

Strayer, J. F., Lischka, A. E., Quinn, C. M., \& Watson, L. A. (2018). Developing Preservice Secondary Mathematics Teachers'(PSMTs') Mathematical Knowledge for Teaching (MKT) in Content Courses. In 21st Annual Conference on Research in Undergraduate Mathematics Education.

Swafford, J. O., Jones, G. A., \& Thornton, C. A. (1997). Increased knowledge in geometry and instructional practice. Journal for Research in Mathematics education, 28(4), 467-483. http://doi.org/10.2307/749683

Tall, D. (1996). Functions and Calculus. In A. J. Bishop, K. Clements, CHeitel, J, Kilpatricks, \& C. Larbode (Eds.), International Handbook of Mathematics Education (Vol. 4, pp. 289-325). Kluwer Academic Publishers,

Tanisli, D., \& Kose, N. Y. (2013). Preservice Mathematics Teachers' Knowledge of Students about the Algebraic Concepts. Australian Journal of Teacher Education, 38(2), 1-18. https://eric.ed.gov/?id=EJ1012901

Taşdan, B. T., \& Koyunkaya, M. Y. (2017). Examination of pre-service mathematics teachers' knowledge of teaching function concept. Acta Didactica Napocensia, 4(3), 1-17.

Taşdan, B. T. (2019). Mathematics Teachers' Use of Mathematical Descriptions, Explanations and Justifications While Teaching Function Concept: The Case of Samet. Journal of Theoretical Educational Science/Kuramsal Eğitimbilim Dergisi, 12(4). 1284-1305. https://doi.org/10.30831/akukeg.478101

Tashakkori, A., Teddlie, C., \& Teddlie, C. B. (1998). Mixed methodology: Combining qualitative and quantitative approaches (Vol. 46). Sage Publications.

Tashakkori, A., \& Teddlie, C. (Eds.). (2010). Sage handbook of mixed methods in social \& behavioral research. Sage Publishing.

Teddlie, C., \& Tashakkori, A. (2009). Foundations of mixed methods research: Integrating quantitative and qualitative approaches in the social and behavioral sciences. Sage Publishing.

Teddlie, C., \& Yu, F. (2007). Mixed methods sampling: A typology with examples. Journal of mixed methods research,1(1), 77-100. https://doi.org/10.1177/1558689806292430

Teo T. S., srivastava, S. C., \& Jiang, L. (2008). Trust and electronic government success: an empirical study. Journal of Management Information Systems, 25(3), 99-132. https://doi.org/10.2753/MIS0742-1222250303

Terrell, S. R. (2012). Mixed-methods research methodologies. Qualitative report, 17(1), 254-280. https://eric.ed.gov/?id=EJ973044

Thomas, M. O., Wilson, A. J., Corballis, M. C., Lim, V. K., \& Yoon, C. (2010). Evidence from cognitive neuroscience for the role of graphical and algebraic representations in understanding function. ZDM, 42(6), 607-619. https://doi.org/10.1007/s11858-010-0272-7 
Thompson, A. G. (1991). The development of teachers' conceptions of mathematics teaching. Proceedings of the thirteenth annual meeting of the North American Chapter of the International Group for the Psychology of Mathematics Education (Vol. 2, pp. 8-14). Virginia Polytechnic University and State University Blacksburg.

Tok, Ş. (2010). The problems of teacher candidates about teaching skills during teaching practice. Procedia-Social and Behavioral Sciences, 2(2), 4142-4146. https://doi.org/10.1016/j.sbspro.2010.03.654

Trevisan, A. L., Ribeiro, A. J., \& da Ponte, J. P. (2020). Professional Learning Opportunities Regarding the Concept of Function in a Practice-Based Teacher Education Program. International Electronic Journal of Mathematics Education, 15(2). http://doi.org/10.29333/iejme/6256

Triangulation, D. S. (2014, September). The use of triangulation in qualitative research. Oncology nursing forum, 41(5), p. 545-547.

Tsao, Y. L. (2020). Pre-Service Elementary Teachers' Knowledge of Linear Function and Slope. US-China Education Review, 10(1), 1-11. http://doi.org/10.17265/2161-623X/2020.01.001

Ubah, I. J. A., \& Bansilal, S. (2018). Pre-service mathematics teachers' knowledge of mathematics for teaching: quadratic functions. Problems of Education in the 21st Century, 76(6), 847-863

Ünver, S. K., Özgür, Z., \& Güzel, E. B. (2020). Investigating Preservice Mathematics Teachers' pedagogical content knowledge through microteaching. REDIMAT-Journal of Research in Mathematics Education, 9(1), 62-87. http://dx.doi.org/10.17583/redimat.2020.3353

Usak, M., Ulker, R., Oztas, F. \& Terzi, I. (2013) The Eff ects of Professors' Pe dago gical Content Knowledge on Elementary Teacher Candidates' Attitude and Achievement Regarding Biology, The Anthropologist, 16(1-2), 251- 261, http://doi.org/10.1080/09720073.2013.11891353

Vecihi, S. Z. (2014). Pre-service Mathematics Teachers' Knowledge Development and Belief Change Within a Technology-Enhanced Mathematics Course. [Doctoral Dissertation, Clemson University]. https://tigerprints.clemson.edu/all_dissertations/1427

Vinner, S. (1991). The role of definitions in the teaching and learning of mathematics. In D. Tall (Ed). Advanced Mathematical Thinkning. Kluwer Academic.

Waltz, C., \& Bausell, R. B. (1983) Nursing Research: design, statistics and computer analysis. F. A. Davis Company.

Wasserman, N. H. (2017). Making sence of abstract algebra: Exploring secondary teachers' understanding of inverse functions in relation to its group structure. International Journal of Mathematical Education in Science and Technology, 19(3), 181-201.

Watson, A., Ayalon, M., \& Lerman, S. (2018). Comparison of students' understanding of functions in classes following English and Israel national curricula. Education Studies in Mathematics, 97(3), 255-272. http://doi.org/10.1007/s10649-017-9798-8 
Watson, A. \& Harel,G.(2013).The role of teachers' knowledge of functions in their teaching: A conceptual approach with illustrations from two cases. Canadian Journal of Science, Mathematics, and Technology Education, 13(2), 154-168. https://doi.org/10.1080/14926156.2013.784826

Wildgans-Lang, A., Scheuerer, S., Obersteiner, A., Fischer, F., \& Reiss, K. (2020). Analyzing prospective mathematics teachers' diagnostic processes in a simulated environment. ZDM, 1-14. http://doi.org/10.1007/s11858-020-01139$\underline{9}$

Wilkerson, T., Kerschen, K., \& Shelton, R. (2018). PreService teachers' critical connections to effective mathematical teaching practices: An instructional approach using vignettes. Action in Teacher Education, 40(4), 358-373. https://doi.org/10.1080/01626620.2018.1512430

Wilkie, K. J. (2014). Upper primary school teachers' mathematical knowledge for teaching functional thinking in algebra. Journal of Mathematics Teacher Education, 17(5), 397-428. https://doi.org/10.1007/s10857-013-9251-6

Wilson, S. M., Shulman, L. S., \& Richert, E. R. (1987). '150 different ways' of knowing: Representations of knowledge in teaching. In J. Calderhead (Ed.), Exploring teachers' thinking (pp. 104-124). Taylor and Francis.

Yavuz, İ., \& Baştürk, S. (2011). Ders kitaplarında fonksiyon kavramı: Türkiye ve Fransa örneği [The concept of function in textbooks: Turkish and the French samples]. Kastamonu Egitim Dergisi, 9(1), 199-220.

Yerushalmy, M., \& Schwartz, J. L. (1993). Seizing the opportunity to make algebra mathematically and pedagogically interesting. In T. Romberg, E. Fennema, \& T. Carpenter (Eds.), Integrating research on the graphical representation of functions (pp. 41-68). Erlbaum

Yin, R. K. (2003). Case study research: Design and methods ( ${ }^{\text {rd }}$ ed., Vol. 5). Sage Publications.

Zaslavsky, O., \& Shir, K. (2005). Students' conceptions of a mathematical definition. Journal for Research in Mathematics Education, 36(4), 317-346. http://doi.org/10.2307/300335043

You, Z. (2010). Preservice teachers' knowledge of linear functions within multiple representation modes [Doctoral dissertation, Texas A \& M University]. https://oaktrust.library.tamu.edu/bitstream/handle/1969.1/ETD-TAMU1663/YOU-DISSERTATION.pdf?sequence=1

Yvonne F., M. (2010). Doing mixed methods research pragmatically: Implications for the rediscovery of pragmatism as a research paradigm. Journal of mixed methods research, 4(1), 6-16. https://doi.org/10.1177/1558689809349691 


\section{Appendices}

\section{Appendix A}

\section{Functions survey}

Dear students

Thank you very much for taking the time to participate in this study. The findings of this study will help us to improve the teaching and learning of the topic of functions in our schools in Zambia. Thus, your responses are VERY IMPORTANT to us. It is important that you be as detailed as possible and try to write down ALL of your thoughts. Remember, I am trying to understand how you THINK about the concept of a function. So, it is important that your process for solving each problem is clearly explained in your written answers. If there is a question you cannot answer, please try to explain the difficulty you had with it.

Thank you again for taking this study seriously.

Thanks also come from my supervisor:

Professor Dr. José María Marbán Prieto of the University of Valladolid (Spain)

Sincerely,

Edgar John Sintema

Ph.D. Candidate

University of Valladolid, Spain

School of Doctoral Studies 


\section{INSTRUCTIONS}

- Write your Name, Gender, Age and Grade level on a separate answer sheet

- There are nine (9) questions in this paper. Answer all the questions showing your working in detail

- If there is a question you cannot answer, please explain the difficulty you had with it.

1. (a) (i) Define a relation in your own words as you can teach it to secondary school pupils.

(ii) Give one example of a relation.

(b) (i)Define a function in your own words as you can teach it to secondary school pupils.

(ii) Give one examples of a function

(iii) A student says he/she does not understand this definition. Give an alternate

version that might help the student understand

(c) Is there a difference between a function and a relation? Explain your view.

(d) How are functions and equations related to each other?

(e) In each of the cases below, state whether the figure represents a function or not. Justify your answers. 

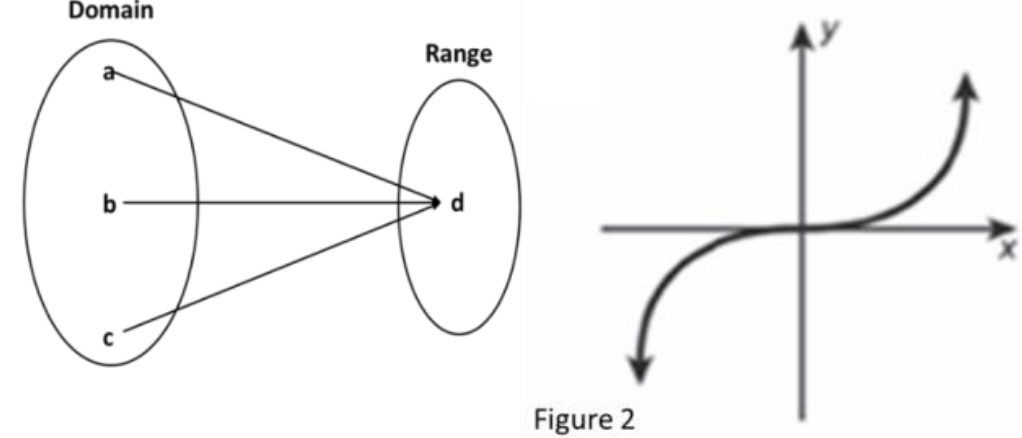

Figure 1

Figure 2
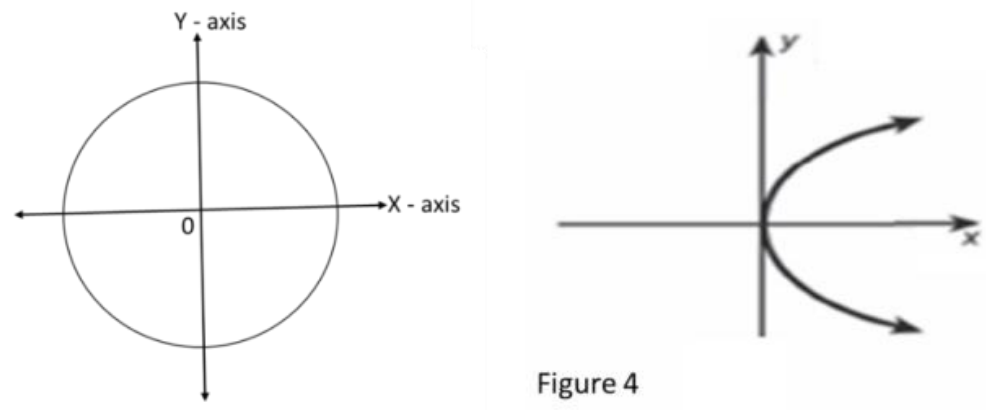

Figure 4

Figure 3

(f) Draw a graph of a function that passes through the points $\mathrm{X}$ and $\mathrm{Y}$ in the figure below.

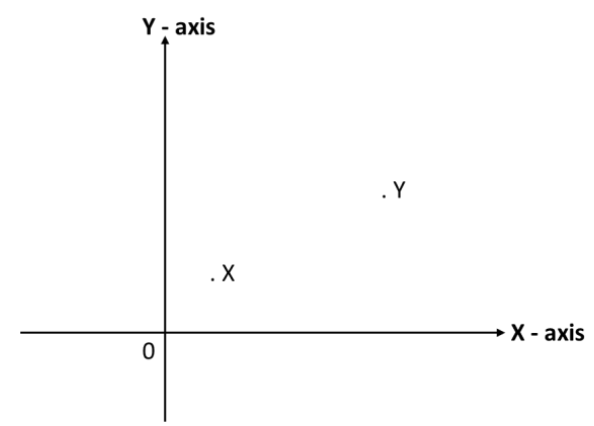

Are there other functions which pass through the points $\mathrm{X}$ and $\mathrm{Y}$ ? If yes, draw the graph of such a function. If no such other function exists, explain why.

2. (a) Represent the function $\mathrm{g}: \mathrm{x} \rightarrow$ whose domain is $\{\mathrm{x}:-3 \leq \mathrm{x} \leq 2$, and $\mathrm{x} \epsilon$ Z) on a Cartesian plane.

(b) Answer this question on a sheet of graph paper provided. The table below shows corresponding values of the objects and images of a function $f(x)=-$ $2 x^{2}-x+8$

\begin{tabular}{|c|c|c|c|c|c|c|c|c|c|}
\hline$X$ & -3 & -2 & -1 & -0.5 & 0 & 0.5 & 1 & 2 & 3 \\
\hline$f(x)$ & -7 & 2 & 7 & 8 & 8 & 7 & 5 & -2 & -13 \\
\hline
\end{tabular}


Taking $2 \mathrm{~cm}$ to represent 1 unit on the $\mathrm{x}$-axis for $-3 \leq \mathrm{x} \leq 2$ and $1 \mathrm{~cm}$ to represent 1 unit on the $y$-axis, draw the graph of $f(x)=-2 x^{2}-x+8$.

(c) Use the graph of $f(x)=-2 x^{2}-x+8$ to solve $f(x)=2$

(d) Complete the square for $f(x)=-2 x^{2}-x+8$ and hence determine the turning point of $f$.

(e) State the maximum value of $f(x)=-2 x^{2}-x+8$ and explain how this value relates to the range of the function $f$.

3. (a) Define a one-to-one function in your own words.

(b) A mathematics textbook shows the following graphs as examples of oneto-one functions:

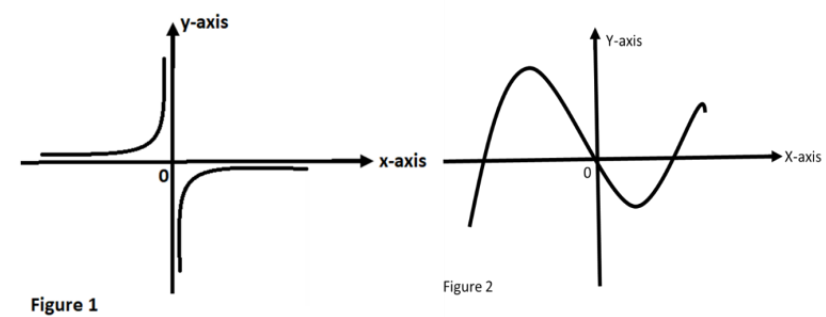

Is the textbook correct in this regard? Explain.

(c) The figure below is a graph of a function $f(x)=a x^{2}+b x+c$. state whether $\mathrm{a}, \mathrm{b}$ and $\mathrm{c}$ are positive, negative or zero. Explain your decision.

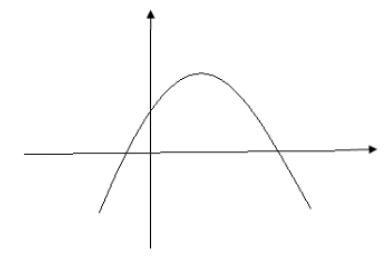

4. Let $h(x)=x^{2}+1$ for $-2 \leq \mathrm{x} \leq 2$ and $f(x)=x^{2}+1$ for $0 \leq \mathrm{x} \leq 2$.

(a) State two differences between $f$ and $h$.

(b) Define an inverse function.

(c) Find an expression for $f^{-1}(\mathrm{x})$ and specify the domain of $f^{-1}$

(d) Determine the range of $h$.

(e) Determine the relationship between the range of $h$ and the domain of $f^{-1}$.

5. Given that $g(\mathrm{x})=\frac{3}{2 \mathrm{x}+1}$ and $z: \mathrm{x} \rightarrow \mathrm{x}^{2}-2 \mathrm{x}$,

(b) Find the value of $g^{-1}(-5)$

(c) State, with justification, two domains on which the function $\mathrm{z}: \mathrm{x} \rightarrow \mathrm{x}^{2}-$ $2 \mathrm{x}$ has an inverse. 
(d) Find an expression for $(z \circ g)(\mathrm{x})$ where $z \circ g$ denotes the composite function of $z$ and $g$.

(e) Evaluate $\left(g \circ g^{-1}\right)(-5)$ where -5 belongs to the domain of $g^{-1}$.

6. Arthur, Ruth, Ian, Naomi, and Liz discussed what a function is. Read each of the students' ideas about function, and write your response to it:

- Arthur said: I see functions as input/output machines, which receive some input and give an appropriate output.

Which one of the following statements reflects your thinking about Arthur's description of functions? Mark your response and explain your choice.

$\square$ All functions fit Arthur's description.

$\square$ Some functions fit Arthur's description.

$\square$ Arthur is wrong.

Explanation:

- Ruth said: I see functions as a mapping of each element of one set to exactly one element of a second set.

Which one of the following statements reflects your thinking about Ruth's description of functions? Mark your response and explain your choice.

All functions fit Arthur's description.

Some functions fit Arthur's description.

Ruth is wrong.

Explanation:

- Ian said: Functions for me represent relations between variables.

Which one of the following statements reflects your thinking about Ian's description of functions? Mark your response and explain your choice.

$\square$ All functions fit Arthur's description.

$\square$ Some functions fit Arthur's description.

$\square$ Ian is wrong.

Explanation: 
- Naomi said: A function shows how one variable changes in relation to another variable.

Which one of the following statements reflects your thinking about Naomi's description of functions? Mark your response and explain your choice.

$\square$ All functions fit Arthur's description.

$\square$ Some functions fit Arthur's description.

$\square$ Naomi is wrong.

Explanation:

- Liz said: I see functions as expressions to calculate y-values from given $\mathrm{x}$-values. For example, $\mathrm{y}=4 \mathrm{x}+7$.

Which one of the following statements reflects your thinking about Liz's description of functions? Mark your response and explain your choice.

All functions fit Arthur's description.

Some functions fit Arthur's description.

Liz is wrong.

Explanation:

7. Could you provide a function so that its graph goes through $(0,2)$ and the value of $y$ increases as $\mathrm{x}$ increases. For example:

One student's response to this problem was as follows:

"No. To do so you would need to know another point on the graph."

(a) Is the answer correct?

(b) What do you think the student is thinking about the equation and graph?

(c) If you think the student has misconceptions with respect to the equation and graph, how would you assist this student?

8. A student is asked to give an example of a graph of a function that passes through the points A and B (See Figure 1).

The student gives the following answer (See Figure 2). 


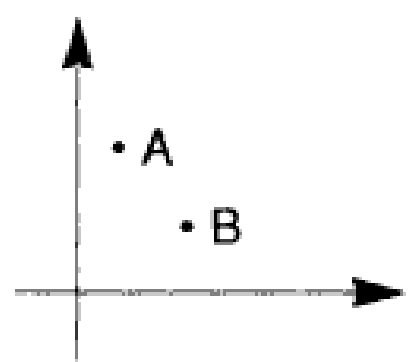

Figure 1

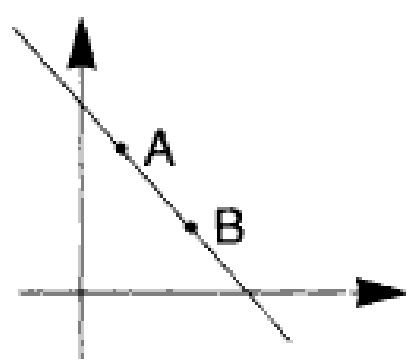

Figure 2

When asked if there is another answer the student says "No".

(a) If you think the student is right, explain why.

(b) If you think the student is wrong, how many functions which satisfy the condition can you find? Explain.

9. Consider the three figures below and answer the questions that follow.

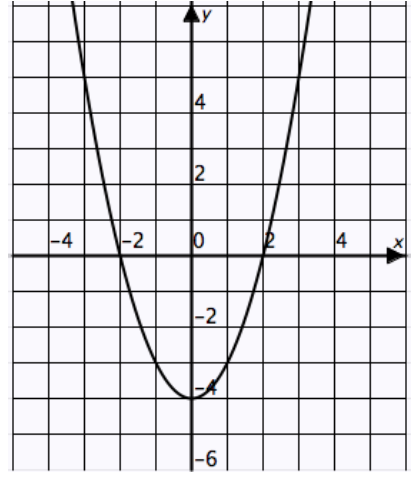

Figure A

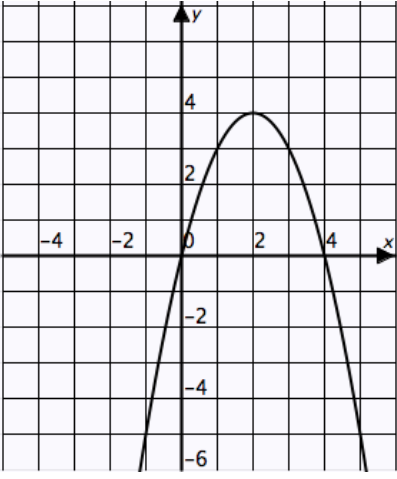

Figure B

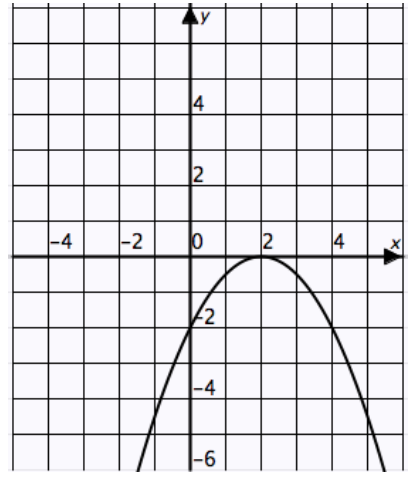

Figure $\mathrm{C}$

(a) Indicate the features that are common to graphs A and B but not to graph C.

(b) Indicate the features that are common to graphs $\mathrm{B}$ and $\mathrm{C}$ but not to graph A.

(c) Indicate the features that are common to graphs A and C but not to graph B.

Here are the three equations for the functions A, B and C. You might want to use them.

D. $\mathrm{y} \square \mathrm{x}^{2} \square 4$

E. $\mathrm{y} \square 4(\mathrm{x} \square 2)^{2}$

F. $\mathrm{y} \square \square \frac{1}{2}(\mathrm{x} \square 2)^{2}$ 


\section{Appendix B}

\section{Scale for measuring Zambian pre-service mathematics teachers' perceptions related to their pedagogical content knowledge}

Programme:

Grade:

Gender:...

University/College:.........................................................

Age:............

Indicate with a Tick $(\checkmark)$ in the corresponding box the option you believe best defines your level of competence with respect to each of the skills listed:

\begin{tabular}{|c|c|c|c|c|c|c|}
\hline & & $\sum_{\bar{z}}^{\grave{Z}}$ & 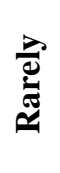 & 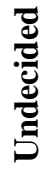 & 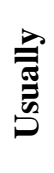 & 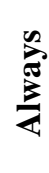 \\
\hline & Knowledge of Teaching Strategies (KTS) & 1 & 2 & 3 & 4 & 5 \\
\hline 1 & $\begin{array}{l}\text { I can design appropriate activities to present mathematical } \\
\text { concepts. }\end{array}$ & & & & & \\
\hline 2 & I can relate mathematical concepts to daily life in instruction. & & & & & \\
\hline 3 & I can use analogies to mathematical concepts in instruction. & & & & & \\
\hline & $\begin{array}{l}\text { Knowledge of Mathematical Language and Symbols } \\
\text { (KMLS) }\end{array}$ & 1 & 2 & 3 & 4 & 5 \\
\hline 4 & $\begin{array}{l}\text { I can use mathematical language properly when presenting } \\
\text { mathematical concepts. }\end{array}$ & & & & & \\
\hline 5 & I can use mathematical symbols properly. & & & & & \\
\hline & Knowledge of Misconceptions (KM) & 1 & 2 & 3 & 4 & 5 \\
\hline 6 & I can anticipate students' possible difficulties about a topic. & & & & & \\
\hline 7 & I know students' possible misconceptions about a topic. & & & & & \\
\hline 8 & $\begin{array}{l}\text { I can design activities that will not cause students to develop } \\
\text { misconceptions about the topic. }\end{array}$ & & & & & \\
\hline & Knowledge of Learners (KL) & 1 & 2 & 3 & 4 & 5 \\
\hline 9 & I know students' prior knowledge about a topic & & & & & \\
\hline 10 & $\begin{array}{l}\text { I can choose appropriate examples for students' developmental } \\
\text { levels } \\
\text { in my lessons. }\end{array}$ & & & & & \\
\hline & Knowledge of Curriculum (KC) & 1 & 2 & 3 & 4 & 5 \\
\hline 11 & $\begin{array}{l}\text { I have knowledge about the purposes of the mathematics } \\
\text { curriculum. }\end{array}$ & & & & & \\
\hline 12 & I can design a lesson plan for a topic. & & & & & \\
\hline 13 & $\begin{array}{l}\text { I plan my lessons so as to relate the purposes of the mathematics } \\
\text { curriculum with students' needs. }\end{array}$ & & & & & \\
\hline 14 & When designing my lesson plans, I consider the goals of the topic. & & & & & \\
\hline 15 & $\begin{array}{l}\text { I can use the assessment tools presented in the mathematics } \\
\text { curriculum. }\end{array}$ & & & & & \\
\hline 16 & $\begin{array}{l}\text { I can evaluate the effectiveness of the activities I use in the class } \\
\text { for } \\
\text { students' conceptual understanding. }\end{array}$ & & & & & \\
\hline 17 & $\begin{array}{l}\text { I can draw on the results of my evaluations in designing and } \\
\text { adjusting } \\
\text { the instruction. }\end{array}$ & & & & & \\
\hline
\end{tabular}




\section{Appendix C}

\section{Interview protocol}

1. Would you define a relation for me?

2. Would you define a function for me?

3. Would you shed some light on your answers to question 1(e)? As a follow up to this question consider the figures on the worksheet. Would you please tell me which of them are functions and which are not? Why?

4. What is the difference between a relation and a function?

5. Would you give one example and one non example of a function?

6. Have you ever heard about univalence of a function? Explain.

7. Would you define a one-to-one function?

8. Let us look at question 2(a). When you were asked to draw the graph of $g(x)=|x|$ for $\{\mathrm{x}:-3 \leq \mathrm{x} \leq 2, \mathrm{x}$ is an integer $\}$, you connected the plotted points. Why did you connect them?

9. In question 2(c) you were asked to use the graph of $f(\mathrm{x})=-2 \mathrm{x}^{2}-\mathrm{x}+8$ to solve $f(\mathrm{x})=2$. How would you explain the procedure involved to a student?

10. In question 2(d) you were asked to complete the square for the function $f(\mathrm{x})=$ $-2 \mathrm{x}^{2}-\mathrm{x}+8$ and to determine the turning point of $f$. How is the turning point related to completing the square of $f(\mathrm{x})=-2 \mathrm{x}^{2}-\mathrm{x}+8$ ? Is it important to teach completing the square to secondary school students? Why?

11. For the function $f(x)=a x^{2}+b x+c$ in question $3(c)$, can you shed more light why you said "a" is negative while " $b$ " and "c" can either be positive or negative? Can you extend this reasoning to other functions than quadratic functions?

12. In question 4(a) you were asked to state two differences between the functions $h(\mathrm{x})=\mathrm{x}^{2}+1$ for $-2 \leq x \leq 2$ and $f(\mathrm{x})=\mathrm{x}^{2}+1$ for $0 \leq x \leq 2$. Could you please justify your answers?

13. Would you justify your answer to question 4(e)?

14. In question 5(b) you were asked to find two domains on which the function $z: x \rightarrow x^{2}-2 x$ has an inverse. How would you explain your answer to secondary school students?

15. Is there any other way you could have approached question 5(d)? How would you explain it to your students? What is a composite function? 
16. In question 6 you were asked to comment on the views of some students concerning what they thought a function was. Would you briefly justify each of your comments?

17. Is important to teach vertical and horizontal line tests for graphs of functions to secondary school students? Why? What is the vertical line test? What is the purpose of the vertical line test? How would you teach it to secondary school students? What about the horizontal line test, explain what you know about it?

18. Would you please justify your answers to question 9 ? 


\section{APPENDIX D}

\section{Vignettes on inverse and composite functions}

\section{Vignette \#1}

You have been discussing the concept of composition of functions in the $10^{\text {th }}$ grade class. You pose the following problem in the class.

Let $h(\mathrm{x})=f[g(\mathrm{x})]$ and determine $f(\mathrm{x})$ and $g(\mathrm{x})$ if $h(\mathrm{x})=2(\mathrm{x}-5)$.

One student suggests that " $g(\mathrm{x})=\mathrm{x}-5$ and $f(\mathrm{x})=2$ ".

Another student interrupts "No $f(\mathrm{x})$ must be equal to $2 \mathrm{x}$ if $g(\mathrm{x})=\mathrm{x}-5$ ".

A third student remarks "Well I think $g(\mathrm{x})=\mathrm{x}-5$ and $f(\mathrm{x})=2 \mathrm{x}$ ".

The class seems confuse confused.

What is the problem in each solution (if there is any)?

Explain how would you respond to these comments and clear up confusion during a class. 


\section{Vignette \#2}

You have been discussing the concept of composite functions in class. You pose the following problem in class.

Determine the composite function $(f \circ g)(\mathrm{x})$ if $f(\mathrm{x})=\mathrm{x}+3$ and $g(\mathrm{x})=\mathrm{x}^{2}+6$

One student answers the problem as " $(f \circ g)(\mathrm{x})=(\mathrm{x}+3)^{2}+6$ ".

Another student answered the problem as " $(f \circ g)(\mathrm{x})=(\mathrm{x}+3)\left(\mathrm{x}^{2}+6\right)$ ".

A third student answered it as " $(f \circ g)(x)=x^{2}+9 "$.

For each of the incorrect solutions

What is the source of the mistake? (Show and explain how they may have found this solution)

Explain how would you respond to these comments and clear up confusion during a class. 


\section{Vignette \#3}

A student asked the following question. Let $\mathrm{f}(\mathrm{x})=4, \mathrm{~g}(\mathrm{x})=2$, and $\mathrm{h}(\mathrm{x})=\mathrm{x}+3$.

Evaluate the followings
a. $($ fog $)(7)$
b. $($ goh $)(x)$
c. (hof)(x)
d. (hof)(3)

Student's answer is the following:
a. $\mathrm{f}(\mathrm{x})=4$ and $\mathrm{g}(\mathrm{x})=2$ then $(\mathrm{fog})=(4.2)=8 \quad($ fog $)(7)=56$
b. $(\mathrm{goh})(\mathrm{x})=2 \mathrm{x}+3$
c. $($ hof $)(x)=7$
d. $($ hof $)(5)=32$

What is the source of the mistake? (Show and explain how they may have found this solution.) Explain how would you respond to these comments and clear up confusion during a class. 


\section{Vignette \#4}

A teacher gave the definition of the composite function and explained it on the board to his/her students. However, some of his/her students stated that they did not understand it completely. Then teacher gave the following example to the students.

In order to clean and dry our clothes in a laundry we use two machines, washing machine and dryer, respectively. Dry\&Wash(clothes)

$\operatorname{Dry}[$ Wash(clothes)]=Dry[cleaned and wet clothes]=dried and cleaned clothes Combination of these machines works can be considered as a composition of functions

What do you think of this example? Can this example cause students to misunderstand any points in the definition? If exists, please explain these points. If you were to explain the composite function by using a real life example, what will be your example? Explain how you will use it in class. 


\section{Vignette \#5}

You have been discussing the concept of inverse functions in class. You pose the following problem in class.

Determine the inverse $\left(f^{1}(\mathrm{x})\right)$ of the function $f(\mathrm{x})=\mathrm{x}-4$.

Five different solutions come out from the class.

First one is " $f^{-1}(\mathrm{x})=\frac{1}{x-4}$ "

The second one is " $f^{-1}(\mathrm{x})=\frac{1}{x}-4$ "

The second is " $f f^{-1}(\mathrm{x})=-\mathrm{x}-4$ ".

The third one is " $f^{-1}(\mathrm{x})=-\mathrm{x}+4$ ".

The last solution is " $f^{-1}(\mathrm{x})=\mathrm{x}+4$ ".

The different solutions reveal that the class is confused.

What is the problem in each solution (if there exists).

Explain how would you respond to these comments and clear up confusion during a class. 
Vignette \#6

A student said the inverse of the function $\mathrm{f}(\mathrm{x})=\mathrm{x}^{2}$ is $\mathrm{f}(\mathrm{x})=\sqrt{x}$.

Is the student right? If you think that the student is correct explain why?

If you think that the student is incorrect, explain where the error lies and how would you respond to these comments and clear up confusion during a class. 


\section{Vignette \#7}

A teacher gave the definition of the inverse function and explained it on the board to his/her students. However, some of his/her students stated that they did not understand it completely. Then teacher gave the following example to the students. If you think of school bus as a function which takes you from home to school at the morning, then the school bus that takes you back from school to home is the inverse of the first function.

- What do you think of this example?

- Can this example cause students to misunderstand any points in the definition?

- If exists, please explain these points. If you were to explain the inverse function by using a real life example, what will be your example?

- Explain how you will use it in class. 
You have been discussing the concept of inverse functions in class. You pose the following problem in class.

If $f(2 \mathrm{x}+1)=2 \mathrm{x}-1$ find $f(3 \mathrm{x})$ in terms of $f(\mathrm{x})$ and explain the steps of your solution. Then the students solved the question correctly as follows:

$$
\begin{aligned}
& \left.\begin{array}{l}
y=2 x+1 \\
x=2 y+1 \\
x-1=2 y \\
y=\frac{x-1}{2}
\end{array}\right\} f(x)=2 \cdot \frac{x-1}{2}-1=x-2 \text { then } f(3 x)=3 x-2 \\
& f(x)+2 \Rightarrow f(3 x)=f(3 x)=3(f(x)+2)+2 \Rightarrow f(3 x)=3 f(x)+4
\end{aligned}
$$

After the solution made, teacher wants from student to explain what she did in the step indicated by *. She said that "I have to get $f(x)$ so that I could calculate $f(3 x)$.

For getting $f(x)$ I made the necessary calculations as you did in our previous examples".

Furthermore, teacher wants from student to explain what she did in the $f(x)+2=x$ step. She said that "we have to single out $\mathrm{x}$ from the equation as you did in our previous examples". However, she couldn't explain what she did.

What should teacher do to make his/her students understand the case. 


\section{APPENDIX E \\ Invitation letter for the experts to participate in content validity}

Respected Scholar:

As part of my $\mathrm{PhD}$ thesis I am currently facing a content validation process of a test to assess/measure some components or sub-dimensions of Zambian Pre-Service Secondary teacher's mathematical knowledge for the teaching of functions being chosen according to their relevance to Zambian curriculum. Your assistance as an expert in Mathematics Education at this stage of the development of such an instrument is crucial and it will be sincerely appreciated. Attached to this letter you will find the following documents:

1.- Test items

2.- Instructions to grade test items.

3.- Evaluation sheet (Excel format)

4.- Constructs under consideration.

5.- A short description of Zambian mathematics curriculum related to functions since the test has been designed taking into consideration this specific context as a framework.

Thank you very much in advance for your time and help. 
APPENDIX F

\section{Coverage of the function concept in the zambian secondary school curriculum}

\begin{tabular}{lll}
\hline TOPIC & SUB TOPIC & SPECIFIC OUTCOME \\
Relations & Describe a relation \\
& Determine domain and range \\
Domain and range & Determine objects and images \\
Representation of relations & Represent relations \\
Types of relations & Identify types of relations \\
& Functions & Determine whether a relation is a function or not \\
Representation of & Represent functions \\
functions & Distinguish types of functions \\
Types of functions & Identify linear functions \\
Linear functions & Find domain, co-domain and range of one-to-one \\
& Fne-to-one functions & Functions \\
& Find the inverse of a functions \\
Inverse functions & Sketch the graph of a function and its inverse \\
Composite function & Find composite functions \\
Graphs of linear functions & Draw graphs of linear functions \\
Application & Solve problems involving linear functions
\end{tabular}




\section{APPENDIX G}

\section{Definition of dimensions}

Common Content Knowledge: Refers to knowledge that teachers use to teach mathematics in classrooms. Teachers use this knowledge domain to solve mathematical problems as prescribed in the curriculum. Teachers rely more on common content knowledge in their work of teaching. Common content knowledge is essentially concerned with defining and identification of examples and nonexamples of the concept.

Specialised Content Knowledge: This is the special form of knowledge needed by teachers to decompress and unpack concepts in such a way that the content being taught is visible to and learnable by their students. Thus, this kind of knowledge provides teachers unique mathematical understanding and reasoning which is key to making students understand and develop desired knowledge. For example, teachers must know different definitions of concepts and be able to decide the appropriate definition to use depending on context. Teachers must know alternative ways of solving mathematical problems to elicit understanding by their students.

Pedagogical Content Knowledge: In the context of my study pedagogical content knowledge basically refers to teachers' knowledge of the difficulties, conceptions, misconception and errors that their students are faced with. The teacher must be able to knowledge the thinking process of their students by merely inspecting student solutions to mathematical problems. Teachers must detect errors in student work and must identify misconceptions and conception students have about mathematical concepts. This enables teachers to develop appropriate interventions that promote understanding among their students. 


\section{APPENDIX H \\ Instructions for content validation experts}

According to the following indicators, grades and categories please rate each of the test items using the evaluation sheet.

\begin{tabular}{|c|c|c|}
\hline INDICATOR & RATING & CATEGORY \\
\hline \multirow{4}{*}{$\begin{array}{l}\text { SUFFICIENCY } \\
\text { The items that belong to } \\
\text { the same dimension } \\
\text { are enough to get the } \\
\text { measurement of this dimension. } \\
\text { Thus, this indicator applies to a } \\
\text { each group of items that } \\
\text { conforms a certain dimension } \\
\text { instead of doing it item by item. }\end{array}$} & 1. Does not meet the criteria & $\begin{array}{l}\text { Items are not enough to measure } \\
\text { the dimension }\end{array}$ \\
\hline & 2. Low Level & $\begin{array}{l}\text { Items measure some aspect of } \\
\text { the dimension but do not } \\
\text { correspond to the total } \\
\text { dimension }\end{array}$ \\
\hline & 3. Moderate level & $\begin{array}{l}\text { Some items must be increased } \\
\text { in order to evaluate the } \\
\text { dimension completely. }\end{array}$ \\
\hline & 4. High level & The items are sufficient \\
\hline \multirow{7}{*}{$\begin{array}{l}\text { CLARITY } \\
\text { The item is understood } \\
\text { easily, that is, its } \\
\text { syntactic and semantic are } \\
\text { adequate. }\end{array}$} & 1. Does not meet the criteria & The item is not clear \\
\hline & & The item requires many \\
\hline & & $\begin{array}{l}\text { modifications or a very big } \\
\text { modification in the use of the }\end{array}$ \\
\hline & 2. Low Level & words of according to their \\
\hline & & $\begin{array}{l}\text { meaning or for the arrangement } \\
\text { of same. }\end{array}$ \\
\hline & 3. Moderate level & $\begin{array}{l}\text { A very specific modification of } \\
\text { some of the terms of the item. }\end{array}$ \\
\hline & 4. High level & $\begin{array}{l}\text { The item is clear, has } \\
\text { appropriate semantics and } \\
\text { syntax. }\end{array}$ \\
\hline \multirow{4}{*}{$\begin{array}{l}\text { COHERENCE } \\
\text { The item is related logically } \\
\text { with the dimension or indicator } \\
\text { that it is } \\
\text { measuring }\end{array}$} & 1. Does not meet the criteria & $\begin{array}{l}\text { The item has no logical relation } \\
\text { to the dimension }\end{array}$ \\
\hline & 2. Low Level & $\begin{array}{l}\text { The item has a tangential } \\
\text { relationship with the dimension. }\end{array}$ \\
\hline & 3. Moderate level & $\begin{array}{l}\text { The item has a moderate } \\
\text { relationship with the dimension } \\
\text { that is measuring. }\end{array}$ \\
\hline & 4. High level & $\begin{array}{l}\text { The item is completely related } \\
\text { to the dimension that is } \\
\text { measuring }\end{array}$ \\
\hline \multirow{5}{*}{$\begin{array}{l}\text { RELEVANCE } \\
\text { The item is essential or } \\
\text { important, that is, it must } \\
\text { be included. }\end{array}$} & 1. Does not meet the criteria & $\begin{array}{l}\text { The item can be eliminated } \\
\text { without affecting the } \\
\text { measurement of the dimension }\end{array}$ \\
\hline & & The item has some relevance, \\
\hline & 2. Low Level & $\begin{array}{l}\text { but another item may be } \\
\text { including what this one } \\
\text { measures }\end{array}$ \\
\hline & 3. Moderate level & The item is relatively important. \\
\hline & 4. High level & $\begin{array}{l}\text { The item is very relevant and } \\
\text { should be included. }\end{array}$ \\
\hline
\end{tabular}


APPENDIX I

Content validation sheet for experts

EVALUATION SHEET

\begin{tabular}{|l|l|}
\hline NAME AND SURNAME & \\
\hline HIGHEST ACADEMIC QUALIFICATION & \\
\hline $\begin{array}{l}\text { MAIN AREA OF PROFESSIONAL } \\
\text { EXPERTISE }\end{array}$ & \\
\hline YEARS OF EXPERIENCE & \\
\hline CURRENT POSITION & \\
\hline INSTITUTION & \\
\hline
\end{tabular}

\begin{tabular}{|c|c|c|c|c|c|c|c|}
\hline Dimension & $\begin{array}{c}\text { Sub- } \\
\text { Dimension } \\
\end{array}$ & Item & $\begin{array}{c}\text { Sufficienc } \\
\mathrm{y}\end{array}$ & $\begin{array}{c}\text { Coheren } \\
\text { ce }\end{array}$ & $\begin{array}{c}\text { Relevan } \\
\text { ce }\end{array}$ & $\begin{array}{c}\text { Clarit } \\
\mathrm{y}\end{array}$ & $\begin{array}{c}\text { Observatio } \\
\text { ns }\end{array}$ \\
\hline \multirow{19}{*}{$\begin{array}{c}\text { Common } \\
\text { Content } \\
\text { Knowledge }\end{array}$} & \multirow{7}{*}{$\begin{array}{l}\text { Definitions of } \\
\text { relations and } \\
\text { functions }\end{array}$} & 1(a) & & & & & \\
\hline & & 2(a)(i & & & & & \\
\hline & & 2(b) & & & & & \\
\hline & & 2(e) & & & & & \\
\hline & & $4(a)$ & & & & & \\
\hline & & $5(b)$ & & & & & \\
\hline & & $8(b)$ & & & & & \\
\hline & \multirow{4}{*}{$\begin{array}{c}\text { Examples and } \\
\text { non-examples } \\
\text { of functions }\end{array}$} & 1(b) & & & & & \\
\hline & & 2(a)(ii & & & & & \\
\hline & & $2(\mathrm{e})$ & & & & & \\
\hline & & 4(b) & & & & & \\
\hline & \multirow{2}{*}{$\begin{array}{l}\text { Calculations } \\
\text { involving } \\
\text { inverse } \\
\text { functions } \\
\end{array}$} & $5(c)$ & & & & & \\
\hline & & 6(a) & & & & & \\
\hline & \multirow{4}{*}{$\begin{array}{l}\text { Calculations } \\
\text { involving } \\
\text { quadratic } \\
\text { functions }\end{array}$} & $3(\mathrm{c})$ & & & & & \\
\hline & & $3(d)$ & & & & & \\
\hline & & 3(e) & & & & & \\
\hline & & $5(d)$ & & & & & \\
\hline & \multirow{2}{*}{$\begin{array}{l}\text { Composite } \\
\text { functions }\end{array}$} & $6(c)$ & & & & & \\
\hline & & $6(d)$ & & & & & \\
\hline \multirow{5}{*}{$\begin{array}{l}\text { Specialised } \\
\text { Content } \\
\text { Knowledge }\end{array}$} & \multirow{5}{*}{$\begin{array}{l}\text { Explaining and } \\
\text { justifying } \\
\text { relationships } \\
\text { and } \\
\text { differences } \\
\text { between } \\
\text { relations and }\end{array}$} & $1(\mathrm{e})$ & & & & & \\
\hline & & 2(c) & & & & & \\
\hline & & 2(d) & & & & & \\
\hline & & $2(\mathrm{~g})$ & & & & & \\
\hline & & 4(c) & & & & & \\
\hline
\end{tabular}




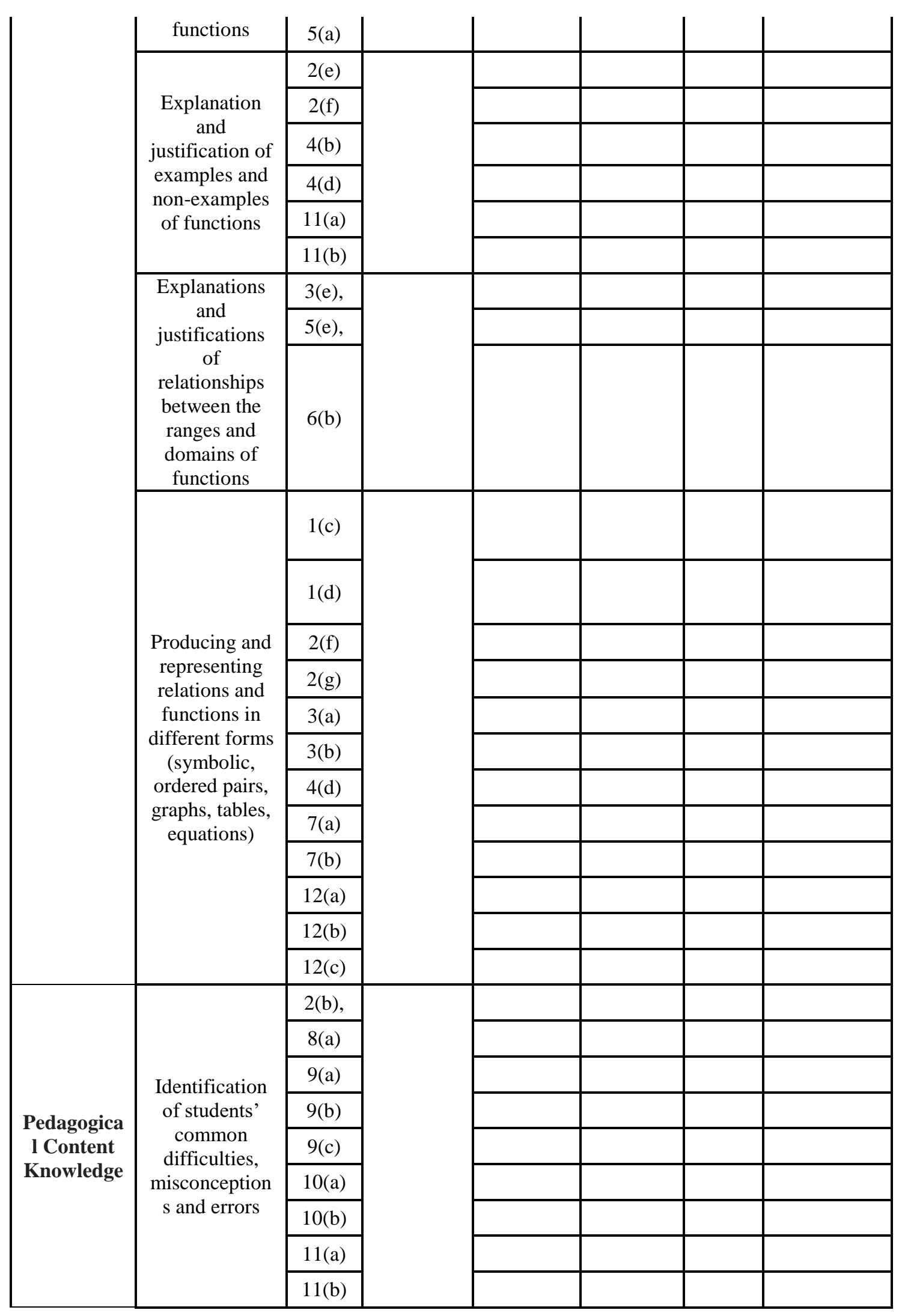




\title{
APPENDIX J
}

\section{Request for permission to conduct research}

\author{
University of Valladolid \\ School of Doctoral Studies \\ Valladolid, Spain
}

The Registrar

Dear Sir/Madam,

\section{RE: PERMISSION TO CONDUCT RESEARCH AT YOUR UNIVERSITY}

The above caption refers.

I am enrolled in a $\mathrm{PhD}$ programme in Mathematics Education at the University of Valladolid in Spain.

As part of my PhD thesis I am currently facing a data collection process of a pencil and paper mathematics test to assess/measure some components or sub-dimensions of Zambian Pre-Service Secondary teacher's mathematical knowledge for the teaching of functions being chosen according to their relevance to Zambian curriculum. I am also facing the data collection of a scale to measure pre-service mathematics teachers' perceptions related to their pedagogical content knowledge.

In order to achieve this purpose I would like to involve some of your mathematics students as participants in the data collection phase. In adhering to the ethical code of conduct as a researcher, I would like to assure your office of high confidentiality of the data to be collected from your students. Only my supervisors and I will have access to the collected data. I would also like to inform you that the data to be collected will only be used for academic purposes.

Attached herewith is a consent form. If you allow me to conduct my research at your institution please complete the attached form and sign. 
Your assistance at this stage of the development of the research instruments is crucial and will be highly appreciated.

Yours faithfully

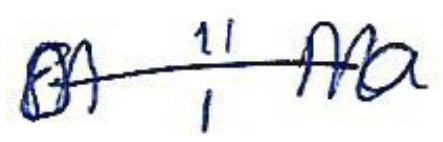

Name: Edgar John Sintema

Designation: $\mathrm{PhD}$ Student

E-mail: edgarsintema@yahoo.com 


\section{CURRICULUM VITAE}

\section{Edgar John Sintema}

Chipata Day Secondary School

P.O. Box 510510

Chipata, Zambia

Mobile: +260977 407938

Mobile: +260955 435361

Mobile: +260968435361

E-mail: edgarsintema@yahoo.com

E-mail: edgarsintema1@gmail.com

Skype ID: edgarsintema1@gmail.com

ORCiD: 0000-0002-8531-8004

Google Scholar: https://scholar.google.com/citations?user=qg6fMV0AAAJ\&hl=en

\section{EDUCATION}

- 2017: MSc in Mathematics Education, Copperbelt University, Zambia

Title of MSc Thesis: Pre-Service Primary Teachers' TPACK Profiles and Attitudes Toward Integration of ICT in Mathematics Teaching

- 2014: Bachelor of Arts with Education in Mathematics, University of Zambia, Zambia

- 2005: Secondary Teachers' Diploma in Mathematics, COSETCO, Zambia

\section{PROFESSIONAL EXPERIENCE}

- Assistant Lecturer (April 2019 - August 2020): Faculty of Education, DMI - St. Eugene University, Zambia

- Lecturer (January 2015 - December 2016): Sambizga College of Education, Zambia

- Mathematics Teacher (June 2006 - Present): Chipata Day Secondary School, Zambia

\section{JOURNAL PUBLICATIONS}

1. Marbán, J. M., \& Sintema, E. J. (2020). Pre-service secondary teachers' knowledge of the function concept: A cluster analysis approach. JRAMathEdu (Journal of Research and Advances in Mathematics Education), 5(1), 38-53. https://doi.org/10.23917/jramathedu.v5i1.9703

2. Sintema, E. J., \& Marbán, J. M. (2020). Pre-service secondary teachers' mathematical pedagogical content knowledge self-concept related to their content knowledge of functions and students. International Electronic Journal of Mathematics Education, 15(3), em0598. https://doi.org/10.29333/iejme/8327

3. Sintema, E. J. (2020). Effect of COVID-19 on the Performance of Grade 12 
Students: Implications for STEM Education. EURASIA Journal of Mathematics, Science and Technology Education, 2020, 16(7), em1851, https://doi.org/10.29333/ejmste/7893

4. Sintema, E. J. (2020). E-learning and smart revision portal for Zambian primary and secondary school learners: A digitalized virtual classroom in the COVID-19 era and beyond. Aquademia, 4(2), ep20017. https://doi.org/1029333/aquademia/8253

5. Sintema, E. J., Marban, J. M., \& Phiri, P. A. (2018). Zambian Mathematics Preservice Secondary Teachers' Knowledge of the Function Concept: Theoretical Framework and a Literature Review with Implications for Zambia. Journal of Global Research in Education and Social Sciences, 12(3), 133-147.

6. Sintema, E. J., \& Phiri, P. A. (2018). An Investigation of Zambian Mathematics Student Teachers' Technological Pedagogical Content Knowledge (TPACK). Journal of Basic and Applied Research International, 24(2), 70-77.

7. Sintema, E. J. (2018). Evolution of Pre-service Primary Teachers' TPACKMATH Profiles. Journal of Global Research in Education and Social Sciences, 11(4), 166-175.

8. Sintema, E. J. (2017). Pre-Service Primary Teachers' TPACK Profiles and Attitudes Toward Integration of ICT in Mathematics Teaching. uvadoc.uva.es

\section{CONFERENCES \& WORKSHOPS}

1. Participant: Mathematics Teaching Framework Workshop (MTF). (March, 2019), University of Witwatersrand, Johannesburg, South Africa.

2. Participant: Zambia Association for Mathematics Education National Conference (2019)

3. Oral presentation: Southern African Association for Research in Mathematics, Science and Technology Education (SAARMSTE) 2018 conference. (January 2018), Gaborone, Botswana.

4. Oral presentation: Kwame Nkrumah University Golden Jubilee International Conference, Kabwe, Zambia (September, 2018) 


\section{APPENDIX K}

\section{RESUMEN EN ESPAÑOL}

Note: The author apologizes for any linguistic inaccuracies in this appendix as a consequence of the fact that Spanish is not his mother tongue.

\section{Introducción}

El concepto de función es un concepto fundamental en el plan de estudios de matemáticas de la escuela secundaria superior y en las matemáticas universitarias avanzadas en Zambia. El concepto ayuda a los estudiantes a reconocer patrones y relaciones entre conceptos en matemáticas y campos relacionados. El conocimiento del concepto de función también ayuda a los estudiantes a mejorar sus habilidades para resolver problemas. El concepto de función ha sido identificado como uno de los temas desafiantes para los estudiantes de secundaria en Zambia. Se ha convertido en uno de los temas en los que los estudiantes obtienen malos resultados durante los exámenes nacionales (Informe ECZ, 2017). Por lo tanto, su presencia en otros temas matemáticos como la trigonometría y el cálculo lo ha convertido en uno de los temas que contribuyen al bajo rendimiento en matemáticas para los estudiantes de secundaria de Zambia.

Esta tesis, basada en un estudio explicativo secuencial, buscó examinar el conocimiento de los docentes en formación inicial del concepto de función mediante la comprensión de sus percepciones de conocimiento de contenido pedagógico matemático (MPCK) sobre las matemáticas y una comprensión profunda de su nivel de conocimiento de contenido común (CCK), conocimiento especializado de contenido (SCK) y conocimiento de contenido y estudiantes (KCS) relacionados con el concepto de función. Si bien estudios anteriores combinaron el estudio de las funciones con otros temas, este estudio se centró exclusivamente en la caracterización del conocimiento de los docentes en formación inicial del concepto de función porque "Examinar un tema específico hace más vívido el contraste entre 
algunas características clave de lo que los maestros de pre-servicio han aprendido como estudiantes y lo que necesitan saber como maestros" (Ball).

Si bien un número significativo de estudios en la literatura se han centrado en el conocimiento del contenido (SMK) en relación con el concepto de función, este estudio incluyó combinar SMK y percepciones de MPCK y KCS porque el conocimiento de la materia por si solo sin el conocimiento de los conceptos erróneos, errores y dificultades de los estudiantes no puede contribuir a una enseñanza efectiva. También, tener poca confianza (percepciones) en la enseñanza de las matemáticas puede afectar negativamente la efectividad del maestro. Por lo tanto, es esencial que el docente tenga un buen dominio de la materia y que posea un buen conocimiento de las características del estudiante porque “... para mejorar la instrucción matemática, los maestros deben desafiar y apoyar a los estudiantes y tener una buena comprensión de la brecha entre lo que los estudiantes saben y lo que necesitan aprender" (Isiksal y Cakiroglu, 2011, p. 214).

\section{Problema de investigación}

Aunque el conocimiento de la materia y las habilidades para la enseñanza son ampliamente reconocidos como un componente central de lo que los maestros necesitan dominar, el diseño del plan de estudios de educación docente en los colegios de educación y universidades parece ignorar el hecho de que los futuros maestros necesitan dominar el conocimiento de la materia y las habilidades que son específicas de su área temática para que tenga lugar una enseñanza efectiva (Frazier, 1999 y Clarke 1971) en Mulenga y Luangala (2015). Ball y McDiarmid (2010) informaron que una investigación reciente que se centró en las formas en que los maestros y los candidatos a maestros entendían las materias que enseñaban, reveló que los maestros a menudo tenían lagunas en el conocimiento y las habilidades similares a las de sus alumnos. De acuerdo con la política del Ministerio de Educación de Zambia titulada Educando nuestro futuro de 1996, la capacitación de maestros en Zambia está orientada a producir maestros que demuestren conocimiento y comprensión de sus materias de enseñanza; experiencia pedagógica adecuada y una comprensión de su papel como docentes. Por lo tanto, es cierto que todos los profesores de matemáticas en Zambia deben demostrar conocimiento de temas matemáticos en el programa de estudios y experiencia pedagógica para poder enseñar 
de manera efectiva. Uno de los conceptos matemáticos importantes que requiere que los maestros exhiban una comprensión profunda es el concepto de función.

El concepto de función es fundamental para comprender las matemáticas, aunque la comprensión de las funciones por parte de los estudiantes parece estar demasiado enfocada o incluir supuestos erróneos (Clement, 2001). El concepto es fundamental para la capacidad de los estudiantes de describir las relaciones de cambio entre variables, explicar los cambios de parámetros e interpretar y analizar gráficos. Aunque el concepto de función es importante en matemáticas, los estudios de investigación de estudiantes de secundaria y universitarios han demostrado que también es uno de los más difíciles de entender para los estudiantes (Tall 1996; Sierpinska 1992; Markovits, Eylon y Bruckheimer 1988; Dreyfus Y Eisenberg 1982). Por lo tanto, para que los maestros enseñen eficazmente un concepto (de funciones) necesitan poseer un nivel adecuado de conocimiento matemático del concepto (de una función) para proporcionar instrucción (Simon, 1993).

Aunque hay muchos estudios sobre la comprensión del concepto de función por parte de los estudiantes, se han llevado a cabo pocos estudios para evaluar la materia y el conocimiento del contenido pedagógico de los docentes en servicio relacionados con el concepto de función. En Zambia apenas hay estudios centrados en el conocimiento de la materia y el contenido pedagógico de los docentes en servicio previo del concepto de función. Esto deja a los programas de educación docente en las universidades y colegios de Zambia que carecen de una comprensión de este dominio. La falta de estudios centrados en el conocimiento del maestro de preservicio del concepto de función en Zambia ha creado una brecha en el conocimiento que este estudio busca llenar. La contribución original de este estudio al conjunto de conocimientos no solo supera la comprensión de las interacciones entre el conocimiento de la materia (SMK) y el conocimiento del contenido pedagógico matemático (MPCK) de los estudiantes docentes de Zambia, sino que también da un anticipo a los estudiantes docentes de Zambia. competencias sobre el concepto de función y formación docente en Zambia.

\section{Propósito del estudio}

El propósito de este estudio fue examinar el conocimiento de los profesores de matemáticas de secundaria en formación inicial en relación con el concepto de función. Este estudio intentó caracterizar la profundidad del conocimiento de la 
materia y el contenido pedagógico de los profesores de matemáticas en formación inicial de Zambia sobre el concepto de función.

\section{Objetivos del estudio \\ Objetivo general}

El objetivo general de este estudio fue describir el conocimiento del contenido y el nivel percibido de conocimiento pedagógico del contenido de los docentes de matemáticas de secundaria en formación inicial en relación con el concepto de función.

\section{Objetivos específicos}

1. Caracterizar la profundidad del conocimiento del contenido común de los docentes de matemáticas de secundaria en formación inicial en Zambia, así como de su conocimiento de contenido especializado y conocimiento pedagógico del contenido en relación con el concepto de función.

2. Proporcionar descripciones del conocimiento de contenido común de los docentes de matemáticas de secundaria en formación inicial en Zambia, así como de su conocimiento de contenido especializado y conocimiento pedagógico del contenido en relación con el concepto de función.

3. Proporcionar una relación comparativa del nivel de conocimiento de las funciones de los docentes zambianos de matemáticas de secundaria en formación inicial con hallazgos de estudios similares realizados en Zambia y en el extranjero.

\section{Preguntas de investigación}

Con el propósito de examinar el nivel de conocimiento de las funciones entre los docentes de matemáticas de secundaria en formación inicial de Zambia en relación con el concepto de función, el estudio buscó respuestas a las siguientes preguntas:

1. ¿Cuál es el nivel de conocimiento de las funciones entre los docentes de matemáticas de secundaria en formación inicial en Zambia? En particular:

(a) ¿Qué nivel de conocimiento de contenido común de funciones tienen?

(b) ¿Qué nivel de conocimiento de contenido especializado?

(c) ¿Cuál es su nivel de conocimiento del contenido y los estudiantes relacionados con las funciones?

(d) ¿Qué percepciones de su conocimiento pedagógico del contenido tienen? 
(e) ¿Cómo explican y justifican su razonamiento al resolver preguntas relacionadas con el concepto de función?

2. ¿Cómo se compara el nivel de conocimiento de las funciones de los docentes de matemáticas de secundaria en formación inicial de Zambia informados en la pregunta 1 con los resultados de estudios similares realizados en Zambia y en el extranjero?

\section{Breve revisión de la literatura}

Se realizó una extensa revisión de la literatura relacionada con el estudio actual. En este resumen y como parte de la revisión de la literatura, se destacan los estudios previos sobre el conocimiento de los maestros en servicio previo del concepto de una función. Este resumen también incluye una breve discusión del marco del Conocimiento de Matemáticas para la Enseñanza (MKT) (Ball et al., 2008), que fue un marco clave para este estudio y guio el marco teórico para todo el estudio.

\section{Conocimiento previo del profesorado del concepto de una función.}

Existe evidencia de investigación en la literatura sobre estudios centrados en el concepto de una función en Zambia (Malambo, 2019; Marban y Sintema, 2020; Sintema, Phiri y Marban, 2018) y en el extranjero (Even, 1992; Kontorovich, 2017; Wasserman, 2017; Ozgen, 2010; Paoletti, 2020; Ubah \& Bansilal, 2018). Los estudios que se han llevado a cabo en Zambia han investigado el conocimiento de los docentes de matemáticas en formación inicial sobre el concepto de función en una base más amplia que incluyó, entre otros, la definición de una función, representaciones cuadráticas, compuestas, inversas, uno a uno y diferentes. Los estudios en contextos fuera de Zambia se centraron en aspectos específicos del concepto de función donde los docentes de matemáticas en formación inicial tenían dificultades, y otros estudios se extendieron a las dificultades de los estudiantes de secundaria.

Se informó en estudios previos que los docentes de matemáticas en formación inicial tenían dificultades con el concepto de dominio y rango de una función (Anold, 2004; Aziz y Kurniasih, 2019; Dorko y Weber, 2014), exhibían ideas falsas y difícilmente podían definir dominio y rango. A menudo se confundieron y confundieron los dos conceptos. Esto a pesar de la evidencia de investigación que muestra que un fuerte conocimiento del dominio y el rango mejoraría su comprensión de las funciones inversas, así como las transformaciones lineales. Se descubrió que los docentes de 
matemáticas en formación inicial tenían un conocimiento débil de las funciones inversas y no podían hacer conexiones significativas entre las funciones inversas y otras funciones. Tampoco pudieron explicar suficientemente la notación utilizada para denotar funciones inversas (Even, 1992; Kontorovich, 2017; Paoletti, 2020; Wasserman, 2017).

Los docentes de matemáticas en formación inicial mostraron en investigaciones previas debilidades en su conocimiento de las funciones compuestas (Kontorovich, 2017; Ozgen, 2010). Se observó que tenían conceptos erróneos sobre la composición de funciones y podían confundir la composición de funciones con la multiplicación ordinaria de dos términos algebraicos. Esto indicaba que algunos de ellos no estaban listos para enseñar conceptos de funciones compuestas en la escuela secundaria. También se informó que su conocimiento de las funciones cuadráticas era débil (Aziz y Kurniasih, 2019; Huang y Kulm, 2012). Como resultado, no pudieron seleccionar buenas representaciones que involucraran funciones cuadráticas para los estudiantes. Su conocimiento inadecuado de este concepto afectaría su enseñanza en el futuro si no mejoraran.

Uno de los aspectos más investigados del concepto de función en relación con los docentes de matemáticas en formación inicial es su conocimiento de las diferentes representaciones del concepto de función (Aziz y Kurniasih, 2019; Dorko y Weber, 2014; Gagatsis y Shiakalli, 2004; Martínez- Planell, Gaisman y McGee, 2015). Las diferentes representaciones del concepto de función generalmente toman la forma de tablas, símbolos algebraicos, pares ordenados y representaciones gráficas. Los maestros de pre-servicio han tenido dificultades para traducir de una representación a otra y esta incapacidad para moverse con flexibilidad entre las representaciones ha sido una brecha importante en su conocimiento de las funciones. Su débil conocimiento de la flexibilidad para traducir entre diferentes representaciones no fue una de las razones por las que tenían un razonamiento matemático débil. La incapacidad para comprender las diferentes representaciones de funciones también se observó en los estudiantes de secundaria. Los estudiantes de secundaria informaron dificultades para completar tareas que implican diferentes representaciones (Elia et al., 2007; Hitt, 1998). 


\section{El marco MKT}

Utilizando el marco MKT (Figura 1), Ball y sus colegas caracterizaron el conocimiento de la materia en términos de conocimiento de contenido común, conocimiento de contenido especializado, conocimiento de contenido de horizonte. También caracterizaron el conocimiento del contenido pedagógico en términos de conocimiento de contenido y estudiantes, conocimiento de contenido y enseñanza, y conocimiento de contenido y plan de estudios. Dieron una explicación detallada de lo que significaba cada dominio de conocimiento y las características del maestro que identificarían la competencia en un dominio de conocimiento particular.

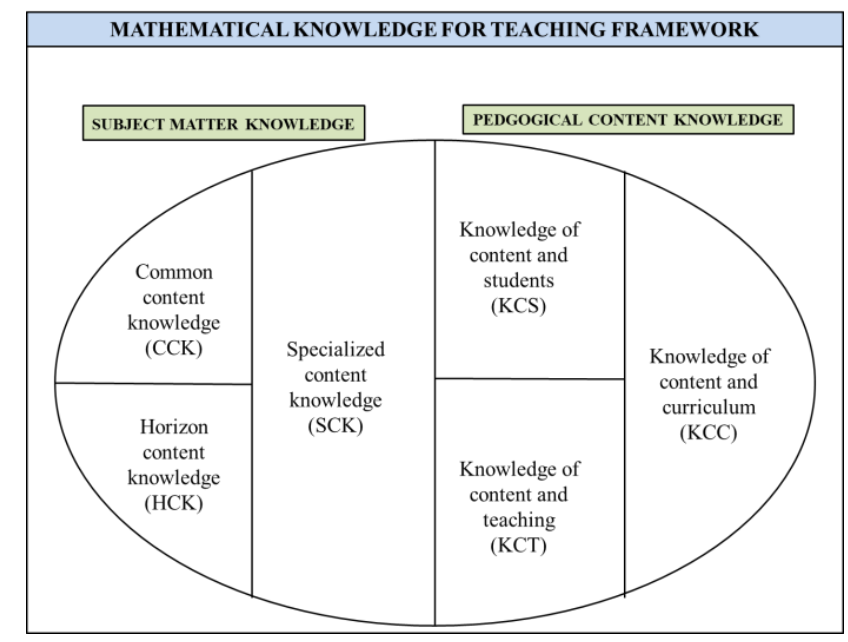

Figura 1. Conocimiento matemático para el marco de enseñanza (Ball et al., 2008)

Basado en el marco MKT (Ball, et al., 2008) y otros estudios relacionados (Nyikahadzoyi, 2015; Steele et al., 2013), se diseñó un marco conceptual para este estudio. De acuerdo con este marco, el conocimiento del docente de matemáticas en formación inicial del concepto de una función estaba compuesto por su conocimiento de la materia y su conocimiento pedagógico del contenido. Para este estudio, el conocimiento de la materia se limitó al conocimiento de contenido común y al conocimiento de contenido especializado del concepto de función. El conocimiento pedagógico del contenido, por otro lado, se limitó al conocimiento del contenido del concepto de función y los estudiantes. 


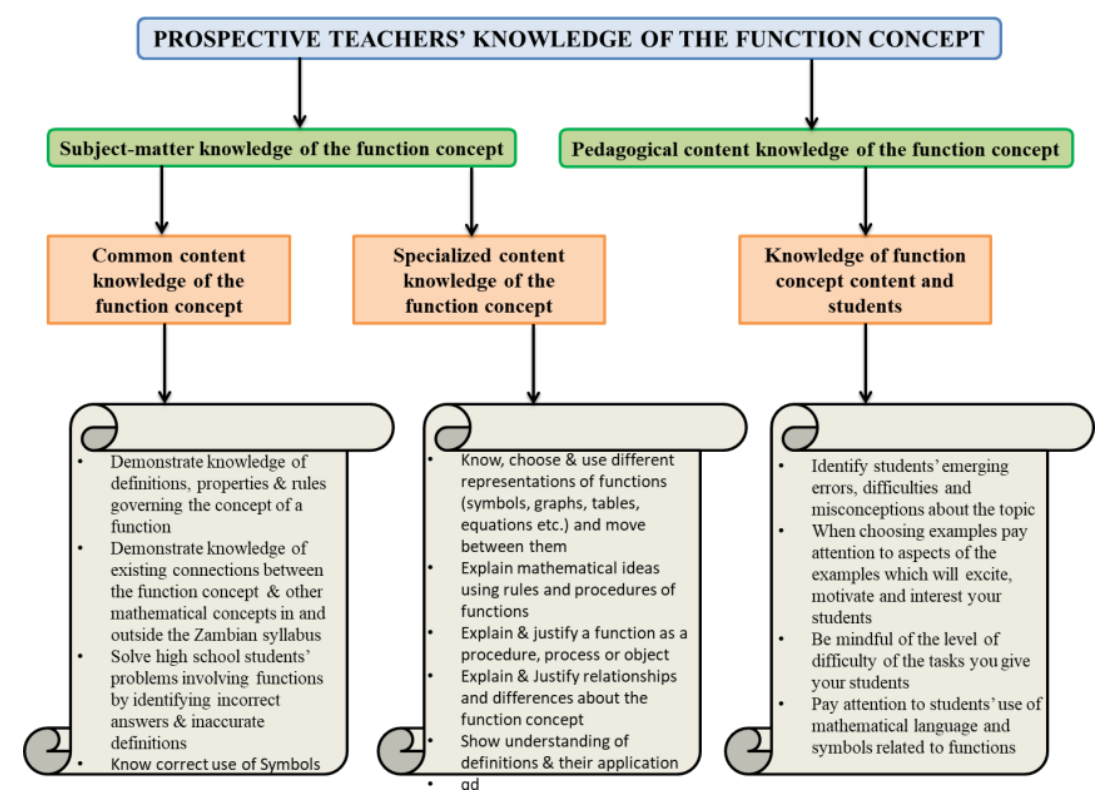

Figura 2. Marco de enseñanza para el conocimiento de los futuros profesores de matemáticas del concepto de función (adaptado de los marcos de MKT por Ball et al., 2008; Nyikahadzoyi, 2015 y Steele et al., 2013)

El conocimiento de contenido común del concepto de función se definió como la capacidad del maestro para demostrar el conocimiento de la definición del concepto de función, incluido el conocimiento de las propiedades y reglas que rigen el concepto de función. El docente también necesita demostrar conocimiento de las conexiones existentes entre el concepto de función y otros conceptos matemáticos. El docente, además, necesita demostrar su habilidad para resolver los problemas de los estudiantes de secundaria que involucran funciones mediante la identificación de respuestas correctas e incorrectas y definiciones inexactas según lo dispuesto en los libros de texto de matemáticas y otros materiales curriculares. El docente también debe mostrar dominio y conocimiento del uso correcto de los símbolos relacionados con el concepto de función y poder mostrar a los estudiantes ejemplos y ejemplos de funciones.

El conocimiento de contenido especializado del concepto de función se definió como el conocimiento del docente que es exclusivo de la enseñanza. Incluye la capacidad del docente para demostrar el conocimiento de cómo usar diferentes representaciones de funciones (símbolos, gráficos, tablas, ecuaciones, etc.) y su flexibilidad para moverse entre ellas durante la instrucción en el aula. También se supone que el docente usa su conocimiento de las propiedades, reglas y procedimientos que rigen el concepto de función para explicar ideas matemáticas relacionadas con las aplicaciones de la vida real del concepto. 
El conocimiento del contenido del concepto de función y los estudiantes se definió como la capacidad del docente para anticipar e identificar los errores emergentes, las dificultades y los conceptos erróneos relacionados con el concepto de función. El docente necesita elegir ejemplos que puedan motivar e interesar a los estudiantes y tener en cuenta el nivel de dificultad de las tareas asignadas a los estudiantes como trabajo de clase y tarea. El profesor debe prestar especial atención al uso que hacen los alumnos del lenguaje matemático y los símbolos relacionados con el concepto de función. Esto se debe a que el uso correcto del lenguaje y los símbolos mejora la comprensión de los conceptos.

\section{Metodología}

Este estudio utilizó un diseño de investigación explicativa secuencial de métodos mixtos. El objetivo del estudio era tener una comprensión holística y detallada del conocimiento de los maestros en servicio previo del concepto de función y proporcionar una explicación en profundidad sobre las preguntas del "por qué" con respecto al conocimiento del concepto de funciones de estos maestros en servicio previo. Por lo tanto, la elección del diseño explicativo secuencial de métodos mixtos fue ideal para abordar las preguntas de investigación y tener una comprensión detallada y completa del problema de investigación. Este diseño consta de dos fases dentro del mismo estudio y se "caracteriza por la recopilación y el análisis de datos cuantitativos en la primera fase de investigación, seguido por la recopilación y el análisis de datos cualitativos en la segunda fase que se basa en los resultados de los resultados cuantitativos iniciales y se usa generalmente para explicar e interpretar resultados cuantitativos mediante la recopilación y el análisis de datos cualitativos de seguimiento "(Creswell, 2017, p. 211). La estrategia explicativa secuencial puede ser muy útil si surgen resultados inesperados de un estudio cuantitativo (Morse, 1991) y, por lo tanto, los datos cualitativos de seguimiento se pueden utilizar para analizar estos sorprendentes resultados.

Este enfoque está respaldado en la literatura por varios autores que postulan que, por lo general, los datos cuantitativos y su posterior análisis proporcionan una comprensión general del problema de investigación. Los datos cualitativos y su análisis refinan y explican los resultados estadísticos explorando las opiniones de los participantes con mayor profundidad (Rossman y Wilson, 1985; Tahsakkori y Teddlie, 1998; Cresswell, 2003). Creswell (2017) propuso seis factores importantes a 
considerar al realizar un estudio secuencial de métodos mixtos, a saber: (i) justificación del diseño, (ii) recopilación de datos cuantitativos y cualitativos, (iii) prioridad para la recopilación de datos cuantitativos y cualitativos, (iv) secuencia de recopilación de datos, (v) análisis de datos coincidentes con el diseño de la investigación y (vi) proporcionar un modelo visual para el procedimiento. La representación visual del diseño de investigación explicativa secuencial de métodos mixtos para este estudio se resumió en el siguiente modelo. En la primera fase, la encuesta MPCK y una prueba de funciones se utilizaron para recopilar datos para el análisis inicial. Esto se complementó con datos recopilados a través de entrevistas semiestructuradas, viñetas y planes de lecciones en la segunda fase.

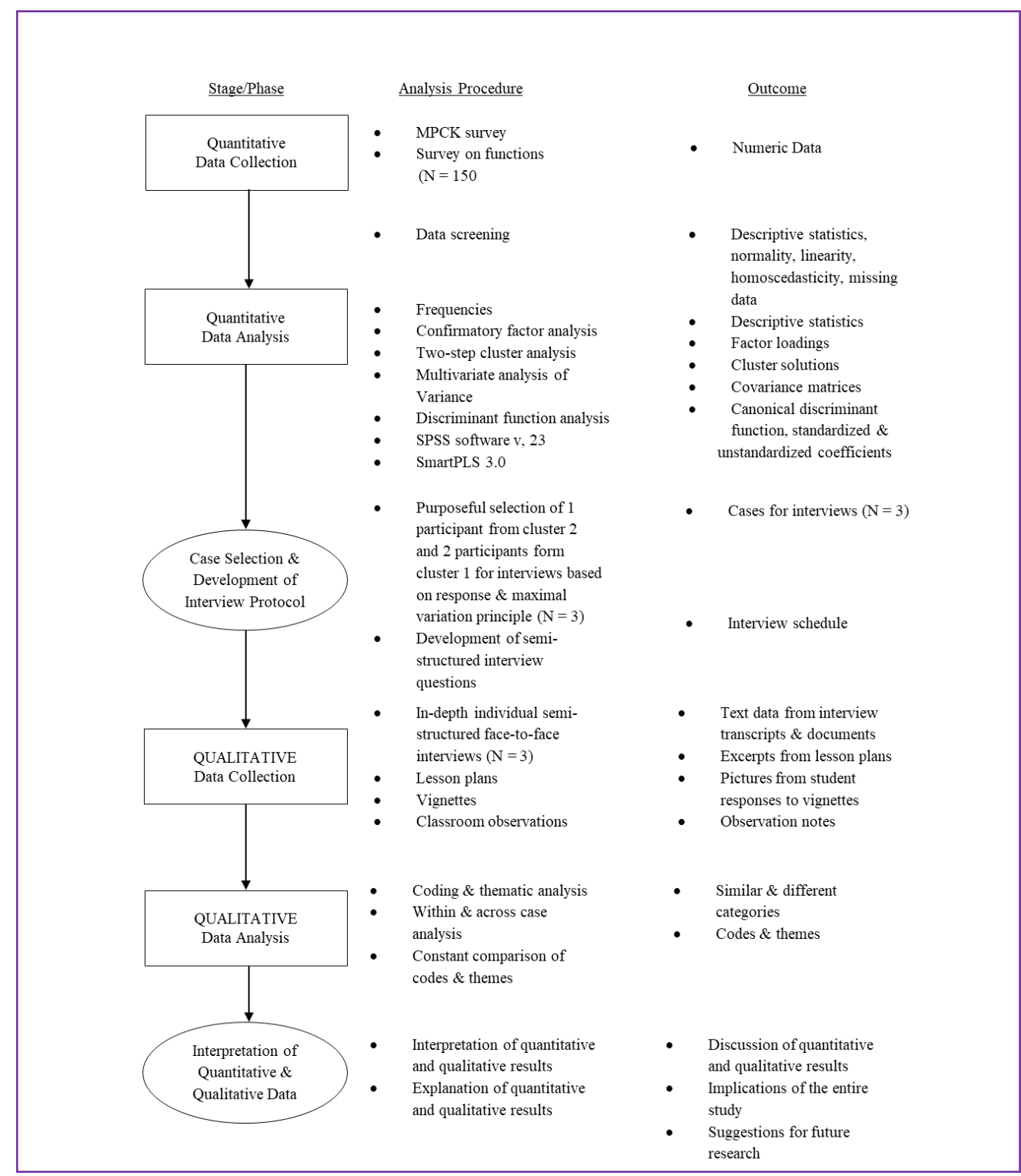

Figura 6: Una representación visual del procedimiento de diseño explicativo secuencial (adaptado de Creswell, 2017, p. 209) 


\section{Las participantes}

Para este estudio, 150 docentes en formación inicial cuya asignatura principal de estudio fueron las matemáticas participaron en la etapa de recolección de datos. Estos fueron seleccionados de una población de docentes de matemáticas de secundaria en formación inicial que cursan programas de 4 años, lo que lleva a la obtención de títulos de licenciatura en educación matemática de las universidades de Zambia. Para seleccionar a los participantes, el estudio actual utilizó un diseño de muestreo secuencial de método mixto utilizando muestras anidadas para los componentes cuantitativos y cualitativos del estudio. Según Kemper, Stringfield \& Teddlie (2003) y Johnson \& Onwuegbuzie (2004), en estudios de métodos mixtos secuenciales, a menudo se requiere información de la primera muestra (derivada de los procedimientos de muestreo probabilístico) para extraer la segunda muestra (derivada de procedimientos de muestreo intencional).

Para la Fase 1 del estudio, el muestreo de conglomerados se usó para seleccionar universidades (conglomerados) de las cuales se seleccionó a los participantes para participar en la encuesta de conocimiento pedagógico de contenido matemático (MPCK) y en la encuesta de concepto de funciones en forma de papel y lápiz. Los participantes fueron elegidos utilizando técnicas de muestreo convenientes para participar tanto en la encuesta MPCK como en la prueba de funciones. El muestreo de conveniencia es un método no probabilístico que se caracteriza por la elección de los participantes que están disponibles, son fáciles de obtener y están dispuestos a participar en el estudio (Gravetter y Forzano, 2012) en Malambo, 2015.

La Fase 2 constituía una sub-muestra de tres docentes de matemáticas en formación inicial seleccionados deliberadamente de entre los que participaron en la Fase 1. Una muestra intencional fue típicamente diseñada para elegir un pequeño número de casos que arrojarían la mayor cantidad de información sobre los hallazgos estadísticos de la Fase 1 Esto se debió a que tenía el potencial de conducir a una mayor profundidad de información de un número menor de casos cuidadosamente seleccionados. Por lo tanto, se adapta a esta fase de este estudio. Se utilizó el criterio de selección que se basa en la estrategia de muestreo de casos extremos (Creswell, 2012). Según Teddlie \& Yu (2007, p. 81), "muestreo de casos extremos o desviados, ... también conocido como" muestreo atípico "... implica seleccionar casos cerca de los" extremos "de la distribución de casos de interés. 


\section{Instrumentos}

Para lograr el propósito del estudio, se utilizaron seis instrumentos para recopilar datos para este estudio: la encuesta MPCK, la encuesta de funciones, viñetas sobre funciones inversas y compuestas, protocolo de entrevista, planes de lecciones y hojas de observación en el aula. La encuesta MPCK fue adaptada de Bukova-Guzel et al., (2013). Esta era una escala Likert con cinco factores: conocimiento de estrategias de enseñanza (KTS), conocimiento de lenguaje y símbolos matemáticos (KMLS), conocimiento de conceptos erróneos (KM), conocimiento de los estudiantes (KL) y conocimiento del plan de estudios (KC). La encuesta de funciones comprendió 35 ítems distribuidos en 9 preguntas utilizadas en estudios anteriores (Even, 1990, 1993; Malambo, 2016; Watson et al., 2018; You, 2006). Ocho viñetas fueron adaptadas de estudios previos (Ebert, 1994; Karahasan, 2010), todos estos instrumentos fueron ampliamente validados. Los planes de lecciones utilizados fueron adoptados de la escuela donde los participantes realizaban su práctica docente. El protocolo de la entrevista fue diseñado por el autor.

\section{Análisis de los datos}

\section{Análisis de datos cuantitativos.}

Para analizar los datos cuantitativos, se usó el paquete estadístico para ciencias sociales (SPSS) versión 23 para realizar un análisis de conglomerados de dos pasos para la categorización de los participantes en grupos según su CCK, SCK y KCS. También se realizó un análisis de varianza multivariado unidireccional seguido de un análisis de función discriminante. También se realizó un análisis factorial confirmatorio utilizando Smart-PLS versión 3.0 para obtener índices de ajuste de la escala MPCK adaptada.

\section{Análisis de datos cualitativos}

Los datos recopilados mediante la prueba de funciones, viñetas y planes de lecciones se analizaron utilizando un marco adaptado de Ebert (1993) que utilizó para evaluar el conocimiento de la materia y el contenido pedagógico de los docentes en servicio relacionado con el concepto de función y los gráficos. La Tabla 15 muestra un resumen de la caracterización del conocimiento de contenido común de los maestros en servicio y sus niveles de conocimiento de contenido especializado del concepto de función. 
Table 34. Framework for analysing pre-service teachers' CCK and SCK

\begin{tabular}{|c|c|c|}
\hline \multirow[b]{2}{*}{ Level } & \multicolumn{2}{|c|}{ Key features } \\
\hline & $\begin{array}{l}\text { Common content knowledge of } \\
\text { functions }\end{array}$ & $\begin{array}{l}\text { Specialized content knowledge of } \\
\text { functions }\end{array}$ \\
\hline \multirow{5}{*}{$\begin{array}{l}\text { Level } 0 \\
\text { Inadequate }\end{array}$} & $\begin{array}{l}\text { Not able to demonstrate knowledge of } \\
\text { definitions, properties \& rules } \\
\text { governing the concept of a function }\end{array}$ & $\begin{array}{l}\text { Have difficulties in explaining } \\
\text { mathematical ideas using rules } \\
\text { and procedures of functions }\end{array}$ \\
\hline & $\begin{array}{l}\text { Not able to demonstrate knowledge of } \\
\text { existing connections between the } \\
\text { function concept and other } \\
\text { mathematical concepts }\end{array}$ & $\begin{array}{l}\text { - Have difficulties in explaining and } \\
\text { justifying a function as a } \\
\text { procedure, process and object }\end{array}$ \\
\hline & $\begin{array}{l}\text { - Have difficulties to solve high school } \\
\text { students' problems involving functions } \\
\text { by failing to identify incorrect answers } \\
\text { and inaccurate definitions }\end{array}$ & $\begin{array}{l}\text { - Have difficulties in explaining and } \\
\text { justifying relationships and } \\
\text { differences about the function } \\
\text { concept }\end{array}$ \\
\hline & $\begin{array}{l}\text { Have difficulties to know and explain } \\
\text { correct use of symbols (notation) to } \\
\text { students }\end{array}$ & $\begin{array}{l}\text { Show little understanding of } \\
\text { definitions of a function and their } \\
\text { applications }\end{array}$ \\
\hline & & $\begin{array}{l}\text { - Have difficulties to choose and use } \\
\text { different representations of } \\
\text { functions (symbols, graphs, tables, } \\
\text { equations etc.) and move between } \\
\text { them }\end{array}$ \\
\hline \multirow{5}{*}{$\begin{array}{l}\text { Level } 1 \\
\text { Good }\end{array}$} & $\begin{array}{l}\text { Show knowledge of definitions, } \\
\text { properties \& rules governing the } \\
\text { concept of a function }\end{array}$ & $\begin{array}{l}\text { Explain mathematical ides using } \\
\text { rules and procedures of functions }\end{array}$ \\
\hline & $\begin{array}{l}\text { - Show knowledge of existing } \\
\text { connections between the function } \\
\text { concept and other mathematical } \\
\text { concepts }\end{array}$ & $\begin{array}{l}\text { Explain and justify a function as a } \\
\text { procedure, process and object }\end{array}$ \\
\hline & $\begin{array}{l}\text { - Solve high school students' problems } \\
\text { involving functions by identifying } \\
\text { incorrect answers and inaccurate } \\
\text { definitions }\end{array}$ & $\begin{array}{l}\text { Explain and justify relationships } \\
\text { and differences about the function } \\
\text { concept }\end{array}$ \\
\hline & $\begin{array}{l}\text { Know and explain correct use of } \\
\text { symbols (notation) to students }\end{array}$ & $\begin{array}{l}\text { - Show understanding of definitions } \\
\text { of a function and their applications }\end{array}$ \\
\hline & & $\begin{array}{l}\text { - Know, choose and use different } \\
\text { representations of functions } \\
\text { (symbols, graphs, tables, equations } \\
\text { etc.) and move between them }\end{array}$ \\
\hline Level 2 & $\begin{array}{l}\text { Demonstrate and apply knowledge of } \\
\text { definitions, properties \& rules } \\
\text { governing the concept of a function to } \\
\text { different situations }\end{array}$ & $\begin{array}{l}\text { Explain mathematical ides using } \\
\text { rules and procedures of functions }\end{array}$ \\
\hline Strong & $\begin{array}{l}\text { - Demonstrate and apply knowledge of } \\
\text { existing connections between the } \\
\text { function concept and other } \\
\text { mathematical concepts to different } \\
\text { situations }\end{array}$ & $\begin{array}{l}\text { Explain and justify a function as a } \\
\text { procedure, process and object }\end{array}$ \\
\hline
\end{tabular}


- Solve high school students' problems involving functions by identifying and diagnosing incorrect answers and inaccurate definitions

- Know, explain and justify correct use of symbols (notation)
- Explain and justify relationships and differences about the function concept

- $\quad$ Show understanding of definitions of a function and their applications

- Know, choose and use different representations of functions (symbols, graphs, tables, equations etc.) and move between them

En la Tabla 16 se muestra un resumen de la caracterización del conocimiento de los maestros de pre-servicio sobre el contenido de las funciones y los estudiantes.

Table 35. Framework for analysing pre-service teachers' KCS

Level Knowledge of functions content and students

- Have difficulties in identifying students' emerging errors, difficulties and misconceptions about the function concept

- Find difficulties to diagnose students' emerging errors and misconceptions about the function concept

Level 0 - When choosing examples, not able to pay attention to aspects of the examples that will excite, motivate and interest the students

- Not able to mind the level of difficulty of the tasks that you assign to students

- Not able to pay attention to students' use of mathematical language and symbols related to functions

- Identify students' emerging errors, difficulties and misconceptions about the function concept

- When choosing examples partially pay attention to aspects of the examples that will

Level 1 excite, motivate and interest the students

- Partially mindful of the level of difficulty of the tasks that you assign to students

- Partially able to pay attention to students' use of mathematical language and symbols related to functions

- Able to easily identify and diagnose students' emerging errors, difficulties and misconceptions about the function concept

Level 2

- Able to easily diagnose students' emerging errors and misconceptions about the function concept

- Able pay attention to aspects of the examples that will excite, motivate and interest the students when choosing examples during lesson preparation 
- Able to be mindful of the level of difficulty of the tasks that you assign to students

- Pay attention to students' use of mathematical language and symbols related to functions

\section{Resultados importantes}

Esta sección destaca algunos de los resultados obtenidos de la investigación. La presentación se ha dividido en dos partes. La primera parte presenta resultados cuantitativos de la encuesta MPCK y la encuesta de funciones, mientras que la segunda presenta resultados cualitativos obtenidos principalmente de viñetas, encuestas de funciones y entrevistas.

\section{RESULTADOS CUANTITATIVOS}

\section{Resultados de MPCK}

Table 4. Cluster profiles: Centroids

\begin{tabular}{|c|c|c|c|c|c|c|c|c|c|c|c|c|c|}
\hline & & \multicolumn{2}{|c|}{ KTS } & \multicolumn{2}{|c|}{ KMLS } & \multicolumn{2}{|c|}{$\mathbf{K M}$} & \multicolumn{2}{|c|}{ KL } & \multicolumn{2}{|c|}{ KC } & \multicolumn{2}{|c|}{$\begin{array}{c}\text { TEST } \\
\text { SCORE }\end{array}$} \\
\hline & & Mean & $\begin{array}{l}\text { Std. } \\
\text { Dev. }\end{array}$ & Mean & $\begin{array}{l}\text { Std. } \\
\text { Dev. }\end{array}$ & Mean & $\begin{array}{l}\text { Std. } \\
\text { Dev. }\end{array}$ & Mean & $\begin{array}{l}\text { Std. } \\
\text { Dev. }\end{array}$ & Mean & $\begin{array}{l}\text { Std. } \\
\text { Dev. }\end{array}$ & Mean & $\begin{array}{l}\text { Std. } \\
\text { Dev. }\end{array}$ \\
\hline \multirow{2}{*}{ Cluster } & 1 & 3.48 & .89 & 3.82 & .98 & 3.48 & .92 & 3.44 & .83 & 3.83 & .72 & 41.23 & 10.56 \\
\hline & 2 & 4.35 & .60 & 4.70 & .35 & 4.34 & .49 & 4.50 & .49 & 4.49 & .39 & 55.80 & 14.73 \\
\hline
\end{tabular}

La Tabla 4 muestra los perfiles de grupo de los docentes de matemáticas en formación inicial de Zambia basados en sus factores de Conocimiento del Contenido Pedagógico Matemático (MPCK) y los resultados de la prueba de lápiz y papel sobre el concepto de una función. Los factores MPCK que se usaron para formar los grupos son Conocimiento de estrategias de enseñanza (KTS), Conocimiento de lenguaje y símbolos matemáticos (KMLS), Conocimiento de conceptos erróneos (KM), Conocimiento de los estudiantes (KL) y Conocimiento del plan de estudios $(\mathrm{KC})$.

El grupo 1 está compuesto básicamente por docentes de matemáticas en formación inicial con bajos niveles de conocimiento en todos los factores MPCK en comparación con sus contrapartes en el grupo 2. Los docentes de matemáticas en formación inicial en el Grupo 1 también se desempeñaron por debajo del promedio en la prueba de rendimiento en funciones que publican un rendimiento medio de 
41.23\% con una desviación estándar de 10.56. los del Grupo 2 registraron un rendimiento medio del 55,80\% con una desviación estándar de 14,73. Se está construyendo una imagen global muy interesante a partir de estos resultados iniciales.

Los docentes de matemáticas en formación inicial que desempeñaron por debajo del promedio en la prueba de rendimiento también registraron puntuaciones más bajas en sus factores de Conocimiento de Contenido Pedagógico Matemático (MPCK). Esto implica que los docentes de matemáticas en formación inicial con bajo rendimiento en la materia tienen más probabilidades de experimentar dificultades en la enseñanza en el aula porque también han exhibido bajos niveles de habilidades de conocimiento del contenido pedagógico matemático. El análisis de correlación de momento principal de Pearson (Tabla 6) ha revelado correlaciones significativas entre los factores de Conocimiento Pedagógico de Contenido (MPCK) y el rendimiento en la prueba de rendimiento. Los estudiantes que obtuvieron un puntaje alto en la prueba de rendimiento también publicaron altas habilidades de MPCK. Estos son maestros de pre-servicio que probablemente tengan una alta autoestima durante sus interacciones con los estudiantes en sus futuras clases.

Table 6. Correlations between factors

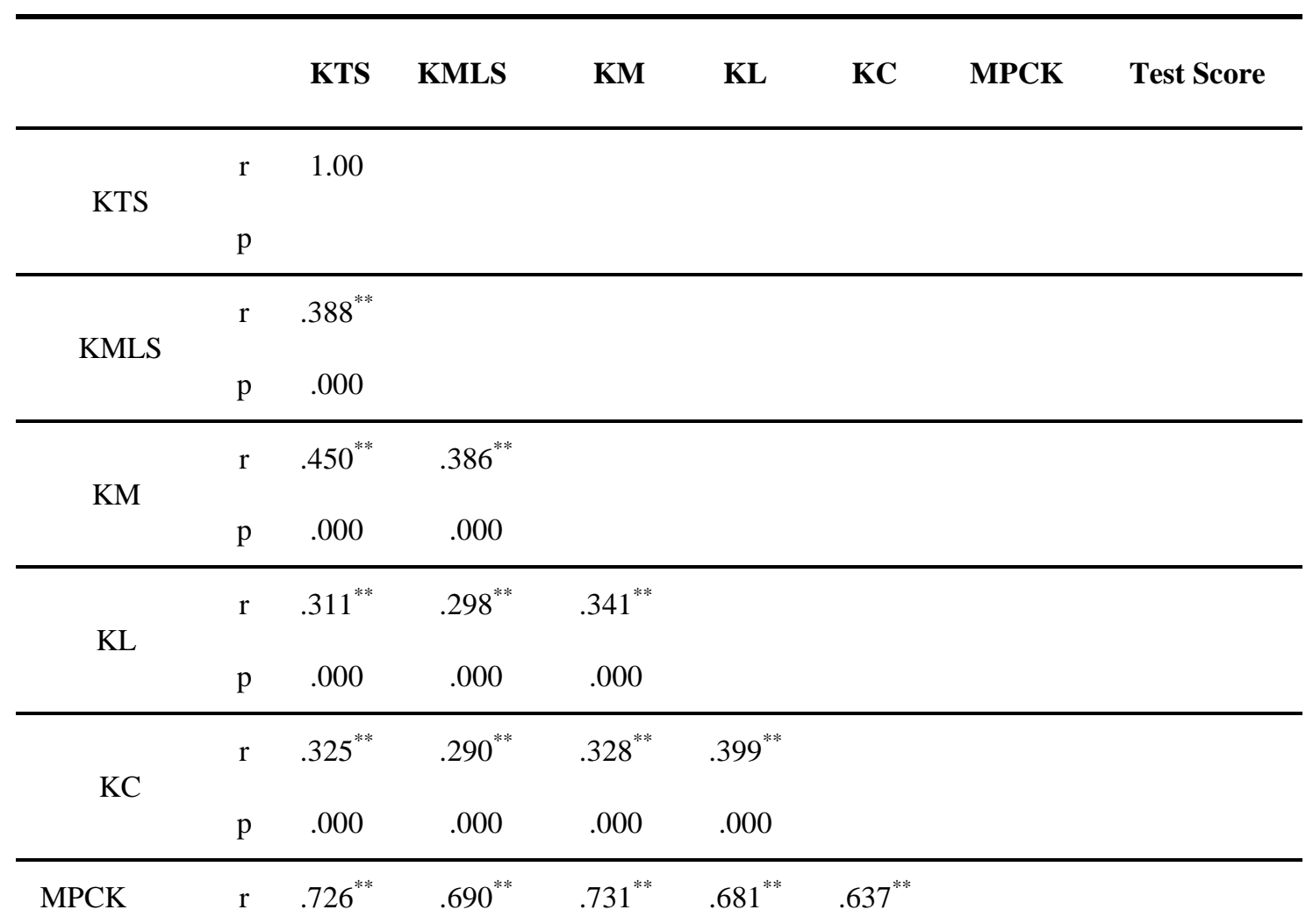




\begin{tabular}{|c|c|c|c|c|c|c|c|c|}
\hline & $\mathrm{p}$ & .000 & .000 & .000 & .000 & .000 & & \\
\hline \multirow{2}{*}{ Test Score } & $\mathrm{r}$ & .134 & $.291^{* *}$ & $.196^{*}$ & $.380^{* * *}$ & $.318^{* *}$ & $.375^{* *}$ & 1.00 \\
\hline & $\mathrm{p}$ & .103 & .000 & .016 & .000 & .000 & .000 & \\
\hline
\end{tabular}

$* * \mathbf{p} \leq 0.01$ (2-tailed).

$* \mathbf{p} \leq 0.05$ (2-tailed).

La Tabla 6 muestra los resultados del análisis de correlación producto-momento de Pearson. Este análisis se realizó para examinar la relación entre los subfactores MPCK y los puntajes de las pruebas de los maestros de matemáticas de pre-servicio de secundaria. Como se muestra en la Tabla 6, hubo una correlación positiva significativa entre KMLS, KM, KL, KC y los puntajes obtenidos de las funciones lápiz y papel. Aunque estas correlaciones fueron positivamente significativas, KMLS $(\mathrm{r}=.291, \mathrm{p}=.000)$ y $\mathrm{KM}(\mathrm{r}=.196, \mathrm{p}=.016)$ publicaron correlaciones débiles con los puntajes de las pruebas, mientras que $\mathrm{KL}(\mathrm{r}=.380, \mathrm{p}=.000)$ y $\mathrm{KC}(\mathrm{r}=.318, \mathrm{p}=$ .000) se correlacionaron moderadamente con los puntajes de las pruebas. Esto implica que los docentes de matemáticas en formación inicial con un alto concepto de MPCK se desempeñaron mejor en las funciones de prueba de lápiz y papel que aquellos con un bajo concepto de MPCK. Sin embargo, la correlación entre KTS (r = $.134, \mathrm{p}=.103)$ y la puntuación de la prueba no fue significativa. Esto implica que el nivel de KTS no estaba relacionado con el rendimiento en matemáticas. Por lo tanto, si un docente de matemáticas en formación inicial tenía un alto nivel de KTS, no necesariamente significa que su conocimiento del concepto de función sería alto.

\section{Resultados de la encuesta de funciones}

Tabla 8. Perfiles de conocimiento de futuros profesores de matemáticas de Zambia basados en sus CCK, SCK y KCS

\begin{tabular}{|c|c|c|c|c|c|c|c|c|}
\hline \multirow{2}{*}{ Dimension } & \multicolumn{2}{|c|}{ Mean } & \multicolumn{2}{|c|}{ Minimum } & \multicolumn{2}{|c|}{ Maximum } & \multicolumn{2}{|c|}{ Std } \\
\hline & $\begin{array}{c}\text { Cluster } \\
1\end{array}$ & $\begin{array}{c}\text { Cluster } \\
2\end{array}$ & $\begin{array}{c}\text { Cluster } \\
1\end{array}$ & $\begin{array}{c}\text { Cluster } \\
2\end{array}$ & $\begin{array}{c}\text { Cluster } \\
1\end{array}$ & $\begin{array}{c}\text { Cluster } \\
2\end{array}$ & $\begin{array}{c}\text { Cluster } \\
1\end{array}$ & $\begin{array}{c}\text { Cluster } \\
2\end{array}$ \\
\hline CCK & 14.83 & 23.14 & 7 & 12 & 24 & 35 & 3.75 & 5.64 \\
\hline SCK & 11.90 & 17.56 & 0 & 11 & 18 & 26 & 3.62 & 4.38 \\
\hline KCS & 11.85 & 16.65 & 6 & 11 & 18 & 25 & 2.63 & 3.80 \\
\hline
\end{tabular}


La Tabla 8 muestra los puntajes mínimos y máximos para cada dominio de conocimiento por grupo. La puntuación mínima de CCK para los dos grupos fue del 7\% (grupo 1), mientras que la puntuación máxima de CCK fue del 35\% (grupo 2). En cuanto a SCK, el grupo 1 registró el puntaje mínimo de $0 \%$ mientras que el $26 \%$ fue el puntaje máximo del grupo 2. El puntaje mínimo de KCS fue del 6\% (grupo 1) mientras que el puntaje máximo de KCS fue del 25\% (grupo 2).

Tabla 9. Perfiles de rendimiento de futuros profesores de matemáticas por conglomerado para las construcciones de dominios de conocimiento

\begin{tabular}{ccccccccc}
\hline & \multicolumn{2}{c}{ Mean } & \multicolumn{2}{c}{ Minimum } & \multicolumn{2}{c}{ Maximum } & \multicolumn{2}{c}{ Std } \\
\cline { 2 - 9 } Sub-Dimension & $\begin{array}{c}\text { Cluster } \\
1\end{array}$ & $\begin{array}{c}\text { Cluster } \\
2\end{array}$ & $\begin{array}{c}\text { Cluster } \\
1\end{array}$ & $\begin{array}{c}\text { Cluster } \\
2\end{array}$ & $\begin{array}{c}\text { Cluster } \\
1\end{array}$ & $\begin{array}{c}\text { Cluster } \\
2\end{array}$ & $\begin{array}{c}\text { Cluster } \\
1\end{array}$ & $\begin{array}{c}\text { Cluster } \\
2\end{array}$ \\
\hline KDRF & 5.66 & 7.15 & 2 & 4 & 8 & 10 & 1.79 & 1.32 \\
KASERF & 2.38 & 3.55 & 1 & 2 & 4 & 6 & .88 & 1.16 \\
CIQCF & 6.79 & 12.44 & 4 & 5 & 13 & 19 & 1.68 & 4.29 \\
EJRDRF & 3.65 & 4.15 & 0 & 2 & 6 & 6 & 0.93 & 1.01 \\
EJEF & 1.10 & 2.26 & 0 & 0 & 3 & 5 & .45 & 1.38 \\
EJRRDF & 1.65 & 3.56 & 0 & 0 & 4 & 6 & 1.27 & 1.31 \\
KDRRF & 6.65 & 10.65 & 0 & 4 & 10 & 17 & 2.26 & 3.72 \\
KSDME & 11.85 & 16.65 & 6 & 11 & 18 & 25 & 2.63 & 3.80 \\
\hline
\end{tabular}

CCK se analizó en términos del conocimiento del docente sobre definiciones de relaciones y funciones (KDRF), cálculos que involucran funciones inversas, cuadráticas y compuestas (CIQCF) y el conocimiento del maestro sobre la selección apropiada de ejemplos y no ejemplos de relaciones y funciones (KASERF). Los futuros docentes del grupo 2 obtuvieron mejores resultados que los del grupo 1 en términos de KDRF, CIQCF y KASERF. Se registró una puntuación máxima del 19\% (CIQCF) y una puntuación mínima del 1\% (KASERF) para los grupos 2 y 1 respectivamente.

SCK se analizó en términos de diferentes representaciones de relaciones y funciones (KDRRF), explicaciones y justificaciones de relaciones entre los rangos y dominios de funciones (EJRRDF), explicación y justificación de ejemplos y no ejemplos de 
funciones (EJEF) y explicando y justificando relaciones y diferencias entre relaciones y funciones (EJRDRF). Ambos grupos 1 y 2 registraron una puntuación mínima de 0\% en EJEF y EJRRDF. 17\% (KDRRF) fue el máximo para los cuatro subdimensiones de SCK. KCS fue analizado en términos de conocimiento de las dificultades, conceptos erróneos y errores de los estudiantes (KSDME). La puntuación máxima de KSDME fue del 25\%, mientras que la mínima fue del $6 \%$.

Para comprender mejor el conocimiento de los futuros docentes sobre el concepto de función, realizamos un análisis de varianza multivariado (MANOVA) unidireccional entre asignaturas y un análisis de función discriminante de seguimiento (DFA) al MANOVA significativo. En la prueba MANOVA, los grupos derivados del procedimiento de análisis de grupos de dos pasos formaron la variable independiente, mientras que los tres dominios de conocimiento MKT CCK, SCK y KCS fueron las variables dependientes. El nivel de significancia de .05 se estableció a priori para el análisis. La comparación del desempeño de los futuros docentes en los dominios de conocimiento CCK, SCK y KCS en los grupos significaba su conocimiento del concepto de función.

Tabla 10. Entre los niveles de efectos de agrupación del futuro conocimiento de los profesores de matemática secundaria del concepto de función

\begin{tabular}{ccccccc}
\hline Group & $\begin{array}{c}\text { Test } \\
\text { factor }\end{array}$ & Df & $\begin{array}{c}\text { Mean } \\
\text { square }\end{array}$ & F & sig & $\begin{array}{c}\text { Observed } \\
\text { power }\end{array}$ \\
\hline & CCK & 1 & 2566.687 & 110.019 & .000 & 1.000 \\
Cluster & SCK & 1 & 1191.826 & 73.259 & .000 & 1.000 \\
& KCS & 1 & 859.480 & 79.116 & .000 & 1.000 \\
\hline
\end{tabular}

La Tabla 10 muestra los resultados de análisis univariados del rendimiento de los futuros profesores de matemática secundaria en los tres dominios de conocimiento CCK, SCK y KCS en cada grupo. Como se puede ver en la tabla, hubo una diferencia estadísticamente significativa $(\mathrm{p}<.01)$ en los CCK, SCK y KCS de los futuros maestros del concepto de función. 
Tabla 11. Análisis multivariante del conocimiento de los futuros profesores de matemática secundaria sobre el concepto de función entre grupos

\begin{tabular}{|c|c|c|c|c|c|c|}
\hline & \multirow{2}{*}{ Box's M } & \multirow{2}{*}{ Sig } & \multirow{2}{*}{$\begin{array}{l}\text { Wilk's } \\
\text { Lambda }\end{array}$} & \multirow{2}{*}{ Sig } & \multicolumn{2}{|c|}{ Log Determinants } \\
\hline & & & & & Cluster 1 & Cluster 2 \\
\hline Cluster & 23.880 & .001 & .551 & .000 & 6.026 & 7.334 \\
\hline
\end{tabular}

Analizando la Tabla 11, vemos que hay una diferencia significativa en los puntajes CCK, SCK y KCS de futuros maestros de matemática secundaria justificados por una significativa lambda de Wilk de $0.55, \mathrm{p}<.001$. Hubo una diferencia estadísticamente significativa entre las matrices de covarianza de los grupos 1 y 2 con un valor $\mathrm{M}$ de Box significativo de $23.88, \mathrm{p} \leq .001$. El DFA generó solo una función discriminante. Esto podría deberse al hecho de que solo se estaban utilizando dos grupos en el análisis. Para verificar la robustez del DFA, consideramos los determinantes logarítmicos de los dos grupos y la tabla 6 muestra que los determinantes logarítmicos no difieren mucho, lo que confirma la robustez del DFA.

Tabla 12. Prueba de igualdad de las puntuaciones medias de los conglomerados para el conocimiento del futuro concepto de los futuros profesores de matemática

\begin{tabular}{rccccc}
\hline & $\begin{array}{c}\text { Wilk's } \\
\text { lambda }\end{array}$ & $\mathrm{F}$ & $\mathrm{df1}$ & $\mathrm{df2}$ & Sig \\
\hline CCK & .572 & 110.019 & 1 & 147 & .000 \\
SCK & .667 & 73.259 & 1 & 147 & .000 \\
KCS & .650 & 79.116 & 1 & 147 & .000 \\
\hline
\end{tabular}

La Tabla 12 muestra los resultados de la prueba de igualdad de las puntuaciones medias de los conglomerados para el conocimiento del concepto de función por parte de los futuros profesores de matemática secundaria. Examinando la Tabla 12, se puede ver que la lambda de Wilk es estadísticamente significativa para todas las variables independientes $(\mathrm{p}<.05)$ usando la prueba F. Siguiendo una regla general que establece que cuanto más pequeña es la lambda de Wilk, más importante es la variable independiente para la función discriminante, el conocimiento de contenido común (CCK) es el factor más importante para discriminar entre los futuros maestros en el grupo 1 y los del grupo 2. 
Tabla 13. Coeficientes de función discriminantes canónicos estandarizados y no estandarizados

\begin{tabular}{ccc}
\hline Knowledge domain & Standardized coefficients & Unstandardized coefficients \\
\hline CCK & .748 & .155 \\
SCK & -.023 & -.006 \\
KCS & .372 & .113 \\
\hline
\end{tabular}

La Tabla 13 muestra coeficientes de función discriminantes estandarizados y no estandarizados. El propósito para el cual se usan estos coeficientes es similar al de los pesos beta en el análisis de regresión. Los coeficientes estandarizados se utilizan para indicar la importancia relativa de la variable independiente en la predicción de la variable dependiente. Por lo tanto, cuanto mayor sea el valor absoluto del coeficiente estandarizado, mayor será la capacidad de discriminación. Al igual que los coeficientes de regresión no estandarizados en el análisis de regresión, los coeficientes no estandarizados en este estudio se usaron para construir la ecuación de predicción para la clasificación de nuevos casos.

\section{RESULTADOS CUALITATIVOS}

Conocimiento previo de los profesores de matemáticas sobre el contenido del concepto de funciones y estudiantes (KCS)

Aquí, las respuestas a las viñetas se muestran como ejemplos de KCS de los maestros de pre-servicio. En particular, se muestran las respuestas a la viñeta 2. El rendimiento de los docentes en esta viñeta es similar a otras viñetas. Por lo tanto, la viñeta 2 fue representativa de los principales resultados a este respecto.

\section{Respuestas de las maestras $\mathrm{X}, \mathrm{Y}$ y $\mathrm{Z}$ a las viñetas}

\section{Viñeta 2}

Un estudiante dijo que el inverso de la función $(\mathrm{x})=\mathrm{x}^{\wedge} 2=\sqrt{ } \mathrm{x}$.

¿Tiene razón el alumno? Si crees que el estudiante tiene razón, ¿por qué?

Si cree que el alumno es incorrecto, explique dónde se encuentra el error y cómo respondería a estos comentarios y aclare la confusión. 
Respuesta de la profesora $X$ a la viñeta 2

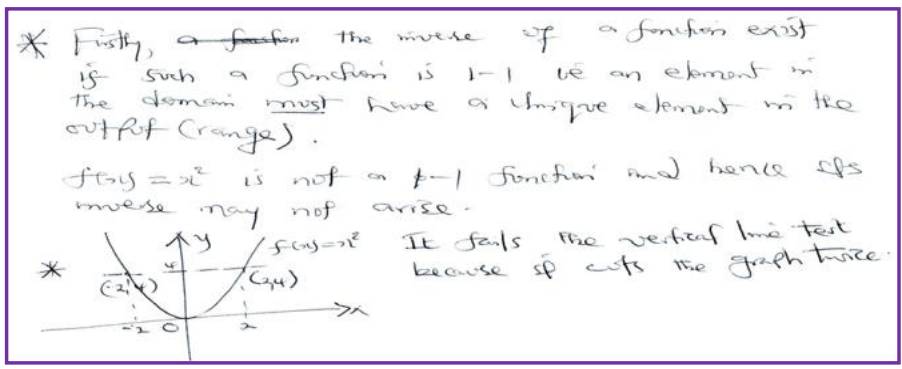

Esta viñeta estaba destinada a evaluar la capacidad del maestro para demostrar el conocimiento de la existencia de funciones inversas y para resaltar las condiciones bajo las cuales puede existir una función. El profesor explicó que para que una función tenga una inversa, debe ser una función uno a uno. Utilizó los conceptos de dominio y rango para enfatizar este punto. Sin embargo, parece confundir la prueba de línea horizontal para probar que una función es uno a uno con una prueba de línea vertical para probar si un gráfico particular es una función. Al usar un gráfico (representación diferente) para explicar la existencia de la función inversa de una función, el maestro demostró una comprensión de alto orden del concepto de la función inversa y las condiciones relacionadas con su existencia. Por lo tanto, sus explicaciones fueron calificadas 1-2.

Respuesta de la profesora Y a la viñeta 2

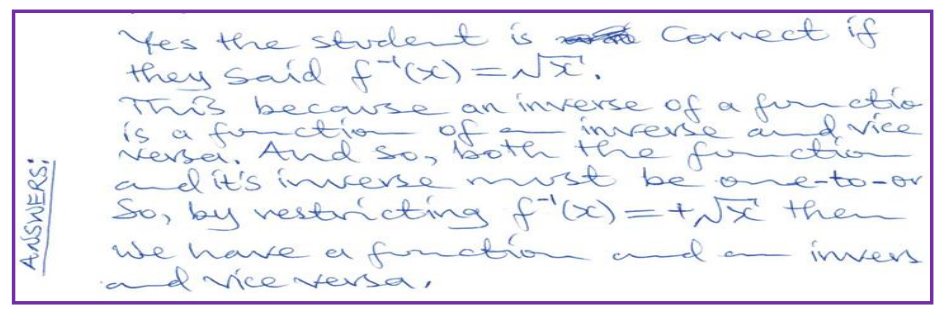

Esta viñeta estaba destinada a evaluar la capacidad del docente para demostrar el conocimiento de la existencia de funciones inversas y para resaltar las condiciones bajo las cuales puede existir una función. El profesor Y destacó correctamente que para que la función tenga un inverso, debe ser uno a uno. Sin embargo, el profesor no reconoció que la función dada $\mathrm{f}(\mathrm{x})=\mathrm{x} 2$ no satisfacía la condición uno a uno ya que el dominio no estaba restringido. La comprensión conceptual del profesor sobre el problema dado era errónea cuando acordó que la inversa de la función $(\mathrm{x})=\mathrm{x}^{\wedge} 2$ era $\sqrt{ } \mathrm{x}$. el profesor podría haber usado un método gráfico para determinar que la función 
$\mathrm{f}(\mathrm{x})=\mathrm{x} 2$ no era uno a uno. Por lo tanto, la falta de comprensión conceptual y la incapacidad de explicar cómo ayudaría a aclarar las ideas falsas que rodean tales situaciones le valieron al maestro una calificación de nivel 0.

Respuesta de la profesora $\mathrm{Z}$ a la viñeta 2

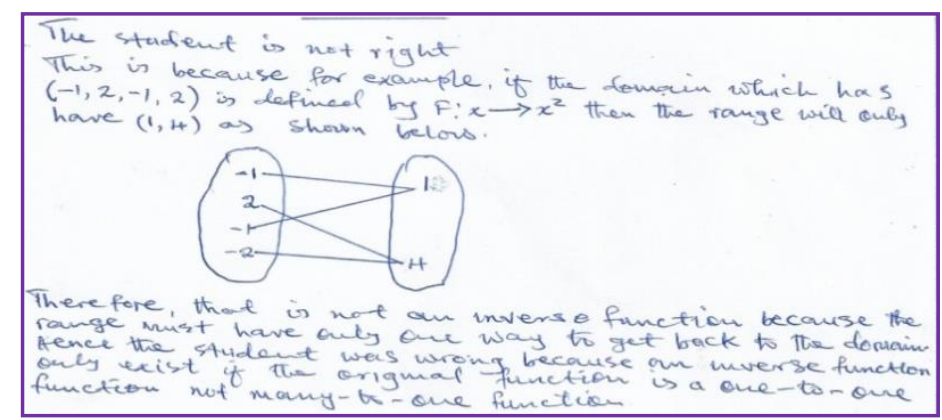

Esta viñeta estaba destinada a evaluar la capacidad del maestro para demostrar el conocimiento de la existencia de funciones inversas y para resaltar las condiciones bajo las cuales puede existir una función. El maestro declaró que para que una función tenga un inverso, debe ser un "uno a uno", que no era el caso con la función dada. Por lo tanto, $\sqrt{ } \mathrm{x}$ no es el inverso de $\mathrm{f}(\mathrm{x})=\mathrm{x} \wedge 2$. Usó diferentes representaciones para enfatizar su punto. Utilizó el concepto de dominio y rango en un diagrama de flecha para demostrar que la función no era unívoca. Por lo tanto, su respuesta a esta viñeta recibió una calificación de nivel 2.

\section{Resumen del conocimiento de contenido común (CCK) de los profesores en servicio}

\section{$\underline{\text { Item 5(b) }}$}

Given that $g(\mathrm{x})=\frac{3}{2 \mathrm{x}+1}$ and $z: \mathrm{x} \rightarrow \mathrm{x}^{2}-2 \mathrm{x}$, Evaluate $\left(g \circ g^{-1}\right)(-5)$ where -5 belongs to the domain of $g^{-1}$.

Este ítem requería que el maestro de pre-servicio encontrara primero la composición de la función g (x) y su inversa g-1 (x) y luego evaluara la función compuesta resultante compuesta.

\section{La respuesta del profesor $X$}




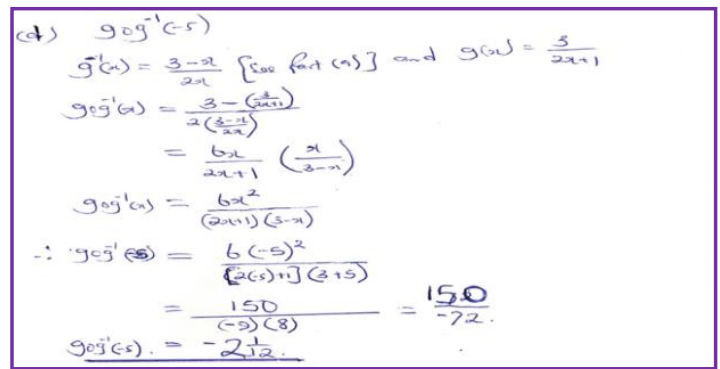

Analizando la respuesta del profesor X, se puede ver que no tenía conocimiento de la regla general que gobierna la composición de una función y su inversa. Es una regla general que si la función $\mathrm{g}(\mathrm{x})$ y su inversa $\mathrm{g}^{-1}(\mathrm{x})$ tienen sus dominios y rangos en el conjunto de números reales, entonces $\operatorname{gog}^{-1}=\mathrm{x} \mathrm{y} \mathrm{g}^{-1} \mathrm{og}=\mathrm{x}$. Con esto en mente, el profesor X podría haber declarado fácilmente el $g \circ g^{-1}(-5)$ sin intentar realizar ningún cálculo. Sin embargo, en su trabajo, el profesor X recordó que ya había encontrado la expresión para el inverso de la función g (x). Pero su trabajo para encontrar la expresión para g o g-1 se caracterizó por errores conceptuales, lo que produjo una expresión incorrecta para g o g-1. Esto a su vez afectó su evaluación de la función compuesta g o g-1 (-5). Desde su inicio, en su trabajo sobre esta cuestión, quedó claro que el profesor X carecía de los requisitos previos sobre la composición de una función y su inversa. La falta de tales conocimientos básicos afectaría su enseñanza en el futuro. Por lo tanto, su respuesta recibió una calificación de nivel 0.

Entrevistador: ¿Hay alguna otra forma en que podría haber resuelto la pregunta 5 (d)?

Maestro X: La composición de una función y su inverso ... debe haber un resultado fundamental para esto [risas]. Entonces, g [g-1 (x)] debería ser x. así que no sé por qué lo resolví de esa manera en la prueba.

Entrevistador: Finalmente, habló sobre las pruebas de línea vertical y horizontal. ¿Crees que es importante enseñar estas pruebas a los estudiantes?

Maestro X: Por lo general, confiamos en las definiciones e intentamos enfatizar desde esa [perspectiva], y creemos que los alumnos determinarán las funciones a partir de las definiciones. Cuando incluimos estas pruebas, será más claro cómo verificar los gráficos. Se vuelve más fácil de usar para los alumnos.

\section{La respuesta del maestro $Z$}

Analizando la respuesta del profesor Z, se puede ver que demuestra conocimiento de la regla general que gobierna la composición de una función y su inversa. Es una regla general que si la función $\mathrm{g}(\mathrm{x})$ y su inversa $\mathrm{g}-1$ (x) tienen sus dominios y rangos en el conjunto de números reales, entonces $\mathrm{g}$ o $\mathrm{g}-1=\mathrm{x}$ y $\mathrm{g}-1$ o $\mathrm{g}=\mathrm{x}$. Con esto en mente, el maestro $\mathrm{Z}$ pudo establecer fácilmente el valor $\mathrm{g}$ o $\mathrm{g}-1(-5)$ sin intentar 
realizar ningún cálculo. Durante la entrevista se le pidió que comentara su respuesta. Su respuesta fue calificada como nivel 2.

$$
\begin{aligned}
& \text { (d) } g \circ g^{-1}(-5) \\
& \Rightarrow \operatorname{gog}^{-1}(-5)=-5 \\
& \text { Since } \operatorname{gog}^{-1}(x)=x
\end{aligned}
$$

Entrevistador: ¿Tiene algún comentario sobre su respuesta a 5 (d)

Maestro Z: Este caso es similar a lo que le estaba enseñando a alguien justo antes de escribir el examen. Entonces, no perdí el tiempo con esto porque sabía que g o g-1 = $\mathrm{x}$.

Entrevistador: ¿Conoces las pruebas de línea horizontal y vertical?

Maestro Z: Aah ... No

Resumen del conocimiento de contenido especializado (SCK) de los profesores en servicio

Item 2(a)

Given that $g(\mathrm{x})=\frac{3}{2 \mathrm{x}+1}$ and $z: \mathrm{x} \rightarrow \mathrm{x}^{2}-2 \mathrm{x}$, Evaluate $\left(g \circ g^{-1}\right)(-5)$ where -5 belongs to the domain of $g^{-1}$.

Este ítem fue diseñado para evaluar el conocimiento del Maestro X de dibujar funciones continuas y discretas.

\section{La respuesta del profesor $X$}

$\mathrm{Al}$ responder a esta pregunta, el aspecto clave fue que el Profesor $\mathrm{X}$ decidiera desde el principio el tipo de gráfico que estaba dibujando. La clave para esto estaba oculta en el dominio de $\mathrm{g}(\mathrm{x})$. El dominio de $\mathrm{g}(\mathrm{x})$ fue un intervalo cerrado en el conjunto de enteros. Este fue un intervalo discreto con números enteros -3, -2, -1, 0, 1, 2 que producirán salidas específicas utilizando la función g (x). El profesor X encontró correctamente el rango de la función $\mathrm{g}$ (x) usando una tabla de valores y pudo aprovechar su conocimiento de moverse entre diferentes representaciones de funciones. En este caso, fue capaz de pasar de la representación tabular de una función de valor absoluto a la representación gráfica de la función. Sin embargo, el Profesor X mostró lagunas en el conocimiento de cómo una gráfica de una función con un dominio discreto difiere de la que tiene un dominio continuo. Se esperaba que el maestro X supiera que los puntos trazados de una función discreta no deberían estar conectados ni por una línea recta ni por una curva suave. La conexión de puntos es una indicación de que un gráfico particular es una función continua. Por lo tanto, 
si bien el trazado de los puntos se realizó correctamente, el gráfico resultante se dibujó incorrectamente porque el profesor $\mathrm{X}$ no necesitaba conectar los puntos trazados con una línea.

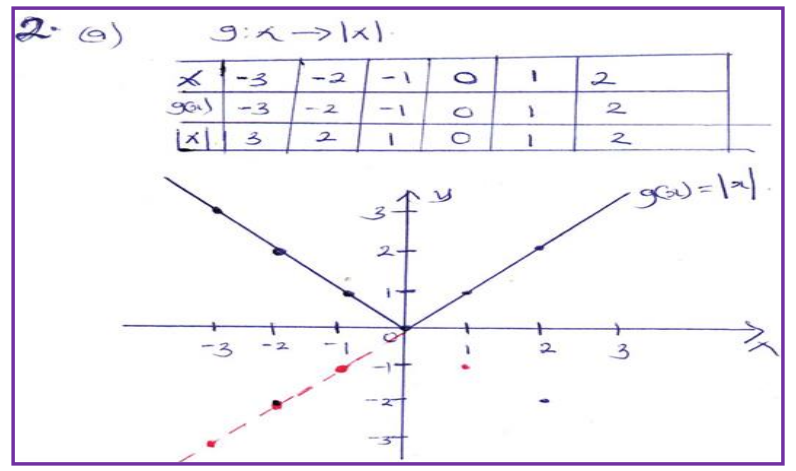

El Maestro X no usó el dominio para determinar si se le pidió o no que dibujara una función discreta o continua. Se le pidió que justificara su respuesta durante la entrevista. La respuesta a esta pregunta recibió una calificación de nivel 0. Sin embargo, durante la entrevista, el Maestro X se dio cuenta del error que cometió en el examen.

Entrevistador: existe esta situación interesante en 2 (a) donde se le pidió que dibujara la gráfica de la función g (x). Observé que conectabas los puntos trazados con una línea recta. Al justificar su respuesta, explique por qué conectó los puntos.

Maestro X: Creo que quizás no se suponía que estuvieran conectados porque creo que no vi la otra condición. Dicen que x es un número entero. Entonces, si fueran enteros, entonces probablemente no serán continuos. Entonces, se suponía que debía mostrar los puntos porque si sale como una línea recta, estamos incluyendo valores que no son enteros. Entonces, el factor clave para responder a esta pregunta fue la condición "x es un número entero".

\section{Resumen de la discusión de resultados.}

Esta sección presenta una breve discusión de los resultados del estudio. La discusión comienza con la de los resultados cuantitativos donde se analiza una discusión sumaria de las percepciones de las matemáticas de los maestros en servicio. Posteriormente, profundizo en una discusión resumida de CCK, SCK y KCS de los maestros en servicio. A continuación, se discuten los resultados cualitativos donde se discuten las respuestas previas al servicio a viñetas, entrevistas, planes de lecciones, actividades de enseñanza en el aula y respuestas para las funciones de prueba de lápiz y papel.

\section{Breve discusión de resultados cuantitativos}

Resumen de las percepciones de los profesores de matemáticas en formación inicial 
La percepción se conoce como el acto de ser consciente y dar sentido a un concepto matemático (Acil, 2011) que una persona encontrará en el curso del aprendizaje. La forma en que los maestros de pre-servicio perciben los conceptos en matemáticas, incluido el concepto de una función, tiene mucho que ver con sus experiencias previas con el tema porque "los individuos aprenden a través de la percepción" (Gokdag, 2008 citado en Bukova-Guzel et al., 2013). Por lo tanto, el aprendizaje de las matemáticas por parte de los maestros de pre-servicio puede ser inmensamente respaldado al examinar constantemente sus percepciones (Bukova-Guzel et al., 2013) y formular materiales de aprendizaje que respondan a sus necesidades.

Un análisis detallado de los docentes de matemáticas en formación inicial que participaron en este estudio trajo consigo dos categorías de maestros en relación con sus percepciones de MPCK. El grupo 1 estaba compuesto por maestros en servicio previo que se percibían débiles en todos los componentes de MPCK (KTS, KMLS, $\mathrm{KM}, \mathrm{KL}, \mathrm{KC})$. Curiosamente, este grupo de maestros registró una puntuación media baja en una prueba de lápiz y papel sobre las funciones en comparación con aquellos en el grupo 2 que exhibieron fuertes percepciones de los dominios de conocimiento de MPCK (Tabla 3).

Una imagen creada en la Tabla 3 sugiere que el grupo 1 consiste en docentes de matemáticas en formación inicial que son débiles en el conocimiento de sus alumnos. Lo que significa que estos docentes de matemáticas en formación inicial probablemente enfrentarían desafíos para identificar y diagnosticar conceptos erróneos, errores, dificultades y errores relacionados con el concepto de función en comparación con los del grupo 2. Esto se unirá a su débil conocimiento del uso de lenguaje y símbolos matemáticos apropiados. relacionado con el concepto de función y no estarán seguros de su implementación del plan de estudios de matemáticas porque su conocimiento del plan de estudios es débil. Los docentes de matemáticas en formación inicial en el grupo 2 tendrán menos de estos desafíos porque su perfil relacionado con los factores MPCK es mucho mejor.

Los docentes en el grupo 2 tienen un gran conocimiento de las estrategias de enseñanza y los métodos de evaluación para permitir que luego enseñen el concepto de función en comparación con los del grupo 1. Por lo tanto, de los datos en la Tabla 3 se puede ver que cuando un docente tiene percepciones débiles de las asignaturas de matemáticas, el conocimiento de la materia y el contenido pedagógico, su 
dominio y conocimiento general sobre un concepto matemático particular se ven afectados. La encuesta de funciones que se administró en forma de una prueba de lápiz y papel contenía elementos matemáticos y pedagógicos que examinaban dominios estrechamente relacionados con los componentes de la encuesta MPCK.

Un análisis de la Tabla 3 reveló que los docentes de matemáticas en formación inicial en el grupo 2 se desempeñaron mejor que aquellos en el grupo 1. Esto se atribuyó a su alta confianza en el tema de las matemáticas y el conocimiento del contenido pedagógico exhibido a través de sus respuestas a los elementos de la encuesta MPCK. El desempeño de los docentes de matemáticas en formación inicial en la encuesta de funciones reflejó su conocimiento de contenido común, conocimiento de contenido especializado y su conocimiento de contenido y estudiantes relacionados con el concepto de función. Esto se discutirá en detalle en la siguiente sección. Sin embargo, vale la pena declarar que las percepciones de los docentes de matemáticas en formación inicial que participaron en este estudio se correlacionaron bien con el rendimiento en la prueba de matemáticas dada. Esto tiene muchas implicaciones para la formación de docentes en Zambia y esas implicaciones y sugerencias de mejora se detallan en el capítulo 6.

Por lo tanto, se puede ver a partir de lo anterior que los docentes de matemáticas en formación inicial de Zambia exhibieron brechas en su percepción del conocimiento de la materia y del contenido pedagógico, lo que abre líneas de investigación que cerrarían esta brecha y áreas donde las universidades de educación pueden revisar sus paquetes de cursos actuales con el objetivo de responder a los desafíos presentados por los maestros de pre-servicio a través de los resultados de este estudio.

Los resultados de este estudio con respecto a la percepción de los docentes de matemáticas en formación inicial para enseñar matemáticas fueron consistentes con los hallazgos de investigaciones anteriores (Bursal y Paznokas, 2006; Duru, 2011; Hine y Thai; 2018; Rosas y West, 2011). quienes encontraron que los niveles de confianza de los maestros en servicio previo en su preparación para enseñar matemáticas no eran adecuados, pero no lo suficientemente altos como para cumplir con el estándar requerido. Llegaron a la conclusión de que los maestros no estaban bien preparados para enseñar matemáticas. Bursal y Paznokas (2006), en su estudio sobre la ansiedad matemática y la confianza de los docentes de primaria en 
formación inicial para enseñar matemáticas y ciencias, descubrieron que los docentes de matemáticas en formación inicial cuyas percepciones de enseñar matemáticas estaban nubladas con alta ansiedad tenían poca confianza.

Hine y Thai (2018) investigaron las autopercepciones de los docentes de matemáticas en formación inicial sobre su preparación para enseñar matemáticas en la escuela secundaria a través del conocimiento del contenido pedagógico matemático, el conocimiento matemático para la enseñanza y el conocimiento de la materia matemática. Los resultados de este estudio revelaron que los docentes de matemáticas en formación inicial tenían poca confianza en su conocimiento del contenido pedagógico para enseñar matemáticas de secundaria superior y necesitaban más capacitación. Duru (2011) investigó a los docentes de matemáticas en formación inicial, percepciones sobre el concepto de un límite de las mismas funciones parciales en sus formas gráficas y simbólicas. Los hallazgos revelaron conceptos erróneos conceptuales y poca confianza por parte de los maestros de pre-servicio.

\section{Resumen de CCK, SCK y KCS de maestros en servicio}

Mediante el análisis cuantitativo, se ha demostrado que los docentes en formación que participaron en este estudio tenían poco conocimiento de la materia y del contenido pedagógico de las funciones. Aunque una comparación de grupo del nivel de CCK de los maestros en servicio previo, SCK y KCS muestra que los maestros de servicio previo en el grupo 2 estaban un paso por encima de sus colegas en el grupo 1, una consideración holística de su nivel de conocimiento en los tres dominios (CCK, SCK, KCS) revelaron lagunas en su comprensión de los conceptos básicos.

Por ejemplo, su conocimiento incompleto de las definiciones de conceptos que involucran funciones era una clara indicación del conocimiento inadecuado de contenido común de los maestros en servicio. Esto a pesar de la abrumadora evidencia de investigación que enfatiza la necesidad de tener un buen conocimiento de las definiciones porque las definiciones ayudan a explicar los conceptos y sus relaciones (Mark, 1990; Star et al., 2005). Los participantes de este estudio también revelaron SCK insuficiente a través de bajos niveles de conocimiento sobre indicadores particulares que se utilizaron para medir SCK. A pesar de la evidencia en la literatura que respalda el conocimiento del uso de diferentes representaciones como un indicador de conocimiento de contenido especializado de funciones, los docentes de matemáticas en formación inicial en este estudio exhibieron lagunas en 
su conocimiento de diferentes representaciones de funciones (algebraico, tabular, gráfico). También se ha detallado en este capítulo que los docentes de matemáticas en formación inicial tenían un conocimiento insuficiente del contenido de las funciones y de los estudiantes. Pero al publicar bajos niveles de conocimiento de los conceptos erróneos de los alumnos, los docentes de matemáticas en formación inicial demostraron la necesidad de aprender más sobre la anticipación, identificación y resolución de los conceptos erróneos de los alumnos.

\section{Resultados cualitativos}

\section{Resumen de CCK, SCK y KCS de los docentes X, Y y Z}

Los CCK, SCK y KCS de los docentes de matemáticas en formación inicial no estaban en un nivel alto, aunque fue bueno en algunos casos. Hubo casos en los que no pudieron abordar conceptos muy básicos como evaluar la inversa de la composición de dos funciones. Las lagunas en el CCK fueron evidentes principalmente por su falta de definiciones y la falta de ejemplos apropiados y errores en sus cálculos que involucran funciones inversas, cuadráticas y compuestas.

$\mathrm{Su}$ incapacidad para proporcionar explicaciones válidas y justificación de sus respuestas en muchos casos significaba que su SCK no estaba en un nivel deseable. Esto se debe a que un maestro debe esforzarse por justificar su trabajo en clase en todo momento, fracaso en el que los estudiantes siempre pierden. Su KCS fue inadecuada en algunos casos, ya que los maestros de pre-servicio no pudieron resolver los conceptos erróneos de los estudiantes relacionados con las funciones inversas y compuestas al responder a viñetas y tampoco pudieron abordar adecuadamente la incomprensión de los estudiantes de situaciones relacionadas con diferentes representaciones de funciones. Por lo tanto, era evidente que los maestros de pre-servicio en el grupo 2 tenían niveles de conocimiento ligeramente más altos de CCK, SCK y KCS como se podía ver en los resultados cuantitativos y el análisis cualitativo del Maestro X que se extrajo del grupo 2. Sin embargo, todos los docentes en servicio necesitan mejorar en algunas áreas su conocimiento del concepto de una función. De lo contrario, no están completamente preparados para enseñar conceptos de secundaria relacionados con otras funciones. 